\title{
อ
}

(2021 The Author(s)

This is an Open Access book distributed under the terms of the Creative Commons Attribution-Non Commercial-No Derivatives Licence (CC BY-NC-ND 4.0), which permits copying and redistribution in the original format for non-commercial purposes, provided the original work is properly cited.

(http://creativecommons.org/licenses/by-nc-nd/4.0/). This does not affect the rights licensed or assigned from any third party in this book.

This title was made available Open Access through a partnership with Knowledge Unlatched.

IWA Publishing would like to thank all of the libraries for pledging to support the transition of this title to Open Access through the $2020 \mathrm{KU}$ Partner Package program.
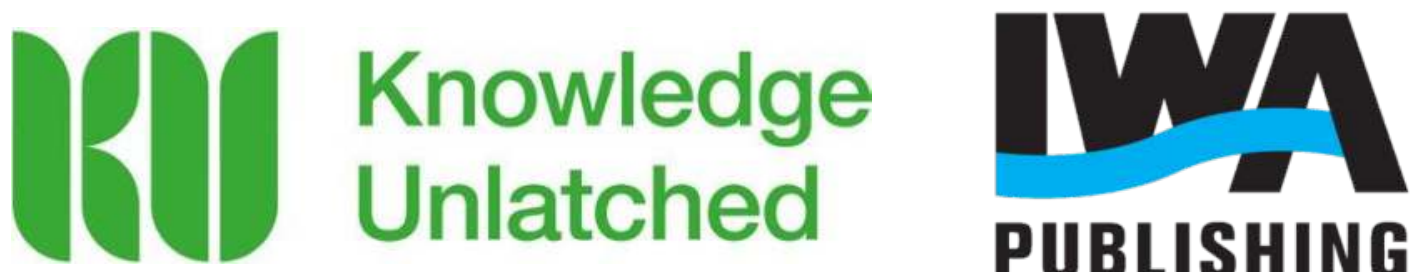

PUBLISHING 


\section{TUNING \\ BIOLOGICAL \\ NUTRIENT \\ REMOVAL PLANTS}

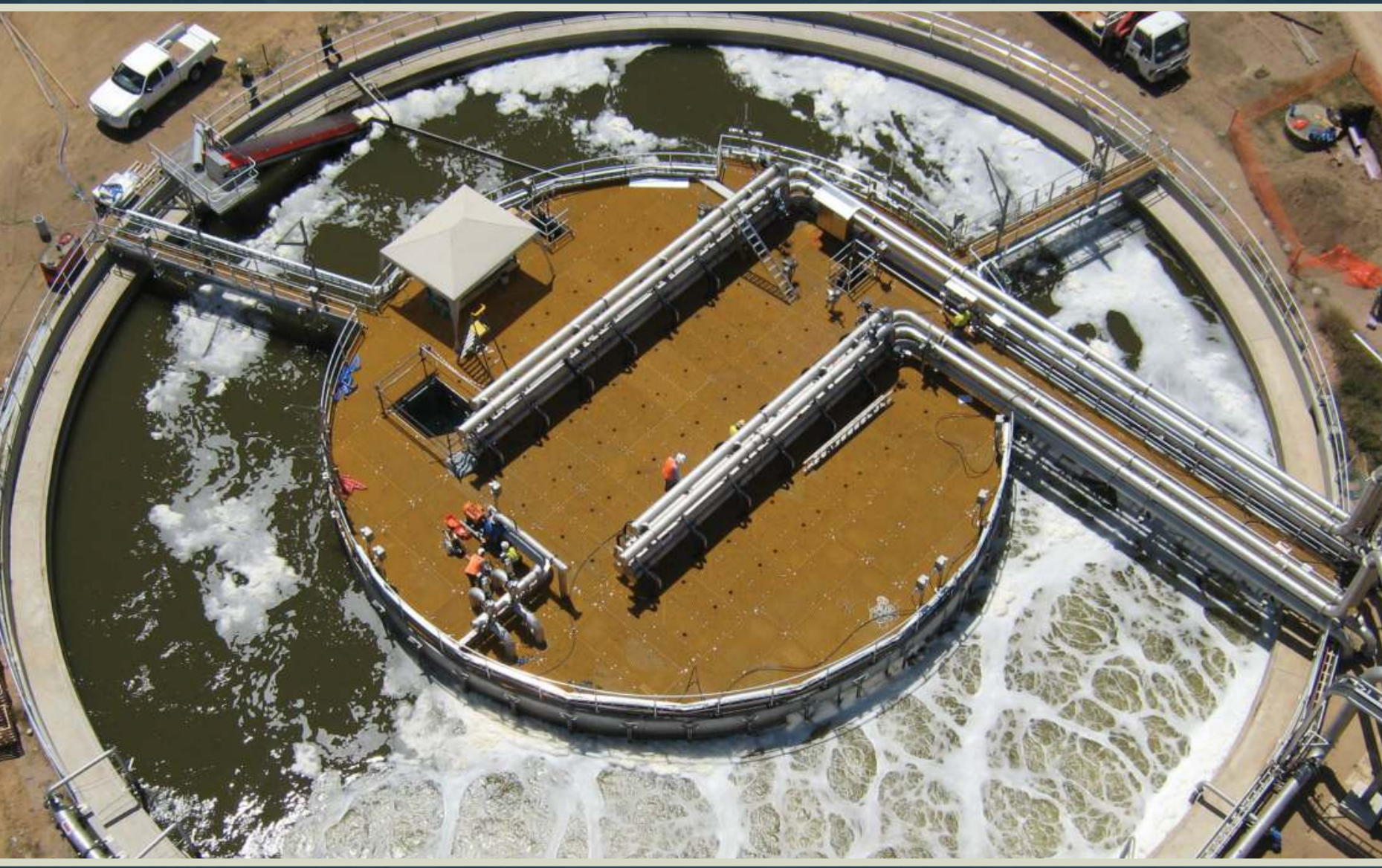

KEN HARTLEY 


\section{Tuning Biological Nutrient Removal Plants}




\section{Tuning Biological Nutrient Removal Plants}

Ken Hartley

Publishing London - New York 
Published by

First published 2013

(C) 2013 IWA Publishing

\author{
IWA Publishing \\ Alliance House \\ 12 Caxton Street \\ London SW1H 0QS, UK \\ Telephone: +44 (0)20 76545500 \\ Fax: +44 (0)20 76545555 \\ Email: publications@iwap.co.uk \\ Web: www.iwapublishing.com
}

Cover Illustration: One of two annular oxidation ditch-MBRs at the 126,000 EP Cleveland Bay Wastewater Treatment Facility in Townsville, Queensland, photographed during startup in late 2007. Effluent discharges to the Great Barrier Reef Marine Park and average effluent limits are TN $4 \mathrm{mg} / \mathrm{L}$, TP $0.8 \mathrm{mg} / \mathrm{L}$. Three existing secondary clarifiers retained from the old plant were converted into a primary clarifier and two MBRs. A three-cell anaerobic reactor and four hollow fibre membrane trains are located in a covered stainless steel centre section, surrounded by an annular oxidation ditch. More information about the plant can be found in Section 6.4.3. Photograph courtesy of Townsville Water.

Apart from any fair dealing for the purposes of research or private study, or criticism or review, as permitted under the UK Copyright, Designs and Patents Act (1998), no part of this publication may be reproduced, stored or transmitted in any form or by any means, without the prior permission in writing of the publisher, or, in the case of photographic reproduction, in accordance with the terms of licenses issued by the Copyright Licensing Agency in the UK, or in accordance with the terms of licenses issued by the appropriate reproduction rights organization outside the UK. Enquiries concerning reproduction outside the terms stated here should be sent to IWA Publishing at the address printed above.

The publisher makes no representation, express or implied, with regard to the accuracy of the information contained in this book and cannot accept any legal responsibility or liability for errors or omissions that may be made.

\section{Disclaimer}

The information provided and the opinions given in this publication are not necessarily those of IWA and should not be acted upon without independent consideration and professional advice. IWA and the Author will not accept responsibility for any loss or damage suffered by any person acting or refraining from acting upon any material contained in this publication.

\section{British Library Cataloguing in Publication Data}

A CIP catalogue record for this book is available from the British Library

ISBN 9781780404820 (Paperback)

ISBN 9781780404837 (eBook) 


\section{Contents}

About the Authors $\ldots \ldots \ldots \ldots \ldots \ldots \ldots \ldots \ldots \ldots \ldots \ldots \ldots \ldots \ldots \ldots \ldots \ldots$

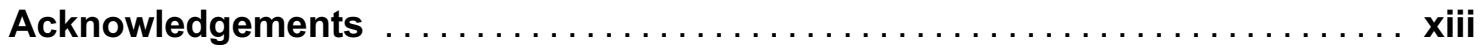

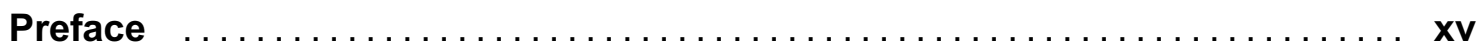

\section{Chapter 1}

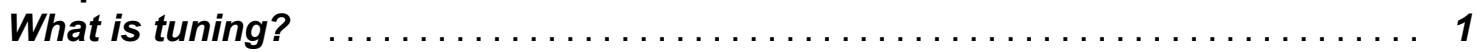

\section{Chapter 2}

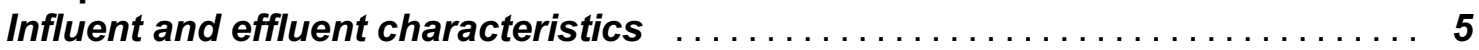

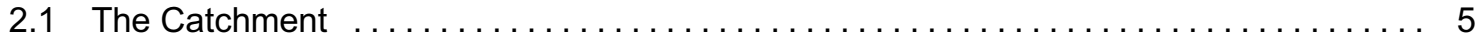

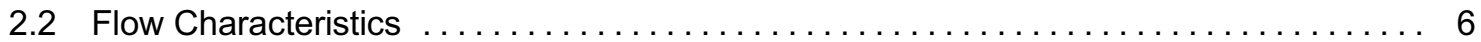

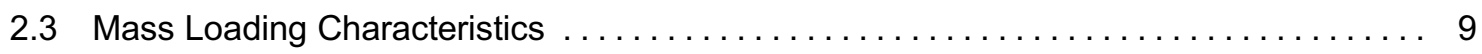

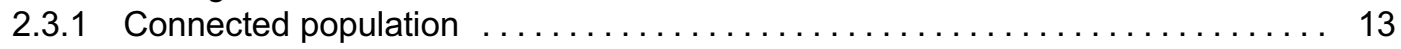

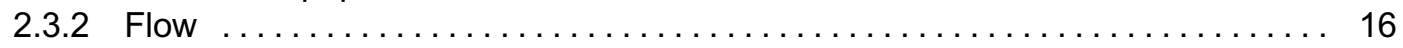

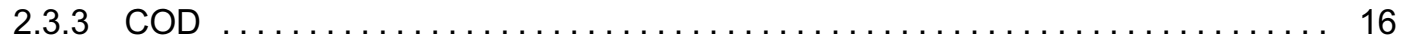

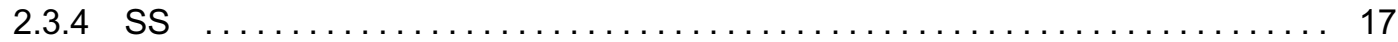

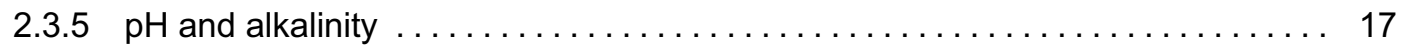

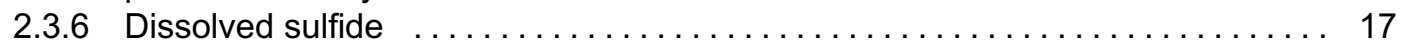

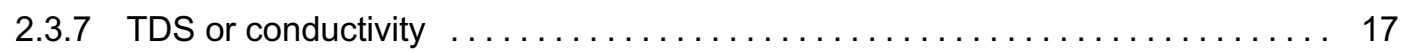

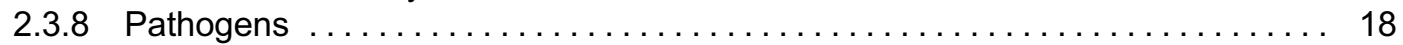

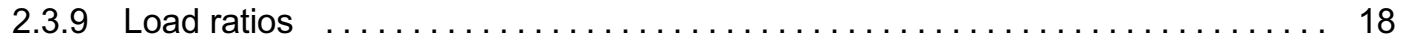

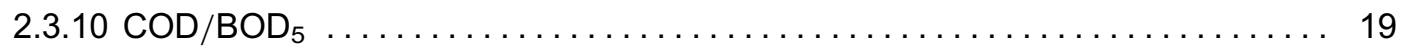

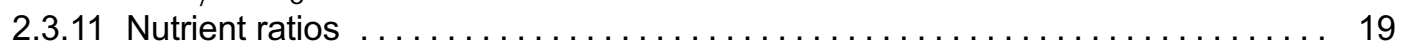


2.3.12 Total COD fractions $\ldots \ldots \ldots \ldots \ldots \ldots \ldots \ldots \ldots \ldots \ldots \ldots \ldots \ldots \ldots \ldots$

2.3.13 Soluble unbiodegradable organic $N \ldots \ldots \ldots \ldots \ldots \ldots \ldots \ldots \ldots \ldots \ldots$

2.3.14 Nitrifier maximum specific growth rate $\ldots \ldots \ldots \ldots \ldots \ldots \ldots \ldots \ldots \ldots \ldots . \ldots \ldots$

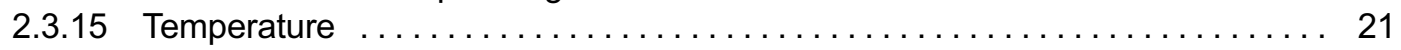

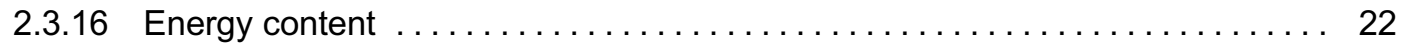

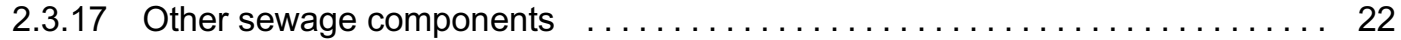

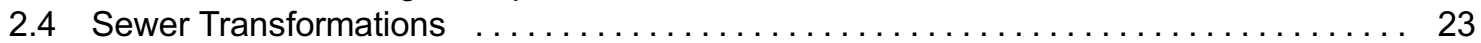

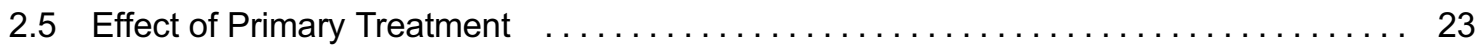

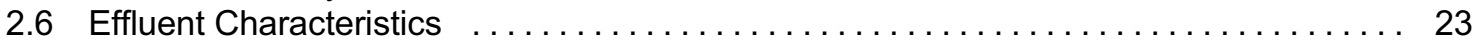

\section{Chapter 3}

Biological nutrient removal - process fundamentals $\ldots \ldots \ldots \ldots \ldots \ldots \ldots 27$

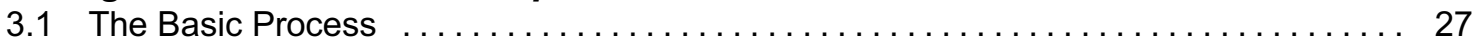

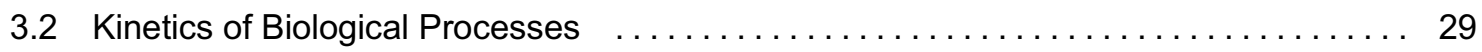

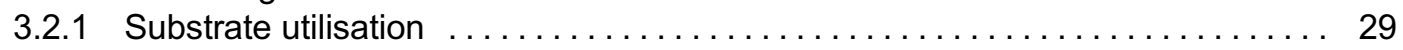

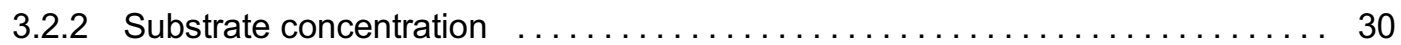

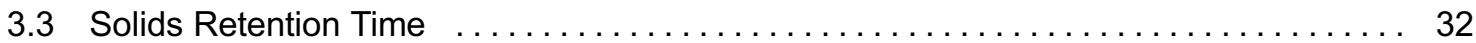

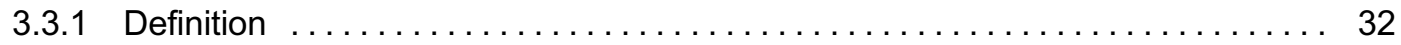

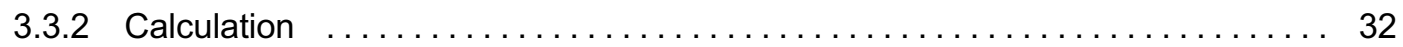

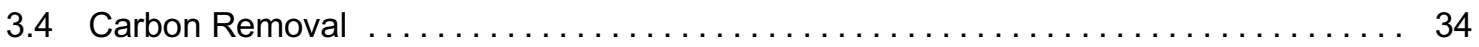

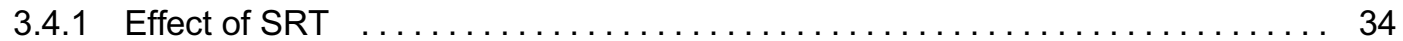

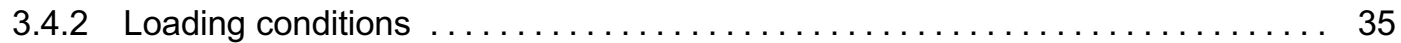

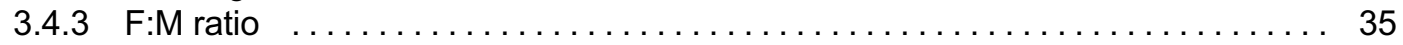

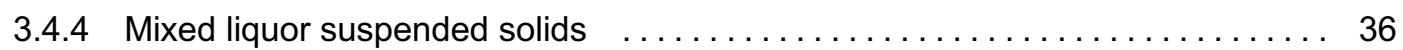

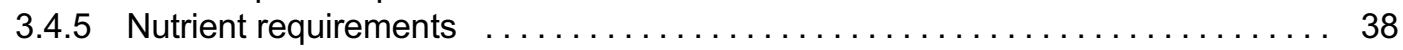

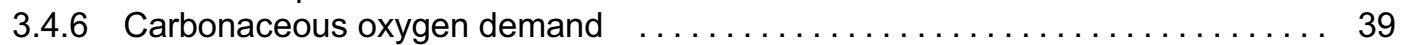

3.5 Nitrogen Removal $\ldots \ldots \ldots \ldots \ldots \ldots \ldots \ldots \ldots \ldots \ldots \ldots \ldots \ldots \ldots \ldots \ldots \ldots \ldots \ldots \ldots$

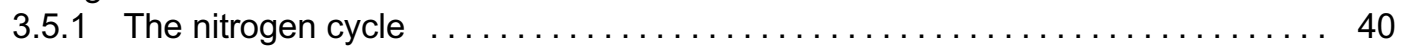

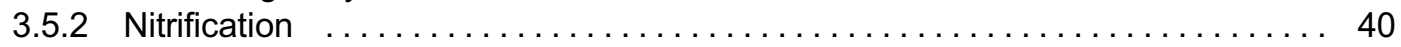

3.5 .3 Denitrification $\ldots \ldots \ldots \ldots \ldots \ldots \ldots \ldots \ldots \ldots \ldots \ldots \ldots \ldots \ldots \ldots \ldots \ldots$

3.5.4 Simultaneous nitrification and denitrification $\ldots \ldots \ldots \ldots \ldots \ldots \ldots \ldots \ldots \ldots$.

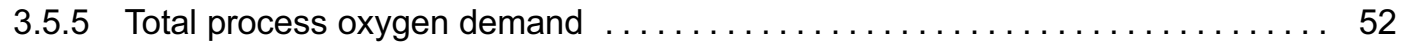

3.6 Phosphorus Removal $\ldots \ldots \ldots \ldots \ldots \ldots \ldots \ldots \ldots \ldots \ldots \ldots \ldots \ldots \ldots \ldots \ldots \ldots \ldots$

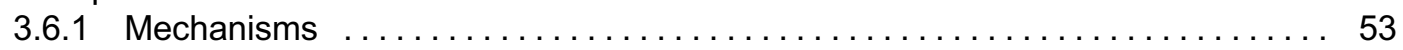

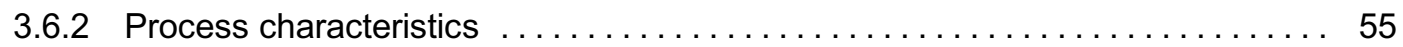

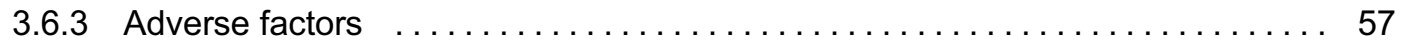

3.7 Supplementary Chemical Dosing $\ldots \ldots \ldots \ldots \ldots \ldots \ldots \ldots \ldots \ldots \ldots \ldots \ldots \ldots \ldots \ldots 6$

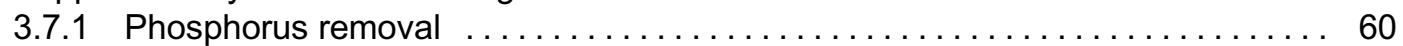

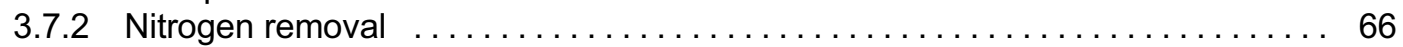

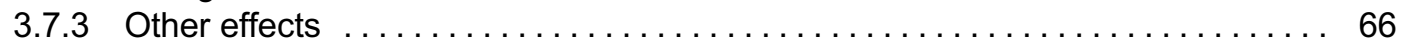

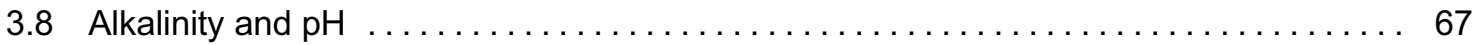

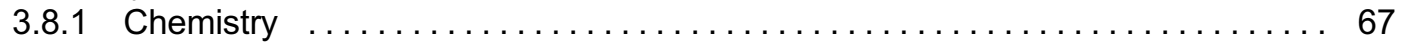

3.8 .2 Process behaviour $\ldots \ldots \ldots \ldots \ldots \ldots \ldots \ldots \ldots \ldots \ldots \ldots \ldots \ldots \ldots \ldots \ldots$

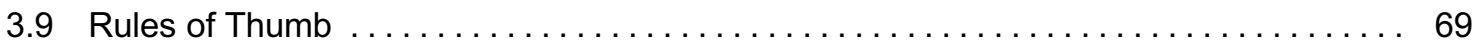




\section{Chapter 4}

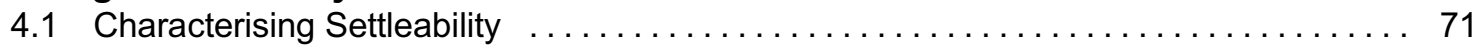

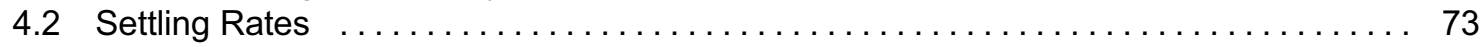

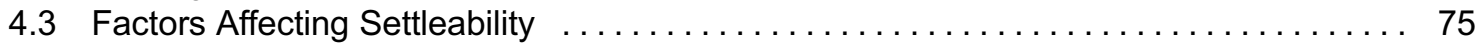

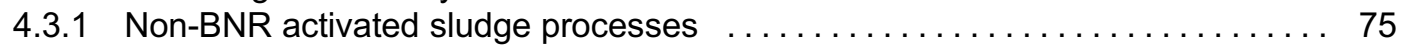

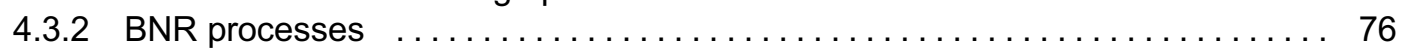

4.4 Effect of SVI on Effluent Quality $\ldots \ldots \ldots \ldots \ldots \ldots \ldots \ldots \ldots \ldots \ldots \ldots \ldots \ldots \ldots \ldots \ldots \ldots \ldots \ldots \ldots \ldots$

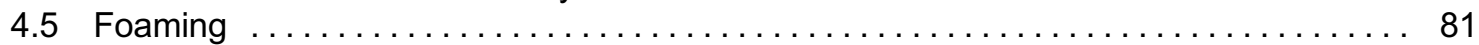

\section{Chapter 5}

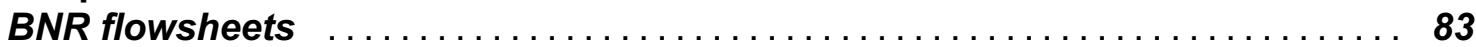

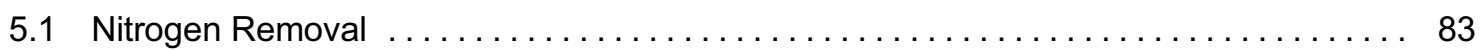

5.1.1 Modified Ludzack-Ettinger (MLE) $\ldots \ldots \ldots \ldots \ldots \ldots \ldots \ldots \ldots \ldots \ldots \ldots \ldots \ldots$

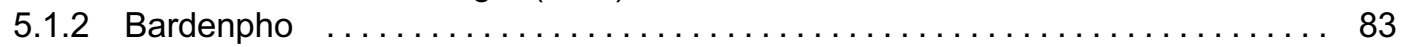

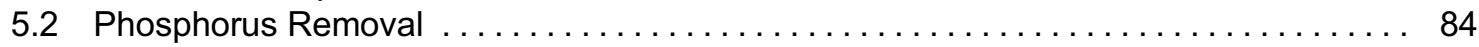

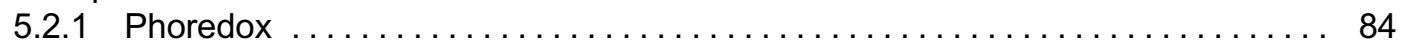

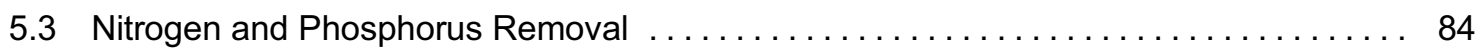

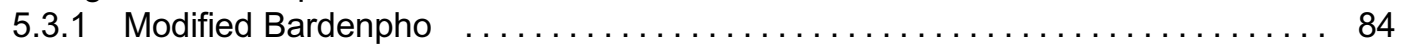

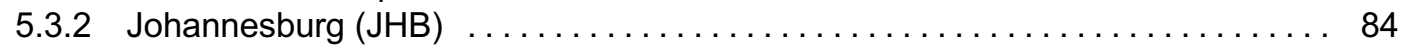

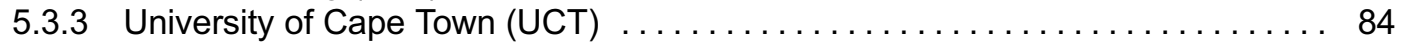

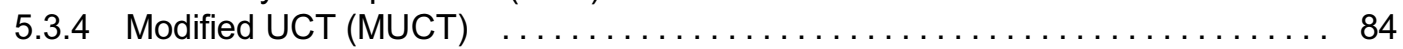

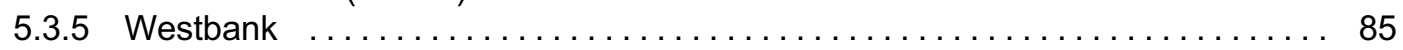

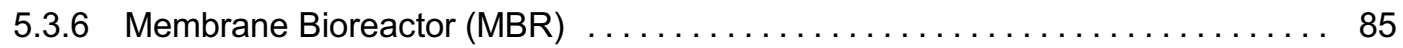

\section{Chapter 6}

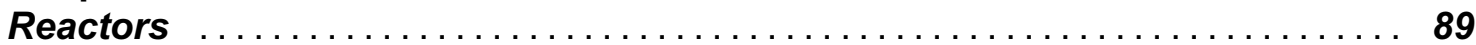

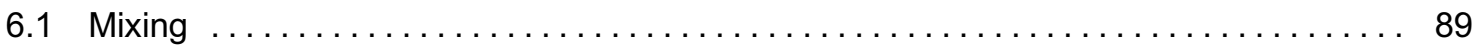

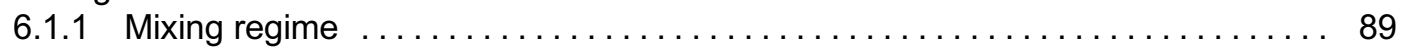

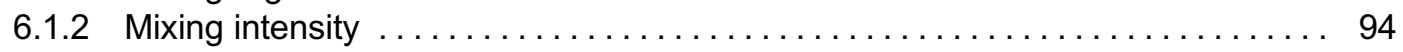

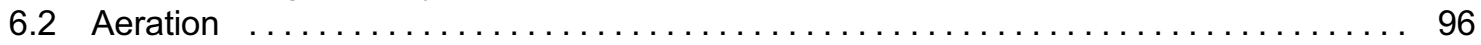

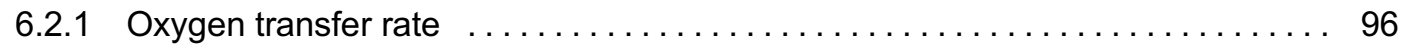

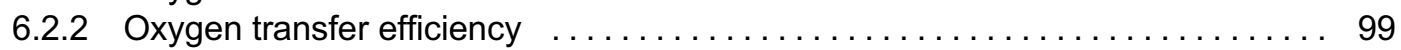

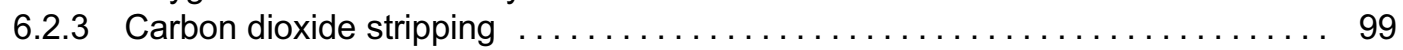

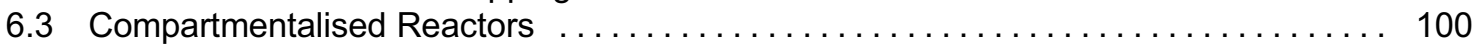

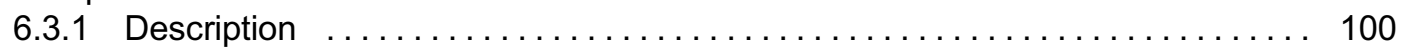

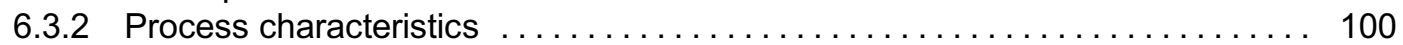

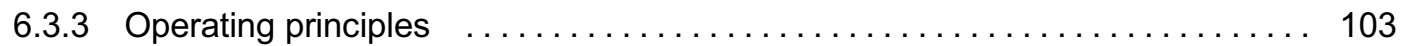

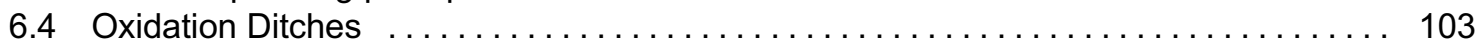

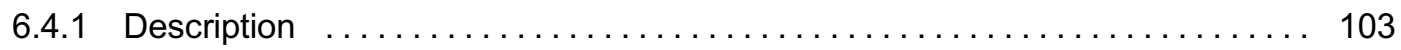

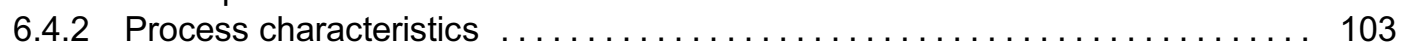

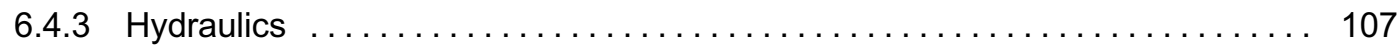

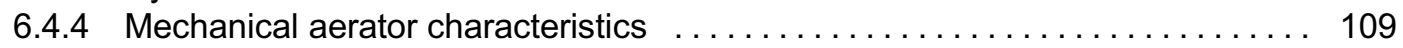

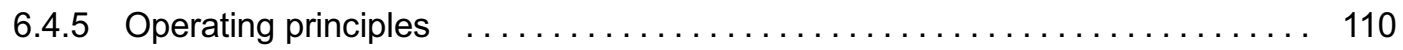


6.5 Membrane Bioreactors $\ldots \ldots \ldots \ldots \ldots \ldots \ldots \ldots \ldots \ldots \ldots \ldots \ldots \ldots \ldots \ldots \ldots \ldots \ldots 110$

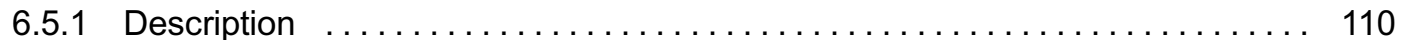

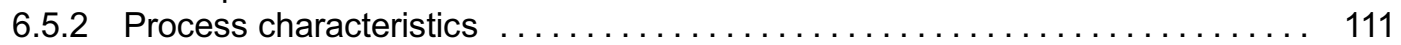

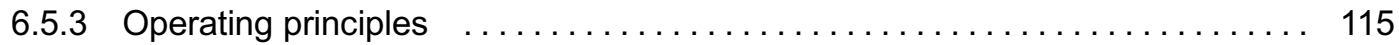

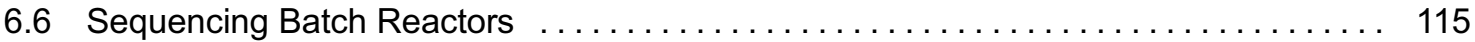

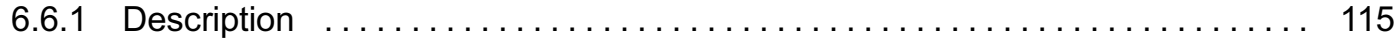

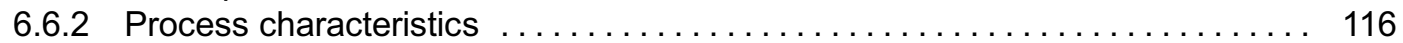

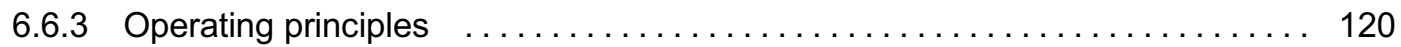

\section{Chapter 7}

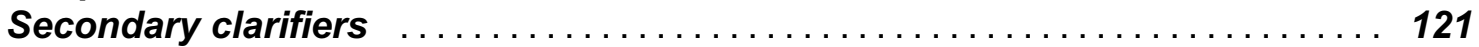

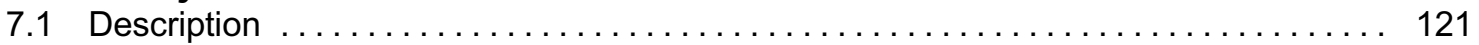

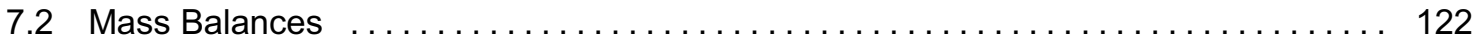

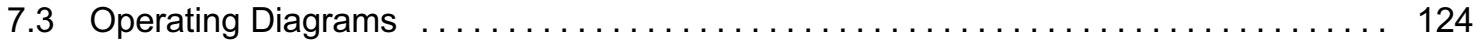

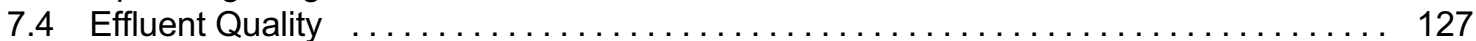

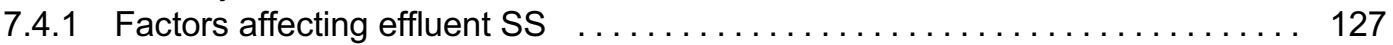

7.4.2 Other effects of clarifiers on effluent quality $\ldots \ldots \ldots \ldots \ldots \ldots \ldots \ldots \ldots \ldots$

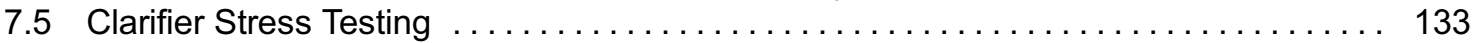

\section{Chapter 8}

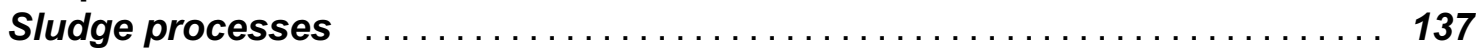

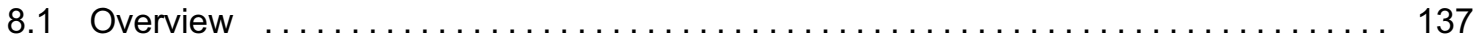

8.2 Aerobic Digestion $\ldots \ldots \ldots \ldots \ldots \ldots \ldots \ldots \ldots \ldots \ldots \ldots \ldots \ldots \ldots \ldots \ldots \ldots \ldots \ldots$

8.2.1 Stabilisation performance $\ldots \ldots \ldots \ldots \ldots \ldots \ldots \ldots \ldots \ldots \ldots \ldots \ldots \ldots \ldots \ldots$

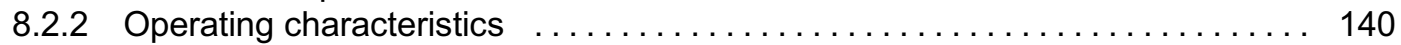

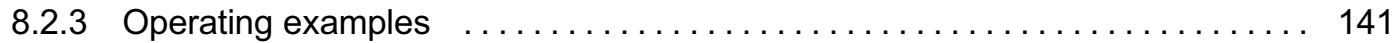

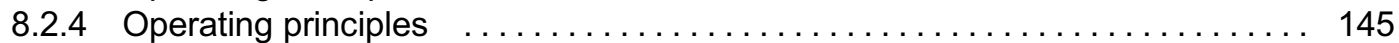

8.3 Sludge Dewatering $\ldots \ldots \ldots \ldots \ldots \ldots \ldots \ldots \ldots \ldots \ldots \ldots \ldots \ldots \ldots \ldots \ldots \ldots \ldots \ldots$

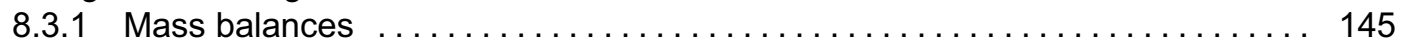

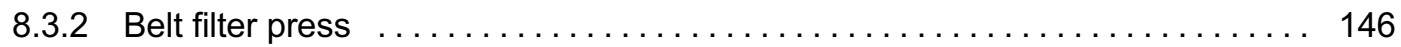

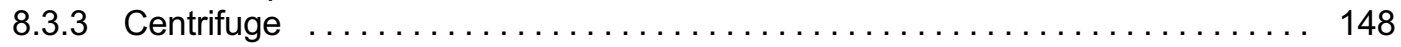

\section{Chapter 9}

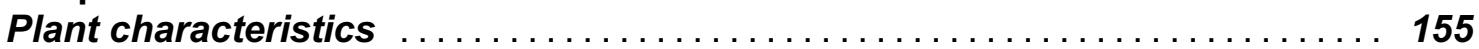

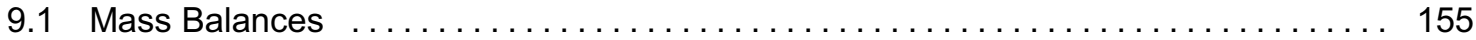

9.2 Operational Process Capacity $\ldots \ldots \ldots \ldots \ldots \ldots \ldots \ldots \ldots \ldots \ldots \ldots \ldots \ldots \ldots \ldots$

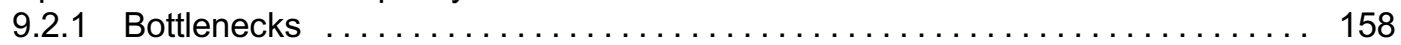

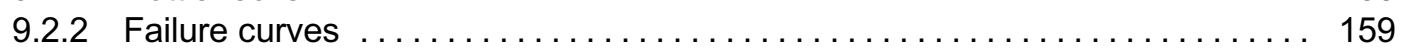

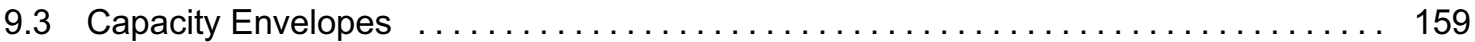

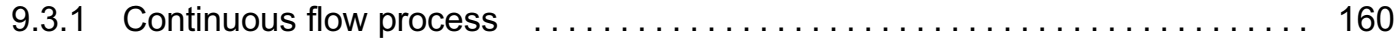

9.3 .2 SBR process $\ldots \ldots \ldots \ldots \ldots \ldots \ldots \ldots \ldots \ldots \ldots \ldots \ldots \ldots \ldots \ldots \ldots \ldots \ldots$ 


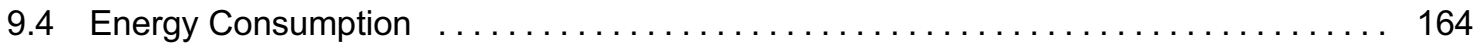

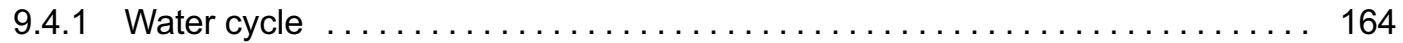

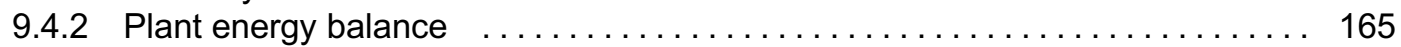

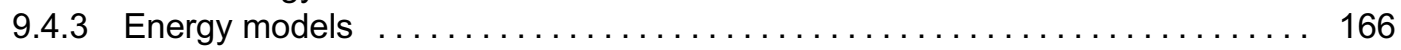

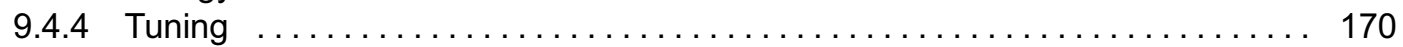

\section{Chapter 10}

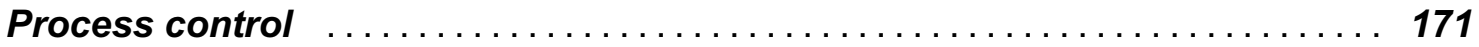

10.1 The Role of Control and Automation $\ldots \ldots \ldots \ldots \ldots \ldots \ldots \ldots \ldots \ldots \ldots \ldots \ldots \ldots \ldots \ldots \ldots \ldots \ldots$

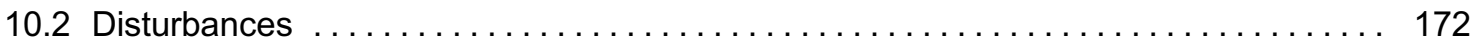

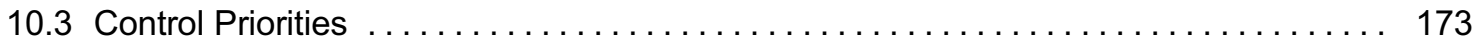

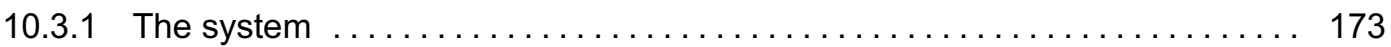

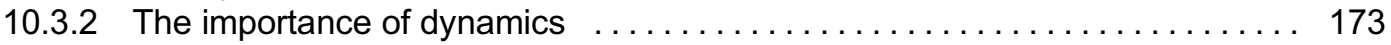

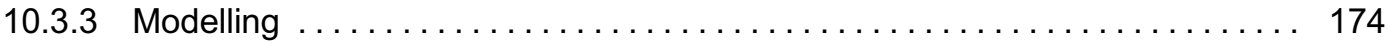

10.4 Feedback Control ............................................. 174

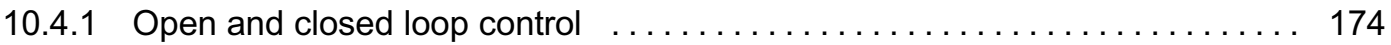

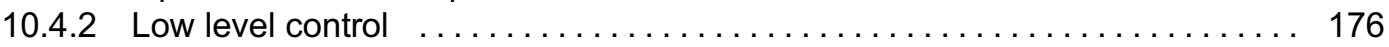

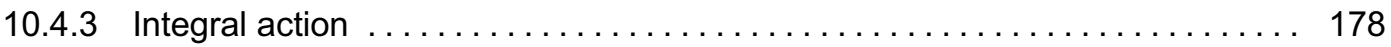

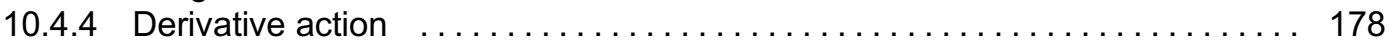

10.4.5 Computer realisation of the PID controller ..................... 179

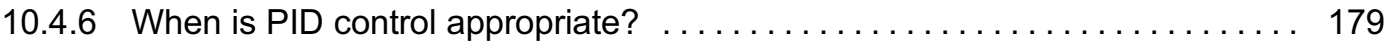

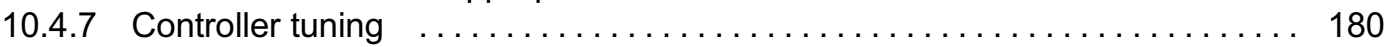

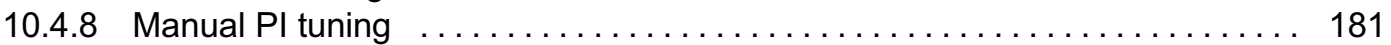

10.4.9 Ziegler-Nichols frequency response method $\ldots \ldots \ldots \ldots \ldots \ldots \ldots \ldots, 182$

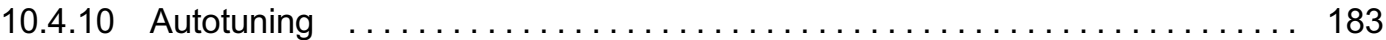

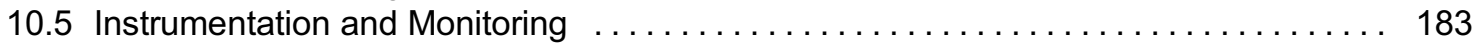

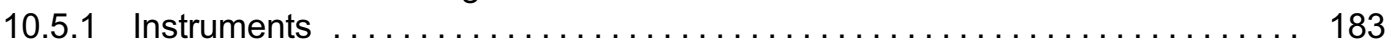

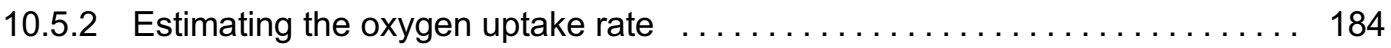

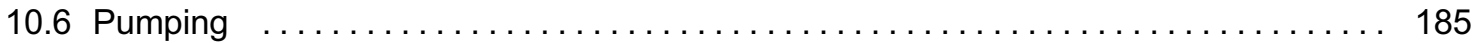

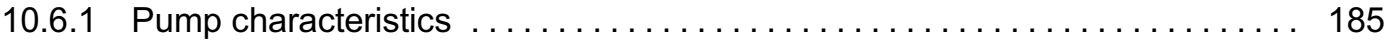

10.6.2 Relationship between flow rate and power $\ldots \ldots \ldots \ldots \ldots \ldots \ldots \ldots \ldots 187$

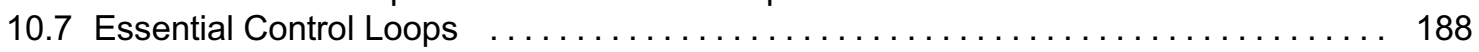

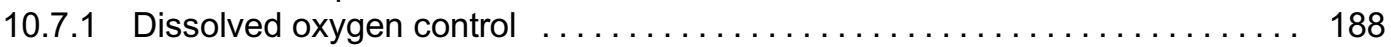

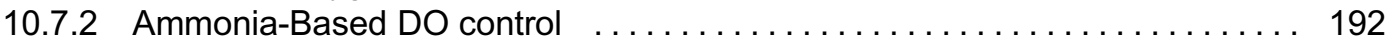

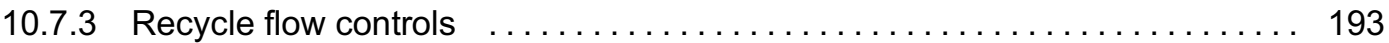

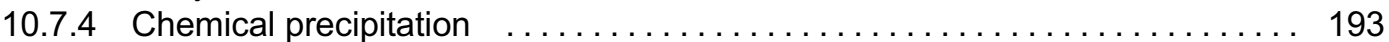

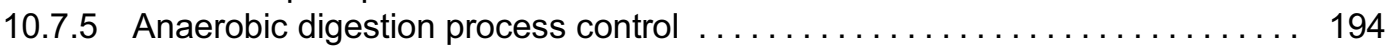

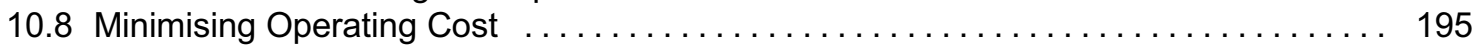

10.8.1 Approaches ........................................... 195

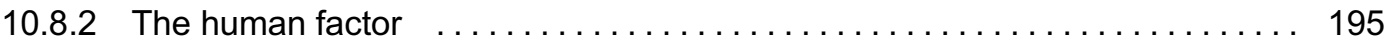

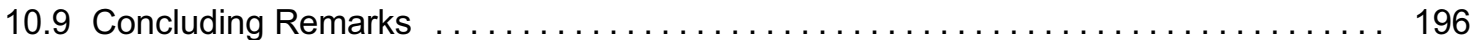




\section{Chapter 11}

Evolutionary operation

11.1 Learning

11.2 Application to Sewage Treatment Plants

11.2.1 Plant improvement strategies

11.2.2 Learning curves

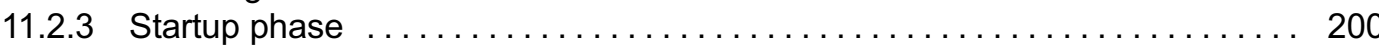

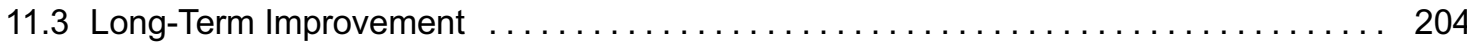

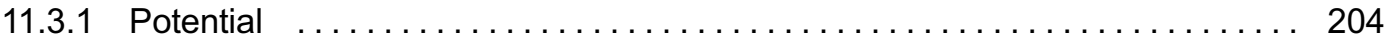

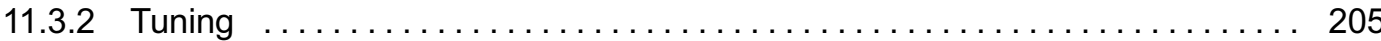

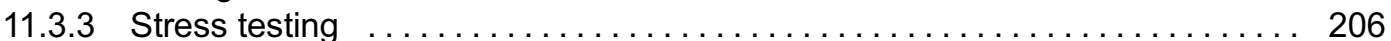

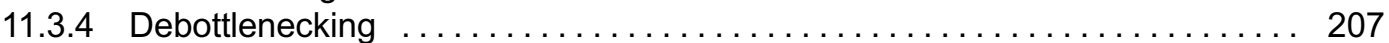

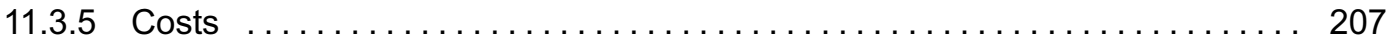

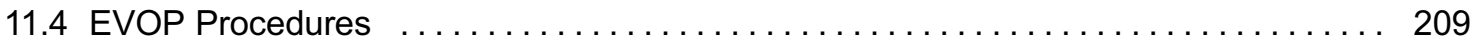

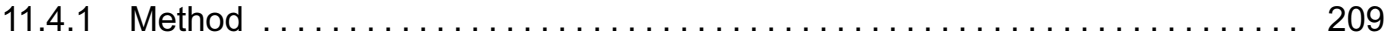

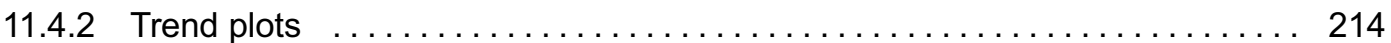

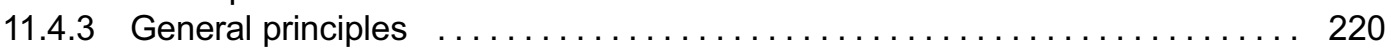

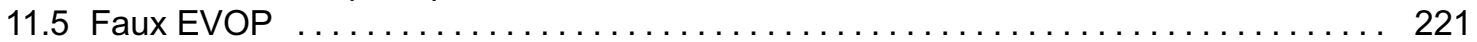

\section{Appendix 1}

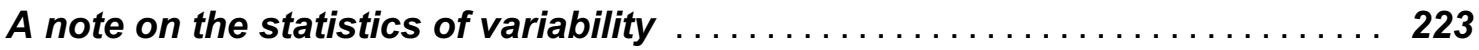

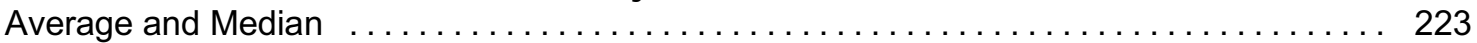

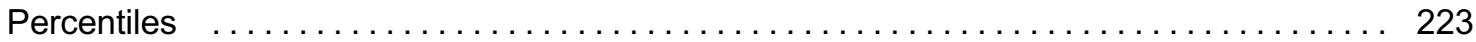

Application ......................................... 224

\section{Appendix 2}

Chemicals: useful properties $\ldots \ldots \ldots \ldots \ldots \ldots \ldots \ldots \ldots \ldots \ldots \ldots \ldots \ldots \ldots$

\section{Appendix 3 \\ Abbreviations}

References

Index 


\section{About the Authors}

\section{Ken Hartley}

Ken Hartley is a water and wastewater process engineer with over forty years experience in ten countries. He has worked for the South Australian Engineering and Water Supply Department (now the South Australian Water Corporation), consulting engineers GHD and The University of Queensland. Since 1998 he has been an independent consulting engineer and since 2005 an adjunct professor in chemical engineering at The University of Queensland.

Ken has authored over fifty published papers and two previous books, Operating the Activated Sludge Process and Chemistry of Chlorinated Swimming Pools.

\section{Gustaf Olsson}

Gustaf Olsson has contributed Chapter 10. Gustaf is professor in industrial automation and since 2006 professor emeritus at Lund University, Sweden. He has devoted his research to control and automation in water systems, electrical power systems and industrial processes. His research has lately been focused on the water-energy nexus.

Gustaf has spent extended periods as a guest professor and visiting researcher at other universities and companies in Sweden, UK, USA, Australia, Japan, Malaysia and China. He has been invited as guest lecturer and speaker in another thirteen countries. Gustaf has authored eight books published in various languages and contributed chapters to another seventeen including this one. He has over 140 scientific publications and has served in various positions within the International Water Association. 


\section{Acknowledgements}

Over the years, the author has had the opportunity to mess about in a large number of interesting treatment plants. Plant owners have generously allowed previously unpublished insights to be incorporated in this book for the benefit of others. Their support is gratefully acknowledged as follows:

ACTEW (ACT Electricity and Water), Canberra. For allowing operating data from their Lower Molonglo plant to be included in Chapter 7.

Byron Shire Council, northern NSW. For allowing operating data from their West Byron and Brunswick Valley plants to be included in Chapters 3, 4, 7, 8, 9 and 11.

Logan Water, southeast Queensland. For allowing operating data from their Flagstone, Jimboomba and Loganholme plants to be included in Chapters 4 and 7.

Melbourne Water Corporation. For allowing operating data from their Eastern plant to be included in Chapter 7.

Queensland Urban Utilities, Brisbane. For allowing energy consumption data from their Gibson Island and Wacol plants to be included in Chapter 9.

Redland Water, southeast Queensland. For allowing operating data from their Thorneside plant to be included in Chapters 9 and 11.

South Australian Water Corporation. For allowing influent data from their Port Pirie plant to be included in Chapter 2.

Townsville Water, north Queensland. For allowing operating data from their Cleveland Bay plant to be included in Chapters 2, 3, 6 and 9 and Appendix 1; and for permission to use the cover photograph.

Unitywater, southeast Queensland. For allowing operating data from their Coolum, Maroochydore, Nambour, Redcliffe and Woodford plants to be included in Chapters 2, 3, 4, 6, 8, 9 and 11.

Water Corporation, Perth. For allowing the results of a study of the effect of sample storage time on BOD and COD results to be included in Chapter 2. 


\section{Preface}

This is a book about understanding and tuning sewage treatment plants. I wrote it for two people - you and me. For myself because I wanted to record my learnings and insights for future reference; for you because I wanted to share my insights so you could use them and build on them. The original title of the book was The Quintessential Operator because I believe tuning is the quintessence of plant operation. However IWA Publishing pointed out that you would be less likely to find the book on the internet if the keywords were not included in the title. So the sub-title became the title.

The intent is not to cover all processes but to focus on the key components of most BNR plants and discuss the approach to or philosophy of tuning for maximum performance and capacity. The underlying tuning principles - based on an understanding of the behavioural characteristics of processes and their interactions - are universally applicable.

We are indeed fortunate that Gustaf Olsson has been willing to contribute Chapter 10 on automatic process control, an area in which I am unknowledgeable. Now that he has joined forces he may feel obliged to answer our further queries! ${ }^{1}$

We are also indebted to the many Australian plant owners who have generously permitted their plant data to be incorporated - they are acknowledged individually in Acknowledgements.

The philosophy of this book is Evolutionary Operation (EVOP) ${ }^{2}$ applied to sewage treatment plants - a process of ongoing improvement. ${ }^{3}$ The capacity and performance capabilities of a plant are not fixed; both are amenable to ongoing enhancement through systematic and enthusiastic effort. I hope this book will encourage sewage treatment enthusiasts to lift their sights and set new benchmarks.

\section{Ken Hartley}

\footnotetext{
${ }^{1}$ You'll enjoy Gustaf in: Olsson G. (2012). ICA and me - a subjective review. Water Research, 46(6), 1585-1624.

${ }^{2}$ Box G. E. P. and Draper N. R. (1969). Evolutionary Operation: A Statistical Method for Process Improvement. John Wiley.

${ }^{3}$ Goldratt E. M. and Cox J. (2004). The Goal: A Process of Ongoing Improvement. $3^{\text {rd }}$ revised ed. North River Press, Great Barrington, Massachusetts, USA.
} 


\section{Chapter 1}

\section{What is tuning?}

Process tuning is the quintessence of plant operation. Tuning is the art of striving to achieve and maintain peak plant performance, or to achieve maximum plant capacity, as defined by a set of operating goals. Tuning increases both performance and capacity by testing and pushing out the operating capacity envelope of the plant.

Sewage treatment plants ${ }^{1}$ have a special role in the nutrient cycle that sustains life on Earth. Sewage treatment provides controlled decomposition of the concentrated human wastes produced in our towns and cities, recycling the nutrients without overloading the local environment. This is illustrated in the simplified nutrient cycle shown in Figure 1.1. Currently the main purpose of treatment is to purify the sewage, however in the future direct nutrient recovery and recycling will become more important.

The core processes used in sewage treatment plants are adaptations of the natural nutrient cycle. Process behaviour is subject to climatic influences and the natural performance variability of all biological systems. The process loading (sewage flow and organic loading) is also variable because of seasonal, diurnal, social and statistical influences. Treatment plants therefore need to be continuously optimised to maintain best performance under variable loading conditions.

Conscious effort applied to any area of human activity results in improvement in performance. Such improvements have been demonstrated repeatedly in construction, manufacturing and chemical processing operations and the curves of gradually increasing production rate, improving performance and decreasing cost are called learning curves. In the process industries this has been termed performance and capacity creep (Brennan \& Greenfield, 1994).

A valuable technique for maximising the rate of learning is a method of routine operation called evolutionary operation, or EVOP (Box \& Draper, 1969). This is a structured method for deliberate learning based on the philosophy "that it is inefficient to run an industrial process in such a way that only a product is produced, and that a process should be operated so as to produce not only a product but also information on how to improve the product." EVOP is a "tool in which a continuous investigative routine becomes the basic mode of operation for the plant and replaces normal static operation" (ibid, p5). A similar process of ongoing improvement in manufacturing plants is the subject of an absorbing novel by Goldratt and Cox (2004).

\footnotetext{
${ }^{1}$ I prefer the original name sewage to wastewater. Wastewater connotes uselessness whereas sewage is a resource containing pure water, nutrients and energy which are amenable to recovery and reuse. From the multitude of plant names in use, I usually choose to use sewage treatment plant (STP).
} 


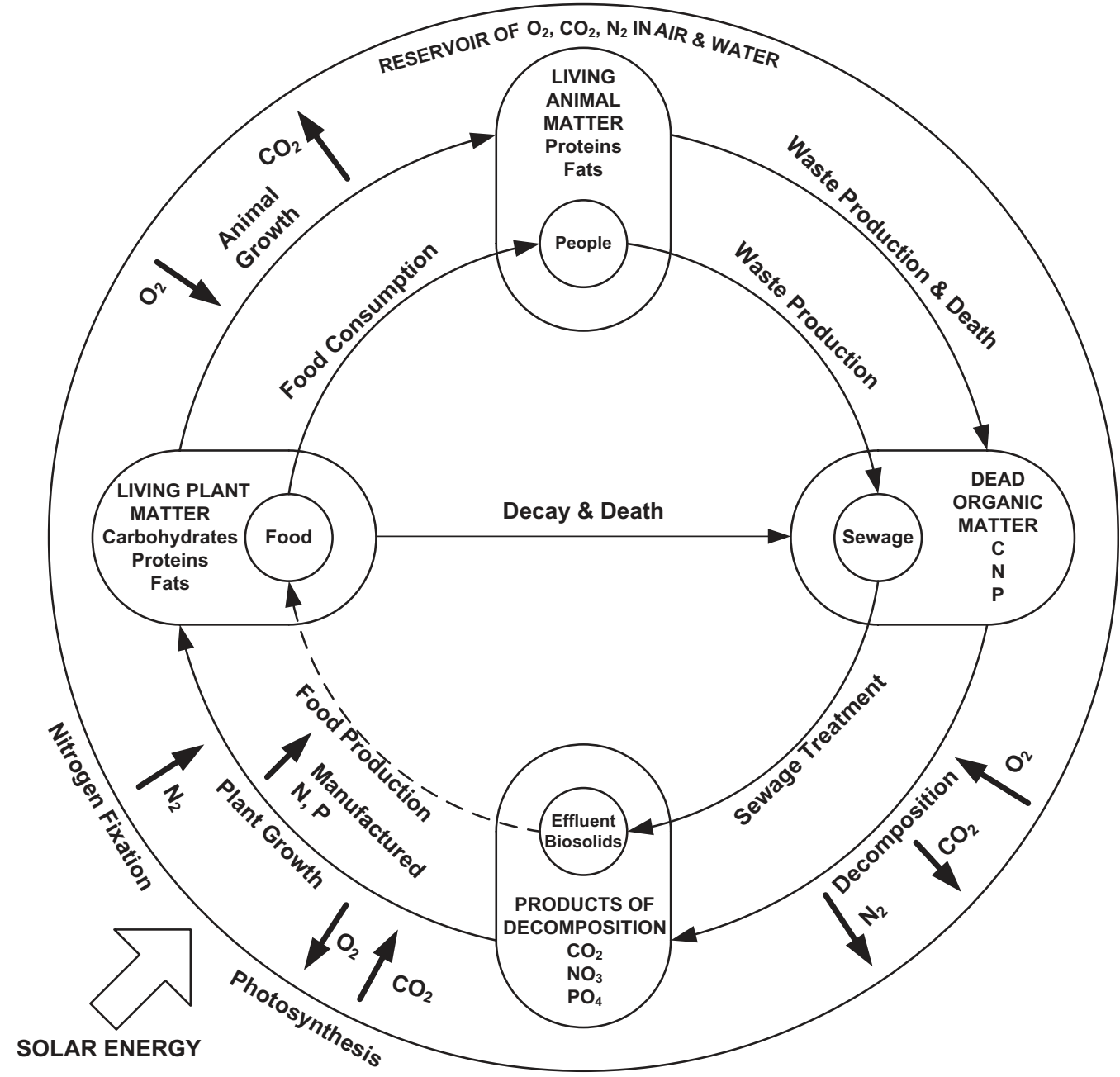

Figure 1.1 Simplified major nutrient cycle (after Fair et al., 1968).

The basic tuning strategy is illustrated in Figure 1.2. The steps are as follows:

(1) Define goals and set targets.

(2) Set the plant control variables.

(3) Measure the outcomes.

(4) Interpret the data and develop ideas for improvement.

(5) Re-adjust the process.

(6) Conduct trials and tests on specific processes or the whole plant.

These steps form the basis of an ongoing EVOP strategy which will produce long-term benefits. Tuning transcends troubleshooting in its usual connotation of major unexpected problems. Close monitoring and interpretation of plant behaviour gives early warning of undesirable trends and the need for corrective action. 


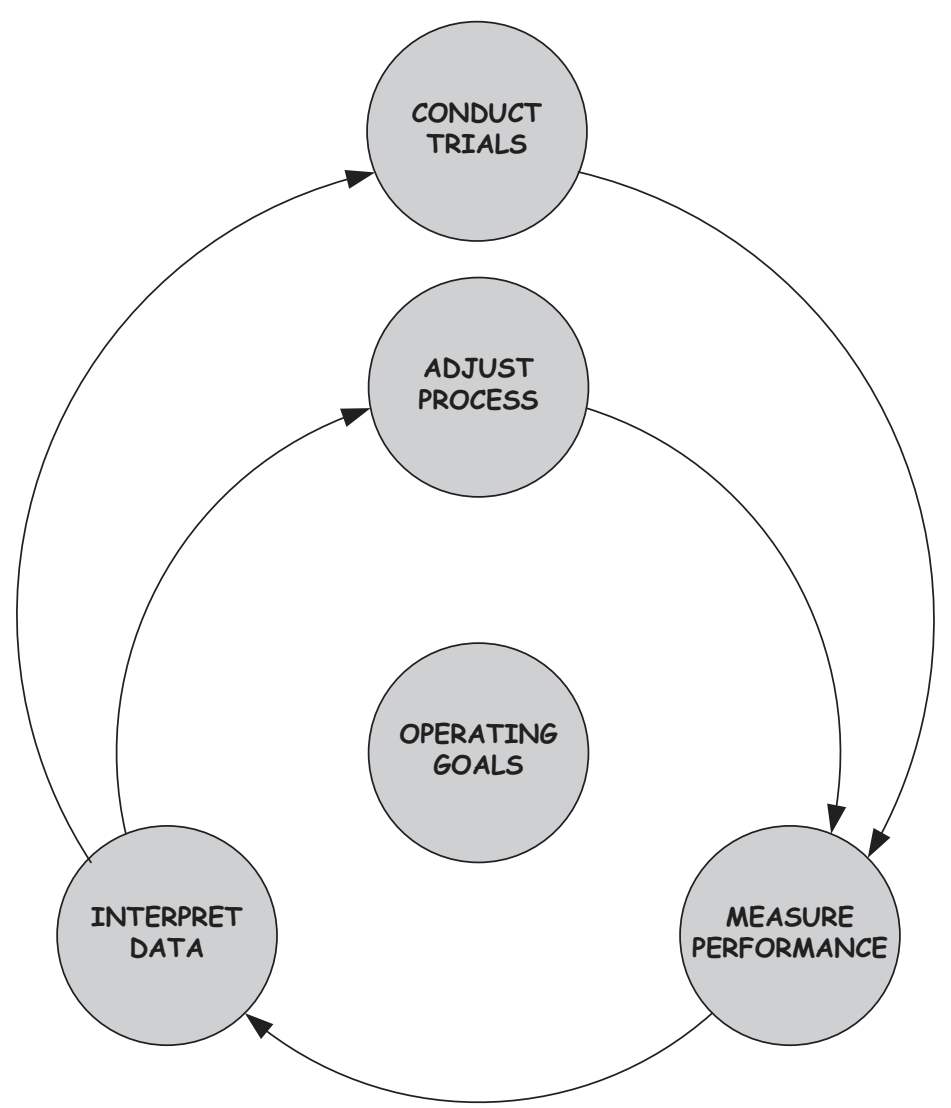

Figure 1.2 Plant operating cycle.

It is important to realise that the actual capacity and performance capabilities of an operating plant are nearly always different from the original design values. This arises because of design and construction margins, influent flow and quality characteristics differing from design, and the accumulation of specific operational know-how on the plant which improves performance and enables bottlenecks to be identified and overcome. The operator's main task is to determine the real capabilities of the plant and to get the very best out of it despite apparent deficiencies in the design. Design and operating perspectives are different. Capital cost, completion time and contractual issues weigh heavily during design and construction. However, savings in initial cost and construction time are soon forgotten once operation begins.

In general terms, the plant operating goals can be expressed as follows:

- Meet effluent quality standards.

- Meet biosolids quality standards.

- Meet odour standards.

- Meet energy consumption or greenhouse emission limits.

- Maximise plant capacity.

- Meet an operating cost limit. 
These goals will be quantified to produce specific targets which may be tightened as plant performance is enhanced over time. Inevitably there will need to be trade-offs among the various goals.

The key to better performance is improved understanding of plant behaviour. This book is therefore ordered as follows: influent and effluent characteristics; individual process characteristics; overall plant characteristics; and the EVOP process. 


\section{Chapter 2}

\section{Influent and effluent characteristics}

\subsection{THE CATCHMENT}

Sewage characteristics vary from plant to plant and operators need to develop a detailed understanding of their own influent. Sewage has several components - domestic, commercial, industrial and institutional effluents, stormwater inflow and groundwater infiltration. The pollutional components of most sewages are predominantly domestic, modified to some degree by the other effluents. This chapter examines the characteristics of domestic sewage conveyed in separate sewers with no deliberate stormwater conveyance.

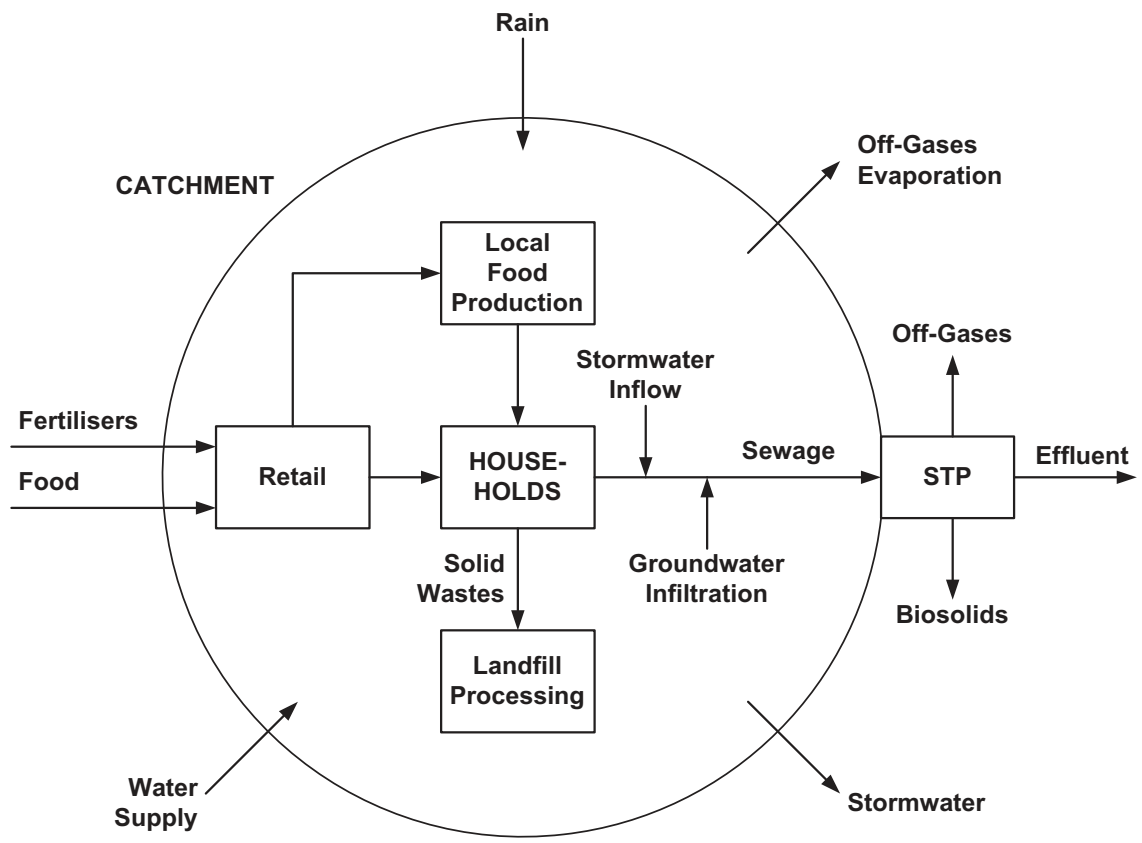

Figure 2.1 The simple sewerage catchment. 
Domestic sewage has many constituents derived from both the water supply and its household uses. Here our attention is focused on the parameters of most importance in nutrient removal plants. Discussion of other constituents can be found in a range of references (e.g. Metcalf and Eddy, 2003; Ternes \& Joss, 2006).

Sewage has two primary characteristics, flow and mass loading. For pollutants added during use of the water, concentration is a secondary characteristic-(mass load)/flow. However, concentration is the predominant characteristic for constituents such as alkalinity which are derived in significant part from the water supply and modified by groundwater and stormwater ingress.

Figure 2.1 shows the behaviour of a simple sewerage catchment. Flow is derived predominantly from household water use. Pollutants come mainly from household food and cleaning products. We look at a mass balance on the human body later but it is interesting to reflect that the truckloads of food and detergents arriving at the local supermarkets represent the main part of the load subsequently arriving at the sewage treatment plant.

\subsection{FLOW CHARACTERISTICS}

Sewage flow generally exhibits seven distinct characteristics: (1) a base flow generally called average dry weather flow (ADWF), (2) a diurnal flow pattern, (3) a (weak) weekly flow pattern resulting from the weekly living cycle, (4) a seasonal flow pattern derived from rainfall-induced inflow and groundwater infiltration, (5) occasional short-term variations associated with holiday periods and special community events, (6) long-term increase caused by growth in the contributing population, and (7) statistical variability overlying the whole picture. The rhythms of life. These characteristics are interwoven in the historical record and it is often difficult to separate them. For practical purposes, it is more useful to use a statistical approach to the whole record. Growth can be quantified from the long-term trend. For periods of more or less constant load, use the median (50 percentile) flow as the baseline. This is the daily flow exceeded on $50 \%$ of days and is usually within $10 \%$ of the average. ${ }^{1}$

Figure 2.2 shows the daily flow and rainfall at the Maroochydore STP for the two years 2005-06. The influences of stormwater inflow and groundwater infiltration can both be seen. The simplest way to reduce this record to a useable form and increase our insight is to produce a flow frequency distribution. Flow frequency plots for Maroochydore and three other plants are shown in Figure 2.3. These diagrams are produced by sorting and ranking the daily flows over several years. Three years of data are needed to reach the $0.1 \%$ level.

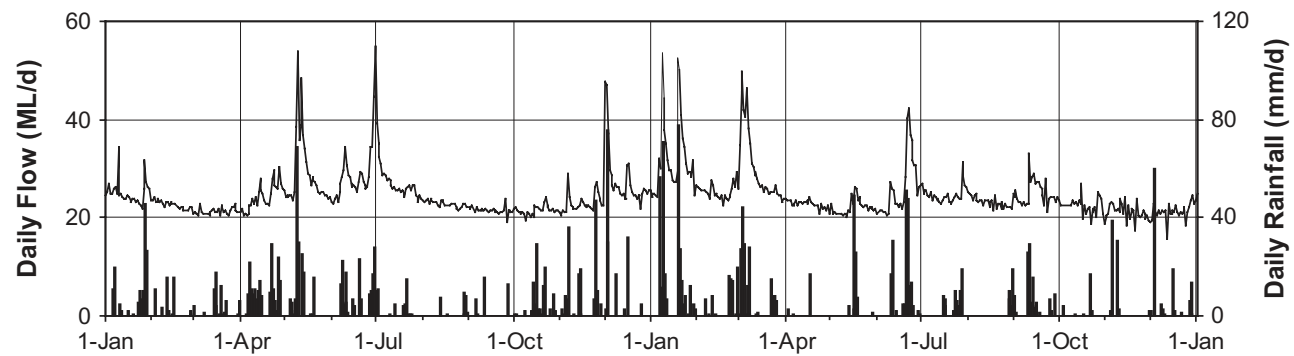

Figure 2.2 Two years of daily flow and rainfall at the Maroochydore STP (QId) (2005-06).

${ }^{1}$ The simple statistics used in this book are explained in Appendix 1. 


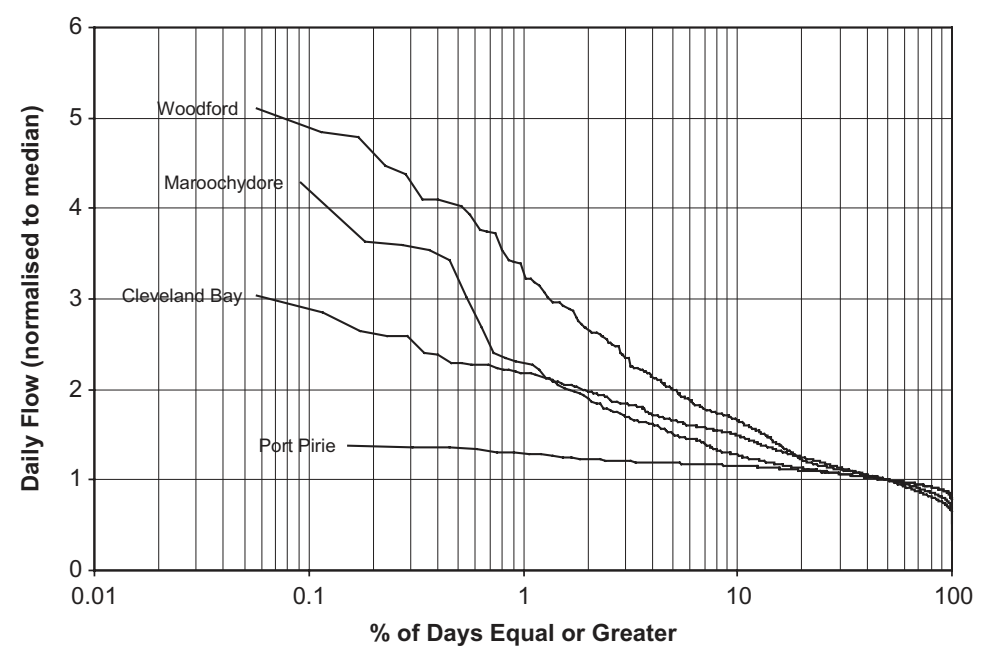

\begin{tabular}{lcccc}
\hline Plant & Data Period & $\begin{array}{l}\text { Average } \\
\text { Rainfall } \\
\text { (mm/y) }\end{array}$ & $\begin{array}{l}\text { Median } \\
\text { Flow } \\
\mathbf{Q}_{\mathbf{5 0}} \text { (ML/d) }\end{array}$ & $\begin{array}{l}\text { Average: } \\
\text { Median Flow } \\
\mathbf{Q}_{\text {AvE: }} \mathbf{Q}_{\mathbf{5 0}}\end{array}$ \\
\hline Woodford (Qld) & 5y, 2004-08 & 957 & 0.29 & 1.12 \\
$\begin{array}{l}\text { Maroochydore (Qld) } \\
\begin{array}{l}\text { Cleveland Bay } \\
\text { (Townsville, Qld) }\end{array}\end{array}$ & 3y, 2005-07 & 1516 & 24 & 1.07 \\
Port Pirie (SA) & 2y, Aug-98 to & 370 & 21 & 1.08 \\
& Jul-00 & & 3.4 & 1.02 \\
\hline
\end{tabular}

Figure 2.3 Flow frequency distributions.

Two orders of plant size are represented (0.3-24 ML/d). The Maroochydore and Cleveland Bay plants are of similar size and the effect of the higher rainfall at Maroochydore is evident. The small plant at Woodford has a lower rainfall than Maroochydore but leakier sewers. At the other end of the scale, the medium size plant at Port Pirie is located in an arid region and suffers very little flow peaking. Because of wet weather peaks the average flow always exceeds the median, with margins of $2-12 \%$ at the four example plants as listed in the Figure.

For practical purposes, the following assumptions are generally made about this type of statistical flow frequency diagram:

- The period of records used is assumed to provide a reasonable representation of future flow characteristics. Rainfall for the historical period can be compared with the long-term rainfall record but predictions are always uncertain.

- The diagram is constructed from the flows on random rather than consecutive days. Because wet days generally occur in runs (see Figure 2.2), it is assumed that a diagram constructed using consecutive days would not be much different. Therefore, for example, the flow shown on the diagram for $8 \%$ exceedance is assumed to be a useful representation of the flow for the peak month in a year (30 consecutive days rather than 30 random high rainfall days). 
- The diagram is based on daily flows but it is assumed that percentage of days in the data period can be interpreted generally as percentage of time. For example, the 0.1 percentile can be interpreted as $0.1 \%$ of a year (8.76 hours per year).

- To provide insight into low probability events, it is assumed the plot can be extrapolated to lower frequencies. Of course, the maximum flow rate is limited by the maximum capacity of the sewerage system to deliver flow to the plant.

With percentiles it is useful to think in approximate practical terms. For example:

\begin{tabular}{lcc} 
& \% greater than & \% less than \\
\hline Peak month in a year & 10 & 90 \\
Peak week in a year & 2 & 98 \\
Peak day in a year & 0.3 & 99.7 \\
Peak day in 5 years & 0.05 & 99.95 \\
Peak hour in a year & 0.01 & 99.99
\end{tabular}

While the frequency plot shows the percentage of time the flow exceeds various values, areas under the curve give percentage of volume discharged. Referring to the Woodford curve replotted in Figure 2.4 (using a natural scale to provide a better perspective on the percentages involved), the total area under the curve (from $0-100 \%$ ) gives the ratio of average flow:median flow (1.12 in this case as listed in Figure 2.3). For illustration, if the plant treatment capacity happened to be $1.8 \mathrm{Q}_{50}$ (which is lower than the real figure) and bypassing occurred at higher flows, the percentage of total sewage flow bypassed would be given by the area ABCA as a percentage of the total area under the curve.

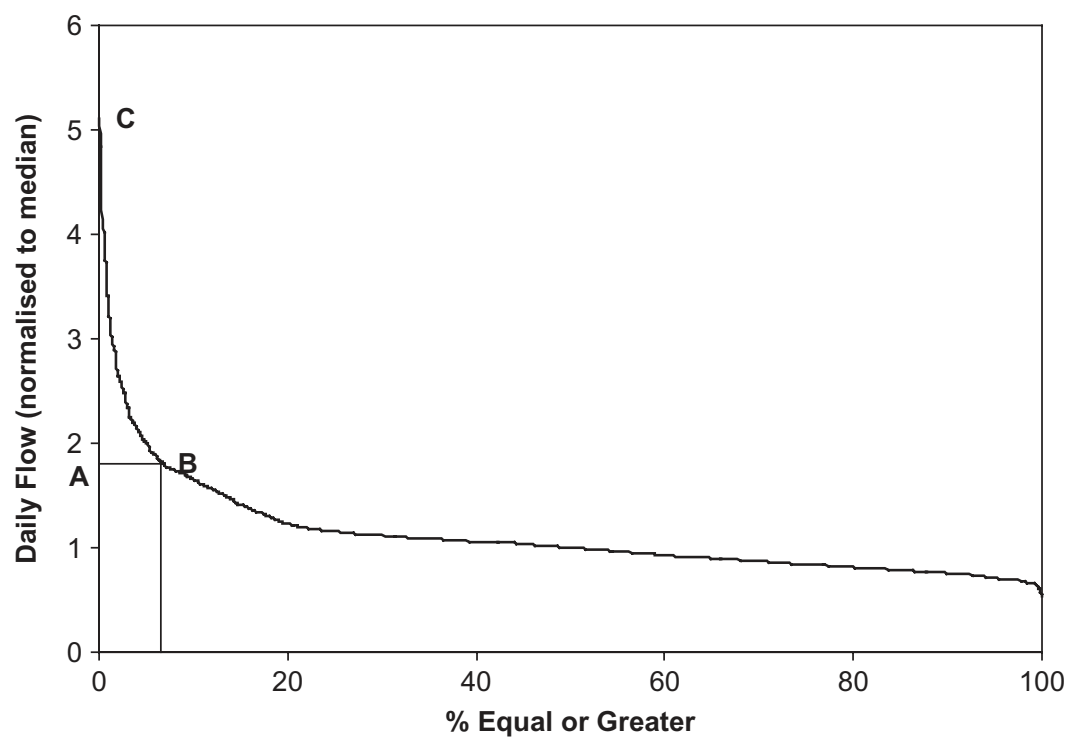

Figure 2.4 Woodford flow frequency distribution. 
Figure 2.5 illustrates diurnal flow patterns for the Redcliffe and Cleveland Bay STPs (both in Qld). For Redcliffe the figure shows the average and range for five weekdays and the average for the two weekend days. The morning peak on the weekend lags the weekdays by about an hour. This is a typical observation, reflecting the change in lifestyle at the weekend. The amplitude and timing of the diurnal curve varies with the size and nature of the catchment, and with the lifestyle of the contributing population.

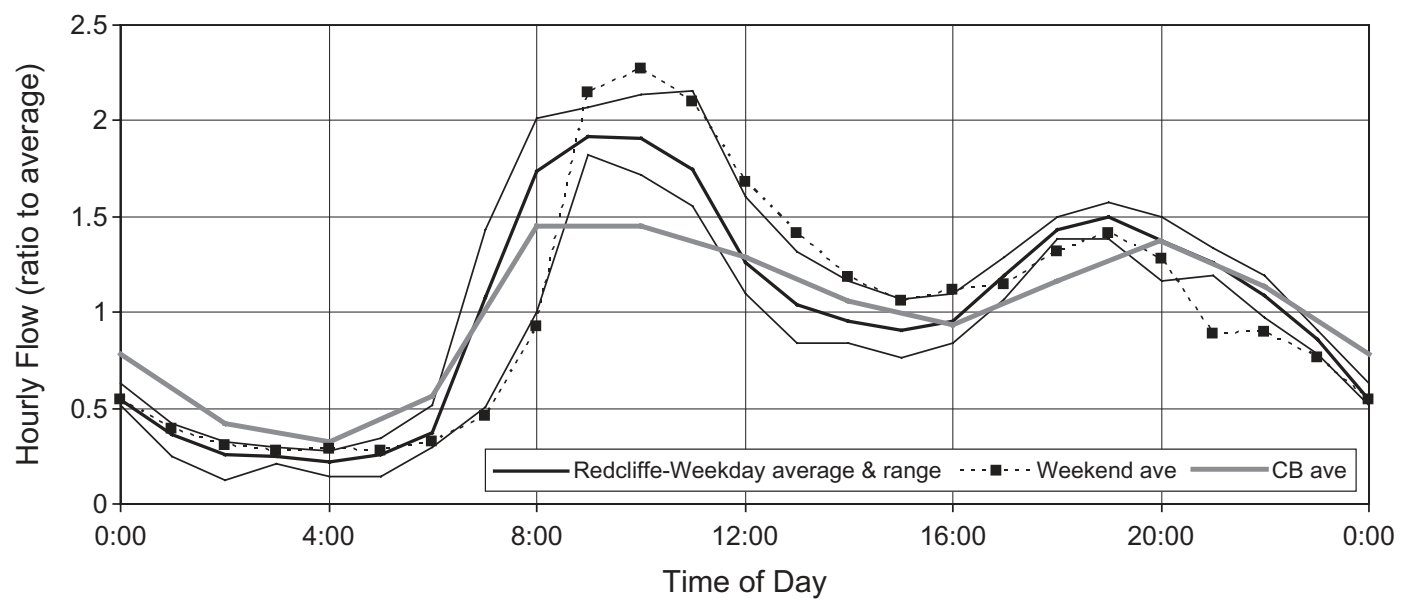

Figure 2.5 Diurnal flow patterns at the Redcliffe STP (QId), median flow $14 \mathrm{ML} / \mathrm{d}$; data for seven days, 8-14 Jun 97. For comparison an average weekday pattern at the Cleveland Bay plant is also shown (2-6 Aug 04).

\subsection{MASS LOADING CHARACTERISTICS}

The constituents of domestic sewage come from three main sources: (1) mass inputs during household use of the water (the most important), (2) the source water supply (inorganics), and (3) groundwater infiltration to the sewers (especially salinity and organic colour). The sewage quality is also often modified by biochemical transformations in the sewerage system, particularly in the rising mains. And like the flow, the quality also exhibits substantial statistical variability.

The domestic mass load comprises human and other household wastes. Bodily wastes constitute the major part of the load and an indicative steady state mass balance on the adult human body is shown in Table 2.1 and Figure 2.6. These figures relate to an adult living a light activity lifestyle on a diet typical in Europe pre-1981 and vary with age, weight, gender, activity level and diet. The total outputs are supplemented in the sewer by other household outputs from the kitchen, bathroom and laundry.

The fundamental constituent is the organic content (organic carbon), quantified here using COD (chemical oxygen demand). This is the residue from the organic food providing the basic energy requirement of the human body. The table indicates that close to $90 \%$ of the chemical energy in food is extracted by the human body. The levels of the primary nutrients, nitrogen and phosphorus, reflect both diet and, in the case of phosphorus, the use of powdered laundry detergent. The table gives a TN:TP ratio of 7.5 whereas detergent use reduces the ratio in a typical Australian sewage to about 5 . 
Table 2.1 Mass balance on a $65 \mathrm{~kg}$ adult (light activity) ${ }^{1}$.

\begin{tabular}{|c|c|c|c|c|c|c|c|c|}
\hline \multirow[t]{2}{*}{ Component } & \multirow{2}{*}{$\begin{array}{l}\text { Whole } \\
\text { body }\end{array}$} & \multicolumn{2}{|c|}{ Intake } & \multicolumn{5}{|c|}{ Output } \\
\hline & & $\begin{array}{l}\text { Diet } \\
(g / d)\end{array}$ & $\begin{array}{l}\text { Air } \\
(g / d)\end{array}$ & $\begin{array}{c}\text { Gases } \\
(\mathrm{g} / \mathrm{d})\end{array}$ & $\begin{array}{l}\text { Sweat } \\
\text { (g/d) }\end{array}$ & $\begin{array}{l}\text { Urine } \\
(\mathrm{g} / \mathrm{d})\end{array}$ & $\begin{array}{l}\text { Faeces } \\
(\mathrm{g} / \mathrm{d})\end{array}$ & $\begin{array}{l}\text { Total } \\
\text { (g/d) }\end{array}$ \\
\hline \multicolumn{9}{|l|}{ Major Items } \\
\hline Water & 63 & 3700 & & 300 & 2000 & 1300 & 80 & 3700 \\
\hline $\mathrm{O}_{2}$ & & & 800 & & & & & \\
\hline $\mathrm{CO}_{2}$ & & & & 900 & 0.2 & $0.1^{3}$ & 0.1 & 900 \\
\hline $\mathrm{CH}_{4}$ & & & & Trace & & & & Trace \\
\hline COD & & 900 & & & 10 & 40 & 60 & 110 \\
\hline TS & 37 & 630 & & & 15 & $45^{4}$ & 35 & 95 \\
\hline VS & 30 & 600 & & & 7 & $25^{4}$ & $30^{6}$ & 60 \\
\hline VFA & & & & & $0.02^{8}$ & 4 & 1 & 5 \\
\hline Total $\mathrm{N}$ & $3.0^{2}$ & 13 & & & 0.6 & 10 & $2^{7}$ & 15 \\
\hline $\mathrm{NH}_{3}-\mathrm{N}$ & & & & & 0.1 & 1.0 & 0.06 & 1.2 \\
\hline Urea $\left[\mathrm{CO}\left(\mathrm{NH}_{2}\right)_{2}\right]$ & & & & & 2 & 21 & 0 & 23 \\
\hline Total P & 1.1 & 2.0 & & & 0.0005 & $1.5^{5}$ & $0.5^{5}$ & 2.0 \\
\hline Total S & & & & & & 1.3 & & \\
\hline Inorganic TDS & & & & & & 17 & & \\
\hline $\mathrm{pH}$ & & & & & $5.8+{ }^{8}$ & 6.2 & 7.1 & \\
\hline \multicolumn{9}{|l|}{ Cations } \\
\hline $\mathrm{Ca}$ & 2.00 & 1.0 & & & 0.06 & 0.24 & 0.67 & 1.0 \\
\hline $\mathrm{Mg}$ & 0.04 & 0.26 & & & 0.006 & 0.13 & 0.12 & 0.26 \\
\hline $\mathrm{K}$ & 0.24 & 3.8 & & & 0.7 & 2.7 & 0.44 & 3.8 \\
\hline $\mathrm{Na}$ & 0.16 & 7.6 & & & 2.2 & 5.2 & 0.15 & 7.6 \\
\hline \multicolumn{9}{|l|}{ Anions } \\
\hline $\mathrm{Cl}$ & 0.16 & 7.0 & & & 2.1 & 4.8 & 0.06 & 7.0 \\
\hline $\mathrm{SO}_{4}-\mathrm{S}$ & & & & & 0.07 & 1.15 & & \\
\hline $\mathrm{HCO}_{3}$ & & & & & $3^{8}$ & 0.05 & 0.2 & 3 \\
\hline \multicolumn{9}{|l|}{$\begin{array}{l}\text { Heavy Metals } \\
\text { (masses in } \mathrm{mg} / \mathrm{d} \text { ) }\end{array}$} \\
\hline Arsenic, As & & & & & & 0.1 & & \\
\hline Cadmium, Cd & & 0.16 & & & & 0.002 & 0.16 & 0.2 \\
\hline Chromium, $\mathrm{Cr}$ & & 0.07 & & & & 0.008 & 0.06 & 0.07 \\
\hline Copper, Cu & 0.00015 & 2.0 & & & & 0.04 & 2 & 2 \\
\hline Iron, Fe & 0.0070 & 6.1 & & & & 0.1 & 6 & 6 \\
\hline Lead, $\mathrm{Pb}$ & & 0.34 & & & & 0.04 & 0.3 & 0.3 \\
\hline Manganese, Mn & & 4.0 & & & & 0.02 & 4 & 4 \\
\hline Mercury, $\mathrm{Hg}$ & & & & & & 0.005 & & \\
\hline
\end{tabular}


Table 2.1 Mass balance on a $65 \mathrm{~kg}$ adult (light activity) ${ }^{1}$ (Continued).

\begin{tabular}{|c|c|c|c|c|c|c|c|c|}
\hline \multirow[t]{2}{*}{ Component } & \multirow{2}{*}{$\begin{array}{l}\text { Whole } \\
\text { body }\end{array}$} & \multicolumn{2}{|c|}{ Intake } & \multicolumn{5}{|c|}{ Output } \\
\hline & & $\begin{array}{l}\text { Diet } \\
(g / d)\end{array}$ & $\begin{array}{l}\text { Air } \\
(g / d)\end{array}$ & $\begin{array}{c}\text { Gases } \\
(\mathrm{g} / \mathrm{d})\end{array}$ & $\begin{array}{l}\text { Sweat } \\
\text { (g/d) }\end{array}$ & $\begin{array}{l}\text { Urine } \\
(g / d)\end{array}$ & $\begin{array}{l}\text { Faeces } \\
(\mathrm{g} / \mathrm{d})\end{array}$ & $\begin{array}{l}\text { Total } \\
(\mathrm{g} / \mathrm{d})\end{array}$ \\
\hline Nickel, Ni & & 0.26 & & & & 0.003 & 0.26 & 0.3 \\
\hline Tin, Sn & & 4.0 & & & & & 4 & 4 \\
\hline Vanadium,V & & 2.0 & & & & & 2 & 2 \\
\hline Zinc, Zn & 0.0025 & 7.0 & & & & 0.5 & $5-10$ & 7 \\
\hline \multicolumn{9}{|l|}{ Overall } \\
\hline \multirow[t]{2}{*}{ Energy } & $\mathrm{MJ} / \mathrm{d}$ & 11 & & & & & & 11 \\
\hline & $\mathrm{MJ} / \mathrm{kgVS}$ & 25 & & & & & & 25 \\
\hline COD:VSS & $\mathrm{g} / \mathrm{g}$ & & & & & & & 2.0 \\
\hline VFA:COD & $\begin{array}{l}\text { gVFA/ } \\
\text { gCOD }\end{array}$ & & & & & & & 0.05 \\
\hline TN:COD & $g / g$ & & & & & & & 0.14 \\
\hline TP:COD & $g / g$ & & & & & & & 0.018 \\
\hline TN:TP & $g / g$ & & & & & & & 7.5 \\
\hline
\end{tabular}

${ }^{1}$ Adapted from Ciba-Geigy Ltd (1981). European diet.

$216 \%$ of protein

${ }^{3}$ Partial pressure $6.7 \mathrm{kPa}$

${ }^{4}$ Dissolved

${ }^{5}$ Dissolved $P$ in urine is mainly inorganic; solid $P$ in faeces is mainly calcium phosphate

${ }^{6}$ Major components: amino acids $2.8 \mathrm{~g} / \mathrm{d}$, lactic acid $1.2 \mathrm{~g} / \mathrm{d}$

${ }^{7} 50 \%$ dissolved

${ }^{8}$ Sweat contains lactic acid; bicarbonate increases from 0 to 6 as sweat production rate increases

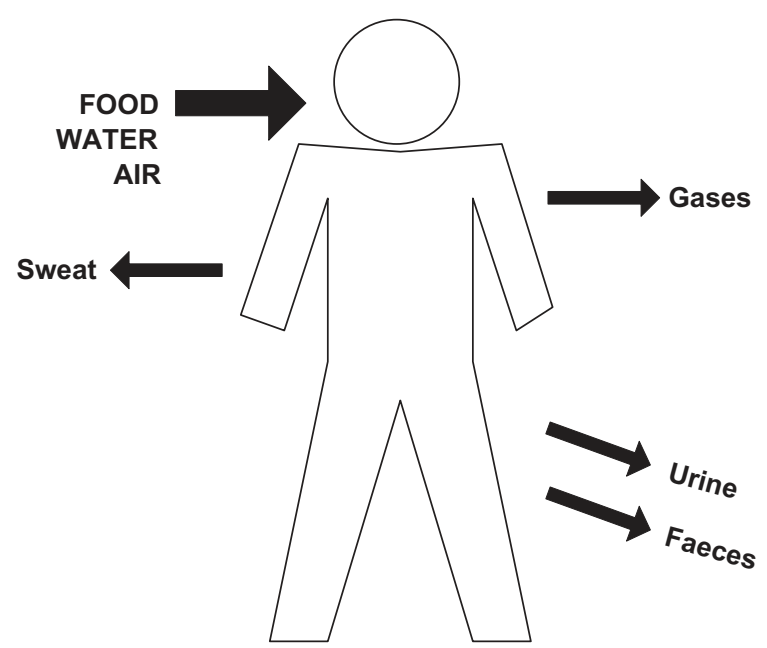

Figure 2.6 Steady state material balance on the human body; see Table 2.1. 
Variability in daily COD loading is illustrated in Figure 2.7 and load frequency distributions are compared with the associated flow frequencies in Figure 2.8. For COD loads, a useful indicator of variability is the $90 \%$ ile load (exceeded on only $10 \%$ of days).

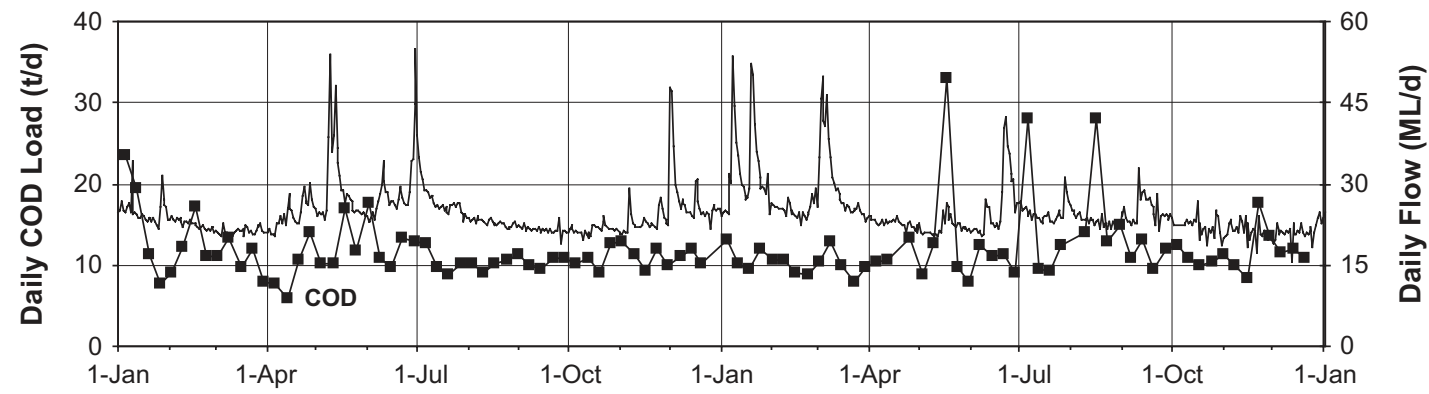

Figure 2.7 Maroochydore STP - daily COD load data added to the daily flow plot in Figure 2.2.

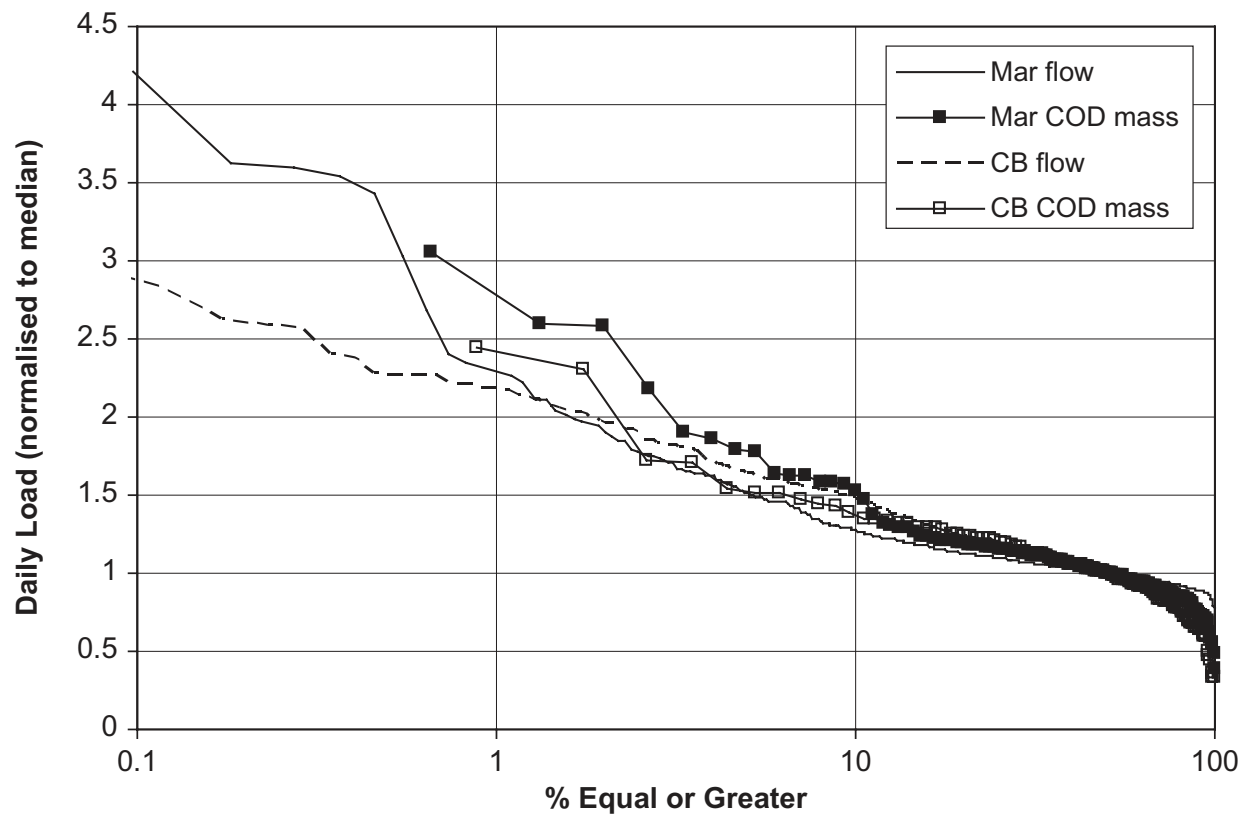

Figure 2.8 Mass load frequency distributions for the Maroochydore and Cleveland Bay plants. The flow lines are repeated from Figure 2.3 for comparison with the COD mass load distributions. The data periods are listed in Figure 2.3.

Examples of diurnal concentration and mass loading patterns are shown in Figure 2.9. These diagrams show the same plants and data periods as the flow diagram in Figure 2.5 and it is clear the factors affecting the diurnal flow pattern also affect the mass loading pattern. 
(a)

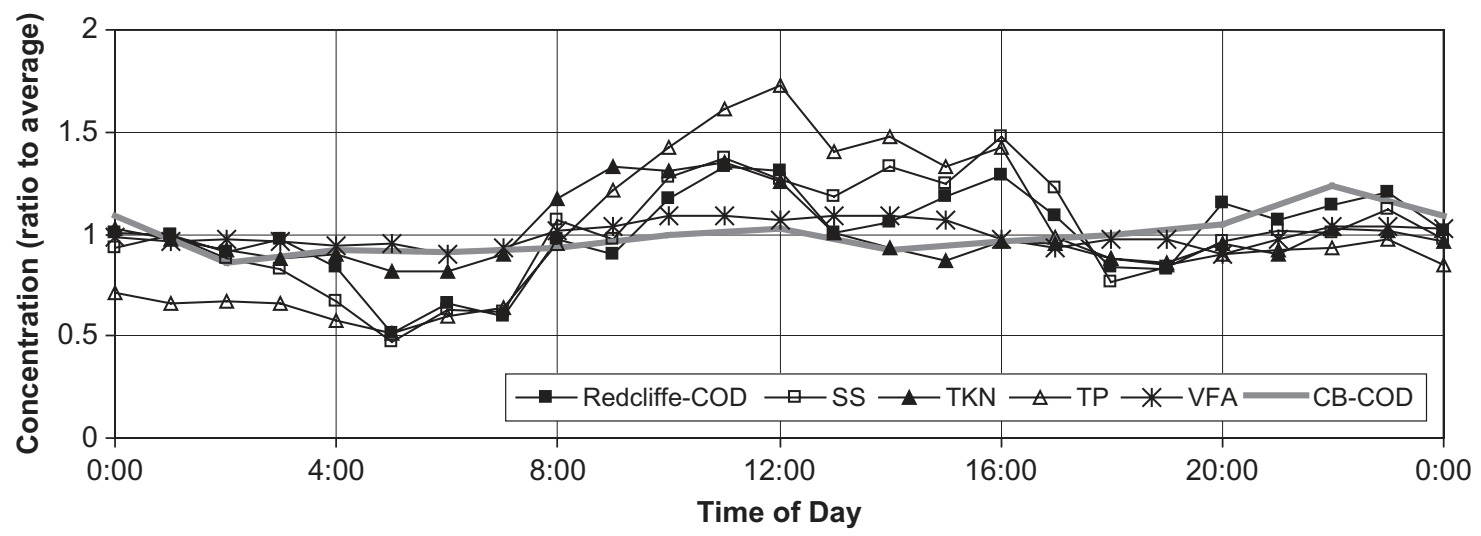

(b)

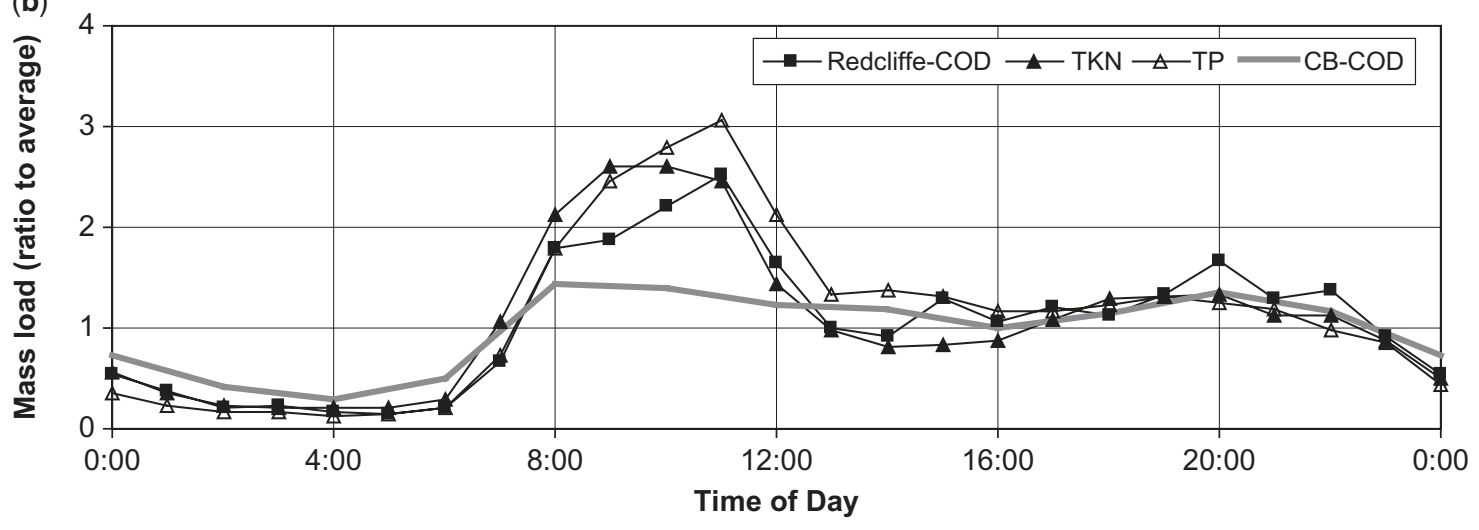

Figure 2.9 Diurnal curves of (a) concentration and (b) mass load for the Redcliffe and Cleveland Bay plants. Data are for the same weekday periods as shown in Figure 2.5.

It is more difficult and expensive to collect quality data than flow data. Twenty four hour composite sampling is required to obtain a reliable estimate of the daily loading, and flow-proportioned sampling provides a more accurate result than time-based sampling. The two sampling methods are compared in Figure 2.10.

The most common sewage characteristics are listed in Table 2.2 and discussed below in the order listed in the table.

\subsubsection{Connected population}

Total plant loading is commonly expressed in terms of equivalent population or persons (EP). This is a rubbery figure because industrial inputs generally have different EP values for flow and the various pollutants. With purely domestic sewage the EP equals the actual connected population. There are about 1000 municipal STPs in Australia with capacities ranging from less than 100 EP to 4 million EP (COD basis - Western TP, Melbourne). The overall average and median capacities are about 20,000 EP and 3000 EP respectively. 


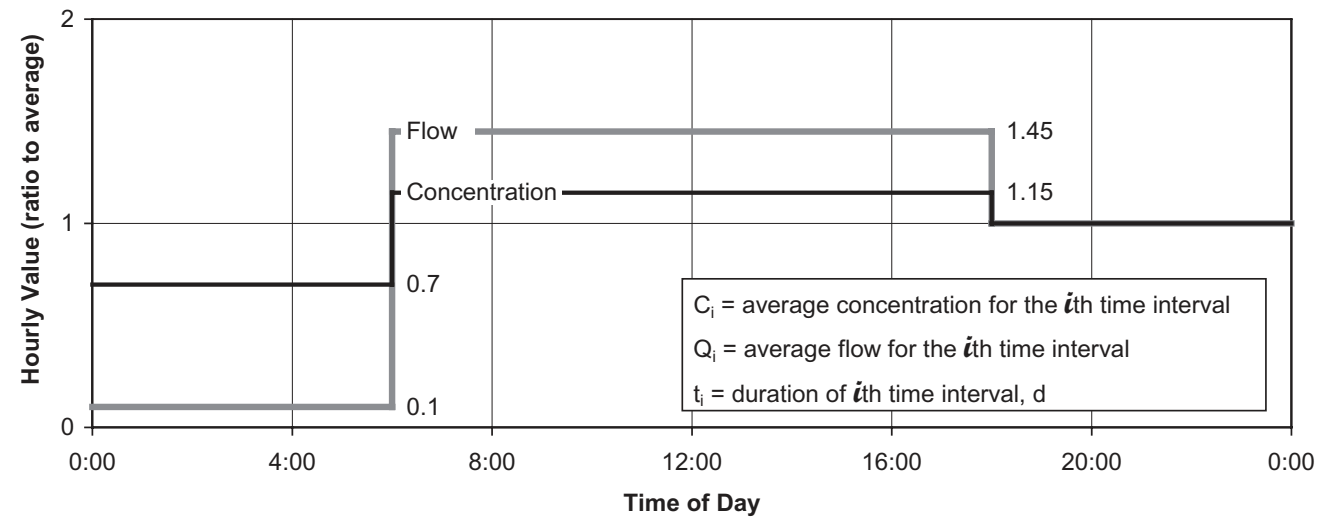

The diagram shows simplified diurnal flow and pollutant concentration profiles (relative to the respective time-based averages). The relationship between the daily time-based and flow-proportioned (true) pollutant loads can be calculated as follows:

Daily flow, $\mathrm{Q}_{\mathrm{d}}=\Sigma\left(\mathrm{Q}_{\mathrm{i}} \mathrm{t}_{\mathrm{i}}\right)$

$$
\begin{aligned}
& =[(0.1 \times 6)+(1.45 \times 12)+(1.0 \times 6)] / 24 \\
& =1.0
\end{aligned}
$$

Time-based daily average concentration, $\mathrm{C}_{\mathrm{t}}$

$$
\begin{aligned}
& =\Sigma\left(\mathrm{C}_{\mathrm{i}} \mathrm{t}_{\mathrm{i}}\right) \\
& =[(0.7 \times 6)+(1.15 \times 12)+(1.0 \times 6)] / 24 \\
& =1.0
\end{aligned}
$$

Time-based daily load

$$
\begin{aligned}
& =\mathrm{Q}_{\mathrm{d}} \mathrm{C}_{\mathrm{t}} \\
& =1.0
\end{aligned}
$$

Flow-proportioned (true) daily load

$$
\begin{aligned}
& =\Sigma\left(\mathrm{Q}_{\mathrm{i}} \mathrm{t}_{\mathrm{i}} \mathrm{C}_{\mathrm{i}}\right) \\
& =[(0.1 \times 6 \times 0.7)+(1.45 \times 12 \times 1.15)+(1.0 \times 6 \times 1.0)] / 24 \\
& =1.101
\end{aligned}
$$

This example demonstrates that the true (flow-proportioned) pollutant load exceeds the time-based value, but not necessarily by a large margin (10\% here). For the Redcliffe profiles in Figure 2.9, the flow-proportioned daily load exceeds the time-based load by $4 \%$ for COD and $11 \%$ for TP.

Figure 2.10 Comparison of time-based and flow-proportioned sampling results. 
Table 2.2 Typical plant load characterisation.

\begin{tabular}{|c|c|c|c|c|}
\hline Parameter & $\begin{array}{l}\text { ( } \& \text { associated } \\
\text { text section) }\end{array}$ & Symbol & \multicolumn{2}{|c|}{ Typical values } \\
\hline Connected population & $(2.3 .1)$ & EP & \multicolumn{2}{|c|}{ Australian average 20,000 EP } \\
\hline Median flow & $(2.3 .2)$ & $\mathrm{Q}_{50}$ & \multicolumn{2}{|c|}{ 200-250 L/EP ·d } \\
\hline \multicolumn{5}{|l|}{ Median Loads: } \\
\hline COD & $(2.3 .3)$ & & \multicolumn{2}{|c|}{$120-130 \mathrm{~g} / \mathrm{EP} \cdot \mathrm{d}$} \\
\hline SS & $(2.3 .4)$ & & \multicolumn{2}{|c|}{$60 \mathrm{~g} / \mathrm{EP} \cdot \mathrm{d}$} \\
\hline $\mathrm{pH}$ & $(2.3 .5)$ & & \multicolumn{2}{|c|}{$7.0-7.5$} \\
\hline Total alkalinity & $(2.3 .5)$ & & \multicolumn{2}{|c|}{$200-250 \mathrm{mgCaCO}_{3} / \mathrm{L}$} \\
\hline Sulfide (dissolved) & $(2.3 .6)$ & & \multicolumn{2}{|c|}{$2-10 \mathrm{mg} / \mathrm{L}$} \\
\hline TDS or conductivity & $(2.3 .7)$ & & \multicolumn{2}{|c|}{ TDS 800-1500 mg/L } \\
\hline & & & \multicolumn{2}{|c|}{ Conductivity TDS $/ 0.64 \mathrm{mS} / \mathrm{cm}$} \\
\hline Pathogens (indicators): ${ }^{1}$ & $(2.3 .8)$ & & & \\
\hline E.coli & & & \multirow{4}{*}{\multicolumn{2}{|c|}{$\begin{array}{l}10^{7}-10^{12} \text {, typical } 10^{11} \mathrm{cfu} / \mathrm{EP} \cdot \mathrm{d} \\
10^{7}-10^{9} \text {, typical } 10^{8} \mathrm{pfu} / \mathrm{EP} \cdot \mathrm{d} \\
10^{8}-10^{11} \text {, typical } 10^{10} \mathrm{pfu} / \mathrm{EP} \cdot \mathrm{d} \\
10^{7}-10^{8} \text {, typical } 10^{8} \mathrm{cfu} / \mathrm{EP} \cdot \mathrm{d}\end{array}$}} \\
\hline F-RNA bacteriophage & & & & \\
\hline Somatic coliphage & & & & \\
\hline Clostridium perfringens & & & & \\
\hline Load Ratios: & $(2.3 .9)$ & & Flow & Mass Load \\
\hline Average/median & & & $1.05-1.1$ & \\
\hline Median/ADWF & & & $1.0-1.05$ & \\
\hline $\begin{array}{l}\text { Diurnal minimum } \\
\text { hour/diurnal average }\end{array}$ & & & $0.2-0.3$ & $0.2-0.3$ \\
\hline $\begin{array}{l}\text { Diurnal maximum } \\
\text { hour/diurnal average }\end{array}$ & & & $1.5-2.0$ & $1.5-2.5$ \\
\hline $\begin{array}{l}90 \% \text { ile } / 50 \% \text { ile } \\
\text { (peak month) }\end{array}$ & & & $1.2-1.7$ & $1.3-1.5$ \\
\hline $\begin{array}{l}99.7 \% \text { ile } / 50 \% \text { ile } \\
\text { (peak day) }\end{array}$ & & & $1.4-4$ & $1.7-2.0$ \\
\hline Peak flow/median flow & & & $3-5$ & \\
\hline \multicolumn{5}{|l|}{ Median Characteristics: } \\
\hline VSS/SS & $(2.3 .4)$ & & \multicolumn{2}{|l|}{$0.85-0.90$} \\
\hline Particulate COD, CODp/VSS & $(2.3 .4)$ & & \multicolumn{2}{|l|}{$1.5-2.0$} \\
\hline $\mathrm{COD} / \mathrm{BOD}_{5}$ & $(2.3 .10)$ & & \multicolumn{2}{|l|}{2.4} \\
\hline Nutrient Ratios: & $(2.3 .11)$ & & & \\
\hline TOC/COD & & & \multicolumn{2}{|l|}{0.30} \\
\hline TKN/COD & & & \multicolumn{2}{|l|}{0.10} \\
\hline $\mathrm{TP} / \mathrm{COD}$ & & & \multicolumn{2}{|l|}{0.020} \\
\hline $\mathrm{NH}_{3}-\mathrm{N} / \mathrm{TKN}$ & & & \multicolumn{2}{|l|}{0.70} \\
\hline $\mathrm{PO}_{4}-\mathrm{P} / \mathrm{TP}$ & & & \multicolumn{2}{|l|}{0.80} \\
\hline
\end{tabular}


Table 2.2 Typical plant load characterisation (Continued).

\begin{tabular}{|c|c|c|c|c|}
\hline Parameter & $\begin{array}{l}\text { ( } \& \text { associated } \\
\text { text section) }\end{array}$ & Symbol & \multicolumn{2}{|l|}{ Typical values } \\
\hline Particulate N/VSS & & & \multicolumn{2}{|l|}{0.07} \\
\hline Particulate P/VSS & & & \multicolumn{2}{|l|}{0.01} \\
\hline Total COD Fractions: & $(2.3 .12)$ & & & \\
\hline $\begin{array}{l}\text { Soluble readily } \\
\text { biodegradable (RBCOD) }\end{array}$ & & $f_{b s}$ & \multicolumn{2}{|l|}{$0.05-0.25$} \\
\hline Particulate biodegradable & & $f_{b p}$ & \multicolumn{2}{|l|}{$0.5-0.7$} \\
\hline Soluble unbiodegradable & & $f_{u s}$ & \multicolumn{2}{|l|}{0.05} \\
\hline $\begin{array}{l}\text { Particulate } \\
\text { unbiodegradable }\end{array}$ & & $f_{\text {up }}$ & \multicolumn{2}{|l|}{0.20} \\
\hline VFA (as COD)/RBCOD & & $f_{b s a}$ & \multicolumn{2}{|c|}{$\begin{array}{l}\text { Variable, depending on } \\
\text { sewer transformations }\end{array}$} \\
\hline $\begin{array}{l}\text { Soluble unbiodegradable } \\
\text { organic N/TKN }\end{array}$ & $(2.3 .13)$ & $f_{\text {nus }}$ & \multicolumn{2}{|l|}{$0.02-0.03$} \\
\hline $\begin{array}{l}\text { Nitrifier maximum specific } \\
\text { growth rate }\end{array}$ & $(2.3 .14)$ & $\mu_{\mathrm{nm} 20}$ & \multicolumn{2}{|l|}{$0.5-1.0 \mathrm{~d}^{-1}$} \\
\hline \multirow[t]{4}{*}{ Temperature $^{2}$} & $(2.3 .15)$ & & Latitude & Seasonal Range \\
\hline & & & 38S (Melbourne) & $14-24^{\circ} \mathrm{C}$ \\
\hline & & & 28S (Brisbane) & $19-28$ \\
\hline & & & 18S (Townsville) & $24-32$ \\
\hline Chemical energy content & $(2.3 .16)$ & & \multirow{2}{*}{\multicolumn{2}{|c|}{$12.5 \mathrm{MJ} / \mathrm{kgCOD}$}} \\
\hline Other sewage components & $(2.3 .17)$ & & & \\
\hline
\end{tabular}

${ }^{1}$ National Resource Management Ministerial Council et al., 2006.

${ }^{2}$ These temperatures are typical bioreactor operating temperatures.

\subsubsection{Flow}

The main external factors influencing the median flow are groundwater infiltration rate and water supply restrictions. For example, a severe drought in southeast Queensland led to the introduction of water restrictions in 2006, reducing domestic sewage flows from $230 \mathrm{~L} / \mathrm{EP} \cdot \mathrm{d}$ to less than $140 \mathrm{~L} / \mathrm{EP} \cdot \mathrm{d}$.

Sewage strength increased proportionately. Subsequently a flow of $200 \mathrm{~L} / \mathrm{EP} \cdot \mathrm{d}$ became a common figure for long-term planning.

\subsubsection{COD}

Domestic COD load generally runs at $120-130 \mathrm{~g} / \mathrm{EP} \cdot \mathrm{d}$ in Australia. This is a little above the human waste output of $110 \mathrm{~g} / \mathrm{EP} \cdot \mathrm{d}$ listed in Table 2.1, the difference being other household inputs and commercial inputs not accounted for separately. The value will vary with the age distribution of the contributing population because of the varying bodily outputs. COD can also be lost through sewer transformations, discussed below.

COD, rather than BOD, is adopted as the organic load basis in this text. COD accounts for the total organic load (biodegradable and unbiodegradable), has the advantage of simple and rapid analysis, and is 
less likely than BOD to decrease with sample storage time. ${ }^{2}$ However, in practice, COD results seem no less susceptible to analytical variability than BOD and are subject to chloride interference (increasing the test result) when TDS levels are elevated. The COD:BOD ratio for Australian sewages is typically about 2.4 although this can vary because of transformations in the sewerage system and in the samples collected.

COD fractions and sewer transformations are discussed in Sections 2.3.12 and 2.4 below.

\subsubsection{SS}

The typical median mass load is about $60 \mathrm{~g} / \mathrm{EP} \cdot \mathrm{d}$ which is $85-90 \%$ volatile (organic). This corresponds well to the human TS outputs of Table 2.1, allowing for a dissolved fraction. The empirical composition of the volatile component of sewage settleable solids is $\mathrm{C}_{10} \mathrm{H}_{19} \mathrm{O}_{3} \mathrm{~N}$ which has a COD of $2.0 \mathrm{kgCOD} / \mathrm{kgVSS}$ and $\mathrm{N}$ and $\mathrm{P}$ contents of about $7 \%$ and $1 \%$ respectively (Parkin \& Owen, 1986). The COD is calculated as follows:

$$
\mathrm{C}_{10} \mathrm{H}_{19} \mathrm{O}_{3} \mathrm{~N}+12.5 \mathrm{O}_{2} \rightarrow 10 \mathrm{CO}_{2}+\mathrm{NH}_{3}+8 \mathrm{H}_{2} \mathrm{O}
$$

MW $\quad 201 \quad 400$

$$
\mathrm{COD}=400 / 201=2.0 \mathrm{mgO}_{2} / \mathrm{mgVSS}
$$

In some sewages subject to high levels of wet weather inflow and infiltration carrying silt, the inorganic fraction of the SS increases substantially during the wet season.

\subsection{5 $\mathrm{pH}$ and alkalinity}

Sewage alkalinity is important for buffering of acidity produced or added during treatment. Alkalinity is typically $200-250 \mathrm{mg} / \mathrm{L}$ as $\mathrm{CaCO}_{3}$, which comes from both the water supply and household products. Saline groundwater infiltration can also increase alkalinity.

\subsubsection{Dissolved sulfide}

Hydrogen sulfide is produced by reduction of sulfate in the sewerage system, particularly the rising mains. Some of this sulfide is precipitated by dissolved metals such as iron and copper. The remaining dissolved sulfide is a potential source of odour and corrosion and may inhibit treatment processes such as biological phosphorus removal. Sulfide is discussed further in Section 2.4 below.

\subsubsection{TDS or conductivity}

High levels of total dissolved solids (TDS) can result from infiltration of saline groundwater. For example, dry weather diurnal variation of sewage TDS concentration in the coastal Port Pirie catchment is shown in

\footnotetext{
${ }^{2}$ A laboratory study conducted by the Western Australia Water Corporation (Beenyup WWTP Laboratory, 2006) examined the effect of sample storage time before testing on the results of BOD and COD analyses. Standard Methods (1998) recommends initiating the BOD analysis within 6 hours of sampling to minimise reduction of the BOD result. COD results are apparently more stable and samples can be preserved by acidification.

In the study, samples from the Beenyup and Subiaco catchments were stored at $4{ }^{\circ} \mathrm{C}$ for up to 48 hours before analysis. It was found that the BOD result decreased as sample storage time increased. However, the COD of samples stored in the same way did not change significantly over that period. This may be due to changes in the form of the organics, perhaps RBCOD being taken up into bacterial cells and becoming slowly biodegradable COD, so that a lower percentage of the total organics is oxidised in the 5-day BOD test period. The percentage decline in BOD with time would then depend on the RBCOD fraction in the original sample.

In the tests conducted in the study, the BOD of Subiaco sewage decreased by an average of $8 \%$ with 24 hours storage, and $12 \%$ with 48 hours storage. The corresponding declines for Beenyup sewage were $9 \%$ and $14 \%$.
} 
Figure 2.11. High TDS is a concern with respect to the effluent receiving environment, reuse of treated effluent and potential inhibition of treatment processes such as nitrification.

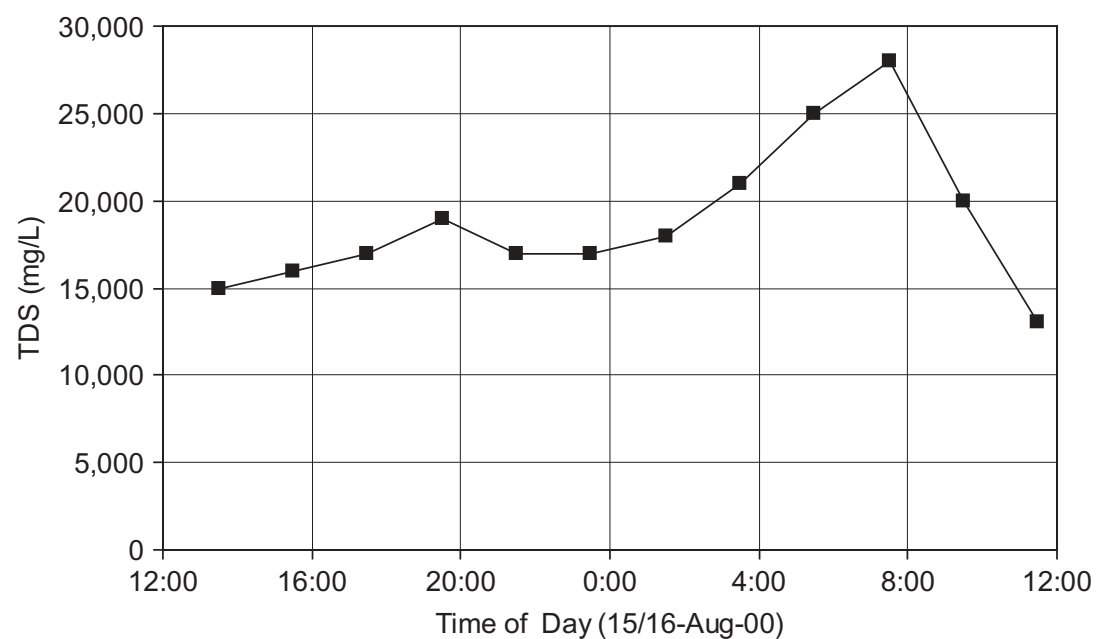

Figure 2.11 Sewage diurnal salinity profile, Port Pirie STP. Salinity is higher when there is less sewage flow to dilute the constant saline inflow.

\subsubsection{Pathogens}

$E$ coli is the indicator organism for pathogenic ${ }^{3}$ bacteria. A typical concentration is $10^{7}-10^{8} \mathrm{cfu} / 100 \mathrm{~mL}$. F-RNA and somatic coliphages ${ }^{4}$ are indicators for pathogenic enteric viruses.

Clostridium perfringens is a spore-forming bacterium ${ }^{5}$ used as an indicator for pathogenic protozoa such as Cryptosporidium and Giardia and for helminths (intestinal worms).

\subsubsection{Load ratios}

The load ratios listed have practical plant application:

Average/median: This facilitates conversion between the median daily flow (exceeded on 50\% of days) and the average daily flow (total annual flow divided by 365 days). The median is relevant to effluent discharge licences expressed in percentile (percentage of time) terms; the average is relevant to licences limiting the total annual mass discharged.

Diurnal minimum and maximum hours: These ratios affect two things: (a) the diurnal variation in load on plant equipment such as recycle pumps and aeration blowers, and (b) the diurnal variability in effluent quality as a result of the plant process response to the loading variation.

\footnotetext{
${ }^{3}$ Pathogenic: disease-causing

${ }^{4}$ Coliphages are viruses that infect bacteria.
}

${ }^{5} \mathrm{~A}$ bacterial spore is a resting form of the organism which is much more resistant than the vegetative form to disinfectants. 
Peak month: This load represents the effective maximum load to which the main plant processes respond. For example, (a) if operating the activated sludge process at a constant solids retention time (SRT), the maximum MLSS concentration will be about the annual average multiplied by the peak month load ratio, and (b) the load on the sludge digesters will also vary by about the same amount.

Peak day: Tells us the likely maximum daily load on the plant over a typical year.

Peakflow: The maximum instantaneous flow rate the plant is designed to pass. Higher sewage flows will overflow in the sewerage system or bypass plant processes. Different parts of the plant may have different design peak flow values.

\subsubsection{COD/BOD 5}

Typically around 2.4 in Australian sewages. The COD fractions discussed below then give a biodegradable COD/BOD ratio of 1.8 .

\subsubsection{Nutrient ratios}

The nutrient ratios listed in Table 2.2 are typical for Australia. While the carbon and nitrogen contents come mainly from bodily wastes, about a third of the phosphorus comes from powdered detergents (which may reduce over time due to change in detergent formulation). Sewage phosphorus characteristics are generally the most stable of all the quality characteristics and can be a useful benchmark for developing a better understanding of a sewage when the overall data are limited and variable.

\subsubsection{Total COD fractions}

To understand the behaviour of biological treatment processes, the total COD is divided into the four main categories listed. This subdivision is illustrated in Figure 2.12. The significance of these fractions is as follows:

Soluble readily biodegradable COD (RBCOD), $f_{b s}$ : This fraction comprises the truly soluble biodegradable COD and is the most rapidly biodegradable component. It can be further subdivided into volatile fatty acids (VFAs) and fermentable COD which can be converted to VFAs. It produces rapid denitrification and it drives the biological phosphorus removal process. It is difficult to measure because it relates to the biodegradable fraction of the "truly soluble" (low molecular weight) component of the total COD. It can be measured in two indirect ways: (a) by bioassay using a bench-scale biological reactor to measure and interpret the varying response of oxygen utilisation rate during oxidation of a sample of the sewage (Ekama et al., 1986; Wentzel et al., 1995), or (b) by measuring the COD of a flocculated and membrane filtered sewage sample (the total "truly soluble" COD), and deducting the "truly soluble" (unbiodegradable) COD in the effluent from an activated sludge process (full-or pilot-scale) treating the same sewage (representing the unbiodegradable soluble COD) (Mamais et al., 1993). ${ }^{6}$ The second method is generally simplest and has become the most popular choice for design and operational purposes.

The VFA fraction of the RBCOD is variable. Table 2.1 shows that in fresh sewage the VFA concentration should be about $5 \%$ of the total COD concentration and this can increase to as much

\footnotetext{
${ }^{6}$ Note that the pore size of filter paper used for routine SS measurements is coarser than that of membranes used for differentiating between "soluble" and "particulate" material where molecular weight cut-offs are involved.
} 
as $25 \%$ through fermentation in the sewerage system (see Section 2.4 below). The VFA and total RBCOD fractions can be boosted by prefermentation processes at the treatment plant.

Unbiodegradable COD, $f_{u s} \& f_{u p}$ : These fractions are readily estimated from normal plant data. The soluble unbiodegradable COD is generally assumed to equal the soluble COD in the effluent from an activated sludge process with a reasonably long SRT (although some of this COD actually comprises metabolic products of the biological treatment process). Infiltration of organically coloured groundwater can sometimes contribute to $f_{u s}$ and residual colour in the plant effluent can then interfere with UV disinfection.

The particulate unbiodegradable COD has its biggest influence on the sludge mass in an activated sludge process. The $\mathrm{f}_{\text {up }}$ value can be estimated from plant operating data using a simple activated sludge model to calibrate the MLSS concentration to the process load and SRT.

Particulate biodegradable COD, $f_{b p}$ : This is the residual COD fraction, $\left(1-\mathrm{f}_{\mathrm{bs}}-\mathrm{f}_{\mathrm{us}}-\mathrm{f}_{\mathrm{up}}\right)$.

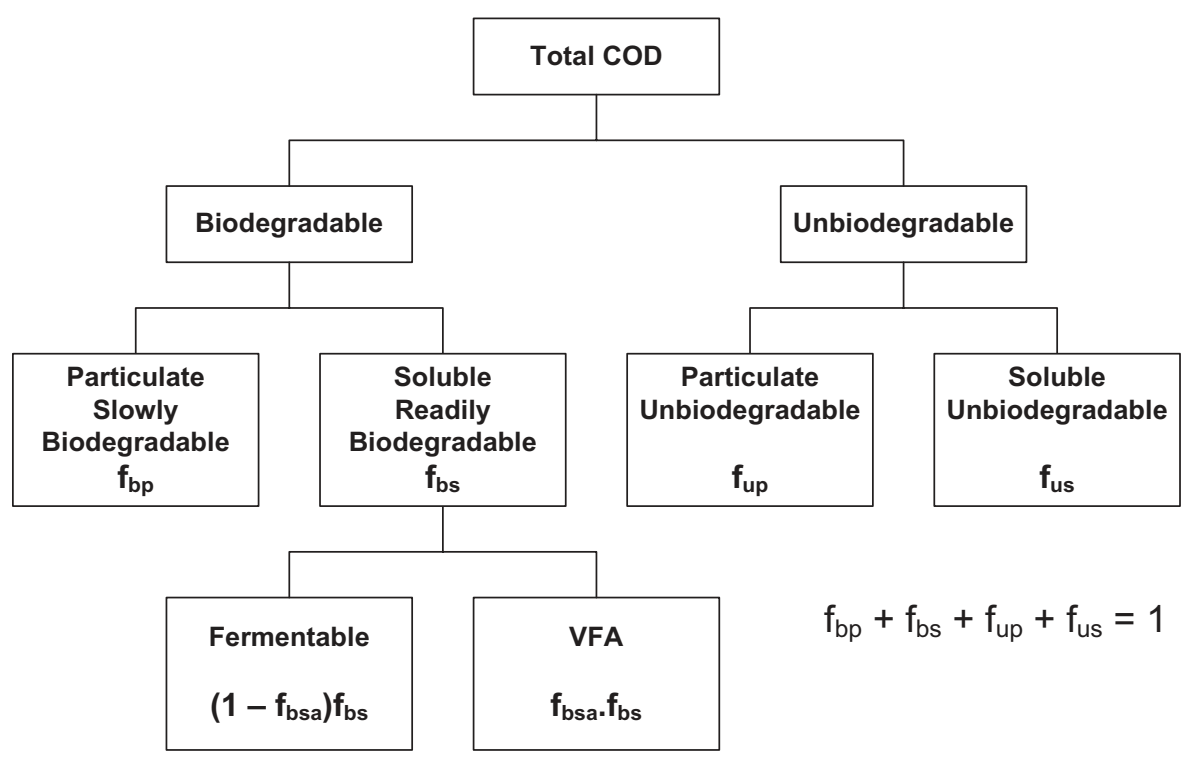

Figure 2.12 Sewage COD components. A small fraction may also be associated with active biomass which has grown during transport in the sewerage system but this can generally be ignored in practice.

\subsubsection{Soluble unbiodegradable organic $\mathbf{N}$}

Sewage nitrogen can be classified in a similar fashion to COD, see Figure 2.13. Ammonia is commonly about $70 \%$ of the sewage $\mathrm{TKN}^{7}$ Of the organic $\mathrm{N}$ (the nitrogenous component of organic compounds), the biodegradable fraction is converted to ammonia and the particulate unbiodegradable fraction is incorporated in the process sludge mass. In purely biological processes, the soluble unbiodegradable fraction, $\mathrm{f}_{\text {nus }}$, passes unchanged into the effluent and thereby constitutes an important part of the effluent total nitrogen. The value of $f_{\text {nus }}$ is typically $0.02-0.03$, representing $1-2 \mathrm{mgN} / \mathrm{L}$.

${ }^{7}$ Oxidised $\mathrm{N}$ is usually, but not always, negligible in sewage. 


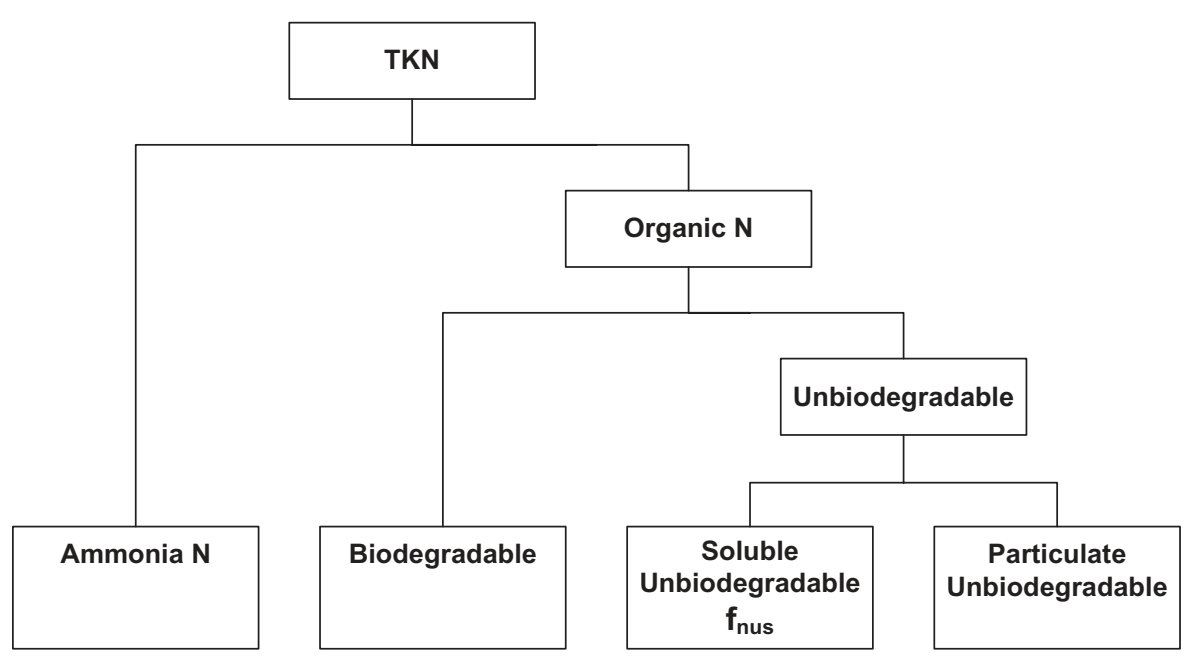

Figure 2.13 Sewage nitrogen components.

The $f_{\text {nus }}$ value is commonly ascribed to the total soluble organic $\mathrm{N}$ measured in the effluent from an operating BNR process. This total concentration may actually have several components soluble unbiodegradable $\mathrm{N}$ from the influent, residual (undegraded) soluble biodegradable $\mathrm{N}$ from the influent and the $\mathrm{N}$ component of soluble metabolites produced by the biomass. It is difficult to measure the individual components and it is commonly assumed that the soluble organic $\mathrm{N}$ measured in the effluent is the unbiodegradable fraction of the influent TKN and that the other components are negligible.

\subsubsection{Nitrifier maximum specific growth rate}

The growth rate of the nitrifying organisms is inhibited by a range of unidentifiable compounds which can be present in sewage, particularly if there is a significant industrial input. The nitrifier maximum specific growth rate, $\mu_{\mathrm{nm} 20}$ or $\mu_{\max },{ }^{8}$ is therefore generally listed as a sewage characteristic.

In conventional activated sludge processes the maximum specific growth rate typically varies from 0.4$0.6 \mathrm{~d}^{-1}(0.4-0.6$ of the organism mass per day). In biological $\mathrm{N}$ and $\mathrm{P}$ removal processes the growth rate can be higher - up to about $1.0 \mathrm{~d}^{-1}$. 9 See Chapter 3 for more detail.

\subsubsection{Temperature}

Detailed temperature data are scarce (see Wanner et al., 2005). Average sewage temperature is in the order of 3 degrees higher than the water supply temperature (depending on per capita flow) because of household

\footnotetext{
${ }^{8}$ Maximum specific growth rate is the organism growth rate in a nitrifying process treating the sewage at high (non-inhibitory) ammonia concentration (several $\mathrm{mg} / \mathrm{L}$ ), high dissolved oxygen concentration (several mg/L), non-inhibitory pH (7.2-8.0) and temperature 20 ${ }^{\circ} \mathrm{C}$.

${ }^{9}$ These growth rates are associated with a nitrifier endogenous decay rate of $0.04 \mathrm{~d}^{-1}$. Some detailed microbiological models use other (higher) combinations of growth and decay rates.
} 
and industrial water heating, and varies diurnally with the heat input. The temperature may dip a few degrees in wet weather due to rainwater infiltration.

Plant process temperatures are $0.5-1{ }^{\circ} \mathrm{C}$ higher than the sewage temperature because of reaction heat and are more stable because of the process thermal mass (Wanner et al., 2005). Table 2.2 lists typical seasonal process temperatures for a range of latitudes.

\subsubsection{Energy content}

Sewage contains both heat energy and chemical energy. The heat energy is represented by the elevation of sewage temperature above the water supply temperature. Heat energy equals the heat capacity of water $\left(4.19 \mathrm{~kJ} / \mathrm{kg} \cdot{ }^{\circ} \mathrm{C}\right)$.

Chemical energy content can be measured as the heat of combustion of the sewage organics. Because the energy content of sewage organics can be transformed into methane by anaerobic bacteria, an alternative approach is to calculate the heat of combustion of an equivalent quantity of methane (Parkin $\&$ Owen, 1986). The equivalent quantity can be determined from the equivalent oxygen demand or COD of the sewage. The COD of methane is $4 \mathrm{kgCOD} / \mathrm{kgCH}_{4}$ as calculated from the following equation:

$$
\mathrm{CH}_{4}+2 \mathrm{O}_{2} \rightarrow \mathrm{CO}_{2}+2 \mathrm{H}_{2} \mathrm{O}
$$

The net energy content of sewage is therefore $50.0\left(\mathrm{MJ} / \mathrm{kgCH}_{4}\right) / 4\left(\mathrm{kgCOD} / \mathrm{kgCH}_{4}\right)=12.5 \mathrm{MJ} /$ $\mathrm{kgCOD}$, where $50 \mathrm{MJ} / \mathrm{kg}$ is the net heat of combustion of methane $\left(25^{\circ} \mathrm{C}\right.$, constant pressure, excluding latent heat from water vapour condensation).

The heat and chemical energy contents of sewage are summarised in Table 2.3. It can be seen that the chemical energy in sewage could raise the sewage temperature by $1.6^{\circ} \mathrm{C}$ and in fact part of the energy released in the plant biological processes does raise the effluent temperature as mentioned in 2.3.15 above.

Table 2.3 Sewage energy content.

\begin{tabular}{lll}
\hline Parameter & Heat energy & Chemical energy \\
\hline $\begin{array}{l}\text { Specific energy } \\
\text { Per unit plant load: }\end{array}$ & $4.19 \mathrm{~kJ} / \mathrm{kg} .{ }^{\circ} \mathrm{C}$ & $12.5 \mathrm{MJ} / \mathrm{kgCOD}$ \\
$\quad$ Energy & $4,190 \mathrm{MJ} / \mathrm{ML} .{ }^{\circ} \mathrm{C}$ & $12,500 \mathrm{MJ} / \mathrm{tCOD}$ \\
$\quad$ Power & $48 \mathrm{~kW} \mathrm{per} \mathrm{ML} / \mathrm{d} \mathrm{per}{ }^{\circ} \mathrm{C}$ & $140 \mathrm{~kW}$ per tCOD $/ \mathrm{d}$ \\
Per EP: & & \\
$\quad$ Per capita load & $230 \mathrm{~L} / \mathrm{EP} \cdot \mathrm{d}$ & $125 \mathrm{gCOD} / \mathrm{EP} \cdot \mathrm{d}$ \\
$\quad$ Energy & $0.96 \mathrm{MJ} / \mathrm{EP} \cdot \mathrm{d} .{ }^{\circ} \mathrm{C}$ & $1.6 \mathrm{MJ} / \mathrm{EP} \cdot \mathrm{d}$ \\
$\quad$ Power & $11 \mathrm{~W} / \mathrm{EP} .{ }^{\circ} \mathrm{C}$ & $18 \mathrm{~W} / \mathrm{EP}$ \\
\hline
\end{tabular}

\subsubsection{Other sewage components}

There are many other sewage components and characteristics which may be individually important in specific circumstances. Examples include heavy metals; synthetic organics such as pharmaceuticals and personal care products (PPCPs), endocrine disruptors and pesticides (Ternes \& Joss, 2006); and illicit drugs (Lai et al., 2011). 


\subsection{SEWER TRANSFORMATIONS}

Biological transformations of sewage quality occur in the sewerage system, particularly the rising mains. These are predominantly anaerobic processes occurring in biofilm growing on the pipe wall at long SRTs. There are three main processes:

- Fermentation of soluble COD to VFAs and hydrogen.

- Metabolic uptake of VFAs by sulfate-reducing bacteria, producing sulfide.

- Metabolic uptake of VFAs and hydrogen by methane-forming bacteria, producing methane.

Sulfide and methane production in the sewerage system reduces the readily biodegradable COD content of the sewage and is therefore detrimental to biological nutrient removal in the downstream treatment plant. Guisasola et al. (2008, 2009) and Sharma et al. (2008) found in both field and laboratory tests that (a) non-VFA soluble COD concentration decreased, (b) VFA concentration increased for about 2 hours, then decreased, (c) sulfide production increased steadily, and (d) methane production also increased steadily. Sulfide and methane production increase with sewage hydraulic residence time and also with the surface area:volume ratio of the sewers. Up to $100 \mathrm{mg} \mathrm{COD} / \mathrm{L}$ of methane was found in one of the two full-scale sewer systems studied, while methane production represented up to about $70 \%$ of the total soluble COD loss in a laboratory-scale sewer system. Some methane concentrations were supersaturated as found in other studies (Hartley and Lant, 2006).

These sewer processes affect the sewage characteristics at the STP inlet and have exerted some average influence on the typical values of the characteristics listed in Table 2.2. Other influences on plant influent characteristics include:

- Chemicals dosed in the sewerage system for control of sulfide, including oxygen, nitrate, hydrogen peroxide, iron, magnesium hydroxide and various proprietary formulations.

- Internal plant recycles from the sludge processing stream back to the plant inlet.

\subsection{EFFECT OF PRIMARY TREATMENT}

The sewage characteristics listed in Table 2.2 are modified by primary treatment when this is used in the treatment train. Table 2.4 shows how these changes can be estimated.

\subsection{EFFLUENT CHARACTERISTICS}

Effluent quality standards can be expressed in two ways, percentile concentration limits and mass discharge limits. Most concentration limits relate to the percentage of daily average concentrations which must not exceed the stipulated limit over a specified time period, usually a month or a year. The mass discharge approach limits the maximum mass of a pollutant that can be discharged over a specified time period. The relationship between the two - percentage of time versus total mass - is similar to time-based versus flow-weighted sampling (Figure 2.10 above).

For an annual mass discharge limit the average effluent concentration has to be limited to the annual mass limit divided by the total flow for the year. The total flow is 365 times the average daily flow, which is greater than the median daily flow (see Section 2.2). The annual average concentration required is less than the median concentration. With a mass discharge limit the precise average effluent quality required is not known in advance because neither the magnitude nor distribution of rainfall and flow to be expected can be known. Close tracking of performance is essential to ensure the overall mass discharge target will be met. 


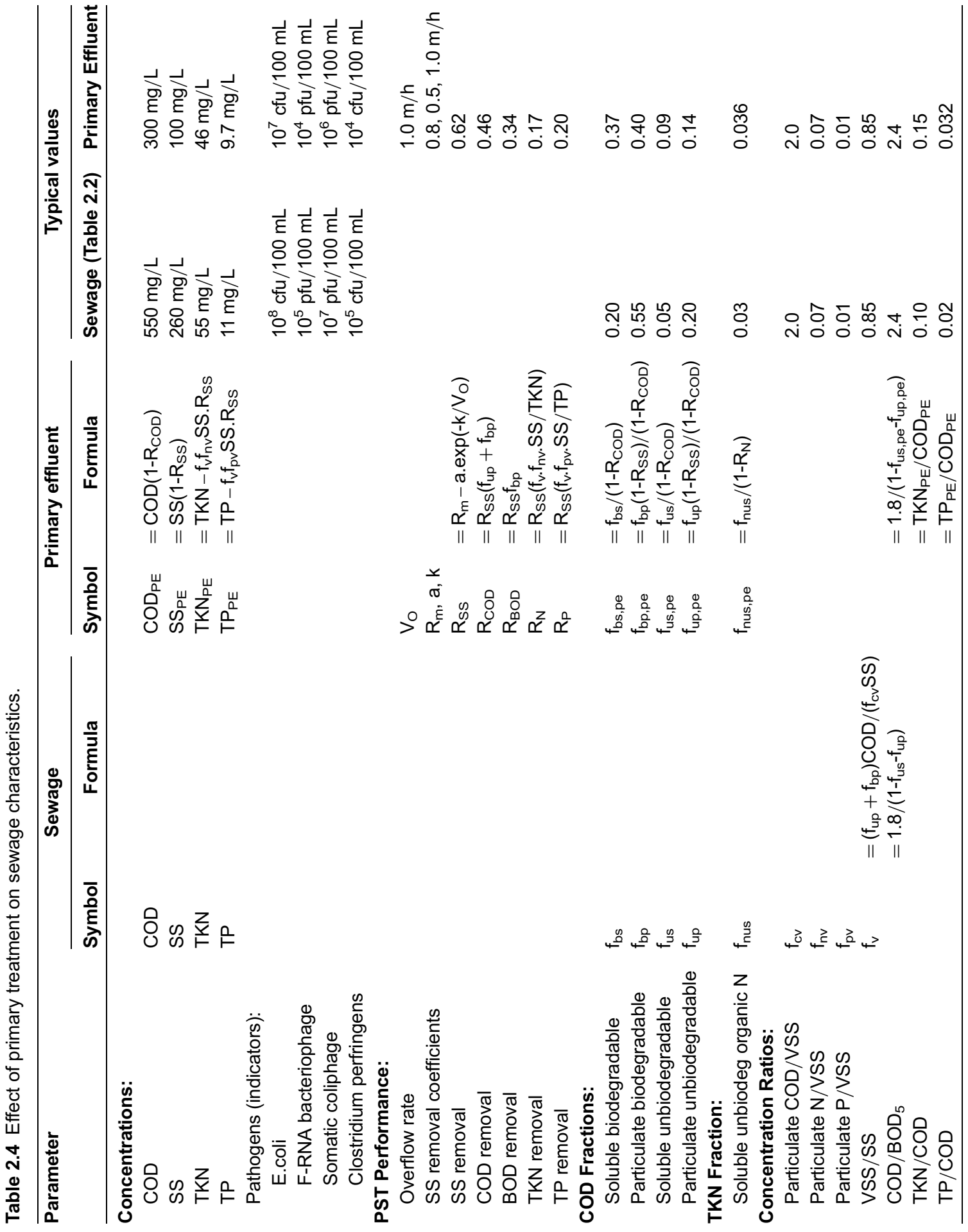


Two other effluent characteristics of interest are interactions between the different parameters, and variability. Common interactions are listed in Table 2.5 and it can be seen that effluent SS is the parameter having the most influence on other parameters.

Table 2.5 Effluent quality interactions.

\begin{tabular}{|c|c|c|}
\hline $\begin{array}{l}\text { Effluent quality } \\
\text { parameter (mg/L UNO) }\end{array}$ & Main components & Source \&/or magnitude \\
\hline \multirow[t]{3}{*}{ COD } & Soluble unbiodegradable COD & $\begin{array}{l}\text { Sewage soluble unbiodegradable COD } \\
\mathrm{f}_{\mathrm{us}} \times \text { sewage } \mathrm{COD}\end{array}$ \\
\hline & $\begin{array}{l}\text { Residual soluble } \\
\text { biodegradable COD }\end{array}$ & --- \\
\hline & Particulate COD & $1.5 \times$ VSS \\
\hline \multirow[t]{2}{*}{ 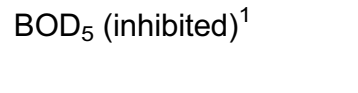 } & Residual soluble BOD & --- \\
\hline & Particulate BOD & $\sim 0.6 \times \mathrm{SS}$ \\
\hline \multirow[t]{2}{*}{ SS } & VSS (volatile) & $0.6-0.8 \times S S$ \\
\hline & ISS (inorganic) & --- \\
\hline Turbidity, NTU & & $\mathrm{SS} /[1.5$ to 2.5$]$ \\
\hline \multirow[t]{3}{*}{ True colour, PCU } & Sewage true colour & --- \\
\hline & $\mathrm{DOC}$ & --- \\
\hline & Iron & --- \\
\hline \multirow[t]{2}{*}{ UV transmissivity, \% } & True colour $^{2}$ & $170 \times(\text { True Colour })^{-0.3}$ \\
\hline & SS & --- \\
\hline \multirow[t]{4}{*}{ Total N } & $\mathrm{NH}_{3}-\mathrm{N}$ & -- \\
\hline & $\mathrm{NO}_{x}-\mathrm{N}\left(\mathrm{NO}_{2}-\mathrm{N}+\mathrm{NO}_{3}-\mathrm{N}\right)$ & --- \\
\hline & $\begin{array}{l}\text { Soluble unbiodegradable } \\
\text { organic } \mathrm{N}\end{array}$ & $\begin{array}{l}\text { Sewage soluble unbiodeg organic } N \\
f_{\text {nus }} \times \text { sewage TKN }\end{array}$ \\
\hline & Particulate organic $\mathrm{N}$ & $0.10 \times$ VSS \\
\hline \multirow[t]{2}{*}{ Total P } & Soluble P (ortho-P) & --- \\
\hline & Particulate P & $\sim 0.03-0.05 \times$ VSS \\
\hline
\end{tabular}

${ }^{1}$ Carbonaceous BOD - nitrification inhibited. Nitrification in the BOD test adds an uncertain fraction of the total nitrification demand of $4.6 \mathrm{mgO}_{2} / \mathrm{mgNH}_{3}-\mathrm{N}$, where $\mathrm{NH}_{3}$ includes the ammonium ion, $\mathrm{NH}_{4}^{+}$.

${ }^{2}$ Correlation of unfiltered UV transmissivity data from 3 trickling filter and 3 activated sludge effluents; data ranges: true colour 10-127 PCU, UVT 27-85\%; R² 0.66.

Typical variabilities are listed in Table 2.6, although it should be noted that variability tends to increase as a plant nears its operating capacity. For BNR effluents, a clear rule of thumb is that for most parameters the 90 percentile is about twice the 50 percentile. The exception is ammonia for which the 90 percentile is four times the 50 percentile. These rules of thumb provide a basis for determining the median effluent concentrations at which the plant has to be operated to meet its percentile limits. Appendix 1 provides more detail about effluent variability characteristics. 
Table 2.6 Typical effluent quality variability.

\begin{tabular}{|c|c|c|}
\hline \multicolumn{3}{|c|}{ BNR PLANTS $^{1}$} \\
\hline Parameter & $\begin{array}{l}\text { Median Concentration } \\
\text { (median \& range, mg/L) }\end{array}$ & $\begin{array}{l}\text { 90:50\%ile Ratio } \\
\text { (median \& range) }\end{array}$ \\
\hline $\mathrm{BOD}_{5}$ & $3(2-10)$ & $2.0(1.3-3.6)$ \\
\hline SS & $6(0.5-15)$ & $2.4(1.8-5.9)$ \\
\hline Oil \& grease & 2 (1 plant) & 1.5 (1 plant) \\
\hline Ammonia $\mathrm{N}$ & $0.5(0.1-11)$ & $4.1(1.7-6.8)$ \\
\hline Nitrate $\mathrm{N}$ & $1.4(0.2-15)$ & $2.4(2.1-7.3)$ \\
\hline Total $\mathrm{N}$ & $5.1(1.9-18)$ & $2.0(1.2-2.6)$ \\
\hline Total P & $1.7(0.3-4.6)$ & $2.4(2.1-3.6)$ \\
\hline \multicolumn{3}{|c|}{ Disinfection of Secondary Effluent } \\
\hline \multicolumn{3}{|c|}{ Chlorination: } \\
\hline \multicolumn{3}{|c|}{ Coliphage count in disinfected effluent: $90: 50 \%$ ile $3.0(0.5 \text { logs })^{2}$} \\
\hline \multicolumn{3}{|c|}{ UV Disinfection: ${ }^{3}$} \\
\hline \multicolumn{3}{|c|}{ Faecal coliform count in disinfected effluent, 90:50\%iles: } \\
\hline \multicolumn{3}{|c|}{ Redcliffe STP: 4.0 (0.6 logs) } \\
\hline \multicolumn{3}{|c|}{ Maroochydore STP: 6.2 (0.8 logs) } \\
\hline \multicolumn{3}{|c|}{ Nambour STP: 20 (1.3 logs) } \\
\hline
\end{tabular}

${ }^{1}$ Hartley, 1995, plus data from author's files. Analysis of 12 months data from 9 BNR plants of various types. Variability does not correlate with plant size or type, or with median effluent quality.

${ }^{2}$ Metcalf \& Eddy, 2003, Table 15-1, p1638.

${ }^{3}$ Author's data for 3 Queensland plants. Redcliffe, contractual acceptance test Feb-Mar 2001, 255 results; Maroochydore, operating data 1997-2000, 550 results; Nambour, operating data 1998-2001, 168 results. 


\section{Chapter 3}

\section{Biological nutrient removal - process fundamentals}

\subsection{THE BASIC PROCESS}

Here we focus on the common suspended growth form of the BNR process, leaving aside fixed film variants. The modern BNR process is a development of the basic activated sludge process which was invented in 1914 by Edward Ardern and William Lockett who were chemists with the Manchester Corporation in England (Ardern \& Lockett, 1914a, 1914b).

Ardern and Lockett began their first historic paper with these words (1914a, p523):

It has long been known that if sewage be exposed to the air for a sufficient period of time, the organic contents are gradually oxidised, with the formation of a deposit of so-called "humus" and the final production of nitrate from the ammonium salts and the nitrogenous organic matter.

This purification change ... takes place, however, comparatively slowly, and even if aided by direct aeration, by no means becomes a practical method of sewage purification.

Ardern and Lockett, working first with bottles and then with casks, solved the problem by aerating a batch of sewage, allowing the humus formed to settle, decanting the supernatant, adding a fresh batch of sewage and resuming aeration in the presence of the humus previously formed. Successive decanting, addition of new batches of sewage and aeration eventually produced a high concentration of settleable solids and 'a percentage purification ... quite equal to that yielded by efficient bacterial filters' in a matter of hours (1914a, p525).

The people attending the meeting at which Messrs Ardern and Lockett presented their first paper recognised immediately the importance of the results. For example, ' $M r F R$ O'Shaughnessy regarded the paper as an epoch-making one, provided that the process experimentally established by the authors could ultimately be applied on a large scale at a reasonable cost' (1914a, p536). 'Mr S E Melling thought the process described was ideal inasmuch as it resolved itself into a single-tank treatment (1914a, p537).' And 'Mr J T Thompson said that one striking feature of the new process was that it was aerobic from beginning to end, and it was probable that the amount of smell would be negligible (1914a, p537).' 
Messrs Ardern and Lockett had discovered the three key features of the activated sludge process:

- During aeration the sewage is mixed with a large mass of previously grown organisms.

- The solids are flocculent and can be removed from the liquid by settlement. In some modern forms of the process the solids are separated using flotation or membranes but the majority of plants still use settling.

- Separate control is exercised over the solid and liquid phases, so that the solids are retained in the process for a much longer time that the liquid.

Ardern and Lockett wrote, 'For reference purposes and failing a better term, the deposited solids resulting from complete oxidation of sewage have been designated "activated sludge" ' (1914a, p524). The sludge is a complex population of microorganisms, mainly bacteria, with some protozoa and rotifers. The bacteria effect treatment by utilising the polluting materials as food and converting much of it into bacterial cells. Dissolved and colloidal materials are thereby transformed into easily removable solids.

Ardern and Lockett's initial experiments were carried out on a batch basis but the first full-scale plants were built on a continuous flow basis. Most plants are still of that type but the sequencing batch reactor (SBR) process is identical in principle to Ardern and Lockett's original experimental arrangement.

The format of the continuous flow process is shown in Figure 3.1. Its features are as follows:

- A bioreactor, often compartmentalised, with provisions for aeration and mixing of the activated sludge and sewage mixture, which is called mixed liquor.

- A settling basin or clarifier to separate activated sludge from the treated effluent.

- A sludge recycling system to return settled activated sludge to the bioreactor. BNR processes also generally have other recycles to transfer mixed liquor between the various bioreactor compartments.

- A sludge wasting system to remove sludge at the rate that it grows, thus maintaining the desired mass of solids in the process. Waste sludge can be extracted from either the bioreactor or the return activated sludge (RAS) flow.

- There may be chemical dosing provisions to enhance nitrogen and phosphorus removal.

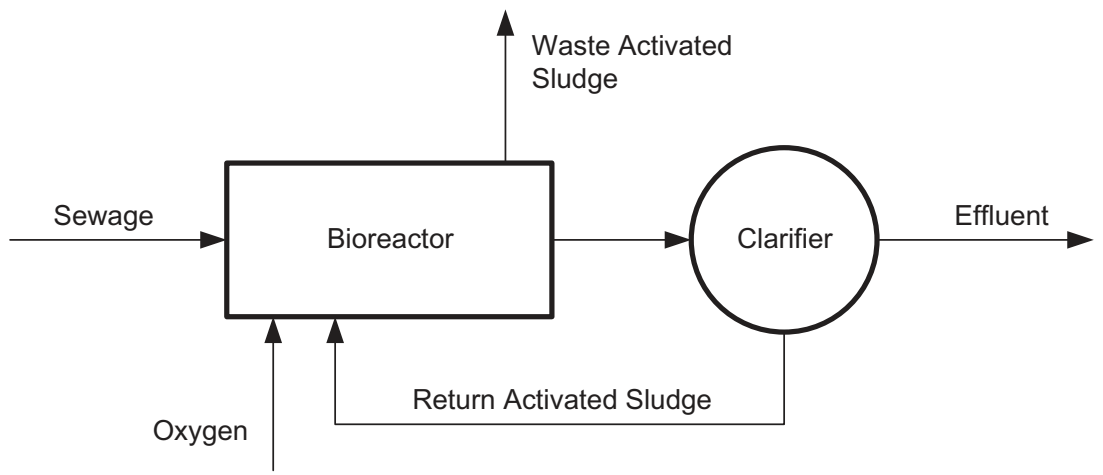

Figure 3.1 Basic format of the continuous flow activated sludge process.

The operator has four main controls:

(1) Sludge wasting rate, governing the solids retention time and mass of solids in the process.

(2) Aeration rate, governing the concentrations of both dissolved oxygen and dissolved carbon dioxide in the bioreactor. 
(3) Sludge recycle rates, governing the solids concentration and mass of sludge in the clarifier and bioreactor compartments.

(4) Chemical dosing rates, influencing nitrogen and phosphorus removal.

Sometimes the bioreactor compartment sizes and feed locations can also be adjusted.

The process can have one or more of the following functions:

- Removal of carbonaceous organic materials - this is the primary function of nearly all BNR plants.

- Oxidation of ammonia to nitrate - nitrification.

- Removal of total nitrogen by nitrification and the subsequent reduction of nitrate to nitrogen denitrification.

- Removal of phosphorus by biological and supplementary chemical means.

\subsection{KINETICS OF BIOLOGICAL PROCESSES}

The kinetics (rates) of BNR processes revolve around bacterial growth rates. This section provides an overview of bacterial kinetics.

Bacteria need a supply of substrate or food, predominantly carbon, for building new cellular material plus a supply of growth energy for carrying out that work. The bacteria utilising organic material, or COD, in sewage are heterotrophs which obtain both their cell carbon and their growth energy from organic substrates. A second group of bacteria called autotrophs obtain their cell carbon from inorganic carbon dioxide and their growth energy from the oxidation of inorganic compounds such as ammonia.

\subsubsection{Substrate utilisation}

In order to grow, bacteria need substrates which can be synthesized into new cellular material, plus a supply of energy with which to carry out this synthesis. In the case of the heterotrophs, part of the organic substrate is oxidised to provide the energy needed to synthesize the rest into new cellular material.

Bacteria also need energy to maintain the existing cells. This maintenance energy is used for activities such as the rebuilding of unstable cellular components and motility. In addition, a percentage of cells die each day and become substrate for living cells. The energy used for cell maintenance and for oxidation of dead cells is considered to be obtained by oxidation of previously formed cellular material and is called endogenous respiration.

About $20 \%$ of cellular mass is relatively resistant to biodegradation and as a result of endogenous respiration a residue of inert cellular material accumulates within the sludge mass.

The heterotrophic growth process is summarised in Figure 3.2. The total mass of substrate utilised with time is $\mathrm{dS} / \mathrm{dt}$ where $\mathrm{S}$ is the substrate composition (measured as COD). A proportion Y.dS/dt is converted into bacterial cells, where $\mathrm{Y}$ is the yield coefficient $\left(0.45 \mathrm{mgVSS} / \mathrm{mgCOD}\right.$ for heterotrophs $\left.{ }^{1}\right)$. The rest of the substrate, $(1-\mathrm{Y}) \mathrm{dS} / \mathrm{dt}$, is oxidised to provide growth energy. At the same time, endogenous respiration causes a decrease in the active bacterial mass. The rate of decrease is $\mathrm{bX}$ where $\mathrm{X}$ is the concentration of active cells and $\mathrm{b}$ is the decay coefficient $\left(0.24 \mathrm{~d}^{-1}\right.$ for heterotrophs). The net growth rate of active bacterial mass is then given by:

$$
\mathrm{dX} / \mathrm{dt}=\mathrm{Y} \cdot \mathrm{dS} / \mathrm{dt}-\mathrm{bX}
$$

\footnotetext{
${ }^{1}$ For sewage organics, $33 \%$ of the COD utilised is oxidised and the resulting energy is used to convert the other $67 \%$ into cellular material with a COD of $1.48 \mathrm{mgCOD} / \mathrm{mgVSS}$. The yield coefficient is therefore $0.67 \mathrm{mgCOD} / \mathrm{mgCOD}$ or $0.67 / 1.48=0.45$ $\mathrm{mgVSS} / \mathrm{mgCOD}$. The yield is different for other organic substrates.
} 

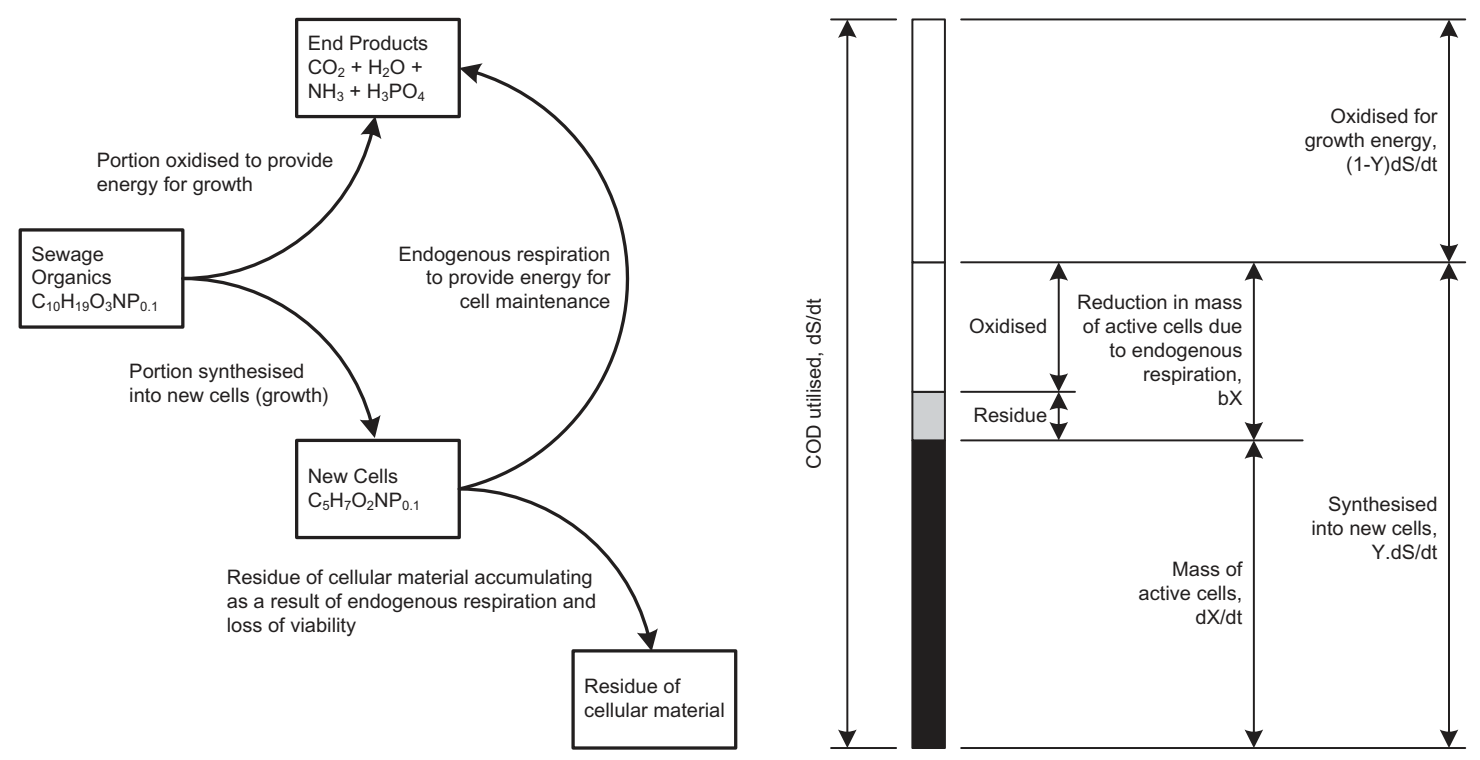

Figure 3.2 Heterotrophic substrate utilisation.

\subsubsection{Substrate concentration}

Bacterial growth in a batch culture is illustrated in Figure 3.3. From A to B (the lag phase) the bacteria are adapting their enzyme systems to the substrate. From B to $\mathrm{C}$ the bacterial growth rate is constant (exponential growth), while the substrate concentration falls exponentially. However, at Point $\mathrm{C}$ the substrate concentration becomes low enough to limit the rate of growth of the bacteria which then enter the so-called declining growth phase. Slowing in the bacterial growth rate can also be caused by other changes in solution chemistry such as accumulation of inhibitory end-products or changes in $\mathrm{pH}$ or temperature but we are here concerned with the effect of substrate concentration.

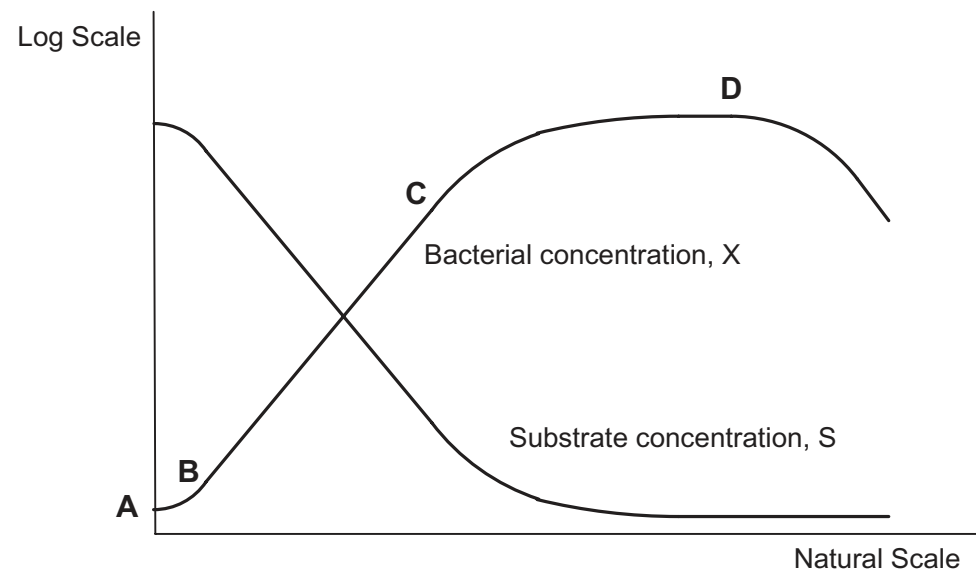

Figure 3.3 Bacterial growth in a batch culture. 
At Point $\mathrm{D}$ the synthesis rate has fallen to equal the decay rate and net growth is stationary. Beyond $\mathrm{D}$ the bacterial mass declines because endogenous respiration exceeds the rate of synthesis of new cells.

The rate of change of active mass is described by the equation:

$$
\begin{aligned}
\mathrm{dX} / \mathrm{dt} & =\mu \mathrm{X}-\mathrm{bX} \\
& =(\mu-\mathrm{b}) \mathrm{X}
\end{aligned}
$$

where

$\mu=$ growth rate of active bacteria, time ${ }^{-1}$

$(\mu-b)=$ net growth rate

A batch culture can be converted to a continuous system by withdrawing cells and oxidation products as they are formed and adding food as it is used, to maintain uniform culture conditions. The continuous culture will then operate indefinitely at some point on the batch culture curve in Figure 3.3. The aim of sewage treatment is to reduce the substrate concentration, $\mathrm{S}$, to a low value. Bacteria in treatment processes therefore normally operate in the declining growth phase between Points C and D.

In 1942 the French microbiologist, Monod, investigated the dependence of the growth rate, $\mu$, on the substrate concentration, S (not published till 1949: Monod, 1949). He produced the now famous Monod relationship (see Figure 3.4) expressing the dependence of bacterial growth rate on substrate concentration:

$$
\mu=\mu_{m} \mathrm{~S} /\left(\mathrm{K}_{\mathrm{S}}+\mathrm{S}\right)
$$

where

$\mu_{\mathrm{m}}=$ maximum specific growth rate (substrate not limiting), time ${ }^{-1}$

$\mathrm{K}_{\mathrm{S}}=$ half velocity (or half saturation) coefficient, equal to the substrate concentration at which $\mu=\mu_{\mathrm{m}} / 2$

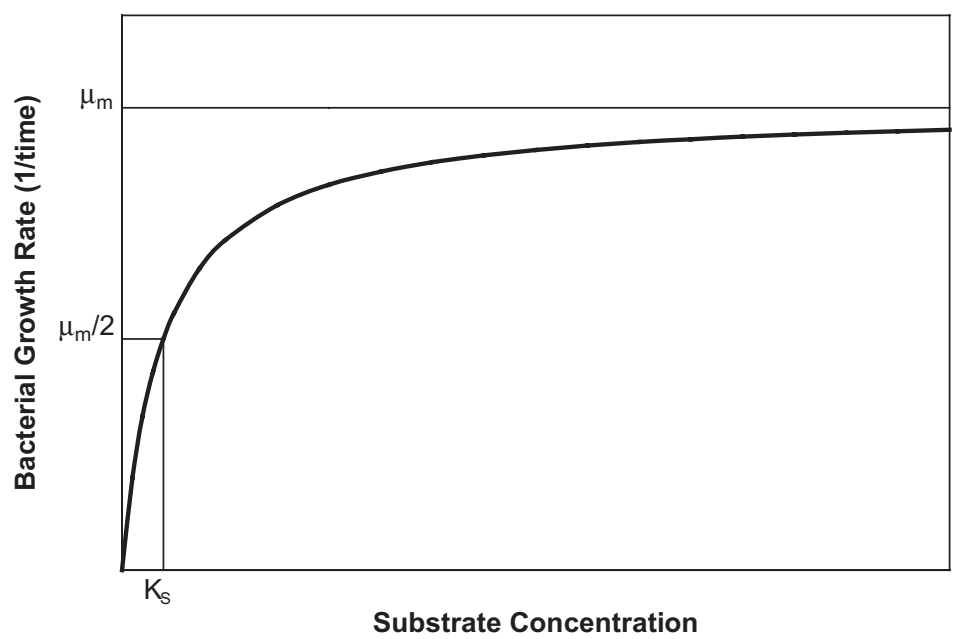

Figure 3.4 The Monod curve.

The substrate which limits growth rate is the nutrient in shortest supply relative to bacterial needs, known as the limiting nutrient. Nutrient requirements are discussed in Section 3.4.5. 
An equation for the rate of change of substrate concentration can be derived from Equations 3.1-3.3:

$$
\mathrm{dS} / \mathrm{dt}=\mathrm{kSX} /\left(\mathrm{K}_{\mathrm{S}}+\mathrm{S}\right)
$$

where

$\mathrm{k}=$ rate coefficient for substrate utilisation

$=\mu_{\mathrm{m}} / \mathrm{Y}$

Standard references (e.g. Metcalf \& Eddy, 2003) can be consulted for more detail.

\subsection{SOLIDS RETENTION TIME}

\subsubsection{Definition}

Process solids retention time (SRT), also called mean cell residence time or sludge age, is the key operating parameter as it governs or influences nearly all other parameters of interest. In the way that hydraulic retention time (HRT) equals the volume of water in the process divided by the hydraulic flow rate, the SRT equals the mass of solids in the process divided by the mass leaving the system each day, or the mass wasting rate. SRT and HRT are independent.

The significance of the SRT is that under steady state operating conditions the net biological growth rate, $(\mu-b)$, is the inverse of the SRT. Thus setting the wasting rate at, say, one tenth of the sludge mass per day (SRT 10 days) sets the sludge growth rate at one tenth of its mass per day. Both the process sludge mass and the effluent substrate concentration will attain constant values.

There is a minimum SRT below which no bacterial growth can occur. This is set by the maximum growth rate of the bacteria and is given by Equation 3.5:

$$
\mathrm{SRT}_{\min }=1 /\left(\mu_{\mathrm{m}}-\mathrm{b}\right)
$$

\subsubsection{Calculation}

The basic equation for SRT is:

$$
\mathrm{SRT}=\left(\mathrm{M}_{\mathrm{R}}+\mathrm{M}_{\mathrm{C}}\right) / \mathrm{M}_{\mathrm{W}}
$$

where

SRT $=$ solids retention time, $\mathrm{d}$

$\mathrm{M}_{\mathrm{R}}=$ mass of solids in the bioreactor, $\mathrm{kg}$

$=\mathrm{V}_{\mathrm{R}} \mathrm{X}_{\mathrm{M}}$ when the MLSS concentration is constant throughout the bioreactor

$=\Sigma \mathrm{V}_{\mathrm{Ri}} \mathrm{X}_{\mathrm{Mi}}$ when various bioreactor compartments have different MLSS concentrations

$\mathrm{X}_{\mathrm{M}}=$ mixed liquor suspended solids (MLSS) concentration, $\mathrm{mg} / \mathrm{L}$

$\mathrm{V}_{\mathrm{R}}=$ bioreactor volume, $\mathrm{ML}$

$\mathrm{M}_{\mathrm{C}}=$ mass of solids in the clarifier, $\mathrm{kg}$

$\mathrm{M}_{\mathrm{W}}=$ mass of solids wasted, $\mathrm{kg} / \mathrm{d}$

$$
=\mathrm{Q}_{\mathrm{W}} \mathrm{X}_{\mathrm{W}}
$$

$\mathrm{Q}_{\mathrm{W}}=$ volume wasted, $\mathrm{ML} / \mathrm{d}$

$\mathrm{X}_{\mathrm{W}}=$ solids concentration in the waste sludge, $\mathrm{mg} / \mathrm{L}$ 
As an example, if one tenth of the mass of solids in the process is wasted each day the SRT is 10 days. Except at short SRT, or under conditions of critical clarifier loading (most commonly, wet weather), the mass of solids in the clarifier is generally only a small fraction of the total and for operational purposes can be ignored or assigned a nominal value such as $10 \%$ of the total solids.

In practice, a portion of the daily solids production is lost in the plant effluent and this must be taken into account in calculating the SRT. Equation 3.6 should therefore be modified to read:

$$
\mathrm{SRT}=\left(\mathrm{M}_{\mathrm{R}}+\mathrm{M}_{\mathrm{C}}\right) /\left(\mathrm{M}_{\mathrm{W}}+\mathrm{M}_{\mathrm{E}}\right)
$$

where

$$
\begin{aligned}
\mathrm{M}_{\mathrm{E}} & =\text { mass of solids lost in the effluent, } \mathrm{kg} / \mathrm{d} \\
& =\mathrm{Q}_{\mathrm{E}} \mathrm{X}_{\mathrm{E}} \\
\mathrm{Q}_{\mathrm{E}} & =\text { effluent flow rate, } \mathrm{ML} / \mathrm{d} \\
\mathrm{X}_{\mathrm{E}} & =\text { effluent } \mathrm{SS} \text { concentration, } \mathrm{mg} / \mathrm{L}
\end{aligned}
$$

If the waste sludge is directed to a thickener or dewatering process and the clarified return flow is directed to the bioreactor, Equation 3.7 should be further modified to account for the solids returned to the process (Figure 3.5):

$$
\mathrm{SRT}=\left(\mathrm{M}_{\mathrm{R}}+\mathrm{M}_{\mathrm{C}}\right) /\left(\mathrm{S}_{\mathrm{C}} \mathrm{M}_{\mathrm{W}}+\mathrm{M}_{\mathrm{E}}\right)
$$

where

$$
\begin{aligned}
\mathrm{S}_{\mathrm{C}} & =\text { thickener solids capture } \\
& =\mathrm{Q}_{\mathrm{U}} \mathrm{X}_{\mathrm{U}} / \mathrm{M}_{\mathrm{W}} \\
& =1-\left[\left(\mathrm{Q}_{\mathrm{W}}-\mathrm{Q}_{\mathrm{U}}\right) \mathrm{X}_{\mathrm{O}} / \mathrm{M}_{\mathrm{W}}\right] \\
\mathrm{Q}_{\mathrm{U}} & =\text { thickened sludge flow, } \mathrm{ML} / \mathrm{d} \\
\mathrm{X}_{\mathrm{U}} & =\text { thickened sludge } \mathrm{SS} \text { concentration, } \mathrm{mg} / \mathrm{L} \\
\mathrm{X}_{\mathrm{O}} & =\text { thickener return flow } \mathrm{SS} \text { concentration, } \mathrm{mg} / \mathrm{L}
\end{aligned}
$$

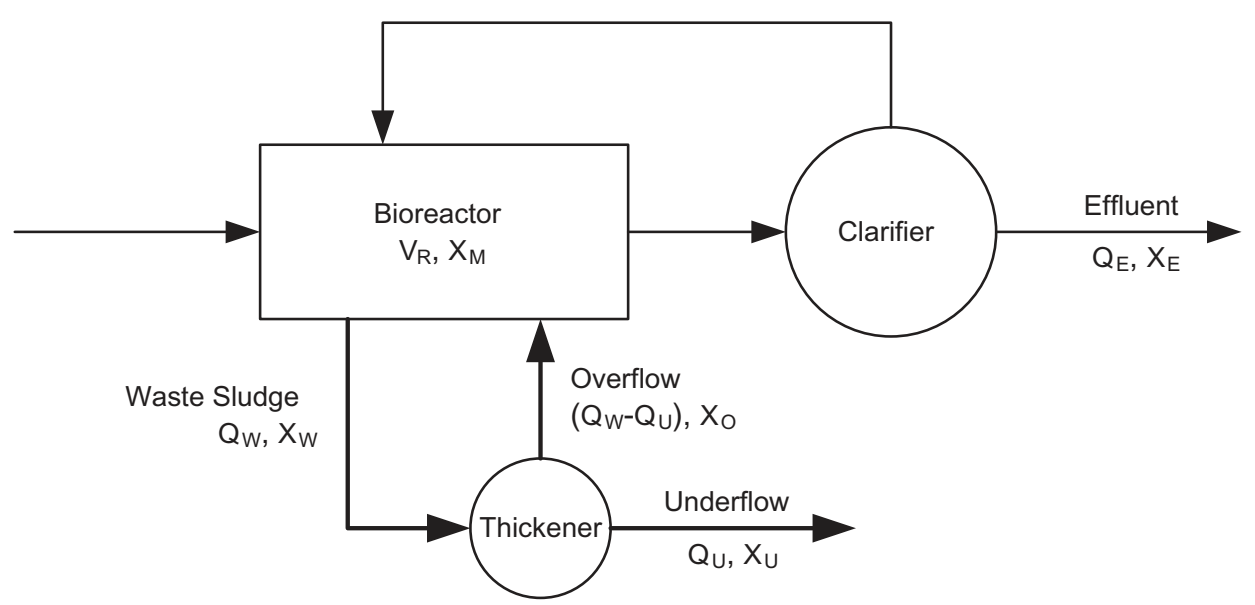

Figure 3.5 Solids flows. 


\subsection{CARBON REMOVAL}

This section deals with the removal of carbonaceous organic materials. In the following Sections the pioneering work of Professor Marais and his colleagues at the University of Cape Town has been heavily drawn upon (Marais \& Ekama, 1976; Ekama \& Marais, 1977; UCT et al., 1984; Henze et al., 2008).

\subsubsection{Effect of SRT}

The main process parameters vary with SRT as shown in Figure 3.6.

- Mass of solids. The mass of solids in the bioreactor increases with SRT; at a particular SRT the mass depends solely on the daily mass COD loading.

- Wasting mass. The daily mass to be wasted declines with increasing SRT because of the effect of endogenous respiration (explained below).

- Oxygen demand. The oxygen demand increases with SRT; at a particular SRT the demand varies with the COD and nitrogen loadings.

- Effluent soluble biodegradable COD (or BOD). For municipal sewage this is low and equals only a few $\mathrm{mg} / \mathrm{L}$ at SRTs greater than about 5 days. The effluent biodegradable COD does not depend on the feed COD - higher feed COD is compensated for by increased biomass.

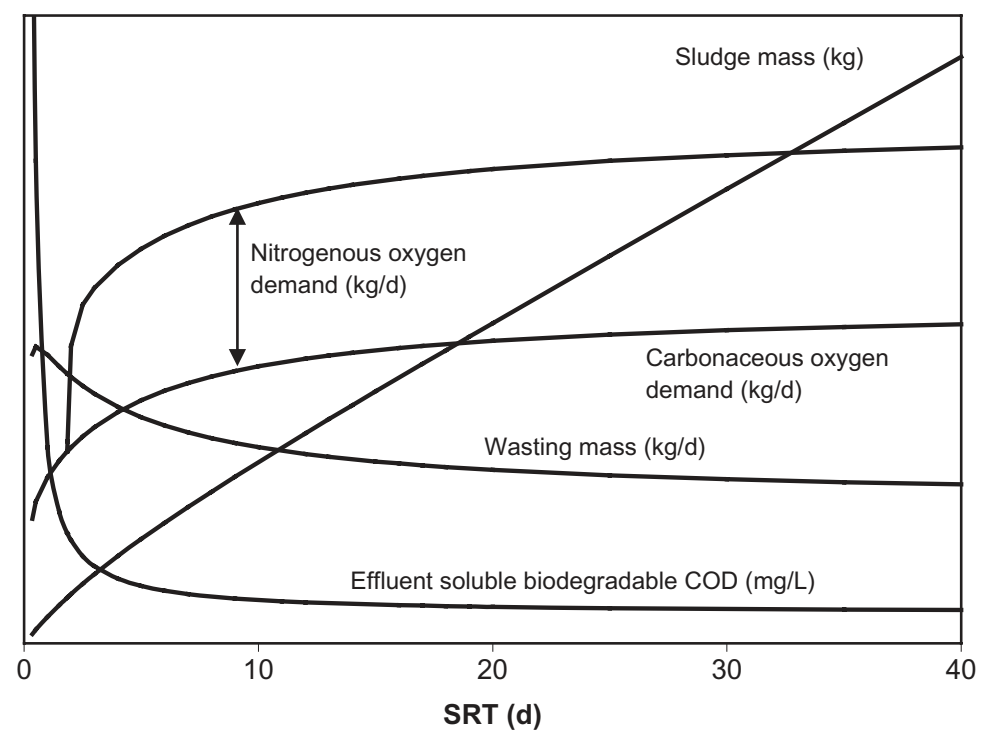

Figure 3.6 Variation of process parameters with SRT at a particular plant loading.

A typical classification of SRTs is as follows: high rate (COD removal only), 2-3 days; so-called conventional (carbon removal plus nitrification), 5-15 days; and extended aeration, 15-40 days or more. Most nitrogen and biological phosphorus removal processes operate in the high conventional to extended aeration range.

There is a minimum SRT below which no bacterial growth can occur. This is given by the inverse of the maximum net growth rate of the bacteria. At shorter SRTs the bacteria cannot grow as fast as they are wasted and the solids are said to be washed out of the process. The minimum SRT for carbon removal is less than 
one day but the high rate range of 2-3 days is the minimum producing sufficient flocculation for effective solids settling and retention.

\subsubsection{Loading conditions}

In practice the loading on a plant is not steady but varies continuously. Instantaneous values of bacterial growth rate and therefore SRT are correspondingly variable and in normal plant operation use of moving average values calculated over several days is the most useful approach for monitoring purposes.

\subsubsection{F:M ratio}

As an alternative to SRT the process can be controlled using the food:microorganism (F:M) ratio. This is also called the sludge loading rate and equals the daily mass COD (or BOD) loading per unit mass of MLSS (kgCOD/kgMLSS.d).

$\mathrm{F}: \mathrm{M}$ ratio is directly related to SRT and the approximate relationship for a typical municipal sewage is shown in Figure 3.7.

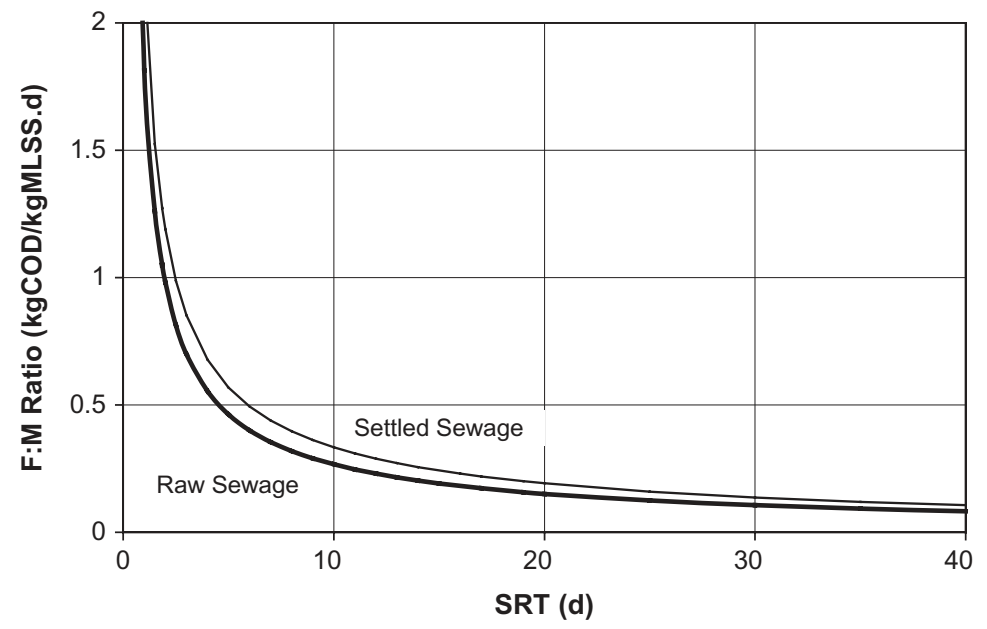

Figure 3.7 Relationship between F:M ratio and SRT for a typical municipal sewage.

Under normal operating conditions F:M ratio is inferior to SRT as a control parameter. F:M ratio has the following disadvantages:

- It is an ambiguous term in that one process condition can be described by different F:M values, depending on whether food loading is expressed as BOD, total or biodegradable COD or TOC, and biomass as total, volatile or active mass (MLSS components are explained later). On theoretical grounds the ratio is correctly expressed in terms of the mass of active bacteria but this cannot be directly measured.

- The ratios of the active mass and mixed liquor volatile suspended solids (MLVSS) to total MLSS depend on the amount of inert solids in the process feed, hence the F:M ratio describing a particular process condition is affected by the feed characteristics. 
- Frequent measurement of BOD, COD or TOC is necessary for process control. If BOD is used, values are five days old when obtained.

- Choice of F:M ratio sets the approximate MLSS concentration to be maintained but gives no direct indication of the solids wasting rate required.

In contrast, operation at a fixed SRT simply requires that the daily wasting equal (1/SRT) of the mass of solids in the process. The appropriate MLSS concentration sets itself automatically. Day to day fluctuations in COD loading result in automatic variations in MLSS concentration, but because of the slow bacterial growth rates employed MLSS concentration varies only slowly. A change in operating SRT can be made simply by adjusting the wasting rate; the MLSS concentration then gradually moves to its new equilibrium value over a period of 2 to 3 SRTs.

A particular case where use of F:M ratio is preferred is process startup using a small quantity of seed sludge. These startup conditions necessarily entail non-steady state operation with the biomass increasing day by day. Where practical, a low initial loading can be applied and then increased daily in proportion to the MLSS concentration to keep the F:M ratio constant.

\subsubsection{Mixed liquor suspended solids Components of MLSS}

The solids mass in the mixed liquor of a carbon removal activated sludge process has five separate components:

(1) Active mass. The mass of live organisms providing treatment.

(2) Endogenous residue. The accumulated inert residue of endogenous respiration.

(3) Inert SS from the feed. A portion of the volatile SS in the feed is unbiodegradable $\left(\mathrm{f}_{\text {up }} \times\right.$ feed COD, Table 2.2). These solids accumulate in the sludge mass.

(4) Stored substrate. Biodegradable organics in colloidal or suspended form are adsorbed onto the bacterial cells and solubilised before being absorbed. Except at very short SRTs or during high peak diurnal loadings the stored mass is a negligible fraction of the total MLSS.

(5) Inorganic mass. Components 1 to 4 are all organic (volatile), forming the MLVSS. There is also an inert inorganic fraction, amounting in carbon and nitrogen removal processes to some $25 \%$ of the MLSS with raw sewage feed and $17 \%$ with settled sewage feed.

In phosphorus removal processes there are two additional components of interest - inorganic polyphosphate granules within the cells of the phosphorus accumulating organisms (PAOs), and inorganic precipitates produced by chemical dosing for phosphorus removal. These are discussed later.

The various components cannot be readily measured in practice and for operational purposes the MLSS is generally divided into the simple volatile and inorganic fractions.

\section{Mass of solids}

The effect of SRT on the process solids mass in a carbon removal process is shown in Figure 3.8. The values shown are approximate only because the quantity of inert organics in the feed can vary considerably. The solids mass is essentially the same for nitrifying and denitrifying processes because the mass of nitrifiers is negligible compared with the heterotrophs. If the process incorporates enhanced phosphorus removal, the sludge mass will be $10-20 \%$ higher. 


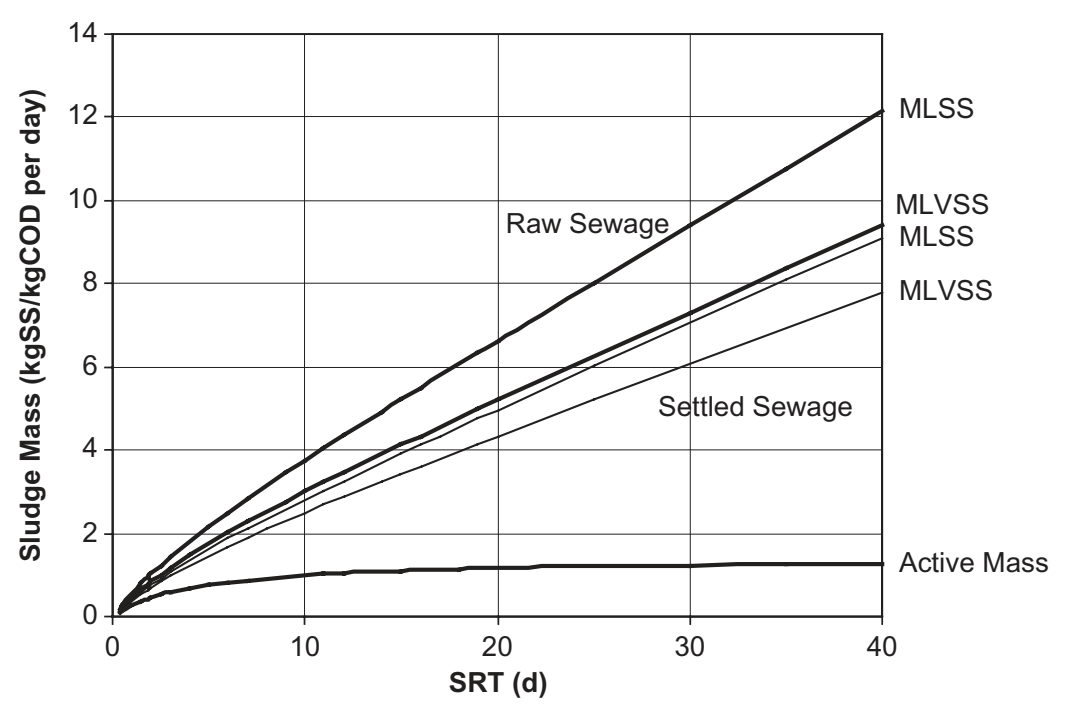

Figure 3.8 Effect of SRTon the sludge mass in a carbon removal process treating a typical municipal sewage at $20^{\circ} \mathrm{C}$. With settled sewage there is less inert feed VSS in the sludge mass. A rise in temperature of $10^{\circ} \mathrm{C}$ reduces the mass by about $9 \%$.

It can be seen that the active mass is only a small part of the total. The active fraction declines as SRT increases because of the increasing effect of endogenous respiration. Because the endogenous respiration rate varies with temperature, the active fraction also declines with temperature rise. The active fraction defines the stability of the waste sludge, or its tendency to produce odours and attract vectors during air drying. Thus at higher temperatures a given degree of stability can be achieved at shorter SRT.

The daily sludge production, or wasting mass, equals the mass of sludge in the process divided by the SRT. Approximate values for municipal sewage are shown in Figure 3.9.

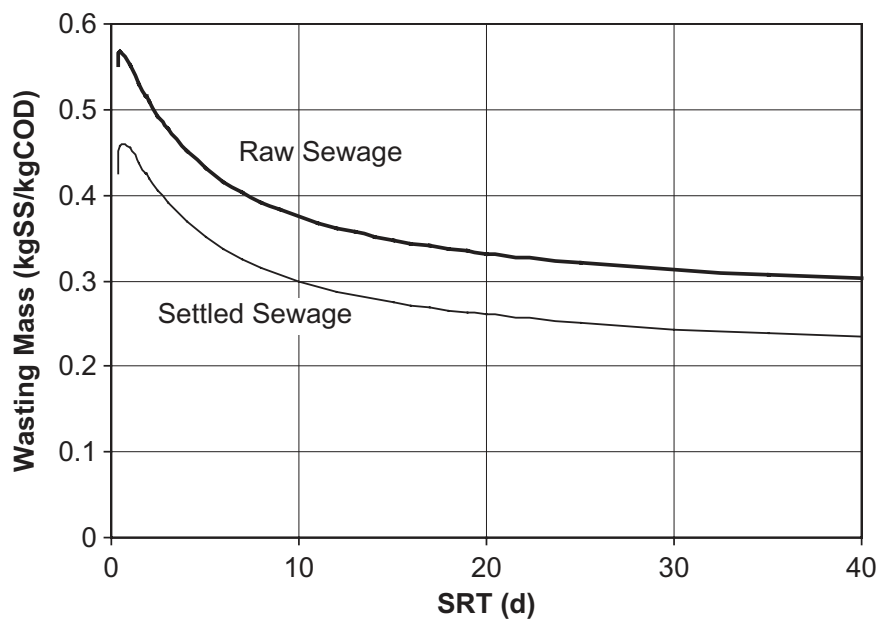

Figure 3.9 Effect of SRT on the mass of solids to be wasted at $20^{\circ} \mathrm{C}$. The mass decreases by about $9 \%$ per $10^{\circ} \mathrm{C}$ rise in temperature. 


\subsubsection{Nutrient requirements}

Bacterial growth requires a large number of different elements, most in trace quantities only (Wood \& Tchobanoglous, 1975).

Heterotrophic cell material contains, in addition to hydrogen and oxygen (which the organism can derive from water), carbon, nitrogen, phosphorus and sulfur, in order of decreasing abundance (see Table 3.1). These six elements account for about $95 \%$ of the cellular dry weight. Many other elements are present in the remaining fraction, including potassium, sodium, magnesium, calcium, iron, manganese, cobalt, copper, molybdenum and zinc (Stanier et al., 1976).

Table 3.1 Composition of the heterotrophic bacterial cell.

\begin{tabular}{lc}
\hline Element & $\begin{array}{c}\text { Approximate percentage } \\
\text { of dry weight }\end{array}$ \\
\hline VSS & 93 \\
Carbon & 49 \\
Oxygen & 26 \\
Nitrogen & 11 \\
Hydrogen & 6 \\
Phosphorus & 3 \\
Sulfur & 1 \\
Potassium & 1 \\
Sodium & 1 \\
Calcium & 0.5 \\
Magnesium & 0.5 \\
Chlorine & 0.5 \\
Iron & 0.2 \\
All Others & 0.3 \\
\hline
\end{tabular}

The general chemical formula for organic cell material in a heterotrophic bacterium is $\mathrm{C}_{5} \mathrm{H}_{7} \mathrm{O}_{2} \mathrm{~N}$ which has a COD of $1.42 \mathrm{mgCOD} / \mathrm{mgVSS}$, calculated as follows:

$$
\begin{array}{lcc} 
& \mathrm{C}_{5} \mathrm{H}_{7} \mathrm{O}_{2} \mathrm{~N}+5 \mathrm{O}_{2} \longrightarrow 5 \mathrm{CO}_{2}+\mathrm{NH}_{3}+2 \mathrm{H}_{2} \mathrm{O} \\
\mathrm{MW} & 113 \quad 160 \\
\mathrm{COD}= & 160 / 113=1.42 \mathrm{mgO}_{2} / \mathrm{mgVSS}
\end{array}
$$

An empirical figure of $1.48 \mathrm{mgCOD} / \mathrm{mgVSS}$ is often used for the total MLVSS including both biomass and residual influent organics.

In municipal sewage organic carbon (or COD) is the nutrient limiting the growth of the biomass and other nutrients are present in excess of minimum requirements. Because net sludge production varies with SRT, nutrient requirements also vary with SRT. Nitrogen and phosphorus constitute about $10 \%$ and $3 \%$ respectively of the overall MLVSS and approximate growth requirements are shown in Figure 3.10. The percentage of phosphorus in the biomass is greater in enhanced $\mathrm{P}$ removal processes (discussed in Section 3.6 below). 


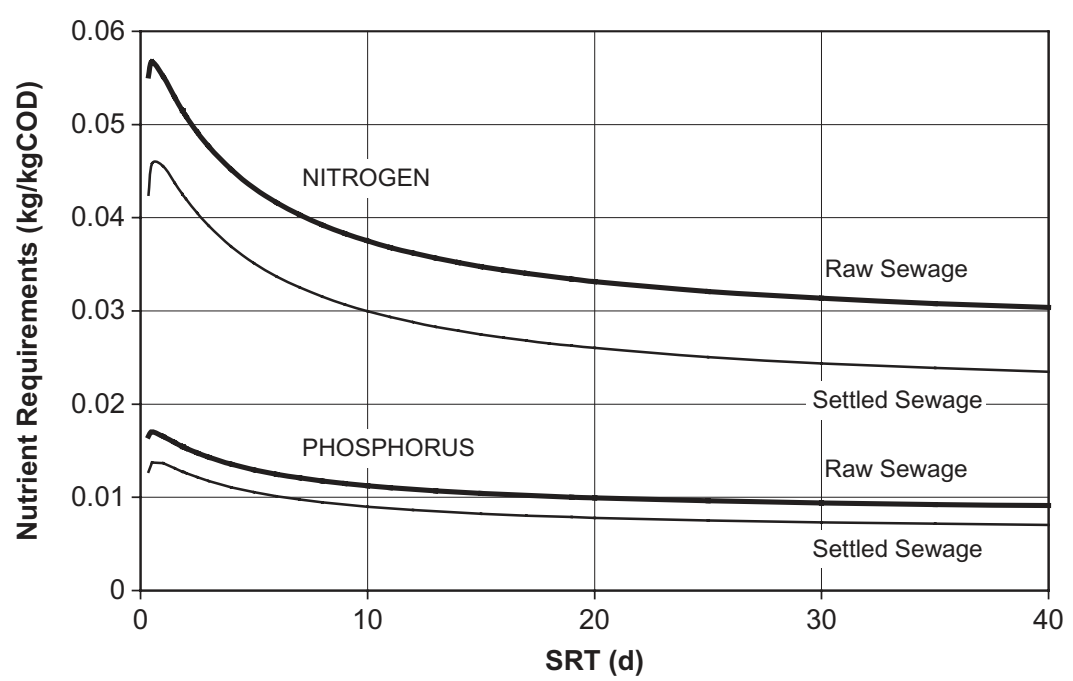

Figure 3.10 Approximate nitrogen and phosphorus requirements at $20^{\circ} \mathrm{C}$. The differing requirements for raw and settled sewage reflect the different percentages of inert feed VSS in the sludge mass.

\subsubsection{Carbonaceous oxygen demand}

In a carbon removal process, oxygen is used for two purposes:

- Oxidation of one third of the feed biodegradable COD to provide growth energy.

- Endogenous respiration.

The magnitude of the carbonaceous oxygen demand under steady state conditions is shown in Figure 3.11.

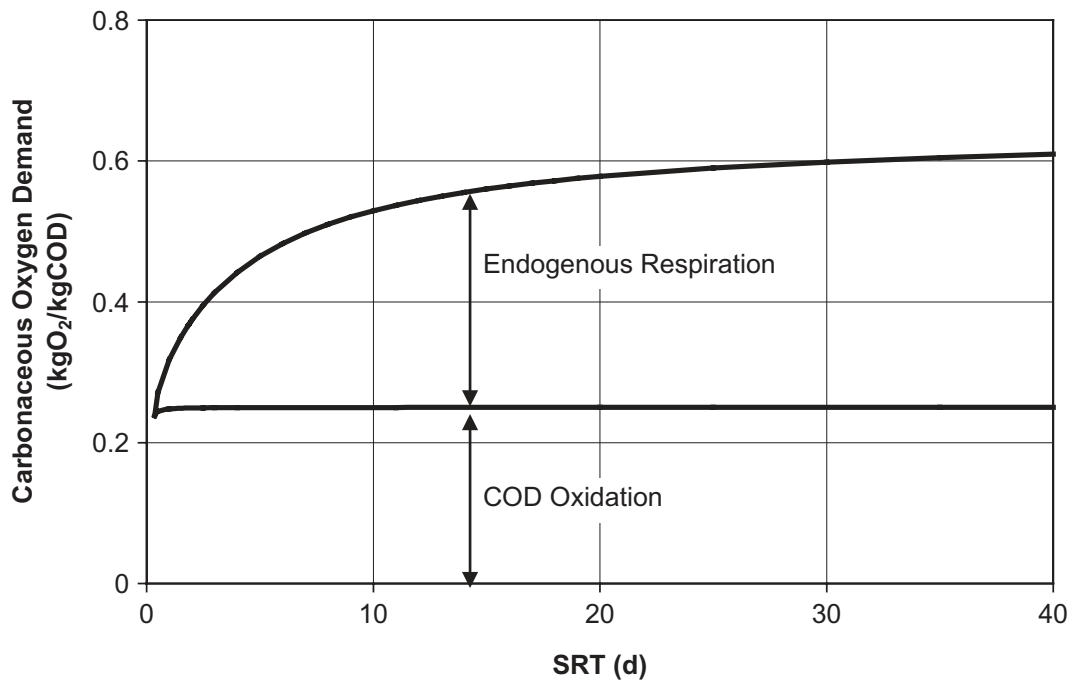

Figure 3.11 Carbonaceous oxygen demand at $20^{\circ} \mathrm{C}$. A $10^{\circ} \mathrm{C}$ rise in temperature increases the oxygen demand by about $5 \%$. 


\subsection{NITROGEN REMOVAL}

\subsubsection{The nitrogen cycle}

Figure 3.12 shows the essentials of the nitrogen cycle as it applies to sewage treatment processes. Gaseous nitrogen is incorporated in organic compounds (nitrogen fixation) by both heterotrophic and autotrophic microorganisms (bacteria, algae and fungi). As discussed in Chapter 2, sewage contains both organic nitrogen and ammonia. In the treatment plant the organic nitrogen is released as ammonia (ammonification) and some of this is reconverted to organic form when supplying the metabolic needs of bacterial growth.

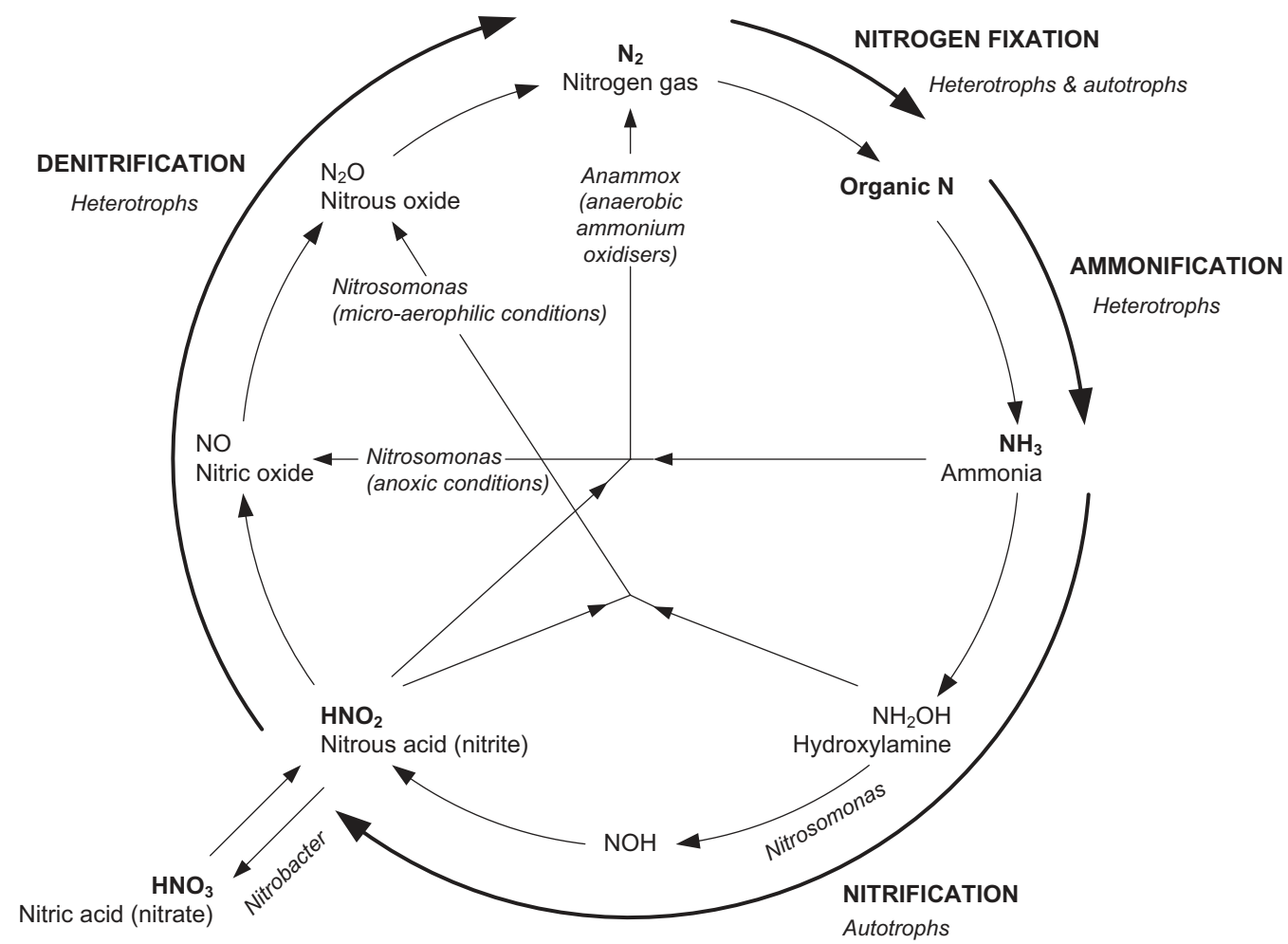

Figure 3.12 The nitrogen cycle (after Henze et al., 2008).

The residual ammonia can then be oxidised progressively to nitrite and nitrate (nitrification). The oxidised nitrogen can in turn be reduced to nitrogen gas (denitrification).

Intermediate nitrogenous compounds and pathways can be involved in these overall conversions as illustrated in Figure 3.12.

\subsubsection{Nitrification}

\section{Nitrifiers}

Oxidation of ammonia to nitrate is carried out by two groups of bacteria (the nitrifiers), generally represented as Nitrosomonas and Nitrobacter although other families are also involved. These organisms are aerobes, 
growing under aerobic conditions and decaying via endogenous respiration under both aerobic and non-aerobic conditions. ${ }^{2}$ They are also classified as chemical autotrophs because they obtain their cellular carbon from dissolved carbon dioxide and their growth energy from oxidation of ammonia to nitrite (Nitrosomonas) and nitrite to nitrate (Nitrobacter). Although Nitrosomonas and Nitrobacter are generally used to represent the ammonium oxidising bacteria (AOBs) and nitrite oxidising bacteria (NOBs), other bacteria are also known to be involved.

The overall nitrification process is described by these two chemical equations:

Nitrosomonas $\quad \mathrm{NH}_{4}^{+}+1.5 \mathrm{O}_{2} \longrightarrow \mathrm{NO}_{2}^{-}+\mathrm{H}_{2} \mathrm{O}+2 \mathrm{H}^{+}$

Nitrobacter $\quad \mathrm{NO}_{2}^{-}+0.5 \mathrm{O}_{2} \longrightarrow \mathrm{NO}_{3}^{-}$

Overall $\quad \mathrm{NH}_{4}^{+}+2 \mathrm{O}_{2} \longrightarrow \mathrm{NO}_{3}^{-}+\mathrm{H}_{2} \mathrm{O}+2 \mathrm{H}^{+}$

These equations show that:

- The nitrogenous oxygen demand is $4.6 \mathrm{kgO}_{2} / \mathrm{kgN}$ nitrified (3.43 for ammonia oxidation and 1.14 for nitrite oxidation).

- Acid production reduces the total alkalinity by $7.1 \mathrm{mg} / \mathrm{L}$ as $\mathrm{CaCO}_{3}$ for each $\mathrm{mg} / \mathrm{L}$ of ammonia-N oxidised. Alkalinity and $\mathrm{pH}$ are discussed in Section 3.8.

The yield of nitrifiers is very low $(0.1 \mathrm{mgVSS} / \mathrm{mgN}$ nitrified), which has three implications: (a) in practical terms, the mass of nitrifiers makes a negligible contribution to the overall process sludge mass in combined carbon and nitrogen removal processes, (b) nitrifier endogenous respiration is low and makes negligible contribution to the overall oxygen demand, and (c) metabolic nitrogen uptake by the nitrifiers is small and has negligible effect on the amount of ammonia nitrified.

Figure 3.13 shows the effect of SRT on the nitrifier active and total masses. The difference between the two comprises the nitrifier endogenous and inorganic fractions. Comparison of Figure 3.13 with Figure 3.8 for the heterotrophs shows two things:

- The small nitrifier mass is evident. For example, assuming raw sewage with a TKN:COD ratio of 0.1, an operating SRT of 20 days and a metabolic $\mathrm{N}$ uptake in accordance with Figure 3.10, the total nitrifier mass is only $1.5 \%$ of the total heterotroph mass.

- As SRT varies, the two types of active mass behave differently. As SRT increases above about 10 days, the heterotroph active mass hardly increases while the nitrifier active mass increases significantly. For example, the ratio of the $40 \mathrm{~d}$ : $10 \mathrm{~d}$ active masses is 1.3 for the heterotrophs but 2.6 for the nitrifiers. This comes about because of the difference in the endogenous decay rates, $\mathrm{b}-0.24 \mathrm{~d}^{-1}$ (at $20^{\circ} \mathrm{C}$ ) for the heterotrophs but only $0.04 \mathrm{~d}^{-1}$ for the nitrifiers. This is an important difference: whereas nitrification can be improved by increasing the SRT, heterotrophic denitrification performance hardly changes as SRT is varied. To increase the denitrifying sludge mass the process anoxic mass fraction has to be increased (denitrification is discussed below).

\section{Kinetics}

SRT is particularly important for nitrification because the nitrifiers grow much more slowly than the heterotrophs. The growth rates of Nitrosomonas and Nitrobacter are given by the Monod equation (3.3)

\footnotetext{
${ }^{2}$ Conditions in which dissolved oxygen is absent but nitrite and/or nitrate are present are called anoxic. When oxygen, nitrite and nitrate are all absent the conditions are called anaerobic.
} 
where the substrate concentration is ammonia- $\mathrm{N}$ for Nitrosomonas and nitrite- $\mathrm{N}$ for Nitrobacter. Nitrosomonas has a slower maximum specific growth rate than Nitrobacter and governs the overall nitrification rate under most conditions. Nitrite is normally oxidised to nitrate as fast as it is formed so little nitrite is generally found in nitrified effluents; however elevated nitrite concentrations may be found under conditions of low dissolved oxygen, high $\mathrm{pH}$ or high temperature (Ma et al., 2009).

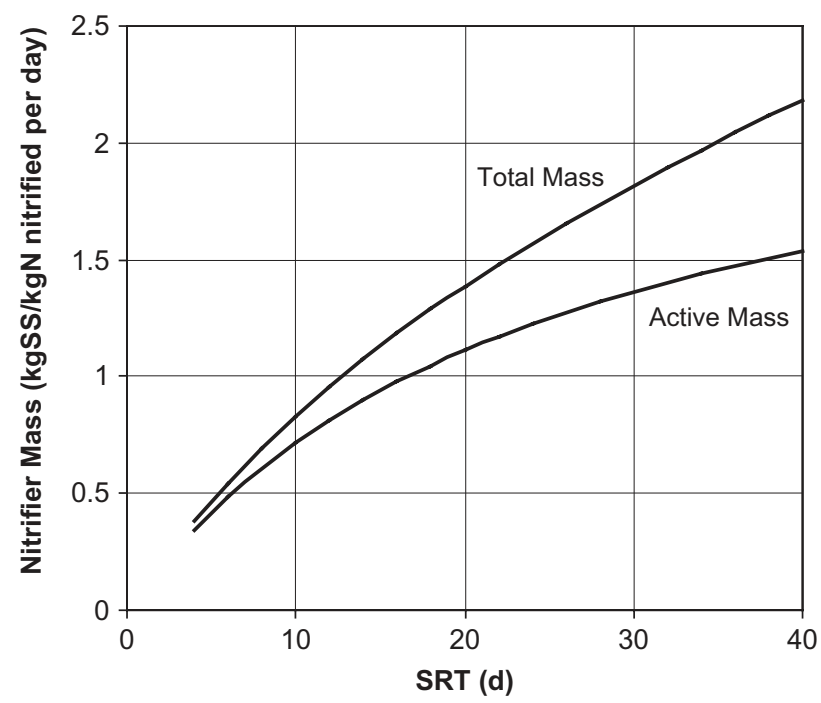

Figure 3.13 Effect of SRT on the nitrifier mass in a fully aerobic process at $20^{\circ} \mathrm{C}$.

Nitrifier growth rate is affected by several factors as discussed below.

\section{Ammonia-N (substrate) concentration ${ }^{3}$}

The relationship between growth rate and ammonia-N concentration is described by the Monod equation (Equation 3.3). The fundamental nitrifier maximum specific growth rate, $\mu_{\mathrm{nm}}$, is sensitive to a wide range of inhibitory substances, some of which are present in sewage but cannot be specifically identified. The maximum specific growth rate is therefore sewage-specific and can vary over a range of $0.3-1.0 \mathrm{~d}^{-1}$ (at $20^{\circ} \mathrm{C}$ ). It has been observed that alum dosing can enhance the nitrification rate, presumably by removing inhibitors (Section 3.7.3). The half velocity coefficient in Equation 3.3, $\mathrm{K}_{\mathrm{n}}$, is about $1.0 \mathrm{mgN} / \mathrm{L}$ at $20^{\circ} \mathrm{C}$.

\section{Temperature}

Nitrification is very sensitive to temperature. Both the maximum specific growth rate and the half velocity coefficient increase by $12 \%$ per ${ }^{\circ} \mathrm{C}$ rise in temperature, or 3.2 times per $10^{\circ} \mathrm{C}$. On the other hand, the endogenous decay coefficient increases by only $3 \%$ per ${ }^{\circ} \mathrm{C}$ rise. A temperature of $20^{\circ} \mathrm{C}$ is used as the reference for maximum specific growth rate, then termed $\mu_{\mathrm{nm} 20}$.

Figure 3.14 illustrates the effects of SRT, maximum specific growth rate and temperature on effluent ammonia concentration under steady state operating conditions.

\footnotetext{
${ }^{3}$ At normal $\mathrm{pH}$ levels ammonia is present in two forms, free ammonia, $\mathrm{NH}_{3}$, and ammonium ion, $\mathrm{NH}_{4}^{+}$. The total concentration is sometimes referred to as free and saline ammonia, FSA. In this book, unless specifically described as free ammonia, the terminology $\mathrm{mgNH}_{3}-\mathrm{N} / \mathrm{L}$ is used to represent the concentration of total free and saline ammonia expressed as nitrogen.
} 


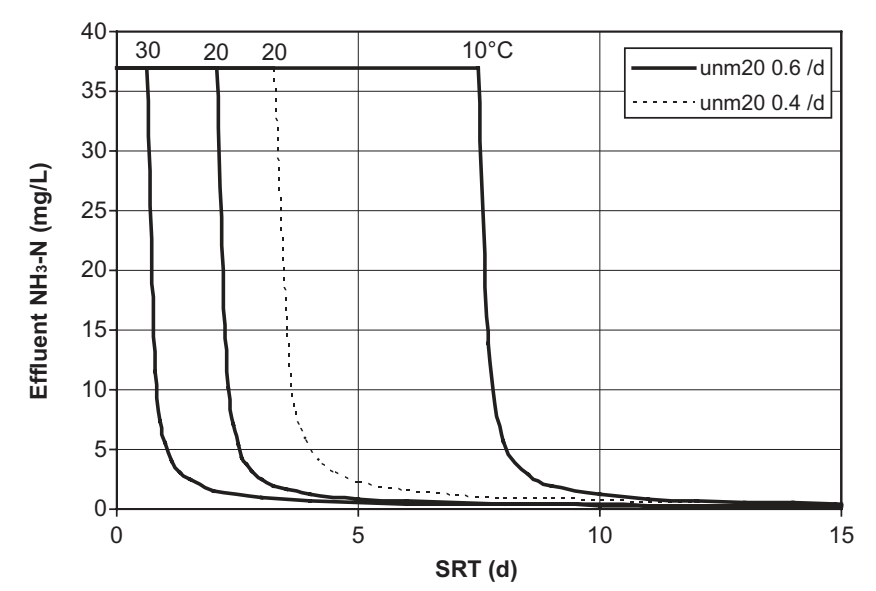

Figure 3.14 Effect of SRT on effluent ammonia nitrogen concentration produced by a steady state complete mix reactor at different temperatures and maximum specific growth rates at DO $2 \mathrm{mg} / \mathrm{L}$ and $\mathrm{pH}$ 7.2.

\section{Dissolved oxygen concentration}

The effect of dissolved oxygen concentration is also described by Monod kinetics, with a half velocity coefficient, $\mathrm{K}_{\mathrm{O}}$, around $0.3 \mathrm{mg} \mathrm{DO} / \mathrm{L}$. The effect of DO concentration on nitrifier growth rate is shown in Figure 3.15.

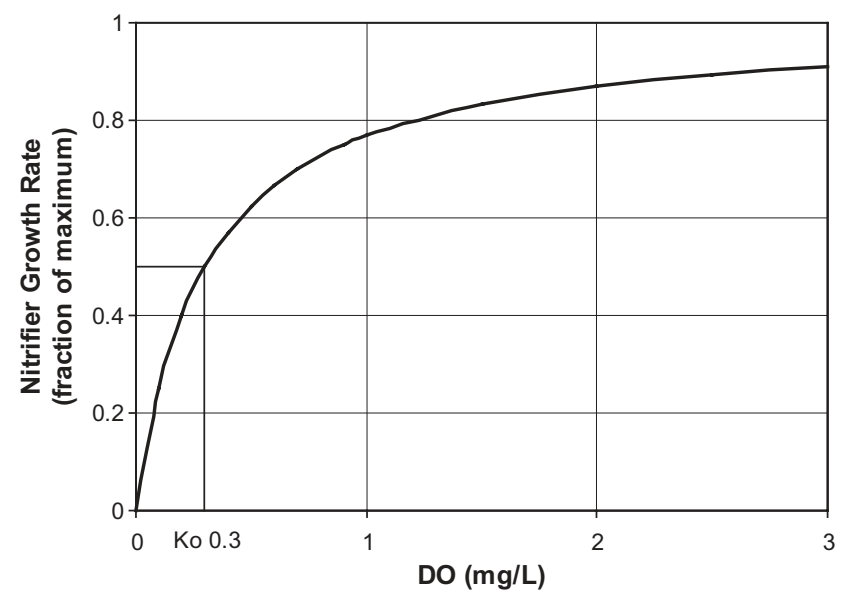

Figure 3.15 Effect of dissolved oxygen concentration on nitrifier maximum specific growth rate.

\section{$\mathrm{pH}$}

Growth rate is very sensitive to $\mathrm{pH}$ outside the range 7-8, as shown in Figure 3.16. The equations describing the effect of $\mathrm{pH}$ are as follows (Henze et al., 2008):

$\mathrm{pH} \leq 7.2$ :

$$
\mu_{\mathrm{nmpH}}=\mu_{\mathrm{nm} 7.2} 2.35^{(\mathrm{pH}-7.2)}
$$


where

$\mu_{\mathrm{nmpH}}=$ maximum specific growth rate at $\mathrm{pH}$ of interest, $\mathrm{d}^{-1}$

$\mathrm{pH} \geq 7.2:$

$$
\mu_{\mathrm{nmpH}}=\mu_{\mathrm{nm} 7.2} 1.13(9.5-\mathrm{pH}) /(9.8-\mathrm{pH})
$$

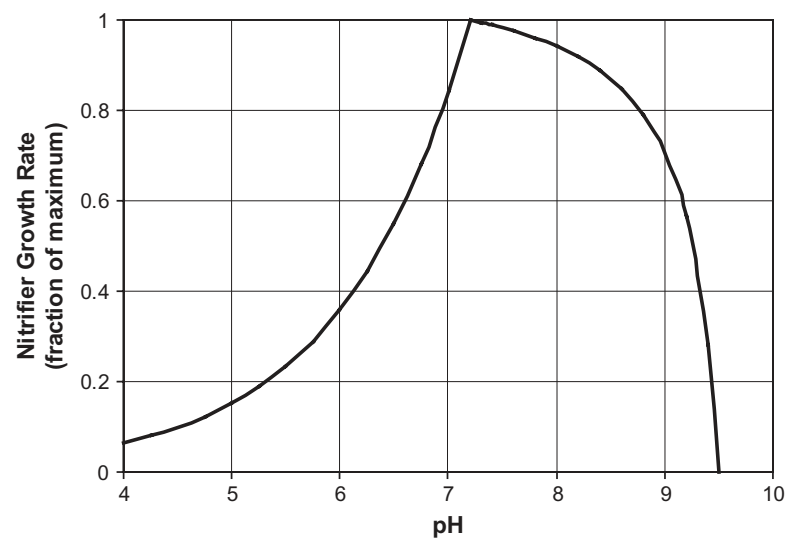

Figure 3.16 Effect of $\mathrm{pH}$ on nitrifier maximum specific growth rate.

\section{Salinity}

Elevated and variable salinity levels also reduce nitrifier growth rates, especially at TDS concentrations above $10 \mathrm{~g} / \mathrm{L}$. Nitrite oxidation may be more affected than ammonia oxidation so that process nitrite levels increase.

\section{Concurrent biological phosphorus removal}

Calibration of process models to the nitrification performance of full-scale nitrogen and phosphorus removal plants indicates that the presence of an anaerobic zone for enhanced biological phosphorus removal at the head of the process train may increase the value of $\mu_{\mathrm{nm} 20}$ to about $1.0 \mathrm{~d}^{-1}$. The reason is uncertain but may result from enhanced removal of nitrification-inhibiting compounds.

\section{Alum dosing}

Calibration of process models to the performance of full-scale plants with bioreactor alum dosing also shows $\mu_{\mathrm{nm} 20}$ values as high as $1.0 \mathrm{~d}^{-1}$. It is presumed this results from precipitation of inhibitors.

\section{Load variation}

Most sewage treatment plants do not operate under steady state conditions. The diurnal plant load varies cyclically as shown in Chapter 2. The effect of this on nitrification is two-fold:

- Effluent ammonia concentration also varies cyclically.

- Because the peaks in effluent ammonia are greater than the troughs (geometric rather than arithmetic variation), the average effluent ammonia concentration increases.

Figure 3.17 shows the approximate magnitudes of these effects. 


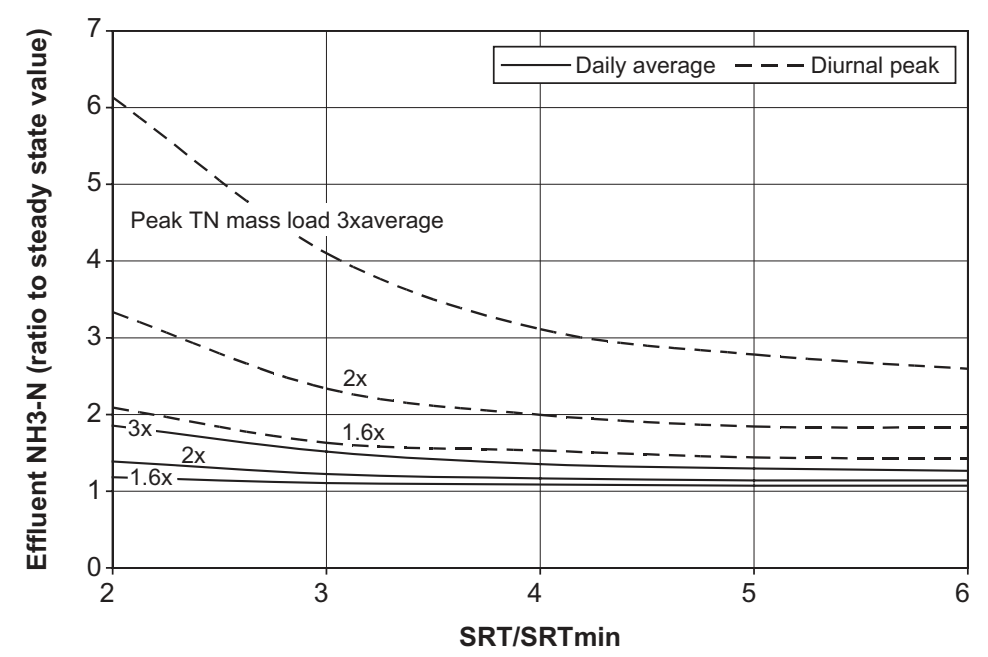

Figure 3.17 Approximate magnitude of variation in effluent ammonia concentration under diurnal cyclic loading conditions. The daily average and peak effluent ammonia concentrations are shown as ratios to the steady state effluent concentration (Henze et al., 2008; Gloag, 2009). SRT $\min$ is the minimum SRT for nitrification as given by Equation 3.5.

\section{Unaerated mass fraction}

Nitrifiers can only grow under aerobic conditions. When a process contains both aerated and unaerated (anoxic or anaerobic) zones, the nitrifiers grow in the aerated zones and decay via endogenous respiration in both aerated and unaerated zones.

Figure 3.18 illustrates the effects of process unaerated mass fraction on nitrification. Two alternative scenarios are shown, a total SRT of 10 days and an aerobic SRT of 10 days. The constant total SRT case represents a process with constant sludge mass but varying aerated and unaerated fractions brought about by different design, or, in an operating plant, change in reactor unaerated fraction or transfer of sludge mass from reactor to clarifier. Under these conditions, as the unaerated mass fraction increases, both the total active nitrifier mass and the active nitrifier mass in the aerobic zone decline and effluent ammonia rises. At the operating conditions shown in the diagram, nitrification fails completely at an unaerated fraction of 0.56 .

The constant aerobic SRT case represents, for example, an operating plant in which sludge transfers from reactor to clarifier but the reactor MLSS concentration is held constant by increasing the total SRT (reducing the sludge wasting). The corresponding total SRT is shown in the figure. It can be seen that, as the unaerated mass fraction and total SRT increase, the total active mass of nitrifiers in the process also increases; however the active mass in the aerobic zone declines and the effluent ammonia concentration slowly deteriorates. Nitrification fails completely when endogenous decay matches growth at an unaerated mass fraction of 0.82 (total SRT 55 days).

In the above discussion, note two important features of the unaerated mass fraction of the sludge. Firstly, there is always an unaerated fraction in the clarifier and this is an integral part of the process just as much as the bioreactor zones. Secondly, the unaerated mass fraction of the process may differ from the unaerated volume fraction because of different concentrations of sludge in the different zones. 


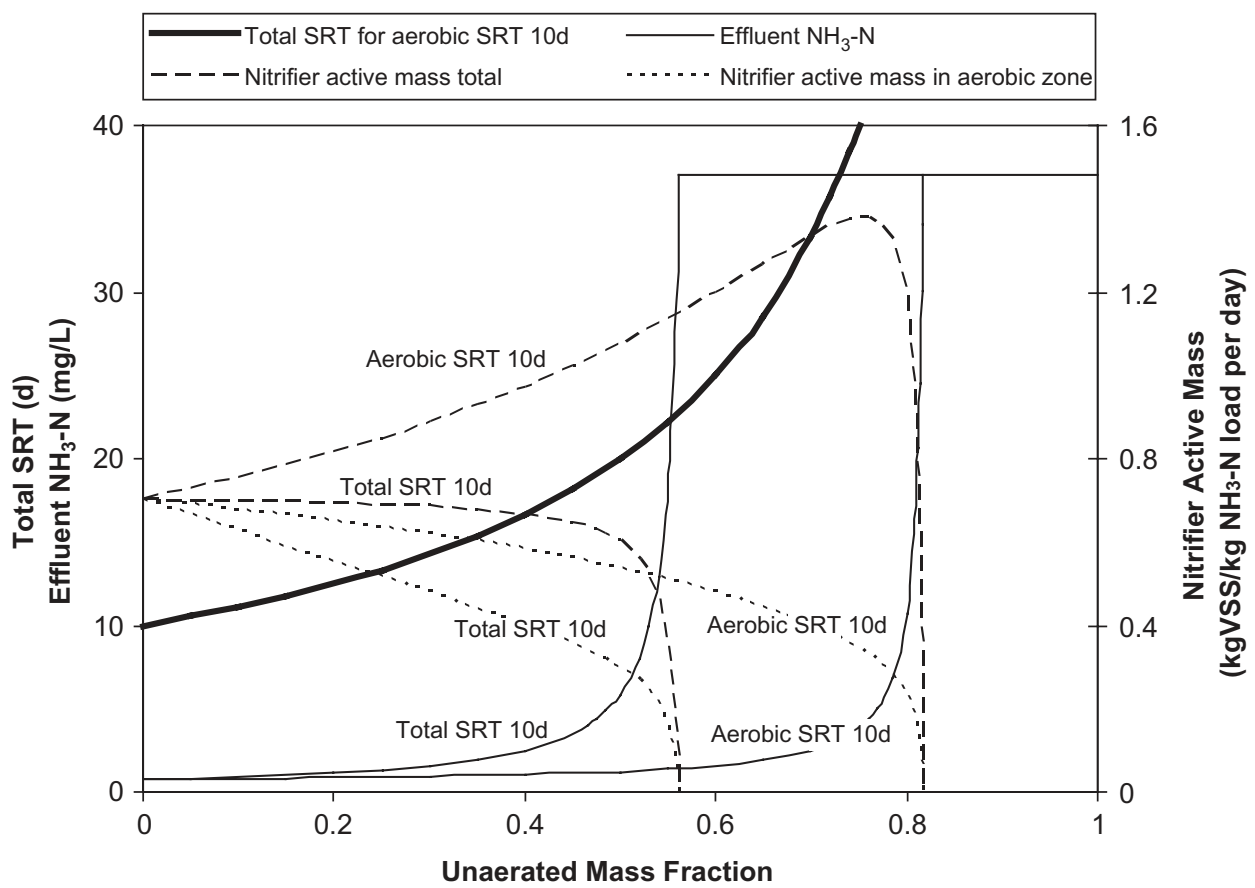

Figure 3.18 Effect of process unaerated mass fraction on nitrifier active mass and effluent ammonia concentration in a complete mix reactor under steady state conditions with temperature $20^{\circ} \mathrm{C}, \mathrm{DO} 1 \mathrm{mg} / \mathrm{L}$, $\mathrm{pH} 6.8, \mu_{\mathrm{nm} 20} 0.6 \mathrm{~d}^{-1}$. The nitrifier active mass is expressed in terms of the nitrification ammonia load, equal to the effluent ammonia concentration with no nitrification.

\section{Nitrification capacity}

Nitrification capacity is a useful parameter which helps in understanding the overall nitrification/denitrification behaviour of a process. Nitrification capacity is the nitrate concentration in the effluent with full nitrification and no denitrification and is calculated using Equation 3.11:

$$
\mathrm{N}_{\mathrm{c}}=\mathrm{N}_{\mathrm{ti}}-\mathrm{N}_{\mathrm{te}}-\mathrm{N}_{\mathrm{s}}
$$

where

$\mathrm{N}_{\mathrm{c}}=$ nitrification capacity, $\mathrm{mgNO}_{3}-\mathrm{N} / \mathrm{L}$ in the effluent flow

$\mathrm{N}_{\mathrm{ti}}=$ process influent $\mathrm{TKN}, \mathrm{mgN} / \mathrm{L}$

$\mathrm{N}_{\mathrm{te}}=$ effluent soluble TKN, $\mathrm{mgN} / \mathrm{L}$

$$
=\mathrm{f}_{\text {nus }} \cdot \mathrm{N}_{\mathrm{ti}}+\mathrm{N}_{\mathrm{ae}}
$$

$\mathrm{f}_{\text {nus }}=$ process influent soluble unbiodegradable organic $\mathrm{N}$ fraction (Table 2.2)

$\mathrm{N}_{\mathrm{ae}}=$ effluent ammonia, $\mathrm{mgN} / \mathrm{L}$

$\mathrm{N}_{\mathrm{s}}=$ nitrogen incorporated in sludge mass, $\mathrm{mgN} / \mathrm{L}$ process influent

Figure 3.19 shows that as the influent COD:TKN ratio increases the nitrification capacity decreases because of the greater fraction of influent nitrogen incorporated in the biomass. 


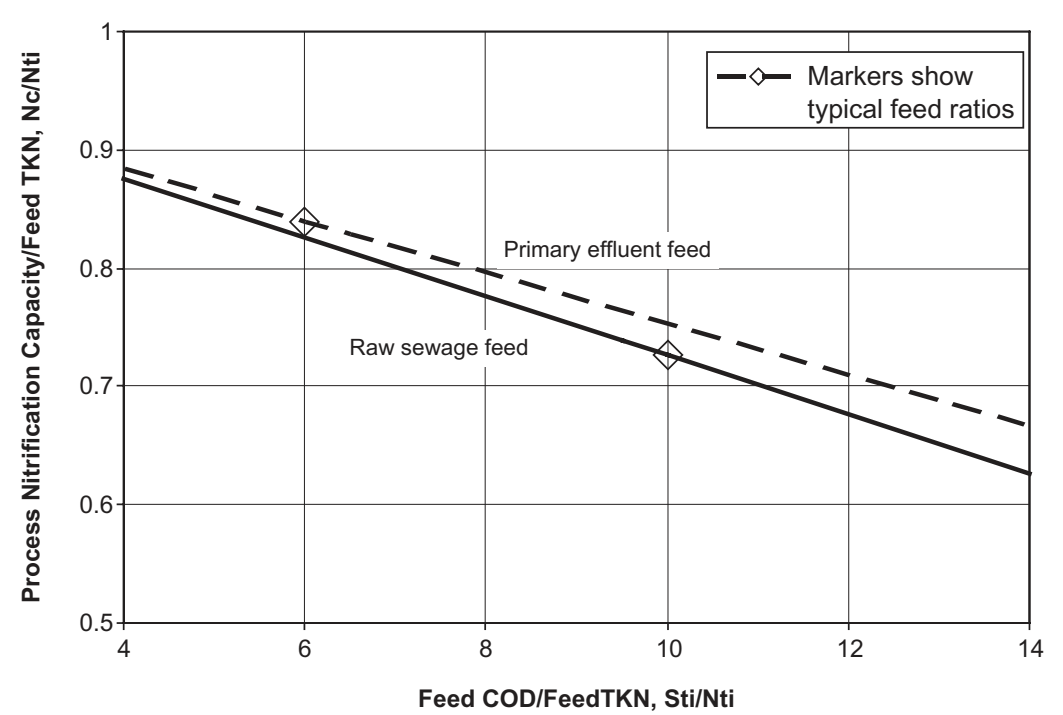

Figure 3.19 Effects of influent quality and primary treatment on process nitrification capacity with complete nitrification (effluent ammonia zero). Based on typical sewage and primary effluent characteristics in Table 2.4. SRT 20d, temperature $20^{\circ} \mathrm{C}$.

\subsubsection{Denitrification}

\section{Stoichiometry}

Under anoxic conditions the oxygen required by the heterotrophic bacteria for oxidation of organics is obtained from nitrate and nitrite (Figure 3.12). The facultative heterotrophs in the biomass can switch between oxygen and nitrate respiration almost instantaneously.

Nitrate respiration is called denitrification because nitrate is reduced to nitrogen gas as follows:

$$
5 \mathrm{C}_{6} \mathrm{H}_{12} \mathrm{O}_{6}+24 \mathrm{NO}_{3}^{-} \rightarrow 30 \mathrm{CO}_{2}+18 \mathrm{H}_{2} \mathrm{O}+12 \mathrm{~N}_{2}+24 \mathrm{OH}^{-}
$$

For comparison, the reaction with oxygen is:

$$
5 \mathrm{C}_{6} \mathrm{H}_{12} \mathrm{O}_{6}+30 \mathrm{O}_{2} \rightarrow 30 \mathrm{CO}_{2}+30 \mathrm{H}_{2} \mathrm{O}
$$

Here, glucose has been used as an example of an organic substrate but the stoichiometry is similar for most organic materials.

From these equations it can be calculated that:

- Each mg of $\mathrm{NO}_{3}-\mathrm{N}$ denitrified is equivalent to $2.9 \mathrm{mg}$ of oxygen.

- Alkali produced during denitrification increases the alkalinity by $3.6 \mathrm{mg} / \mathrm{L}$ as $\mathrm{CaCO}_{3}$ for each $\mathrm{mg} / \mathrm{L}$ of $\mathrm{NO}_{3}-\mathrm{N}$ denitrified.

If denitrification is included in a nitrifying process, oxygen use for nitrification can be reduced by up to $60 \%$ and alkalinity depletion by up to $50 \%$.

The total COD utilised in heterotrophic denitrification is $2.9 /\left(1-\mathrm{Y}_{\mathrm{HD}}\right)$ where $\mathrm{Y}_{\mathrm{HD}}$ is the bacterial yield coefficient under anoxic operating conditions (see Section 3.2 above). Table 3.2 lists the denitrification COD requirements reported for various substrates. 
Table 3.2 Denitrification COD requirements.

\begin{tabular}{|c|c|c|c|c|c|c|}
\hline \multirow[t]{2}{*}{ Substrate } & & \multirow{2}{*}{$\begin{array}{l}\text { Substrate } \\
\text { COD } \\
\text { (gCOD/g } \\
\text { substrate) }\end{array}$} & \multicolumn{2}{|c|}{$\begin{array}{l}\text { Yield coefficient } \\
\text { (gCOD/gCOD) }\end{array}$} & \multirow{2}{*}{$\begin{array}{l}\text { COD needed for } \\
\text { denitrification } \\
\left(\mathrm{gCOD} / \mathrm{gNO}_{3}-\mathrm{N}\right) \\
{\left[2.86 /\left(1-\mathrm{Y}_{\mathrm{HD}}\right)\right]}\end{array}$} & \multirow{2}{*}{$\begin{array}{l}\text { Reference } \\
\text { (table } \\
\text { footnotes) }\end{array}$} \\
\hline & & & $\begin{array}{c}\text { Aerobic }^{1} \\
{\left[\mathrm{Y}_{\mathrm{H}}\right]}\end{array}$ & $\begin{array}{c}\text { Anoxic } \\
{\left[Y_{\mathrm{HD}}\right]}\end{array}$ & & \\
\hline Sewage & & & 0.67 & 0.53 & 6.1 & 2 \\
\hline Acetic Acid & $\mathrm{CH}_{3} \mathrm{COOH}$ & 1.07 & 0.54 & 0.45 & 5.2 & 3 \\
\hline Carbohydrate & $\mathrm{CH}_{2} \mathrm{O}$ & 1.07 & 0.72 & 0.61 & 7.3 & 4 \\
\hline Glucose & $\mathrm{C}_{6} \mathrm{H}_{12} \mathrm{O}_{6}$ & 1.07 & 0.67 & 0.57 & 6.7 & 3 \\
\hline Lactic Acid & $\mathrm{CH}_{3} \mathrm{CHOHCOOH}$ & 1.07 & 0.65 & 0.52 & 6.0 & 4 \\
\hline Methanol & $\mathrm{CH}_{3} \mathrm{OH}$ & 1.5 & 0.67 & 0.36 & 4.5 & 4 \\
\hline Protein & $\mathrm{C}_{16} \mathrm{H}_{24} \mathrm{O}_{5} \mathrm{~N}_{4}$ & 1.5 & 0.64 & 0.51 & 5.8 & 4 \\
\hline
\end{tabular}

${ }^{1}$ Aerobic yield shown for comparison.

${ }^{2}$ Muller et al. (2003)

${ }^{3}$ Sperandio et al. (1999)

${ }^{4}$ Orhon et al. (1996)

\section{Kinetics}

The fundamental process format used for nitrogen removal uses the Modified Ludzack-Ettinger (MLE) flowsheet shown in Figure 3.20 (Ludzack \& Ettinger, 1962; Barnard, 1973). Influent nitrogen passes through the anoxic zone and is nitrified in the aerobic zone. Nitrate is then recycled to the anoxic zone where it is denitrified using the influent readily biodegradable and slowly biodegradable COD. This process format is sometimes extended by adding secondary anoxic and aerobic zones downstream of the primary zones (see Chapter 5).

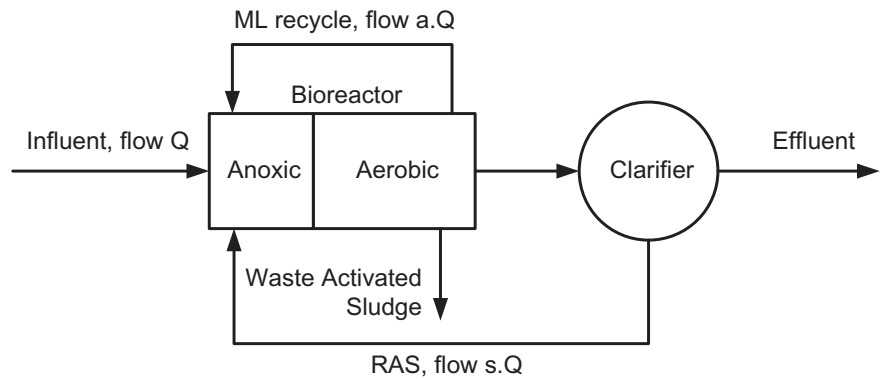

Figure 3.20 MLE process for nitrogen removal.

The denitrification rate is zero order with respect to the nitrate concentration, that is, the denitrification rate is not affected by the nitrate concentration down to very low nitrate levels $(<1 \mathrm{mg} / \mathrm{L})$. There are four different denitrification rates, known as $\mathrm{K}_{1}, \mathrm{~K}_{2}, \mathrm{~K}_{3}$ and $\mathrm{K}_{4}$, progressively decreasing in magnitude as listed in Table 3.3. $\mathrm{K}_{1}$ applies for denitrification with readily biodegradable COD (RBCOD) and $\mathrm{K}_{2}$ with slowly biodegradable COD (SBCOD). $\mathrm{K}_{3}$ is the denitrification rate in secondary anoxic reactors where nitrate is used only for endogenous respiration while $\mathrm{K}_{4}$ is an even slower endogenous rate applying during aerobic digestion of waste activated sludge. 
Table 3.3 Denitrification rates.

\begin{tabular}{|c|c|c|}
\hline Rate & $\begin{array}{l}\text { Value at } 20^{\circ} \mathrm{C} \\
(\mathrm{mgNO}-\mathrm{N} / \mathrm{mgVASS} \cdot \mathrm{d})^{1}\end{array}$ & $\begin{array}{l}\text { Temperature } \\
\text { coefficient, } \theta^{2}\end{array}$ \\
\hline $\mathrm{K}_{1}(\mathrm{RBCOD})$ & 0.720 & 1.200 \\
\hline $\mathrm{K}_{2}(\mathrm{SBCOD})$ & 0.101 & 1.080 \\
\hline $\mathrm{K}_{3}$ (endogenous) & 0.072 & 1.029 \\
\hline $\mathrm{K}_{4}$ (aerobic digestion) & 0.048 & 1.029 \\
\hline
\end{tabular}

The maximum concentration of nitrate (relative to the influent flow) that an anoxic reactor can denitrify is called the denitrification potential, $\mathrm{D}_{\mathrm{p}}$. This depends primarily on the influent RBCOD and SBCOD and the process anoxic mass fraction. Whether the denitrification potential is achieved depends on the quantities of nitrate and oxygen fed to the anoxic reactor.

The behaviour of a primary anoxic reactor is depicted in Figure 3.21. This shows how effluent nitrate concentration (expressed as a fraction of maximum nitrification capacity - effluent nitrate concentration with complete nitrification and no denitrification) varies with primary anoxic mass fraction for a range of operating conditions. Several sets of lines are shown. Solid lines ABC, D, E relate to a process operating at $20^{\circ} \mathrm{C}$ with raw sewage influent.

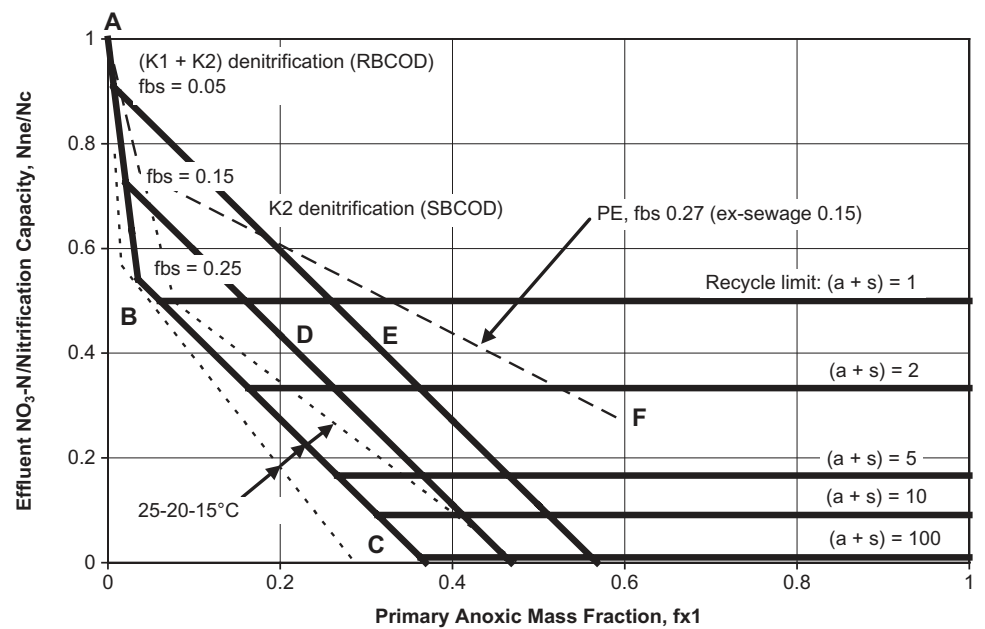

Figure 3.21 Denitrification behaviour of a primary anoxic reactor. In this diagram, $\mathrm{N}_{\mathrm{c}}$ is the nitrification capacity with full nitrification (zero effluent ammonia); temperature is $20^{\circ} \mathrm{C}$ (except as noted), SRT is 20 days and sewage and primary effluent characteristics are typical values from Table 2.4. Secondary denitrification in the clarifier is assumed to be negligible.

$\mathrm{AB}$ depicts the initial high rate $\left(\mathrm{K}_{1}+\mathrm{K}_{2}\right)$ denitrification. At $\mathrm{B}$ the influent RBCOD (for influent $\mathrm{RBCOD} /$ total COD, $\mathrm{f}_{\mathrm{bs}}$, of 0.25 ) is exhausted and denitrification slows to the $\mathrm{K}_{2}$ rate depicted by $\mathrm{BC}$. The dashed lines on either side of $\mathrm{ABC}$ show performance at 15 and $25^{\circ} \mathrm{C}$. 
Lines $\mathrm{AD}$ and $\mathrm{AE}$ show the denitrification performance with $\mathrm{f}_{\mathrm{bs}}$ values of 0.15 and 0.05 .

Long-dashed line A-F shows the reduced denitrification performance with primary effluent as the influent. This line is drawn for a primary effluent $f_{b s}$ value of 0.27 , increased from a sewage value of 0.15 by primary sedimentation (Table 2.4 ).

These sloping denitrification lines depict the denitrification potential of the primary anoxic zone. However, whether the full potential denitrification is achieved depends on the process recycle ratios, a and s. Because only part of the aerobic reactor effluent can be recycled to the anoxic zone, the minimum effluent nitrate achievable by the MLE process (ignoring any secondary denitrification in the clarifier) is given by:

$$
\mathrm{N}_{\mathrm{ne}} / \mathrm{N}_{\mathrm{c}}=1 /(\mathrm{a}+\mathrm{s}+1)
$$

where

$\mathrm{N}_{\text {ne }}=$ effluent nitrate concentration

$\mathrm{N}_{\mathrm{c}}=$ nitrification capacity, $\mathrm{mgNO}_{3}-\mathrm{N} / \mathrm{L}$ in the effluent flow (Equn 3.11)

$\mathrm{a}=$ mixed liquor recycle ratio, recycle flow/influent flow

$\mathrm{s}=\mathrm{RAS}$ recycle ratio, RAS flow/influent flow

In the diagram, the horizontal lines show the recycle limits for a range of recycle ratios.

Two further factors affect denitrification. Firstly, dissolved oxygen input to the anoxic reactor in the influent or recycles reduces denitrification potential. Each $\mathrm{mg}$ of DO fed to the anoxic reactor reduces denitrification potential by $(1 / 2.9) \mathrm{mgNO}_{3}-\mathrm{N}$. A DO concentration of $\mathrm{O}_{\mathrm{a}} \mathrm{mg} / \mathrm{L}$ in the mixed liquor recycle increases effluent nitrate concentration by $\left(a \cdot \mathrm{O}_{\mathrm{a}} / 2.9\right) \mathrm{mgNO}_{3}-\mathrm{N} / \mathrm{L}$. A higher recycle ratio returns more nitrate to the anoxic zone for removal but it also brings more oxygen which reduces denitrification; therefore, when the recycles contain DO there is an optimum recycle ratio which gives the lowest effluent nitrate concentration. The optimum recycle ratio is illustrated in Figure 3.22 and the effect on effluent nitrate in Figure 3.23.

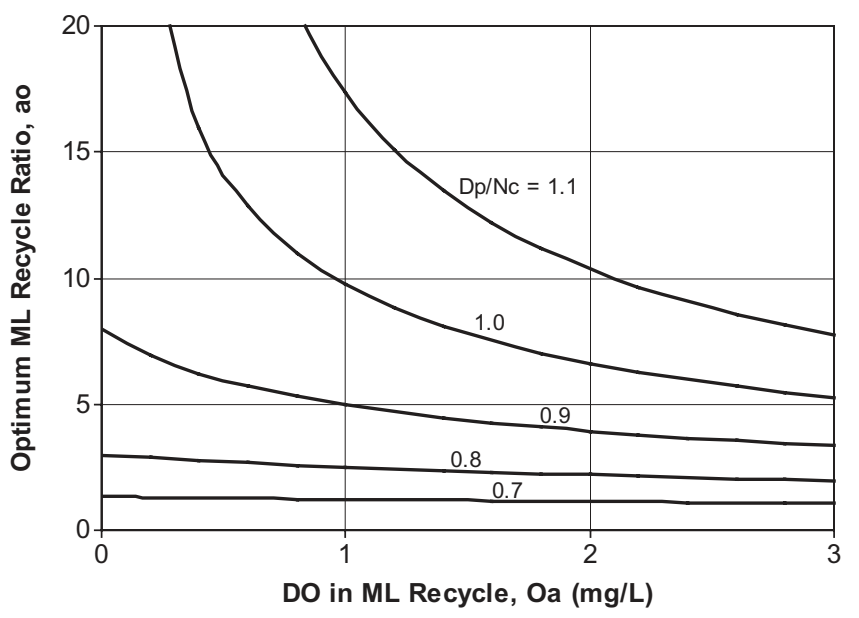

Figure 3.22 Effect of dissolved oxygen in the mixed liquor recycle flow on the optimum recycle ratio giving minimum effluent nitrate concentration. $D_{p} / N_{c}$ is the ratio of the anoxic reactor denitrification potential, $D_{p}$, to the process nitrification capacity, $\mathrm{N}_{\mathrm{c}}$. This diagram is drawn for a nitrification capacity of $40 \mathrm{mg} / \mathrm{L}$, a RAS recycle ratio, $\mathrm{s}$, of 1 and zero DO in the RAS flow. 


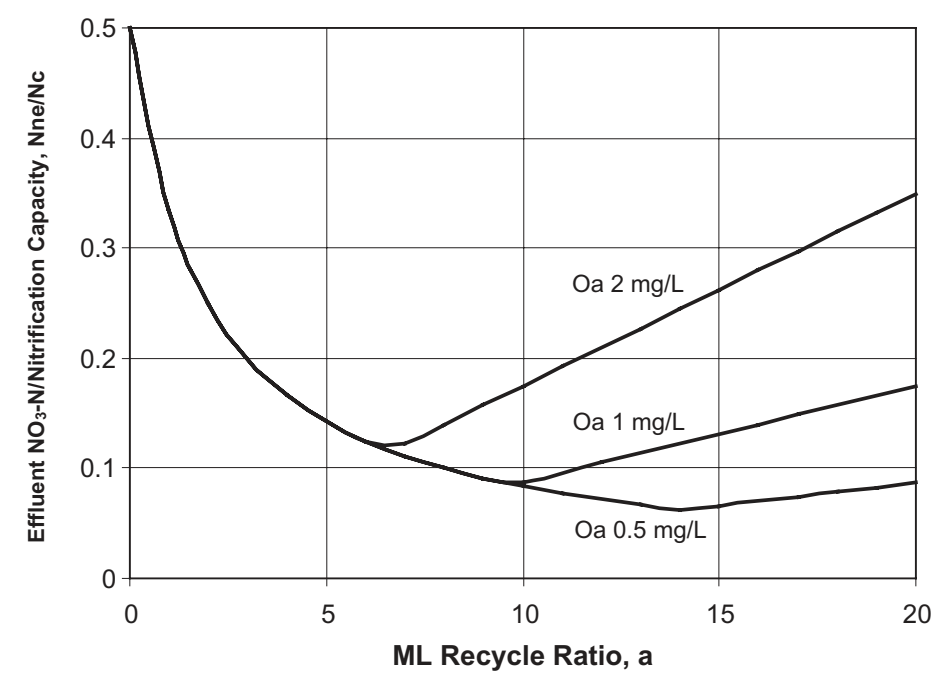

Figure 3.23 Effect of dissolved oxygen in the mixed liquor recycle flow on the effluent nitrate concentration. Corresponds to the $D_{p} / N_{c}=1.0$ line in Figure 3.22 .

The second factor is the provision of an anaerobic reactor at the head of the process train for enhancement of biological phosphorus removal. The anaerobic reactor causes respective increases in the $\mathrm{K}_{2}$ and $\mathrm{K}_{3}$ denitrification rates in the anoxic reactors of about 2.5 and 1.5 times (Henze et al.,). The fundamental reason for this is currently unknown. In the author's full-scale plant experience, the $\mathrm{K}_{2}$ denitrification rate increases from $0.101 \mathrm{mgNO}_{3}-\mathrm{N} / \mathrm{mgVASS}$.d (Table 3.3) to about 0.21 . The net result is that, with the same total unaerated mass fraction, the process denitrification performance is unchanged by the addition of an anaerobic reactor. For example, Figure 3.21 shows that, for a process without an anaerobic reactor, at an $f_{b s}$ value of 0.15 and a recycle ratio of 100 the effluent nitrate concentration reaches a minimum at a primary anoxic mass fraction of 0.46 . If an anaerobic reactor with a mass fraction of 0.10 is placed at the head of the process, the effluent nitrate concentration still reaches its minimum at a total unaerated mass fraction of 0.46 , made up of 0.10 anaerobic and 0.36 primary anoxic.

\subsubsection{Simultaneous nitrification and denitrification}

So far, the discussion has assumed that nitrification and denitrification occur in separate reactors or locations. However, under conditions of low dissolved oxygen nitrification and denitrification can both occur in the same volume. This is called simultaneous nitrification and denitrification (SND).

DO concentration varies within the bacterial flocs and both integrated biochemical conversions and local spatial zonation can be involved. Integrated biochemical SND can release larger quantities of the active greenhouse gas nitrous oxide, $\mathrm{N}_{2} \mathrm{O}$.

For practical purposes, SND can be considered to function through spatial aerobic/anoxic zonation of the flocs resulting from the consumption of oxygen diffusing inwards, as shown in Figure 3.24. The nitrifiers inhabit the aerobic annulus while denitrification occurs in the anoxic core. The relative aerobic and anoxic fractions depend on the operating bulk liquor DO concentration and the oxygen uptake rate (OUR) or respiration rate. 


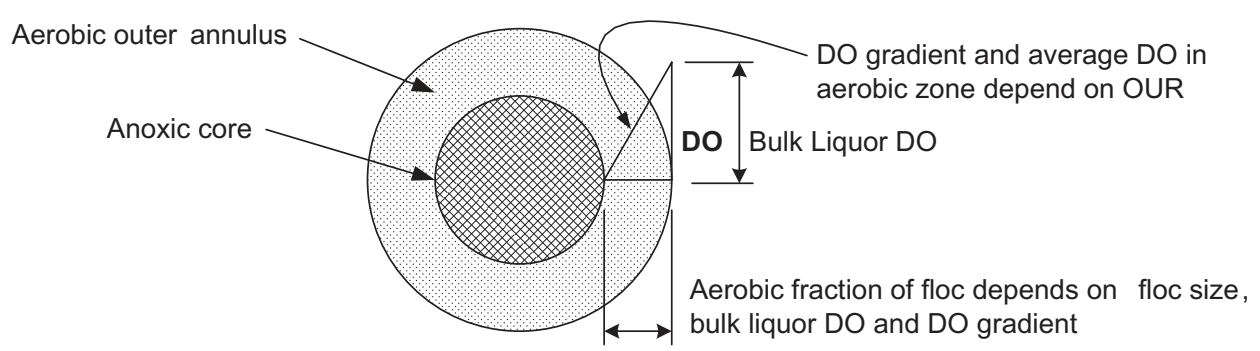

Figure 3.24 SND floc model.

Note two features of this process. Firstly, COD is utilised aerobically as well as anoxically so the extent of denitrification for a given amount of COD is less than for compartmentalised formats. Secondly, the aerobic and anoxic fractions are sensitive to variations in operating conditions, so effluent ammonia and nitrate concentrations can be variable. The nitrifiers are motile and it has been observed under steady state operating conditions that a reduction in bulk liquor DO set point can cause an immediate rise in effluent ammonia concentration followed by a gradual recovery as nitrifiers move up-gradient to the smaller aerobic zone (Hartley, 1997b).

\subsubsection{Total process oxygen demand}

\section{Steady state conditions}

The process oxygen demand consists of the total carbonaceous demand, plus the nitrogenous demand for nitrification, less the oxygen equivalent of the nitrate denitrified for anoxic oxidation of organics. When the process incorporates enhanced biological phosphorus removal, the carbonaceous demand is shared between two groups of organisms, the ordinary heterotrophs and the phosphorus- and glycogenaccumulating organisms (discussed in the next Section).

The carbonaceous and nitrogenous demands have been discussed in Section 3.4.6, 3.5.2 and 3.5.3 above. The total picture is shown in Figure 3.25.

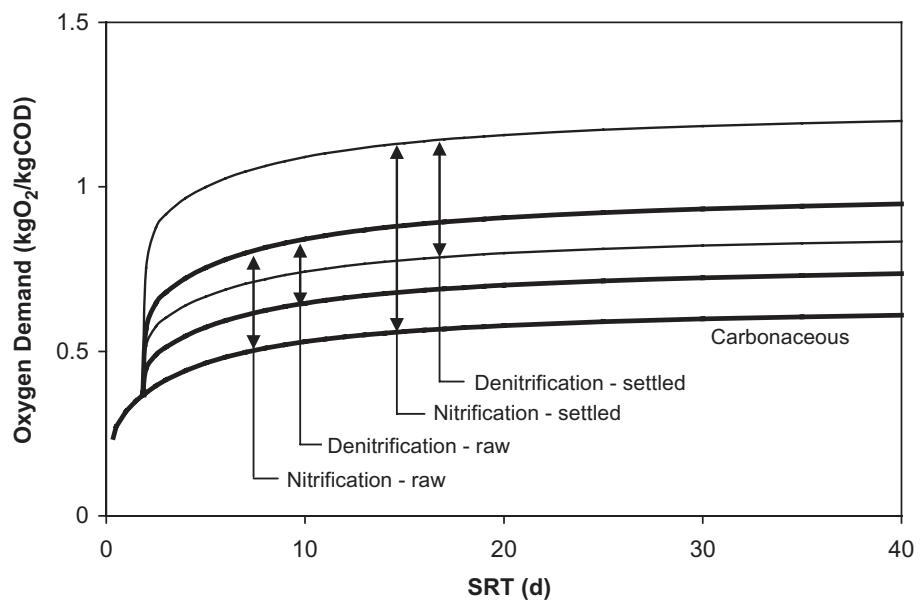

Figure 3.25 Total process oxygen demand under steady state conditions at $20^{\circ} \mathrm{C}$, showing the effects of full nitrification and denitrification. 
The oxygen demand manifests itself as a respiration rate or oxygen uptake rate in the mixed liquor. The respiration rate can be calculated by dividing the oxygen demand (Figure 3.25) by the sludge mass (Figure 3.8) and is shown in Figure 3.26.

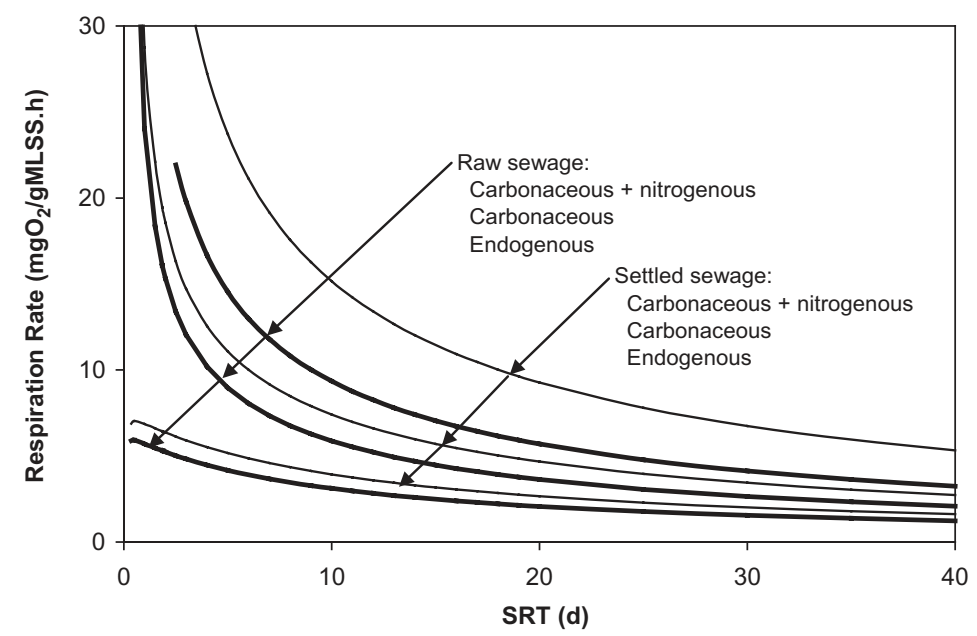

Figure 3.26 Mixed liquor respiration rate under steady state conditions at $20^{\circ} \mathrm{C}$. If the process incorporates enhanced biological or chemical phosphorus removal, the respiration rates will be $10-20 \%$ lower than shown due to the increased sludge mass. Values in $\mathrm{mgO}_{2} / \mathrm{gMLSS} \mathrm{h}$ can be converted to $\mathrm{mgO}_{2} / \mathrm{L} \cdot \mathrm{h}$ by multiplying by MLSS concentration in $\mathrm{g} / \mathrm{L}$.

\section{Dynamic conditions}

The loading on sewage treatment plants generally follows a cyclic diurnal loading pattern (Chapter 2). Under this type of loading the process oxygen demand also varies cyclically. A simple rule of thumb to estimate the variation in oxygen demand over the day is that the amplitude of the total oxygen demand varies by about one third of the amplitude of the COD mass load, where the amplitude is the maximum departure (up or down) from the daily average (Ekama \& Marais, 1977).

\subsection{PHOSPHORUS REMOVAL}

\subsubsection{Mechanisms}

So far two groups of bacteria have been discussed, the ordinary heterotrophic organisms (OHOs) which grow on carbonaceous organic substrate under aerobic or anoxic conditions, and the autotrophic nitrifiers which grow on inorganic carbon dioxide and oxidise ammonia or nitrite to obtain their energy requirements. Enhanced biological phosphorus removal (EBPR) results from the activities of a third group of bacteria, the phosphorus accumulating organisms (PAOs).

PAOs are special heterotrophs which are able to compete with the OHOs under appropriate conditions by sequestering VFAs in the sewage for their own exclusive use. The basic process format required for PAO growth is shown in Figure 3.27. It consists of an anaerobic reactor (no oxygen or nitrate) followed by an aerobic reactor. In the anaerobic reactor the PAOs take up VFAs and store them within their cells; then in the aerobic reactor the stored VFAs are used as substrate for their normal heterotrophic growth. The 
OHOs cannot utilise VFAs in the anaerobic reactor but a proportion of them can ferment influent non-VFA RBCOD to VFAs, benefiting the PAOs. Therefore the PAOs are able to sequester much of the influent RBCOD for their own use.

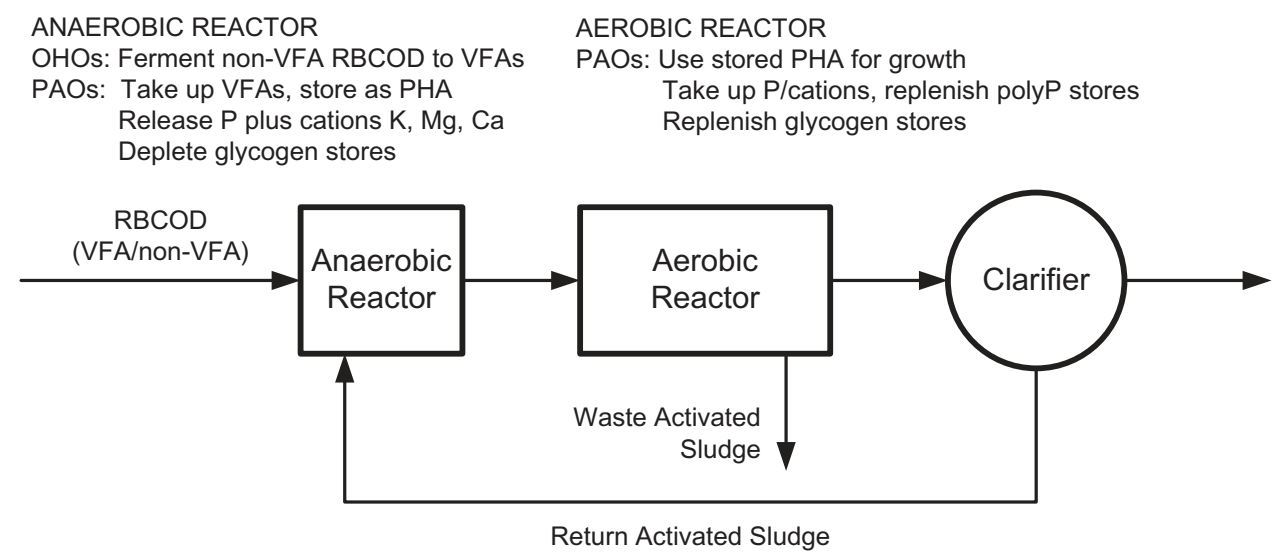

Figure 3.27 Behaviour of the EBPR process.

The energy required by the PAOs to take up VFAs under anaerobic conditions is provided by the degradation of internal reserves of both glycogen and polyphosphates. Glycogen is formed of linked glucose units and is universally used by animals as a ready-energy store. However, the use of polyphosphates for this purpose is confined to the small group of bacteria called PAOs. As VFAs are taken up in the anaerobic reactor, phosphate is released from the cells into the bulk liquor. When the cells pass into the aerobic reactor, phosphorus is taken up to replenish their polyphosphate reserves. EBPR occurs by taking the normal wasting of daily sludge growth from the aerobic reactor where the phosphorus content of the PAOs is at a maximum (P/VSS 0.38 for PAO cells, compared with the normal 0.03 for the OHOs in the overall biomass).

The VFA molecules taken up in the anaerobic reactor are stored as complex long-chain linkages of fatty acids called polyhydroxyalkanoates (PHAs). Animals commonly store food reserves as fatty acids which have a high energy content. The stored PHA is then used in the aerobic reactor for heterotrophic energy and growth, including replenishment of polyphosphate and glycogen reserves.

The counter-ions potassium, magnesium and calcium provide electrical neutrality in the polyphosphate reserves. These elements are released in the anaerobic zone and taken up in the aerobic zone in parallel with phosphorus. The approximate stoichiometry involved is as follows (Henze et al., 2008; Wentzel et al., 1989):

$\begin{array}{lll}\text { P release: } & 0.5 \mathrm{gP} / \mathrm{gCOD} \text { uptake } \\ & \text { (for acetic acid, } \mathrm{CH}_{3} \mathrm{COOH}, \mathrm{COD}=1.07 \mathrm{mg} / \mathrm{mg} \text { acid) } \\ \text { Cation release: } & \text { P:K:Mg:Ca } & 1: 0.33: 0.33: 0.05 \text { molar } \\ & & 1: 0.42: 0.25: 0.06 \text { by mass }\end{array}$

From Table 2.1, waste output from the human body contains $\mathrm{P}: \mathrm{K}: \mathrm{Mg}: \mathrm{Ca}$ in the mass ratios of about 1:1.9:0.13:0.5. The only element potentially deficient with respect to the requirements of EBPR is magnesium and most water supplies will easily make up the shortfall. 
The process kinetics in the anaerobic reactor are dominated by the rate of fermentation of non-VFA RBCOD to VFAs by the OHOs. This governs the anaerobic mass fraction required and, being a first order reaction, makes a plug flow (or cells-in-series) configuration most efficient.

The minimum aerobic SRT required to fully utilise the stored PHA has been modeled and tested using enriched culture laboratory systems (Henze et al., 2008). The value varies from 10 days at $5^{\circ} \mathrm{C}$ to 1.5 days at $25^{\circ} \mathrm{C}$. A simple exponential fit to the results gives:

$$
\mathrm{SRT}_{\mathrm{AER}, \mathrm{MIN}}=92 \mathrm{~T}^{-1.33} \text {, where } \mathrm{SRT}_{\mathrm{AER}, \mathrm{MIN}}=\text { days and } \mathrm{T}={ }^{\circ} \mathrm{C}
$$

\subsubsection{Process characteristics}

Process models have been developed from intensive laboratory studies using almost pure PAO cultures and mixed cultures of PAOs and other organism groups (Henze et al., 2008; Wentzel et al., 1990). The overall performance characteristics of the process when treating raw sewage are summarised in Figures 3.28 to 3.31. These graphs show the following:

- Figure 3.28 shows that P removal is greatest at low SRT and declines as SRT increases because of the decrease in net sludge production. P removal increases with anaerobic mass fraction because of the increased fermentation of non-VFA RBCOD. Given that sewage typically has a TP:COD ratio of about 0.02 (Chapter 2), the figure shows that EBPR can potentially provide full $\mathrm{P}$ removal.

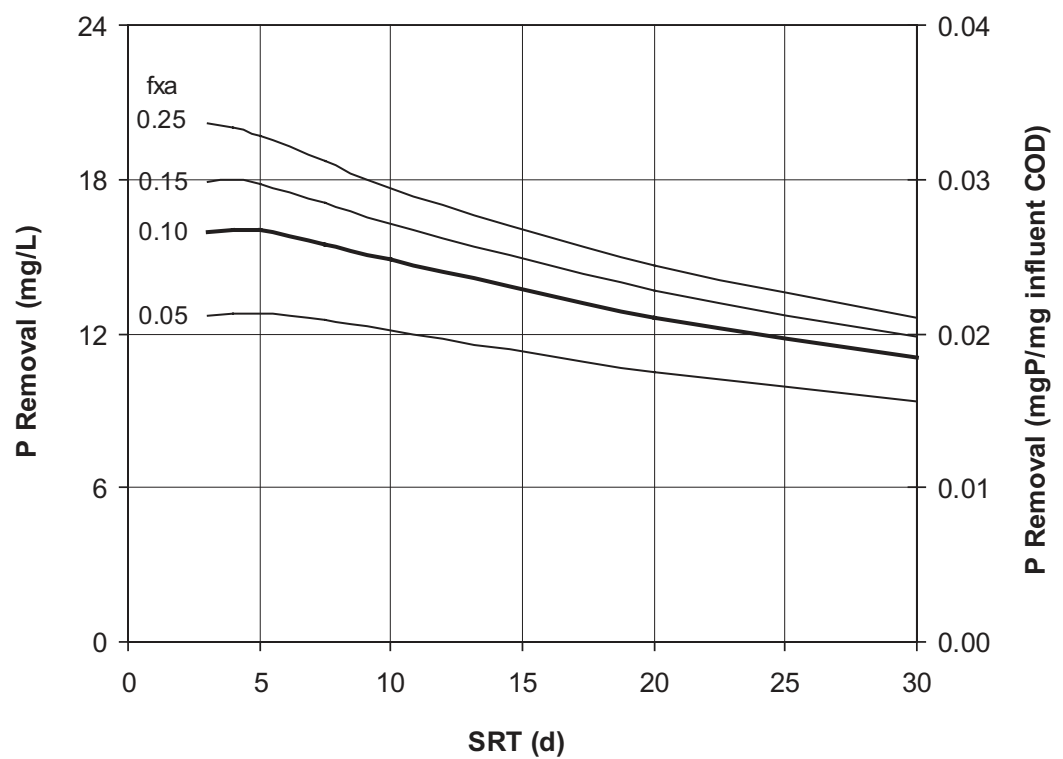

Figure 3.28 Predicted performance of an EBPR process treating raw sewage over a range of anaerobic mass fractions, $f_{\text {xa. }}$. Process conditions: COD $600 \mathrm{mg} / \mathrm{L}, \mathrm{f}_{\mathrm{us}} 0.05, \mathrm{f}_{\mathrm{up}} 0.20, \mathrm{f}_{\mathrm{bs}} 0.20$, sewage VFA negligible, temperature $20^{\circ} \mathrm{C}, 3$ anaerobic cells in series, zero $\mathrm{DO}$ and $\mathrm{NO}_{3}$ input, effluent SS zero.

- Figure 3.29 shows the degree of performance improvement provided by subdividing the anaerobic reactor into cells in series. This arises from the first order nature of the RBCOD fermentation process. 


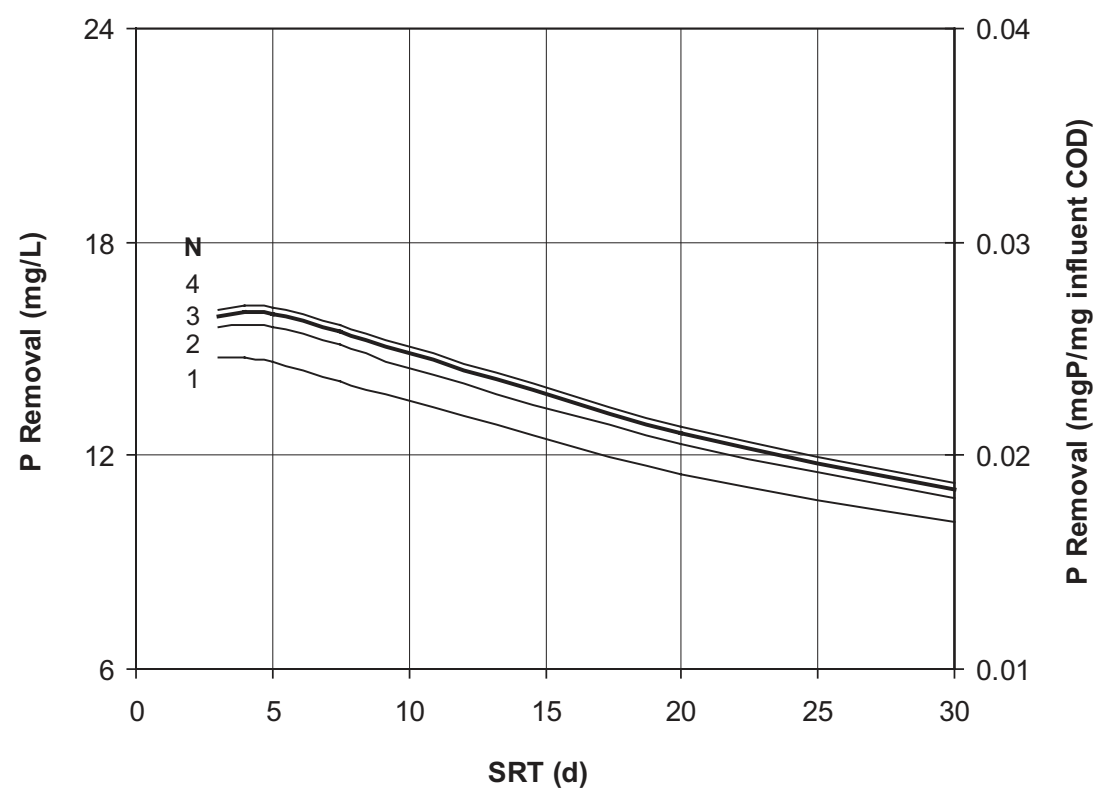

Figure 3.29 Effect of the number of anaerobic cells in series, $N$, on $P$ removal for $f_{x a} 0.10$. Other process conditions as for Figure 3.28.

- The effect of sewage $\mathrm{f}_{\mathrm{bs}}$, the RBCOD fraction of total COD, is shown in Figure 3.30. P removal at zero RBCOD is the normal metabolic uptake of the OHOs. As RBCOD increases, the PAO fraction of the biomass increases at the expense of the OHOs and total $\mathrm{P}$ removal is almost tripled at an $\mathrm{f}_{\mathrm{bs}}$ value of 0.2. It can also be seen that the absolute COD concentration also affects performance because of the impact on $\mathrm{OHO}$ population and RBCOD fermentation.

- Figure 3.30 also shows the P fraction of the MLSS and therefore of plant effluent SS. The P content reaches $5 \%$ at an $\mathrm{f}_{\mathrm{bs}}$ value of 0.15 .

- Figure 3.31 shows that as $\mathrm{f}_{\mathrm{bs}}$ and $\mathrm{P}$ uptake increase, the total sludge mass increases and the MLVSS: MLSS ratio declines. These changes are caused by the increasing polyP content of the sludge. At an $\mathrm{f}_{\mathrm{bs}}$ value of 0.2 , the sludge mass increases by about $20 \%$ (compare with Figure 3.8); also, although not shown in the figure, the carbonaceous oxygen demand decreases by about $5 \%$.

The effect of temperature on EBPR is complex (Henze et al., 2008). Different temperature coefficients apply to the anaerobic and aerobic components of the process. The anaerobic process rate reaches a maximum at $20^{\circ} \mathrm{C}$ while the aerobic rate continues to increase up to $30^{\circ} \mathrm{C}$. In fullscale plants better $\mathrm{P}$ removal performance has sometimes been reported at lower temperatures. The effect of temperature on PAO performance is confounded by the interaction of another group of bacteria, the glycogen accumulating organisms or GAOs; this interaction is discussed in Section 3.6.3 below.

Increased $\mathrm{P}$ release and uptake have been observed as $\mathrm{pH}$ increases over the typical plant operating range. This is attributed to the greater energy requirement for VFA uptake at higher $\mathrm{pH}$ levels. Like temperature, the effect of $\mathrm{pH}$ is also confounded by interactions with GAOs (discussed below). 


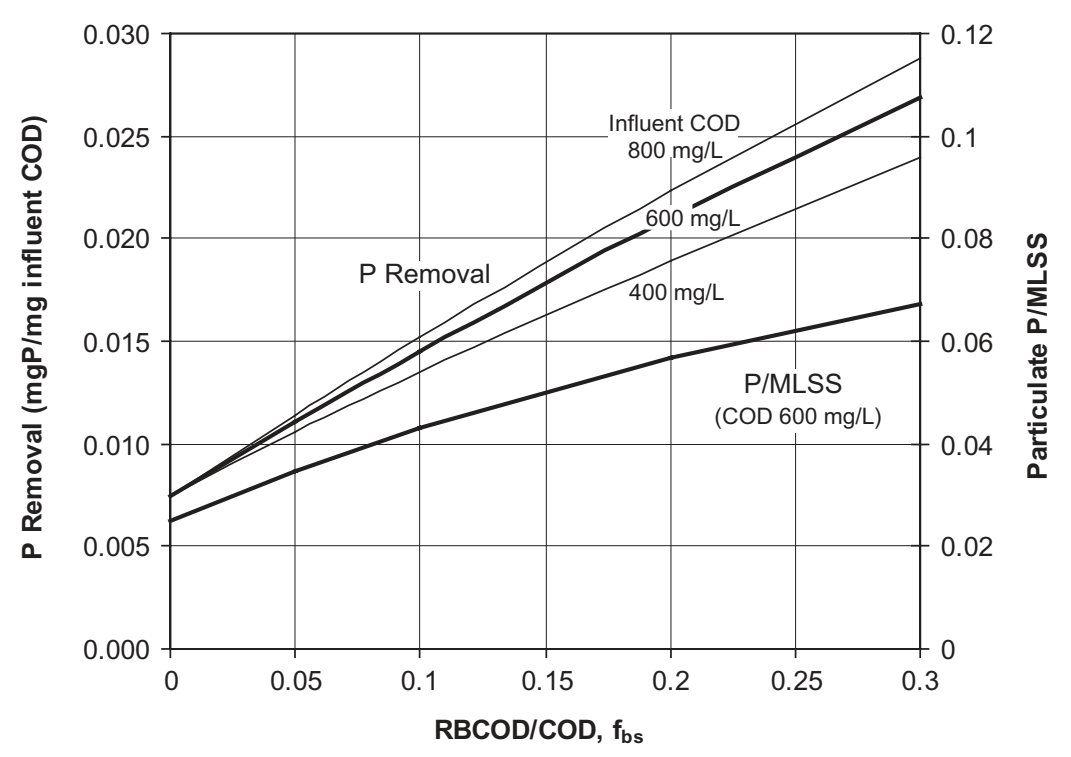

Figure 3.30 Effect of RBCOD fraction of total COD, $\mathrm{f}_{\mathrm{bs}}$, on $\mathrm{P}$ removal and on the $\mathrm{P}$ fraction of the MLSS. SRT 20d; except as shown, other process conditions as for Figure 3.28.

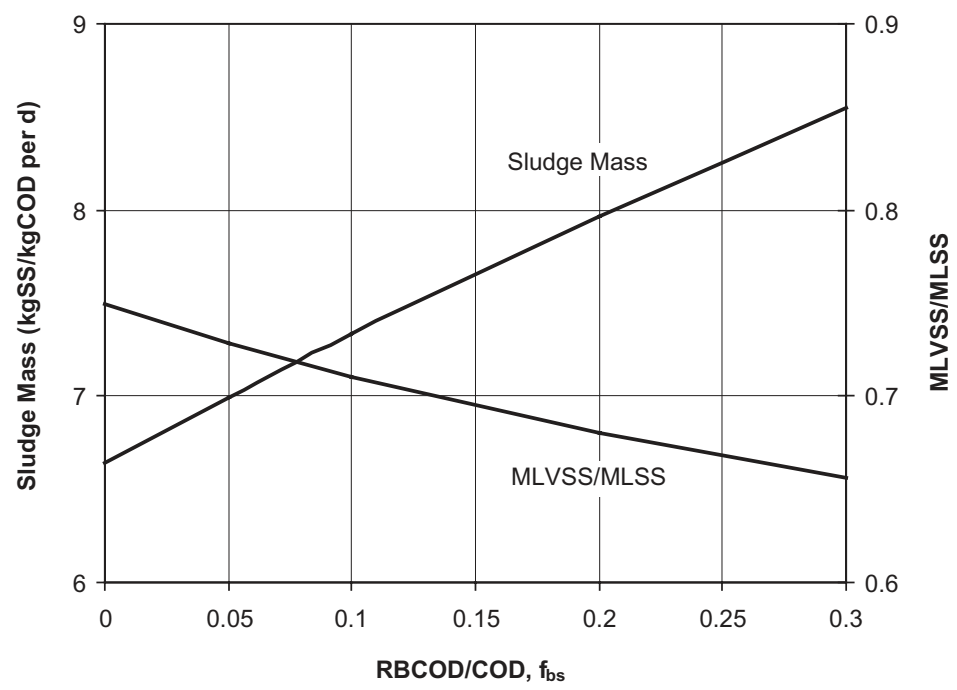

Figure 3.31 Effect of RBCOD fraction of total COD, $\mathrm{f}_{\mathrm{bs}}$, on the process total sludge mass and the MLSS volatile fraction. SRT 20d; other process conditions as for Figure 3.28.

\subsubsection{Adverse factors}

Factors adversely affecting biological $\mathrm{P}$ removal are the feeding of dissolved oxygen, nitrate or sulfide to the anaerobic reactor, and the competitive growth of glycogen accumulating organisms (GAOs). 


\section{Dissolved oxygen and nitrate}

Dissolved oxygen and oxidised nitrogen (nitrite and nitrate) can enter the anaerobic reactor in the feed and recycle flows. DO and nitrate are used by the OHOs for oxidation of RBCOD, thereby reducing the RBCOD available to the PAOs. The resulting reductions in RBCOD are $3.0 \mathrm{mgCOD} / \mathrm{mgDO}$ and $8.6 \mathrm{mgCOD} / \mathrm{mgNO}_{3}-\mathrm{N}$.

Figure 3.32 shows a gross correlation of $\mathrm{P}$ removal versus influent TKN for thirteen full-scale BNR plants in Australia and the USA (Hartley, 1995; Morales et al., 1991). The data show a small decline in $\mathrm{P}$ removal as the influent nitrogen increases, presumably due to increased recycling of nitrate to the anaerobic reactor.

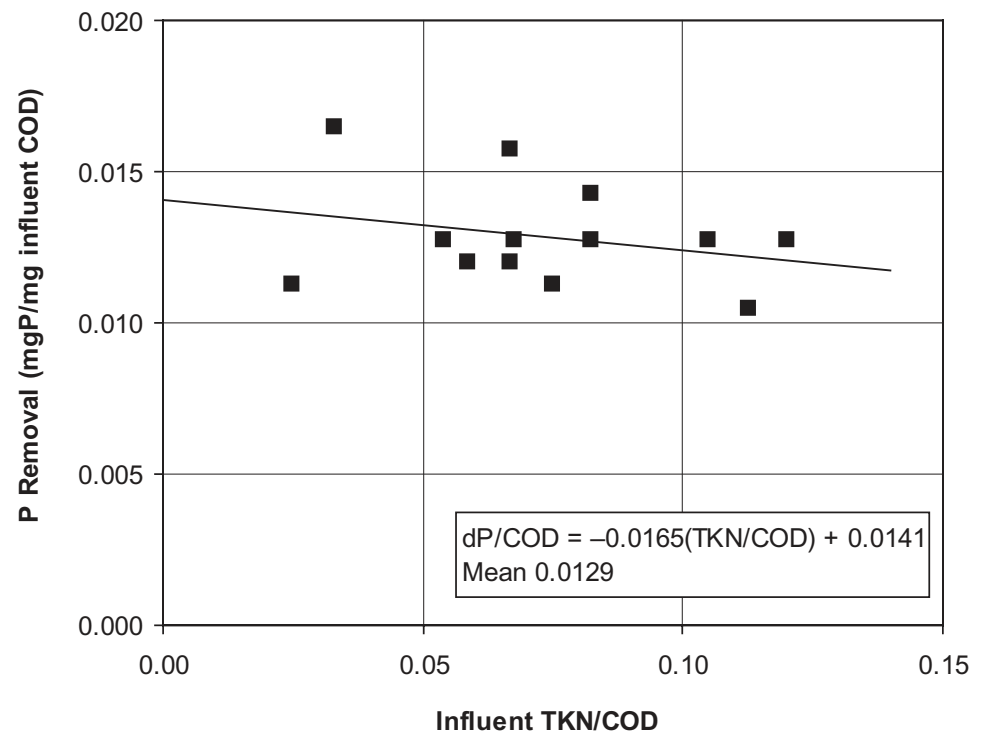

Figure 3.32 Effect of influent TKN on EBPR performance in full-scale BNR plants. Five Australian plants and eight US plants of various configurations; SRT variable up to $25 \mathrm{~d}$.

The ordinate value is $0.014 \mathrm{mg}$ P removed $/ \mathrm{mgCOD}$ and the overall mean is 0.013 . These values are at the low end of the performance range shown in Figure 3.30 and presumably reflect the action of adverse factors in these full-scale plants.

\section{Sulfide}

Sulfide fed to the anaerobic reactor causes inhibition of EBPR. Figure 3.33 shows P removal performance plotted against sulfide concentration in the combined anaerobic reactor feed after sewage was mixed with return activated sludge (Hartley et al., 1999; Yamamoto et al., 1991). The Yamamoto data are from a pilot plant study while the Thorneside data are from a full-scale BNR plant incorporating a prefermenter generating considerable sulfide. The Thorneside data points are the averages for three operating periods when the BNR process was nominally operating at steady state. Sulfide concentration measured within the anaerobic reactor was zero. 


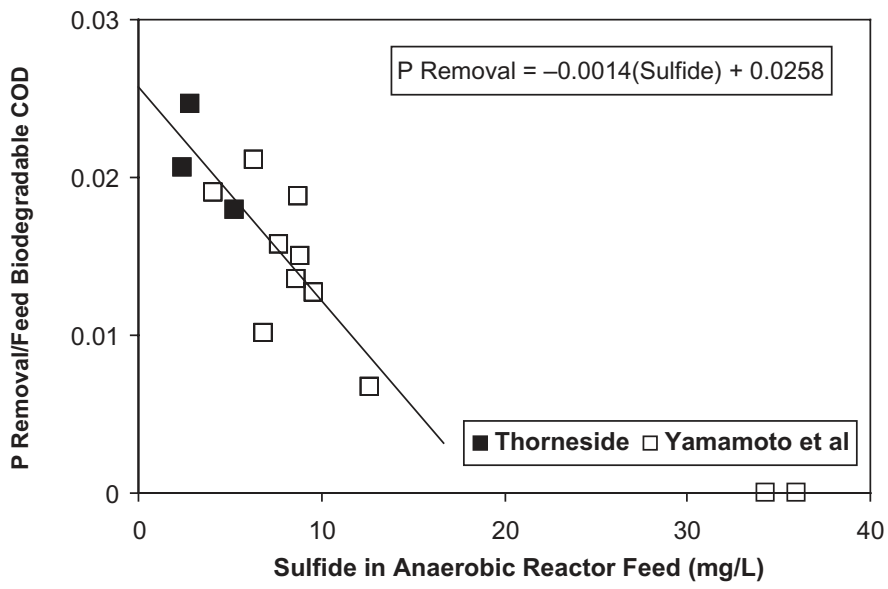

Figure 3.33 Effect of sulfide on biological $P$ removal. Feed sulfide is the effective combined concentration after the influent mixes with process recycles.

Note that $\mathrm{P}$ removal at zero sulfide was $0.026 \mathrm{mgP} / \mathrm{mg}$ biodegradable COD, equivalent to 0.019 $\mathrm{mgP} / \mathrm{mg}$ total $\mathrm{COD}$ at a $\mathrm{COD}_{\mathrm{b}}: \mathrm{COD}_{\mathrm{t}}$ ratio of 0.75 . This reflects a better performance than Figure 3.32, possibly because of the presence of a prefermenter at Thorneside.

\section{PAO-GAO competition}

Glycogen accumulating organisms (GAOs) have a similar metabolism to PAOs except that they rely solely on glycogen stores for energy to take up VFAs under anaerobic conditions (Henze et al., 2008). They compete with PAOs for the available RBCOD and therefore reduce the biological $\mathrm{P}$ removal performance. The important factors governing the relative activities of PAOs and GAOs in operating EBPR processes are type of carbon source (acetate or propionate), $\mathrm{pH}$ and temperature.

Lopez-Vasquez et al. (2009) conducted a detailed modeling study to determine the relative PAO-GAO populations over a range of temperature, $\mathrm{pH}$ and VFA speciation conditions. The main results are condensed into the contour diagram in Figure 3.34a. This diagram shows isopleths (contours) of PAO mass as a percentage of the total (PAO + GAO) mass. They therefore represent the percentage of RBCOD sequestered by the PAOs and used for $\mathrm{P}$ removal. The axes show the two parameters which are potentially controllable by the plant operator, VFA speciation (acetate concentration as a percentage of total VFA concentration) and mixed liquor $\mathrm{pH}$. There are three sets of isopleths on the diagram relating to three (uncontrollable) operating temperatures, 10, 20 and $30^{\circ} \mathrm{C}$.

Because of the different growth characteristics of the PAOs and GAOs, each group of organisms is favoured under different operating conditions. To highlight the area of the diagram giving good PAO growth, Figure 3.34b shows the PAO 80\% (or 87\%) isopleths for the three temperatures. In the areas above these isopleths, PAOs make up more than $80 \%$ of the total PAO-GAO biomass meaning the same percentage of the total RBCOD sequestered goes to the PAOs. At $10^{\circ} \mathrm{C}$ virtually the whole biomass is PAOs over the whole area of the diagram (the $87 \%$ isopleth is the lowest appearing in this operating window). At $20^{\circ} \mathrm{C}$ the operating region favouring PAOs has shrunk considerably, while at $30^{\circ} \mathrm{C}$ good PAO growth occurs only within a very narrow range of conditions. 
(a)

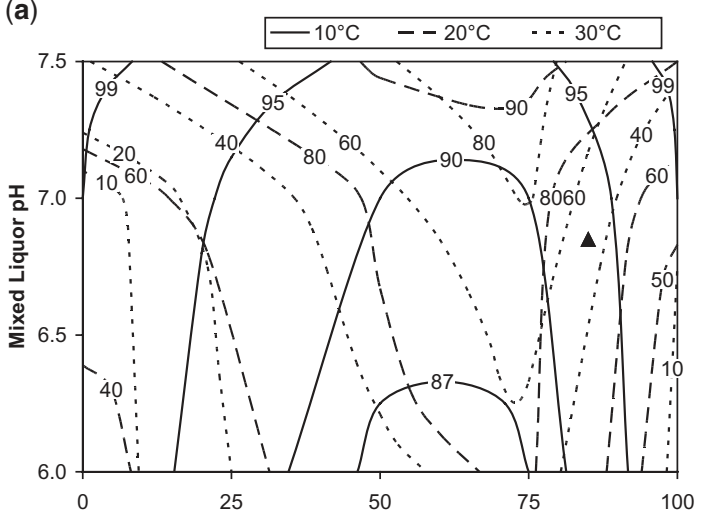

Substrate Composition:

Acetic Acid (as C) Mass \% (HAc/[HAc+HPr]) (b)

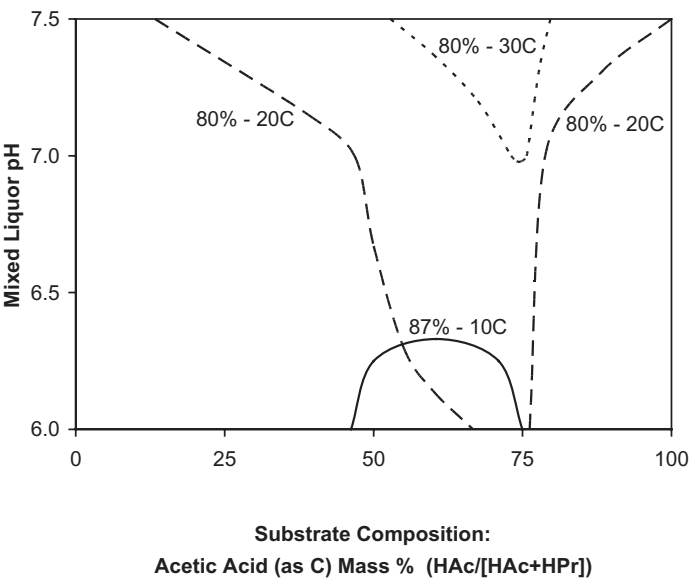

Figure 3.34 (a) PAO-GAO diagram showing isopleths of PAO mass as a percentage of total PAO + GAO mass. The triangular marker shows the Cleveland Bay STP operating point (refer to text).(b) 80 (or 87) percentile lines from (a). Zones of PAO dominance lie above the 80 percentile lines.

While the composition of the VFAs is known if they are fed to the anaerobic reactor from an external source, this is not the case for an EBPR process relying predominantly on VFA production by internal fermentation.

The author has found the diagram reliable in the course of a review of the EBPR performance of the Cleveland Bay Wastewater Treatment Facility in the tropical Australian city of Townsville (Hartley, 2009). The sewage was well fermented in-sewer and during the review period the anaerobic zones of two parallel independent bioreactors were fed primary effluent with a mean total COD of $292 \mathrm{mg} / \mathrm{L}$ and a total VFA concentration of $59 \mathrm{mg} / \mathrm{L}$ (VFA-COD/total COD 0.22). Acetic acid was $85 \%$ of total VFAs. Mixed liquor temperature and $\mathrm{pH}$ were $30^{\circ} \mathrm{C}$ and 6.85 respectively. The operating point is shown by the triangular marker in Figure 3.34(a). By linear interpolation, the PAO percentage of PAOs + GAOs given by the diagram is $49 \%$. PAO and GAO enumeration was conducted on mixed liquor samples from both bioreactors, giving PAO percentages of $43 \%$ and $51 \%$ for a mean of $47 \%$, very close to the diagram figure.

\subsection{SUPPLEMENTARY CHEMICAL DOSING}

Chemical dosing is commonly used to supplement biological nutrient removal, with the aims of enhancing phosphorus and/or nitrogen removal, and increasing the operating $\mathrm{pH}$. Chemicals can be dosed upstream or downstream of the biological process or direct to the process itself. In this chapter the focus is on integral dosing direct to the biological process.

\subsubsection{Phosphorus removal}

Phosphorus removal can be enhanced by dosing aluminium or iron salts to the mixed liquor. The use of alum (aluminium sulfate) is discussed here but iron salts behave in a similar fashion. 
When alum is dosed to the mixed liquor the useful reactions which occur are as follows (Letterman et al., 1999):

- Aluminium precipitates as aluminium hydroxide, $\mathrm{Al}(\mathrm{OH})_{3}{ }^{4}$

- The higher molecular weight fraction of dissolved organics is adsorbed onto the hydroxide precipitate.

- Phosphate is incorporated to form a mixed aluminium hydroxide phosphate precipitate (Boisvert et al., 1997; Galarneau \& Gehr, 1997).

The extent to which these reactions occur depends mainly on the concentrations of the reactants and the $\mathrm{pH}$. The solid phase acts as a sorbent for phosphorus and an equilibrium is established between the phosphorus concentrations in the liquid and solid phases; as process conditions change, phosphorus is released or taken up to maintain the equilibrium. ${ }^{5}$ Phosphate is also sorbed by preformed aluminium hydroxide flocs (in water treatment sludge, e.g.) but the degree of sorption decreases with the age of the flocs.

Typical performance is shown by the alum dosing jar test results plotted in Figure 3.35 (GHD, 1994). Twenty four tests were performed on an effluent from an activated sludge process exhibiting a degree of EBPR (filtered P $2.2 \mathrm{mg} / \mathrm{L}$ ). Depending on alum dose and $\mathrm{pH}$, the final filtered $\mathrm{P}$ varied from $0.01-$ $0.9 \mathrm{mg} / \mathrm{L}$ as shown in Figure 3.35a. Optimum $\mathrm{pH}$ was 5.5-6.0. Removal of true colour (used as an indicator of dissolved organics) was best at $\mathrm{pH} 5.5$ (Figure 3.35b) while removal of SS was best at $\mathrm{pH}$ 6.0-6.5 (Figure 3.35c).

Phosphorus removal efficiency can be expressed in terms of aluminium adsorption capacity, $\mathrm{mgP} / \mathrm{mgAl}$. The stoichiometric maximum for aluminium phosphate, $\mathrm{AlPO}_{4}$, is the atomic weight ratio, 31/27 or 1.15 $\mathrm{mgP} / \mathrm{mgAl}$. The jar test results in Figure 3.35a can be displayed in the form of Langmuir adsorption isotherms by taking vertical slices at chosen $\mathrm{pH}$ values.

The Langmuir adsorption isotherm (Metcalf \& Eddy, 2003) has the same mathematical form as the Monod bacterial growth equation:

$$
\mathrm{q}=\mathrm{q}_{\mathrm{m}} \mathrm{P}_{\mathrm{S}} /\left(\mathrm{K}_{\mathrm{P}}+\mathrm{P}_{\mathrm{S}}\right)
$$

where

$$
\begin{aligned}
\mathrm{q}= & \text { aluminium adsorption capacity, } \mathrm{mgP} / \mathrm{mgAl} \\
\mathrm{q}_{\mathrm{m}}= & \text { maximum (saturation) aluminium adsorption capacity, mgP/mgAl } \\
\mathrm{P}_{\mathrm{S}}= & \text { soluble phosphate concentration, } \mathrm{mgP} / \mathrm{L} \\
\mathrm{K}_{\mathrm{P}}= & \text { half saturation coefficient, equal to the soluble } \mathrm{P} \text { concentration at } \\
& \text { which } \mathrm{q}=\mathrm{q}_{\mathrm{m}} / 2, \mathrm{mgP} / \mathrm{L}
\end{aligned}
$$

Table 3.4 lists the calculated $\mathrm{q}_{\mathrm{m}}$ and $\mathrm{K}_{\mathrm{P}}$ values for the $\mathrm{pH}$ range of interest in biological processes and Figure 3.36 shows the resulting isotherms.

\footnotetext{
${ }^{4}$ Nielsen et al. (1973) found that after drying alum sludge at $103^{\circ} \mathrm{C}, 1.25 \mathrm{H}_{2} \mathrm{O}$ molecules per molecule of $\mathrm{Al}(\mathrm{OH})_{3} \mathrm{remained}$.

${ }^{5}$ This means that under steady state operation, the alum dosing location within the bioreactor is not critical; no saving of alum accrues from dosing in the anaerobic reactor where $\mathrm{PO}_{4}$ is higher as the $\mathrm{P}$ is released again downstream where $\mathrm{PO}_{4}$ concentrations are lower. $\mathrm{A}$ common dosing location is the reactor outlet to the secondary clarifiers which has the potential advantage of providing a more rapid effluent response to changes in dose rate but a sufficient contact time is required (which could be determined by jar testing).
} 

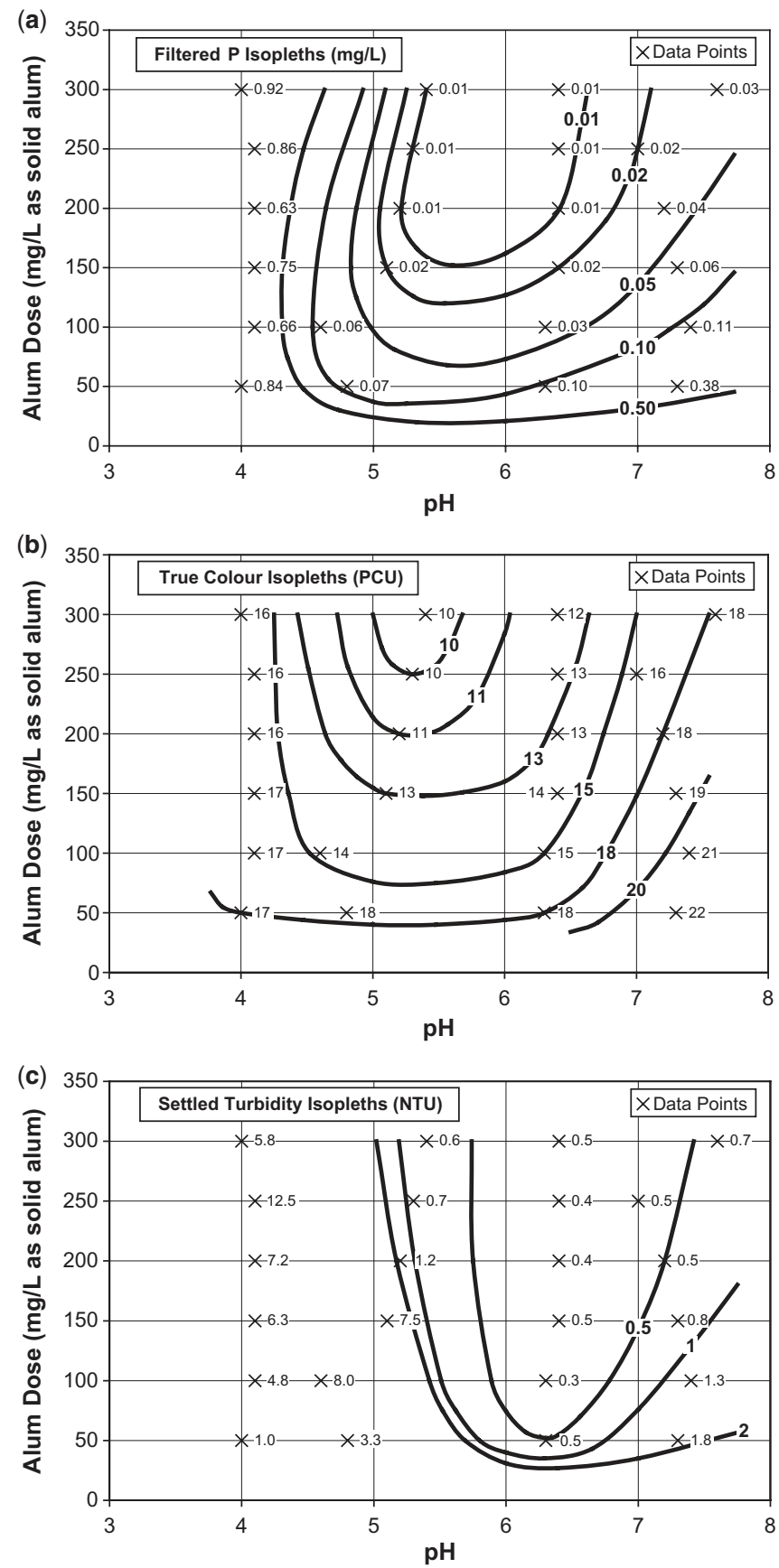

Figure 3.35 Jar test results for alum dosing of a biological process effluent with the following quality: BOD 10 $\mathrm{mg} / \mathrm{L}, \mathrm{SS} 7 \mathrm{mg} / \mathrm{L}$, turbidity $4.5 \mathrm{NTU}$, true colour $30 \mathrm{PCU}$, total P $2.9 \mathrm{mg} / \mathrm{L}$, filtered P $2.2 \mathrm{mg} / \mathrm{L}$. Test procedure: dose predetermined quantity of acid or alkali and mix, dose alum and flash mix, flocculate at a velocity gradient (G) of $40 \mathrm{~s}^{-1}$ for 15 minutes, settle for 30 minutes. 
Biological nutrient removal - process fundamentals

Table 3.4 Aluminium adsorption constants. ${ }^{1}$

\begin{tabular}{ccc}
\hline $\mathbf{p H}$ & $\mathbf{q}_{\mathbf{m}} \mathbf{\text { mgP}} / \mathbf{m g A l}$ & $\mathbf{K}_{\mathbf{P}} \mathbf{~ m g P} / \mathbf{L}$ \\
\hline 6.0 & 1.10 & 0.10 \\
6.5 & 0.96 & 0.13 \\
7.0 & 0.83 & 0.18 \\
7.5 & 0.75 & 0.27 \\
\hline
\end{tabular}

${ }^{1}$ Empirical correlations are:

$\mathrm{q}_{\mathrm{m}}=24.9(\mathrm{pH})^{-1.74}, \mathrm{r}^{2}=0.998$

$\mathrm{K}_{\mathrm{P}}=0.00183 \exp (0.661 \mathrm{pH}), \mathrm{r}^{2}=0.991$

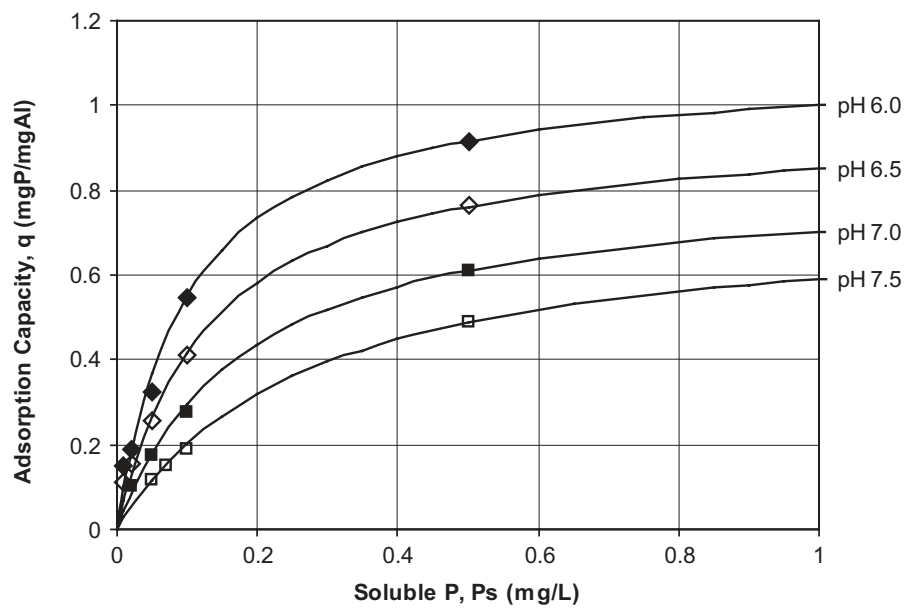

Figure 3.36 Adsorption isotherms for the removal of phosphate with alum.

Chemical phosphorus removal characteristics can be derived using Equation 3.14 in conjunction with the following chemical equations:

Distribution of ortho-phosphate species in pH range of interest

$$
\mathrm{H}_{2} \mathrm{PO}_{4}^{-} \longleftrightarrow \mathrm{H}^{+}+\mathrm{HPO}_{4}^{2-} \quad \mathrm{pK}_{2}=7.20^{6}
$$

Phosphate precipitation

$$
\begin{aligned}
& \mathrm{Al}^{3+}+\mathrm{H}_{2} \mathrm{PO}_{4}^{-} \longleftrightarrow \mathrm{AlPO}_{4}+2 \mathrm{H}^{+} \\
& \mathrm{Al}^{3+}+\mathrm{HPO}_{4}^{2-} \longleftrightarrow \mathrm{AlPO}_{4}+\mathrm{H}^{+}
\end{aligned}
$$

\footnotetext{
${ }^{6}$ Second dissociation constant for phosphoric acid, $\mathrm{K}_{2}=\left[\mathrm{H}^{+}\right]\left[\mathrm{HPO}_{4}^{2-}\right] /\left[\mathrm{H}_{2} \mathrm{PO}_{4}^{-}\right] ; \mathrm{pK}_{2}=$ negative logarithm of $\mathrm{K}_{2} ;\left[\mathrm{HPO}_{4}^{2-}\right]=$ $\left[\mathrm{H}_{2} \mathrm{PO}_{4}^{-}\right]$at $\mathrm{pH}=\mathrm{pK}_{2}$. $\mathrm{pK}$ values vary slightly with temperature and are normally expressed as the $25^{\circ} \mathrm{C}$ values.
} 
Aluminium hydroxide precipitation

$$
\mathrm{Al}^{3+}+4.25 \mathrm{H}_{2} \mathrm{O} \longleftrightarrow \mathrm{Al}(\mathrm{OH})_{3} 1.25 \mathrm{H}_{2} \mathrm{O}+3 \mathrm{H}^{+}
$$

Solids production is the sum of aluminium phosphate and aluminium hydroxide precipitates. Alkalinity depletion is the total hydrogen ion production. The formulas used are listed in Table 3.5. The derived process characteristics are shown in Table 3.6 and Figure 3.37.

Table 3.5 Alum dosing relationships.

\section{Alum Dose}

$d_{A}=11.1\left(K_{P}+P_{S}\right) /\left(q_{m} P_{S}\right)$

where $\mathrm{d}_{\mathrm{A}}=$ alum dose as solid alum, $\mathrm{Al}_{2}\left(\mathrm{SO}_{4}\right)_{3} 14.3 \mathrm{H}_{2} \mathrm{O}$, mg alum $/ \mathrm{mg} \Delta \mathrm{P}$

and other symbols are defined in the text

\section{Solids Production}

$\mathrm{X}_{\mathrm{A}}=0.334+0.064 \mathrm{q}_{\mathrm{m}} \mathrm{P}_{\mathrm{S}} /\left(\mathrm{K}_{\mathrm{P}}+\mathrm{P}_{\mathrm{S}}\right)$

where $\mathrm{X}_{\mathrm{A}}=$ solids production, $\mathrm{mgSS} / \mathrm{mg}$ solid alum dosed

\section{Alkalinity Depletion}

$\Delta \mathrm{T}_{\mathrm{A}}=\left\{\mathrm{q}_{\mathrm{m}} \mathrm{P}_{\mathrm{S}} /\left[11.1\left(\mathrm{~K}_{\mathrm{P}}+\mathrm{P}_{\mathrm{S}}\right)\right]\right\}\left\{2 /\left[1+10^{\wedge}\left(\mathrm{pH}-\mathrm{pK}_{2}\right)\right]+1 /\left[1+10^{\wedge}\left(\mathrm{pK}_{2}-\mathrm{pH}\right)\right]-4 \cdot 84\right\}+0.501$

where $\Delta \mathrm{T}_{\mathrm{A}}=$ decrease in total alkalinity, $\mathrm{mgCaCO}_{3} / \mathrm{mg}$ solid alum dosed

\section{Estimate of Biological P Removal}

$\Delta \mathrm{P}_{\mathrm{B}}=\mathrm{P}_{\mathrm{TI}}-\mathrm{P}_{\mathrm{S}}-\mathrm{D}_{\mathrm{A}} / \mathrm{d}_{\mathrm{A}}$

where $\Delta P_{B}=P$ removed biologically, $\mathrm{mg} / \mathrm{L}$

$\mathrm{P}_{\mathrm{TI}}=$ process influent total $\mathrm{P}, \mathrm{mg} / \mathrm{L}$

$\mathrm{P}_{\mathrm{S}}=$ process effluent soluble phosphate concentration, $\mathrm{mgP} / \mathrm{L}$

$\mathrm{D}_{\mathrm{A}}=$ process alum dose as solid alum, $\mathrm{Al}_{2}\left(\mathrm{SO}_{4}\right)_{3} 14.3 \mathrm{H}_{2} \mathrm{O}, \mathrm{mg}$ alum/ $\mathrm{L}$ of influent and $d_{A}$ is defined above (Equation 3.15)

Table 3.6 Alum dosing stoichiometry.

\begin{tabular}{ccc}
\hline Final $\mathbf{p H}$ & $\begin{array}{l}\text { Final soluble } \mathbf{P} \\
\left(\mathbf{m g P O}_{\mathbf{4}}-\mathbf{P} / \mathbf{L}\right)\end{array}$ & $\begin{array}{l}\text { Alum dose required } \\
\text { (mg solid alum/mg } \mathbf{~ P )}\end{array}$ \\
\hline 2.0 & 2 & 14.6 \\
& 1 & 15.8 \\
& 0.5 & 18.2 \\
& 0.2 & 25.4 \\
6.5 & 0.1 & 37.4 \\
& 2 & 12.3 \\
& 1 & 13.1 \\
& 0.5 & 14.6 \\
& 0.2 & 19.1 \\
& 0.1 & 26.6 \\
\hline
\end{tabular}


(a) Alum dose required

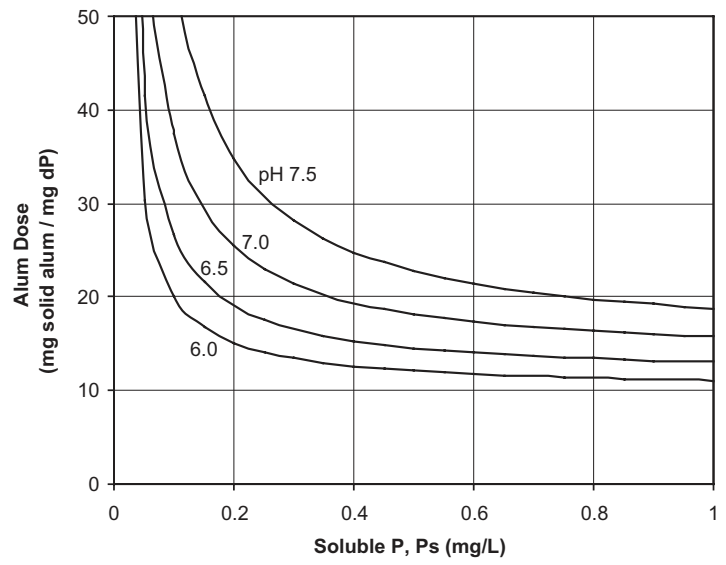

(b) SS production

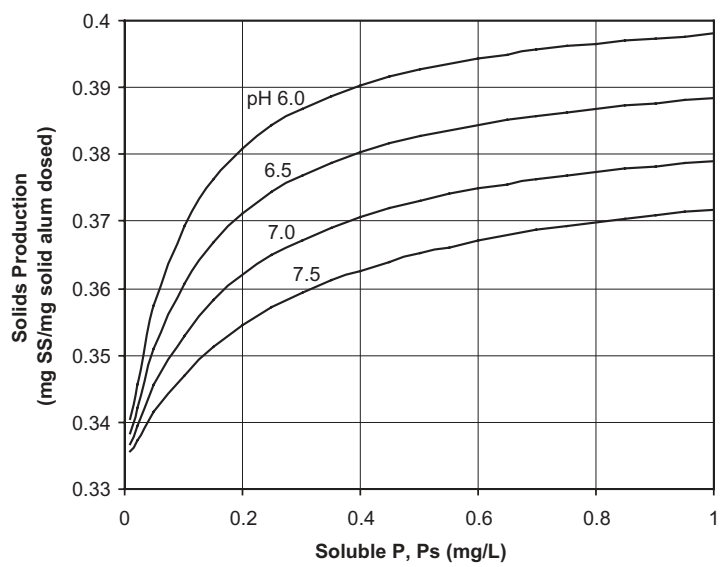

(c) Alkalinity depletion

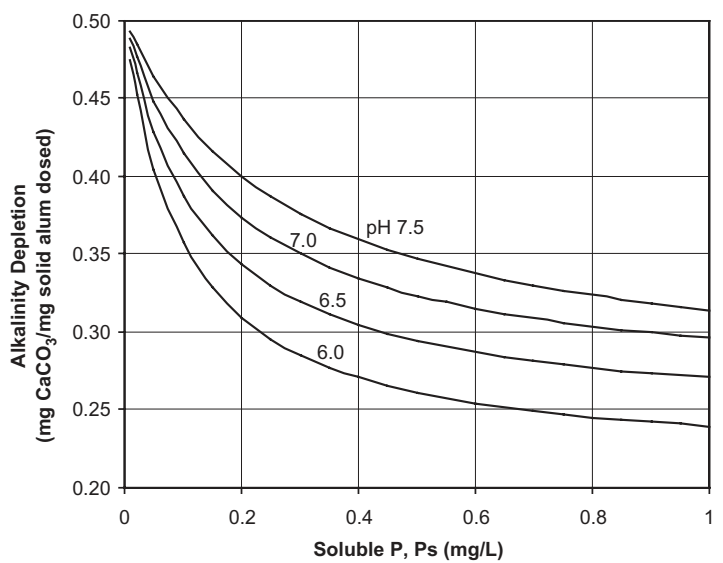

Figure 3.37 Alum dosing characteristics. 
Equation 3.18 in Table 3.5 enables an estimate to be made of the magnitude of the biological phosphorus removal occurring in a bioreactor operating with supplementary alum dosing.

\subsubsection{Nitrogen removal}

Aluminium hydroxide sorption of dissolved organics is shown by the removal of true (dissolved) colour in Figure $3.35 \mathrm{~b}$. The organics sorbed contain nitrogen. Alum dosing therefore reduces soluble unbiodegradable organic N. Figure 3.38 shows the effect of alum dosing to the mixed liquor of two BNR plants over 18-22 month periods. The effluent concentrations exhibit a wide scatter, partly because they have been calculated indirectly from several analyses:

West Byron: $\mathrm{N}_{\mathrm{ue}}=\mathrm{N}_{\mathrm{te}}-\mathrm{N}_{\mathrm{ae}}-\mathrm{N}_{\mathrm{xe}}$

Maroochydore: $\mathrm{N}_{\mathrm{ue}}=\mathrm{N}_{\mathrm{e}}-\mathrm{N}_{\mathrm{ae}}-\mathrm{N}_{\mathrm{ne}}-\mathrm{N}_{\mathrm{xe}}$

where

$\mathrm{N}_{\mathrm{ue}}=$ effluent soluble unbiodegradable organic $\mathrm{N}, \mathrm{mg} / \mathrm{L}$

$\mathrm{N}_{\mathrm{te}}=$ effluent TKN, mg/L

$\mathrm{N}_{\mathrm{e}}=$ effluent $\mathrm{TN}, \mathrm{mg} / \mathrm{L}$

$\mathrm{N}_{\mathrm{ae}}=$ effluent ammonia $\mathrm{N}, \mathrm{mg} / \mathrm{L}$

$\mathrm{N}_{\mathrm{ne}}=$ effluent nitrate $\mathrm{N}, \mathrm{mg} / \mathrm{L}$

$\mathrm{N}_{\mathrm{xe}}=$ effluent particulate organic $\mathrm{N}, \mathrm{mg} / \mathrm{L}$

$=0.07 \mathrm{X}_{\mathrm{e}}$

$\mathrm{X}_{\mathrm{e}}=$ effluent SS, mg/L

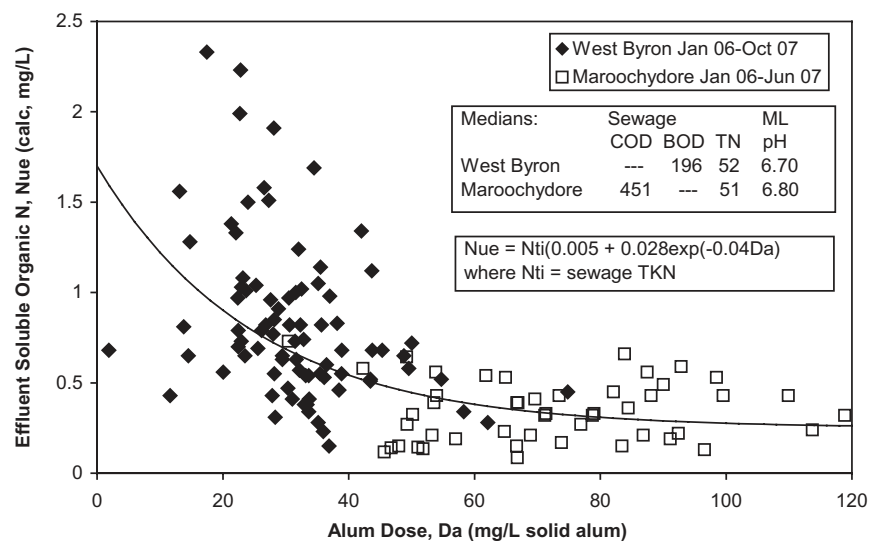

Figure 3.38 Effect of biological process alum dose on effluent soluble organic $\mathrm{N}$ at the West Byron and Maroochydore STPs.

\subsubsection{Other effects}

In the author's experience, the removal of soluble organics by alum dosing to the bioreactor can have two other beneficial effects:

(1) Increasing the nitrification rate, presumably by the removal of inhibitory substances; this can counterbalance any decrease in nitrification rate associated with an alum-caused decline in $\mathrm{pH}$.

(2) Reducing the chlorine demand in a tertiary disinfection or oxidation process. 


\subsection{ALKALINITY AND pH}

\subsubsection{Chemistry}

The alkalinity of a water is its acid-neutralising capacity. ${ }^{7}$ In sewage treatment processes, $\mathrm{pH}$ is controlled mainly by the carbonate system, although other acid-base systems such as ammonia and phosphate contribute when their concentrations are high (in digesters, e.g.) or the $\mathrm{pH}$ is particularly high or low.

The carbonate system is formed from the dissolution of carbon dioxide (Loewenthal \& Marais, 1976). A small proportion of the dissolved carbon dioxide hydrolyses to carbonic acid which then dissociates into bicarbonate and carbonate ions. These carbonic species together with the hydrogen and hydroxyl ions of the water exist in a state of dynamic equilibrium described by the following equations:

$$
\begin{array}{llll}
\mathrm{CO}_{2}+\mathrm{H}_{2} \mathrm{O} \longleftrightarrow \mathrm{H}_{2} \mathrm{CO}_{3} & \text { Carbonic acid } & \\
\mathrm{H}_{2} \mathrm{CO}_{3} \longleftrightarrow \mathrm{H}^{+}+\mathrm{HCO}_{3}{ }^{-} & \text {Bicarbonate } & \mathrm{pK}_{1}=6.37^{8} \\
\mathrm{HCO}_{3}{ }^{-} \longleftrightarrow \mathrm{H}^{+}+\mathrm{CO}_{3}{ }^{2-} & \text { Carbonate } & \mathrm{pK}_{2}=10.33 \\
\mathrm{H}_{2} \mathrm{O} \longleftrightarrow \mathrm{H}^{+}+\mathrm{OH}^{-} & \text {Water } & \mathrm{pK}_{\mathrm{w}}=14.0
\end{array}
$$

The relative concentrations of the different species vary with $\mathrm{pH}$ as shown in Figure 3.39. This chemical system provides buffering against $\mathrm{pH}$ change when acid or base is dosed to the process or produced by reaction. The degree of buffering available in the water is measured by total alkalinity. In simple terms, total alkalinity is the mass of strong acid required to convert the $\mathrm{CO}_{3}{ }^{2-}$ and $\mathrm{HCO}_{3}{ }^{-}$ions to $\mathrm{H}_{2} \mathrm{CO}_{3}$ and is given by:

$$
[\mathrm{TA}]=2\left[\mathrm{CO}_{3}{ }^{-}\right]+\left[\mathrm{HCO}_{3}^{-}\right]+\left[\mathrm{OH}^{-}\right]-\left[\mathrm{H}^{+}\right]
$$

where [ ] represents molar concentration, moles/L.

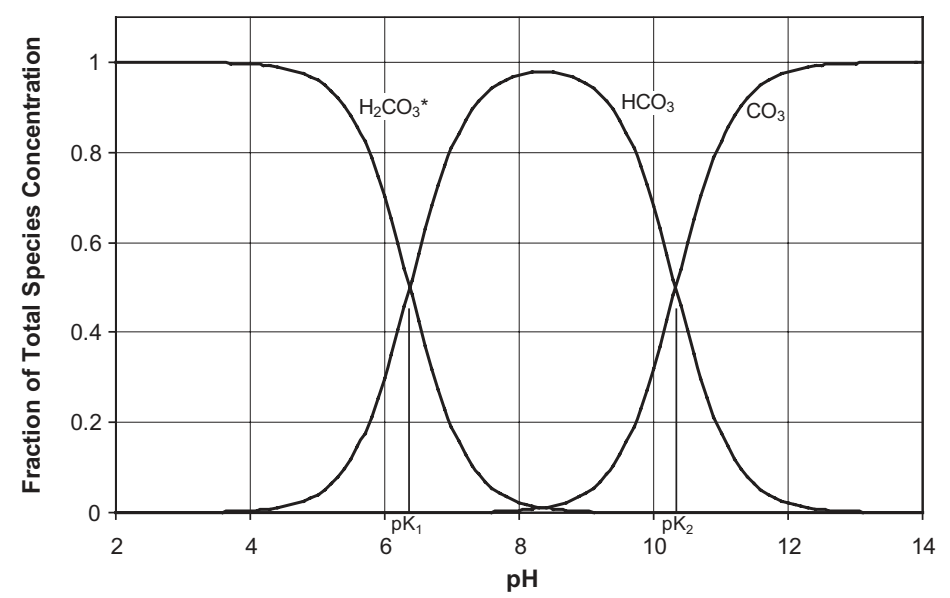

Figure 3.39 Variation of carbonic species concentration with $\mathrm{pH}$.

\footnotetext{
${ }^{7}$ Conversely, the acidity of a water is its alkali-neutralising capacity.

${ }^{8}$ Only a small fraction of the $\mathrm{CO}_{2}$ is hydrolysed to $\mathrm{H}_{2} \mathrm{CO}_{3}$ and the equilibrium is virtually unaffected by temperature or $\mathrm{pH}$. $\mathrm{K}_{1}$ is therefore calculated as $\left[\mathrm{H}^{+}\right]\left[\mathrm{HCO}_{3}^{-}\right] /\left[\mathrm{H}_{2} \mathrm{CO}_{3} *\right]$ where $\left[\mathrm{H}_{2} \mathrm{CO}_{3} *\right]=\left[\mathrm{CO}_{2}\right]+\left[\mathrm{H}_{2} \mathrm{CO}_{3}\right]$. In common usage the star symbol is omitted.
} 
Total alkalinity is measured by the quantity of strong acid required to reduce the sample $\mathrm{pH}$ to about 4.5 (Standard Methods, 1998). It is normally expressed in terms of equivalent calcium carbonate, $\mathrm{CaCO}_{3}$, calculated by multiplying the mass of acid by the ratio of equivalent weights, $\left\{\mathrm{CaCO}_{3}\right\} /\{$ acid $\}$. ${ }^{9}$

\subsubsection{Process behaviour}

The $\mathrm{pH}$ value in a nutrient removal process depends mainly on the following factors:

- The alkalinity and $\mathrm{pH}$ of the sewage.

- Carbon dioxide produced by oxidation of organics.

- The acid produced by nitrification.

- The alkali produced by denitrification.

- The acidity produced by dosing of chemicals such as alum or iron salts.

- Chemical alkali dosed to control the $\mathrm{pH}$.

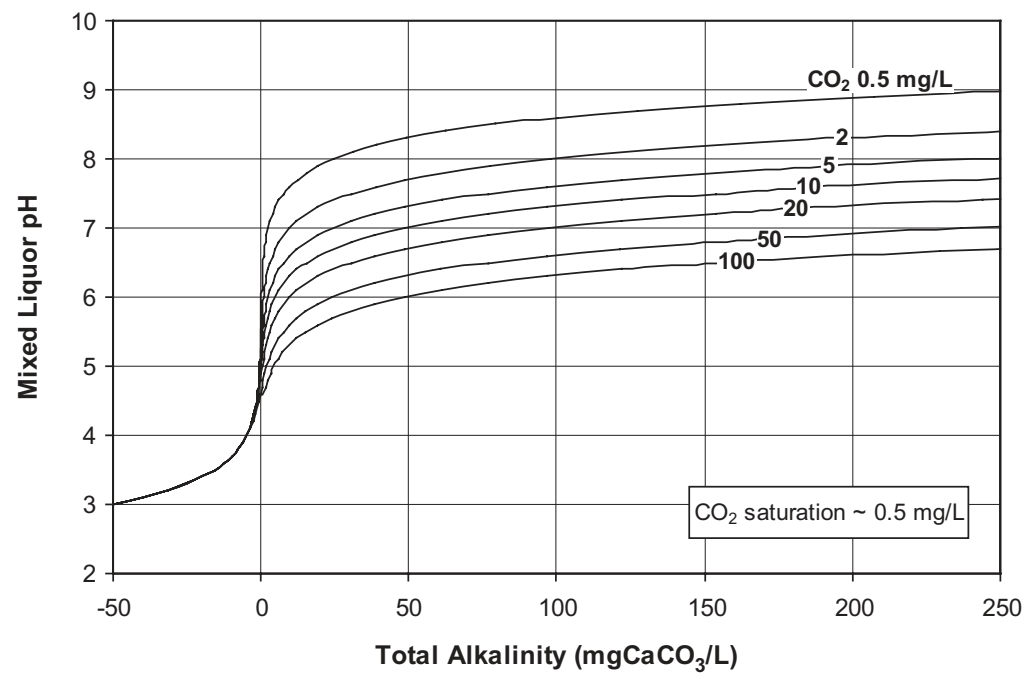

Figure 3.40 Variation of mixed liquor $\mathrm{pH}$ with alkalinity and dissolved $\mathrm{CO}_{2}$ concentration.

About one third of the influent biodegradable COD is converted to carbon dioxide. This is dissolved in the water and reduces the $\mathrm{pH}$. The concentration of dissolved carbon dioxide in equilibrium with the small quantity in the atmosphere is only about $0.5 \mathrm{mg} / \mathrm{L}$, hence the water becomes supersaturated. Carbon dioxide therefore transfers from the water to the air phase, primarily in the aeration zones. Thus the aerators fulfil two functions - they transfer oxygen from the air to the water and they also transfer carbon dioxide from the water to the air. The aerators are the lungs of the process.

The carbon dioxide concentration in the water is governed by the balance between the rate of production and the rate of mass transfer to atmosphere. The carbon dioxide does not reduce the alkalinity, but does reduce the $\mathrm{pH}$ at a given alkalinity. It will be observed that the $\mathrm{pH}$ of a clarified effluent is higher than

${ }^{9}$ Equivalent weights of $\mathrm{CaCO}_{3}, \mathrm{H}_{2} \mathrm{SO}_{4}$ and $\mathrm{HCl}$ are 50,49 and 36.5 respectively. 
that of the mixed liquor because additional carbon dioxide is stripped from the surface of the clarifier, particularly at the weirs and launders. However, alkalinity is unchanged.

The effect of mixed liquor alkalinity and carbon dioxide concentration on mixed liquor $\mathrm{pH}$ is shown in Figure 3.40 (UCT et al., 1984). It can be seen that regardless of the actual concentration of carbon dioxide, once the alkalinity falls below about $50 \mathrm{mgCaCO}_{3} / \mathrm{L}$ the $\mathrm{pH}$ becomes unstable and falls rapidly. The effect of aeration efficiency on $\mathrm{pH}$ is discussed in more detail in Chapter 6.

\subsection{RULES OF THUMB}

Useful rules of thumb are listed in Table 3.7.

Table 3.7 Nutrient removal rules of thumb.
A. Nitrification
1. Oxygen demand $=4.6$ times $\mathrm{NH}_{3}-\mathrm{N}$ oxidised
2. TA lost $=7.1$ times $\mathrm{NH}_{3}-\mathrm{N}$ oxidised
B. Denitrification
1. Oxygen recovered $=2.9$ times $\mathrm{NO}_{3}-\mathrm{N}$ denitrified
2. TA recovered $=3.6$ times $\mathrm{NO}_{3}-\mathrm{N}$ denitrified
C. Nitrogen Removal
3. $\mathrm{COD}$ used $=4.5-6.1$ times $\mathrm{NO}_{3}-\mathrm{N}$ denitrified (Table 3.2)
1. Nitrification is governed by aerobic SRT
2. Denitrification is governed by anoxic fraction
3. DO discharged to the anoxic zone reduces denitrification by $0.3 \mathrm{mgN} / \mathrm{mgDO}$
D. Biological Phosphorus Removal
4. $\mathrm{N}$ removal capacity $=0.1$ times $\mathrm{COD}$
1. $\mathrm{RBCOD}$ needed $=10 \mathrm{mgRBCOD} / \mathrm{mgP}$ removed
2. $\mathrm{DO}$ added to the sewage reduces $\mathrm{RBCOD}$ by $3 \mathrm{mgRBCOD} / \mathrm{mgDO}$
3. $\mathrm{DO}$ added to the anaerobic zone reduces $\mathrm{P}$ removal by $0.3 \mathrm{mgP} / \mathrm{mgDO}$
4. $\mathrm{NO}_{3}-\mathrm{N}$ added to the anaerobic zone reduces $\mathrm{P}$ removal by $1 \mathrm{mgP} / \mathrm{mgNO}_{3}-\mathrm{N}$
5. Biological $P$ removal capacity $=0.015$ times COD
6. $\mathrm{P}$ release in anaerobic reactor $=0.5 \mathrm{mgP} / \mathrm{mgCOD}$ uptake $=$ $5 \mathrm{mgP} / \mathrm{mgP}$ removed
E. Alum Dosing
1. Alum dose (as solid alum) required for $P$ removal $=20$ times $P$ removed
2. Alkali needed to counteract alum acidity $=0.35$ $\mathrm{mgCaCO}_{3} / \mathrm{mg}$ solid alum 


\section{Chapter 4}

\section{Sludge settleability}

\subsection{CHARACTERISING SETTLEABILITY}

Sludge settleability is one of the most important design and operating characteristics of the traditional forms of activated sludge process utilising settling for biomass retention. Both the operating capacity of the process and the effluent quality produced are dependent on the sludge settling and thickening characteristics. Sludge quality is characterised using the simple Sludge Volume Index (SVI) test, which came into use during the early years of activated sludge plant operation and was formalised by Mohlman (1934).

SVI is the volume in $\mathrm{mL}$ occupied by one gram of MLSS after 30 minutes settling, commonly in a standard one litre measuring cylinder. This represents the sludge volume after all of the flocs have been brought into contact as closely as possible without being compacted. Values range from $50-100 \mathrm{~mL} / \mathrm{g}$ for dense, well-compacting sludges to several hundred for light, poorly compacting sludges. The latter are known as bulking sludges and an SVI of $150 \mathrm{~mL} / \mathrm{g}$ has often been used as a cut-off for this description. The SVI value is the inverse of the settled sludge density and Mohlman chose this mode of expression because increasing values reflect the increase in settled sludge blanket depth as settleability deteriorates.

Activated sludge flocs are built around a backbone of filamentous bacteria which give the flocs their strength. High SVI occurs when the filament length extending outside of the flocs becomes excessive, interfering with settling and compaction. SVI does not become excessive until filament lengths exceed $10 \mathrm{~km} / \mathrm{gMLSS}$ and highly filamentous sludges can have filament lengths of $100 \mathrm{~km} / \mathrm{gMLSS}$ (Sezgin et al., 1978; Sezgin, 1982)!

When measured in a one litre cylinder, SVI is calculated from:

$\mathrm{SVI}(\mathrm{mL} / \mathrm{g})=$ settled volume $(\mathrm{mL}) /$ initial concentration $(\mathrm{g} / \mathrm{L})$

When the sludge is so filamentous that no settlement takes place in the cylinder at all, the SVI is a maximum. Equation 4.1 shows that the maximum SVI value declines as the MLSS concentration increases.

When the settled volume is greater than $300-400 \mathrm{~mL}$ the small diameter of the cylinder tends to impede agglomeration and settlement and increase the measured SVI value (Dick \& Vesilind, 1969). This is commonly known as the wall effect. If samples of mixed liquor are diluted or concentrated and SVI measured at different initial concentrations, the test values vary as shown in Figure 4.1. This change in the test value occurs even though there is no change in the nature of the sludge itself. 


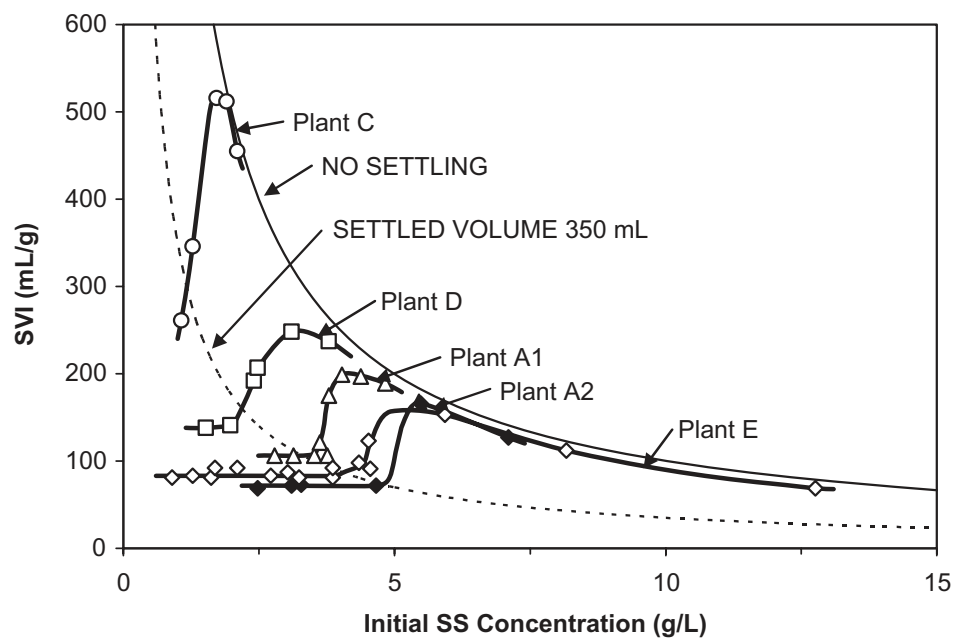

Figure 4.1 Effect of initial concentration in the test cylinder on the SVI value measured (after Dick \& Vesilind, 1969).

To overcome this problem, three alternative test procedures have come into use:

- Diluted SVI (DSVI): Serial dilutions of the sludge are used to reduce the settled sludge volume to less than $350 \mathrm{~mL} / \mathrm{g}$ (Stobbe, 1964; Lee et al., 1983).

- Stirred SVI (sSVI): A slow speed stirrer is fitted to the standard one litre test cylinder to overcome the wall effect (Standard Methods, 1998).

- Stirred Specific Volume Index (SSVI 3.5 or simply SSVI): A larger cylinder fitted with a slow speed stirrer is used (approximately $100 \mathrm{~mm}$ diameter $\times 500 \mathrm{~mm}$ water depth) and the sludge is initially diluted or concentrated to a standard initial concentration of $3.5 \mathrm{~g} / \mathrm{L}$. This test procedure was developed by White $(1975,1976)$ who originally designated it the Stirred Specific Volume (SSV).

The standard unstirred SVI test has enjoyed widespread acceptance as an aid to operation because it is simple and requires no special apparatus. Stirring is not essential for normal plant control where comparative values are of more significance than absolute values, but the limitations of the unstirred test should be kept in mind:

- At settled volumes above 300-400 mL, a change in MLSS concentration may produce a change in the measured value of SVI when no change in the nature of the sludge has occurred.

- When settlement during the test is small, the measured SVI is rather insensitive to actual changes in sludge settling characteristics.

- The test result is sensitive to temperature, methods of sampling and agitation, diameter of the settling column and time between sampling and the start of testing so useful results can only be obtained by following exactly the same procedure each time the test is performed.

SSVI produces the most reliable measure of the actual settling characteristics of the sludge and is generally accepted as the standard. In practice this test is often performed at the sample SS concentration rather than $3.5 \mathrm{~g} / \mathrm{L}$; this usually gives reliable results because of the large cylinder and the stirring employed. The sSVI test is identical except for the smaller cylinder and for practical purposes is usually considered equivalent to the SSVI. 


\subsection{SETTLING RATES}

At the usual MLSS concentrations, sludge settles in the hindered settling mode. The flocs displace water as they settle and because they are close together the resultant upward flow of water has sufficient velocity to produce a measurable reduction in the floc settling rate relative to a fixed plane. The sludge settling rate therefore varies with the SS concentration and the relationship is well represented by the exponential equation:

$$
\mathrm{V}_{\mathrm{S}}=\mathrm{V}_{\mathrm{O}} \mathrm{e}^{-\mathrm{nX}}
$$

where

$\mathrm{V}_{\mathrm{S}}=$ zone (sludge interface) settling velocity, $\mathrm{m} / \mathrm{h}$

$\mathrm{V}_{\mathrm{O}}=$ constant, nominally equal to the settling velocity at $\mathrm{X}=0, \mathrm{~m} / \mathrm{h}$

$\mathrm{n}=$ constant, $\mathrm{L} / \mathrm{gSS}$

$\mathrm{X}=$ initial sludge $\mathrm{SS}$ concentration, $\mathrm{gSS} / \mathrm{L}$

Table 4.1 Ozinsky \& Ekama settleability relationships.

Settling Parameters:

$$
\begin{array}{rlr}
\mathrm{V}_{\mathrm{O}} & =\alpha \cdot \exp (-\beta \cdot \mathrm{SSP}) & \mathrm{m} / \mathrm{h} \\
\mathrm{n} & =\gamma+\delta \cdot \mathrm{SSP} & \mathrm{L} / \mathrm{g}
\end{array}
$$

Where SSP $=$ sludge settleability parameter (SVI, DSVI or SSVI, $\mathrm{mL} / \mathrm{g}$ ) and values of constants $\alpha, \beta, \gamma$ and $\delta$ are listed below.

\section{Settling Rate:}

$\mathrm{V}_{\mathrm{S}}=\mathrm{V}_{\mathrm{O}} \mathrm{e}^{-\mathrm{nX}}$

or, substituting for $\mathrm{V}_{\mathrm{O}}$ and $\mathrm{n}$ above:

$\ln \mathrm{V}_{\mathrm{S}}=\ln \alpha-\beta \cdot \mathrm{SSP}-\gamma \cdot \mathrm{X}-\delta \cdot \mathrm{SSP} \cdot \mathrm{X}$

Conversions:

From Equation 4.5, conversions between SSPs can be made for the same sludge settling rate:

$\mathrm{SSP}_{2}=\left[\ln \alpha_{\mathrm{SSP} 2}-\gamma_{\mathrm{SSP} 2} \mathrm{X}-\left(\ln \alpha_{\mathrm{SSP} 1}-\beta_{\mathrm{SSP} 1} \mathrm{SSP}_{1}-\gamma_{\mathrm{SSP} 1} \mathrm{X}-\delta_{\mathrm{SSP} 1} \mathrm{X} \cdot \mathrm{SSP}_{1}\right)\right] /\left[\beta_{\mathrm{SSP} 2}+\delta_{\mathrm{SSP} 2} \mathrm{X}\right]$

\section{Constants:}

\begin{tabular}{lcccc}
\hline Process Type & NDEBPR & \multicolumn{1}{c}{ ND } & \\
\cline { 3 - 5 } SSP & SSVI & SSVI & DSVI & SVI \\
\hline $\ln \alpha$ & 2.70065 & 2.45095 & 2.30854 & 2.14370 \\
$\alpha$ & 14.88941 & 11.59936 & 10.05973 & 8.53094 \\
$\beta$ & 0.00808 & 0.00636 & 0.00297 & 0.00165 \\
$\gamma$ & 0.22632 & 0.15128 & 0.29721 & 0.20036 \\
$\delta$ & 0.00264 & 0.00287 & 0.00095 & 0.00091 \\
Correlation coeff, $\mathrm{r}^{2}$ & 0.916 & 0.849 & 0.776 & 0.842 \\
\hline
\end{tabular}


Several studies have shown that the values of the constants $\mathrm{V}_{\mathrm{O}}$ and $\mathrm{n}$ can be related to the SVI of the sludge. The most comprehensive was undertaken by Ozinsky and Ekama (1995), who examined the data from nine previous studies, rejecting the data from four as being statistically inadequate. The data from the other five were analysed to produce statistically significant and useful relationships between the sludge settling constants and the associated SVI, DSVI and SSVI values. The main outcomes of their study are set out in Table 4.1.

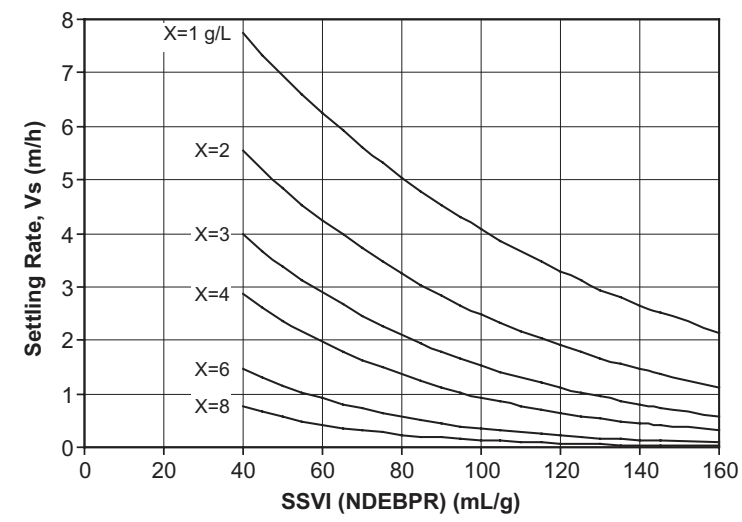

Figure 4.2 Effect of SSVI on sludge settling rate.
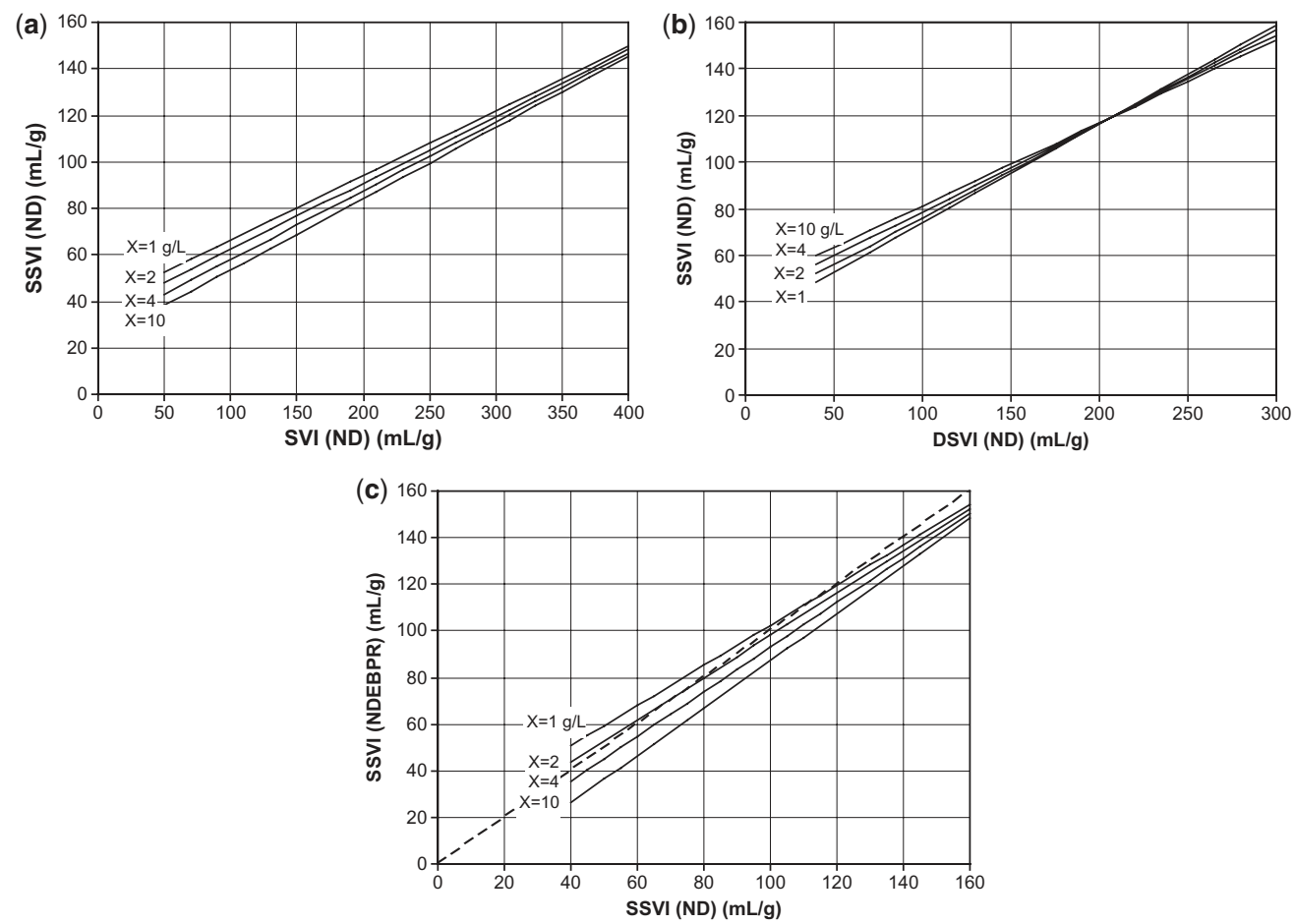

Figure 4.3 Conversions between sludge settleability parameters. 
Figure 4.2 shows the relationship between sludge settling rate and SSVI. Figure 4.3 shows conversions from the other settleability parameters prepared using Equation 4.6 in Table 4.1. Note from Figure 4.3c that there is a small difference between the SSVI data for nitrification denitrification (ND) versus nitrification denitrification excess biological phosphorus removal (NDEBPR) processes, however, given the variable nature of sludge settleability, this is small enough to be ignored for practical purposes within the normal range of MLSS concentration.

Bear in mind that these settling relationships are purely empirical and are not precise (as reflected in the correlation coefficients listed in Table 4.1). Individual plants may have sludge characteristics differing somewhat from the overall mean. One factor which can reduce the settling rates of denitrifying sludges is the formation of gaseous microbubbles within the flocs.

\subsection{FACTORS AFFECTING SETTLEABILITY}

Nearly one hundred years after the activated sludge process was invented (Ardern \& Lockett, 1914a, b), positive prediction and control of SVI remain elusive. SVI is a measure of the relative proportions of zoogleal and filamentous bacteria in the sludge. This depends on their relative growth characteristics which in turn depend on the process operating environment and the concentrations and form (soluble or particulate) of macro- and micronutrients.

There has been considerable research into the types of filamentous organisms and the associated filament lengths affecting settleability. However this has not proven particularly useful from a practical perspective. SVI changes at the same time as the filament length so microbiological monitoring does not provide useful early warning of changes in SVI.

\subsubsection{Non-BNR activated sludge processes}

A range of factors has been reported to affect settleability in activated sludge processes generally, including feed quality, SRT, DO concentration, $\mathrm{pH}$, reactor mixing characteristics, anoxic fraction and chemical dosing (Jenkins et al., 2004; Henze et al., 2008).

\section{Feed quality}

Feed parameters reported to affect SVI include nutrient availability, the level of soluble readily biodegradable COD (discussed below), sulfide level and the presence of industrial wastes; some industrial wastes, carbohydrates for example, are notorious for producing bulking sludge.

\section{Operating parameters}

In short SRT conventional processes DO concentration affects SVI as shown in Figure 4.4. The effect of DO concentration varies with SRT because of the variation of respiration rate with SRT (Figure 3.26). Bacteria within the flocs are supplied with oxygen by diffusion from the bulk liquor. The resulting DO gradient is steeper at higher respiration rates, requiring higher bulk liquor DO concentrations to maintain a particular DO concentration at the centre of the floc. When the interior of the floc is under oxygen stress the filamentous organisms growing from the floc into the bulk liquor have an advantage and become more dominant.

At extremely short SRTs (very high growth rates) bacterial growth becomes more dispersed and floc sizes smaller. SVI therefore becomes less dependent on DO concentration. 


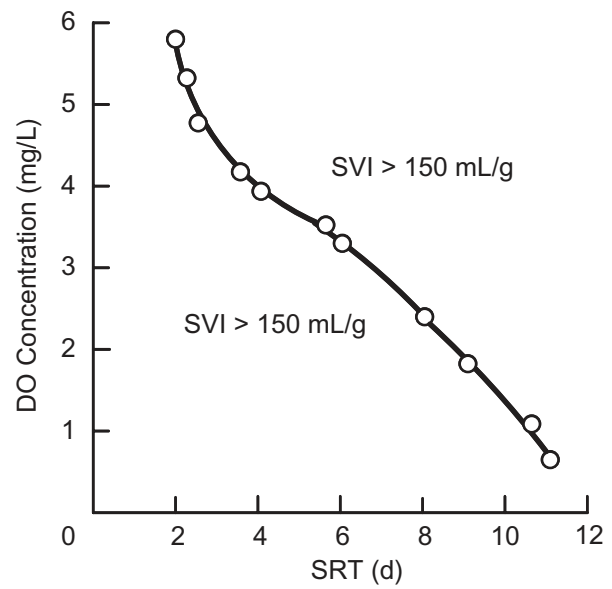

Figure 4.4 DO concentration needed to maintain SVI below $150 \mathrm{~mL} / \mathrm{g}$ in a complete mix aeration basin treating settled municipal sewage (after Palm et al., 1980).

\section{Reactor mixing characteristics}

Continuous flow systems having a low degree of longitudinal mixing (plug flow or a large number of cells in series) are less prone to bulking than complete mix systems, reportedly because the higher substrate concentration at the inlet end of the reactor gives the floc-forming bacteria a competitive advantage over the filamentous bacteria. The use of small compartments (selectors) at the head of the reactor can provide the same effect. Anaerobic, anoxic and aerobic selectors have all been used but are not always successful in providing a low SVI.

\subsubsection{BNR processes}

Sludge settleability in BNR processes seems to be governed predominantly by process anoxic fraction, influent RBCOD and chemical dosing.

\section{Anoxic fraction}

In a study of seven full-scale BNR plants in South Africa, Casey and Alexander (2001) found a significant inverse correlation between average DSVI and process aerobic mass fraction. In these compartmentalised plants the DSVI increased from $61 \mathrm{~mL} / \mathrm{g}$ at an aerobic mass fraction of $76 \%$ to $162 \mathrm{~mL} / \mathrm{g}$ at an aerobic fraction of $44 \%$. Figure 4.5 shows the results.

Hartley and Lant (2010) reported another study of sludge settleability in eight full-scale Australian BNR plants. Process formats covered a wide range including ND, EBPR and NDEBPR in continuous or intermittently decanted formats, with or without primary treatment and prefermentation. None of the plants had chemical dosing to the liquid stream processes. The first part of the study involved analysis of one or two years of routine operating data from six continuous flow, compartmentalised BNR plants. In the second part, the operating regime of two continuous inflow, intermittently aerated and decanted plants was systematically varied over fifteen and eleven month periods and process behaviour monitored. Settleability data were standardised to SSVI where necessary using Ozinsky \& Ekama's relationships. For all eight plants it was found that SSVI increased with primary anoxic mass fraction in a consistent manner. Correlation of SSVI with other process parameters was poor. 


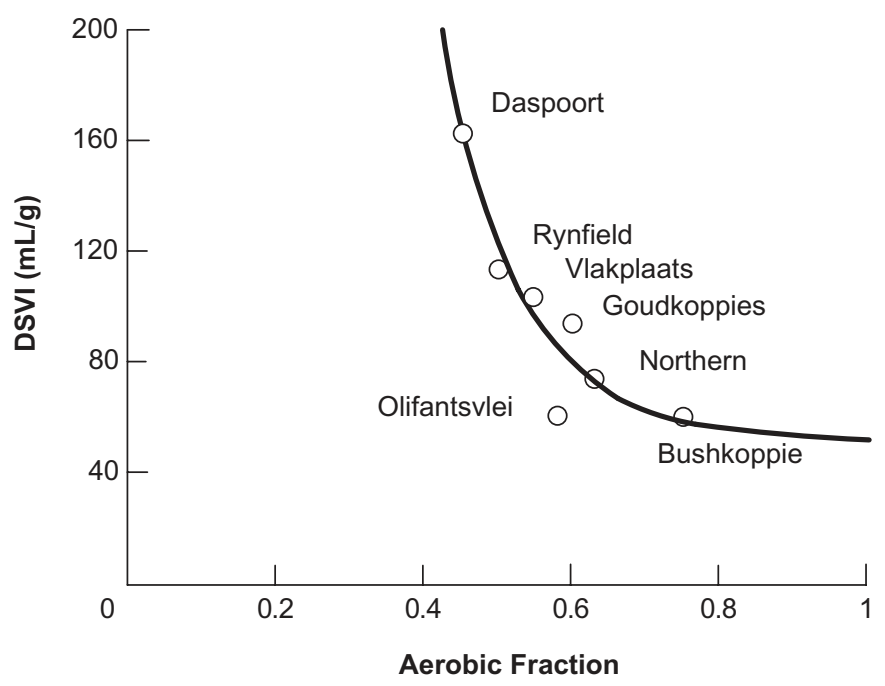

Figure 4.5 Relationship between DSVI and process aerobic mass fraction (after Casey \& Alexander, 2001).

Primary anoxic referred to the anoxic zone or period in which the biomass was mixed with process influent or influent which had passed through an anaerobic zone only. Secondary anoxic referred to an anoxic zone or period fed only with mixed liquor which had already passed through an aerobic zone or period. It was demonstrated in the intermittent plants that secondary anoxic mass fraction (settle and decant phase) had no effect on SSVI.

As an example of the data, Figure 4.6 shows the raw MLSS and SVI trends from one of the six compartmentalised plants. Figure 4.7 shows the excellent correlation between SSVI and primary anoxic fraction for all eight plants. Compartmentalised process formats included ND (one plant), EBPR (one plant, primary anoxic fraction zero), and NDEBPR (four plants). The relationship shown is generally consistent with Casey and Alexander's (Figure 4.5). For each of the compartmentalised plants, variability of the SSVI over the data period, expressed as the ratio of 90:50 percentiles, varied from 1.16 to 1.45 with a median ratio of 1.3 .

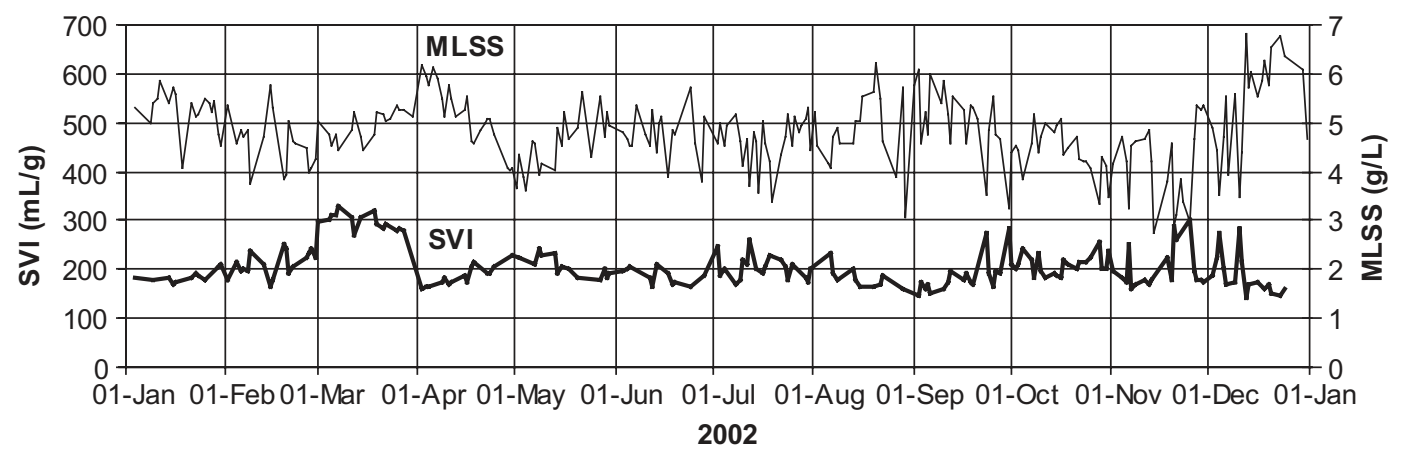

Figure 4.6 Data trends for the Loganholme Stage 5-6 NDEBPR plant. Median values for MLSS, SVI, equivalent SSVI: $4.4 \mathrm{~g} / \mathrm{L}, 195 \mathrm{~mL} / \mathrm{g}, 77 \mathrm{~mL} / \mathrm{g}$. 


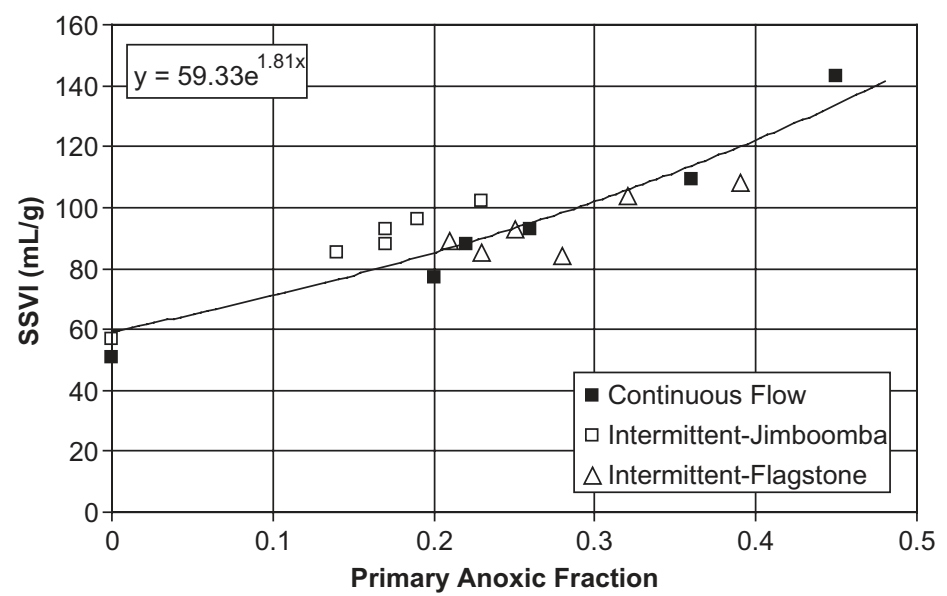

Figure 4.7 Overall correlation of compartmentalised and intermittent plant results.

In a study of full-scale Australian oxidation ditch plants, Hartley (2008) used the effluent ammonia: nitrate ratio as a surrogate for the operating anoxic mass fraction. He found that SSVI was a minimum at an optimum ammonia:nitrate ratio and increased at higher and lower ratios, as shown in Figure 4.8. The optimum ratio varied between plants within the range $0.1-10$ and SSVI could be controlled by appropriate aeration control.

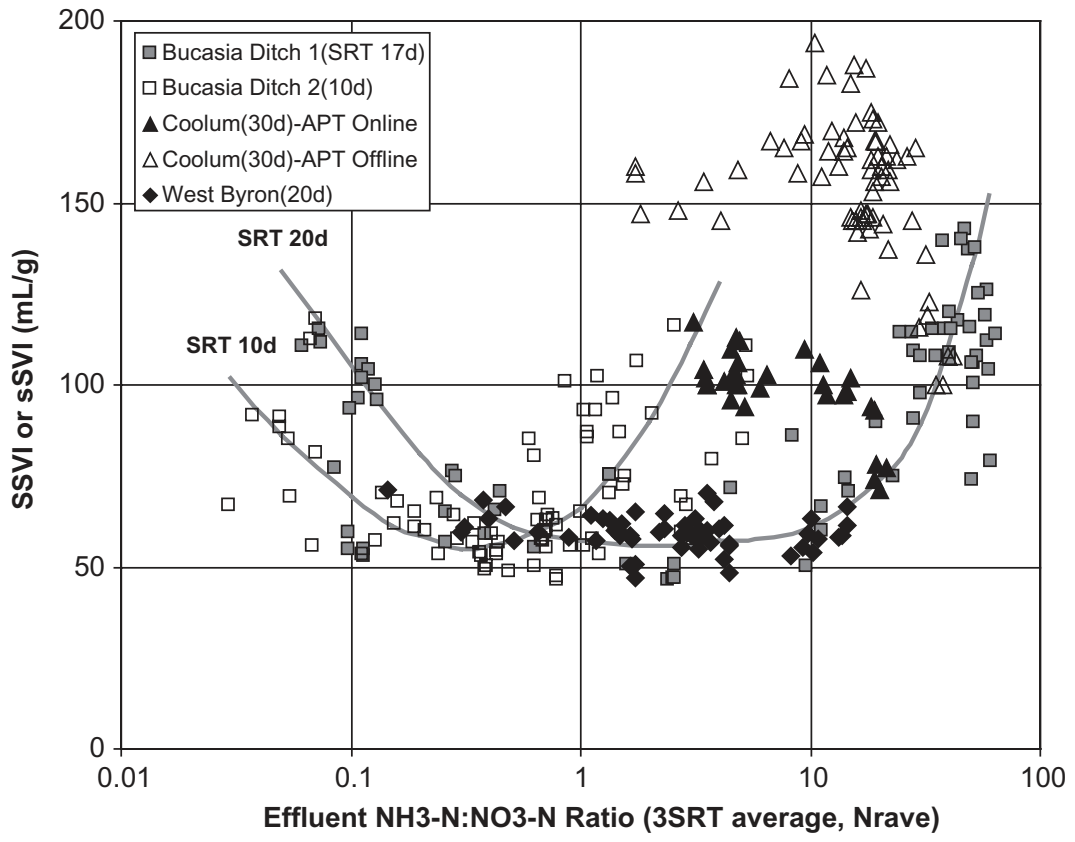

Figure 4.8 Relationship between SSVI and effluent ammonia:nitrate ratio in four oxidation ditches (Hartley, 2008). 
The various data sets have somewhat different correlations because (a) SSVI is also affected by the influent RBCOD fraction (see below), and (b) ammonia:nitrate ratio is affected not just by anoxic fraction, but also by several factors affecting the ammonia concentration; these include SRT, DO concentration in the aerobic zone, $\mathrm{pH}$, temperature and nitrifier maximum specific growth rate (affected by sewage composition).

All of these results show that sludge settleability in the BNR plants studied (compartmentalised, intermittent and oxidation ditch process formats) was governed largely by primary anoxic fraction. This is consistent with the UCT hypothesis, described below, that settleability is related to the biochemistry of denitrification. The oxidation ditch, with a very large recirculation between the aerobic and anoxic zones, appears to differ from the other process formats in that lowest SSVI occurs at some positive anoxic fraction rather than zero.

\section{Influent RBCOD}

For ND and NDEBPR processes, the Water Research Group at the University of Cape Town (UCT) conducted a comprehensive settleability study which they published in a lengthy series of papers and summarised in Ekama et al. (1996) and Casey et al. (1999). They found that the low F/M group of filaments (such as Microthrix parvicella and 0092) caused practically all bulking problems in long SRT nutrient removal processes and that they could not be controlled by anaerobic, anoxic or aerobic selectors. Whether or not the process included biological phosphorus removal, it was the operating nitrogen regime which governed sludge settleability.

According to the model they developed, in a two-stage anoxic-aerobic system utilising mainly slowly biodegradable COD, if denitrification in the primary anoxic zone was incomplete and nitrite was present, the intracellular intermediate nitric oxide persisted and inhibited the denitrifying floc-formers in the aerobic zone. The filamentous organisms, which did not compete well in the anoxic zone because they could only denitrify nitrate to nitrite, were not inhibited in the aerobic zone where they proliferated. Intracellular nitric oxide did not accumulate when the COD was readily biodegradable (RBCOD) so a significant fraction of RBCOD relieved the competitive pressure on the floc-formers.

Data from the Coolum oxidation ditch BNR plant (Figure 4.8) are consistent with this model (Hartley, 2008). The ditch was preceded by an anaerobic reactor (process mass fraction 0.10) for biological phosphorus removal. Because sewage RBCOD was low (RBCOD:total COD about 0.05), an in-line activated primary tank (APT) was provided for prefermentation of the influent. Operating data for the three years 2001-03 are shown in Figure 4.9. For the 20 months 3-Jul-01 to 3-Mar-03 the APT was off-line for maintenance. The sSVI increased when the APT was taken off-line and decreased again when it was returned to service. With the APT on-line and off-line the median sSVIs were 100 and $158 \mathrm{~mL} / \mathrm{g}$ respectively.

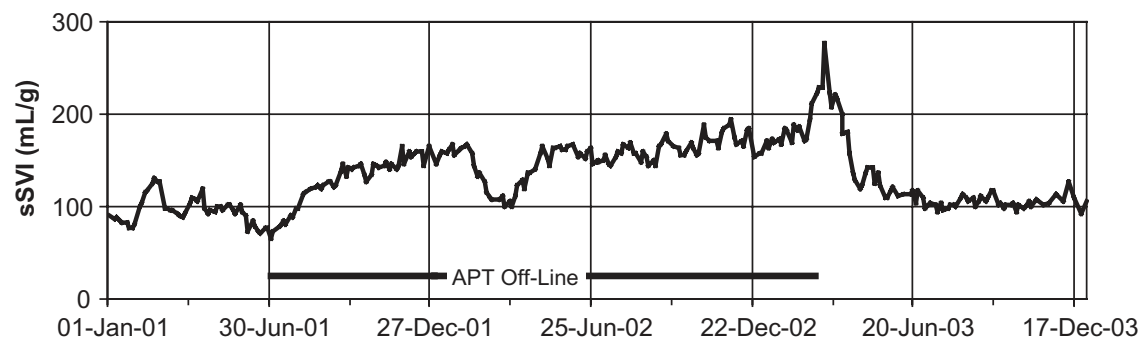

Figure 4.9 Effect of prefermentation on SSVI in the Coolum NDEBPR oxidation ditch process. 
Prefermented influent RBCOD was not measured at Coolum but the RBCOD:total COD ratio monitored in APT effluent at a sister plant at Thorneside (Brisbane) averaged about 0.25 (Hartley et al., 1999; alluded to in Section 3.6.3, Sulfide).

\section{Chemical dosing}

When biological phosphorus removal is supplemented by alum or iron dosing to the mixed liquor, the MLSS concentration increases because of the accumulation of chemical precipitate and simultaneously the SSVI decreases. A useful rule of thumb is that the sludge settling rate is unchanged by chemical dosing.

Figure 4.10 shows the changes in MLSS and sSVI when alum dosing was introduced to the NDEBPR Maroochydore B Plant. After initiation, the dose rate was eased back to achieve the desired effluent phosphorus concentration (not shown). Over a period of about three SRTs the MLSS increased and the sSVI declined. Median data for the period before dosing, and for the eventual period of more or less steady state performance after dosing, are tabulated below the trend plot. The MLSS increased from 4.3 to $5.7 \mathrm{~g} / \mathrm{L}$ while the sSVI fell from 91 to $64 \mathrm{~mL} / \mathrm{g}$. The associated sludge settling rates calculated from the Ozinsky \& Ekama equations are listed, showing that the settling rate was essentially unchanged after the introduction of alum dosing.

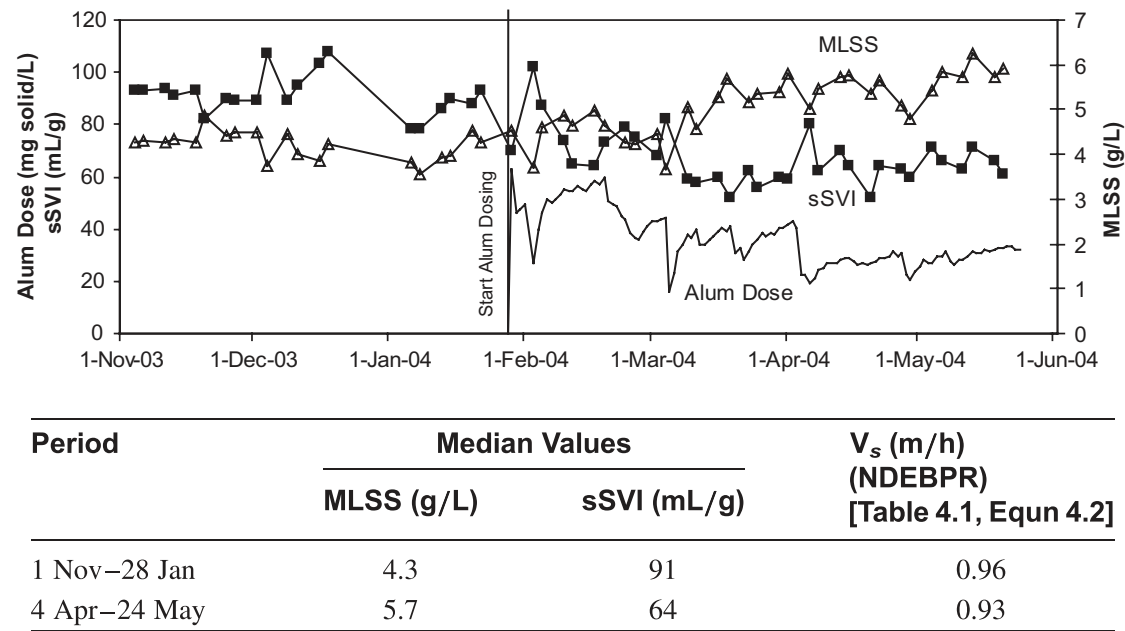

Figure 4.10 Change in MLSS and SSVI with the introduction of alum dosing to the Maroochydore B Plant. Alum is dosed to the mixed liquor, with dose rate expressed relative to the sewage flow. Process SRT was 25 days. The time required for the full effect to occur (29-Jan to 4-Apr) was about 2.7SRTs, consistent with the 3 residence time rule for biomass changes in complete mix systems (see Section 6.1).

\subsection{EFFECT OF SVI ON EFFLUENT QUALITY}

There is a strong relationship between effluent suspended solids concentration and SVI. Flocculation improves as filamentous growth increases, reducing the loss of dispersed solids in the effluent. This is illustrated for three different process types in Figure 4.11. 


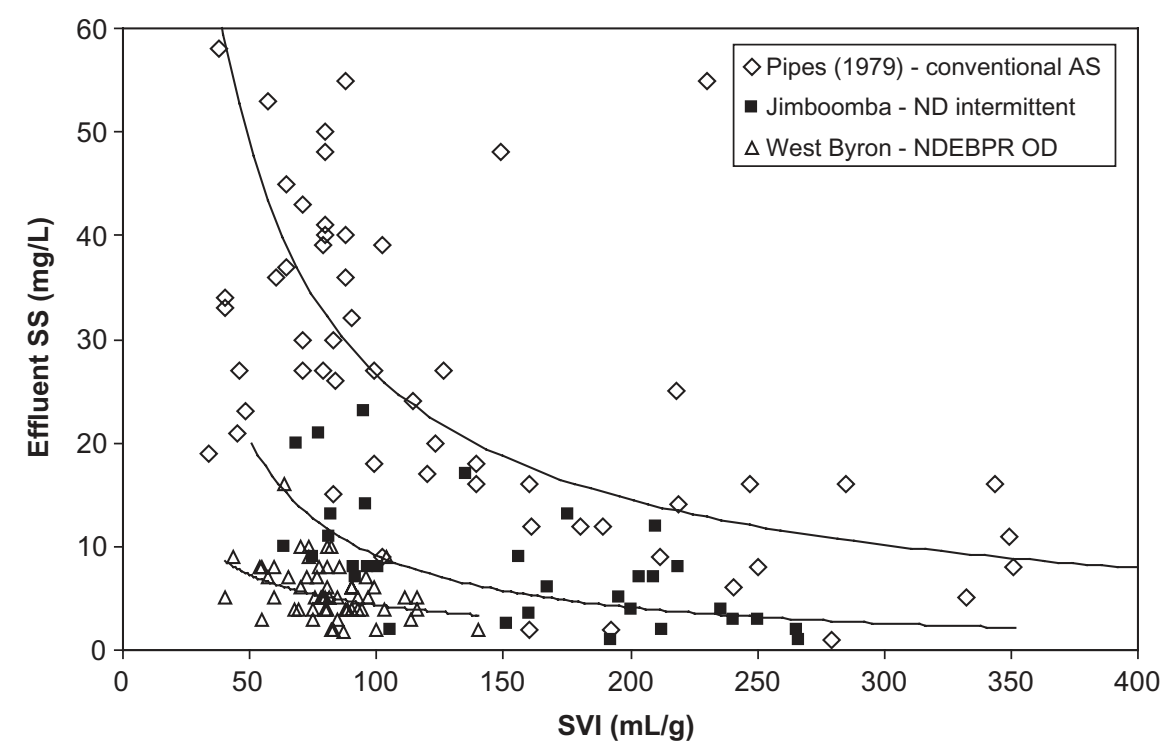

Figure 4.11 Relationship between effluent SS and SVI for three different process types, conventional activated sludge, ND continuous feed intermittent decant (Hartley \& Lant, 2010) and NDEBPR oxidation ditch (Hartley 2008). The oxidation ditch reactor had a median chemical precipitant dosage of $51 \mathrm{mg} / \mathrm{L}$ as solid alum which tended to increase the effluent SS concentration (see Chapter 7, Section 7.4.1).

\subsection{FOAMING}

Foaming is not directly related to settleability but is another sludge characteristic prone to causing operator concern. There is an extensive literature on this subject (for example, Jenkins et al, 2004) but no universal approach to control.

Foam or scum is commonly formed by the actinomycete group of filamentous bacteria of which Microthrix and Nocardia are two of the most common. These organisms are slow growing heterotrophs mainly restricted to using long chain fatty acids (LCFAs) and lipids (fats) in treatment plants (Andreasen \& Nielsen, 2000). They flourish in BNR plants because they are able to take up and store sparingly soluble LCFAs under anaerobic conditions and are able to grow both anoxically and aerobically. They increase their competitive advantage at lower temperatures when (a) the solubility of LCFAs and lipids decreases further, and (b) predation by rotifers is reduced (Pajdak-Stos \& Fialkowska, 2012).

From a practical perspective:

(1) The concentration of LCFAs and lipids in the process influent varies depending on catchment inputs and the degree of removal by prefermentation upstream of the biological process.

(2) These filamentous organisms have a foam-forming propensity in aerated reactors and there is a dynamic equilibrium between the proportion of foam-formers in the liquid phase and in the surface foam.

(3) This equilibrium varies from time to time, presumably because of changes in bioreactor chemistry caused by changes in process influent quality. As a result the extent of surface foam can vary rapidly as illustrated by the example monitoring results depicted in Figure 4.12. 
(4) The most positive method of foam control is mechanical removal from the surface of both bioreactors and clarifiers. In the reactor, this reduces foam-former numbers in both the surface and liquid phases because of the dynamic equilibrium between the two phases. The SRT of the foam-formers is reduced, enabling their numbers to be controlled.

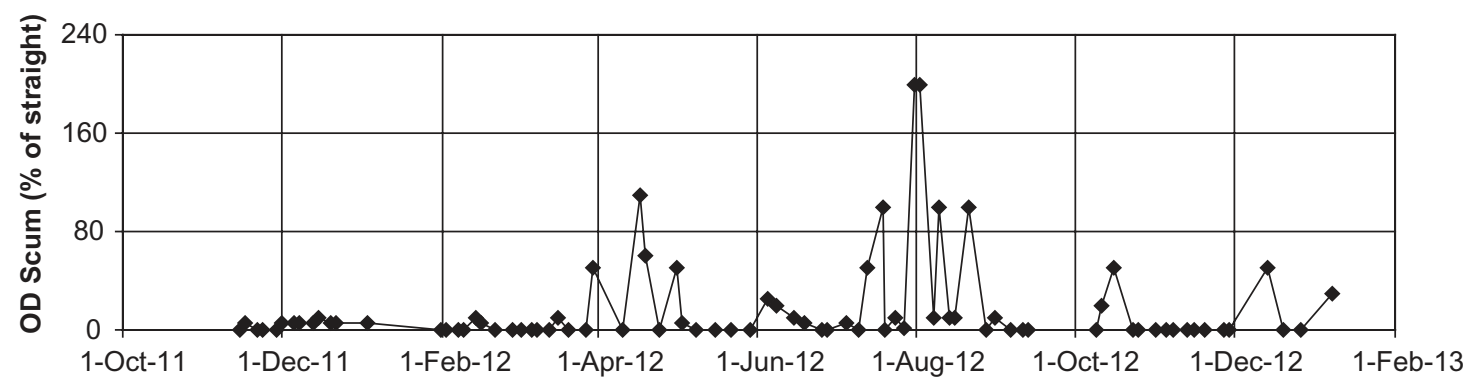

Figure 4.12 Extent of oxidation ditch scum coverage at the Brunswick Valley STP. The chain and flight scum harvester ran for preset periods each day, generally totalling about 40 minutes. Length of channel scum coverage upstream of the harvester was quantified relative to the length of straight channel between the harvester and the first upstream bend (see Figure 6.11). Process SRT averaged approximately 30 days. The behaviour is consistent with the premise of greater scum former advantage in winter. 


\section{Chapter 5}

\section{BNR flowsheets}

The development of biological nutrient removal technology has been marked by a succession of different process flowsheets aimed variously at overcoming limitations, improving performance, making operation simpler or more flexible, minimising cost or differentiating products. The main configurations developed are shown in Figure 5.1 and the logic is explained below.

In these flowsheets the recycle ratios are expressed as:

recycle ratio $=$ recycle flow $/$ influent flow

where

$\mathrm{s}=$ recycle ratio for RAS recycle (or s-recycle)

$\mathrm{a}=$ recycle ratio for mixed liquor recycle (or a-recycle)

$\mathrm{r}=$ recycle ratio for anaerobic recycle (or r-recycle)

Although the flowsheets are drawn for continuous flow processes with separate spatial zones and secondary clarifiers, most of the basic process configurations can be implemented, in whole or in part, as sequential time steps in sequencing batch reactors.

\subsection{NITROGEN REMOVAL}

\subsubsection{Modified Ludzack-Ettinger (MLE)}

See Figure 5.1a. This is the basic nitrogen removal process described in Chapter 3 and shown in Figure 3.20 (Ludzack \& Ettinger, 1962; Barnard, 1973). Given a sufficient anoxic fraction, the mixed liquor recycle ratio limits the degree of nitrogen removal which can be achieved because it sets the proportion of nitrified liquor recycled for denitrification.

\subsubsection{Bardenpho}

See Figure 5.1b. The nitrogen removal performance of the MLE process can be increased by adding secondary anoxic and aerobic zones (Barnard, 1973). COD may be dosed to the secondary anoxic zone. The secondary aerobic or reaeration zone is intended to strip nitrogen bubbles from the floc ahead of the clarifier and oxidise ammonia released by endogenous respiration in the secondary anoxic zone. 


\subsection{PHOSPHORUS REMOVAL}

\subsubsection{Phoredox}

See Figure 5.1c. This is the basic phosphorus removal process described in Chapter 3 and shown in Figure 3.27 (Barnard 1976a). It is also known as the A/O process (for anaerobic/oxic). This process is only viable at low temperatures because it has to be operated in a non-nitrifying mode to protect the anaerobic zone from recycled nitrate.

\subsection{NITROGEN AND PHOSPHORUS REMOVAL 5.3.1 Modified Bardenpho}

See Figures 5.1d and e. N and P removal can be integrated by adding an anaerobic reactor ahead of the primary anoxic reactor in the MLE or Bardenpho processes (Barnard, 1976b). These configurations have become known as 3-stage and 5-stage Modified Bardenpho respectively. The 3-stage process is also known as A2O (for anaerobic/anoxic/oxic).

A disadvantage of the 3-stage process is a propensity for nitrate recycle in the RAS, reducing the effectiveness of the anaerobic zone. This is overcome in the 5-stage process by removal of the residual nitrate in the secondary anoxic zone (to which COD may be dosed).

\subsubsection{Johannesburg (JHB)}

See Figure 5.1f. When full $\mathrm{N}$ removal is not required, an alternative method of protecting the anaerobic zone of a 3-stage process from recycled nitrate is to add an anoxic reactor to the RAS recycle (which supplements the sludge mass in the secondary clarifier). This approach was developed at the Johannesburg treatment plant (Osborn \& Nicholls, 1978). The RAS anoxic reactor is smaller than the secondary anoxic reactor in the 5-stage Modified Bardenpho process because (a) only part of the residual nitrate, that in the RAS stream, has to be denitrified, and (b) the RAS SS concentration is higher than the MLSS concentration.

As shown in Figure 5.1f, the RAS reactor can be implemented as a pre-anoxic zone to which part of the sewage can be fed to enhance RAS denitrification and ensure the anaerobic zone is fully anaerobic.

\subsubsection{University of Cape Town (UCT)}

See Figure 5.1g. The UCT format was developed to enable the anaerobic zone to be positively protected from recycled nitrate over a wide range of loading and operating conditions (Rabinowitz \& Marais, 1980). In this process the RAS is denitrified in the primary anoxic zone and a third r-recycle is fed back to the anaerobic zone. However, the a-recycle requires close control to ensure the anoxic zone is not overloaded with recycled nitrate which will then be recycled to the anaerobic zone.

\subsubsection{Modified UCT (MUCT)}

See Figure 5.1h. The operating flexibility of the UCT process was improved by splitting the primary anoxic zone into two as shown in Figure 5.1h (Siebritz et al., 1982; UCT et al., 1984). This completely separates the nitrogen and phosphorus removal cycles of the process, allowing them to be optimised separately. When operated in a short SRT mode this process has sometimes been called VIP (for Virginia Initiative Plant, Daigger et al., 1987). 


\subsubsection{Westbank}

See Figure 5.1i. A variety of other formats have been used to suit specific circumstances. The Westbank format is an example which was developed in Canada and first applied in the small town of Westbank (USEPA, 2009). It provides a high level of operational flexibility to adjust the process to best suit the actual influent characteristics. It includes prefermentation of primary sludge to enhance the level of RBCOD in the influent. Westbank is basically a Johannesburg process with step feed of influent to the pre-anoxic, anaerobic and primary anoxic zones. The fermented primary sludge stream can be fed to the anaerobic zone either directly or after separation of the solids for separate processing. The step feeds can be adjusted to optimise nitrogen and/or phosphorus removal and to protect the anaerobic zone from storm flows.

The primary clarifier and sludge fermenter can be replaced by an activated primary tank (APT) combining both clarification and sludge fermentation (Barnard, 1984; Hartley et al., 1999).

\subsubsection{Membrane Bioreactor (MBR)}

See Figure 5.1j. In all of the preceding formats there is a sludge fraction in the clarifier which acts like the RAS anoxic zone in the Johannesburg process. In the MBR the membranes replace the clarifier and most commonly they are submerged in the sludge. The effluent is referred to as permeate. For high levels of nitrogen removal the membranes need to be placed in a separate membrane zone which is usually highly aerobic due to aeration used for membrane cleaning. The membrane zone therefore forms a secondary aerobic zone and the membrane recycle (equivalent to the RAS in the clarifier formats) is usually directed to the primary aerobic zone to protect the primary anoxic zone from the high DO recycle.

The membrane recycle ratio also tends to be quite high, 4 say, to minimise the overall process volume by minimising the difference in MLSS concentration between the membrane zone and the upstream zones.

In a similar way, membranes can be incorporated in any of the BNR formats. In all formats which include a secondary anoxic zone the primary aerobic zone upstream can incorporate a de-aeration zone to reduce the dissolved oxygen concentration in the anoxic zone feed.

(a) MLE

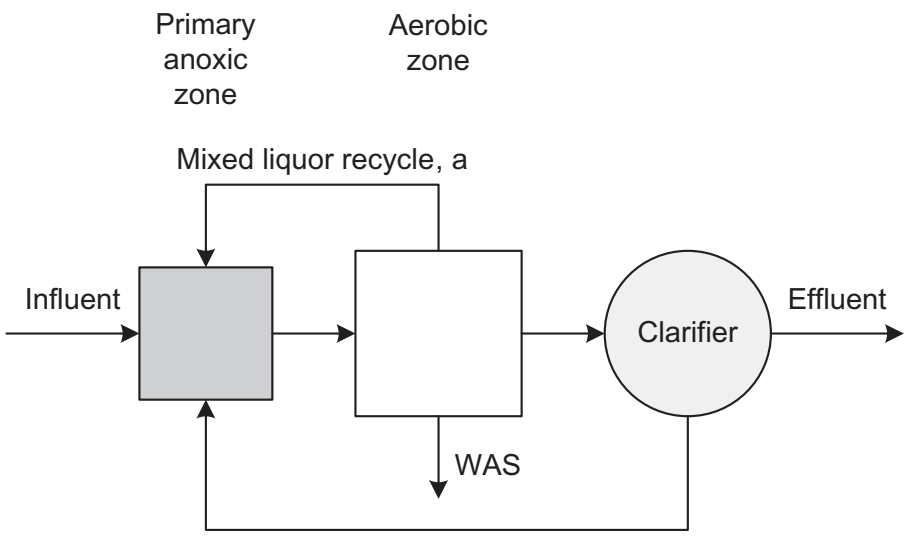

RAS recycle, $s$

Figure 5.1 The major BNR flowsheets. Other combinations and variants are also in use. 
(b) Bardenpho

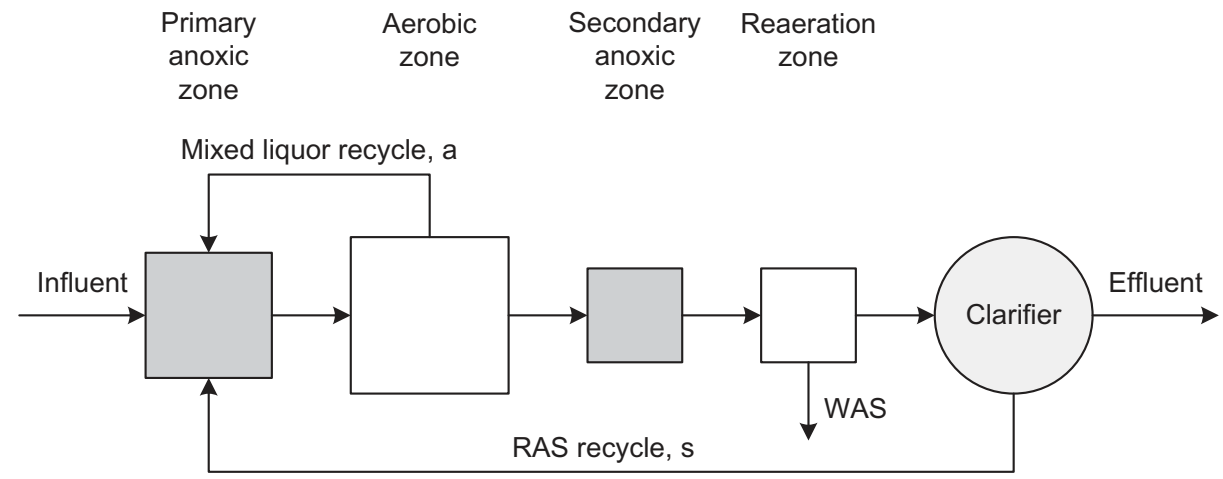

\section{PHOSPHORUS REMOVAL}

(c) Phoredox

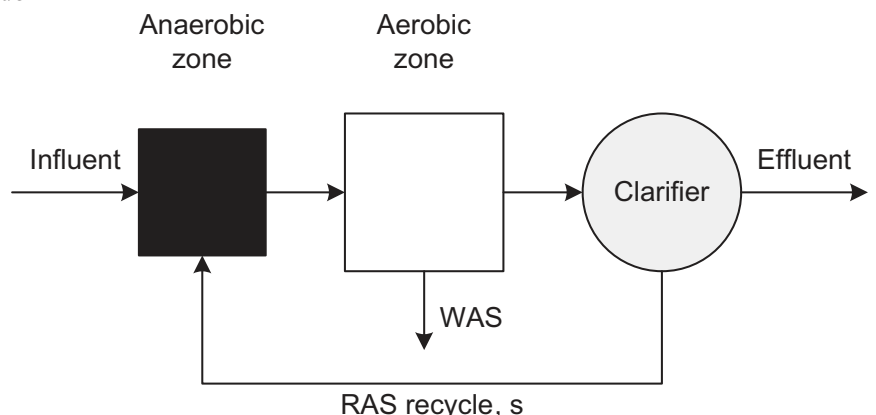

\section{NITROGEN \& PHOSPHORUS REMOVAL}

(d) 3-Stage Modified Bardenpho

$\begin{array}{ccc}\text { Anaerobic } & \text { Anoxic } & \text { Aerobic } \\ \text { zone } & \text { zone } & \text { zone }\end{array}$

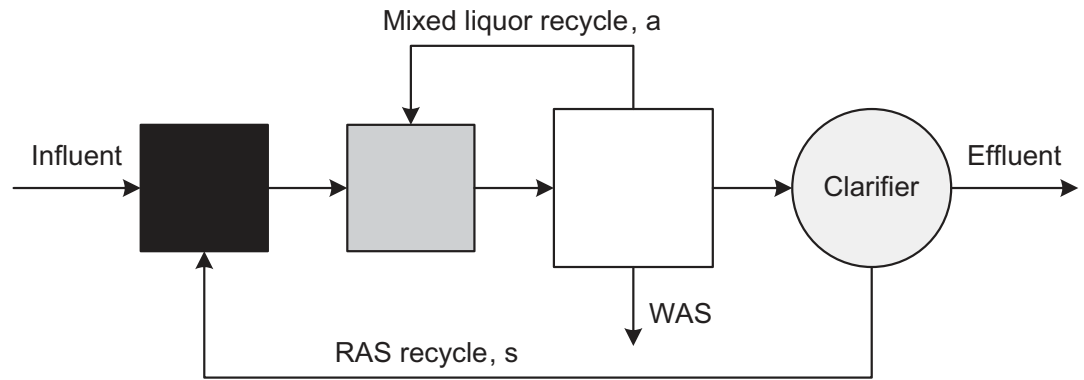

Figure 5.1 The major BNR flowsheets. Other combinations and variants are also in use (Continued). 
(e) 5-Stage Modified Bardenpho

$$
\begin{array}{ccccc}
\text { Anaerobic } & \text { Primary } & \text { Aerobic } & \text { Secondary } & \text { Reaeration } \\
\text { zone } & \text { anoxic } & \text { zone } & \text { anoxic } & \text { zone }
\end{array}
$$

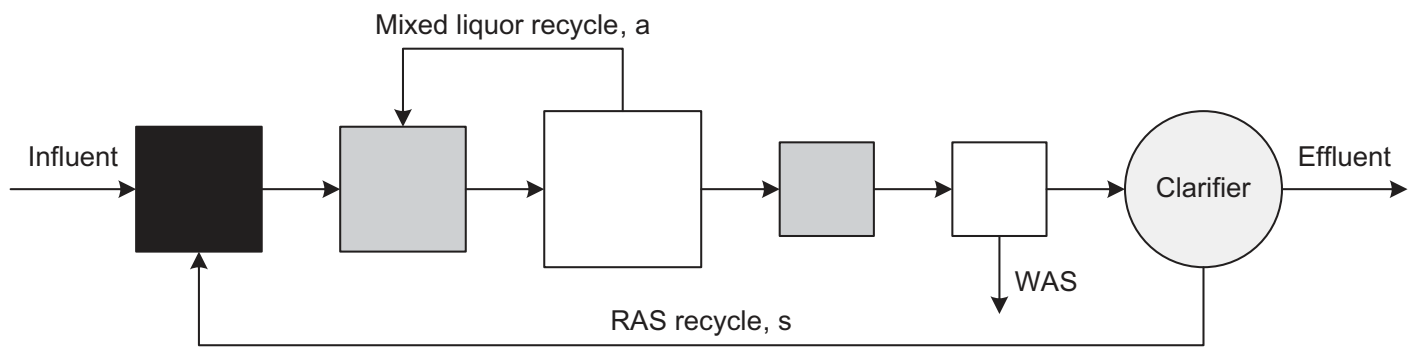

(f) Johannesburg

\begin{tabular}{|c|c|c|}
\hline $\begin{array}{c}\text { Pre-anoxic } \\
\text { zone }\end{array}$ & $\begin{array}{c}\text { Anaerobic } \\
\text { zone }\end{array}$ & $\begin{array}{c}\text { Primary } \\
\text { anoxic } \\
\text { zone }\end{array}$ \\
\hline
\end{tabular}

Influent

Mixed liquor recycle, a

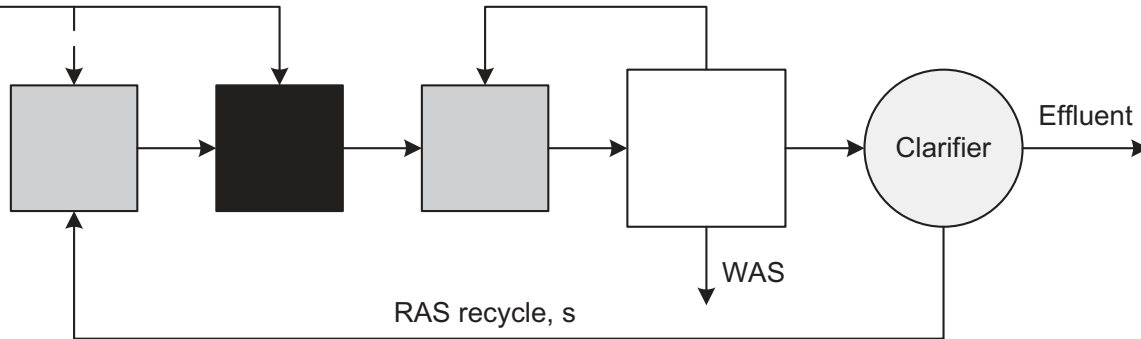

(g) UCT

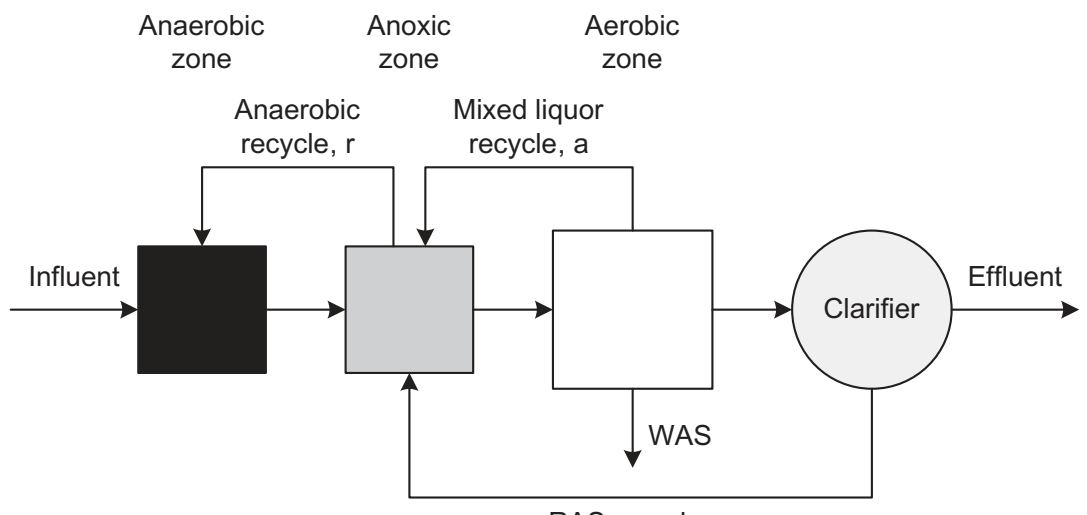

RAS recycle, $\mathrm{s}$

Figure 5.1 The major BNR flowsheets. Other combinations and variants are also in use (Continued). 
(h) Modified UCT

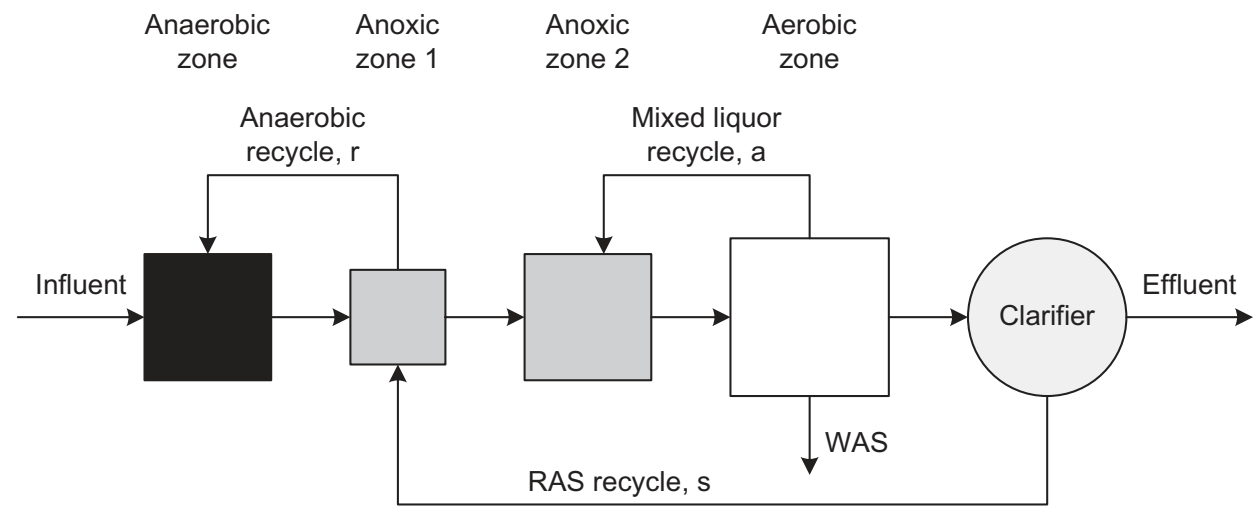

(i) Westbank

$\begin{array}{cccc}\begin{array}{c}\text { Pre-anoxic } \\ \text { zone }\end{array} & \begin{array}{c}\text { Anaerobic } \\ \text { zone }\end{array} & \begin{array}{c}\text { Primary } \\ \text { anoxic } \\ \text { zone }\end{array} & \begin{array}{c}\text { Aerobic } \\ \text { zone }\end{array} \\ & & & \end{array}$

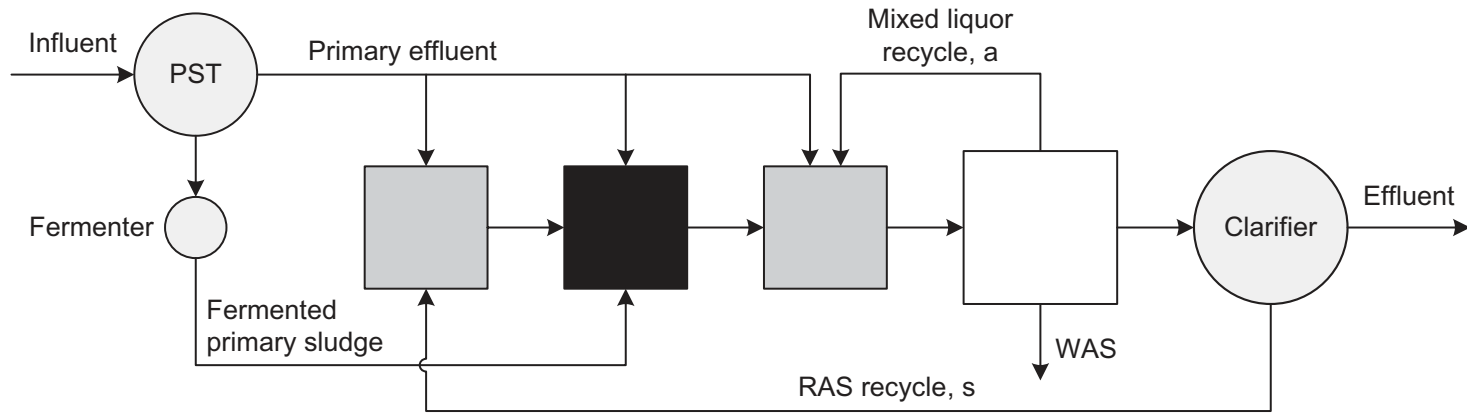

(j) MBR-BNR

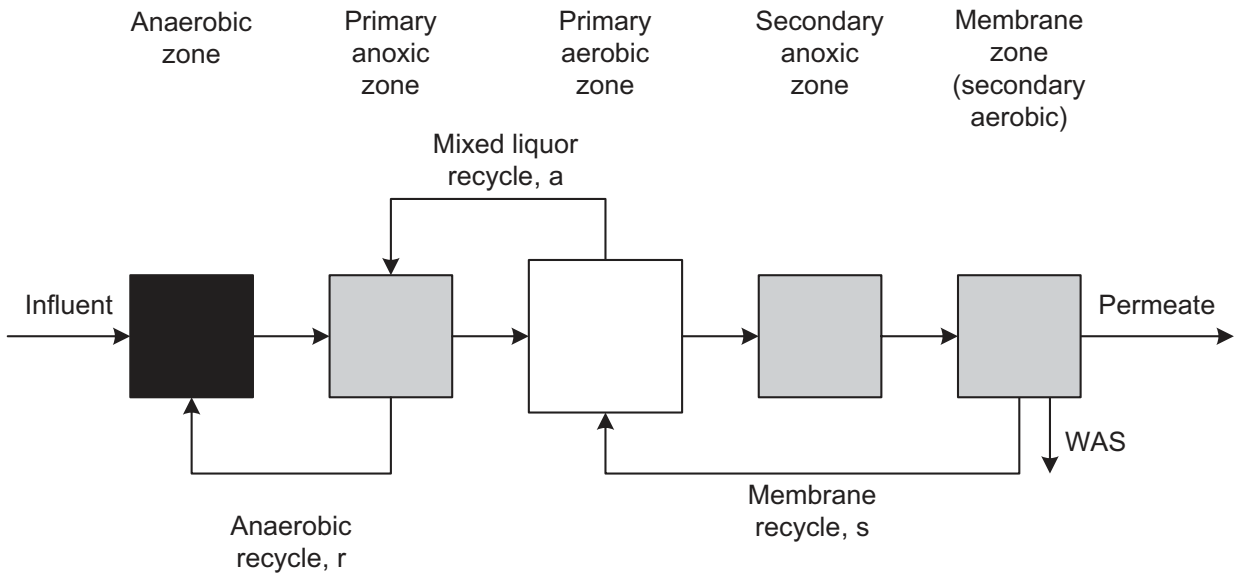

Figure 5.1 The major BNR flowsheets. Other combinations and variants are also in use (Continued). 


\section{Chapter 6}

\section{Reactors}

The biological reactor (or bioreactor) is the heart of the process, where treatment takes place. This chapter looks firstly at reactor mixing and aeration characteristics, and then discusses the basic behavioural characteristics of four major categories of bioreactor-compartmentalised, oxidation ditch, sequencing batch and membrane.

\subsection{MIXING}

Different types of reactors are characterised by their mixing patterns. There are two separate aspects to mixing: mixing regime and mixing intensity. These are discussed in turn.

\subsubsection{Mixing regime}

Mixing regime relates to the residence time distribution (RTD) of water passing through the reactor. There are three different classifications of mixing regime-complete mix, plug flow and arbitrary flow (Levenspiel, 1972).

\section{Complete mix}

In the ideal complete mix reactor the inflow is instantaneously mixed uniformly throughout the whole volume. This type of reactor is commonly depicted as shown in Figure 6.1a. A complete mix reactor therefore has the following properties:

- The reactor contents are of uniform quality throughout.

- The quality of the contents and the quality of the effluent leaving the reactor are identical.

(a)

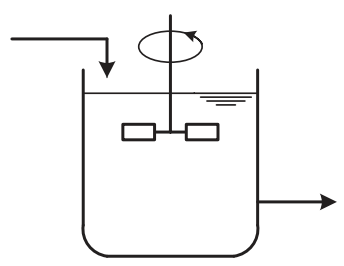

(b)

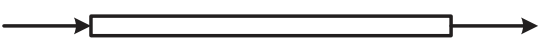

Figure 6.1 (a) Complete mix and (b) plug flow reactors. 
Because the inflow is mixed through the whole volume, some of the influent leaves the reactor with the effluent immediately. On the other hand, because the inflow remaining in the reactor at any time is mixed uniformly, other parts of the inflow remain in the reactor for a very long time. The RTD can be determined by injecting a slug of inert chemical tracer into the inflow, representing a parcel of inflow, and measuring its concentration in the outflow over time. The complete mix RTD is shown in Figure 6.2a.

(a)

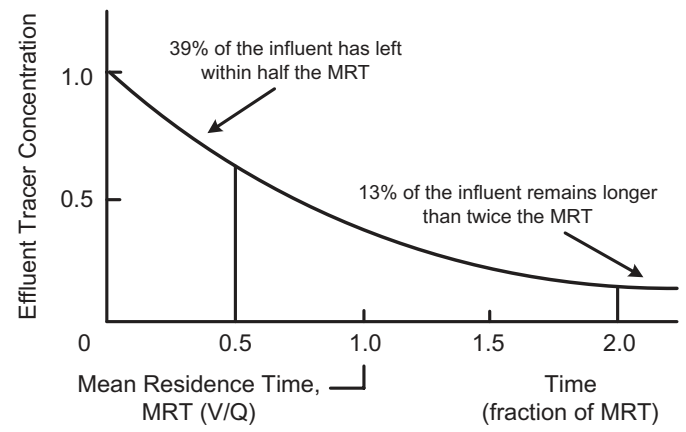

(b)

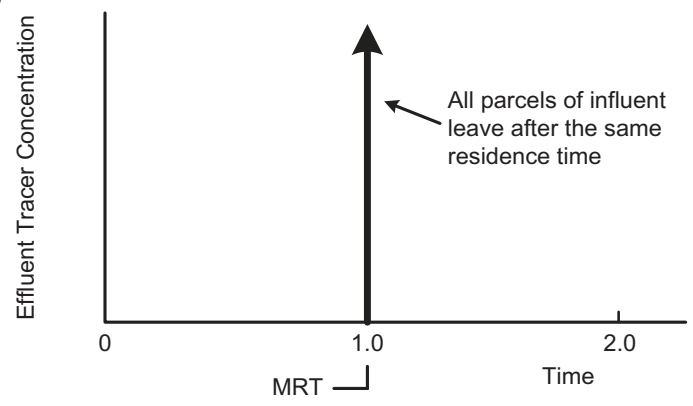

(c)

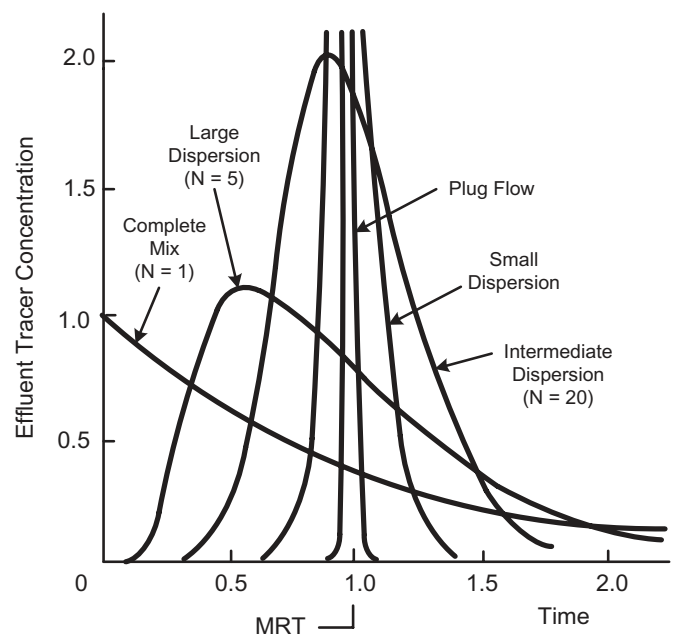

Figure 6.2 Residence time distributions for (a) complete mix, (b) plug flow, and (c) arbitrary flow reactors. $\mathrm{N}$ is the equivalent number of complete mix reactors in series. 
The rates of many process reactions approximate first order kinetics, in which the rate of consumption of a reactant is proportional to its concentration:

$$
\mathrm{dC} / \mathrm{dt}=\mathrm{kC}
$$

where

$\mathrm{C}=$ reactant concentration

$\mathrm{k}=$ rate constant, time $\mathrm{e}^{-1}$

For a first order removal reaction in a complete mix reactor, the steady state effluent concentration of the reactant is given by:

$$
\mathrm{C}_{\mathrm{E}}=\mathrm{C}_{\mathrm{I}} /(1+\mathrm{kt})
$$

where

$\mathrm{C}_{\mathrm{E}}=$ effluent concentration

$\mathrm{C}_{\mathrm{I}}=$ influent concentration

$\mathrm{t}=$ reactor mean hydraulic residence time, $\mathrm{V} / \mathrm{Q}$

$\mathrm{V}=$ reactor volume

$\mathrm{Q}=$ flow rate

\section{Plug flow}

The plug flow reactor is the opposite of complete mix and is depicted in Figure 6.1b. There is no mixing of influent with the reactor contents and all parcels of inflow take the same time to pass through. The RTD for the plug flow reactor is shown in Figure 6.2b.

For a first order removal reaction in a plug flow reactor, the steady state effluent concentration of the reactant is given by:

$$
\mathrm{C}_{\mathrm{E}}=\mathrm{C}_{\mathrm{I}} \mathrm{e}^{-\mathrm{kt}}
$$

where the nomenclature is the same as in Equations 6.1 and 6.2.

A batch reactor has a similar performance characteristic to a plug flow reactor but reaction conditions vary with time rather than space. The batch reactor is filled, reactions take place over time and the reactor is then emptied. As for the plug flow reactor, all parcels of inflow remain within the reactor for the same time.

\section{Arbitrary flow}

The complete mix and plug flow regimes represent the extremes of a range. In between is arbitrary flow, where an intermediate degree of mixing takes place. Typical RTDs are shown in Figure 6.2c. Most real reactors fit into this intermediate category.

Within a continuous flow reactor, the internal mixing which governs the shape of the RTD is referred to as longitudinal dispersion, or backmixing. Similar types of RTDs are produced by placing complete mix reactors in series or by recycling from the outlet to the inlet of a plug flow reactor.

For first order reactions, the effluent concentration from a plug flow reactor is significantly lower than from a complete mix reactor. If a complete mix reactor is subdivided into $\mathrm{N}$ complete mix cells in series 
the effluent concentration, as given by Equation 6.4, approaches plug flow quality for large N:

$$
\mathrm{C}_{\mathrm{E}}=\mathrm{C}_{\mathrm{I}} /(1+\mathrm{kt} / \mathrm{N})^{\mathrm{N}}
$$

where

$\mathrm{t}=$ mean hydraulic residence time of the total reactor

In nutrient removal plants, the two processes most sensitive to the mixing regime are the fermentation reactions within the anaerobic reactor and nitrification within the aerobic reactor. The effect of subdividing the anaerobic reactor is illustrated in Chapter 3, Figure 3.29, while the effect of the aerobic reactor mixing regime on nitrification is illustrated in Figure 6.3. In contrast, denitrification is a zero order reaction over the usual nitrate operating range, meaning that denitrification rate is not affected by nitrate concentration and complete mix conditions are as effective as plug flow. However reactor subdivision is often used to prevent short circuiting under non-ideal mixing conditions.

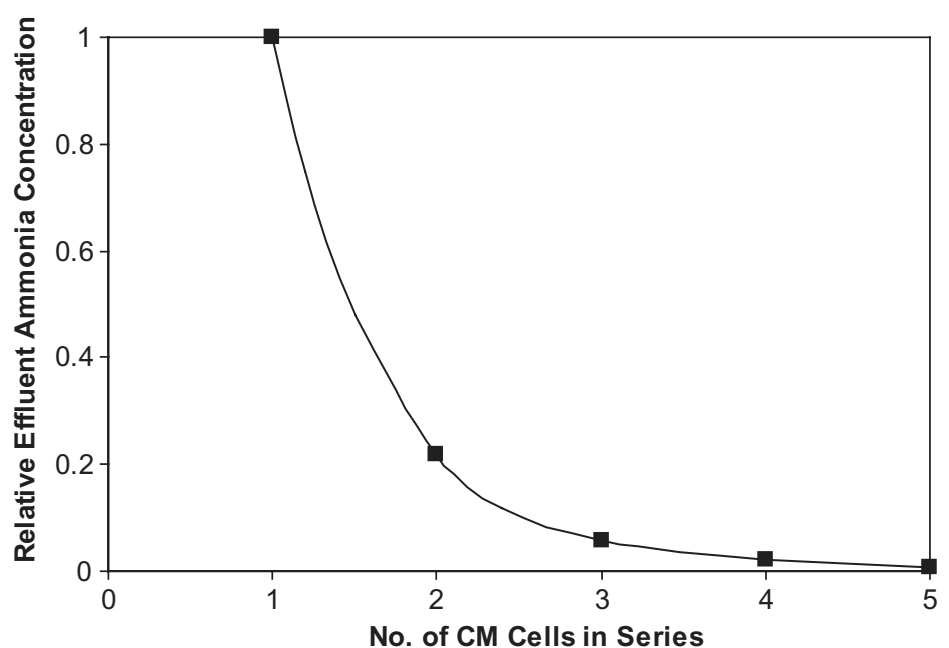

Figure 6.3 Typical effect of subdividing a nitrifying reactor on effluent ammonia concentration.

The complete mix regime has a particular advantage when the plant load is highly variable, due to industrial inputs for example: complete mix reactors provide resilience to shock loads because the biomass is exposed only to effluent-level, rather than influent-level, concentrations. In addition, spatial oxygen demand is uniform in complete mix reactors but varies in plug flow reactors.

Poor mixing occurs in various ways, the most common being dead (inactive) volume, partial short circuiting (bypassing) around the active volume and internal recirculation. Tracer testing can be used to determine the actual mixing characteristics of a plant reactor (Levenspiel, 1972; Monteith and Stephenson, 1981). Practical operational targets for a complete mix reactor could be set at, for example: active volume fraction $>90 \%$, bypass flow $<5 \%$. Guidelines for the conduct of a tracer test are set out in Table 6.1. 
Table 6.1 Tracer testing guidelines.

1. These guidelines relate to the testing of a simple flow-through reactor. More complex flow patterns require special consideration.

2. Select an inert tracer which has a low background concentration. Fluorescent tracers used in clean water are not generally suitable in operating sewage treatment plants. Lithium (in the form of $\mathrm{LiOH}$ ) is a common choice but other common elements such as fluoride have also been used. Check that the tracer is not chemically reactive in the test situation, for example, fluoride reacts with aluminium and is not suitable where alum sludge is present.

3. Over the test period, operate the test reactor as close to steady state as possible. Record the flow rate over the full test period.

4. Slug dose the reactor feed with sufficient tracer solution to allow accurate measurement of the tracer at $10 \%$ of its initial concentration when uniformly distributed through the reactor volume.

5. Run the test for about 3HRTs (hydraulic residence times). Ideally, collect outflow grab samples at about the following times (percentage of nominal HRT): just before dosing (for background tracer concentration), then $0.5 \%, 2 \%, 7 \%$ then $7 \%$ increments to $0.5 \mathrm{HRT}$, then $13 \%$ increments to $1.5 \mathrm{HRT}$, then $20 \%$ increments to $3 \mathrm{HRT}$, making 30 samples altogether. Record the sample collection times.

6. Analyse the results using a formula applicable to the hydraulic regime. A useful model for a simple reactor with a complete mix active zone is shown below (Monteith \& Stephenson, 1981). The complete mix portion of the results can be analysed using:

$$
\mathrm{C} / \mathrm{C}_{\mathrm{O}}=\left[\left(\mathrm{Q}_{1} \mathrm{~V} / \mathrm{Q}^{2}\right) / \mathrm{t}_{\mathrm{A}}\right] \operatorname{EXP}\left(-\mathrm{t} / \mathrm{t}_{\mathrm{A}}\right)
$$

where $\mathrm{C}, \mathrm{C}_{\mathrm{O}}=$ tracer concentration at time $\mathrm{t} \&$ time zero, and $\mathrm{t}_{\mathrm{A}}=\mathrm{V}_{\mathrm{A}} / \mathrm{Q}_{1}$

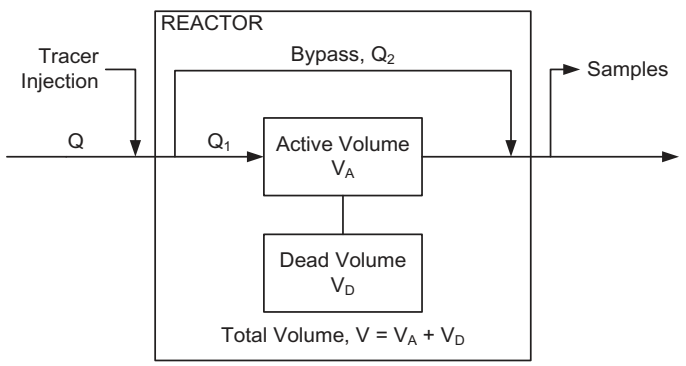

Example test results for an anaerobic digester with a hydraulic jet mixing system are plotted below (20 samples): analysis gives active volume fraction $98.8 \%$, bypass flow fraction $-3.2 \%$, HRT 15.2 days.

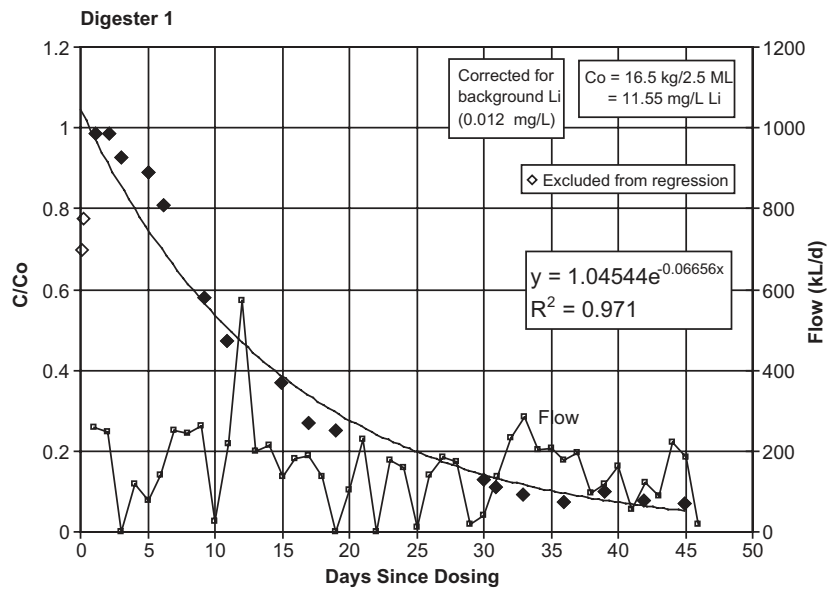




\section{Time constant}

A useful rule of thumb for the response of a complete mix process to a step change in input is illustrated in Figure 6.4. If the process has a conservative steady state input, an alkali dose for example, and a step change in input dose rate occurs, the output responds as shown. At a time equal to the process mean residence time, $\tau$, the change in output reaches $63 \%$ of the ultimate change. At three mean residence times it reaches $95 \%$ of the ultimate. This is the basis for the rule of thumb that when a process change is made, it will take about three residence times for the full effect to become evident.

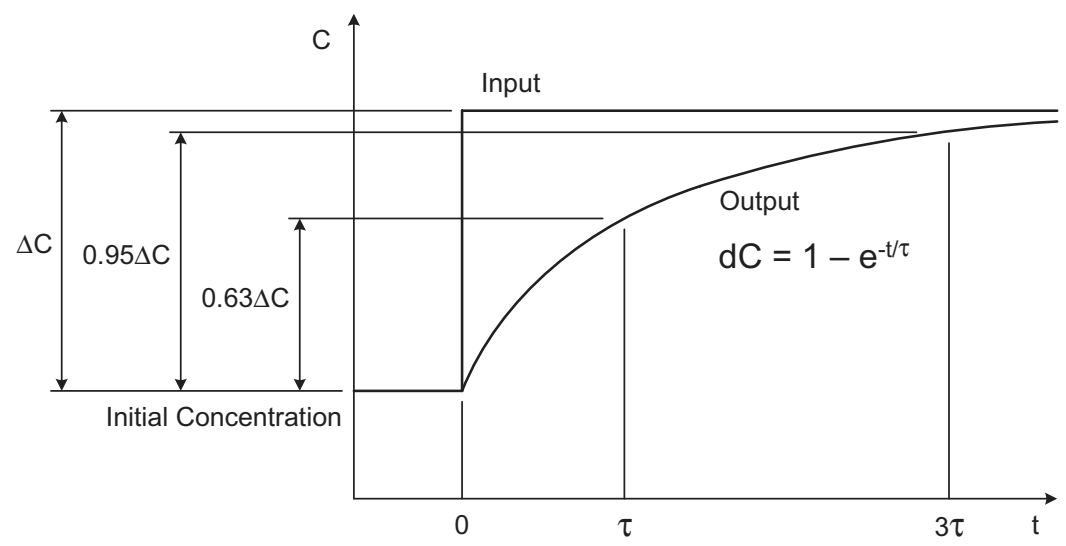

Figure 6.4 Response of complete mix process output to a step change in input.

Although this rule is illustrated here in relation to flow, it will be seen later that it applies in other disparate areas such as the process solids phase and the rate of performance improvement achieved in plant optimisation programs. In non-residence time applications the mean residence time, $\tau$, is referred to as the time constant, equal to the time to achieve $63 \%$ of the ultimate change.

\subsubsection{Mixing intensity}

Mixing intensity is the level of turbulence. There are two separate aspects to mixing intensity in reactors: (a) ensuring the mixed volume is fully active and the biomass (solids phase) is uniformly distributed, and (b) the effect of the associated shear level on flocculation of the biomass.

\section{Active mixing}

Commonly accepted inputs required for active mixing are listed in Table 6.2.

\section{Flocculation}

Activated sludge flocs are complex structures made up of bacteria, organic particles adsorbed from the sewage and inorganic components, all embedded in a cloud of exopolymeric substances (EPS) produced by the bacteria (Biggs, 2000; Wilen et al., 2010). They are considered to have three structural levels (Biggs \& Lant, 2000; Snidaro et al., 1997): individual bacterial cells (size in the order of $1 \mu \mathrm{m}$ ), bacteria tightly bound together by a gel matrix to form microcolonies (median diameter around $13 \mu \mathrm{m}$ ), and 
polymer linkages of microcolonies to form flocs. As described at the start of Chapter 4, the flocs are generally built around a backbone of filamentous bacteria which give them additional strength. The floc particle size distribution is bimodal, with a small unflocculated cell and microcolony group in the 0.5$5 \mu \mathrm{m}$ range and a large particle size group in the 25-2000 $\mu \mathrm{m}$ range (Parker et al., 1971, 1972; Ekama et al., 1997). Sludge settling rate and effluent SS concentration both relate to the particle size distribution of the solids.

Table 6.2 Minimum power inputs for active mixing.

\begin{tabular}{|c|c|c|c|}
\hline Type of system & $\begin{array}{l}\text { Minimum } \\
\text { mixing }\end{array}$ & $\begin{array}{l}\text { Equivalent } \\
\text { power }\end{array}$ & $\begin{array}{l}\text { Equivalent } \\
\text { velocity } \\
\text { gradient (G) }\end{array}$ \\
\hline Unaerated reactors, mechanical mixers & - & $10 \mathrm{~W} / \mathrm{m}^{3}$ & $100 s^{-1}$ \\
\hline Fine bubble diffused air, uniformly distributed & $\begin{array}{c}0.6 \mathrm{~L} / \mathrm{s} \text { per } \mathrm{m}^{2} \\
\text { tank surface }\end{array}$ & $5 \mathrm{~W} / \mathrm{m}^{3}$ & $70 s^{-1}$ \\
\hline Coarse bubble diffused air, spiral flow & $\begin{array}{r}0.3 \mathrm{~L} / \mathrm{s} \text { per } \mathrm{m}^{3} \\
\text { tank volume }\end{array}$ & $\begin{array}{l}10 \mathrm{~W} / \mathrm{m}^{3} \text { in a } \\
4 \mathrm{~m} \text { deep } \\
\text { tank }\end{array}$ & $100 \mathrm{~s}^{-1}$ \\
\hline Mechanical aeration & - & $15 \mathrm{~W} / \mathrm{m}^{3}$ & $120 \mathrm{~s}^{-1}$ \\
\hline \multicolumn{4}{|l|}{ Oxidation ditch } \\
\hline Mechanical aeration & $\begin{array}{l}0.2 \mathrm{~m} / \mathrm{s} \\
\text { circulation } \\
\text { velocity }\end{array}$ & $5-10 \mathrm{~W} / \mathrm{m}^{3}$ & $70-100 s^{-1}$ \\
\hline Diffused air; low speed propellers & $\begin{array}{l}0.2 \mathrm{~m} / \mathrm{s} \\
\text { circulation } \\
\text { velocity }\end{array}$ & $\begin{array}{r}\text { Propellers } \\
2 \mathrm{~W} / \mathrm{m}^{3}\end{array}$ & $50 \mathrm{~s}^{-1}$ \\
\hline
\end{tabular}

The size distribution of the flocs is determined by the turbulence level of their environment. Flocs grow by turbulent aggregation but they also suffer breakage and surface erosion through turbulent shear; for a particular turbulence level a given sludge has a steady state floc size distribution. Using sludge from the Wacol nitrifying-denitrifying plant in Brisbane, Biggs \& Lant (2000) showed that, over a G range of 19$346 \mathrm{~s}^{-1}$, the steady state volume-weighted median floc diameter, $\mathrm{d}$ (in $\mu \mathrm{m}$ ), varied inversely with the velocity gradient, $\mathrm{G}\left(\mathrm{s}^{-1}\right)$, according to:

$$
\mathrm{d}=450 \mathrm{G}^{-0.49}
$$

The 95:50 percentile diameter ratio was about 3 . When diluted sludge samples were first flocculated at various $G$ values (19-113 $\mathrm{s}^{-1}$ ), then deflocculated completely to microcolonies (median diameter $13 \mu \mathrm{m}$ ) by sonication and finally reflocculated at the original $\mathrm{G}$ values, the median floc sizes increased again to their original values, reaching $90 \%$ of their steady state diameters in 25-30 minutes. Repeated sonication and reflocculation gave the same result. Therefore, as the sludge within a plant encounters varying shear conditions, the degree of flocculation will vary; at normal MLSS concentrations (an order higher than the test value) reflocculation after a high-G zone will normally take only a few minutes.

The sludge flocculation characteristics also depend on a range of other conditions which are discussed in Chapter 7, Secondary Clarifiers. 


\subsection{AERATION}

The reactor aerators are the lungs of the treatment process - they transfer oxygen to the water and strip the carbon dioxide produced; the aerators also provide mixing for full reactor utilisation and are one of the plant's major energy consumers.

\subsubsection{Oxygen transfer rate}

Oxygen transfer occurs predominantly by diffusion of oxygen from air bubbles mixed with the water. Aeration performance is measured using two main parameters - oxygen transfer rate $\left(\mathrm{OTR}, \mathrm{kgO}_{2} / \mathrm{h}\right)$ and oxygen transfer efficiency $\left(\mathrm{OTE}, \mathrm{kgO}_{2} / \mathrm{kWh}\right)$. Oxygen transfer rate is proportional to the dissolved oxygen saturation deficit and, in clean water, can be described by the following equation (Metcalf \& Eddy, 2003):

$$
\mathrm{r}_{\mathrm{C}}=\mathrm{dC} / \mathrm{dt}=\mathrm{K}_{\mathrm{L}} \mathrm{a}\left(\mathrm{C}_{\mathrm{S}}-\mathrm{C}_{\mathrm{W}}\right)
$$

where

$$
\mathrm{r}_{\mathrm{C}}=\text { rate of change in concentration, } \mathrm{mg} / \mathrm{L} \cdot \mathrm{h}
$$

$\mathrm{K}_{\mathrm{L}} \mathrm{a}=$ overall oxygen mass transfer coefficient, $\mathrm{h}^{-1}$

$\mathrm{C}_{\mathrm{S}}=$ saturation concentration, $\mathrm{mg} / \mathrm{L}$

$\mathrm{C}_{\mathrm{W}}=$ dissolved oxygen concentration, $\mathrm{mg} / \mathrm{L}$

In an activated sludge system where the biomass exerts an oxygen demand:

$$
\mathrm{r}_{\mathrm{C}}=\mathrm{K}_{\mathrm{L}} \mathrm{a}\left(\mathrm{C}_{\mathrm{S}}-\mathrm{C}_{\mathrm{W}}\right)-\mathrm{r}_{\mathrm{M}}
$$

where

$\mathrm{r}_{\mathrm{M}}=$ rate of oxygen use by the microorganisms, $\mathrm{mg} / \mathrm{L} \cdot \mathrm{h}$

Under steady state conditions the rate of oxygen transfer equals the rate of oxygen utilisation and the DO concentration remains constant. Then $\mathrm{r}_{\mathrm{C}}=0$ and:

$$
\mathrm{r}_{\mathrm{M}}=\mathrm{K}_{\mathrm{L}} \mathrm{a}\left(\mathrm{C}_{\mathrm{S}}-\mathrm{C}_{\mathrm{W}}\right)
$$

Under operating conditions the transfer rate is modified by several factors as follows:

- $\mathrm{K}_{\mathrm{L}}$ a varies with temperature according to:

$$
\mathrm{K}_{\mathrm{L}} \mathrm{a}_{\mathrm{T}}=\mathrm{K}_{\mathrm{L}} \mathrm{a}_{20} \theta^{\mathrm{T}-20}
$$

where

$\mathrm{K}_{\mathrm{L}} \mathrm{a}_{\mathrm{T}}$ and $\mathrm{K}_{\mathrm{L}} \mathrm{a}_{20}=\mathrm{K}_{\mathrm{L}}$ a values at $\mathrm{T}^{\circ} \mathrm{C}$ and $20^{\circ} \mathrm{C}$

$\theta=$ temperature correction factor, 1.024

In practice, the transfer rate does not change significantly with temperature because the change in mass transfer coefficient is almost counterbalanced by an opposite change in saturation concentration. Tables of oxygen solubility can be found in Standard Methods, 1998.

- $\mathrm{K}_{\mathrm{L}}$ a varies with the type of aeration device, reactor geometry, mixing intensity and wastewater characteristics. These aspects are accounted for by the alpha factor:

$$
\alpha=\mathrm{K}_{\mathrm{L}} \mathrm{a} \text { (wastewater) } / \mathrm{K}_{\mathrm{L}} \mathrm{a} \text { (clean water) }
$$


Values of alpha vary with all the factors noted above and can range from 0.3 to 1.2 . Typical values are 0.4 to 0.8 for diffused air and 0.6 to 1.2 for mechanical aeration.

- Fine pore diffusers, both ceramic and membrane, generally suffer from some degree of external fouling by biological slimes and chemical precipitates. Internal fouling can also occur from excessive dust in the airflow or from sludge which enters the piping through leaks during air outages. The reduction in transfer rate resulting from external fouling is accounted for by a fouling factor, F (USEPA, 1989; Hartley, 1990; Hartley \& Gobbie, 1991). The fouling factor is generally applied in conjunction with alpha to give an overall factor, $\alpha \mathrm{F}$.

Fouling increases with time and can vary widely depending on industrial components of the sewage, chemical composition of the mixed liquor, the process SRT, the uniformity of conditions through the reactor and the diffuser characteristics and history. Biological fouling is the most common. Fouling is slower at longer SRT (Rosso \& Stenstrom, 2006). Hartley \& Gobbie (1991) found for three plants that the decline in performance caused by fouling followed a semi-logarithmic relationship. Taking the value of $\mathrm{F}$ as 1 at a service life of one month, they found that each tenfold increase in service time decreased $\mathrm{F}$ by $3-13 \%$. In addition, each doubling of service time increased diffuser pressure loss at constant airflow by $10-38 \%$.

For diffuser pressure loss:

$$
\mathrm{P}=\mathrm{At}^{\mathrm{M}}
$$

where

$\mathrm{P}=$ diffuser element pressure loss, $\mathrm{kPa}$

$\mathrm{t}=$ diffuser service time, months

$\mathrm{A}=$ constant equal to pressure loss at a service time of one month, $\mathrm{kPa}$

$\mathrm{M}=$ pressure increase coefficient, $\mathrm{kPa}$ month units

An unpublished study (Hartley, 2002) using data from 32 treatment plants found that the $\mathrm{M}$ value varied from 0.041 to 0.46 as shown in Figure 6.5. A range of ceramic and membrane diffuser types were included but the fouling rate did not correlate with the diffuser material. Fouling rates were highest when the sewage contained a significant organic industrial component (such as abattoir, dairy or poultry wastewaters).

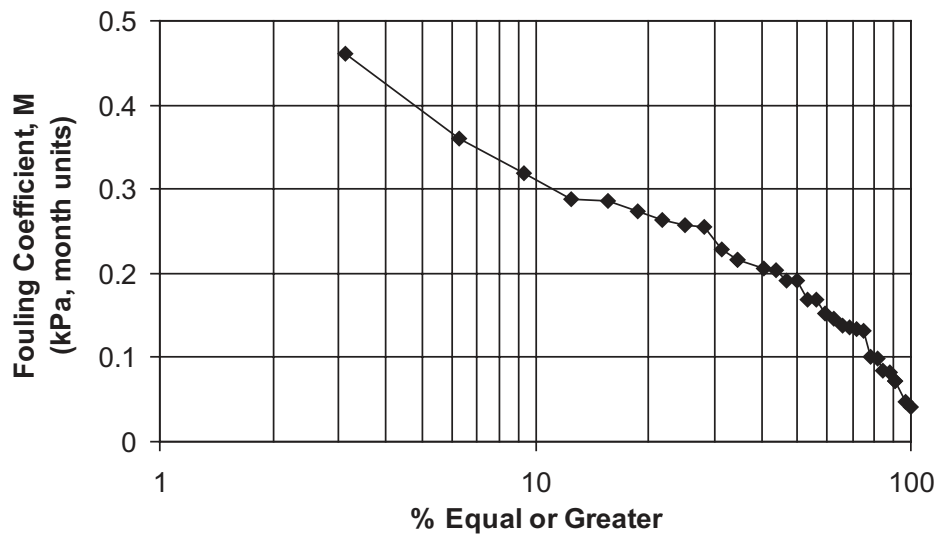

Figure 6.5 Range of diffuser fouling rates. 
- Oxygen saturation concentration varies with the chemical composition of the wastewater. This is accounted for by the beta factor:

$\beta=C_{S}($ wastewater $) / C_{S}($ clean water $)$

The value of beta varies from 0.7 to 0.98 and is commonly assumed to be 0.95 .

- Oxygen saturation concentration also varies with atmospheric pressure. This is of special significance for plants located at high altitude and is accounted for by using an appropriate value of $\mathrm{C}_{\mathrm{S}}$.

Aerator performance is rated at so-called standard conditions, defined as zero DO concentration, $20^{\circ} \mathrm{C}\left(10^{\circ} \mathrm{C}\right.$ in Europe), standard atmospheric pressure $(101.3 \mathrm{kPa})$ and clean water.

The field oxygen transfer rate, OTR, is related to the standard oxygen transfer rate, SOTR, by:

$$
\mathrm{OTR}=\mathrm{SOTR} \alpha \mathrm{F} \theta^{\mathrm{T}-20}\left(\beta \mathrm{C}_{\mathrm{S}}-\mathrm{C}_{\mathrm{W}}\right) / \mathrm{C}_{\mathrm{S} 20}
$$

where

$\mathrm{C}_{\mathrm{S}}=$ oxygen saturation concentration in clean water at operating temperature and pressure $\mathrm{C}_{\mathrm{S} 20}=$ oxygen saturation concentration in clean water at $20^{\circ} \mathrm{C}$ and one atmosphere pressure

For surface aeration the operating pressure is taken as atmospheric pressure. However, for diffused air where the diffusers are submerged at greater than $90 \%$ of the reactor water depth, the tank average saturation concentration corresponds to a water depth of 20-45\% (commonly $40 \%$ ) of the full depth and the operating pressure is taken as the absolute pressure at that depth (US EPA, 1989).

Oxygen transfer rate is controlled by varying the power input to keep the DO concentration constant at a set point value. In mechanical aeration systems the impeller immersion, speed or number of impellers operating can be varied while in diffused air systems the air flow is varied. A typical SOTR characteristic for fine pore ceramic dome diffusers is shown in Figure 6.6.
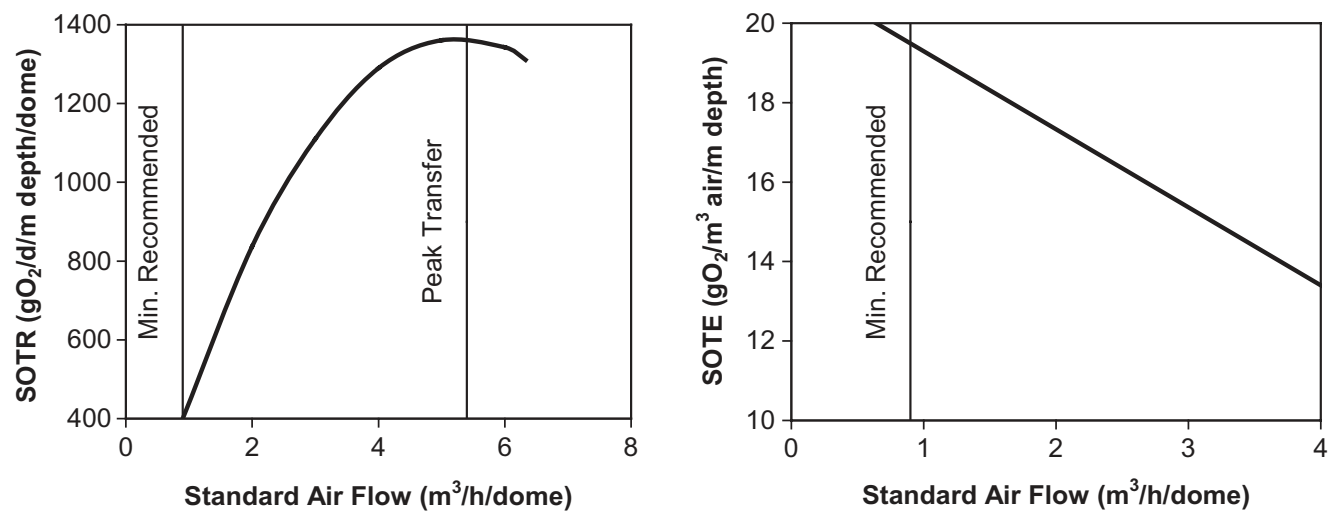

Figure 6.6 Typical performance characteristics for fine pore ceramic dome diffusers (Hartley, 1990). Range of air flow is $6.5: 1$ for a range in transfer rate of $3.4: 1$. SOTE $(\%)=\left(\mathrm{gO}_{2} / \mathrm{m}^{3}\right.$ air $) / 2.77$. 


\subsubsection{Oxygen transfer efficiency}

Two parameters are used to describe oxygen transfer efficiency:

- Standard oxygen transfer efficiency (SOTE), used for diffused air systems to describe the percentage of oxygen which dissolves in clean water under standard conditions. Under field conditions this is simply called oxygen transfer efficiency (OTE). OTE is greater at higher SRT as oxygen transfer inhibitors such as surfactants are more completely degraded (Rosso \& Stenstrom, 2006). SOTE depends on water depth, air flow rate per diffuser pore (which governs bubble size) and diffuser layout (which governs bubble travel time to the surface). Typical values are 5-8\% per metre depth for fine bubble systems and 2-3\% per metre depth for coarse bubble systems (Metcalf \& Eddy, 2003).

- Standard aeration efficiency (SAE), used for both mechanical surface aeration and diffused air to describe energy efficiency $\left(\mathrm{kgO}_{2} / \mathrm{kWh}\right)$ at standard conditions (ASCE, 2007). Typical values (wire to water) are $2 \mathrm{~kg} / \mathrm{kWh}$ for mechanical aeration and up to $4 \mathrm{~kg} / \mathrm{kWh}$ for fine pore diffused air.

Typical performance characteristics for fine pore ceramic dome diffusers are shown in Figure 6.6. Note that air at $20^{\circ} \mathrm{C}$ and standard atmospheric pressure has a density of $1.20 \mathrm{~kg} / \mathrm{m}^{3}$ and its oxygen content is $23 \%$ by mass $\left(276 \mathrm{gO}_{2} / \mathrm{m}^{3}\right.$ air).

Fine pore diffusers need periodic cleaning to restore aeration capacity and reduce energy consumption. A study of three plants using ceramic diffusers (Hartley, 1990; Hartley \& Gobbie, 1991) concluded that refiring was the most effective cleaning technique, and provided sufficient blower capacity was available, the most economic cleaning interval was 5-10 years. For plants using membrane or sintered plastic diffusers which could be cleaned satisfactorily by hosing, Rosso \& Stenstrom (2006) concluded that annual cleaning was the most economic. Blower power and diffuser back-pressure should be monitored to track the degree of fouling.

\subsubsection{Carbon dioxide stripping}

The mixed liquor $\mathrm{pH}$ is governed by the concentration of dissolved carbon dioxide produced by COD oxidation as explained in Section 3.8. Carbon dioxide is stripped by the aeration air bubbles. However, the stripping rate and therefore the mixed liquor $\mathrm{pH}$ varies with the airflow rate which is governed by the oxygen transfer efficiency. The net effect on $\mathrm{pH}$ is illustrated in Figure 6.7. The figure shows the effect of diffused air oxygen transfer efficiency on $\mathrm{pH}$ for a range of influent total alkalinity:COD ratios for both sewage and primary effluent. The sewage lines are drawn assuming full nitrification and denitrification; however for primary effluent it is assumed only $60 \%$ of the nitrate is denitrified due to the higher TKN:COD ratio (see Figure 3.21). Observations are as follows:

- Reactor $\mathrm{pH}$ falls as oxygen transfer efficiency increases and as feed alkalinity decreases.

- Reactor $\mathrm{pH}$ is lower with primary treatment because of the decrease in alkalinity recovery associated with denitrification.

- Alkalinity dosing required to increase $\mathrm{pH}$ can be determined from the graph.

Mixed liquor leaving the reactor is still supersaturated with carbon dioxide and $\mathrm{pH}$ rises through the clarifiers due to further stripping from the surface and effluent weirs. At loads below plant capacity it may be possible to increase mixed liquor $\mathrm{pH}$ by reducing the number of diffusers operating. This increases the air flow per diffuser, reducing transfer efficiency and increasing total air flow required (Figure 6.6).

Mechanical aerators have lower oxygenation efficiencies (higher effective air flows) than fine pore diffused air and will generally operate towards the left hand side of the $\mathrm{pH}$ graph. 


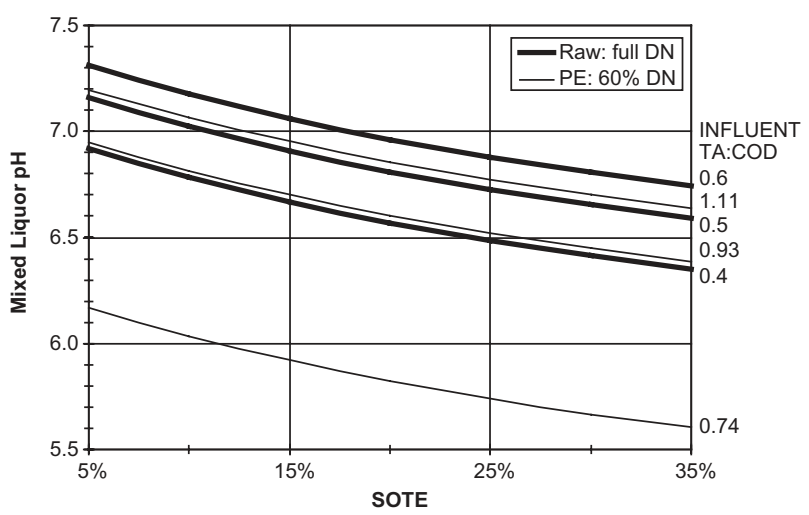

Figure 6.7 Effect of oxygen transfer efficiency on reactor $\mathrm{pH}$. Lines are shown for reactors treating raw sewage or primary effluent. For raw sewage, nitrification and denitrification are complete; for primary effluent, nitrification is complete but denitrification is only $60 \%$ complete. For each influent there are three lines representing different influent alkalinities (native alkalinity plus any alkali dosing); the primary effluent alkalinities are the same as the raw sewage values and the TA:COD ratios shown represent $46 \%$ COD removal by primary treatment. The typical sewage and primary effluent qualities listed in Table 2.4 have been used in the preparation of this figure.

\subsection{COMPARTMENTALISED REACTORS}

\subsubsection{Description}

Compartmentalised reactors separate the various process steps into individual compartments generally as reflected in the BNR flowsheets in Chapter 5. Compartments may range from complete mix to plug flow and are commonly subdivided for control of mixing characteristics. Swing zones and de-aeration zones may be provided. A swing zone is located at the head of the main aerobic zone and can be operated either aerobically or anoxically, providing flexibility to adjust mass fractions. A de-aeration zone is located at the end of the main aerobic zone and operates at low DO concentration to minimise oxygen transfer to both primary and secondary anoxic zones.

Equipment is provided for aeration, mixing, mixed liquor recycling, sludge wasting, scum harvesting and chemical dosing. Instruments may be provided for monitoring and/or control of liquid and air flows, and dissolved oxygen, $\mathrm{pH}$, ammonia, nitrate, phosphate and MLSS concentrations.

This type of reactor can be the most straightforward to operate process-wise but provision of increased operating flexibility generally brings increased process and equipment complexity.

\subsubsection{Process characteristics}

The main operating characteristics of a compartmentalised process are set by the relative volumes of the various zones and the arrangement and magnitudes of the recycles. The recycles are generally arranged to protect the anoxic zones from recycled oxygen and the anaerobic zone from recycled oxygen and nitrate. Where mixed liquor is recycled upstream within the reactor, MLSS concentration will decrease in the same direction.

Tables 6.3 and 6.4 list the equations for calculating MLSS concentrations from recycle ratios and for calculating the actual operating recycle ratios from measured MLSS concentrations. These are needed for effective SRT control. The tables also provide equations for sludge mass fractions which can be varied by adjusting the recycle ratios. Sludge settleability in compartmentalised processes is affected by the primary anoxic fraction (see Chapter 4). 
Table 6.3 UCT \& Modified UCT process balance.

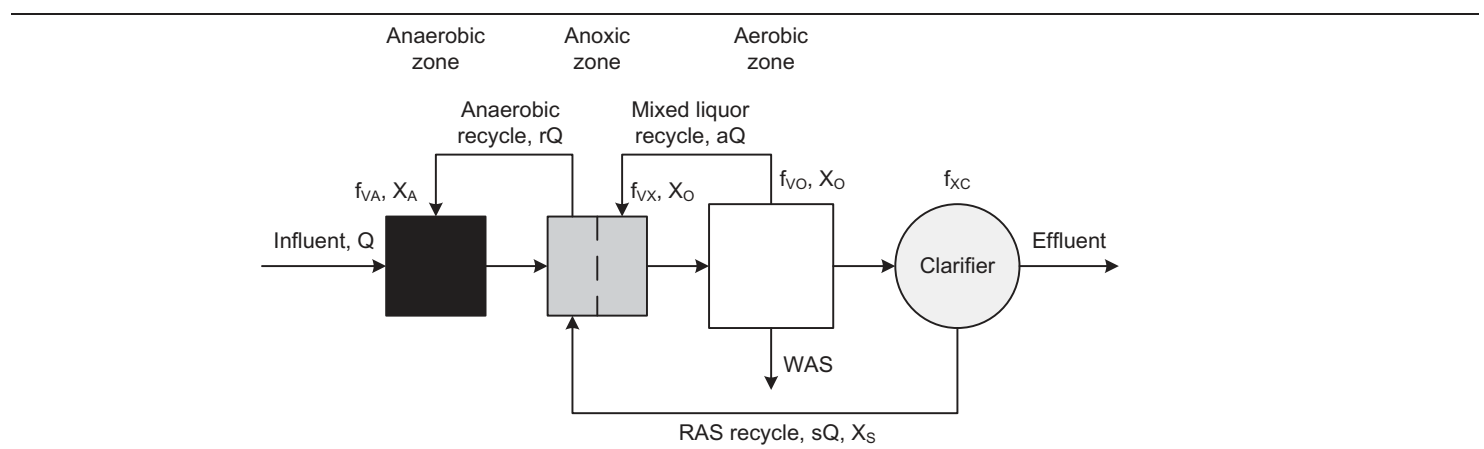

\section{Mixed Liquor Suspended Solids (MLSS) concentrations}

$$
\begin{aligned}
& X_{S}=X_{O}[(1+s) / s] \\
& X_{A}=X_{O}[r /(1+r)]
\end{aligned}
$$

\section{Recycle ratios}

$$
\begin{aligned}
& \mathrm{s}=\mathrm{X}_{\mathrm{O}} /\left(\mathrm{X}_{\mathrm{S}}-\mathrm{X}_{\mathrm{O}}\right) \\
& \mathrm{r}=\mathrm{X}_{\mathrm{A}} /\left(\mathrm{X}_{\mathrm{O}}-\mathrm{X}_{\mathrm{A}}\right)
\end{aligned}
$$

\section{Sludge mass fractions}

$$
\begin{aligned}
& f_{X A}=f_{V A}\left(1-f_{X C}\right)[r /(1+r)] /\left\{f_{V A}[r /(1+r)]+f_{V X}+f_{V O}\right\} \\
& f_{X X}=f_{V X}\left(1-f_{X C}\right) /\left\{f_{V A}[r /(1+r)]+f_{V X}+f_{V O}\right\} \\
& f_{X O}=f_{V O}\left(1-f_{X C}\right) /\left\{f_{V A}[r /(1+r)]+f_{V X}+f_{V O}\right\} \\
& f_{X A}+f_{X X}+f_{X O}+f_{X C}=1
\end{aligned}
$$

\section{Volume fractions}

$$
f_{V A}+f_{V x}+f_{V O}=1
$$

where

$$
\begin{aligned}
a & =\text { mixed liquor recycle ratio relative to } Q \\
r & =\text { anaerobic recycle ratio relative to } Q \\
S & =\text { RAS recycle ratio relative to } Q \\
f_{V A} & =\text { anaerobic zone volume fraction } \\
f_{V O} & =\text { aerobic zone volume fraction } \\
f_{V X} & =\text { total anoxic zone volume fraction } \\
f_{X A} & =\text { anaerobic zone mass fraction } \\
f_{X C} & =\text { clarifier sludge mass fraction, typically in the order of } 0.10 \\
f_{X O} & =\text { aerobic zone mass fraction } \\
f_{X X} & =\text { total anoxic zone mass fraction } \\
Q & =\text { influent flow rate } \\
X_{A} & =\text { MLSS concentration in anaerobic zone } \\
X_{O} & =\text { MLSS concentration in aerobic zone } \\
X_{S} & =\text { RAS SS concentration } \\
X_{X} & =\text { MLSS concentration in anoxic zone }
\end{aligned}
$$


Table 6.4 Westbank \& Johannesburg process balance.

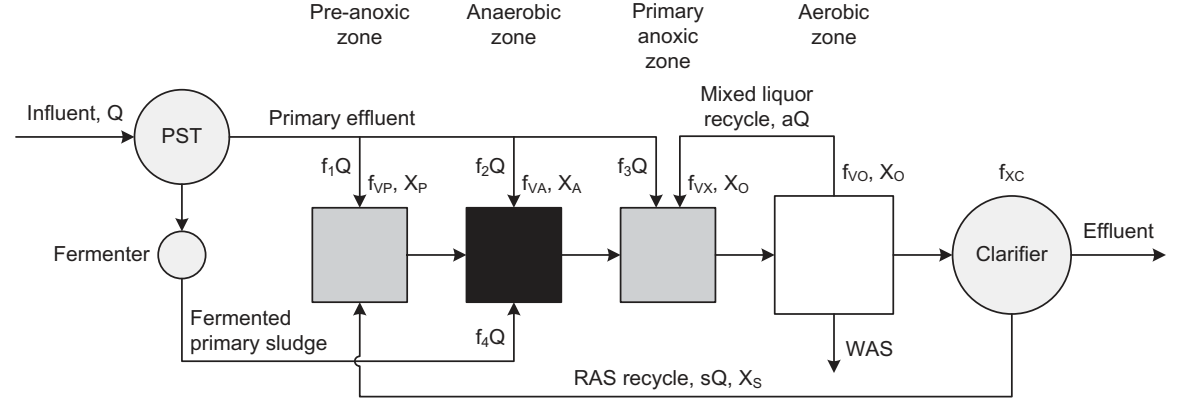

\section{Flow balance}

$f_{1}+f_{2}+f_{3}+f_{4}=1$

Mixed Liquor Suspended Solids (MLSS) concentrations

$$
\begin{aligned}
& X_{S}=X_{O}[(1+s) / s] \\
& X_{P}=X_{O}\left[(1+s) /\left(f_{1}+s\right)\right] \\
& X_{A}=X_{O}\left[(1+s) /\left(f_{1}+f_{2}+f_{4}+s\right)\right]
\end{aligned}
$$

\section{Recycle ratio}

$$
\mathrm{s}=\mathrm{X}_{\mathrm{O}} /\left(\mathrm{X}_{\mathrm{S}}-\mathrm{X}_{\mathrm{O}}\right)
$$

\section{Sludge mass fractions}

$$
\begin{aligned}
& F=f_{V P}(1+s) /\left(f_{1}+s\right)+f_{V A}(1+s) /\left(f_{1}+f_{2}+f_{4}+s\right)+f_{V X}+f_{V O} \\
& f_{X P}=f_{V P}(1+s)\left(1-f_{X C}\right) /\left[F\left(f_{1}+s\right)\right] \\
& f_{X A}=f_{V A}(1+s)\left(1-f_{X C}\right) /\left[F\left(f_{1}+f_{2}+f_{4}+s\right)\right] \\
& f_{X X}=f_{V X}\left(1-f_{X C}\right) / F \\
& f_{X O}=f_{V O}\left(1-f_{X C}\right) / F \\
& f_{X P}+f_{X A}+f_{X X}+f_{X O}+f_{X C}=1
\end{aligned}
$$

\section{Volume fractions}

$$
f_{V P}+f_{V A}+f_{V X}+f_{V O}=1
$$

where

$$
\begin{aligned}
\mathrm{a} & =\text { mixed liquor recycle ratio } \\
\mathrm{s} & =\text { RAS recycle ratio } \\
\mathrm{f}_{1} & =\text { fraction of influent fed to pre-anoxic zone } \\
\mathrm{f}_{2} & =\text { fraction of influent fed to anaerobic zone } \\
\mathrm{f}_{3} & =\text { fraction of influent fed to primary anoxic zone } \\
\mathrm{f}_{4} & =\text { fraction of influent fermented and fed } \\
& \text { to anaerobic zone } \\
\mathrm{f}_{\mathrm{VA}}= & \text { anaerobic zone volume fraction } \\
\mathrm{f}_{\mathrm{VO}}= & \text { aerobic zone volume fraction } \\
\mathrm{f}_{\mathrm{VP}}= & \text { pre-anoxic zone volume fraction } \\
\mathrm{f}_{\mathrm{VX}} & =\text { primary anoxic zone volume fraction }
\end{aligned}
$$

$\mathrm{f}_{\mathrm{XA}}=$ anaerobic zone mass fraction

$f_{X C}=$ clarifier sludge mass fraction, typically in the order of 0.10

$\mathrm{f}_{\mathrm{XO}}=$ aerobic zone mass fraction

$\mathrm{f}_{\mathrm{XP}}=$ pre-anoxic zone mass fraction

$f_{X X}=$ primary anoxic zone mass fraction

$Q=$ influent flow rate

$X_{A}=$ MLSS concentration in anaerobic zone

$\mathrm{X}_{\mathrm{O}}=$ MLSS concentration in primary anoxic and aerobic zones

$X_{P}=$ MLSS concentration in pre-anoxic zone

$X_{S}=$ RAS SS concentration 


\subsubsection{Operating principles}

The basic operating principles are as follows:

(1) Set the daily sludge wasting to maintain the desired SRT. The solids distribution within the reactor and the associated WAS concentration need to be known for this purpose.

(2) Set appropriate DO concentrations in the aerobic and de-aeration zones.

(3) Set appropriate mixed liquor recycle ratios.

(4) For a Westbank type process, set an appropriate feed distribution.

(5) Set appropriate chemical dose rates for secondary denitrification, supplementary phosphorus removal and $\mathrm{pH}$ control.

(6) Monitor performance and adjust process settings as required.

\subsection{OXIDATION DITCHES}

\subsubsection{Description}

The oxidation ditch (OD) is a bioreactor configured like a race track with a recirculating flow pattern. It was invented by Pasveer in the Netherlands in 1954 (Pasveer, 1959; Baars, 1962) as a continuous feed, intermittent decant (CFID) process. The initial plants for small communities were constructed as ditches fitted with floating horizontal shaft brush type aerators and in the original format the reactors are still commonly called Pasveer channels.

The OD reactor format has since developed into four main types:

Pasveer channel: CFID format, also commonly known as IDEA (intermittently decanted extended aeration), used for small communities; no clarifiers.

Horizontal shaft OD: Continuous flow OD fitted with horizontal shaft mechanical aerators for aeration and circulation. Usually has multiple aerobic and anoxic zones. Horizontal shaft aerators are not generally available in powers above $45 \mathrm{~kW}$, which limits the capacity of individual reactors.

Vertical shaft $O D$ : Continuous flow OD fitted with vertical shaft mechanical aerators for aeration and circulation. Vertical shaft aerators are available in powers of up to about $132 \mathrm{~kW}$, allowing larger reactors to be used. These reactors are commonly referred to as Carrousels after the trade name used when the system was originally patented (since expired) by the Dutch inventors, DHV consultants, in the 1960's.

Diffused air OD: Continuous flow OD aerated with diffused air and circulated using large diameter propeller mixers. Generally has one aerobic and one anoxic zone and is more energy efficient. The aeration and circulation rates are independent. There are no equipment constraints on reactor size.

\subsubsection{Process characteristics}

Figure 6.8 illustrates the basic mechanically aerated OD format. Mixed liquor is impelled around the circuit by one or more mechanical aerators. To maintain the biomass in suspension the circulating velocity needs to be a minimum of about $0.2 \mathrm{~m} / \mathrm{s}$ at typical SSVI values. This circulation typically provides a mixed liquor:feed flow ratio in the order of 100. The DO concentration jumps up at each aerator and declines downstream due to the sludge respiration. With zero DO upstream, the DO concentration at the aerator equals the oxygen transfer rate divided by the circulating flow rate. The slope of the DO profile varies with the respiration rate and the anoxic fraction is controlled by varying the aeration rate to maintain a DO set point at a probe located towards the downstream end of the aerobic zone. The anoxic fraction can be varied by adjusting the set point. 

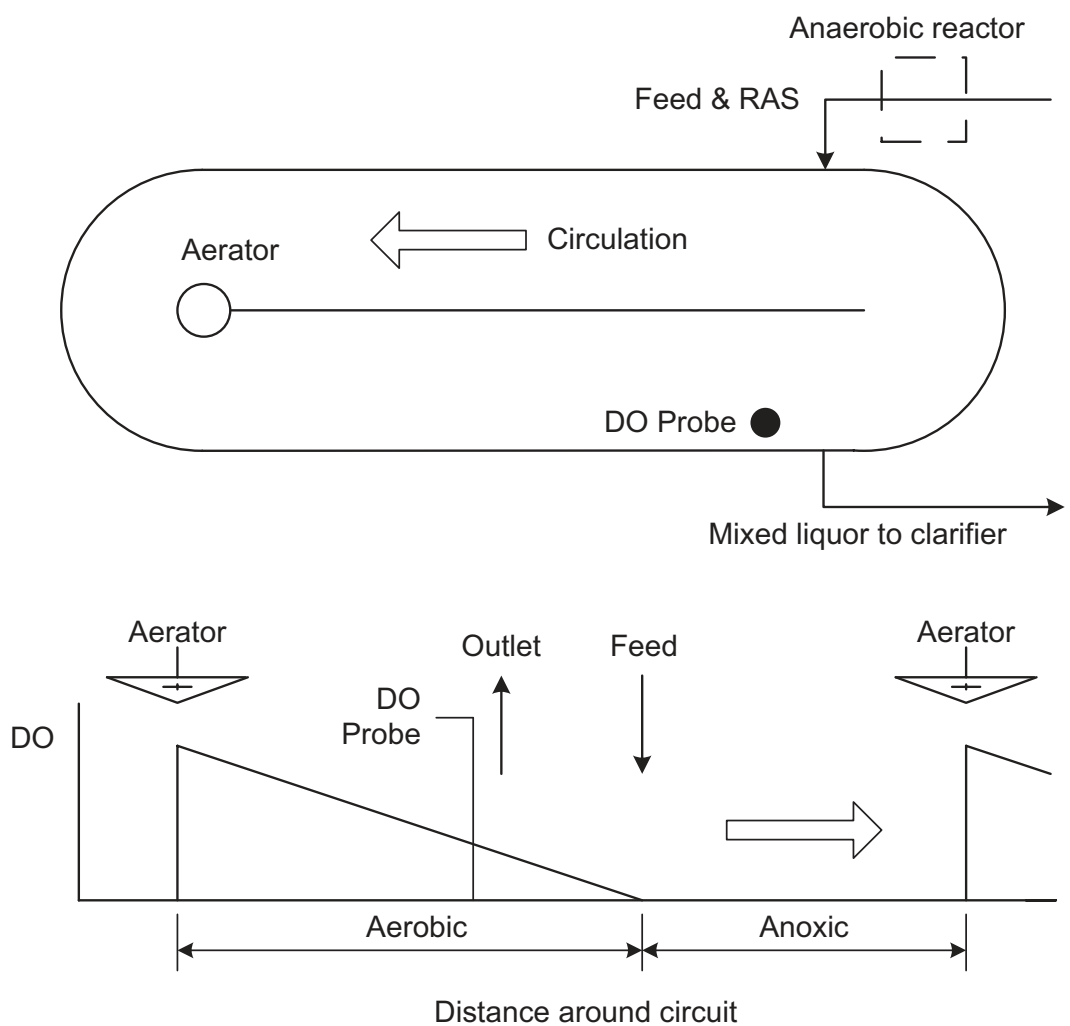

Figure 6.8 Basic oxidation ditch reactor format.

The basic BNR OD process has the 3-stage Modified Bardenpho format as shown in Figures 5.1 and 6.9. The OD circulating flow is the mixed liquor recycle, with a ratio in the order of 100 . Because of the large recycle and the tapering DO profile, the OD can achieve full $\mathrm{N}$ removal without the need for a secondary anoxic reactor. Provided the anoxic fraction is large enough and the influent COD:TKN is sufficient, the minimum effluent nitrate $\mathrm{N}$ achievable is governed by the recycle ratio and is in the order of $0.4 \mathrm{mgN} / \mathrm{L}$ at a recycle ratio of 100 (refer to Figure 3.21; Equation 3.12; Table 2.4). With additional denitrification in the clarifier sludge layer, there is essentially no nitrate recycle to the anaerobic reactor. In addition, because the mixed liquor recycle ratio is so high, the ammonia and nitrate concentrations are almost constant, and equal to the effluent concentrations, throughout the OD circuit.

The anoxic fraction of the OD governs both nitrogen removal and sludge settleability (see Chapter 4). The process nitrogen removal characteristic is illustrated in Figure 6.10 (Hartley, 1997a). There is an anoxic fraction operating window which gives lowest $\mathrm{TN}$ in the effluent. As anoxic fraction increases nitrate decreases while ammonia increases. As a rule of thumb, lowest TN occurs where ammonia and nitrate are equal.

Nitrate is governed predominantly by anoxic fraction and influent TKN:COD ratio with the minimum achievable governed by the mixed liquor recirculation ratio. Ammonia is governed by a range of process factors, primarily aerobic SRT, DO concentration, $\mathrm{pH}$ and temperature. 


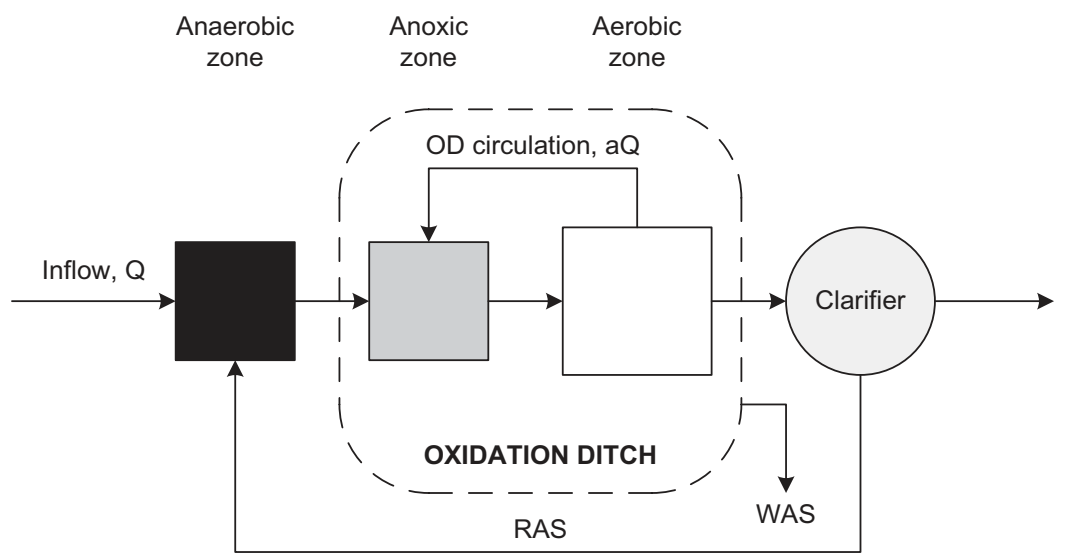

Figure 6.9 OD 3-stage Modified Bardenpho format.
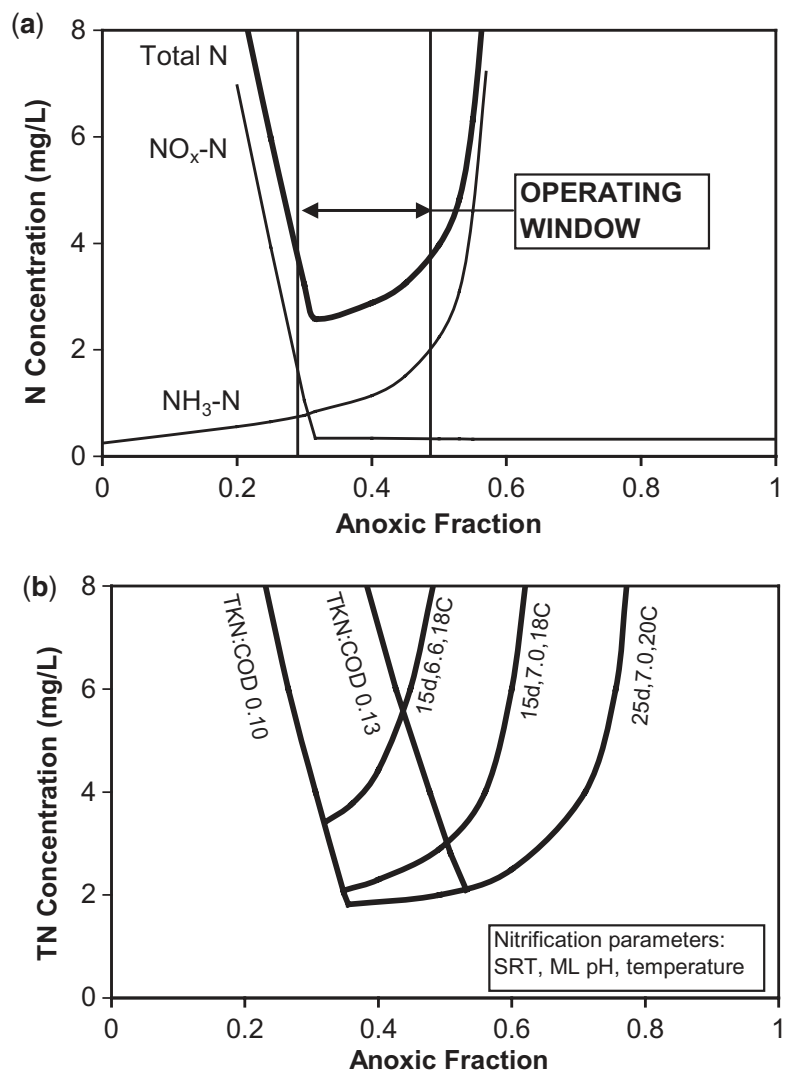

Figure 6.10 (a) OD anoxic fraction operating window concept for producing minimum effluent TN. (b) Effects of influent TKN:COD ratio and nitrification parameters on the width of the operating window and the minimum achievable TN (typical). 
The operating window shifts as operating conditions change. Figure 6.10 illustrates how changes in the ammonia and nitrate limbs affect the window - changing its width, shifting the optimum anoxic fraction, varying the effluent ammonia:nitrate ratio and changing the minimum effluent TN achievable.

Figure 6.11 shows how the anoxic fraction is controlled using the DO set point (SP). The OD shown in this figure is aerated by a uniform diffused air zone. The DO rises through the aeration zone and then declines downstream. The maximum DO at the end of the aeration zone equals the process oxygen demand minus the oxygen consumption within the aeration zone, divided by the circulation flow around the circuit. A short, high-intensity aeration zone and a low circulation rate are desirable to maximise the average DO concentration. It can be seen that with a constant circulation velocity the DO concentration increases with load, enhancing the nitrification rate and reducing effluent ammonia variability. The average DO is lowest at plant startup when the connected population is lowest but nitrification performance can be maintained by increasing the operating SRT.

(a)

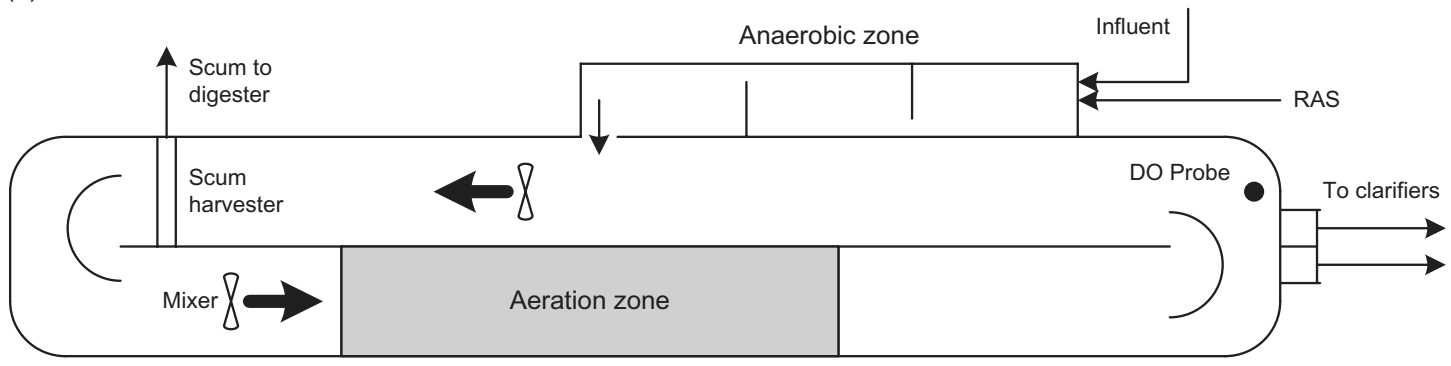

(b)

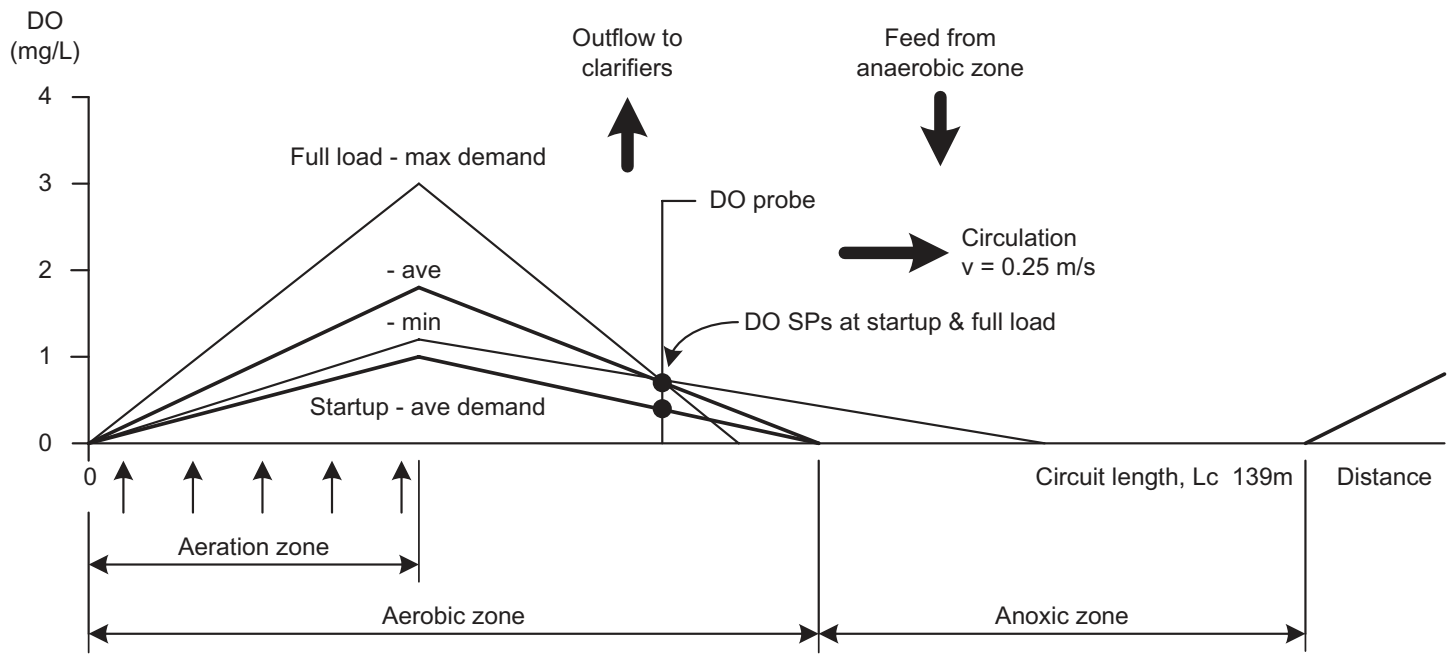

Figure 6.11 (a) 18,000 EP diffused air oxidation ditch (Brunswick Valley STP): OD $6 \mathrm{~m} \times 4 \mathrm{~m}$ WD $\times 139 \mathrm{~m}$ circuit length, $3.3 \mathrm{ML}$ volume; anaerobic reactor $0.37 \mathrm{ML}$, (b) DO profiles over the full range of operating conditions. 
The effect of DO concentration on nitrification rate is non-linear and the effect of the tapering DO profile on nitrification rate is given by:

$$
\mu_{\mathrm{n}}=\mu_{\mathrm{nm}}\left\{1-\left(\mathrm{K}_{\mathrm{O}} / \mathrm{DO}_{\max }\right) \mathrm{LN}\left[1+\left(\mathrm{DO}_{\max } / \mathrm{K}_{\mathrm{O}}\right)\right]\right\}
$$

where

$\mu_{\mathrm{n}}=$ nitrifier average specific growth rate in tapering DO zone, $\mathrm{d}^{-1}$

$\mu_{\mathrm{nm}}=$ nitrifier maximum specific growth rate, DO non-limiting, $\mathrm{d}^{-1}$

$\mathrm{K}_{\mathrm{O}}=$ nitrifier half velocity coefficient for DO, around $0.3 \mathrm{mg} / \mathrm{L}$

$\mathrm{DO}_{\text {max }}=$ maximum DO concentration at the downstream end of a diffuser zone or at a mechanical aerator, $\mathrm{mg} / \mathrm{L}$

The anoxic zone is nominally the circuit length devoid of oxygen downstream of the aerobic zone. The length of the aerobic zone is controlled using a DO probe located towards its downstream end. The DO SP controls the aeration blowers. In operation it is not necessary to know the anoxic fraction; effluent ammonia and nitrate are monitored and the DO SP adjusted from time to time as necessary to minimise effluent TN or sludge SSVI (Chapter 4).

To achieve satisfactory DO concentrations, very long diffused air ODs can use non-uniform diffused air zones. A short high intensity section to raise the DO is followed by a uniform low intensity section to maintain the DO to the end of the zone. Generally, two DO probes are provided for separate aeration control of the two sections. Varying the anoxic fraction for tuning purposes may then involve turning air headers on or off at the downstream end of the aeration zone and shifting the DO control location.

The appropriate locations for the ditch inflow and outflow are shown in Figure 6.11 - inflow near the start of the main anoxic zone where COD is needed, outflow to the clarifiers near the downstream end of the aerobic zone where COD and ammonia are lowest and the sludge has had time for flocculation downstream of the higher energy aeration zone. This applies to both diffused air and mechanically aerated ditches.

\subsubsection{Hydraulics}

The key feature of an oxidation ditch is the large flow of mixed liquor around an open channel circuit. The low velocity provides good flocculation, resulting in very low effluent SS (see Section 6.1.2 and Figure 4.11). It also provides effective conditions for scum separation and removal by mechanical harvesting.

To prevent solids settlement and allow effective control, a uniform velocity distribution has to be achieved in the channel cross-section. Channel bends contribute to vertical distribution by inducing spiral flow (Chow, 1959). However at sharp bends without aerators turning vanes are generally used to control horizontal distribution (as shown in Figure 6.11). Diffused air and vertical shaft ditches have good vertical mixing and no other hydraulic controls are needed.

With horizontal shaft aerators, however, baffles are needed to achieve good vertical flow distribution in the channel and maximise aerator performance (Hartley, 1987). In general, an inclined baffle is used downstream of each aerator to distribute the surface discharge downwards while a vertical baffle is provided upstream where necessary to reduce the surface inflow velocity to the aerator, maximising its oxygen transfer rate. 
Annular ditches have spiral flows which affect their velocity distributions and dissolved oxygen profiles. Figure 6.12 shows the DO contours measured in an annular oxidation ditch-MBR plant with diffused air; on the basis of this survey, location $\mathrm{H}$ was chosen for the DO probe used for aeration control. Velocity tests conducted in the same plant showed that air flow rate had no effect on channel velocity - see Figure 6.13.

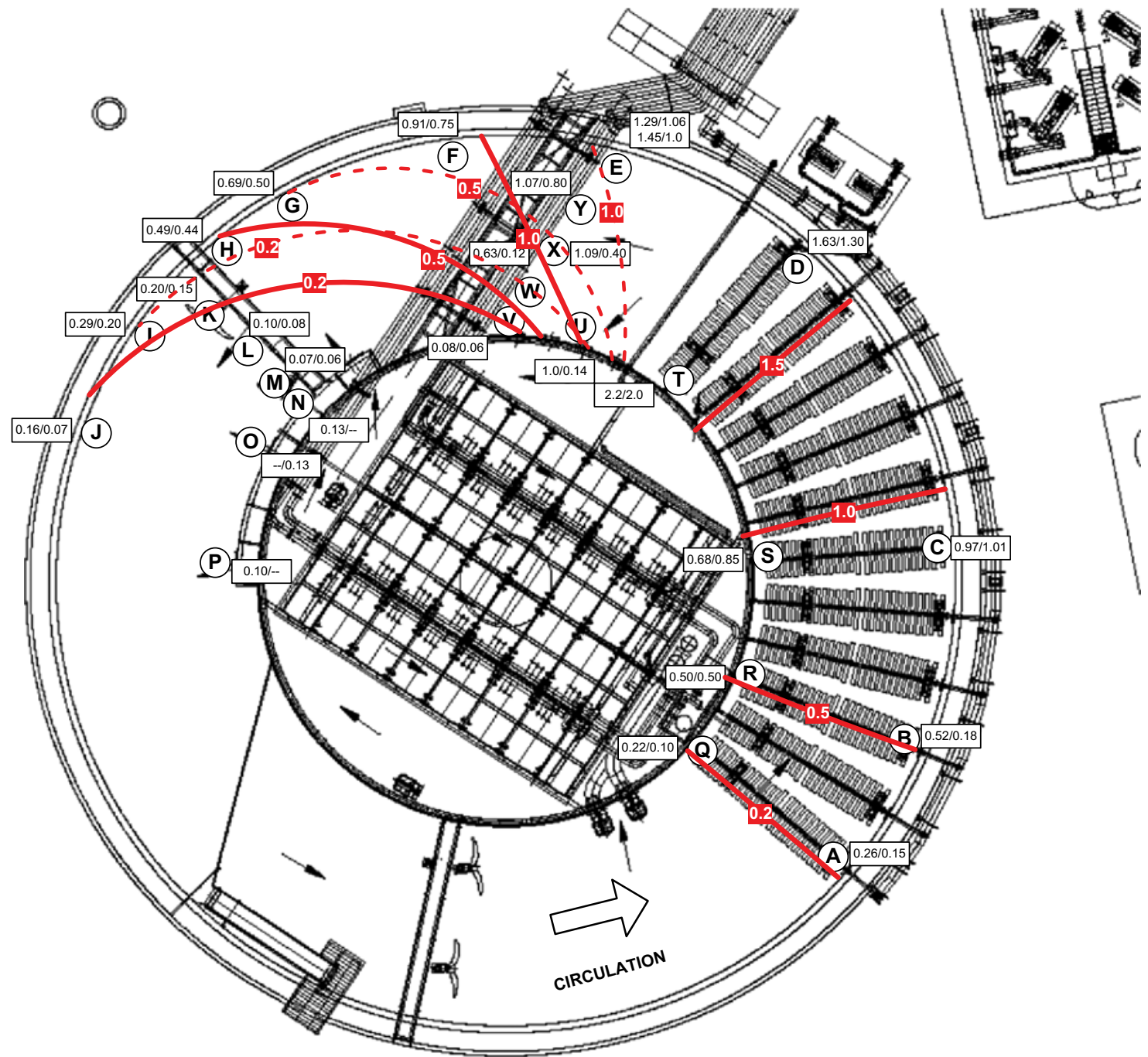

Figure 6.12 Dissolved oxygen profile in an annular oxidation ditch-MBR at the Cleveland Bay plant (Townsville, Queensland; see cover photograph). The membrane trains form the rectangular centre section; anaerobic cells surround the membrane compartment and feed into the oxidation ditch anoxic zone. The figure shows DO and velocity test locations, DO readings at surface/at $1-1.5 \mathrm{~m}$ depth, and DO contours at the surface (solid lines) and at 1-1.5 m depth (dashed lines). 


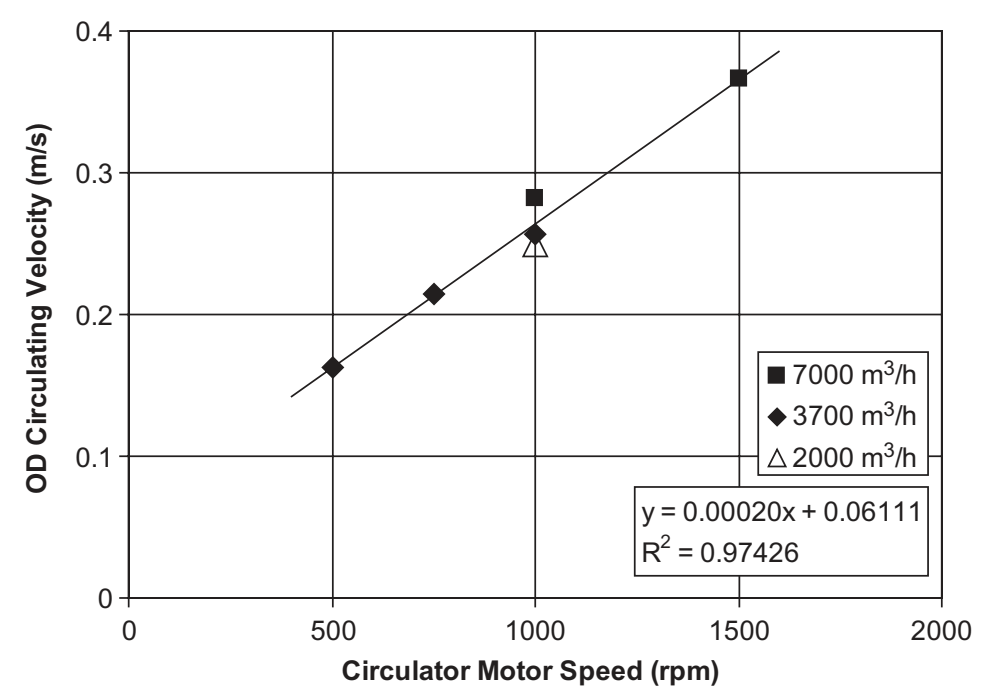

Figure 6.13 Velocity test results for the diffused air OD in Figure 6.12 measured at three different air flows. Liquid flow was circulated with large diameter banana blade mixers. Velocity was independent of aeration air flow.

\subsubsection{Mechanical aerator characteristics}

\section{Horizontal shaft aerators}

For a horizontal shaft oxidation ditch, the oxygen transfer rate is approximately proportional to the aeration power over the design operating range. The aeration power is related to the aerator operating parameters approximately as follows (Hartley, 1987):

$$
\mathrm{P} \propto(\mathrm{N} . \mathrm{I})^{0.9} \mathrm{n}^{2.4}
$$

where

$\mathrm{P}=$ total aerator operating power

$\mathrm{N}=$ number of aerators operating

$\mathrm{I}=$ aerator immersion

$\mathrm{n}=$ aerator speed

The ditch circulating velocity, $\mathrm{v}$, varies with power and aerator speed approximately as follows:

$\mathrm{v} \propto \mathrm{P}^{0.5} \mathrm{n}^{-0.67}$

\section{Vertical shaft aerators}

Vertical shaft aerators are located at 180 degree bends. The aerator acts as a radial flow pump with a hydraulic jump at the impeller discharge which entrains air bubbles for aeration. The flow around the channel is the combined primary pumping capacity of the operating impellers.

At very low speed (and normal immersion settings) the impeller is drowned and the pumping rate is proportional to the impeller speed. As the speed increases the water level at the impeller discharge is 
depressed by the velocity head and the operating immersion decreases. When the water level reaches the top of the impeller blades (full immersion), the pumping rate reaches its maximum. With further increase in speed the impeller becomes partly immersed, however the pumping rate (and velocity around the ditch) remain approximately constant because the decrease in operating immersion is counterbalanced by the increase in speed.

Oxygen transfer rate is approximately proportional to the aeration power over the design operating range.

\subsubsection{Operating principles}

The oxidation ditch is a simple reactor with significant operating flexibility. Its particular operating advantages are as follows:

- Effective nitrogen control: Effluent nitrogen concentration can be continuously optimised by control of the operating anoxic fraction. Any desired nitrogen concentration can be maintained - very low values for discharge to the environment or higher values for recycle to agriculture.

- Control of sludge settleability: Appropriate control of the anoxic fraction allows the SSVI to be maintained at a low value to maximise plant capacity.

- Low effluent SS: Effective flocculation in the circulating channel produces very low effluent SS concentration.

- Simple scum control: The circulating channel geometry facilitates effective scum harvesting.

The basic operating principles are as follows:

(1) Set the daily sludge wasting to maintain the desired SRT.

(2) Set the oxidation ditch circulators to maintain an average velocity of $0.2-0.25 \mathrm{~m} / \mathrm{s}$; this maximises DO concentration and flocculation effectiveness while preventing sludge settlement.

(3) Monitor effluent ammonia and nitrate continuously or daily.

(4) Choose a DO set point to maintain the desired ammonia:nitrate ratio or total $\mathrm{N}$ concentration in the effluent and an acceptable SSVI. Adjust the DO set point periodically as necessary to compensate for variations in loading and operating conditions - feed TKN:COD ratio and mixed liquor temperature, for example. Aeration control could be cascaded from the channel ammonia:nitrate ratio using continuous metering.

(5) Set appropriate chemical dose rates for supplementary phosphorus removal and $\mathrm{pH}$ control.

\subsection{MEMBRANE BIOREACTORS}

\subsubsection{Description}

The use of membranes in a BNR process increases its process and hardware complexity. The particular benefits provided by the (UF) membranes are:

- Very low effluent SS: SS concentration below $1 \mathrm{mg} / \mathrm{L}$ and turbidity below 0.1 NTU.

- Very low particulate nutrients: Particulate N and P concentrations are respectively about $10 \%$ and 3$5 \%$ of effluent VSS concentration (Chapter 3).

- Pathogen removal: Typical log removals of 6-7 for faecal coliforms (producing effluent $<1$ $\mathrm{cfu} / 100 \mathrm{~mL}$ ) and 4 for viruses; complete removal of protozoan cysts and helminths. Removals vary with the degree of biomass caking on the membranes.

In the MBR-BNR flowsheet the secondary clarifier is replaced by membrane solids separation. Pressure membranes can be used but more commonly the membranes are submerged in the mixed liquor and the 
permeate is extracted by pump. Figure 6.14 shows the flowsheet for a typical five-stage MBR-BNR process. In small plants, flat plate membranes are sometimes incorporated in the main aerobic zone. However, in the larger plants hollow fibre membranes are arranged in a separate membrane zone containing parallel trains which can be taken off-line individually for automated chemical cleaning. This zone can be highly aerobic because the membranes are continually cleaned by aeration.

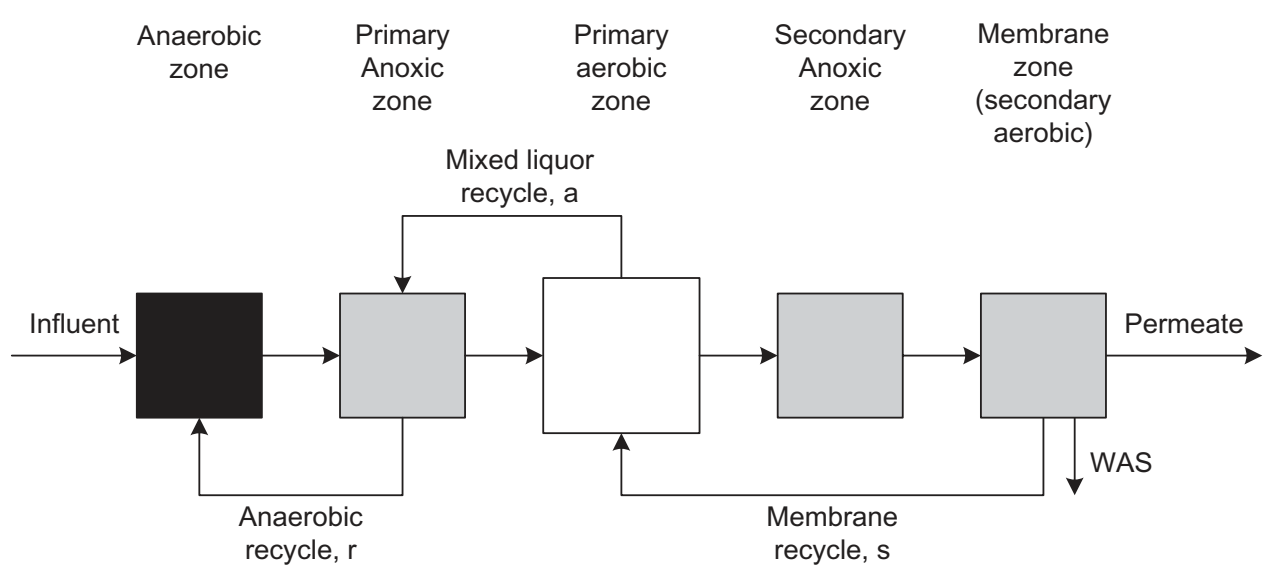

Figure 6.14 Typical MBR-BNR flowsheet, from Figure 5.1j.

Membranes can substitute for clarifiers in any of the BNR flowsheets but adaptation of the UCT process is used here as an example. In the UCT process the RAS recycle is directed to the anoxic zone to protect the anaerobic zone from recycled nitrate (Chapter 5). In the MBR version shown in Figure 6.14 the RAS (membrane recycle) discharge is shifted downstream to the aerobic zone to protect the anoxic zone from the high level of recycled oxygen (both high DO concentration and high recycle rate).

\subsubsection{Process characteristics}

\section{Bioreactor}

Incorporation of a membrane zone in the flowsheet as shown in Figure 6.14 produces five notable characteristics. Firstly, because of the recycle arrangement the MLSS concentration steps up through the zones with the highest concentration in the membrane zone. The MLSS relationships calculated by mass balance are summarised in Table 6.5. The membranes limit the maximum operating MLSS concentration, typically to a value of about $12 \mathrm{~g} / \mathrm{L}$. From a design perspective, the recycle ratios are economic variables - the higher the recycle ratios the less the difference in MLSS between the zones, therefore the smaller the zone volumes required for a given process sludge mass. From an operating perspective, varying the recycle ratios can change both the total operating sludge mass (and associated SRT) and the mass fractions of the various zones - see Figure 6.15. The operating recycle ratios can be calculated from the measured MLSS concentrations using the equations given in Table 6.5.

Secondly, the membrane zone contains a significant fraction of the total sludge mass, typically about $20 \%$. This reduces the mass fractions available to the other zones. 
Table 6.5 MBR-BNR process balance.

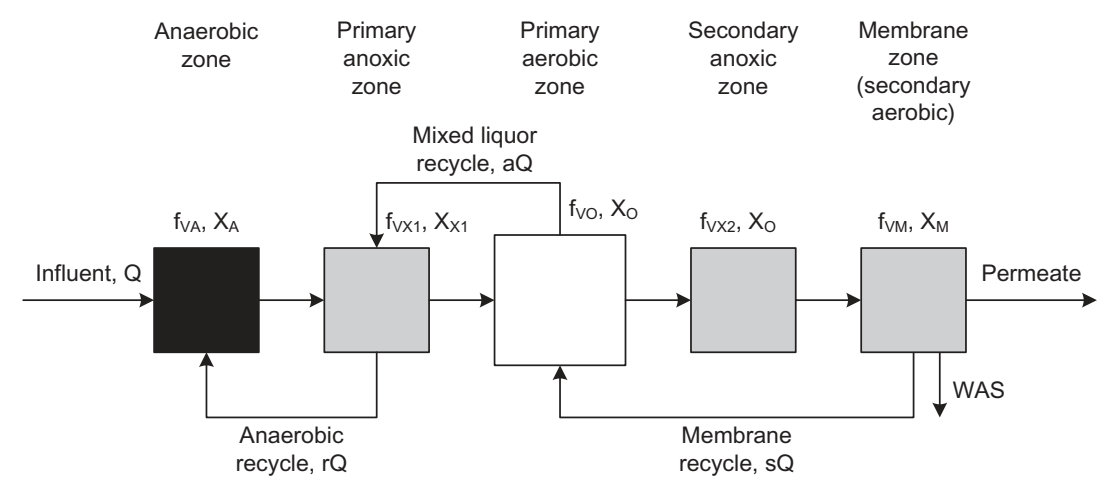

\section{MLSS concentrations}

$$
\begin{aligned}
X_{O} & =X_{M}[s /(1+s)] \\
X_{X 1} & =X_{O}[a /(1+a)] \\
X_{A} & =X_{X 1}[r /(1+r)]
\end{aligned}
$$

\section{Recycle ratios}

$$
\begin{aligned}
& \mathrm{s}=1 /\left[\left(\mathrm{X}_{\mathrm{M}} / \mathrm{X}_{\mathrm{O}}\right)-1\right] \\
& \mathrm{a}=1 /\left[\left(\mathrm{X}_{\mathrm{O}} / \mathrm{X}_{\mathrm{X} 1}\right)-1\right] \\
& \mathrm{r}=1 /\left[\left(\mathrm{X}_{\mathrm{X} 1} / \mathrm{X}_{\mathrm{A}}\right)-1\right]
\end{aligned}
$$

\section{Sludge mass fractions}

$$
\begin{aligned}
F_{X} & =f_{V A} X_{A}+f_{V X 1} X_{X 1}+\left(f_{V O}+f_{V X 2}\right) X_{O}+f_{V M} X_{M} \\
f_{X M} & =f_{V M} X_{M} / F_{X} \\
f_{X X 2} & =f_{V X 2} X_{O} / F_{X} \\
f_{X O} & =f_{V O} X_{O} / F_{X} \\
f_{X X 1} & =f_{V X 1} X_{X 1} / F_{X} \\
f_{X A} & =f_{V A} X_{A} / F_{X} \\
f_{X M} & +f_{X X 2}+f_{X O}+f_{X X 1}+f_{X A}=1
\end{aligned}
$$

where

$$
\begin{aligned}
& a=\text { mixed liquor recycle ratio } \\
& r=\text { anaerobic recycle ratio } \\
& \mathrm{s}=\text { membrane recycle ratio } \\
& \mathrm{f}_{\mathrm{VA}}= \text { anaerobic zone volume fraction } \\
& \mathrm{f}_{\mathrm{VM}}= \text { membrane zone volume fraction } \\
& \mathrm{f}_{\mathrm{VO}}=\text { primary aerobic zone volume fraction } \\
& \mathrm{f}_{\mathrm{VX} 1}=\text { primary anoxic zone volume fraction } \\
& \mathrm{f}_{\mathrm{VX} 2}=\text { secondary anoxic zone volume } \\
& \text { fraction } \\
& \mathrm{f}_{\mathrm{XA}}= \text { anaerobic zone mass fraction }
\end{aligned}
$$

$\mathrm{f}_{\mathrm{XM}}=$ membrane zone mass fraction

$\mathrm{f}_{\mathrm{XO}}=$ primary aerobic zone mass fraction

$f_{X X 1}=$ primary anoxic zone mass fraction

$f_{X X 2}=$ secondary anoxic zone mass fraction

$F_{X}=$ zone mass function

$X_{A}=$ MLSS concentration in anaerobic zone

$X_{M}=$ MLSS concentration in membrane zone

$\mathrm{X}_{\mathrm{O}}=$ MLSS concentration in primary aerobic \& secondary anoxic zones

$\mathrm{X}_{\mathrm{X} 1}=$ MLSS concentration in primary anoxic zone 


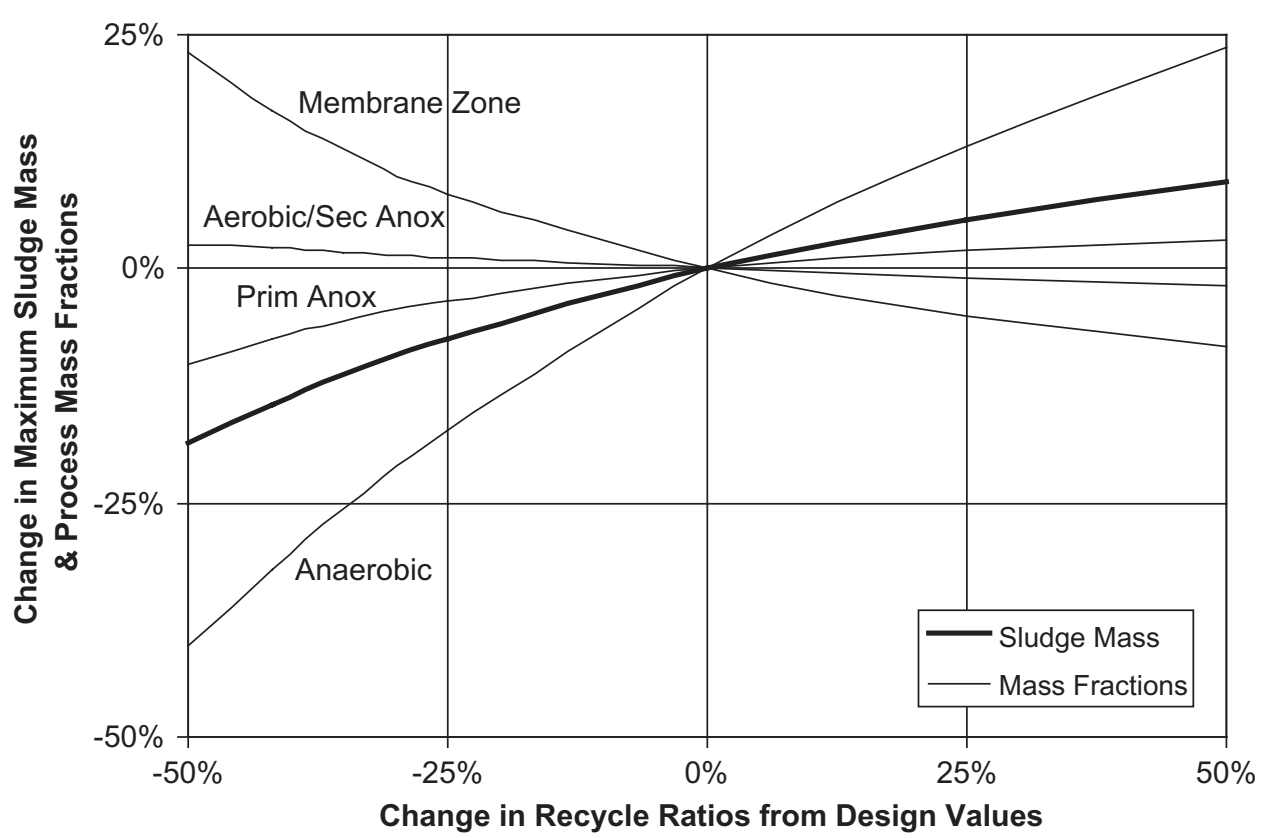

Figure 6.15 Effects of changes in the operating recycle ratios on maximum allowable sludge mass and reactor mass fractions. MLSS concentration in the membrane zone is constant; design $\mathrm{r}$, a and $\mathrm{s}$ recycle ratios are 1, 6 and 4 and are varied in concert; process volume fractions/design mass fractions areanaerobic $0.15 / 0.07$, anoxic $0.30 / 0.28$, aerobic $0.36 / 0.40$, secondary anoxic $0.05 / 0.05$, membrane $0.14 / 0.20$.

Thirdly, nitrogen removal is mediated only by the anoxic and primary aerobic zones. The membrane zone further nitrifies residual ammonia from the upstream zones, meaning the process produces low effluent ammonia. However, tuning of nitrogen removal performance requires effluent data from the upstream zones rather than the final discharge from the membrane zone.

Fourthly, MBR processes are reported to have somewhat lower nitrification rates than conventional processes (Monti \& Hall, 2008), and to be more prone to foaming (Monti et al., 2006). Prevention of effluent solids discharge by replacement of clarifiers with membranes leads to shifts in the composition of the biomass (Hall et al., 2010).

Fifthly, because MBRs operate at average MLSS concentrations 2-3 times higher than conventional processes, the reactor hydraulic residence time is 2-3 times shorter (for the same SRT). This means the effluent quality is more responsive to load variability; effluent concentrations are more variable which increases average values (see Chapter 2 and Appendix 1).

\section{Membranes}

This section discusses hollow fibre ultrafiltration membranes with water flow from outside to inside. These membranes are generally arranged in parallel trains with a number of modules in each train. Trains can be isolated for chemical cleaning. Feed to the biological process is fine screened (typically $1 \mathrm{~mm}$ apertures) to protect the modules from debris accumulation. 
This type of membrane has a nominal pore size in the ultrafiltration range of $0.01-0.1 \mu \mathrm{m}$ and is capable of producing an effluent turbidity of less than 0.1 NTU. Faecal coliform counts can be reduced to zero.

MLSS concentration in the membrane zone is limited to about $12,000 \mathrm{mg} / \mathrm{L}$ to enable the required flux rates to be maintained.

General process principles are as follows (Trussell et al., 2006; Trussell et al., 2007):

- As permeate flows into the membranes, biomass cakes on the membrane surface, increasing the transmembrane pressure (TMP). In addition, microbial growth occurs on the membranes and soluble microbial products (SMP - colloidal organic material) accumulate in the pores. High intensity aeration is applied intermittently to scour the membrane surfaces and limit the degree of caking. Aeration frequency varies with permeate flow and cleaning may be assisted by resting and backflow phases. Permeability gradually decreases and chemical cleans (using hypochlorite for organics and citric acid for any inorganic precipitants) are used to restore permeability at intervals governed by the system's TMP limit. Nevertheless, the permeability will suffer a long-term decline and membrane life expectancy (based on required hydraulic capacity) may be about 10 years.

- As MLSS concentration increases, the associated increase in ML viscosity requires increasing aeration intensity to maintain permeability. At constant aeration intensity, an increase in MLSS concentration reduces membrane permeability and increases the ongoing fouling rate. The MLSS limit is set to suit the design aeration intensity and the expected duration of flow peaks.

- Operating permeability also varies with SRT because of the variation in mixed liquor SMP level. As SRT increases from 2 to 10 days the membrane fouling rate decreases 20 -fold. Fouling rate continues to decline up to an SRT of around 20 days.

- A study on the effects of carbon dosing to enhance nutrient removal (Ahmed et al., 2008) found that synthetic wastewaters of different compositions caused increasing deterioration in membrane permeability in the following dominant substrate order: glucose (least) $<$ acetate $<$ propionate $<$ methanol (worst). This contrasts with a reported improvement in permeability characteristics produced by alum dosing which coagulates mixed liquor SMP (Holbrook et al., 2004); the author has also observed this alum permeability enhancement at the Cleveland Bay (Townsville) plant.

- Membrane permeability can be calculated and monitored using the following formula:

$$
\mathrm{L}_{\mathrm{P} 20}=\mathrm{J} \cdot \mathrm{e}^{-0.0239(\mathrm{~T}-20)} / \mathrm{TMP}
$$

where

$\mathrm{L}_{\mathrm{P} 20}=$ membrane permeability standardised at $20^{\circ} \mathrm{C}, \mathrm{L} / \mathrm{m}^{2} \mathrm{~h} \cdot \mathrm{kPa}$

$\mathrm{J}=$ membrane operating flux, $\mathrm{L} / \mathrm{m}^{2} \mathrm{~h}$

$\mathrm{T}=$ membrane operating temperature, ${ }^{\circ} \mathrm{C}$

$\mathrm{TMP}=$ transmembrane pressure, $\mathrm{kPa}$

Permeability values are typically about $1.5 \mathrm{~L} / \mathrm{m}^{2} \mathrm{~h} \cdot \mathrm{kPa}$ at $20^{\circ} \mathrm{C}$.

- MBRs have a well defined hydraulic capacity which declines as the duration of the peak flow increases. Controls may be provided to automatically reduce throughput after a preset peak flow duration. Because membrane systems are expensive there is generally little reserve capacity and excess flow has to be bypassed or stored. This contrasts with clarifier systems where capacity varies with MLSS concentration, SVI, RAS flow rate and internal sludge storage capacity and failure is more gradual and more easily managed. 


\subsubsection{Operating principles}

Refer to Sections 6.3 or 6.4 for operating principles related to the main process format used in the MBR. Principles specific to the MBR variant are as follows:

(1) To maximise SRT, operate at maximum MLSS concentration in the membrane zone and with maximum recycle ratios.

(2) Adjust recycle ratios to change the mass fractions in the various zones.

(3) To tune nitrogen removal performance, use data from the membrane zone feed rather than effluent. The membrane zone further nitrifies ammonia to nitrate but does not remove nitrogen.

(4) Manage membrane cleaning to maximise membrane availability during the peak flow season.

(5) Because of the reliance on significant quantities of mechanical, electrical and control equipment, a sound maintenance management plan is essential.

\subsection{SEQUENCING BATCH REACTORS 6.6.1 Description}

A sequencing batch reactor (SBR) or intermittent process in its most basic form is a simple box reactor operated in a sequential fashion. In a repetitive cycle, the reactor is filled with sewage, the batch of sewage is reacted, the treated effluent is discharged. As described at the start of Chapter 3, Ardern and Lockett used this batch treatment mode in their original development of the activated sludge process. Physically it is the simplest of processes, however process-wise it is one of the most complex.

Development of the full-scale SBR was begun in earnest by Pasveer with his CFID (continuous flow intermittent decant) oxidation ditch as mentioned in the introduction to Section 6.4 above. A variety of process formats is now in use with a range of cycle designs, control methods and hardware (Figure 6.16). The process is controlled by combinations of time, water level and on-line analytical instruments. Some forms of the process incorporate mixed liquor recycles to inlet compartments designed as selectors for SVI control or to promote biological N and P removal. The main advantage of the SBR is low capital cost; its disadvantages are difficulty in reliably achieving high levels of biological $\mathrm{N}$ and $\mathrm{P}$ removal and process complexity which makes operational tuning difficult.

(a)

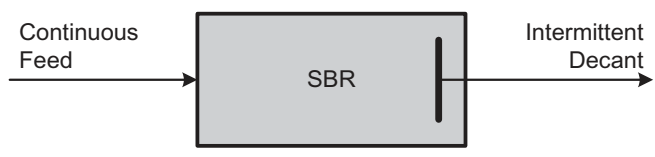

(b)

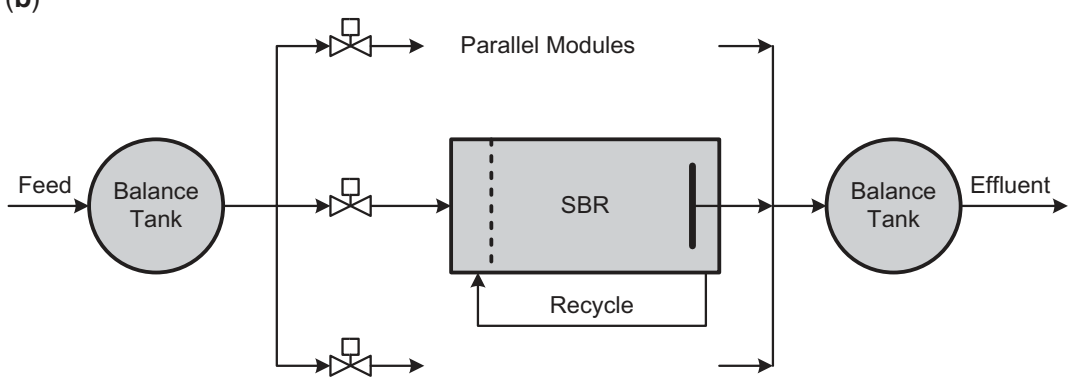

Figure 6.16 SBR process formats: (a) the simplest, a single tank CFID process, and (b) a generic format. 
The generic name SBR was coined by Irvine in 1967 (Wilderer et al., 2001). Irvine provided a classic summary of this process as summarised in Wilderer et al. (ibid, p70): "the SBR's greatest strength was that an infinite number of positive operating strategies could be employed to meet effluent limits and ...... its greatest weakness was that an infinite number of negative operating strategies were also possible."

Because of its commercial competitiveness and black box nature, a variety of proprietary formats has developed. Process variants are described by a range of names - IDEA (intermittently decanted extended aeration), IDAL (intermittently decanted aerated lagoon), ICEAS (intermittent cycle extended aeration system), CASS (cyclic activated sludge system).

\subsubsection{Process characteristics}

Figure 6.17 shows an example process format used here to explain SBR process characteristics. Figure 6.18 shows the tank geometry and Figure 6.19 the process operating cycle for each SBR.

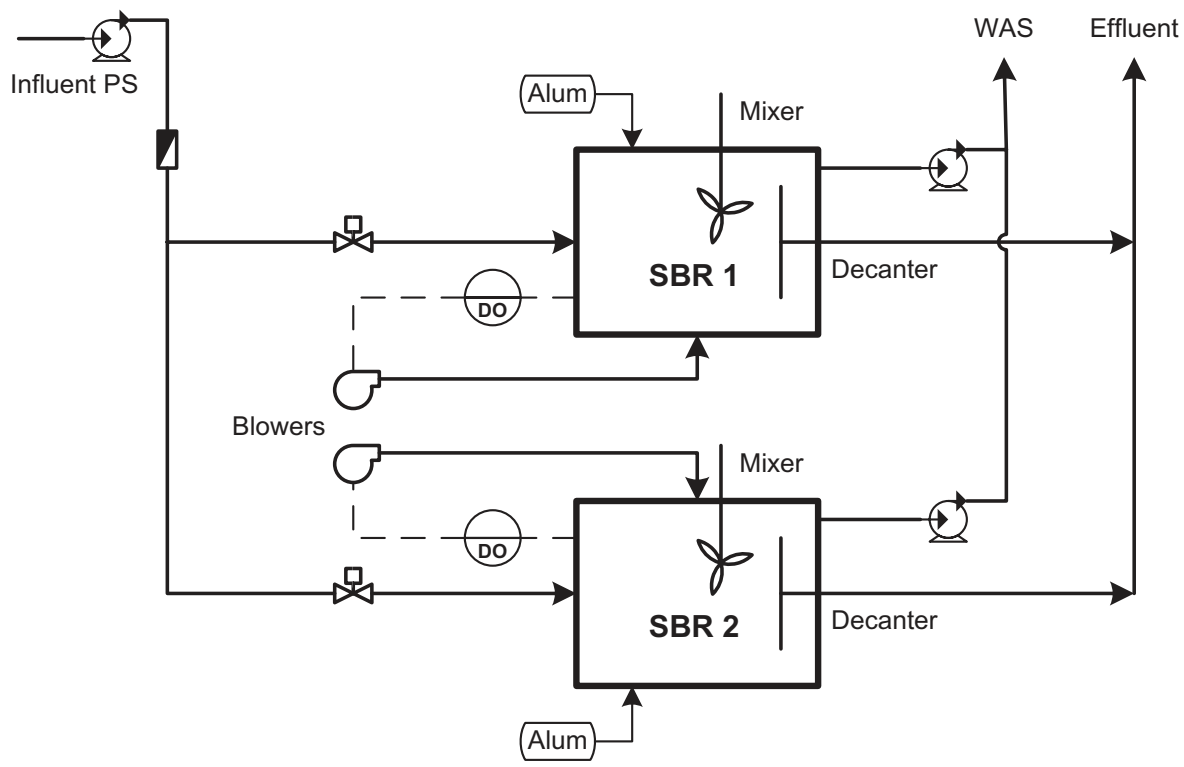

Figure 6.17 Example SBR flowsheet.

Two parallel SBRs are fitted with mechanical mixers and diffused air aeration; blowers are controlled from DO probes. Effluent is discharged using decanting troughs. There is no upstream balancing tank. EBPR is not included and alum dosing is used for P removal. The two SBRs are operated 180 degrees out of phase, each being fed separately for $50 \%$ of the time. Normal control is by time but the rate of increase in water level is monitored and high flow events trigger a switch to a shorter high flow cycle which increases the decant time from $13 \%$ to $27 \%$ of the total cycle time. If necessary, to prevent loss of biomass under extreme flow conditions treatment can be interrupted and continuous decanting implemented. 


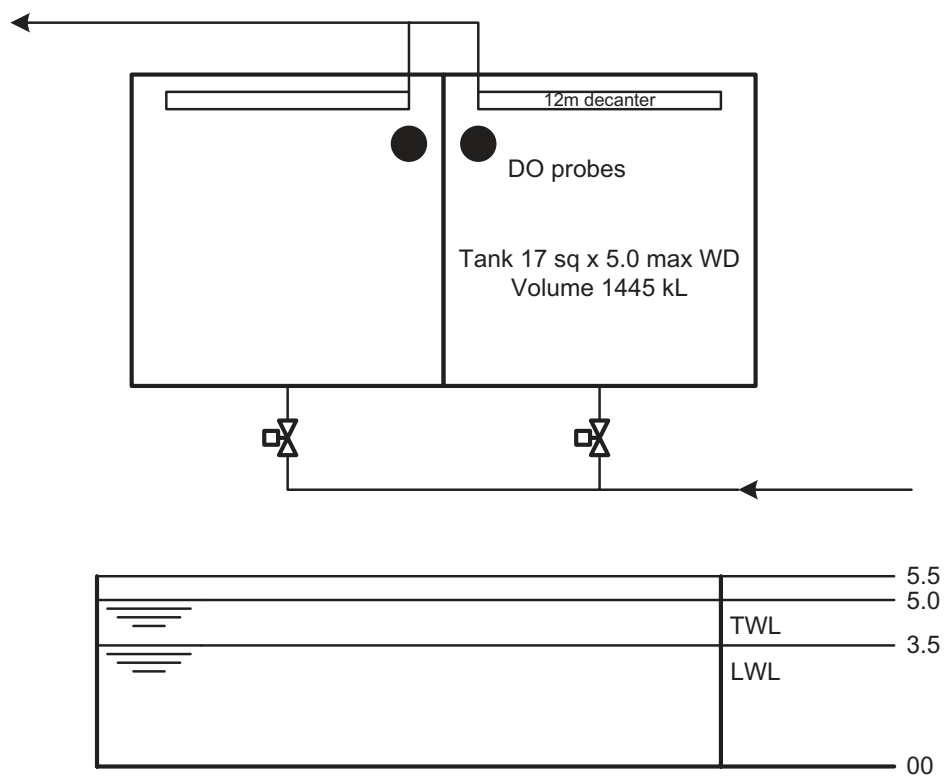

Figure 6.18 SBR geometry.
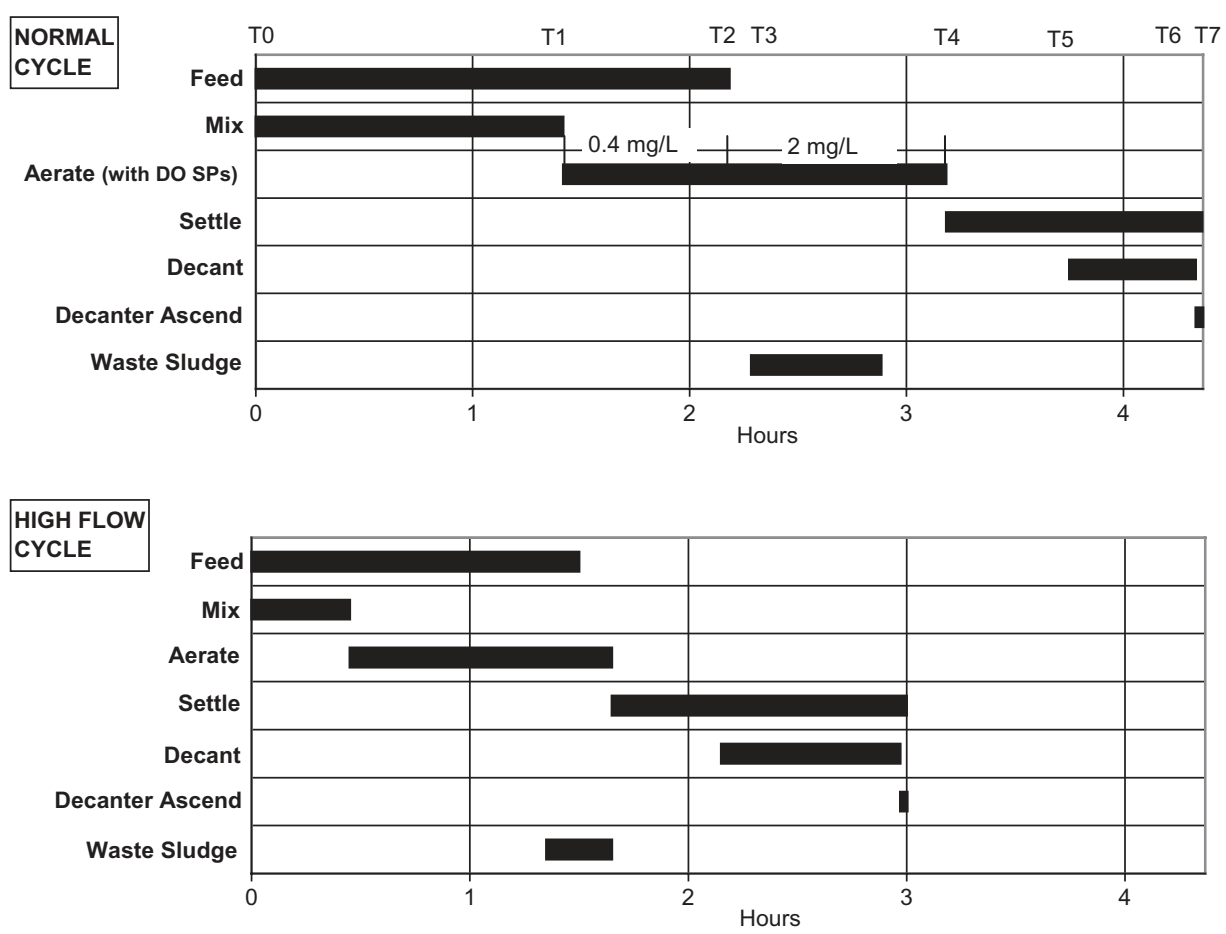

Figure 6.19 Normal and high flow cycles. 
The normal cycle time is 4.36 hours, giving 5.5 cycles per day. The half cycle alternates the times the two SBRs are fed each day so that the daily sewage loads are shared equally. The treatment phases are as follows:

Mix: An anoxic phase in which feed is used for denitrification.

Aerate: Split into two phases - aerobic feed, then aerobic batch after feed ceases. As shown, different dissolved oxygen set points are used for these two phases.

Settle: Aeration ceases and sludge settling occurs.

Decant: About halfway through the settling period the decanter descends to draw off effluent. At the end of decant the decanter starts its rise a few minutes before the next cycle starts so that the trough is above the water level when feeding and aeration start.

Waste: To control SRT, sludge is wasted during each aeration phase after feed ceases so that the reactor is well mixed and the volume to be extracted can be calculated accurately from the water level.

Figure 6.20 shows the process decanting behaviour. Plot (a) shows the water and sludge interface levels while (b) shows the weir approach velocity, which is maintained below a typical design limit of $40 \mathrm{~m} / \mathrm{h}$ to prevent scour of the sludge blanket and carryover of solids in the effluent. Weir approach velocity is calculated from the cross-sectional area defined by the width of the weir and the depth to the top of the settling sludge layer. Ideally, decanting should start at the appropriate time to maintain the clear water depth constant over the decanting time, producing a constant weir approach velocity and minimising the risk of solids carryover; however, sludge settling rate varies from time to time as MLSS and SVI vary. The decant needs to finish before sludge compaction starts to reduce the clear water depth as depicted in the post-decant extension of Plot (a).
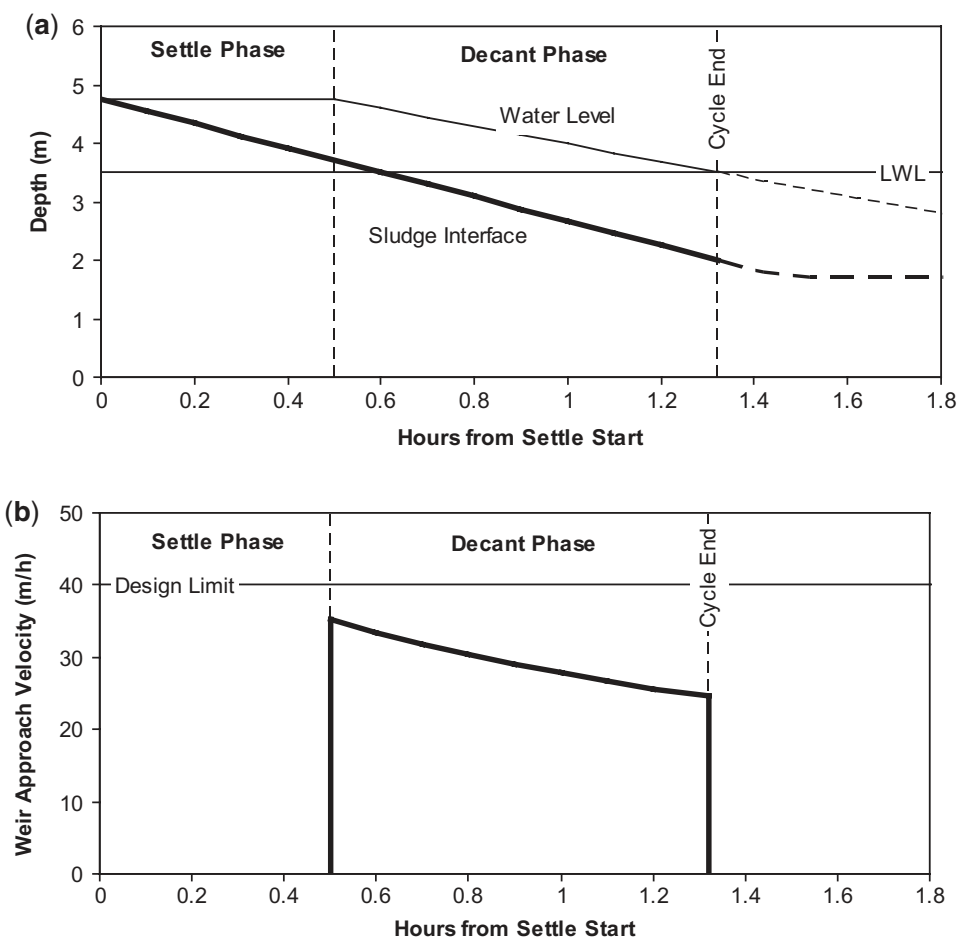

Figure 6.20 Process behaviour during the settle and decant phases for the high flow cycle. 
Sludge settleability in the SBR process appears to be governed predominantly by the primary anoxic fraction - see Chapter 4 .

Figure 6.21 shows typical cycle profiles for ammonia, oxidised nitrogen and biodegradable influent COD. Decanted effluent quality is represented by the concentrations at the start of settle. Processes occurring during the various phases are as follows:

Anoxic Feed Phase: COD increases only slowly as part of the feed mass is consumed by denitrification of the residual nitrate from the previous cycle. Feed ammonia and ammonification of feed organic $\mathrm{N}$ cause the ammonia concentration to increase. Ideally this phase ends when nitrate is exhausted as shown in the figure.

Aerobic Feed Phase: Operates at a low DO (say $0.4 \mathrm{mg} / \mathrm{L}$ ) for simultaneous nitrification and denitrification (SND, see Chapter 3, Section 3.5.4). Ammonia is fed and nitrified.

Aerobic Batch Phase: Feeding ceases. Residual biodegradable COD is oxidised and ammonia nitrified.

Settle and Decant Phase: The sludge settles and respires endogenously using residual DO and nitrate. There is little change to ammonia and COD concentrations.

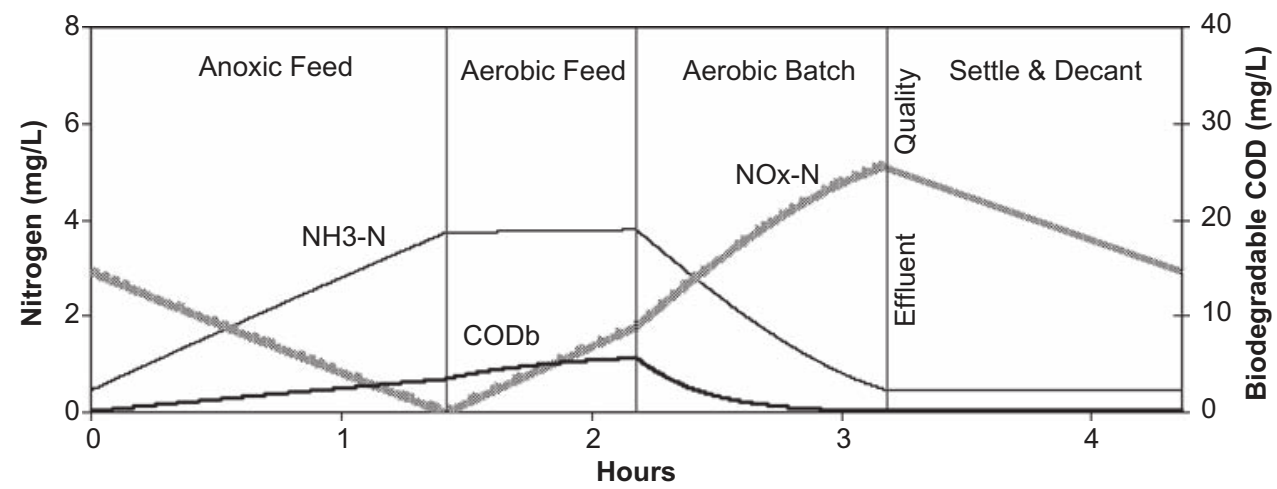

Figure 6.21 Typical cycle profiles for ammonia, oxidised $\mathrm{N}$ and biodegradable COD. Effluent nitrate varies with influent TKN:biodegradable COD ratio ( 0.15 in this example).

The SBR process is subject to the same limitations on minimum achievable nitrate as the continuous flow process. In the continuous process the mixed liquor recycle ratio sets the proportion of nitrified effluent recycled for denitrification and limits the minimum nitrate concentration (Chapter 3, Section 3.5.3). The SBR process behaves the same way. After nitrification in the aerobic phases a proportion of the reactor contents is decanted as effluent. The retained proportion is then mixed with influent for denitrification during the following anoxic phase.

SBR volumetric exchange can be related to the continuous flow recycle ratio as follows:

$$
\begin{aligned}
\mathrm{a} & =\text { recycled flow } / \text { discharged flow } \\
& =\text { retained volume } / \text { decanted volume } \\
& =(\text { total volume }- \text { decant volume }) / \text { decant volume } \\
& =(1 / \alpha)-1
\end{aligned}
$$


or

$$
\alpha=1 /(\mathrm{a}+1)
$$

where

$\mathrm{a}=$ continuous flow recycle ratio

$\alpha=$ SBR volumetric exchange ratio (Wilderer et al., 2001)

$=$ decant volume/total volume

The smaller the fraction of reactor volume decanted and refilled during each cycle, the lower the minimum nitrate achievable. Achieving low nitrate in the SBR process therefore requires a large reactor volume; this has a relatively greater cost impact than the larger recycle required in the continuous flow process. In the SBR process, therefore, greater reliance tends to be placed on supplementary SND (simultaneous nitrification and denitrification) during the aerated feed phase to increase the extent of denitrification.

\subsubsection{Operating principles}

The SBR is physically simple but operationally complex. The basic operating principles, based on the example process format described above, are as follows:

(1) Set the basic cycle as described above.

(2) Set the sludge wasting to maintain the desired SRT.

(3) Monitor effluent ammonia and nitrate

(4) To vary effluent ammonia concentration, adjust the cycle fractions and DO set points for the aerobic feed and aerobic batch phases, and the process SRT.

(5) To vary effluent nitrate concentration, adjust the anoxic feed fraction and the DO concentration in the aerobic feed phase. The cycle time can also be shortened to reduce the volumetric exchange ratio if this is a limiting factor.

(6) To minimise effluent SS concentration, increase the duration of the settle and decant phase and adjust the start of the decant phase so that the water level falls at the same rate as the sludge interface (assuming that the decant rate can be varied). The SRT can also be shortened to reduce MLSS concentration and increase settling rate if this is a limiting factor.

(7) Set appropriate chemical dose rates for supplementary phosphorus removal and $\mathrm{pH}$ control. 


\section{Chapter 7}

\section{Secondary clarifiers}

This chapter explains the behavioural characteristics of secondary clarifiers and provides some useful operating diagrams. It focuses on the popular circular centre-feed clarifier however the principles are similar for other forms.

\subsection{DESCRIPTION}

The primary function of the secondary clarifier is to clarify - to produce a clear effluent by separating the solids from the mixed liquor for return to the bioreactor. Thickening of the return sludge is a secondary function and should not be allowed to compromise the primary clarification function (avoid the tail wagging the dog).

Secondary clarifiers may be circular or rectangular; circular clarifiers can have centre or peripheral feed. The circular centre feed clarifier is the most common because of its simplicity and good performance. Diameters above $45 \mathrm{~m}$ are uncommon, even in large plants, because of equipment and operational limitations. Side water depths are typically at least $10 \%$ of the diameter and vary from 3-6 m. Greater depths tend to produce lower effluent SS concentrations because of greater resistance to hydraulic and wind disturbances (Ekama et al., 1997). They also provide more sludge storage capacity for handling wet weather flow events.

Feed enters radially near the surface within a circular feed well. Flocculator feed wells are sometimes used to reduce effluent SS concentration. This is unnecessary if the feed is already well flocculated, for example, mixed liquor direct from an oxidation ditch (see Figure 4.11, Chapter 4).

Effluent is collected by peripheral or inboard launders. Effluent SS concentration is lower if the launders are arranged to minimise the effect of the typical upwelling current at the side wall; peripheral launders may be hung on the inside of the wall or a peripheral Stamford baffle may be used to deflect the current.

Sludge may be scraped to a centre well for drawoff or collected by suction (hydraulic) collectors hung from a rotating bridge. Scrapers require a conical floor, typically at a 1:12 slope, and solids flow to the centre well, partly as a hydraulic density current and partly under the impetus of the scraper. Log spiral scrapers (making a constant angle to any radius) provide the best performance; echelon scrapers having a number of parallel blades provide poorer performance because several revolutions of the scraper are required to mechanically move a particle to the centre well.

Suction sludge collectors operate on a flat floor and remove sludge from the whole radius or diameter at once. The underflow is drawn from a moving location hence the hydraulic behaviour of the clarifier is more 
complex. One drawback of the suction collector is its fixed maximum hydraulic capacity - it is not amenable to increase in the RAS flow should that ever be desired.

Both scrapers and suction collectors are usually also fitted with scum removal systems.

\subsection{MASS BALANCES}

Secondary clarifiers are mass balance driven. Under steady state conditions, what goes in must come out. Diurnal and wet weather variations in flow rate produce increases and decreases in the clarifier solids inventory. Table 7.1 summarises the steady state mass balance relationships. Although the flow patterns in a clarifier are more complex than shown, the idealised approach depicted provides a good representation of clarifier behaviour and capacity.

Table 7.1 Idealised clarifier behaviour.

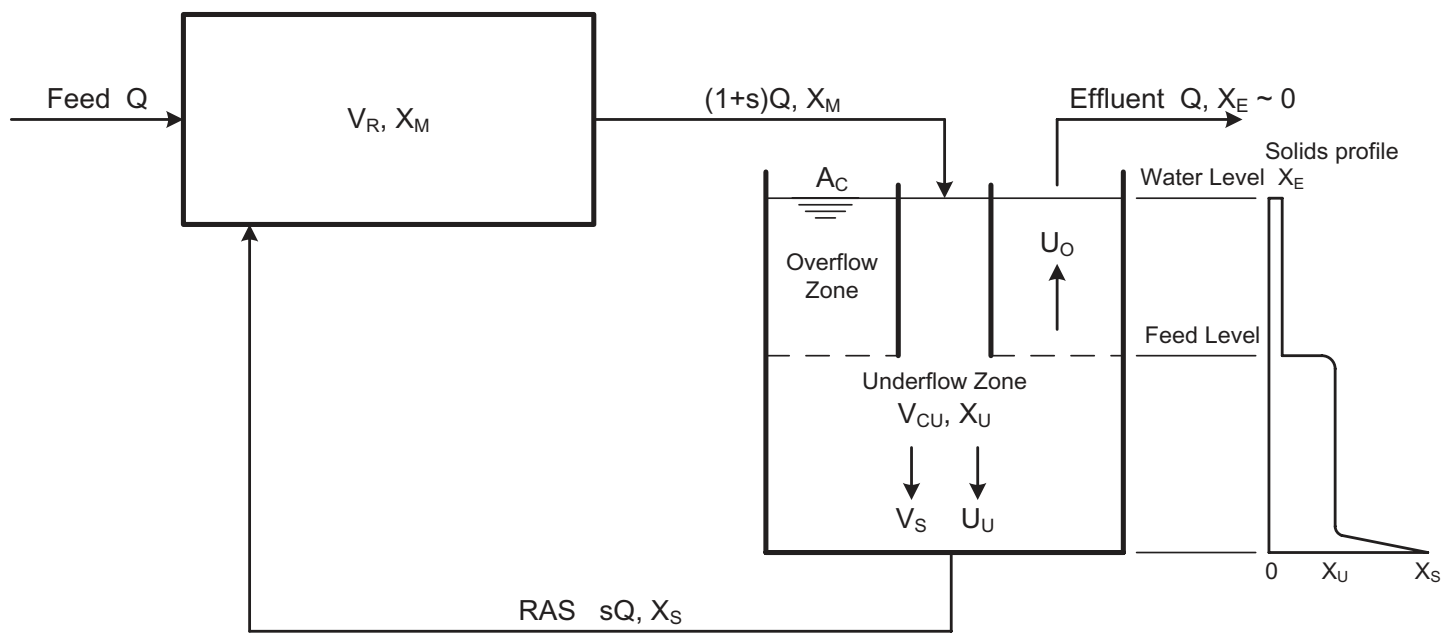

\section{Nomenclature:}

$\mathrm{A}_{C} \quad$ Clarifier surface area

$\mathrm{MX}_{\mathrm{T}}$ Process total sludge mass

n Settling constant (see Table 4.1)

Q Plant flow

S RAS recycle ratio

$\mathrm{S}_{\mathrm{NL}} \quad$ Non-limiting RAS recycle ratio

$\mathrm{U}_{\mathrm{O}} \quad$ Overflow rate, $\mathrm{Q} / \mathrm{A}_{\mathrm{C}}$

$\mathrm{U}_{U} \quad$ Underflow rate, $s Q / A_{C}=s U_{O}$

$\mathrm{V}_{\mathrm{CU}} \quad$ Clarifier underflow zone volume 
Table 7.1 Idealised clarifier behaviour (Continued).

\begin{aligned} & \hline$V_{O}$ Settling constant (see Table 4.1) \\ &$V_{R}$ Reactor volume \\ &$V_{S}$ Solids settling rate in the underflow zone \\ &$X_{E}$ Effluent $S S$ concentration \\ &$X_{M}$ MLSS concentration \\ &$X_{M C}$ MLSS concentration at maximum capacity with equal SS concentrations in reactor and clarifier \\ & underflow zone \\ &$X_{S}$ RAS SS concentration \\ &$X_{U}$ Underflow SS concentration \\ &$R_{\text {Relationships: }} \\ & M_{X T}=V_{R} X_{M}+V_{C U} X_{U} \\ & V_{S}=V_{O} \cdot \exp \left(-n X_{U}\right) \\ & X_{M C}=M_{T} /\left(V_{R}+V_{C U}\right) \\ & X_{S}=X_{M}(1+s) / s \\ & X_{U}=X_{M}(1+s) /\left[\left(V_{S} / U_{O}\right)+s\right] \\ & S_{N L}=\exp \left(n X_{M}-2\right)\end{aligned}$

There are three process zones: the reactor, the clarifier overflow zone and the clarifier underflow zone. Under normal operating conditions the solids mass in the clarifier overflow zone is negligible. The process biomass is distributed between the reactor and the clarifier underflow zone but under dry weather flow conditions the solids mass in the underflow zone is also generally negligible. As plant flow increases, solids transfer from the reactor to the underflow zone.

In the underflow zone solids are transported downwards by two mechanisms - the bulk downward RAS flow and settlement through the water. The solids concentration, $\mathrm{X}_{\mathrm{U}}$, is constant for most of the depth (Equation 7.4) and then increases to the RAS concentration, $X_{S}$ (Equation 7.3), near the floor where the settlement mechanism ceases.

As the plant feed flow increases, the underflow concentration $\mathrm{X}_{\mathrm{U}}$ also increases because the overflow rate, $\mathrm{U}_{\mathrm{O}}$, is increasing (Equation 7.4). However, the RAS concentration remains constant if the recycle ratio, $s$, is held constant. Because $\mathrm{X}_{\mathrm{U}}$ increases the solids mass in the underflow zone increases, reducing the reactor MLSS concentration, $\mathrm{X}_{\mathrm{M}}$.

The maximum capacity is reached when the increasing overflow rate, $U_{O}$, reaches the settling rate of the incoming mixed liquor. The underflow concentration is then at the MLSS concentration (Equation 7.2). To ensure the RAS flow does not impose a lower capacity limit due to thickening limitations, the recycle ratio at the limiting overflow rate should be not less than the value given by Equation 7.5 (see Section 7.3 below). Thickening failure can be overcome by increasing the recycle ratio, however recovery from clarification failure requires reduction in overflow rate, reduction in MLSS concentration or decrease in SSVI.

Clarifier behaviour is well illustrated by the clarifier sludge profile shown in Figure 7.1. The data were measured at the Lower Molonglo Water Quality Control Centre in Canberra during a 1997 clarifier study. This plant incorporated chemically enhanced primary treatment and, because of the low primary effluent strength, had a very high clarifier:reactor volume ratio of $2: 1$. At the time the solids profile was measured the sludge blanket was stable and extended well above the feed level, with a concentration equal to the MLSS value. The large clarifier volume allowed for large transfers of solids between the reactors and 
clarifiers. When plant flow increased the blanket rose but the associated transfer of solids from the reactors reduced the MLSS concentration until a new equilibrium blanket level was attained. In effect the plant was operating with a variable volume reactor - the main reactor plus the clarifier sludge volume.

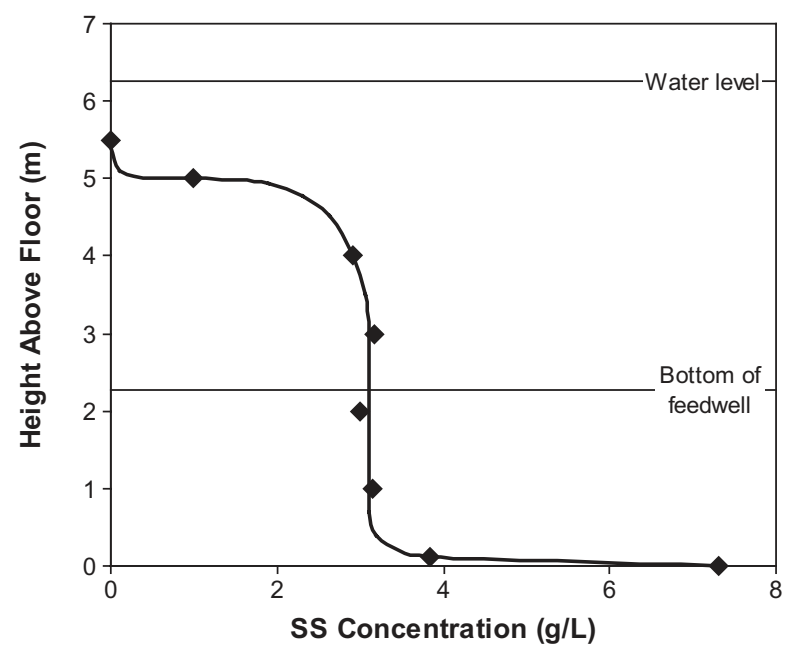

Figure 7.1 Clarifier SS profile measured at the Lower Molonglo WQCC. Clarifier dimensions $36 \mathrm{~m}$ dia $\times$ $6.26 \mathrm{~m}$ side water depth, flat floor; feed well extends $4 \mathrm{~m}$ below WL. MLSS concentration $3.1 \mathrm{~g} / \mathrm{L}$, SSVI $74 \mathrm{~mL} / \mathrm{g}$, overflow rate $0.86 \mathrm{~m} / \mathrm{h}$, RAS recycle ratio 0.75 , measured RAS concentration $7.3 \mathrm{~g} / \mathrm{L}$.

Significant endogenous denitrification occurred within the sludge blanket. Nitrogen micro-bubbles trapped within the blanket may have contributed to the low sludge settling rate and the apparent decrease in solids concentration in the upper levels.

Note particularly that, in accordance with the theory, (a) in stable operation, the blanket concentration equalled the MLSS concentration, (b) the recycle concentration was $(1+\mathrm{s}) / \mathrm{s}$ times the MLSS concentration, and (c) with a safe recycle ratio (Section 7.3), the depth of the sludge thickening zone was minimal.

\subsection{OPERATING DIAGRAMS}

The operating condition of a clarifier can be evaluated using the operating diagrams shown in Figure 7.2 (UCT et al., 1984; Ekama et al., 1997). The diagrams show whether clarifier failure can be expected at any particular operating condition but give no information on the quantity of solids in the tank.

The diagrams have been drawn for an NDEBPR process and separate diagrams are provided for SSVI values of 50,70, 90 and $120 \mathrm{~mL} / \mathrm{g}$. Interpolation can be used for other values. Table 7.2 describes diagram construction to facilitate production of further diagrams to suit specific plant circumstances.

The diagrams can be explained by reference to Table 7.2. Each diagram has three sets of lines. Lines A are clarification failure boundaries. These are drawn at the sludge settling rate applicable to the particular SSVI and MLSS values. Regardless of the recycle ratio, if the overflow rate at the operating MLSS concentration lies above the appropriate failure boundary, the clarifier will fail in clarification with gross loss of solids. The safe and failure operating regions are noted on the diagram. 
(a)

NDEBPR Process

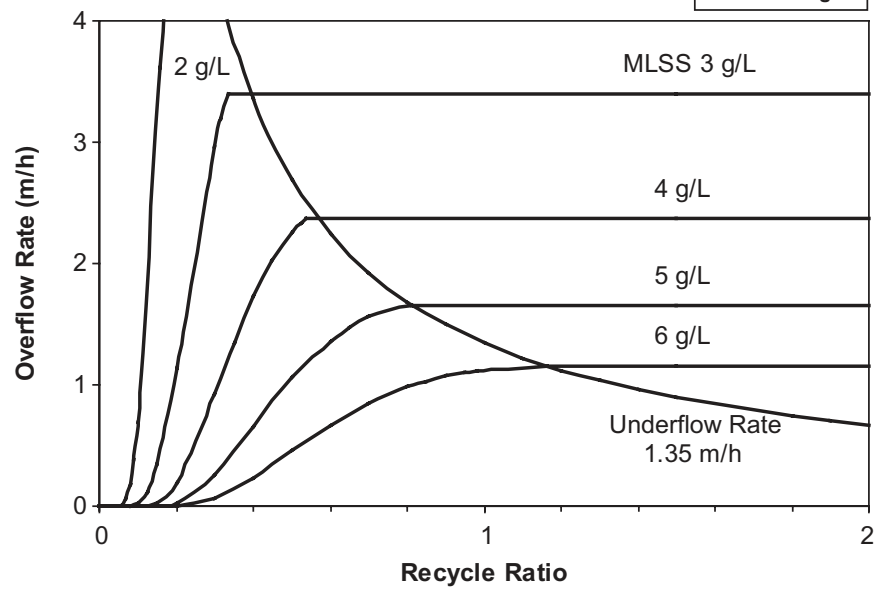

NDEBPR Proces

SSVI $70 \mathrm{~mL} / \mathrm{g}$
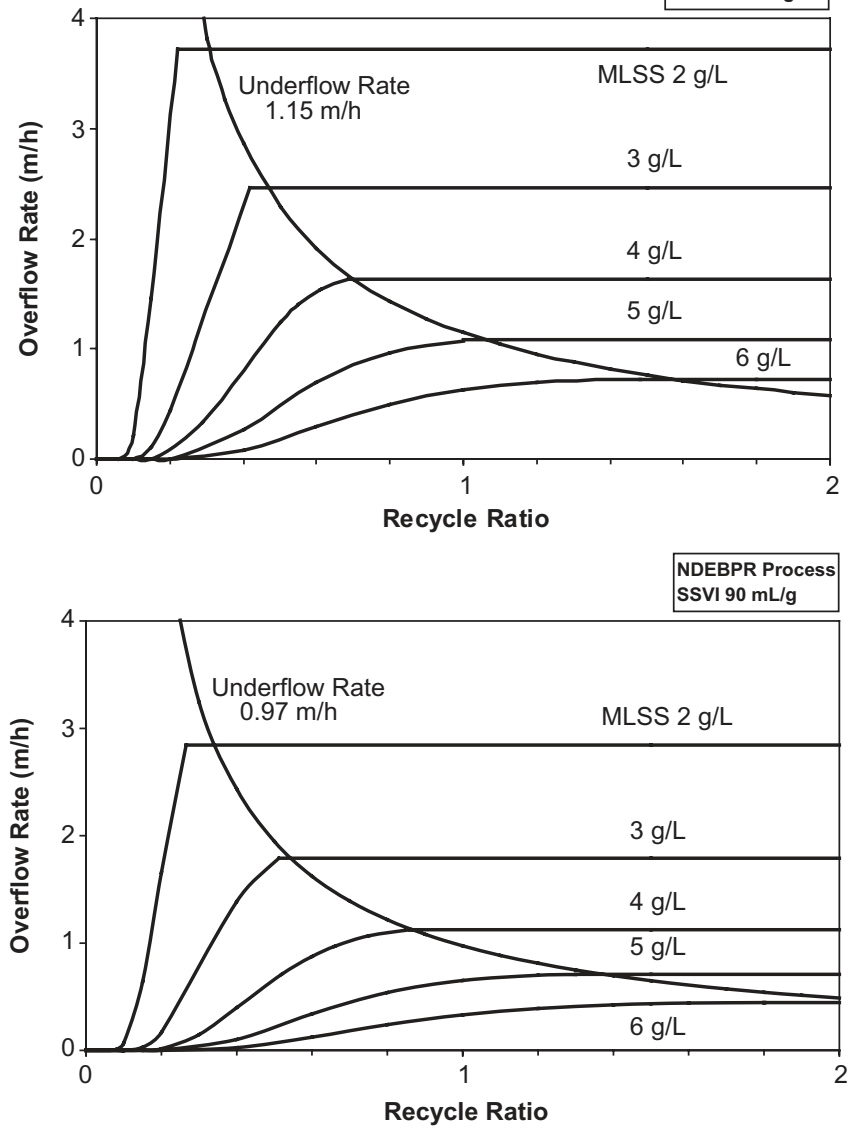

Figure 7.2a Clarifier operating diagrams for SSVIs of 50,70 and $90 \mathrm{~mL} / \mathrm{g}$. 


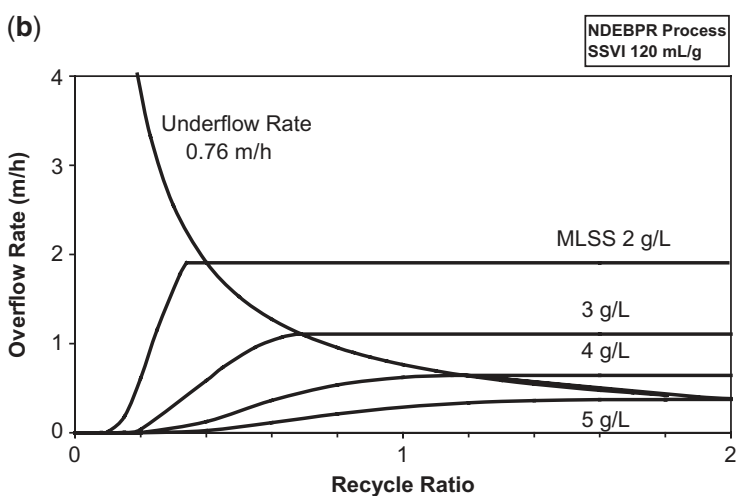

Figure 7.2b Clarifier operating diagram for SSVI of $120 \mathrm{~mL} / \mathrm{g}$.

Table 7.2 Clarifier operating diagram.

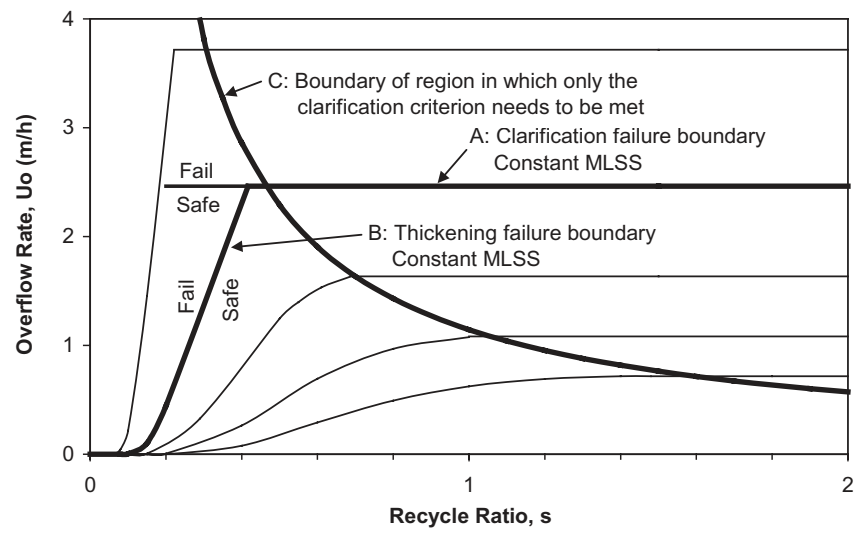

\section{Nomenclature:}

$\mathrm{A}_{\mathrm{C}} \quad$ Clarifier surface area

n $\quad$ Settling constant (see Table 4.1)

Q Plant flow

S RAS recycle ratio

$U_{O} \quad$ Overflow rate, $Q / A_{C}$

$U_{U} \quad$ Underflow rate, $s Q / A_{C}=s U_{O}$

$V_{O} \quad$ Settling constant, $\mathrm{m} / \mathrm{h}$ (see Table 4.1)

$X_{M} \quad$ MLSS (clarifier feed) concentration

$\alpha \quad$ Function in equation for thickening failure boundary

\section{Relationships:}

A. Clarification failure boundary

$$
\left.\mathrm{U}_{\mathrm{O}}=\mathrm{V}_{\mathrm{O} \cdot \exp (-\mathrm{nX}}\right)
$$


Table 7.2 Clarifier operating diagram (Continued).

$$
\begin{aligned}
& \text { B. Thickening failure boundary } \\
& U_{O}=\left(V_{O} / s\right)[(1+\alpha) /(1-\alpha)] \exp \left[-n(1+s) X_{M}(1+\alpha) /(2 s)\right] \\
& \text { Where } \quad \alpha=\left\{1-4 s /\left[n(1+s) X_{M}\right]\right\}^{0.5} \\
& \text { C. Boundary of region in which only the clarification criterion has to be met } \\
& U_{O}=V_{O} /[s \cdot \exp (2)] \\
& \text { or } \\
& s=\exp \left(n X_{M}-2\right)
\end{aligned}
$$

Lines B are thickening failure boundaries. These show the minimum RAS recycle ratio required to avoid thickening failure at particular values of overflow rate, SSVI and MLSS concentration. The safe and failure operating regions are marked.

Line $\mathrm{C}$ divides the operating region in which both clarification and thickening failure can occur from the region in which only clarification failure can occur. If the operating overflow rate is above the clarification boundary for the operating MLSS, clarification failure will occur regardless of the recycle ratio. If the operating recycle ratio is to the left of the appropriate failure boundary, thickening failure will occur. The safe operating region lies below and to the right of the appropriate failure boundaries; failure will occur by clarification and/or thickening if the operating point lies anywhere above or to the left of the failure boundary.

Clarifiers have two safety mechanisms providing robustness against failure. If the operating point moves outside of the failure boundaries, gross solids loss will not occur until sufficient sludge has accumulated in the clarifier to be entrained in the effluent. Short-term (diurnal) overloads can be tolerated if the failure condition is reversed before solids loss begins. Further, the clarifier has a self-compensating mechanism as solids transfer to the clarifier the feed MLSS concentration declines, expanding the safe operating region. The MLSS concentrations shown on the diagrams relate to the values at the peak flow condition, which will be somewhat lower than the preceding values.

\subsection{EFFLUENT QUALITY}

\subsubsection{Factors affecting effluent SS}

This section discusses the factors affecting the effluent SS concentration produced by the clarifiers. The effect of the reactor mixing regime on sludge flocculation is discussed in Chapter 6, Reactors. Other factors are discussed here.

In essence, under average operating conditions (no gross solids loss), the clarifier effluent SS concentration is governed by four factors:

(1) The degree of flocculation, which governs the floc size distribution.

(2) The clarifier overflow rate, governing the percentage of flocs whose settling rate is less than the overflow rate (dispersed solids) and which are therefore carried over in the effluent.

(3) Rising sludge due to denitrification in the clarifier.

(4) Excessive scraper speed which can produce a trailing cloud of SS overflowing the tank. Effluent SS may increase measurably at peripheral scraper speeds above 2-3 m/minute, depending on tank depth, blade height, SSVI and sludge accumulation. 
Factors 1-3 are discussed below.

\section{Degree of flocculation}

The degree of flocculation is dependent on the following:

- Shear history

- Environmental chemistry

- SRT

- SSVI

- MLSS concentration

- Chemical precipitant dosing

Shear history is discussed in Chapter 6; the other drivers are discussed in turn here.

\section{Environmental chemistry}

Flocculation is affected by the ionic strength, inorganic composition and $\mathrm{pH}$ of the aqueous environment. In particular, elevated cation concentrations enhance the binding capacity of the EPS. In laboratory flocculation studies, Biggs (2000) found that adding $160 \mathrm{mg} / \mathrm{L}$ of calcium to the ND sludge increased the median steady state floc size by $40 \%$. Calcium additions of $80 \mathrm{mg} / \mathrm{L}$ or less had no effect on steady state floc size but reflocculation after shear was faster.

\section{SRT}

Flocculation is better at lower growth rates (longer SRTs) because EPS production is greater (Wilen et al., 2010). Figure 7.3 shows the effect of SRT on the percentage of dispersed solids in the mixed liquor and the resultant performance of a full-scale plant. At very short SRT the bacterial growth rate is high and flocculation poor. As SRT increases the bacteria excrete greater quantities of natural polymer and flocculation becomes more complete.
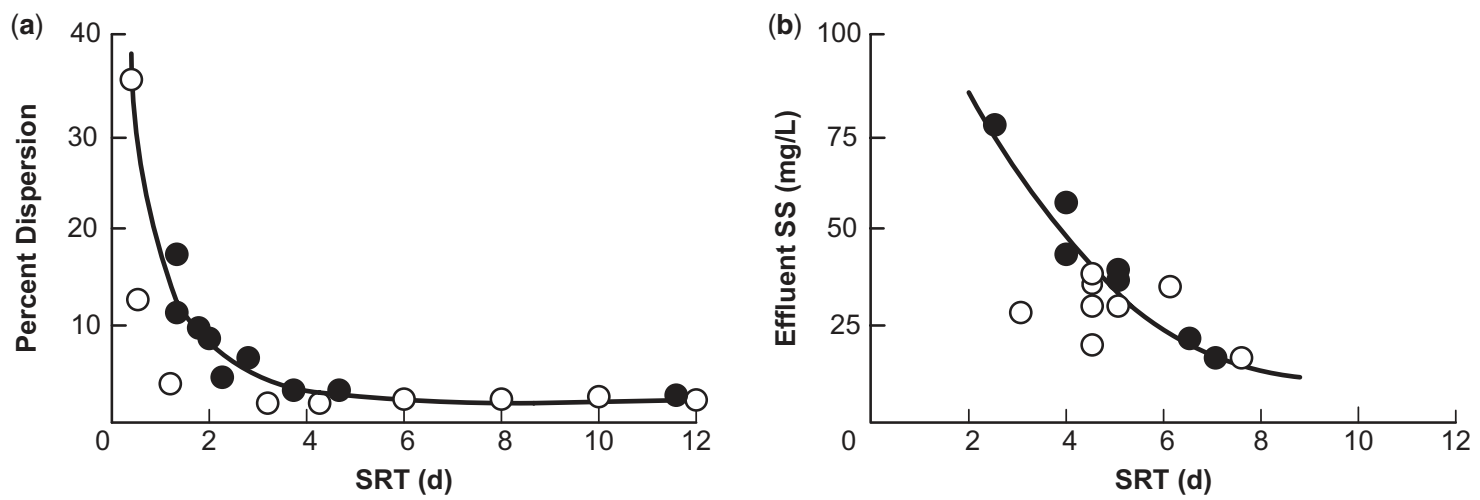

Figure 7.3 (a) Percentage of MLSS which are dispersed, measured on laboratory activated sludge units. - Chao and Keinath (1979), SVI 100-725; O Bisogni \& Lawrence (1971), SVI 80-600.

(b) Effect of SRT on effluent SS at the 25,000 EP, mechanically aerated, conventional activated sludge plant at Redcliffe, Queensland (Hartley, 1985). Monthly average data for Jan-81 to Mar-82.

- SVI 77-112; O SVI 142-430. 
SSVI

The impacts of both settleability (as SVI) and shear history are illustrated in Figure 4.11. For a given plant type, the higher the SVI the lower the percentage of very small flocs and the lower the effluent SS. There is a fair scatter due to the effects of other parameters but the general SVI trends are clear.

The three plant types shown represent a gradation in mixed liquor shear history ahead of clarification. The conventional activated sludge plants had shorter SRTs and higher mixing intensities in both reactors and sludge transfer systems. The intermittently decanted plant (Jimboomba) had no primary treatment, long SRT (greater than 20d), lower reactor mixing intensity and no sludge transfer requirement prior to settling.

The oxidation ditch plant (West Byron) also had long SRT, plus the low mixing intensity characteristic of oxidation ditches, enhanced in this case by the use of fine pore diffused air rather than mechanical aeration. Flow along an oxidation ditch channel provides uniform mixing at the lowest practical turbulence level; if the mixed liquor offtake is located well downstream of the aeration zone, reflocculation can take place before transfer to the clarifier. Flow at a typical velocity of $0.25 \mathrm{~m} / \mathrm{s}$ in the $6 \mathrm{~m}$ wide $\times 4 \mathrm{~m}$ deep channel at West Byron had a mean $\mathrm{G}$ value of only $3 \mathrm{~s}^{-1}$.

\section{MLSS concentration}

Increasing MLSS concentration improves flocculation and reduces effluent SS concentration. Figure 7.4 illustrates this using data from a pilot plant settleability study and from the parallel full-scale plant (Lower Molonglo, Canberra) which is an ND plant with chemically enhanced primary treatment.

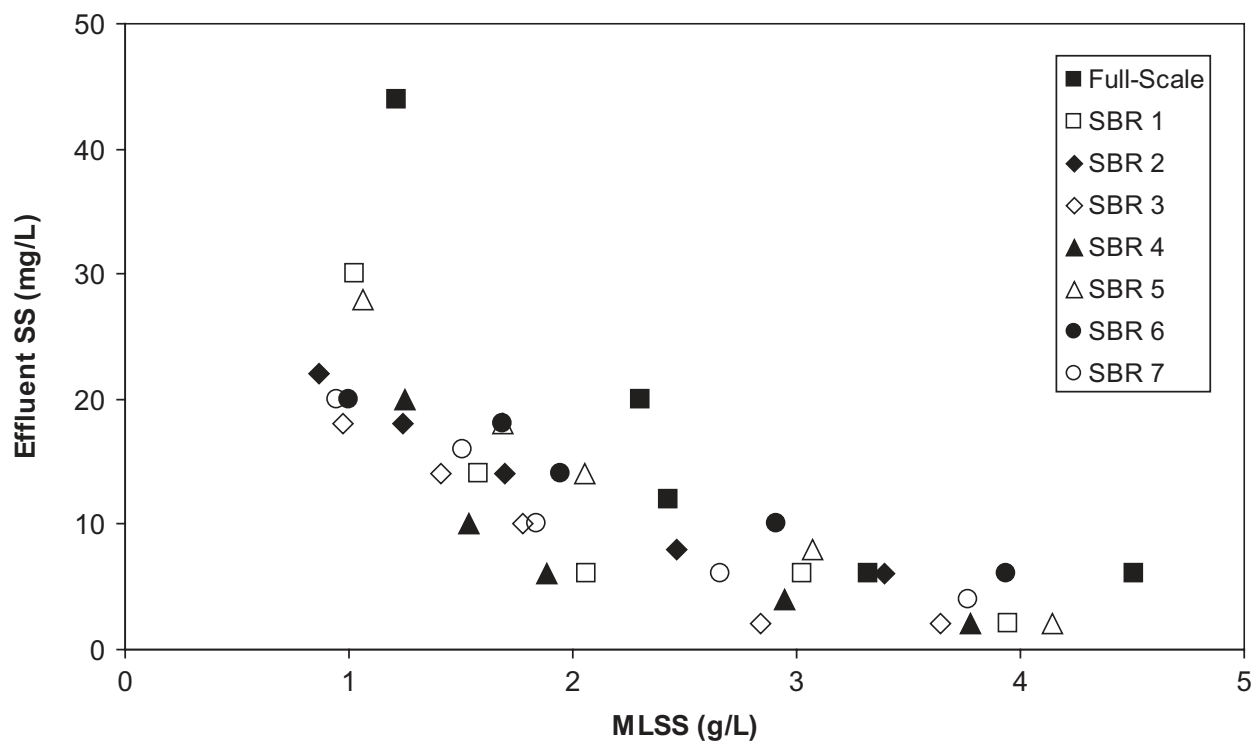

Figure 7.4 Effect of MLSS concentration on the supernatant SS concentration at the end of 30 minute mixed liquor settling tests (Wastewater Futures, 2007). Data were collected during a pilot sludge settleability study conducted using seven SBRs operated in parallel with the full-scale Lower Molonglo plant in Canberra. The SBRs all operated with different cycle regimes and different SSVIs. Representative data from the full-scale plant are also shown. 


\section{Chemical precipitant dosing}

Dosing of alum or iron to the biological reactor causes hydroxide and phosphate precipitates to be incorporated in the floc structure (see Chapter 3). This weakens the floc, reducing the average floc size and increasing the percentage of smaller flocs discharged in the effluent.

Figure 7.5 illustrates this using operating trends from the West Byron NDEBPR oxidation ditch plant in Byron Bay, NSW. Ferric sulfate was dosed at the plant inlet for sulfide precipitation and alum was dosed to the bioreactor for supplementation of bio-P removal. Ferric sulfide entering the reactor would have been oxidised to ferric sulfate which formed co-precipitates with the alum.

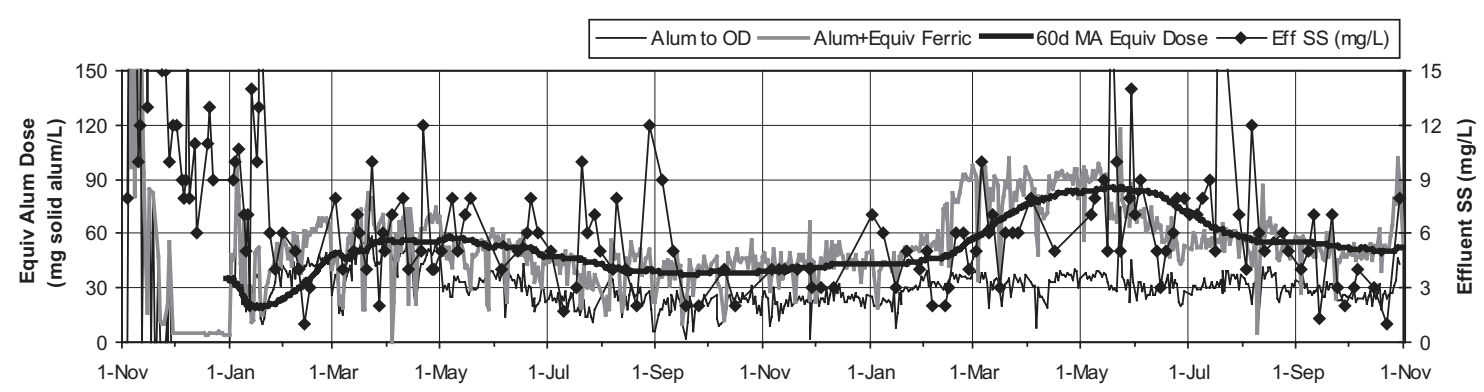

Figure 7.5 West Byron STP: two-year trends from plant startup in Nov-05. Correlation between effluent SS and 3SRT moving average precipitant dose. Median MLSS and unstirred SVI were $3.2 \mathrm{~g} / \mathrm{L}$ and $80 \mathrm{~mL} / \mathrm{g}$ respectively.

The figure shows two years of trends for precipitant dose (alum plus equivalent ferric) and effluent SS. Both daily and three-SRT (60 day) moving average chemical dose rates are shown because it takes about three SRTs for changes in reactor dose rate to have full effect. By using appropriate scales the chemical dose rate and SS trends have been aligned. It can be seen that the 3SRT moving average dose rate aligns well with the effluent SS trend, indicating that precipitant dosing had a significant effect on effluent SS behaviour which varied in proportion to the dose rate.

Further insight is provided by the behaviour of an SBR treating the discharge from anaerobic lagoons receiving beef abattoir wastewater. Figure 7.6 shows operating trends for a five month period at the end of 2003. The SBR was operated using a 6-hour cycle which achieved near-complete nitrogen removal anoxic feed $0.5 \mathrm{~h}$, aerobic feed $2.5 \mathrm{~h}$, aeration with no feed $0.5 \mathrm{~h}$, settle and decant $2.5 \mathrm{~h}$. On 5-Aug a trial period of alum dosing began in order to reduce the phosphorus discharge in the effluent. Table 7.3 summarises the average performance for the two weeks before alum dosing began and for the two months following a 60 day (three SRT) adjustment period after dosing began.

It can be seen that alum dosing caused the MLSS to increase and the SVI to fall, consistent with the Maroochydore example discussed in Chapter 4. Effluent SS also increased as seen in the West Byron example above. Further, ammonia became less stable because of the reduction in mixed liquor $\mathrm{pH}$ associated with the alum dosing. An unexpected result was an increase in effluent nitrate concentration. Part of the nitrate removal was occurring by simultaneous nitrification and denitrification (SND) during the aerated feed phase (as discussed in Chapters 3 and 6). The observed reduction in nitrate removal was consistent with a reduction in average floc size, causing a diminution of the volume percentage occupied by the anoxic core. The required nitrate removal was subsequently reinstated by reducing the operating DO concentration during the aerobic feed phase. 
(a)

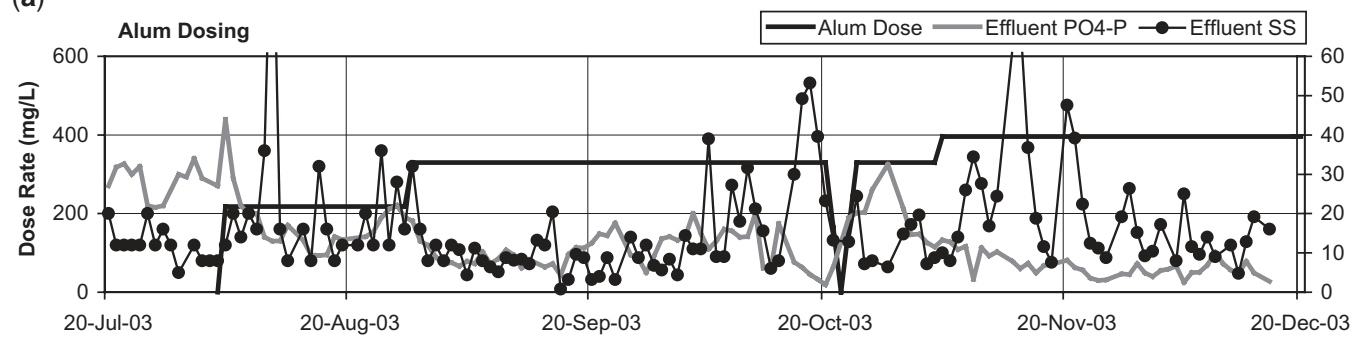

(b)

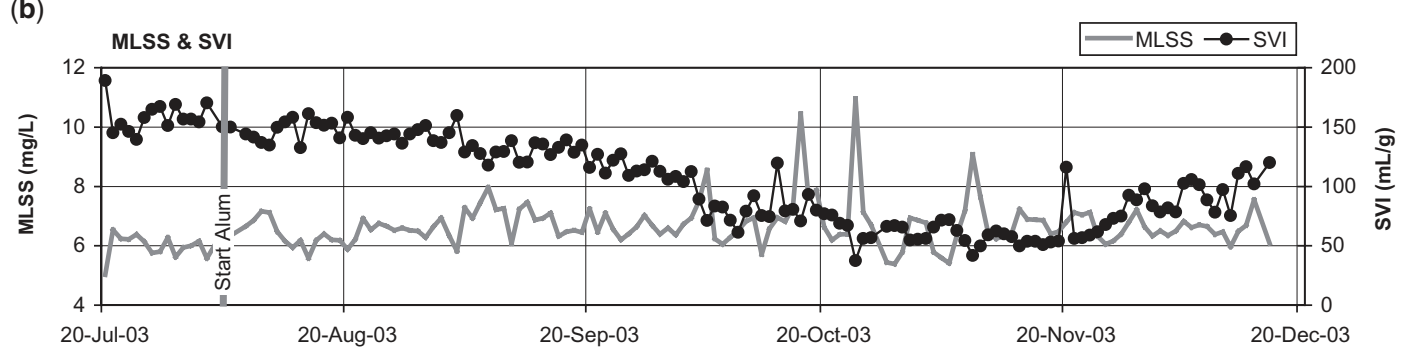

(c)

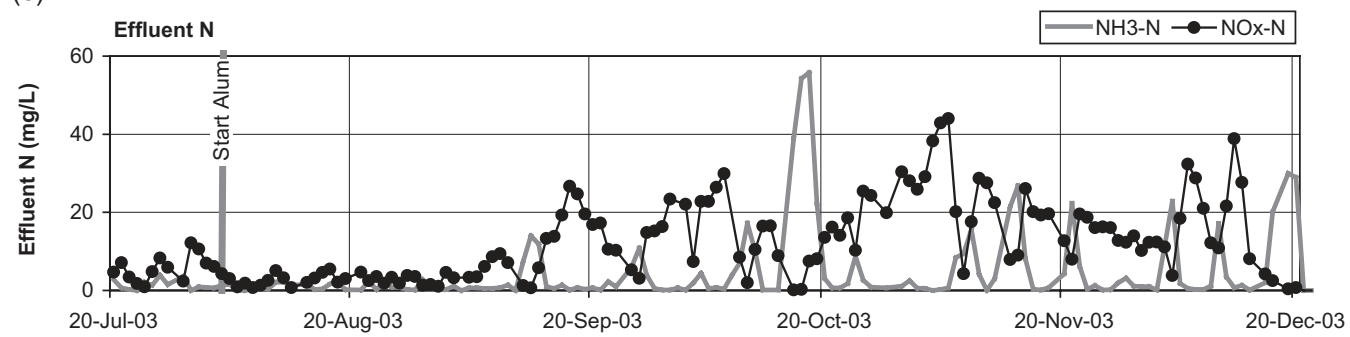

Figure 7.6 Trend plots from an SBR treating abattoir wastewater, showing the behaviour when alum dosing for $P$ removal was initiated.

Table 7.3 Abattoir SBR - operating data.

\begin{tabular}{|c|c|c|c|}
\hline \multirow[t]{2}{*}{ Parameter } & & \multicolumn{2}{|c|}{ Average Operating Value } \\
\hline & & $\begin{array}{l}\text { Before Alum } \\
\text { Dosing 20-Jul to } \\
\text { 4-Aug-03 }\end{array}$ & $\begin{array}{l}\text { With Alum } \\
\text { Dosing }^{1} 5-\text { Oct to } \\
\text { 16-Dec-03 }\end{array}$ \\
\hline \multicolumn{4}{|l|}{ Influent } \\
\hline COD biodegradable & $\mathrm{mg} / \mathrm{L}$ & 1350 & 1350 \\
\hline Total N & $\mathrm{mg} / \mathrm{L}$ & 190 & 206 \\
\hline Total P & $\mathrm{mg} / \mathrm{L}$ & 40 & 43 \\
\hline
\end{tabular}

(Continued) 
Table 7.3 Abattoir SBR - operating data (Continued).

\begin{tabular}{llcc}
\hline Parameter & & \multicolumn{2}{c}{ Average Operating Value } \\
\cline { 3 - 4 } & & $\begin{array}{l}\text { Before Alum } \\
\text { Dosing 20-Jul to } \\
\text { 4-Aug-03 }\end{array}$ & $\begin{array}{c}\text { With Alum } \\
\text { Dosing }\end{array}$ \\
16-Dec-03
\end{tabular}

${ }^{1}$ Period beginning three SRTs (60d) after dosing began.

This experience supports the premise that alum or iron dosing weakens the floc structure, producing a reduction in average floc size and an increase in effluent SS.

\section{Overflow and settling rates}

Figure 7.7 shows two years of SSVI and clarifier effluent SS data from a large conventional activated sludge plant with primary treatment and step feeding. Median SSVI and effluent SS values for this period were $90 \mathrm{~mL} / \mathrm{g}$ and $19 \mathrm{mg} / \mathrm{L}$ respectively, which are generally consistent with the conventional activated sludge data in Figure 4.11. However, in Figure 7.7 it can be seen that judicious choice of scales highlights a strong correlation between the effluent SS trend and the ratio of overflow rate (Uo) to sludge settling velocity (Vs) at the feed MLSS concentration. The sludge settling velocity, governed by both MLSS concentration and SSVI, was measured as initial settling velocity in the routine SSVI tests, and is generally consistent with expectations from Equation 4.2.

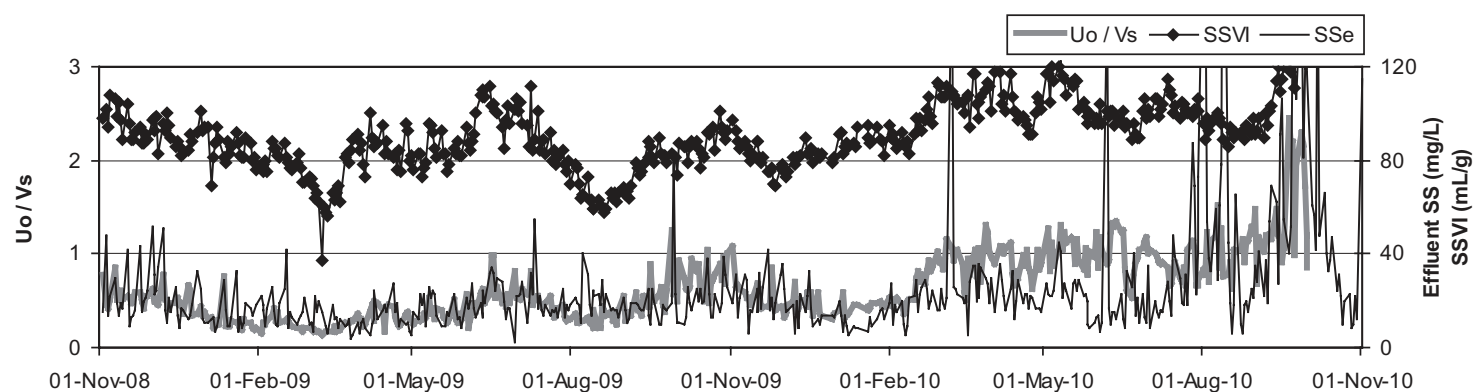

Figure 7.7 Two years of daily data from the circular secondary clarifiers at Melbourne's $350 \mathrm{ML} / \mathrm{d}$ Eastern Treatment Plant. SSe is the clarifier effluent SS concentration, Uo the clarifier overflow rate and Vs the sludge settling rate at the MLSS concentration in the clarifier feed. 
It can also be seen in Figure 7.7 that over the last few months, when the operating Uo:Vs ratio increased to 1 or more, the effluent SS concentration became more variable and excessive solids losses occurred, as would be expected.

\section{Rising sludge}

Rising sludge occurs in the clarifier of a nitrifying plant when denitrification in the clarifier underflow zone produces sufficient volume of precipitated gas bubbles to float solids to the surface. Incipient rising sludge can be seen as a few isolated lumps of sludge, particularly just behind the scraper, while a full blown problem produces a thick scum layer covering the whole tank.

When mixed liquor enters the clarifier any residual dissolved oxygen is exhausted within a few minutes. The biomass then switches to nitrate respiration, producing nitrogen. When the water becomes supersaturated with nitrogen, bubbles form and attach themselves to the solids. Other gases, predominantly nitrogen and carbon dioxide, also precipitate so that the composition of the gas bubbles reflects the partial pressures of all the gases in solution. When the solids density has been reduced sufficiently, clumps of sludge break free and rise to the surface.

Experience shows that rising sludge will generally not occur if the nitrate concentration in the clarifier feed is less than $15-20 \mathrm{mgN} / \mathrm{L}$.

\subsubsection{Other effects of clarifiers on effluent quality}

Impacts of clarification on effluent SS and denitrification have been discussed above. Clarifiers can also affect effluent quality in other ways:

- Depending on the relative volumes of reactors and clarifiers, large feed wells can contain up to $10 \%$ of the total sludge mass in the process. This volume acts as a secondary zone in which endogenous ammonia release and further nitrification/denitrification may occur. These processes may have a measurable effect on very low effluent ammonia and total $\mathrm{N}$ concentrations.

- Chemical precipitant dosing reduces effluent soluble organic N (Chapter 3). Given that chemical precipitant dosing increases effluent SS and associated particulate $\mathrm{N}$, there may therefore be an optimum precipitant dose producing minimum total $\mathrm{N}$ concentration.

- Similarly, precipitant dosing will increase effluent particulate P. There may therefore be an optimum precipitant dose producing minimum total $\mathrm{P}$ concentration.

\subsection{CLARIFIER STRESS TESTING}

Plant clarifier capacity can be assessed by stress testing - taking clarifiers off-line to increase the load on the remaining operating units. The procedure can be illustrated using a stress test conducted at the Loganholme oxidation ditch plant in Brisbane (Hartley, 2012). The facility comprised parallel A and B Plants with design peak wet weather flow capacities of 90 and $110 \mathrm{ML} / \mathrm{d}$ respectively $(200 \mathrm{ML} / \mathrm{d}$ total).

The A Plant had four secondary clarifiers, two of $32 \mathrm{~m}$ diameter and two of $36 \mathrm{~m}$ diameter, all with $3 \mathrm{~m}$ side water depths. The B Plant had four $40 \mathrm{~m}$ diameter clarifiers with $5 \mathrm{~m}$ side water depths. Operating SRT was 10 days. The test was intended to provide data on (a) the relationship between overflow rate and effluent SS, and (b) the clarifier gross failure capacity. The test was carried out by progressively reducing the number of clarifiers on-line, at constant RAS flow per clarifier, to increase the clarifier overflow rates and reduce the RAS recycle ratios. 
The impact on effluent SS is shown in Figure 7.8. The effluent SS concentration was lower in the B Plant than in the A Plant, possibly because of the B Plant's greater side water depth.

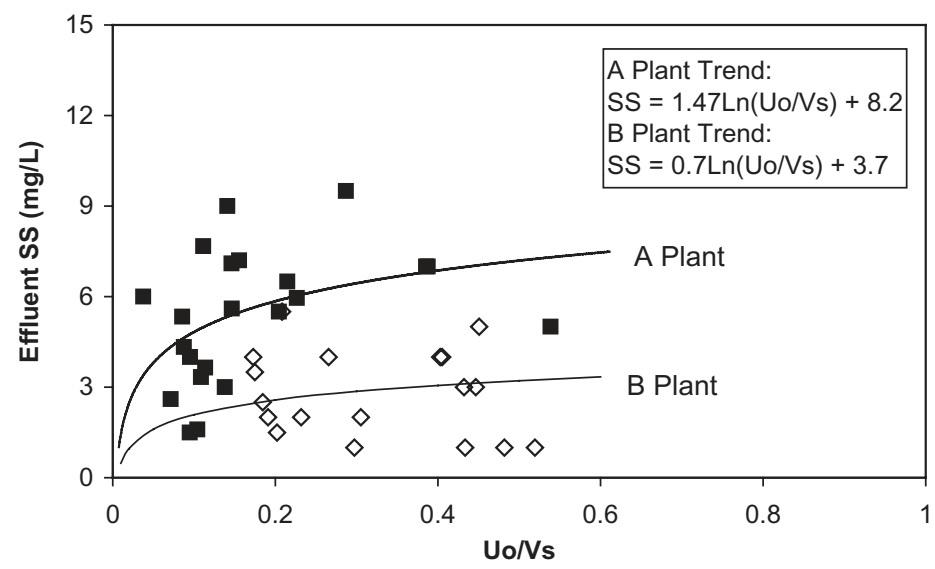

Figure 7.8 Effluent SS correlated with clarifier loading. Uo is clarifier average overflow rate based on the average plant inflow rate for the hour preceding the sampling time; Vs is the sludge settling rate at the MLSS concentration, calculated from the MLSS and SSVI using the relationships of Ozinsky \& Ekama (Table 4.1).

Figure 7.9a shows the results of the A Plant test with only one $32 \mathrm{~m}$ diameter clarifier on-line. In this test the clarifier loading was high enough to demonstrate thickening failure. The following can be observed:

(1) The ratio of overflow rate to theoretical settling rate at the MLSS concentration, $U_{\mathrm{O}} / \mathrm{V}_{\mathrm{S}}$, increased steadily over the morning from 0.1 to 0.9 .

(2) At the same time the RAS recycle ratio (at a constant $95 \mathrm{~L} / \mathrm{s}$, governed by the RAS bellmouth setting - full down) decreased from greater than 1 to 0.2 .

(3) As a result the sludge blanket level (measured with hand-held instrument) increased from near-zero to $50 \%$ of the side water depth, above the bottom of the feed well located at $32 \%$ ( $2 \mathrm{~m}$ below the surface).

(4) Effluent SS was $7 \mathrm{mg} / \mathrm{L}$ at 07:30 and 08:30 when the blanket was below the feedwell; effluent SS was consistent with previous tests (Figure 7.8). At 09:30 the blanket level at the monitoring point was above the bottom of the feedwell and the effluent SS was measured at only $5 \mathrm{mg} / \mathrm{L}$, presumably because the blanket was providing a degree of additional flocculation. However, at 10:30 when the blanket level was nearly $0.6 \mathrm{~m}$ above the bottom of the feedwell and $1.4 \mathrm{~m}$ below the surface, the effluent SS had increased to $120 \mathrm{mg} / \mathrm{L}$, suggesting that disturbance of the blanket was causing carryover.

The clarifier operating condition during the test is shown in the operating diagram in Figure 7.9b, drawn for the operating SSVI of about $80 \mathrm{~mL} / \mathrm{g}$. The lines rising from the origin are failure boundaries for the MLSS concentrations shown. Above the curved $1.15 \mathrm{~m} / \mathrm{h}$ underflow rate line, clarification (overflow rate) governs capacity whereas below the underflow rate line thickening (RAS recycle ratio) governs.

The failure boundary for MLSS $2.8 \mathrm{~g} / \mathrm{L}$ is the failure line for the test condition. The operating conditions during the test are shown as the $0.43 \mathrm{~m} / \mathrm{h}$ underflow rate line. It can be seen that the operating line lies well 
within the thickening zone, meaning that the RAS recycle ratio (thickening) governs capacity. Failure occurs when the underflow line reaches the failure boundary at point $F$, shown in both (a) and (b). This means that at an SSVI of $80 \mathrm{~mL} / \mathrm{g}$, an MLSS concentration of $2.8 \mathrm{~g} / \mathrm{L}$, and a recycle flow of $95 \mathrm{~L} / \mathrm{s}$, when the RAS recycle ratio falls below about 0.3 the sludge cannot thicken sufficiently for the solids outflow in the RAS to match the solids inflow to the clarifier. Solids will therefore accumulate in the clarifier until solids loss in the effluent makes up the difference. It can be seen in Figure (a) that just after Point $F$ was reached the effluent SS had increased to $120 \mathrm{mg} / \mathrm{L}$.
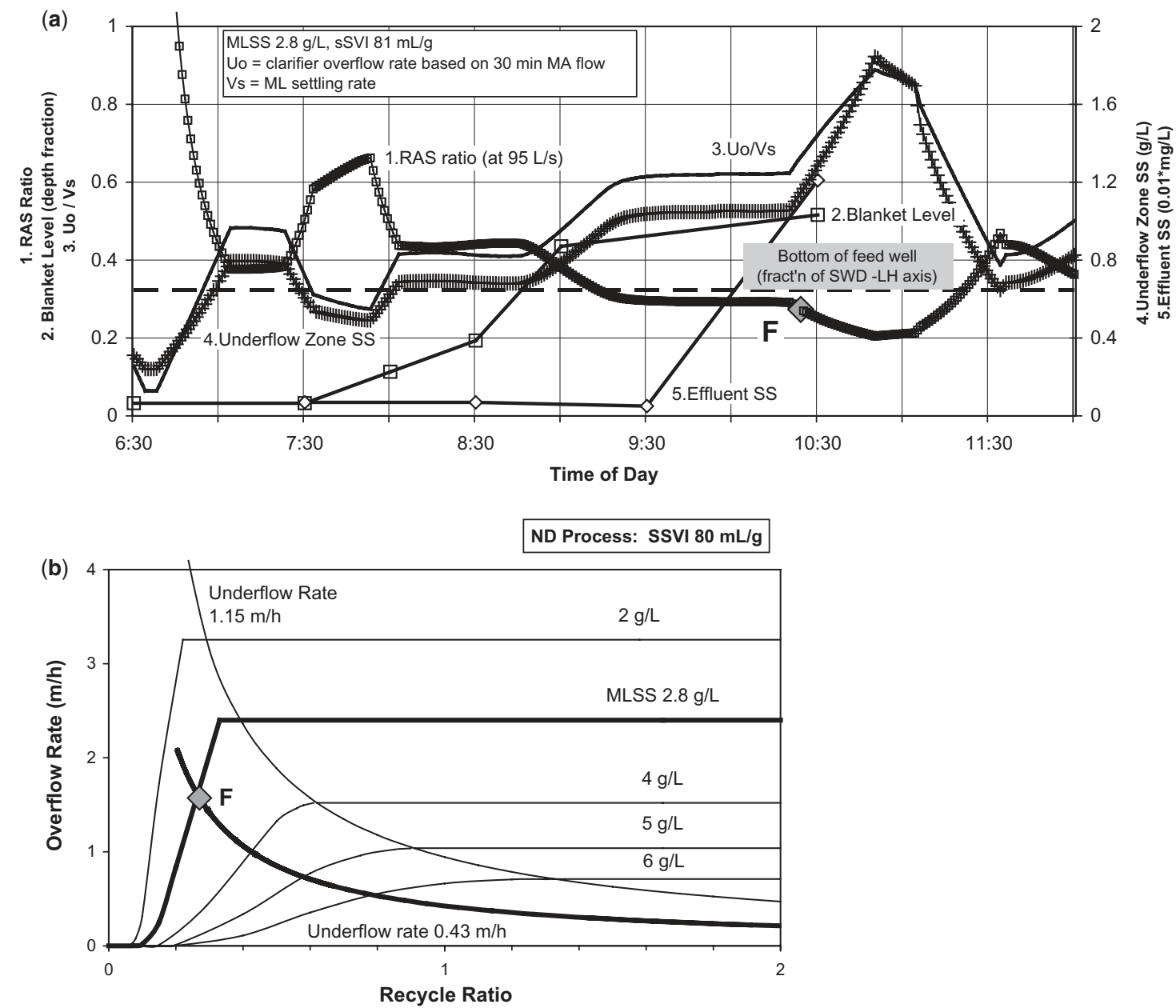

Figure 7.9 (a) A Plant clarifier behaviour with only one clarifier online. When effluent SS were seen to have risen sharply at 10:30 am the stress test was abandoned and other clarifiers brought back online. RAS flow $95 \mathrm{~L} / \mathrm{s}$ (maximum flow from one bellmouth). Parameters 1, 2 \& 5 were measured, other parameters were calculated. (b) Clarifier operating diagram showing the operating conditions during the stress test (underflow rate $0.43 \mathrm{~m} / \mathrm{h}$ ). As the test progressed and the recycle ratio declined the operating condition moved up the $0.43 \mathrm{~m} / \mathrm{h}$ line until thickening failure occurred at point $F$, marked in both (a) and (b). 
The A Plant gross clarifier capacity at SSVI $80 \mathrm{~mL} / \mathrm{g}$ can be estimated from these test results as follows:

- Point F in Figure 7.9b represents the A Plant test capacity (with minimal sludge transfer to the clarifiers as only $20 \%$ of the total clarifier area was on-line).

- During the test period the plant COD load was only $60 \%$ of the design load. At the full design load the A Plant MLSS concentration would increase to $4.7 \mathrm{~g} / \mathrm{L}$, however sludge transfer to the clarifiers under peak conditions would reduce that to $3.6 \mathrm{~g} / \mathrm{L}$.

- From Figure 7.9b, at an MLSS concentration of $3.6 \mathrm{~g} / \mathrm{L}$ the maximum overflow rate would be $1.2 \mathrm{~m} / \mathrm{h}$ (limited by the RAS capacity), giving an A Plant clarifier peak flow capacity of $105 \mathrm{ML} / \mathrm{d}$.

The clarifier testing produced results consistent with theoretical expectations and provided insight into the clarifier behaviour under high load conditions. 


\section{Chapter 8}

\section{Sludge processes}

\subsection{OVERVIEW}

This chapter describes the characteristics of the sludge stabilisation and dewatering processes common to BNR plants. Primary treatment is rare and the waste activated sludge is usually stabilised by aerobic digestion.

A typical solids stream process format is shown in Figure 8.1. The aerobic digester may be decanted periodically to thicken the sludge and increase the solids digestion time. Sludge is usually dewatered by belt filter press (BFP) or centrifuge. Belt washwater is required for the BFP.

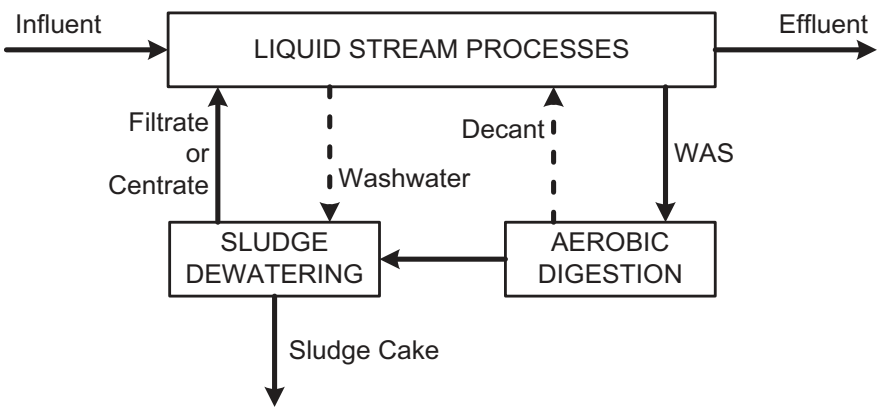

Figure 8.1 Interaction between the liquid stream and solids stream processes.

The following sections discuss the characteristics of aerobic digesters, BFPs and centrifuges.

\subsection{AEROBIC DIGESTION}

The usual goal of aerobic digestion is to stabilise the WAS to a standard suitable for agricultural reuse. A standard commonly applied is a reduction of the biosolids specific oxygen uptake rate at $20^{\circ} \mathrm{C}$ $\left(\mathrm{SOUR}_{20}\right.$ ) to less than $1.5 \mathrm{mgO}_{2} / \mathrm{h} / \mathrm{gTS}$ (Grade A solids stabilisation for vector attraction reduction, EPA NSW, 1997). 
Figure 8.2 shows the basic single stage digester which has the following features:

- Single tank with variable volume to allow wasting and dewatering to be operated at different times and rates. For example, sludge may be wasted to the digester on seven days per week but sludge dewatering may operate on only five days.

- Possible supernatant decanting to increase the SRT over the HRT and increase VS destruction.

- Intermittent aeration for nitrification and denitrification of released nitrogen. Aerating intermittently reduces alkalinity loss and reduces nitrogen recycle to the bioreactor in the dewatering return stream.

- Alum (or iron) dosing may also be provided to precipitate P released by VSS destruction. This reduces phosphorus recycle to the bioreactor. When a plant requires alum for supplementary $\mathrm{P}$ removal, dosing of the digester reduces overall alum consumption, and therefore the alum content of the digested sludge, if the digester is operated at a phosphate concentration higher than the reactor level (because alum $\mathrm{P}$ uptake is greater at higher $\mathrm{P}$ level, see Figure 3.36). In addition, alum precipitate in the digester feed can take up additional $\mathrm{P}$ at the higher digester phosphate level.

- Alkali dosing to counteract the alkalinity loss due to nitrification/denitrification and alum dosing and maintain an acceptable digester $\mathrm{pH}$.

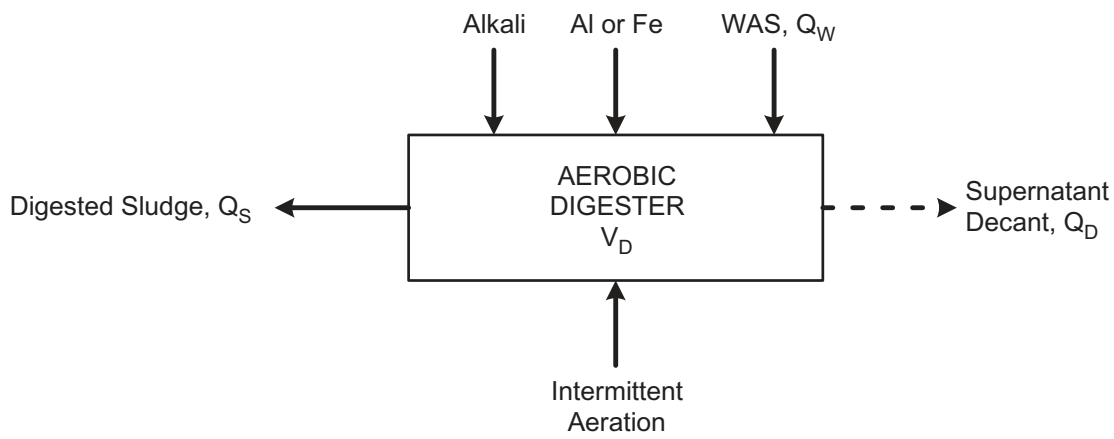

Figure 8.2 Basic single stage aerobic digester with alum or ferric dosing for precipitation of released $\mathrm{P}$ and alkali dosing to counterbalance alkalinity loss due to nitrification/denitrification and alum dosing.

The hydraulic and solids residence times can be calculated as follows:

$$
\begin{aligned}
\mathrm{HRT} & =\mathrm{V}_{\mathrm{D}} / \mathrm{Q}_{\mathrm{W}} \\
\mathrm{SRT} & =\mathrm{V}_{\mathrm{D}} / \mathrm{Q}_{\mathrm{S}}
\end{aligned}
$$

where

HRT $=$ hydraulic retention time, $\mathrm{d}$

$\mathrm{SRT}=$ solids retention time, $\mathrm{d}$

$\mathrm{Q}_{\mathrm{S}}=$ sludge flow to dewatering, $\mathrm{kL} / \mathrm{d}$

$\mathrm{Q}_{\mathrm{W}}=$ WAS flow into digester, $\mathrm{kL} / \mathrm{d}$

$\mathrm{V}_{\mathrm{D}}=$ digester operating volume, $\mathrm{kL}$

\subsubsection{Stabilisation performance}

Figure 8.3 shows the sludge stabilisation performance of a single stage complete mix digester. Multi-stage digesters can achieve the same degree of stabilisation with a shorter total residence time. 

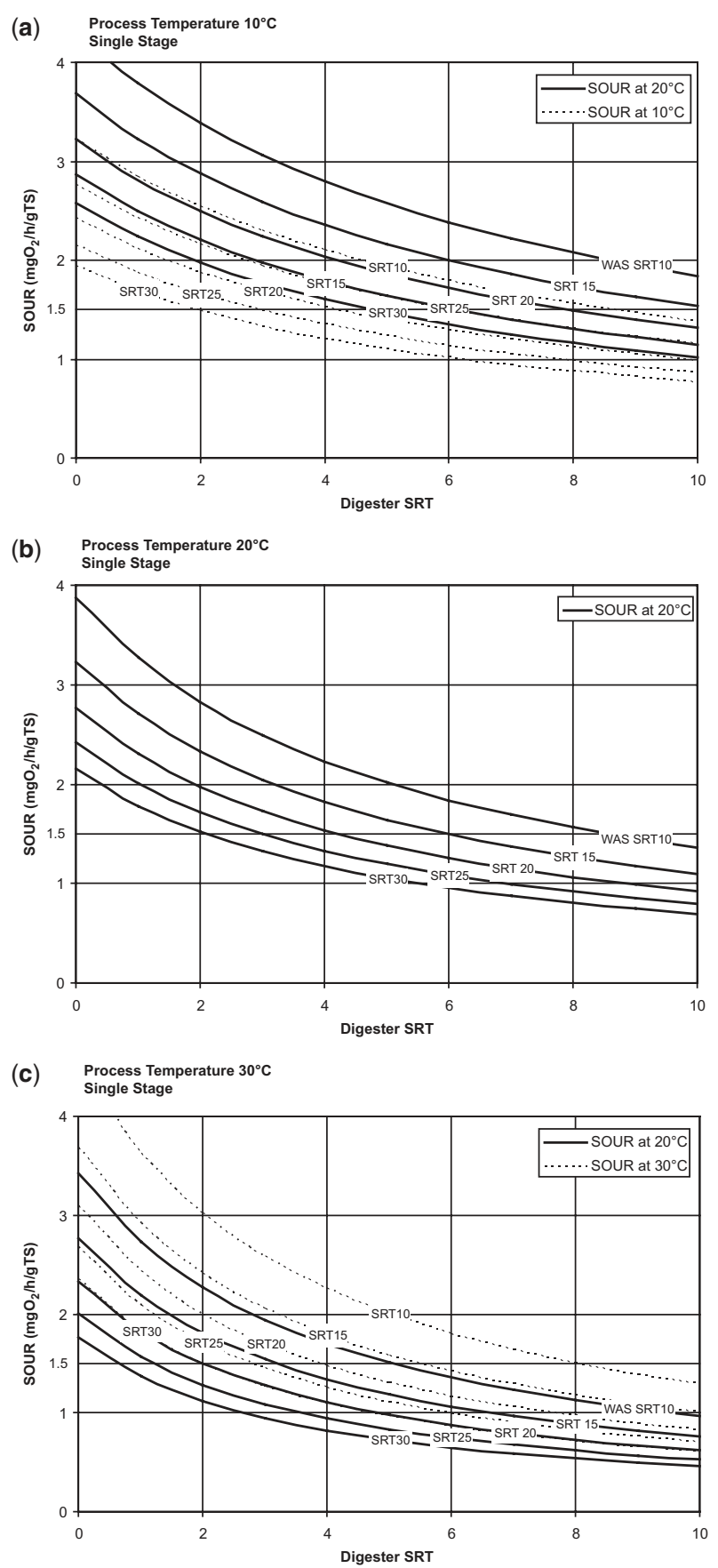

Figure 8.3 Sludge stabilisation performance of single stage aerobic digesters fed WAS with MLVSS/MLSS 0.7 . Figures (a) to (c) relate to process operating temperatures (WAS source and digester) of $10-30^{\circ} \mathrm{C}$ and show lines for WAS source SRTs of 10-30d. Dotted lines represent the SOUR within the digester and solid lines the SOUR measured on samples adjusted to $20^{\circ} \mathrm{C}$. 
Table 8.1 summarises the single stage digester residence time needed to achieve an SOUR $_{20}$ of 1.5 $\mathrm{mgO}_{2} / \mathrm{h} / \mathrm{gTS}$.

Table 8.1 Digester SRT to achieve grade A solids stabilisation ${ }^{1}$.

\begin{tabular}{|c|c|c|c|c|c|c|c|c|c|c|}
\hline WAS Source SRT & d & & 10 & & & 20 & & & 30 & \\
\hline Temperature & ${ }^{\circ} \mathrm{C}$ & 10 & 20 & 30 & 10 & 20 & 30 & 10 & 20 & 30 \\
\hline Digester SRT & d & $>10$ & 9 & 5 & 8 & 4 & 2 & 5 & 2 & $<1$ \\
\hline
\end{tabular}

${ }^{1}$ WAS MLVSS/MLSS 0.7 .

\subsubsection{Operating characteristics}

Table 8.2 lists typical characteristics for an aerobic digester fed WAS from a bioreactor operating at $20^{\circ} \mathrm{C}$ and 20d SRT. A simple test procedure for measuring SOUR is set out in Table 8.3.

Table 8.2 Typical digester operating characteristics.

\begin{tabular}{|c|c|c|c|c|c|c|}
\hline \multirow[t]{3}{*}{$\begin{array}{l}\text { SRT } \\
\text { (d) }\end{array}$} & \multirow[t]{3}{*}{$\begin{array}{l}\text { Oxygen Demand } \\
\text { (mg/g feed SS) }\end{array}$} & \multicolumn{2}{|c|}{$\begin{array}{c}\text { Nutrient } \\
\text { Release } \\
\text { (mg/g feed SS) }\end{array}$} & \multicolumn{3}{|c|}{ Chemical Dose Rate (when used) } \\
\hline & & \multirow[t]{2}{*}{$\mathbf{N}$} & \multirow[t]{2}{*}{$\mathbf{P}$} & \multirow[t]{2}{*}{$\begin{array}{l}\text { Alum }{ }^{1} \text { (mg solid } \\
\text { alum } / \mathrm{g} \text { feed } S S \text { ) }\end{array}$} & \multicolumn{2}{|c|}{$\begin{array}{c}\text { Alkali }^{2} \\
\text { (mgCaCO } 3 / \text { feed SS) }\end{array}$} \\
\hline & & & & & N/DN & N/DN plus alum \\
\hline 5 & 1.4 & 9 & 6 & 50 & 30 & 40 \\
\hline
\end{tabular}

Table 8.3 SOUR test procedure.

\section{Procedure}

1. Sample the digester during the period sludge is being fed to the dewatering system.

2. Mix the sample and divide into two. Measure the SS concentration of one portion.

3. Use the other portion to measure the oxygen uptake rate. Conduct the test at a temperature as near as possible to $20^{\circ} \mathrm{C}$. Aerate the sample to raise its $\mathrm{DO}$ concentration to several $\mathrm{mg} / \mathrm{L}$. Record the sample temperature. Stop aerating and maintain uniform SS by gentle stirring (to minimise surface aeration) with a magnetic stirrer or similar. Monitor the rate at which DO falls - time and DO.

4. Plot the falling $D O$ profile and calculate the slope of the straight part of the line $(\mathrm{mg} / \mathrm{L} \cdot \mathrm{min})$. To adjust to $20^{\circ} \mathrm{C}$, multiply the result by $1.029^{(20-\mathrm{T})}$, where $\mathrm{T}$ is the test temperature.

5. Calculate the specific oxygen uptake rate in $\mathrm{mgO}_{2} / \mathrm{h} / \mathrm{gTSS}$ from:

$\mathrm{SOUR}_{20}=$ rate of decrease in $\mathrm{DO}(\mathrm{mg} / \mathrm{L} \cdot \mathrm{min}) \times 60 / \mathrm{SS}(\mathrm{g} / \mathrm{L})$ 
Table 8.3 SOUR test procedure (Continued).

\section{Example Results}

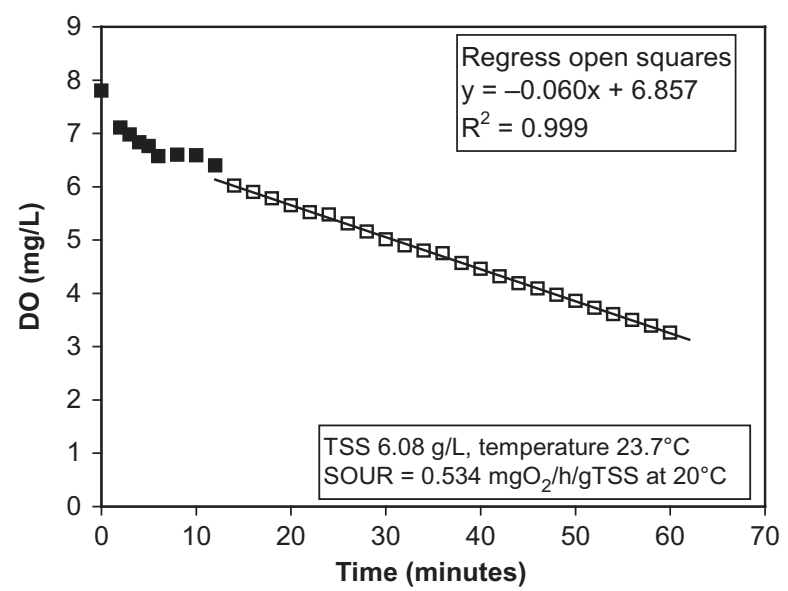

\subsubsection{Operating examples}

\section{West Byron STP}

The various features of aerobic digester operation are illustrated in Figure 8.4. These trends are taken from the first two years operation of the new West Byron plant, with a plant load of about half the design load. The plant comprised an oxidation ditch with anaerobic prereactor and an aerobic digester; biological P removal was supplemented by dosing of alum and magnesium hydroxide to the oxidation ditch.

For the first six months the digester operation was quite variable while the behaviour and interaction of the various plant operating characteristics were explored and a routine monitoring schedule developed. Performance became more settled as understanding grew.

Plot 1 shows that, once operation was stabilised, the WAS feed was taken from a bioprocess operated at an SRT around 20 days. The digester HRT and SRT were both around 15 days (no supernatant was decanted). The digester was fed 7 days per week and digested sludge was dewatered 5 days per week, causing the digester water level to vary. WAS was taken from the RAS line and SS averaged $7 \mathrm{~g} / \mathrm{L}$, while the SS of the digested sludge averaged about $5 \mathrm{~g} / \mathrm{L}$.

Plot 2 shows that the digester was aerated for about $40 \%$ of the time and the DO concentration during aeration averaged about $7 \mathrm{mg} / \mathrm{L}$. With this aeration regime the effluent ammonia and nitrate were both low. The optimum aeration regime giving low $\mathrm{N}$ and maximum alkalinity recovery depends on the oxygen demand and aeration DO concentration and can be established by trial. Figure 8.5 shows a useful aeration profile but the daily percentage of aeration time giving lowest $\mathrm{N}$ will vary with the operating DO and the associated decay time when aeration ceases.

Plot 2 also shows that for most of the time digester phosphate was maintained at a low level by digester alum dosing. Plot 3 shows that the average alum dose was high compared with the $50 \mathrm{mg} / \mathrm{g}$ feed SS listed in Table 8.2 for full $\mathrm{P}$ removal. This is because the digester $\mathrm{pH}$ was maintained at high level by alkali dosing (Plots 3 and 4); alum P uptake is lower at higher $\mathrm{pH}$ (see Figure 3.36). Digester P rose over the period 
Nov-06 to Mar-07 when the alum dose was reduced. Note the lag of about six weeks between change in alum dose and the full P response, roughly equal to three HRTs (see Chapter 6). The most economical alum dose would have maintained the $\mathrm{P}$ level at about $1 \mathrm{mg} / \mathrm{L}$ where alum $\mathrm{P}$ uptake is near its maximum.
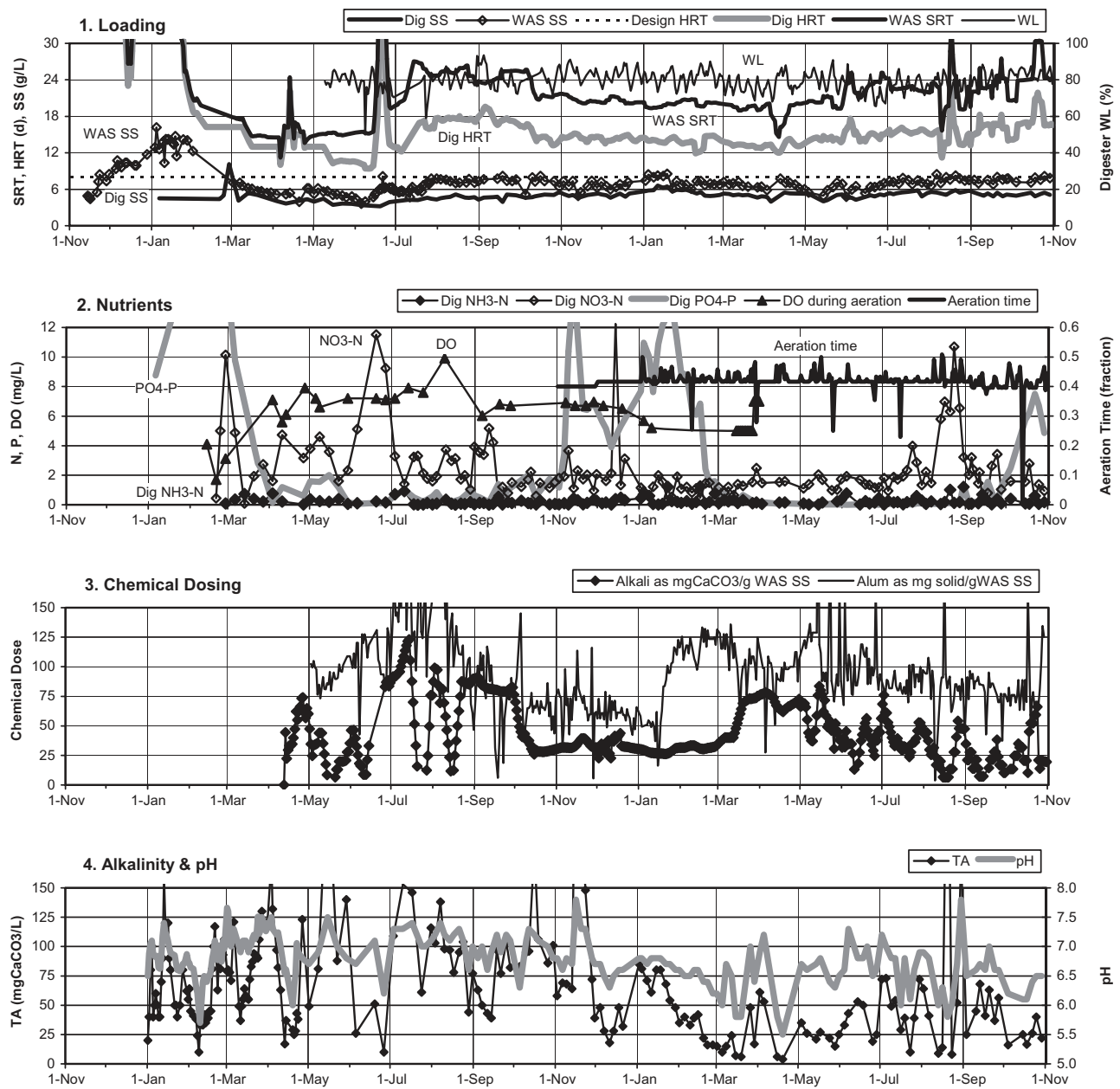

Figure 8.4 Operating trends for the aerobic digester at the West Byron STP after plant startup, Nov-05.

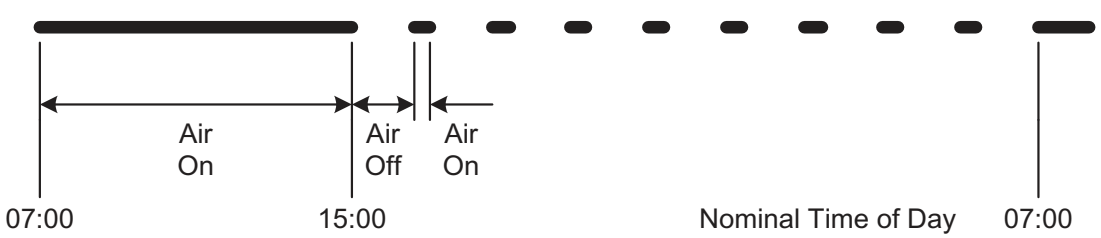

Figure 8.5 A practical digester aeration regime allowing for continuous aeration and mixing during the day while sludge is being fed to the dewatering system and intermittent aeration at night to provide an adjustable daily anoxic mass fraction for ammonia and nitrate control. 


\section{Brunswick Valley STP}

Figure 8.6 shows operating trends from the aerobic digester at the new Brunswick Valley STP after startup in Dec-10 at about half the design load. Relationships between operating characteristics are highlighted by appropriate choice of scales.
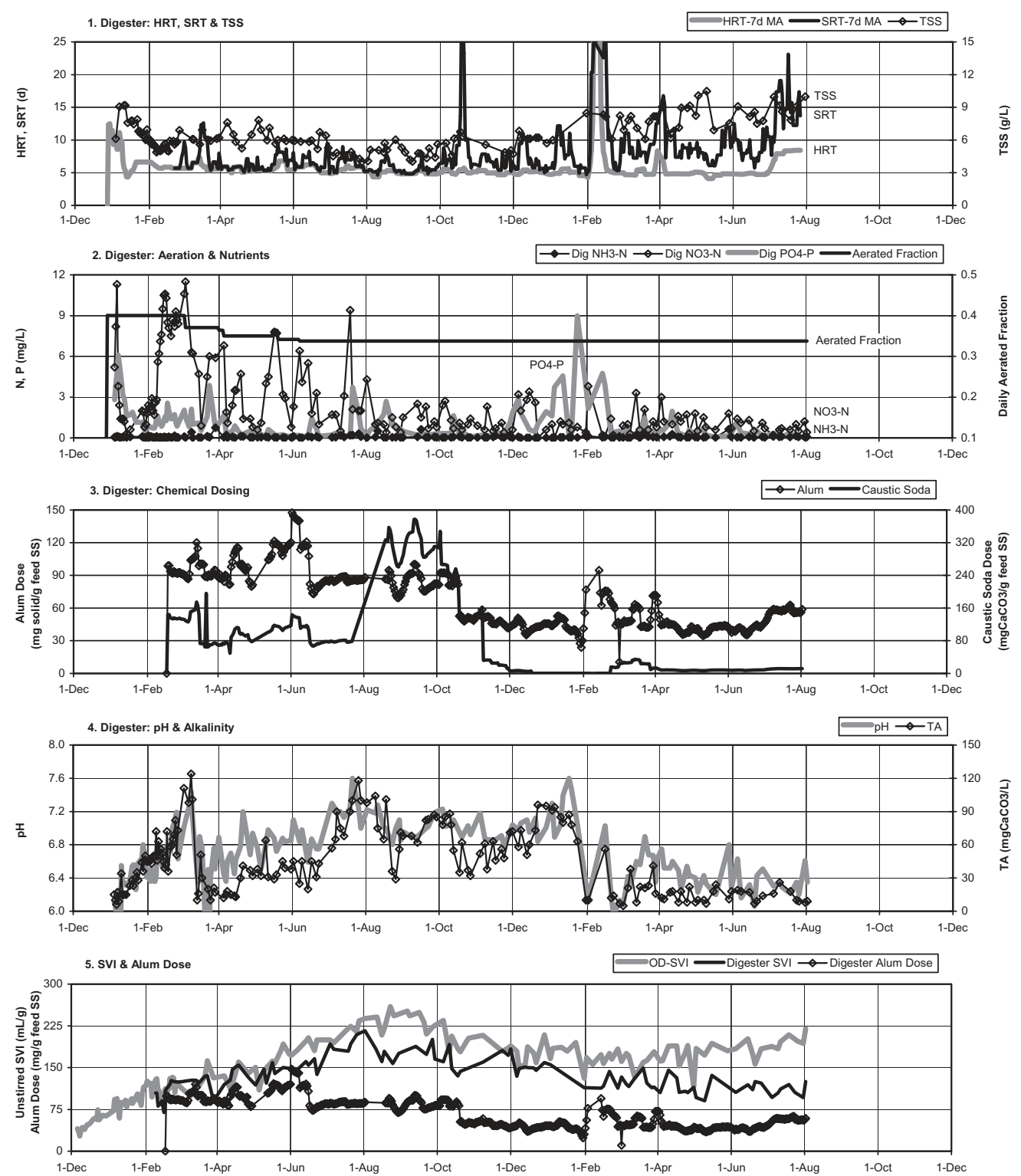

Figure 8.6 Operating trends for the aerobic digester at the Brunswick Valley STP after plant startup, Dec-10. The bioreactor was initially seeded with dewatered sludge cake from sister plant West Byron, producing a very low initial SVI. Coloured versions of Plots 1, 2, 3, 4 \& 5 can be seen in Figure 11.13, Plots 19, 22, 23, 24 \& 21 respectively. 
The digester was fed with WAS taken from the RAS system. To supplement bio-P removal, the bioreactor was dosed with alum at an initial rate of about $100 \mathrm{mg}$ solid alum/L of plant flow, gradually declining to about $30 \mathrm{mg} / \mathrm{L}$; like West Byron, the WAS therefore contained alum precipitate. Over the nineteen month data period plotted, the bioreactor SRT was gradually decreased from about 40 days to 27 days.

The trend plots in Figure 8.6 show the following digester behaviour:

(1) Digester SRT was gradually increased from 5 to 15 days (Plot 1 ) by increasing the extent of supernatant decanting (and reduced feed rate in the last month).

(2) Virtually complete $\mathrm{N}$ removal was maintained using a daily aerated fraction of 0.34 (Plot 2).

(3) Alum and caustic soda doses were maintained to the digester over the data period to precipitate $\mathrm{P}$ released and maintain $\mathrm{pH}$ above 6.0 (Plot 3). Plot 2 shows the resulting P levels. Plot 4 shows the relationship between digester $\mathrm{pH}$ and alkalinity. An alkalinity of $10-20 \mathrm{mg} / \mathrm{L}$ was sufficient to maintain the $\mathrm{pH}$ above 6.0. Over Dec-11/Jan-12 the alum dose decreased (Plot 3) and $\mathrm{PO}_{4}-\mathrm{P}$ rose (Plot 2). Alum dose was therefore increased at the start of Feb-12 to reduce P recycle from the digester; this reduced $\mathrm{pH}$ (Plot 4). Note that reduction of alum dose has a two-fold effect on $\mathrm{P}$ uptake because the associated $\mathrm{pH}$ increase reduces the adsorption capacity of the remaining alum (Section 3.7.1).

(4) Trend Plot 5 shows that the digester SVI lies below the bioreactor (oxidation ditch) trend, presumably resulting primarily from the additional alum dosed to the digester. It can be seen that the step increase in alum dose at Feb-12 widened the gap between the bioreactor and digester SVIs while the previous step decreases (Jun-11 and Oct-11) had the opposite effect.

Figure 8.7 shows the belt filter press dewatering characteristics of the sludge. Cake TS concentration varies inversely with digested sludge SVI (Plot 1) while solids capture varies directly with SVI (Plot 2). Further, comparison of Figure 8.7, Plot 2 with Figure 8.6, Plot 4 shows that solids capture is higher at lower $\mathrm{pH}-$ filtrate SS concentration is lowest around Apr-11 and from Feb-12 onwards when $\mathrm{pH}$ is lowest; this is presumably because the coagulation properties of the alum sludge component are best at low $\mathrm{pH}$ values (see Chapter 3, Section 3.7).
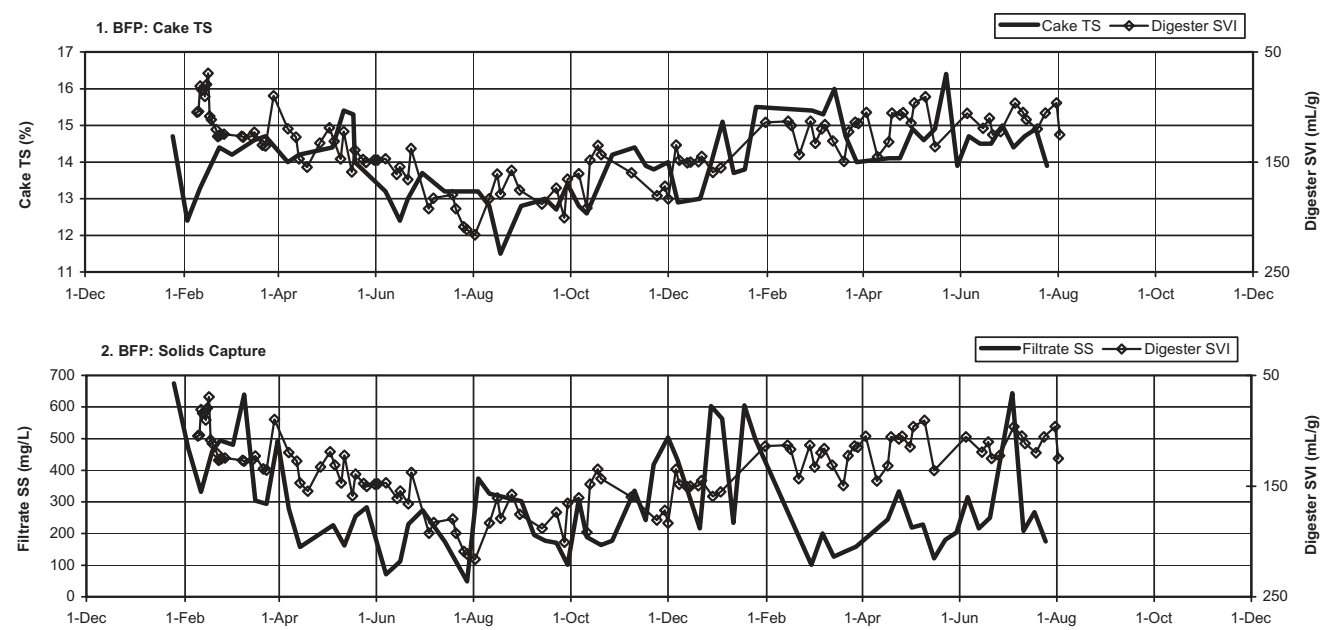

Figure 8.7 Dewatering characteristics of aerobically digested sludge on the belt filter press at the Brunswick Valley STP, Dec-10 to Jul-12. Coloured versions of Plots $1 \& 2$ can be seen in Figure 11.13, Plots 25 \& 26 respectively. 
Bane (1997) shows that cake TS also varies inversely with the VS:TS ratio of the sludge.

Theoretically, there may be an economic optimum alum dose giving the lowest total sludge disposal cost. Increasing the digester alum dose reduces SVI and increases cake TS. In rough terms, Plot 5 of Figure 8.6 suggests that an increase in digester alum dose from about 50 to $70 \mathrm{mg} / \mathrm{g}$ feed SS as occurred at Feb-12 would decrease the digester SVI from 150 to $130 \mathrm{~mL} / \mathrm{g}$. This increase in alum dose would theoretically generate an increase in sludge SS mass of about $5 \mathrm{mg} / \mathrm{g}$ feed SS or $0.5 \%$ (Section 3.7). Plot 1 of Figure 8.7 suggests the BFP cake TS may increase from $14 \%$ to about $14.5 \%$, giving a net decrease in cake tonnage of about $3 \%$ (fairly insignificant).

\subsubsection{Operating principles}

The basic operating principles for an aerobic digester are as follows:

(1) Aerate intermittently to nitrify and denitrify. This reduces $\mathrm{N}$ recycle to the bioreactor and minimises loss of alkalinity. The DO concentration is not critical. The optimum aerobic fraction is about $50 \%$ and the aeration time may have to be set somewhat shorter to allow for the DO decay time.

(2) If practical, periodically allow the sludge to settle and decant supernatant to maximise the SRT and digestion performance (VS destruction).

(3) Dose alum (or $\mathrm{Fe}$ ) to precipitate the $\mathrm{P}$ released and prevent recycle to the bioreactor. A digester $\mathrm{PO}_{4}-\mathrm{P}$ concentration of about $1 \mathrm{mg} / \mathrm{L}$ will utilise close to the maximum alum $\mathrm{P}$ uptake capacity (Figure 3.36) and give lowest overall plant chemical consumption. Because the phosphorus sorption capacity of alum decreases as $\mathrm{pH}$ increases, upward spikes in digester $\mathrm{pH}$ can cause significant release of chemical $\mathrm{P}$ as can be seen in Figure 8.6 (Plots 2 and 4, Jan-12).

(4) Dose alkali as necessary to maintain the $\mathrm{pH}$ just above 6.0. This is a low $\mathrm{pH}$ that can be maintained without too much instability, is not too corrosive, allows effective nitrification and minimises digester alum and alkali consumptions. Alkali dosed to the digester increases the alkalinity of the return flow to the liquid stream process and contributes to the overall process alkalinity balance.

(5) Routinely monitor operating volume, $\mathrm{NH}_{3}-\mathrm{N}, \mathrm{NO}_{3}-\mathrm{N}, \mathrm{PO}_{4}-\mathrm{P}, \mathrm{pH}$ and total alkalinity. Other parameters worth tracking are HRT, SRT, TSS, VSS and SOUR.

\subsection{SLUDGE DEWATERING}

This section describes the operating characteristics of the two most common sludge dewatering devices - the belt filter press and the decanter centrifuge.

\subsubsection{Mass balances}

Sludge thickening and dewatering are mass balance processes - they are usually operated under more or less steady state conditions and the flow and solids outputs have to equal the inputs. The two main performance parameters are thickened or dewatered sludge concentration and solids capture. Table 8.4 sets out the useful mass balance equations which can be used to calculate and monitor these parameters. 
Table 8.4 Mass balance for thickening and dewatering processes.

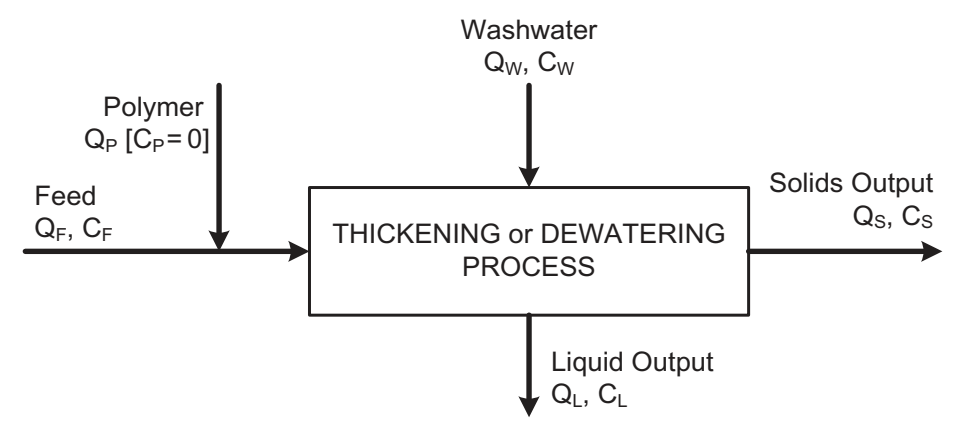

Aim:

1. To determine the process solids capture and solids output flow, knowing:

(a) All input flows and SS concentrations

(b) SS concentrations in solids and liquid outputs

2. Alternatively (for a thickener with a thickened sludge flow meter), to determine the solids output (thickened sludge) concentration when the solids output flow is known.

\section{Nomenclature:}

$Q$ Flow rate

C SS concentration

$\mathrm{S}_{\mathrm{C}}$ Solids capture (output solids mass/input solids mass)

\section{Relationships:}

By mass balance:

$\mathrm{S}_{\mathrm{C}}=1-\left[\mathrm{Q}_{\mathrm{L}} \mathrm{C}_{\mathrm{L}} /\left(\mathrm{Q}_{\mathrm{F}} \mathrm{C}_{\mathrm{F}}+\mathrm{Q}_{\mathrm{W}} \mathrm{C}_{\mathrm{W}}\right)\right]$

$Q_{L}=Q_{F}+Q_{P}+Q_{W}$ (cake flow negligible)

$Q_{S}=\left[Q_{F} C_{F}+Q_{W} C_{W}-\left(Q_{F}+Q_{P}+Q_{W}\right) C_{L}\right] /\left(C_{S}-C_{L}\right)$

For a thickener with a thickened sludge flow meter:

$\mathrm{C}_{\mathrm{S}}=\mathrm{C}_{\mathrm{L}}+\left\{\left[\mathrm{Q}_{\mathrm{F}}\left(\mathrm{C}_{\mathrm{F}}-\mathrm{C}_{\mathrm{L}}\right)-\mathrm{Q}_{\mathrm{P}} \mathrm{C}_{\mathrm{L}}\right] / \mathrm{Q}_{\mathrm{S}}\right\}$

\subsubsection{Belt filter press}

In the belt filter press (BFP), sludge is dewatered firstly by drainage through a filter belt and then by compression between the filter belt and a press belt. The two belts are guided by rollers and run at the same speed. Polymer is used for conditioning of the feed.

To effectively optimise the performance of any process there must be some understanding of its performance characteristics. For the BFP, the performance characteristics of most interest are cake solids concentration (dryness), solids capture and polymer dosing rate. Cake solids and solids capture are affected by several operating variables:

(1) Machine Settings:

1.1 Belt tension

1.2 Washwater flow rate and pressure 
(2) Machine Operating Parameters:

2.1 Belt speed

2.2 Feed rate

2.3 Polymer type and dosing rate

(3) Feed Sludge Characteristics

3.1 Solids concentration

3.2 Dewaterability

The machine settings, belt speed and polymer type can usually be left once set up. Day-to-day operation requires periodic adjustment of the feed rate and polymer dose to match variations in the feed sludge dewaterability. Sludge dewaterability is affected particularly by chemical dosing, SVI and $\mathrm{pH}$ as shown above. Operating guidelines are set out in Table 8.5 and a generalised test procedure in Table 8.6.

Table 8.5 BFP operating guidelines.

To achieve maximum cake solids concentration at acceptable solids capture $(>90 \%)$ with minimum polymer dose:

1. Set standard washwater flow rate and belt tension.

2. Operate at slow belt speed.

3. Operate at high feed rate.

4. Adjust the polymer dose to achieve full drainage within $300 \mathrm{~mm}$ of the end of the drainage zone.

5. Where the BFP is fed aerobically (rather than anaerobically) digested sludge, allow for the BFP solids capture in the calculation of the bioprocess sludge wasting rate to achieve the desired SRT.

6. Conduct a planned test program to determine the process characteristics of the specific machine/sludge combination.

7. Conduct ongoing monitoring of loading and performance to facilitate tuning.

Table 8.6 BFP test procedure.

Systematically vary feed rate, polymer dose and belt speed while holding belt tension, washwater flow rate and feed sludge characteristics constant. Each of the variables should be varied over the full practical range to enable the optimum operating region to be defined. Steps in the testing procedure are as follows (assuming the BFP is fed from an aerobic digester):

1. Decide the test values for each of the variables.

2. The filtrate flow rate has to be determined for each test run. It can be calculated from Equation 8.4, Table 8.4:

$$
Q_{L}=Q_{F}+Q_{P}+Q_{W}
$$

where $Q_{L}=$ liquid (filtrate) flow rate

$Q_{F}=$ feed (sludge) flow rate

$Q_{P}=$ polymer flow rate, including any dilution water

$Q_{W}=$ washwater flow rate 
Table 8.6 BFP test procedure (Continued).

The polymer and washwater flow rates can be measured manually prior to the test series. If washwater flow cannot be measured directly, one method is to disconnect the washwater piping from the spray bars and direct the flow into a drum. Throttle the washwater line to adjust the pressure to the normal operating value.

3. Polymer dose rate has to be adjusted for the various test runs. A method of measuring the dose rate set, or the total consumption over a test period, is required. Any dilution water flow also needs to be measured.

4. To maintain constant feed quality, ensure no WAS is fed to the digester during the test series. This may require that the digester be filled before testing begins. Aerate the digester continuously while tests are in progress to maintain a uniform feed solids concentration. Sample the digester at the start, middle and end of the tests to determine an average feed SS concentration. Measure the digester SVI and pH.

5. Conduct BFP test runs. Continue each run until steady state performance is judged to have been achieved. Record the operating conditions and sample the cake and filtrate for TS and SS analysis. During the first test it may be worthwhile continuing the run for a further 10 minutes and resampling twice at 5 minute intervals to assess whether steady state has been achieved and the degree of variability in the results.

6. Analyse the samples and record all test conditions and results.

7. As far as possible, review the test results progressively and adjust the test program if necessary. Analyse the overall test results and extend the tests if further performance improvements appear possible.

Figure 8.8 shows the results of a BFP test conducted on the aerobically digested sludge at the Brunswick Valley STP. Twenty four test runs were conducted over a range of belt speeds, feed rates and polymer doses.

The figure shows both the test results and the derived performance contours. With a limited number of test runs it is difficult to draw accurate curves, however the trends are clear. The significant features of these characteristics are as follows:

(1) For the sludge tested, there is an optimum solids feed rate of about $200 \mathrm{kgDS} / \mathrm{h} \cdot \mathrm{m}$ belt width (equivalent to a sludge feed rate of $10 \mathrm{~L} / \mathrm{s}$ at a sludge SS concentration of $6.7 \mathrm{~g} / \mathrm{L}$ ). This feed rate gives the highest cake solids concentration and solids capture.

(2) There is a minimum polymer dose of about $3 \mathrm{~kg}$ powder/tDS which gives an acceptable cake TS concentration (about 14\%). Above this dose the TS increases slightly. Below this dose the cake solids decreases to about $12 \%$ TS and then increases again, however the solids capture deteriorates sharply.

(3) Belt speed has little effect on performance over the tested range of 70\%-90\% (3.68-4.64 m/min).

It also became apparent that the routine operating point (shown) as determined intuitively by the operator was close to optimum - acceptable cake solids concentration and solids capture at low polymer dose.

\subsubsection{Centrifuge}

The centrifuge used most commonly for sludge dewatering is the solid bowl decanter. A relatively high dose of polymer is required for conditioning of the feed because of the high shear forces caused by turbulence at the inlet to the bowl and by the high settling rates occurring in the clarification zone. 
(a) Cake TS

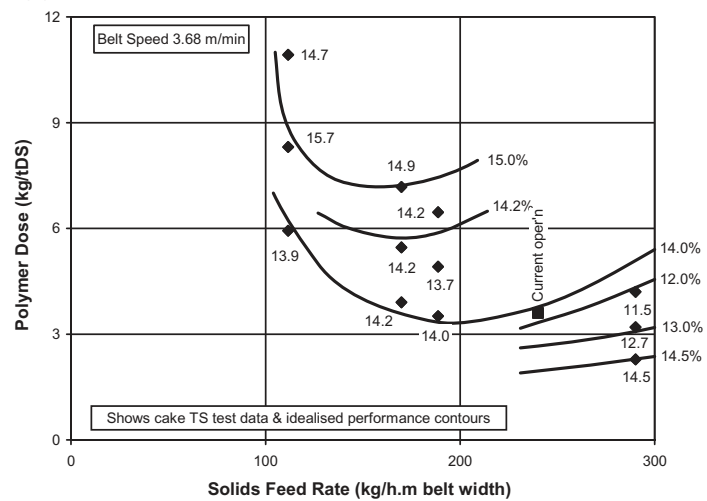

(b) Solids capture

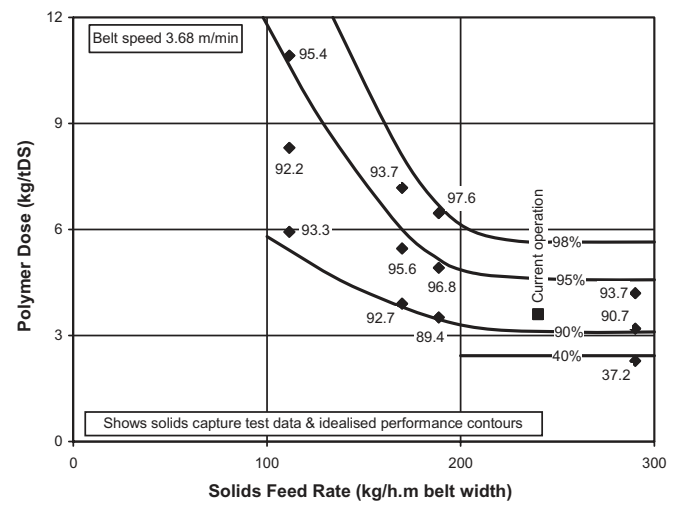

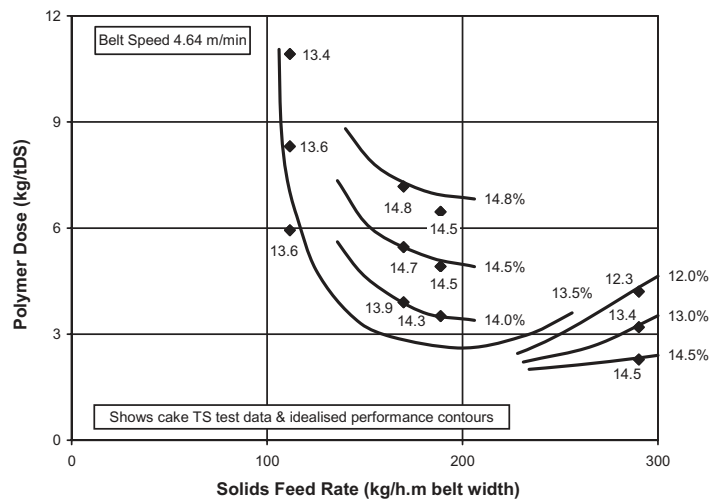

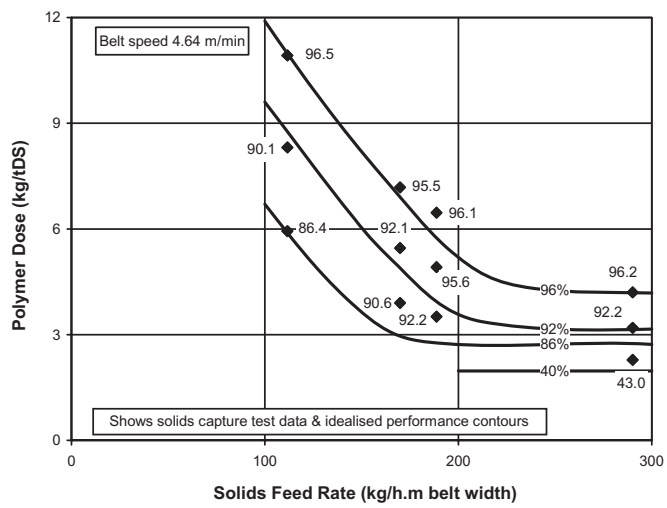

Figure 8.8 Dewatering performance of a $1.2 \mathrm{~m}$ effective belt width BFP fed from the aerobic digester at the Brunswick Valley plant in Aug-12. The then current operating point is also shown. Over the test period, the bioreactor was being alum dosed at an average of $52 \mathrm{mg}$ solid alum/L of sewage flow and the digester was being further dosed at $97 \mathrm{mg} / \mathrm{g}$ feed SS. Digested sludge concentration was $6.9 \mathrm{~g} / \mathrm{L}$, unstirred SVI $124 \mathrm{~mL} / \mathrm{g}$ and $\mathrm{pH}$ 6.5. Digester characteristics are further discussed in the text.

A cross-section of a typical solid bowl centrifuge is shown in Figure 8.9. This is a counter-current machine in which the liquid and solids streams flow in opposite directions. Co-current machines in which both streams discharge at the same end are also available.

The bowl rotates at high speed causing the solids to settle to the bottom of the pool whose depth is controlled by adjustable centrate outlets at the wide end of the bowl. The bowl acts simply as a settling basin and gravity thickener operating under greatly increased acceleration. The conveyor or scroll rotates at a slightly different speed to the bowl and moves the solids up the conical section at the end. As the solids move up the inclined beach and out of the end of the bowl they are subjected to additional dewatering by drainage on the dry section of beach. As the solids emerge from the pool their weight is increased because of the loss of buoyancy, and at the point of emergence the centrifugal acceleration is greater than further up the beach due to the greater diameter. A component of the solids weight acts along the sloping beach, hence only solids at a concentration high enough to withstand this slippage force can be conveyed up the beach and out of the machine. 


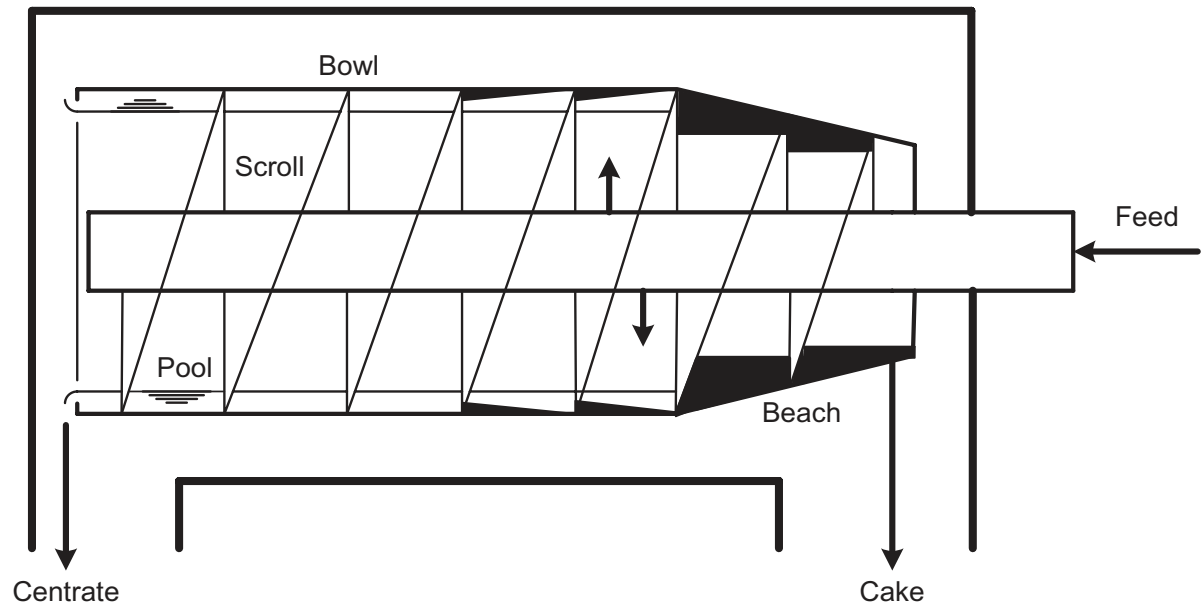

Figure 8.9 Cross-section of a typical counter-current solid bowl centrifuge.

The operating variables affecting centrifuge performance are as follows:

(1) Machine Settings:

1.1 Bowl speed (centrifugal force in units of $g$ )

1.2 Pool depth

(2) Machine Operating Parameters:

2.1 Scroll differential speed (sometimes controlled by a scroll torque setting)

2.2 Feed rate

2.3 Polymer type and dosing rate, including dilution water

(3) Feed Sludge Characteristics

3.1 Solids concentration

3.2 Dewaterability

In this list the machine settings are the parameters which do not need frequent adjustment. The operating parameters are adjusted as necessary to match variations in the feed sludge characteristics. Feed rate and pool depth can be combined into hydraulic residence time (HRT; see Table 8.7). First order variables are then $g$ value, HRT, scroll differential and polymer dose. The scroll differential governs the depth of the sludge layer in the pool and the corresponding solids thickening time. Note that the polymer and associated dilution water flows contribute to the total feed rate and residence time. Because of the high $g$ forces, a high molecular weight polymer with a high cationic charge is necessary.

The relationship between centrifuge $g$ value and bowl speed is as follows:

$$
\text { Centrifugal acceleration }(g \text { value })=(\pi \mathrm{Dn} / 60)^{2} /[(\mathrm{D} / 2) \mathrm{g}]
$$

where

$\mathrm{D}=$ bowl inside diameter, $\mathrm{m}$

$\mathrm{n}=$ bowl rotational speed, $\mathrm{rpm}$

$g=$ gravitational acceleration, $9.8 \mathrm{~m} / \mathrm{s}^{2}$ 
Table 8.7 Centrifuge pool volume and HRT.

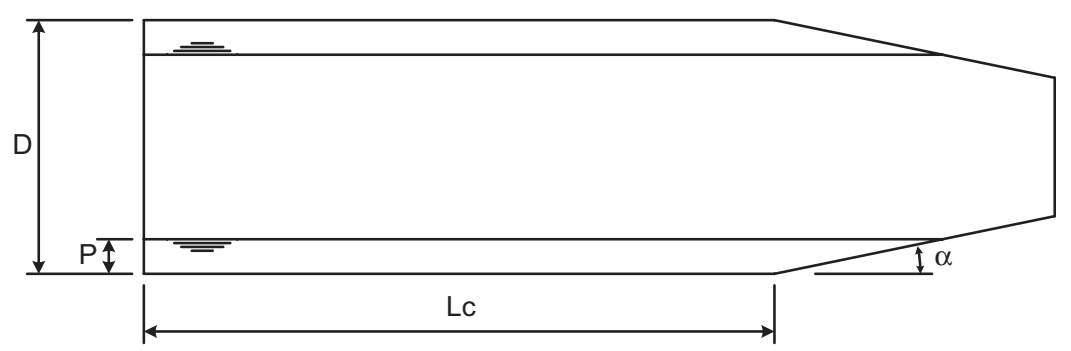

\section{Nomenclature:}

D Bowl internal diameter, $m$

$\mathrm{L}_{\mathrm{C}} \quad$ Bowl cylindrical length, $m$

$P \quad$ Pool depth (weir height), $m$

Q Total feed flow, sludge + polymer + polymer dilution water, L/s

$\mathrm{R}_{\mathrm{H}} \quad$ Hydraulic residence time, $\mathrm{s}$

$\mathrm{V}_{\mathrm{P}}$ Pool volume, $\mathrm{L}$

$\alpha \quad$ Beach angle, degrees

\section{Relationships:}

$V_{P}=(1000 \pi / 4)\left[4 L_{C} D P-\left(4 L_{C}-D / \tan \alpha\right) P^{2}-5 P^{3} /(3 \tan \alpha)\right]$

$\mathrm{R}_{\mathrm{H}}=\mathrm{V}_{\mathrm{P}} / \mathrm{Q}$

Idealised performance characteristics are shown in Figure 8.10 (Vesilind, 1974). Cake solids concentration and solids capture depend on residence time generally as shown but actual dewatering characteristics vary with the nature of the sludge. At very low residence time (Zone 1), only the heavier solids are removed as cake, yielding a dry cake and poor capture. As the residence time is increased (Zone 2), the finer solids, which are more difficult to dewater, are also captured, resulting in higher solids recovery but lower cake solids concentration. Once all the solids are captured, further increase in the residence time may increase the cake solids concentration (Zone 3).

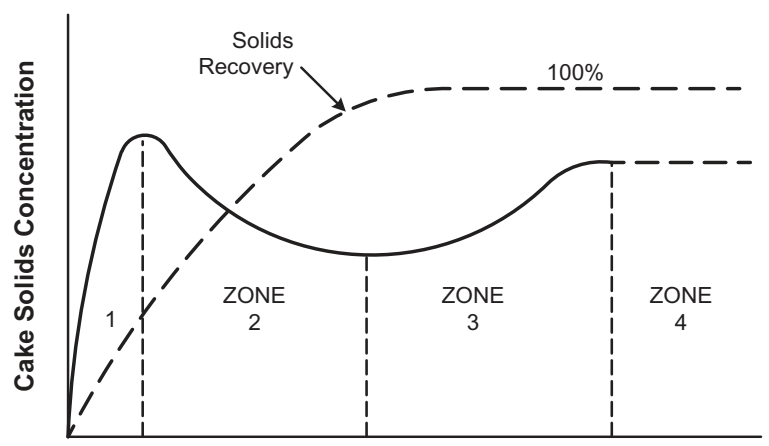

Hydraulic Residence Time

Figure 8.10 Idealised decanter performance characteristics. 
If the centrifuge is operating in Zone 2, increasing the centrifugal force (bowl speed) increases the solids recovery but not the cake solids concentration. Once the recovery is approaching $100 \%$ increased centrifugal force can increase the solids concentration, but usually only marginally. As low a speed as possible should be used as this reduces operating costs and increases the life of the machine.

A centrifuge test procedure is set out in Table 8.8. This is the original set of procedures used to collect the test results shown in Figure 8.11. The centrifuge was fed anaerobically digested sludge and operated at a $g$ value of 2460. It is apparent that centrifuge performance with this type of feed is somewhat different from the idealised pattern shown in Figure 8.10: Zone 2 behaviour does not occur. The dominant operating parameters are HRT and scroll torque (differential speed). Polymer dose has a second order effect on cake TS but this can be inconsistent and periodic adjustments may be required to maintain the desired trade-off between polymer consumption and cake TS. Minimum polymer dose is that required to produce acceptable solids capture.

Table 8.8 Decanter centrifuge test procedure.

The general test procedure, showing the expected outputs, is as follows:

1. Select bowl speed, pool depth and conveyor differential:

a. Vary feed rate

b. At each feed rate, vary polymer dose

Output:

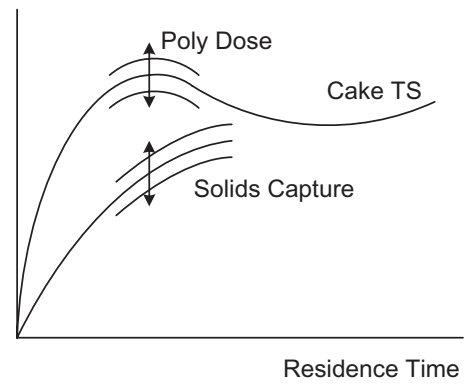

2. At selected residence time and conveyor differential:

a. Vary bowl speed

b. At each bowl speed, vary polymer dose

Output:

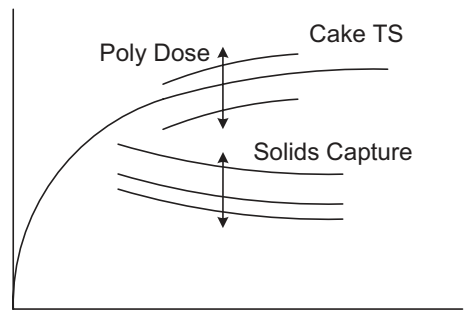

Bowl Speed (g-value) 
Table 8.8 Decanter centrifuge test procedure (Continued).

3. At selected residence time, bowl speed and polymer dose:

a. Vary pool depth

b. At each pool depth, vary conveyor differential

Ouput:

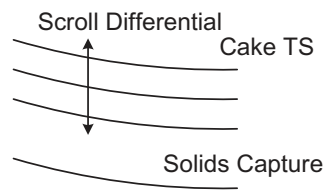

Pool Depth

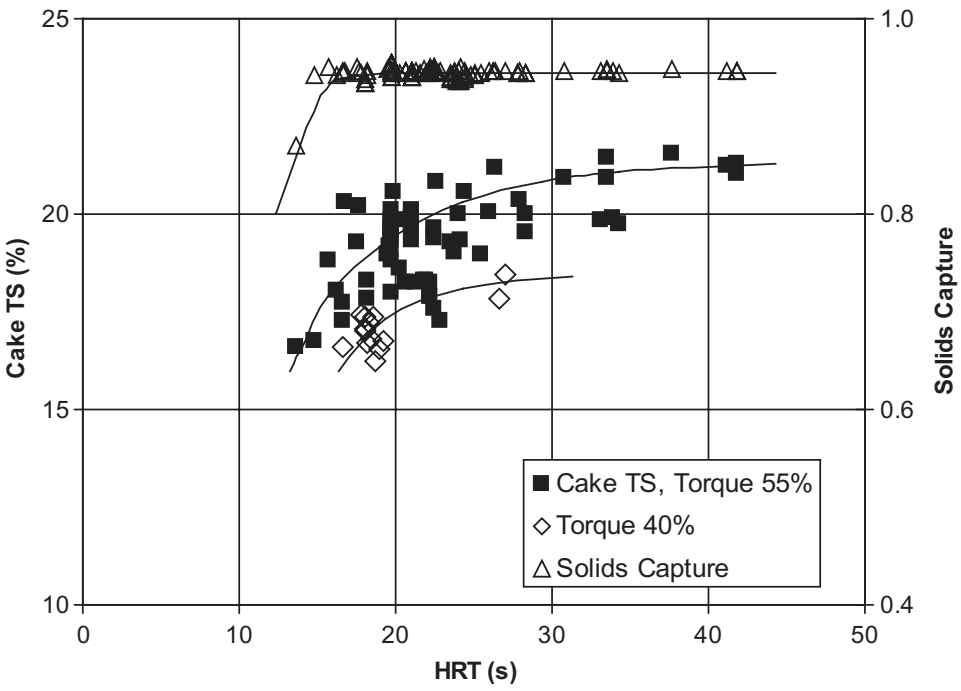

Figure 8.11 Test characteristics for a high speed solid bowl decanter centrifuge dewatering anaerobically digested sludge. Digester feed solids were $25 \%$ fermented primary sludge, $75 \%$ WAS from a BNR process; the digested sludge averaged TS $2.7 \%$, VS/TS $63 \%$. Bowl speed was $3200 \mathrm{rpm}, g$ value 2460. Scroll differential was controlled by the torque settings shown. Polymer dose rates were $8-15 \mathrm{~kg} / \mathrm{tDS}$ for the $55 \%$ torque setting, $9-22 \mathrm{~kg} / \mathrm{tDS}$ for the $40 \%$ torque setting; within these ranges, variation in polymer dose had no consistent effect on performance. Reduction of the $g$ value to 1390 at an HRT of 26 seconds and a scroll torque setting of $55 \%$ reduced the cake TS concentration from $20.4 \%$ to $19.3 \%$. 
Operating guidelines are set out in Table 8.9.

Table 8.9 Decanter centrifuge operating guidelines.

To achieve maximum cake solids concentration at acceptable solids capture ( $>90 \%)$ with minimum polymer dose:

1. Set appropriate bowl speed and pool depth.

2. Operate at slow scroll differential speed/high scroll torque (high solids residence time)

3. Operate at low feed rate (high hydraulic residence time).

4. Adjust the polymer dose to give acceptable solids capture.

5. When the centrifuge is fed aerobically (not anaerobically) digested sludge, allow for the centrifuge solids capture in the calculation of the bioprocess sludge wasting rate to achieve the desired SRT.

6. Conduct a planned test program to determine the process characteristics of the specific machine/sludge combination.

7. Conduct ongoing monitoring of loading and performance to facilitate tuning. 


\section{Chapter 9}

\section{Plant characteristics}

This chapter discusses some operating characteristics of the total integrated plant - mass balances, operational capacity and energy consumption.

\subsection{MASS BALANCES}

The various processes within the plant interact and simple mass balances help in understanding plant behaviour. Steady state balances based on average operating conditions are generally sufficient to achieve the following:

(1) Understanding what governs the flow rates and strengths of the various streams.

(2) Understanding the interactions of the various processes.

(3) Checking the accuracy of sampling results for various streams. Alternatively, calculating the constituent concentrations in various streams without the need for sampling, especially where accurate sampling is difficult.

(4) Determining the performance of processes when not all the performance data can be measured.

(5) Reducing the number of flow meters needed, or checking the accuracy of flow meters. Redundant flow meters can cause heartache when the metered flows do not balance accurately.

The principles involved can be illustrated using the simple single-train flowsheet shown in Figure 9.1. The simple steady state mass balance is set out in Table 9.1. Note that mass balances can be calculated in different ways depending on the data available but the version shown is practical.

Examples of the application of mass balance principles are as follows:

\section{RAS concentration}

As shown in Chapter 7 (Table 7.1), the RAS SS concentration as calculated by mass balance is directly related to the recycle ratio. At constant recycle ratio the RAS SS concentration is a constant multiple of the MLSS concentration. Therefore when sludge wasted for SRT control is taken from the RAS line, there is no need for RAS SS sampling if the RAS is flow-paced to the plant throughput. 


\section{Sludge thickeners}

The concentrations of thickened sludge samples are notoriously variable. However, if the feed and thickened sludge volumes, and the feed and return stream SS, are monitored, the average thickened sludge SS concentration can be reliably calculated by mass balance. See Chapter 8, Table 8.4, Equation 8.6.

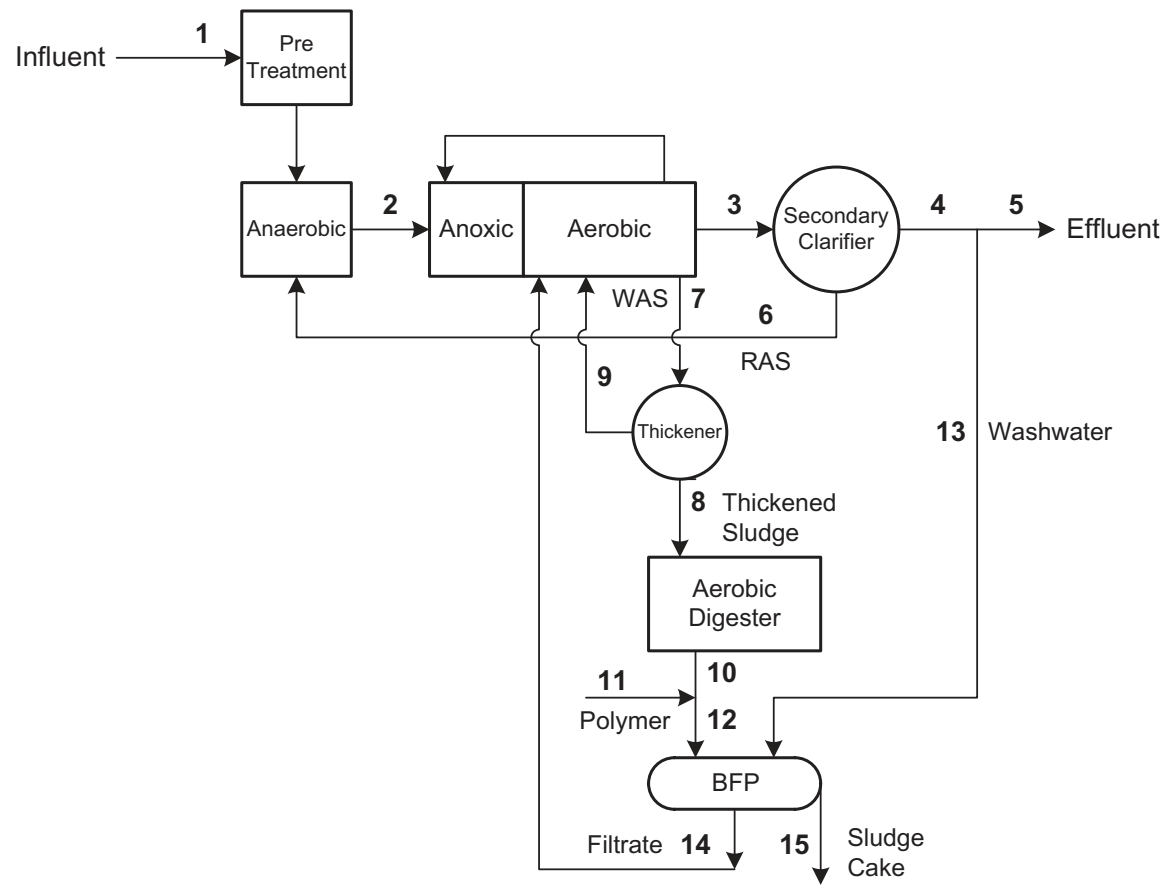

Figure 9.1 Simple BNR plant flowsheet.

Table 9.1 Mass balance for flowsheet shown in Figure 9.1.

\begin{tabular}{|c|c|c|c|c|c|c|c|c|}
\hline Stream & 1 & 2 & 3 & 4 & 5 & 6 & 7 & 8 \\
\hline Volumetric Flow, Q & $Q_{1}$ & $\begin{array}{r}Q_{1} \\
+Q_{6}\end{array}$ & $\begin{array}{r}Q_{4} \\
+Q_{6}\end{array}$ & $\begin{aligned} & Q_{5} \\
+ & Q_{13}\end{aligned}$ & $\begin{aligned} & Q_{1} \\
- & Q_{15}\end{aligned}$ & $Q_{6}$ & $Q_{7}$ & $Q_{8}$ \\
\hline $\begin{array}{l}\text { Constituent Mass Flow, } \\
\qquad M=Q \cdot C \\
(C=\text { concentration })\end{array}$ & $\mathrm{Q}_{1} \mathrm{C}_{1}$ & $\mathrm{Q}_{2} \mathrm{C}_{2}$ & $\mathrm{Q}_{3} \mathrm{C}_{3}$ & $\mathrm{Q}_{4} \mathrm{C}_{5}$ & $\mathrm{Q}_{5} \mathrm{C}_{5}$ & $\mathrm{Q}_{6} \mathrm{C}_{6}$ & $\mathrm{Q}_{7} \mathrm{C}_{3}$ & $\begin{array}{r}M_{7} \\
-M_{9}\end{array}$ \\
\hline Stream & 9 & 10 & 11 & 12 & 13 & 14 & 15 & \\
\hline Volumetric Flow, Q & $\begin{array}{r}Q_{7} \\
-Q_{8}\end{array}$ & $\mathrm{Q}_{8}$ & $Q_{11}$ & $\begin{aligned} & Q_{8} \\
+ & Q_{11}\end{aligned}$ & $Q_{13}$ & 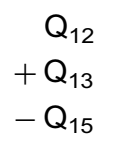 & $\begin{array}{l}\mathrm{M}_{15} / \mathrm{C}_{15} \\
(\sim 0)\end{array}$ & \\
\hline $\begin{array}{l}\text { Constituent Mass Flow, } \\
\qquad \mathrm{M}=\mathrm{Q} \cdot \mathrm{C}\end{array}$ & $\mathrm{Q}_{9} \mathrm{C}_{9}$ & $\mathrm{Q}_{8} \mathrm{C}_{10}$ & $\begin{array}{l}\mathrm{Q}_{11} \mathrm{C}_{11} \\
(\sim 0)\end{array}$ & $\begin{array}{r}M_{10} \\
+M_{11}\end{array}$ & $\mathrm{Q}_{13} \mathrm{C}_{5}$ & $\mathrm{Q}_{14} \mathrm{C}_{14}$ & $\begin{aligned} & M_{12} \\
&+ M_{13} \\
&- M_{14} \\
&\end{aligned}$ & \\
\hline
\end{tabular}




\section{Sludge dewatering}

The same principle applies to sludge dewatering. However, in this case the measurements of cake TS concentration are more reliable than estimates of cake volume. Solids capture and cake production are readily calculated from Equations 9.1 and 9.2, assuming the cake volume (at 10-20\% TS) is negligible compared with the total feed flow:

Solids capture $($ fraction $)=1-($ filtrate or centrate SS $/$ feed SS)

Cake DS mass $(\mathrm{kg} / \mathrm{d})=$ feed $\mathrm{SS}(\mathrm{g} / \mathrm{L}) \times$ feed flow $(\mathrm{kL} / \mathrm{d}) \times$ solids capture

Cake total mass $(\mathrm{t}$ cake $/ \mathrm{d})=$ cake DS mass/cake TS concentration (fraction)

\section{Dewatered sludge $P$ content}

A plant mass balance shows that all the phosphorus removed from the sewage reports to the dewatered sludge cake. The cake $\mathrm{P}$ content is therefore:

Cake $\mathrm{P}$ content (fraction of DS $)=\mathrm{Q}\left(\mathrm{P}_{\mathrm{TI}}-\mathrm{P}_{\mathrm{TE}}\right) /[$ cake DS mass $](\mathrm{kg} / \mathrm{d})$

where

$\mathrm{Q}=$ sewage flow, $\mathrm{ML} / \mathrm{d}$

$\mathrm{P}_{\mathrm{TI}}=$ sewage total $\mathrm{P}, \mathrm{mg} / \mathrm{L}$

$\mathrm{P}_{\mathrm{TE}}=$ effluent total $\mathrm{P}, \mathrm{mg} / \mathrm{L}$

\section{Biological P removal}

When biological P removal is supplemented by chemical dosing the degree of biological P removal can be simply estimated by deducting the calculated chemical P removal from the total removal:

$$
\Delta \mathrm{P}_{\mathrm{B}}=\mathrm{P}_{\mathrm{TI}}-\mathrm{P}_{\mathrm{SE}}-\Delta \mathrm{P}_{\mathrm{AL}}
$$

where

$$
\begin{aligned}
\Delta \mathrm{P}_{\mathrm{B}} & =\text { biological } \mathrm{P} \text { removal, } \mathrm{mg} / \mathrm{L} \text { of effluent flow } \\
\mathrm{P}_{\mathrm{SE}} & =\text { effluent soluble } \mathrm{P}, \mathrm{mg} / \mathrm{L} \\
\Delta \mathrm{P}_{\mathrm{AL}} & =\mathrm{P} \text { removed by alum, } \mathrm{mg} / \mathrm{L} \text { of effluent flow }
\end{aligned}
$$

See Equation 3.18 in Table 3.5 for more detail.

\subsection{OPERATIONAL PROCESS CAPACITY}

The process capacity of a plant can be defined as the load at which the effluent quality will just meet (or will just start to fail) its licensed performance standards, taking into account the inherent variability of the influent and the process performance. This is different to the hydraulic capacity which is the maximum flow which the plant can safely pass. It is also possible for the sludge stabilisation standards to limit capacity.

It is convenient to express the process capacity in terms of the median flow rate at the maximum load. At higher loads one or more effluent quality parameters will exceed their license limits on an unacceptable percentage of days. The operational capacity is inevitably different from the original design capacity because of design and construction margins, differences between the design and actual sewage qualities (strength and constituent ratios), and operating skill levels. 


\subsubsection{Bottlenecks}

Process failure is caused by the single component of the plant, referred to as the bottleneck, which first reaches its capacity. The capacity of the bottleneck governs the capacity of the whole plant. Potential process bottlenecks and other factors affecting the liquid stream capacity include:

- Primary clarifier area when provided

- Flow distribution between parallel trains or units

- Reactor volume (governing MLSS concentration for a desired SRT)

- Secondary clarifier area

- RAS pumping capacity

- Aeration capacity

- Process control settings and tuning (responsiveness, variability): SRT, DO, mass fractions, recycle ratios, chemical dose rates

- Biomass settleability (SVI)

- Recycles from the solids processing stream

- Degree of influent flow and quality variability resulting from diurnal and seasonal influences, storm events, industrial wastewater inputs, special community events and the like.

Optimum flow distribution between parallel trains is important. Maximum plant capacity is achieved when all trains fail at the same time; one train failing before the others wastes unused capacity in the non-failing trains. This is explained in Table 9.2. As a rule of thumb, if one train in a plant receives $10 \%$ more than its optimum share of the load, the total plant capacity is reduced by $9 \%$ (or putting it another way, the plant capacity can be increased by $10 \%$ simply by redistributing the load).

Table 9.2 Effect of plant flow distribution on capacity.

Suppose a plant has two parallel trains, A and B. Each train fails when its load exceeds the capacity of its bottleneck (the train component with the lowest capacity). As an example, suppose secondary clarification is the bottleneck in each train and failure occurs by gross solids loss in the clarifier effluent. In this discussion Train $A$ is the failing train; Train $B$ represents the rest of the plant and may be one or multiple parallel trains.

Suppose that the capacity of Train B is $50 \%$ greater than Train A. If the trains are loaded optimally, Train A receives $40 \%$ of the total (optimum) plant load, $\mathrm{L}_{\mathrm{O}}$, Train $\mathrm{B}$ $60 \%$, and the clarifiers on both trains fail at the same time. The train loads at failure equal the train capacities as shown in Figure (a).

Suppose now that the trains are loaded non-optimally

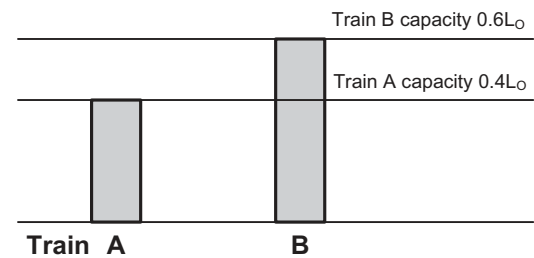

Figure (a) Optimal loading at plant failure. and that Train A receives $10 \%$ too much load, that is, Train A receives $44 \%$ of the total plant load instead of $40 \%$. Train B therefore receives $56 \%$ instead of $60 \%$ as depicted in Figure (b). 
Table 9.2 Effect of plant flow distribution on capacity (Continued).

The train loads when Train A fails are now $0.4 \mathrm{~L}_{\mathrm{O}}$ for Train A (from Fig (a)) but only $(0.56 / 0.44) 0.4 \mathrm{~L}_{\mathrm{O}}=0.51$ $L_{\circ}$ for Train $B$. The total plant capacity is reduced by $9 \%$ to $0.91 \mathrm{~L}_{\mathrm{O}}$.

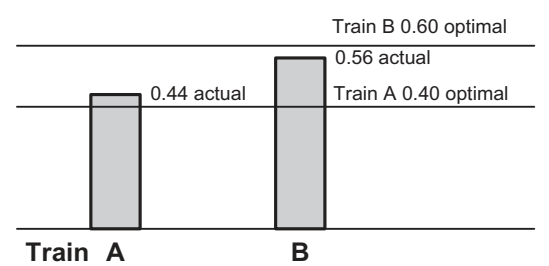

Figure (b) Flow distribution to one train is $10 \%$ higher than optimal.

Generalising, if several parallel trains with a total capacity of $C_{O}$ are loaded such that one train receives $(1+x)$ times its optimum share, the total plant capacity, $C$, is reduced to $C_{O} /(1+x)$. The result is as follows:

\begin{tabular}{rllllll}
$\mathrm{x}:$ & 0 & 0.1 & 0.2 & 0.3 & 0.4 & 0.5 \\
$\mathrm{C} / \mathrm{C}_{\mathrm{O}}:$ & 1.0 & 0.91 & 0.83 & 0.77 & 0.71 & 0.67 \\
\hline
\end{tabular}

\subsubsection{Failure curves}

Failure frequency analysis can be used to identify bottlenecks and determine theoretical plant capacity (Gloag \& Hartley, 2005). The technique involves using a dynamic process model to replicate several years of historical loading and performance data. Once the model is calibrated the average plant load can be progressively increased to simulate catchment growth while maintaining the historical variability of influent flow and quality. By comparing the predicted effluent quality with the plant's licence standards a failure frequency diagram can be constructed that links the likelihood of failure to load growth. The bottlenecks causing failure can also be identified.

Example failure curves for total $\mathrm{N}$ generated by this method are shown in Figure 9.2. Each of the curves shows the percentage of days on which a particular licence limit would be breached at the associated plant median loading and with the historical load variability. These curves illustrate typical plant failure responses to increasing load.

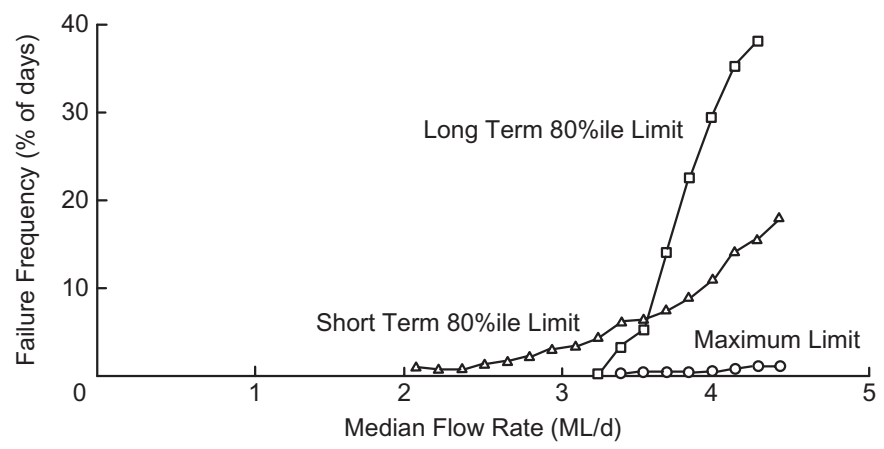

Figure 9.2 Example of plant failure curves for effluent TN.

\subsection{CAPACITY ENVELOPES}

A capacity envelope is a useful aid to understanding the operating limitations of a process. A capacity envelope is a graph showing the process failure boundaries as they are currently understood. It shows 
what combinations of circumstances will cause a steady state process failure, but not the frequency with which failure will occur. Provided the plant operating point lies within the failure boundaries gross process failure will not occur.

The initial envelope can be drawn using the design parameters for the process. After a period of operating experience with the plant, the diagram can be adjusted to reflect its actual operational capacity. With time, improved understanding of the process behaviour allows the boundaries to be pushed out and additional capacity or performance to be realised.

The capacity envelopes discussed here relate to the flow-COD capabilities which define the gross capacity of the process. Similar diagrams can be drawn for $\mathrm{N}$ and P removal performance.

\subsubsection{Continuous flow process}

An example of a flow-COD capacity envelope for a BNR process is shown in Figure 9.3. This diagram is based on the plant design data and shows flow rate (influent or RAS) on the abscissa and organic loading on the ordinate. It is drawn for one SRT (the design value of 25 days) and separate diagrams can be drawn for other SRTs.

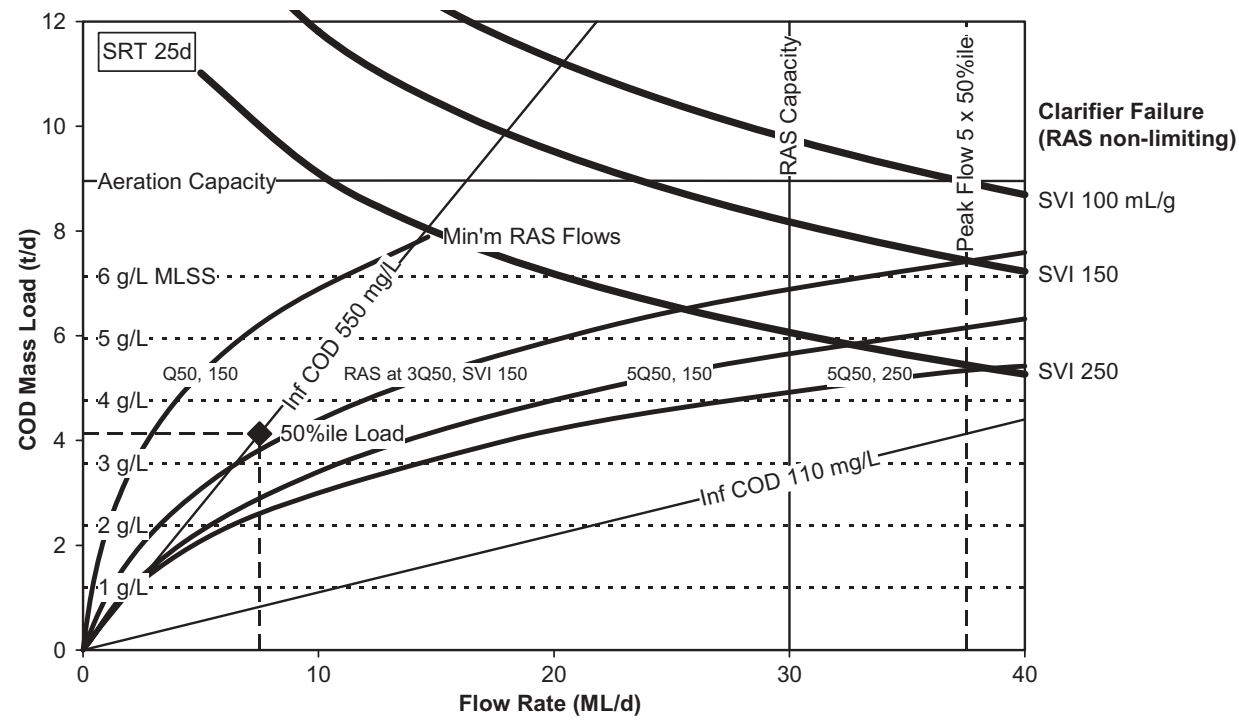

Figure 9.3 Flow-COD capacity envelope for a continuous flow process.

The diagram depicts seven sets of information:

(1) Firstly, the two sloping lines drawn through the origin are operating lines drawn for (a) dry weather flow with a median influent COD strength of $550 \mathrm{mg} / \mathrm{L}$ (equal to the slope of the line), and (b) wet weather flow of five times dry weather flow, with a COD strength of $110 \mathrm{mg} / \mathrm{L}$. The diamond marker shows the median dry weather operating point at the full design load $(4.1 \mathrm{tCOD} / \mathrm{d})$.

(2) The horizontal dotted lines show the MLSS concentrations produced by the associated COD loads.

(3) The dashed vertical line at far right shows the plant design peak hydraulic capacity, $37.5 \mathrm{ML} / \mathrm{d}$.

(4) The horizontal line at $9 \mathrm{t} / \mathrm{d}$ shows the aeration capacity as the maximum sustained COD load that can be handled. 
(5) The curved lines in the top right hand corner show the clarifier overflow limits for three different SVI values. Ignoring any reduction in MLSS concentration through solids accumulation in the clarifiers, operation outside of these lines would produce significant loss of solids in the effluent.

(6) The solid vertical line shows the installed maximum RAS flow rate. Note that the abscissa here represents RAS flow, not plant flow.

(7) The four curved lines through the origin are also represented as RAS flow on the abscissa. These lines show the minimum RAS flows required at given COD mass loads to ensure RAS flow does not limit clarifier capacity to less than the overflow limit. Four lines are shown for the four sets of plant flow and SVI value noted in the figure - 1, 3 and $5 \mathrm{Q} 50$ and 150 or $250 \mathrm{~mL} / \mathrm{g}$. These lines are the equivalent of Line $\mathrm{C}$ in a clarifier operating diagram (see Table 7.2).

The plant can operate safely within the envelope (operating space) defined by the various failure boundaries. Table 9.3 explains how to draw this type of capacity diagram.

Table 9.3 Failure boundaries for a continuous flow process.

Peak Flow Limit

Design value as may be modified by testing

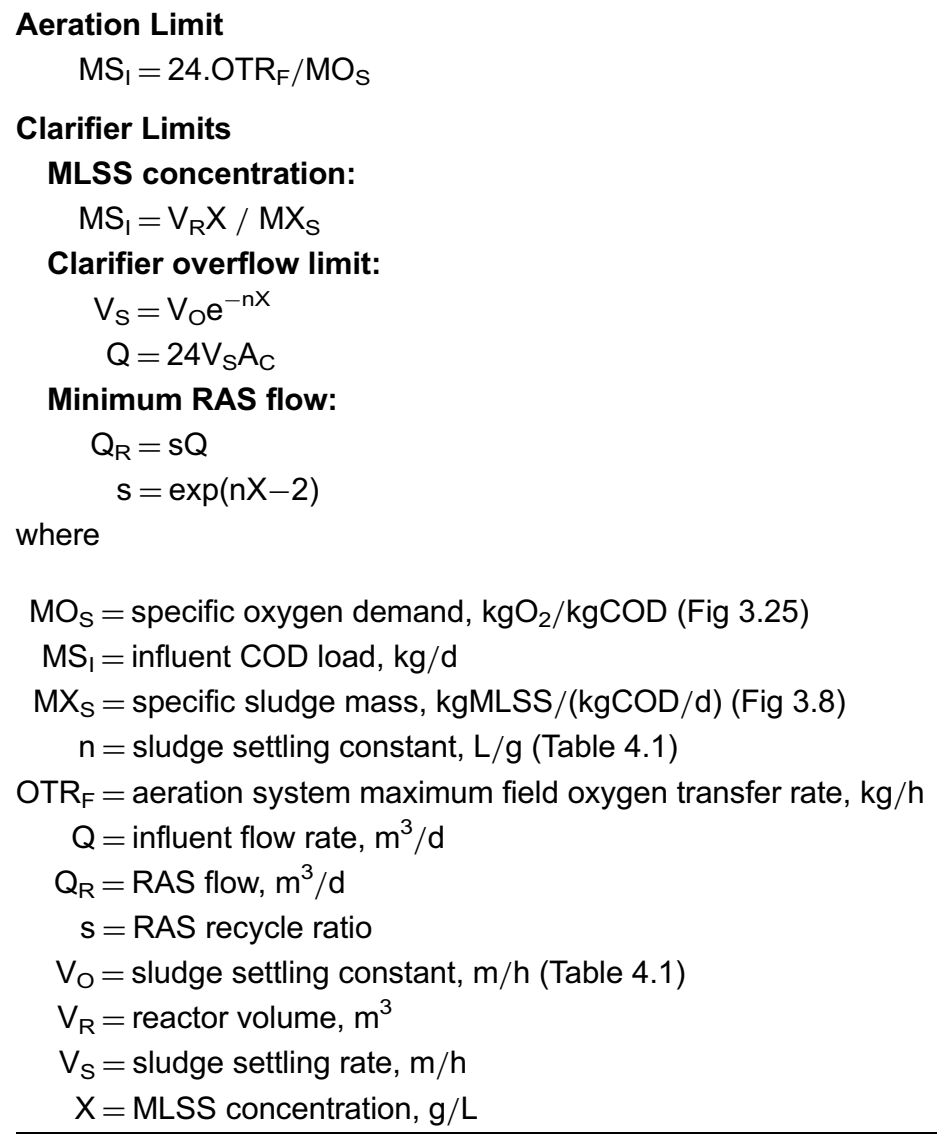

Minimum RAS flow:

$$
\begin{aligned}
Q_{R} & =s Q \\
s & =\exp (n X-2)
\end{aligned}
$$

where

$$
\begin{aligned}
\mathrm{MO}_{\mathrm{S}} & =\text { specific oxygen demand, } \mathrm{kgO}_{2} / \mathrm{kgCOD}(\mathrm{Fig} 3.25) \\
\mathrm{MS}_{\mathrm{I}} & =\text { influent COD load, } \mathrm{kg} / \mathrm{d} \\
\mathrm{MX}_{\mathrm{S}} & =\text { specific sludge mass, } \mathrm{kgMLSS} /(\mathrm{kgCOD} / \mathrm{d})(\text { Fig } 3.8) \\
\mathrm{n} & =\text { sludge settling constant, } \mathrm{L} / \mathrm{g}(\text { Table } 4.1) \\
\mathrm{OTR}_{\mathrm{F}} & =\text { aeration system maximum field oxygen transfer rate, } \mathrm{kg} / \mathrm{h} \\
\mathrm{Q} & =\text { influent flow rate, } \mathrm{m}^{3} / \mathrm{d} \\
\mathrm{Q}_{\mathrm{R}} & =\text { RAS flow, } \mathrm{m}^{3} / \mathrm{d} \\
\mathrm{S} & =\text { RAS recycle ratio } \\
\mathrm{V}_{\mathrm{O}} & =\text { sludge settling constant, } \mathrm{m} / \mathrm{h}(\text { Table } 4.1) \\
\mathrm{V}_{\mathrm{R}} & =\text { reactor volume, } \mathrm{m}^{3} \\
\mathrm{~V}_{\mathrm{S}} & =\text { sludge settling rate, } \mathrm{m} / \mathrm{h} \\
\mathrm{X} & =\text { MLSS concentration, } \mathrm{g} / \mathrm{L}
\end{aligned}
$$




\subsubsection{SBR process}

The SBR process has a high degree of operating flexibility. To maximise its capacity and performance it is important to understand how the process behaves.

A capacity envelope for an SBR process (treating an abattoir wastewater - discussed in Section 7.4) is shown in Figure 9.4. Construction of the diagram is explained in Table 9.4. The example diagram relates to an SRT of 20 days and separate diagrams are needed for other SRTs. Four sets of information are shown:

(1) Four vertical lines (decant volumetric limits) show the maximum throughput over a cycle time or greater based on the physical decanter constraint. The shorter the cycle time the greater the maximum throughput because the maximum decant volume can be discharged more frequently.

(2) Two horizontal lines show the maximum COD load that the aeration system can handle. Greater aeration capacity can be realised by increasing the aerated fraction of the cycle.

(3) The curved lines in the upper right hand sector show the decant scour limits, that is, the combination of flow and COD load at which the settled sludge blanket will start to scour into the effluent during decant. These boundaries are the equivalent of the clarifier failure boundaries for the continuous flow process. Scour limits are shown for several operating conditions: (a) A, B and C show the limits for cycle times of 4, 6 and 8 hours (with react fraction 0.5 and SVI $150 \mathrm{~mL} / \mathrm{g}$ ), (b) D and E show the extremes for an SVI of 100 at a cycle time of 8 hours, and an SVI of 250 for a cycle time of 4 hours, (c) F shows what happens to the 8 hour line if the react fraction is increased from 0.5 to 0.6 .

(4) Horizontal lines show the MLSS concentrations expected at reactor TWL for various COD loads.

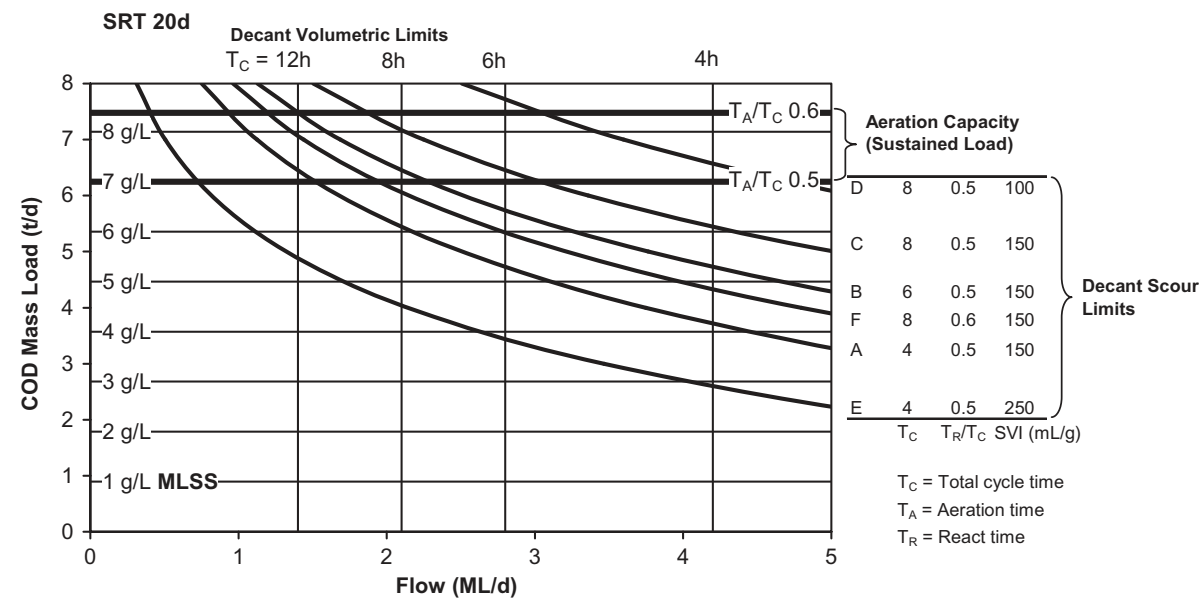

Figure 9.4 Capacity envelope for an arbitrary SBR process.

This diagram shows clearly the trade-offs inherent in maximising the operating capacity of an SBR process. To achieve greater throughput the cycle has to be shortened. With a shorter cycle time the scour limit decreases because the sludge has less time to settle. Aeration capacity (and aerobic sludge age for nitrification) can be enhanced by increasing the aerated fraction of the cycle. But then the scour limit decreases because of the shorter settling time or denitrification is reduced because of the shorter anoxic mix time. The decrease in scour limit can be compensated for by increasing the cycle time (e.g. the diagram shows that if the process was operating at a 4 hour cycle time with 0.5 aerated fraction, an increase to 0.6 aerated fraction would be safe if the cycle time was also increased to 8 hours). 
Table 9.4 Failure boundaries for an SBR process.

\section{Decant Volumetric Limit}

$$
Q=24 Q_{D} / T_{C}
$$

Aeration Limit

$$
\mathrm{MS}_{\mathrm{I}}=\left(24 . \mathrm{OTR} / \mathrm{MO}_{\mathrm{S}}\right)\left(\mathrm{T}_{\mathrm{A}} / \mathrm{T}_{\mathrm{C}}\right)
$$

Decant SCOUR limit

$$
\begin{aligned}
& V_{S}=V_{O} e^{-n X} \\
& Q=6 L_{W} V_{W} V_{S} T_{C}\left[1-\left(T_{R} / T_{C}\right)\right]^{2}
\end{aligned}
$$

\section{MLSS Concentration}

$$
\mathrm{MS}_{\mathrm{I}}=\mathrm{V}_{\mathrm{R}} \mathrm{X} / \mathrm{MX}_{\mathrm{S}}
$$

where

$$
\begin{aligned}
& D_{C}=\text { supernatant depth, }\left(D_{W}-D_{S}\right), m \\
& D_{\mathrm{O}}=\text { reactor depth at TWL, } \mathrm{m} \\
& D_{S}=\text { sludge depth, } m \\
& D_{\mathrm{W}}=\text { water depth, } \mathrm{m} \\
& \mathrm{L}_{\mathrm{w}}=\text { decanting weir length, } \mathrm{m} \\
& \mathrm{MO}_{\mathrm{S}}=\text { specific oxygen demand, } \mathrm{kgO}_{2} / \mathrm{kgCOD} \\
& \text { (Figure 3.25) } \\
& \mathrm{MS}_{\mathrm{I}}=\text { influent COD load, } \mathrm{kg} / \mathrm{d} \\
& \mathrm{MX}_{\mathrm{S}}=\text { specific sludge mass, } \mathrm{kgMLSS} / \\
& \text { (kgCOD/d) (Figure 3.8) } \\
& \mathrm{MX}_{\mathrm{T}}=\text { MLSS mass, } \mathrm{kg} \\
& \mathrm{n}=\text { sludge settling constant, } \mathrm{L} / \mathrm{g} \text { (Table 4.1) } \\
& \text { OTR }=\text { aeration system maximum field oxygen } \\
& \text { transfer rate, } \mathrm{kg} / \mathrm{h} \text { (Equn 6.13) } \\
& \mathrm{Q}=\text { daily feed volume, } \mathrm{m}^{3} / \mathrm{d} \\
& Q_{D}=\text { maximum decant volume, } \mathrm{m}^{3} / \text { decant }
\end{aligned}
$$

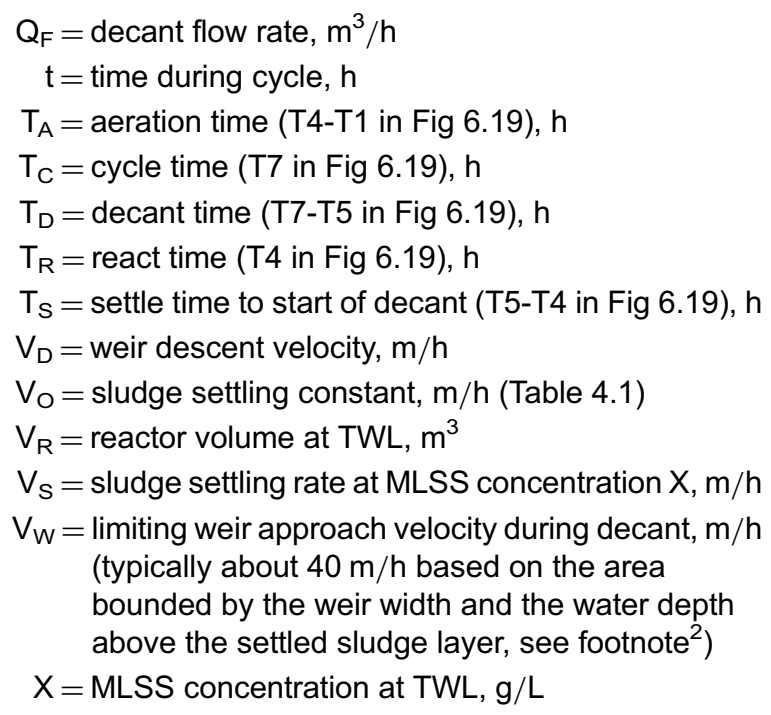

\footnotetext{
${ }^{1}$ The clarification limit (Equn 9.13) is based on the maximum safe weir approach velocity (no scour of settled solids). The equation is based on the settling \& decant behaviour depicted in Figure 6.20, assuming the effluent is decanted optimally such that the water level decrease parallels the sludge interface settling rate (by adjustment of T5 in Figure 6.19). The derivation is as follows (symbols are defined in Table 9.4). From Equn 9.11, $Q_{D}=Q . T_{C} / 24$ (Equn (i)). The decant flow rate, $Q_{F}=Q_{D} / T_{D}$ (ii). The reactor sludge depth, $D_{S}=D_{O}-V_{S} t$ (iii). The water level during decant is $D_{W}=D_{O}-V_{D}\left(t-T_{S}\right.$ ) (iv), and the supernatant depth is $D_{C}=D_{W}-D_{S}(v)$. Now, the weir approach velocity, $V_{W}$, is given by: $V_{W}=Q_{F} /\left(L_{W} D_{C}\right)$. Substituting Equns (i) $-(v)$, setting $T_{S}=T_{D}$ (where minimum $V_{W}$ generally occurs) and simplifying gives $Q=6{ }_{W} V_{W} V_{S} T_{C}\left[1-\left(T_{R} / T_{C}\right)\right]^{2}$ (Equn 9.13 above).

${ }^{2}$ Fair, Geyer \& Okun (1968) recommend a maximum horizontal velocity to prevent scour of settled sludge in sedimentation tanks of 10 times the particle settling velocity. For activated sludge, the settling constant $V_{O}$ represents the particle settling velocity (i.e. the sludge settling velocity at zero MLSS concentration - Equn 4.2). A maximum weir approach velocity of 40 $\mathrm{m} / \mathrm{h}$ should then be safe for $V_{O}$ values above $4 \mathrm{~m} / \mathrm{h}$, equivalent to SSVI values for ND processes of less than $160 \mathrm{~mL} / \mathrm{g}$ (Table 4.1).
} 


\subsection{ENERGY CONSUMPTION}

To provide some perspective on sewage treatment plant energy consumption it is useful to start with the overall water cycle energy balance.

\subsubsection{Water cycle}

The water cycle with typical energy inputs is shown in Figure 9.5. Evaporation of a nominal $300 \mathrm{~L} /$ person.d total community water consumption from the ocean requires a solar energy input of about $680 \mathrm{MJ} / \mathrm{p} . \mathrm{d}$ or 8 $\mathrm{kW} /$ person. The water supply and sewerage systems consume about $0.9 \mathrm{MJ} / \mathrm{p}$.d of which the STP uses about $60 \%$. In comparison, the average household consumes electricity and food at the rates of 36 and $10 \mathrm{MJ} /$ p.d respectively.

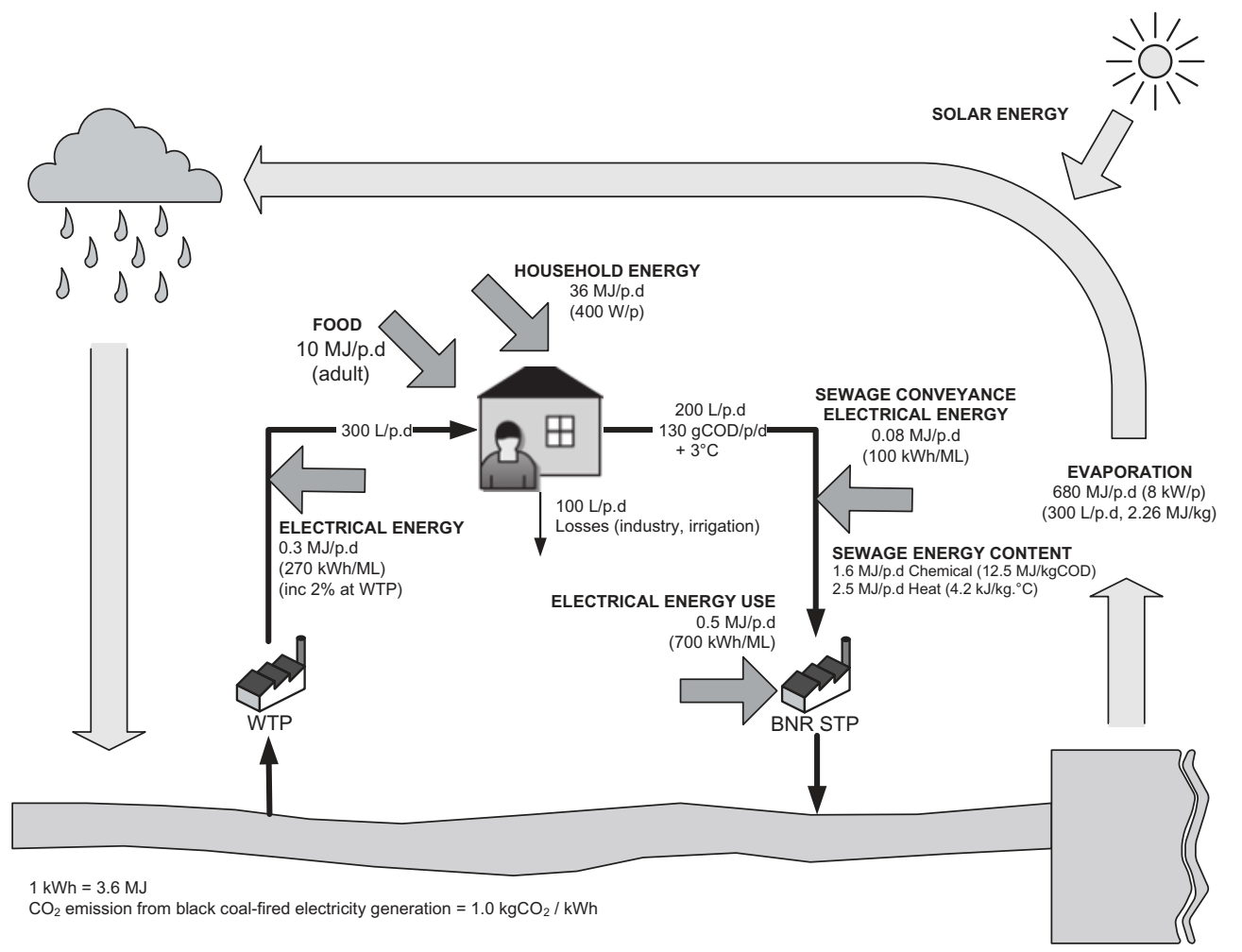

Figure 9.5 Typical water cycle energy balance for nominal per capita water consumptions.

The sewage contains wastes with a chemical energy content of $1.6 \mathrm{MJ} / \mathrm{p}$.d and waste heat in the order of $2.5 \mathrm{MJ} / \mathrm{p} . \mathrm{d}$ (Chapter 2).

Figure 9.6 shows the overall 1998 energy consumptions of the fifteen largest water and sewerage businesses in Australia. The median sewerage energy consumption was $330 \mathrm{kWh} / \mathrm{ML}$, less than half the figure of 800 shown in Figure 9.5 for systems with BNR plants. BNR plants are more energy intensive than conventional non-BNR plants and in 1998 totalled less than 10\% of all plants in Australia. Further, the energy consumption figures in Figure 9.6 relate to energy purchased, not energy used. Energy purchased is lower at the larger plants where power is generated using digester gas. 


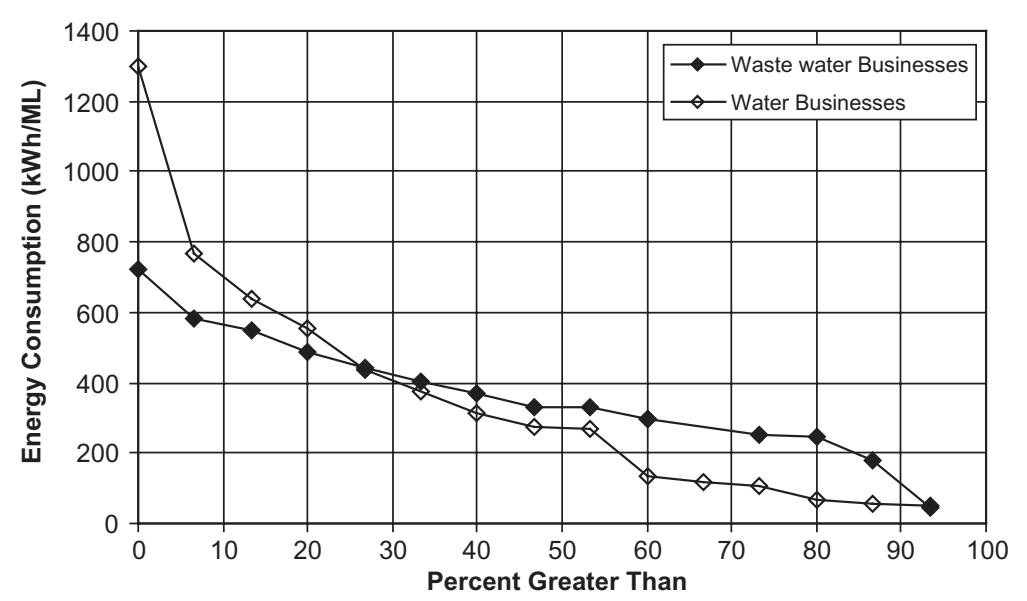

Figure 9.6 The 1998 purchased energy consumptions for the fifteen largest Australian water and wastewater businesses - water collection, treatment and distribution; sewage collection, treatment and disposal (WSAA, 1999).

The total wastewater business energy consumptions are also affected by topography. The sewage pumping component is greater when the topography is flat or undulating and where the sewage has to be pumped a substantial distance for treatment and disposal.

\subsubsection{Plant energy balance}

A simple energy balance for a typical BNR plant with no primary treatment is shown in Figure 9.7. Specific energy consumption in Australian plants using secondary clarifiers is in the order of $6 \mathrm{~W} /$ person $(1.1$ $\mathrm{kWh} / \mathrm{kgCOD}$ ) at full load, increasing at lower loads (see Section 9.4.3 below). This figure excludes non-BNR demands such as influent and effluent pump stations and UV disinfection. The influent chemical energy is about three times the plant electrical demand but this is not recovered in most BNR plants.

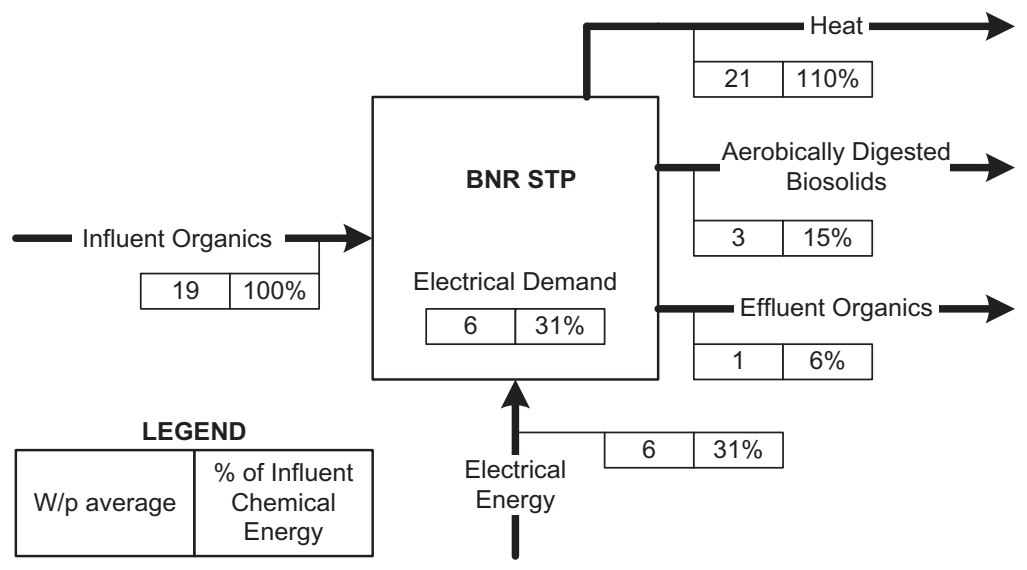

Figure 9.7 Average energy balance for a BNR plant operating at full design load. 


\subsubsection{Energy models}

\section{General}

Plant power can be formulated generally as:

$$
\mathrm{P}_{\mathrm{T}}=\mathrm{P}_{\mathrm{I}}+\mathrm{P}_{\mathrm{COD}}+\mathrm{P}_{\mathrm{Q}}
$$

where

$$
\begin{aligned}
\mathrm{P}_{\mathrm{T}} & =\text { average total plant power, } \mathrm{kW} \\
\mathrm{P}_{\mathrm{I}} & =\text { average load-invariant power }{ }^{3}, \mathrm{~kW} \\
& =\mathrm{k}_{\mathrm{I}} \mathrm{L}_{\mathrm{D}} / 24 \\
\mathrm{P}_{\mathrm{COD}} & =\text { average COD mass load-dependent power, } \mathrm{kW} \\
& =\mathrm{k}_{\mathrm{L}} \mathrm{L}_{\mathrm{O}} / 24 \\
\mathrm{P}_{\mathrm{Q}} & =\text { average flow-dependent power, } \mathrm{kW} \\
& =\mathrm{k}_{\mathrm{Q}} \mathrm{Q}_{\mathrm{O}} / 24 \\
\mathrm{k}_{\mathrm{I}} & =\text { load-invariant energy constant, } \mathrm{kWh} / \mathrm{kgCOD} \\
\mathrm{k}_{\mathrm{L}}= & \text { load-dependent energy constant, } \mathrm{kWh} / \mathrm{kgCOD} \\
\mathrm{k}_{\mathrm{Q}}= & \text { flow-dependent energy constant, } \mathrm{kWh} / \mathrm{ML} \\
\mathrm{L}_{\mathrm{D}}= & \text { plant design average load, } \mathrm{kg} \text { total COD } / \mathrm{d} \\
\mathrm{L}_{\mathrm{O}}= & \text { plant average operating load, } \mathrm{kg} \text { total COD } / \mathrm{d} \\
\mathrm{Q}_{\mathrm{O}}= & \text { plant average operating flow, } \mathrm{ML} / \mathrm{d} \\
\mathrm{E}_{\mathrm{T}}= & \text { specific total energy consumption at operating load, } \mathrm{kWh} / \mathrm{kg} \\
& \text { total COD operating load } \\
\mathrm{S}_{\mathrm{O}}= & \text { plant average influent COD concentration, } \mathrm{mg} / \mathrm{L} \\
= & \mathrm{L}_{\mathrm{O}} / \mathrm{Q}_{\mathrm{O}}
\end{aligned}
$$

and specific energy consumption is:

$$
\begin{aligned}
\mathrm{E}_{\mathrm{T}} & =24 \mathrm{P}_{\mathrm{T}} / \mathrm{L}_{\mathrm{O}} \\
& =\left(\mathrm{k}_{\mathrm{I}} \mathrm{L}_{\mathrm{D}}+\mathrm{k}_{\mathrm{L}} \mathrm{L}_{\mathrm{O}}+\mathrm{k}_{\mathrm{Q}} \mathrm{Q}_{\mathrm{O}}\right) / \mathrm{L}_{\mathrm{O}} \\
& =\mathrm{k}_{\mathrm{I}} \mathrm{L}_{\mathrm{D}} / \mathrm{L}_{\mathrm{O}}+\left(\mathrm{k}_{\mathrm{L}}+\mathrm{k}_{\mathrm{Q}} / \mathrm{S}_{\mathrm{O}}\right)
\end{aligned}
$$

The specific energy could alternatively be related to flow rather than COD load:

$$
\mathrm{E}_{\mathrm{T}, \mathrm{Q}}=\mathrm{E}_{\mathrm{T}, \mathrm{COD}} \cdot \mathrm{S}_{\mathrm{O}}
$$

The average energy data for sixteen conventional Australian BNR plants are listed in Table 9.5 and plotted in Figure 9.8. The overall correlation gives:

$\mathrm{E}_{\mathrm{T}}=0.36\left(\mathrm{~L}_{\mathrm{D}} / \mathrm{L}_{\mathrm{O}}\right)+0.75=1.1 \mathrm{kWh} / \mathrm{kgCOD}$ when operating at design load

(or $550 \mathrm{kWh} / \mathrm{ML}$ for $\mathrm{S}_{\mathrm{O}}=500 \mathrm{mgCOD} / \mathrm{L}$ )

Published figures for twelve Austrian BNR plants, all incorporating anaerobic sludge digestion and on-site power generation, give: average $0.74 \mathrm{kWh} / \mathrm{kgCOD}$, range 0.36-1.67 (Nowak, 2002).

\footnotetext{
${ }^{3}$ Load invariant terminology is used in lieu of fixed to differentiate from the fixed rate component of electricity tariffs.
} 
Table 9.5 Design and operating data. ${ }^{1}$

\begin{tabular}{|c|c|c|c|}
\hline Plant & $\begin{array}{l}\text { Design ave } \\
\text { flow (ML/d) }\end{array}$ & $\mathrm{L}_{\mathrm{D}} / \mathrm{L}_{\mathrm{O}}$ & $\begin{array}{l}\text { Specific energy } \\
\text { consumption } \mathrm{kWh} / \mathrm{kgCOD}\end{array}$ \\
\hline \multicolumn{4}{|c|}{ With PST, Diffused Air } \\
\hline Maroochydore ${ }^{2}$ & 27 & 1.29 & 0.89 \\
\hline Nambour $^{3}$ & 8 & 1.23 & 1.81 \\
\hline St Marys ${ }^{4}$ & 24 & 1.23 & 1.80 \\
\hline \multicolumn{4}{|l|}{ No PST, Diffused Air } \\
\hline Banora Point ${ }^{4}$ & 11.5 & 0.93 & 0.74 \\
\hline Brendale $^{4}$ & 7.5 & 1.21 & 1.05 \\
\hline Brunswick Valley $^{6}$ & 3.8 & 2.28 & 1.65 \\
\hline Gibson Island ${ }^{5}$ & 34 & 1.00 & 0.59 \\
\hline Noosa Coastal $^{4}$ & 12 & 1.50 & 1.62 \\
\hline Penrith $^{4}$ & 20 & 1.17 & 1.41 \\
\hline South Windsor ${ }^{4}$ & 3.2 & 1.26 & 1.59 \\
\hline Wacol $^{5}$ & 6.9 & 1.00 & 1.50 \\
\hline West Wodonga $^{4}$ & 5.9 & 1.72 & 0.96 \\
\hline \multicolumn{4}{|c|}{ No PST, Mechanical Air } \\
\hline Albury ${ }^{4}$ & 12 & 1.00 & 0.88 \\
\hline Bendigo $^{4}$ & 27 & 1.67 & 1.01 \\
\hline Coolum 6 & 8.3 & 1.72 & 1.33 \\
\hline Thorneside $^{6}$ & 7.5 & 1.23 & 1.38 \\
\hline
\end{tabular}

${ }^{1}$ Ratio of average design to operating flows used for load ratio in Equn 9.18.

2 Hartley (2000)

3 JWP (2001)

4 AWWA (1997)

5 Tarong Energy (2000)

${ }^{6}$ Plant data

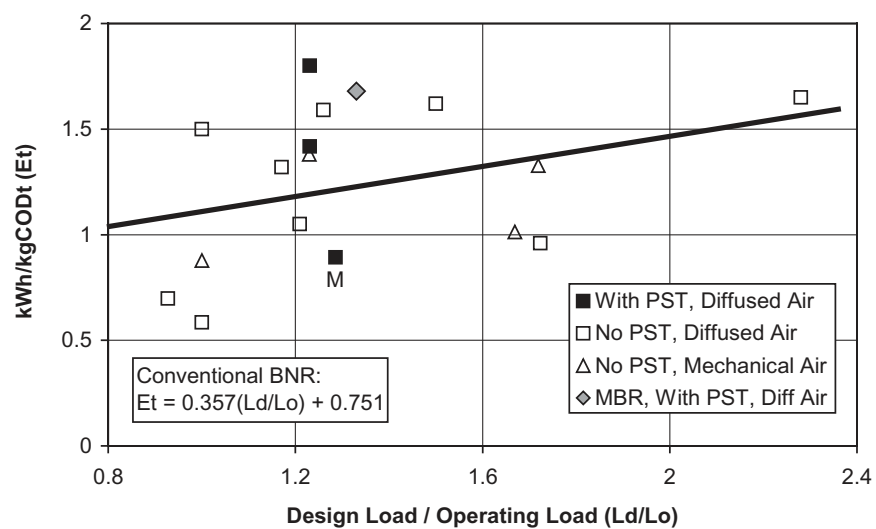

Figure 9.8 Average specific energy consumptions for sixteen Australian continuous flow BNR plants, with and without primary treatment. Non-core demands such as influent and effluent pumping and effluent UV disinfection have been excluded. $M$ is the Maroochydore STP discussed in the text. The MBR plant is not included in the correlation and is discussed in the text. 


\section{Plant-specific energy characteristics}

It is evident that energy consumptions can vary widely. Operators are encouraged to examine the energy characteristics of their own plants to find ways to reduce consumption.

As an example, the energy characteristics of the Maroochydore STP have been explored in more detail. This is a plant with primary treatment, Westbank BNR format and anaerobic sludge digestion (but no on-site power generation). The monthly average plant powers for the 23 months Jan-99 to Nov-00 are plotted against the monthly average flows in Figure 9.9. Over that period the connected population increased by only $6 \%$ and the plant COD load can be regarded as essentially constant. There was a good spread of monthly flows because 1999 was a wet year while 2000 was dry.

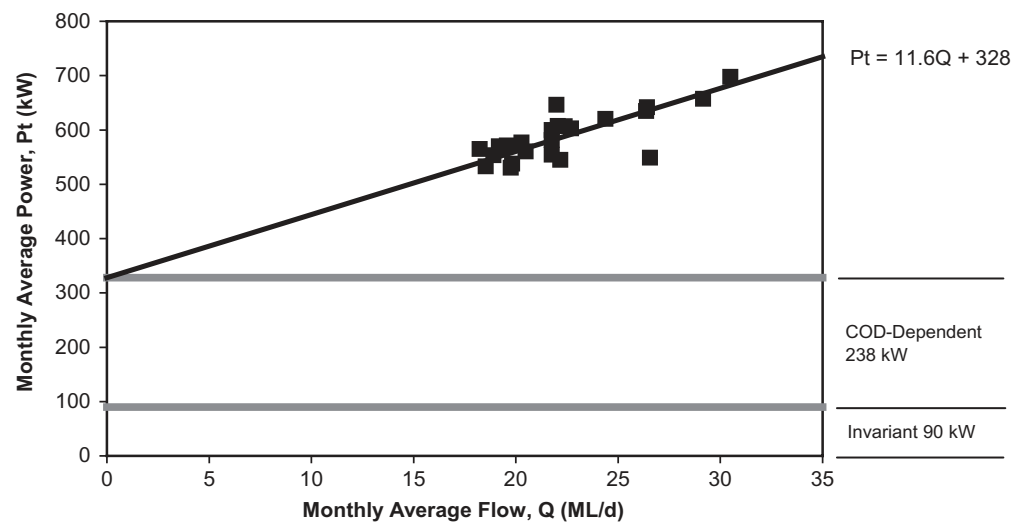

Figure 9.9 Monthly average electrical energy consumptions at the Maroochydore STP Jan-99 to Nov-00. Average COD load was $9.9 \mathrm{t} / \mathrm{d}$ compared with the design average of $13 \mathrm{t} / \mathrm{d}$.

The electric drives in the plant can be categorised as load-invariant (screening, odour control, scrapers, mixers, lighting, building services), COD-dependent (aeration blowers, sludge pumps, sludge thickening and dewatering), or flow-dependent (influent pumps, grit handling, recycle pumps, UV disinfection, effluent pumps). The estimated average operating power for each category is shown in the figure. Maroochydore has a more significant flow-dependent power component than many STPs because of influent and effluent pumping and UV disinfection. Without these demands, the average flow-dependent power falls by two thirds. They are not included in the specific energy shown in Figure 9.8 (as noted in the caption).

Note that invariant power will increase at the lower flows if the flow- and COD-dependent drives have insufficient turndown and become invariant at the lower plant loads. In some cases it may be possible to reduce invariant power by implementing intermittent operation of fixed speed drives.

\section{MBRs}

Membrane bioreactors generally have a somewhat higher energy consumption than conventional BNR plants for several reasons:

- Membrane aeration for cleaning purposes

- Increased pumping associated with (a) fine screening of the influent, (b) higher recycle rate from the membrane reactor compared with a clarifier, (c) additional recycle system to protect the anoxic zone from dissolved oxygen, and (d) effluent head loss through the membranes. 
- Greater switchroom complexity and cooling requirements associated with an increased number of drives and controls.

The Cleveland Bay STP (Townsville) is used here as an example of MBR energy consumption characteristics (with UF membranes). The BNR flowsheet is as shown in Figure $5.1 \mathrm{j}$, with an oxidation ditch for the nitrifying/denitrifying reactor. One of the two reactors is shown in Figure 6.12 and in the cover photograph. The plant has primary treatment and anaerobic sludge digestion but no on-site power generation. There is no on-site influent pumping or UV disinfection and effluent pumping is minimal.

The plant power characteristics are summarised in Figure 9.10. Power varies with flow rate, Figure (a), but is insensitive to COD load, Figure (b), possibly because the COD-dependent power is a small component of total power. Overall, the average specific energy consumption was $1.68 \mathrm{kWh} / \mathrm{kgCOD}$ which is $40 \%$ above the conventional BNR trend as shown in Figure 9.8.
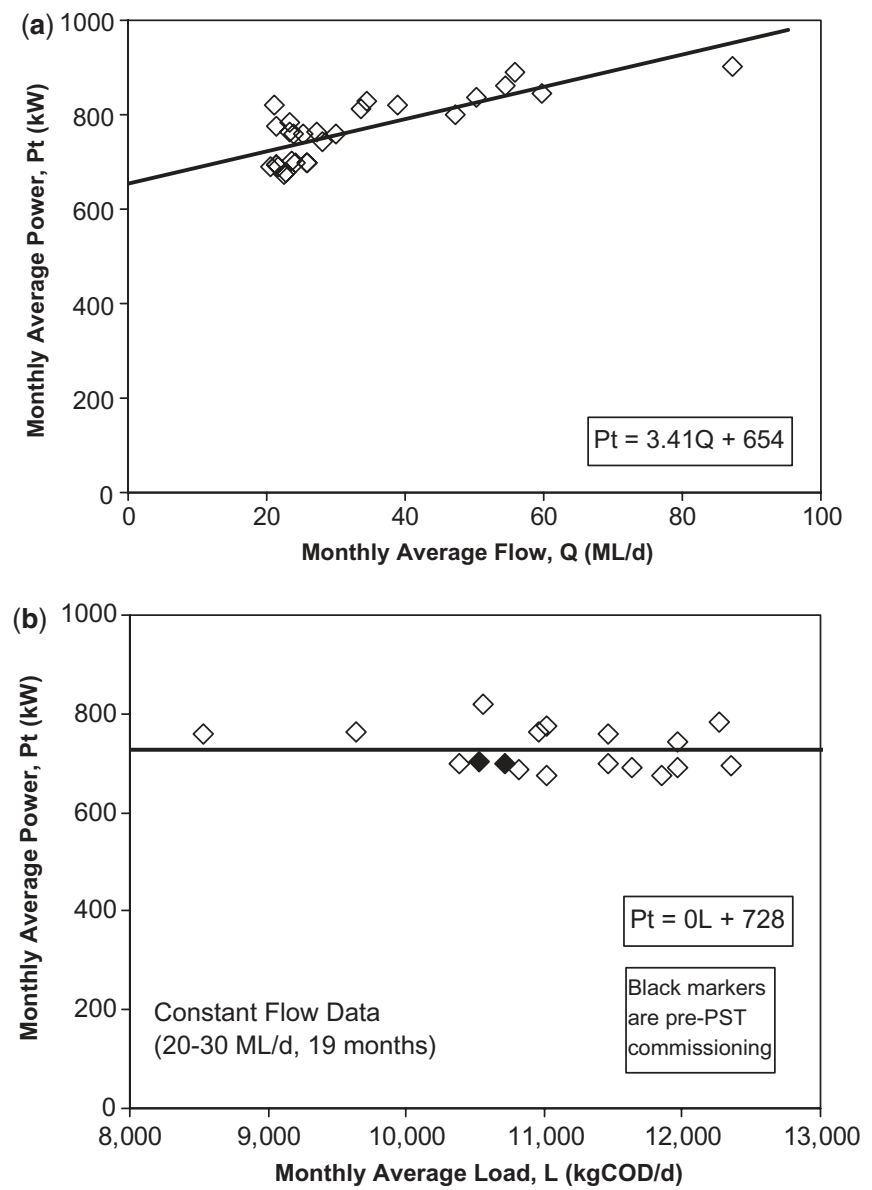

Figure 9.10 Monthly average electrical energy consumption at the Cleveland Bay MBR-BNR plant Feb-08 to Jun-10. Design ADWF $29 \mathrm{ML} / \mathrm{d}$, design average load $14.5 \mathrm{tCOD} / \mathrm{d}$. Operating COD load $10.9 \mathrm{t} / \mathrm{d}$ average. Monthly flow varied widely because of the impact of the tropical wet season. Plot (b) shows only dry season data. 


\subsubsection{Tuning}

It can be seen that plant energy consumptions vary over a wide range. There is obviously scope for reduction in many plants. Operators should explore their own plants' energy consumption characteristics in detail and pursue practical reduction methods. 


\section{Chapter 10}

\section{Process control}

\section{Gustaf Olsson}

Instrumentation, control and automation (ICA) attracted the attention of the water and wastewater industry in the 1970s. Still, however, dynamic systems and process control are seldom part of the general civil engineering or environmental engineering curricula. Consequently many water and wastewater system designers are unaware of the potential of ICA. It has been demonstrated that ICA may increase the capacity of BNR plants by $10-30 \%$ today. The advanced knowledge of the mechanisms involved in biological nutrient removal that is being gained today is producing an increased understanding of the processes and the possibilities for control. There is a sophisticated relationship between the operational parameters in a treatment system and its microbial population and biochemical reactions, and hence its performance. With further understanding and exploitation of these relationships the improvements due to ICA may reach 20-50\% of the total system investments within the next 10-20 years. Various case studies of advanced control in water and wastewater treatment systems have shown significant savings in operating costs and remarkably short payback times (Olsson et al., 2005).

\subsection{THE ROLE OF CONTROL AND AUTOMATION}

ICA in wastewater treatment systems has come a long way and is now an established and recognized area of technology in the profession (Olsson \& Newell, 1999). A number of factors have contributed to make this progress possible:

- Instrumentation technology is today much more mature. Complex instruments like on-line nutrient sensors and respirometers are now regularly used in the field.

- Actuators have improved over the years. Today variable speed drives in pumps and compressors are proven technologies and are commonly used to allow a better controllability of the plant.

- Instrumentation technology is today much more mature. Complex instruments like on-line nutrient sensors and respirometers are now regularly used in the field.

- Computing power can be considered almost "free".

- Data collection is no longer a great obstacle. Software packages and SCADA systems are available for data acquisition and plant supervision. 
- Control theory and automation technology offer powerful tools. Benchmarking and various tools for evaluating control strategy performance have been developed.

- Advanced dynamic models of many unit processes have been developed. Commercial simulators are available to package the knowledge of plant dynamics.

- Operators and process engineers are often educated in instrumentation, computers and control ideas. Still, however, there is a great need for better education in these areas.

- There are obvious incentives for ICA, not the least from an economic point of view. Plants are also becoming increasingly complex which necessitates automation and control.

Today the main obstacle for more ICA is the lack of process flexibility. Plant design and operation still have to be integrated in a systematic way.

\subsection{DISTURBANCES}

A major incentive for control is the presence of disturbances, and their impact has to be compensated. Liquid and mass flow disturbances related to the influent have been described in Chapter 2. Compared to most other process industries the disturbances to a wastewater treatment plant are significant. The wastewater influent typically varies substantially both in its concentration, composition and flow rate, with time scales ranging from fraction of hours to months. Discrete events such as rainstorms, toxic spills and peak loads may also occur from time to time. As a result, the plant is hardly ever in steady state, but is subject to transient behavior all the time (Olsson \& Newell, 1999).

Consistent performance must be maintained despite the disturbances. The traditional way of dampening the disturbances has been to design plants with large volumes to attenuate large load disturbances. This solution incurs large capital costs. On-line control systems, which have been demonstrated to cope well with most of these variations, are a much more cost-effective and thus attractive alternative. Disturbance rejection is indeed one of the major incentives for introducing on-line process control.

Too often unnecessary disturbances are created within the plant itself. Often this depends on a lack of understanding how the various parts of the plant interact. One example may illustrate the problem: if the influent flow rate cannot be varied continuously but the pumps are operated in an on/off mode the consequence is that the plant will be subject to sudden flow rate changes. In particular, the clarifier operation will suffer from such sudden flow rate changes (see further Section 7.4 and in particular Figure 7.8).

Recycling of water and sludge in a wastewater treatment plant creates apparent couplings between various unit processes. If these interactions are not considered, then the plant operation will suffer. For example, if anaerobically digested sludge supernatant is recycled to the plant influent during a high load, then the nitrogen load to the plant may be very large and can be measured as a significant increase in the oxygen uptake rate.

It is crucial to identify the sources of disturbances in order to obtain a high performance operation of a plant. Then the control system can be structured so that disturbances are attenuated or even avoided (Olsson et al., 2005). Further internal disturbances may be generated due to inadequate or inappropriate operations including human errors, unsuitable or malfunctioning actuators and/or sensor breakdowns. These may potentially cause major operational problems. Many of the internal disturbances may be avoided (or their impacts minimized) through introducing on-line control systems, including early warning systems. 


\subsection{CONTROL PRIORITIES}

\subsubsection{The system}

It is quite apparent that a good operation and control depends on a whole chain of components that have to work together. Online sensors and analyzers have to be maintained and calibrated. Actuators, such as pumps, valves, motors and blowers, have to satisfy the requirements of good operation. In other words: they have to deliver the control actions that are demanded by the control algorithms. The communication system for signals between sensors, actuators and computers has to produce reliable information with a minimum of signal disturbances. The software includes not only control algorithms, but also a data acquisition system, methods for data screening, signal filtering, data bases, and human friendly operator communication.

Most important of all: people. No control system can be presented to operators who have not been able to influence the design of it. It is all built on trust. Any well-intended and functioning control system can be a total failure if the operating people do not trust it. Therefore people involvement and education is a crucial part of a successful system. So, what are the priorities?

(1) Keep the plant running. Section 10.4.

(2) Satisfy the effluent requirements by controlling key concentrations. Section 10.7.

(3) Minimize the cost by advanced control. This includes more advanced control of single variables. By coordinating the control of various plant parts - such as the sludge treatment and the wastewater treatment - the plant operation can be further improved. Finally a system-wide operation is obtained if the sewer operation is integrated with the influent flow pumping control to the wastewater treatment plant. This can make it possible to optimally use the available volumes and the sludge for the best operation. See Section 10.8 .

\subsubsection{The importance of dynamics}

Every operator knows that the plant is never in steady state. Instead most flow rates and concentrations are varying with time. The fact that the plant is a dynamic system also means that the result of a corrective action will take some time; it will never appear immediately. Therefore the time scales of the process changes are so important. The dynamics of a wastewater treatment system involve a wide range of time scales, from seconds to months. Typical time scales in a wastewater treatment plant are:

(1) Fast: minutes - hours

(2) Medium fast: hours - several hours

(3) Slow: days - months

The time scale influences the design of the control strategies. One way to express the control task is - for example - to supply the right amount of air, or add the correct amount of chemicals, or move the sludge to the right place to match the substrate load, at the right time.

In a sequential batch reactor the system is purposefully in a transient state (see Section 6.6). An oxidation phase will continue until the oxidation is completed, and then a reduction phase (such as denitrification) will take over and will finish when the reduction has been completed. A sequential batch system is therefore very suitable for dynamic process control.

We can see that there is a wide difference between the fast and the slow time scales. Often it is possible to separate the various control actions into different time domains. This means that in the fast time scale the variables that change very slowly will be considered constant. For example, the dissolved oxygen (DO) controller can act as if the biomass concentration is constant. In the slow time scale, for example 
for the control of the total sludge inventory, then the DO concentration can be considered to change instantaneously.

Sometimes the sensor time lag has to be taken into consideration. To get a DO reading takes a number of seconds. This delay is small compared to the typical time for a DO change, a fraction of an hour. A respirometer reading will take a longer time, typically half an hour. It is obvious that such a measurement can be used only for slower corrective actions, in the order of hours.

It is always important to consider the dynamics when closing the loop. Sometimes the controllers are tuned to be too "ambitious". For example, a DO sensor may show a new DO concentration value every 10 seconds. This does not mean that the airflow rate should be changed so often, since the typical response time in a full-scale aerator is 15-30 minutes. A change of the airflow more often than every minute will only produce meaningless control actions and wear out the actuators. Instead a control action every 5-12 minutes is more adequate. Then the DO measurement fed to the controller should be an averaged value (and possibly further filtered) over the same time interval of 5-12 minutes.

\subsubsection{Modelling}

Modelling for control is not the same as modelling for understanding basic kinetic mechanisms. Consequently models like the Activated Sludge Models 1,2,3 (Henze et al., 2000) or the Anaerobic Digestion Model (Batstone et al., 2002) are not meant to be the basis for controller design. Instead, they represent detailed descriptions of the way we understand the mechanisms of the biological processes. In control, on the other hand, one has to identify certain key parameters that are crucial for the operation of the plant. Such parameters can be the oxygen uptake rate (OUR), respiration rate, and reaction rates for BOD removal, nitrification or denitrification. Redox (ORP) can reflect the progress of the reactions, in particular in the oxygen-free denitrification process, where nitrate is reduced to nitrogen gas.

Key parameters can be calculated from simpler measurements. For example the DO concentration can be used as a basis for the estimation of oxygen uptake rates, see further Section 10.5. On-line measurements of ammonia nitrogen or nitrate can be further elaborated to find the adequate reaction rates. Consequently estimation of dynamic parameters is an important part of the modelling that can form the basis for more advanced control.

\subsection{FEEDBACK CONTROL}

The automation of a wastewater treatment plant is based on feedback control (also called closed loop control). The automation has to be implemented from the bottom up, starting with all the equipment that keeps the plant running. Pumps, valves and motors have to operate properly, the sensors must be calibrated and maintained and the signals have to be communicated correctly to the control system.

\subsubsection{Open and closed loop control}

To get a proper understanding of control we have to distinguish between open loop and closed loop (feedback) control. Many processes are manipulated without any measurements made. For example:

- Sludge scrapers in a clarifier may be operated based only on timers.

- Screens are cleaned at regular intervals.

- Air blowers are turned on and off based on timers.

These control actions are examples of open loop control. There is no measurement made. Instead the actuator is working at regular intervals. In other words: after having made the control action 
there is no confirmation about the result of the action. For better operation it is necessary to make measurements.

The fundamental principle of control is feedback, Figure 10.1. The process (for example, an aerator, a chemical dosage system, or an anaerobic reactor) is all the time subject to disturbances. This is why the control action can never be the same. In our daily life we experience feedback all the time. Driving a car is built on feedback: the eyes and the ears are the sensors that measure and monitor the environment, which is changing all the time. Based on this information we make a decision in the brain (our computer). The brain signal has to be transferred to the muscles, the hands and arms (the actuators) and further on to the steering wheel and the speed control of the car.

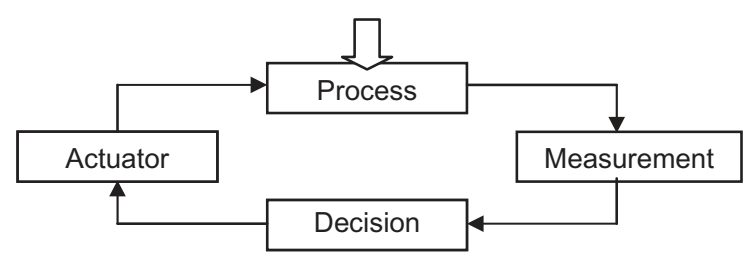

Figure 10.1 Illustration of the feedback principle. The process is influenced by external disturbances, illustrated by the arrow from above to the process.

So, a control system has to include:

- Measurements - a sensor system

- Signal treatment - take away all non-essential data (noise)

- Decision - calculation of a control action

- Actuators - transferring the computer system to "muscles", to motors, valves, pumps etc.

- A goal for the control - this may be, for example, "to keep the flow rate constant", "to maintain a constant pressure", "to keep the DO constant", or "to ramp up the pump speed from zero to full speed". This goal is often expressed as the setpoint (or reference value).

The open loop examples mentioned above can be converted to feedback control:

- Sludge scrapers in a primary clarifier: if the sludge depth in the clarifier is monitored, then the scrapers will start only when the sludge depth reaches a preset value.

- Screen cleaning: the differential pressure over the screen is measured and cleaning initiated when the pressure reaches a preset value.

- Aeration blowers: the DO in the reactor is monitored; based on this measurement a correction of the air flow is made.

The reason for control is the appearance of disturbances. If there were no disturbances we would not need any control! If the effect of the disturbance is measured within the plant, such as a change in the DO concentration, a rising sludge blanket, or a varying suspended solids concentration, the measured information is fed back to a controller that will activate a pump, a valve, or a compressor, so that the influence on the plant behavior is minimized. Having made the decision it has to be implemented via an actuator, which is typically a motor, a pump, a valve or a compressor. In other words: control is about how to operate the plant or process towards a defined goal, despite disturbances (Olsson \& Newell, 1999; Olsson et al., 2005). 
In control engineering feedback control is represented by a block diagram that describes the signals of the control system, Figure 10.2. This kind of a simple control loop appears in all the local control of levels, pressures, temperatures and flow rates. The controller has two inputs, the measurement (actual) value $y$ and the reference (setpoint) value $u_{c}$ and one output, the control signal $u$. In this simple case the controller uses only the difference between the two inputs. The controller tries to make the error e as small as possible in the best possible way. Here is the challenge: what do we mean by "best"? This is why controller tuning becomes important. This is discussed later in this Section.

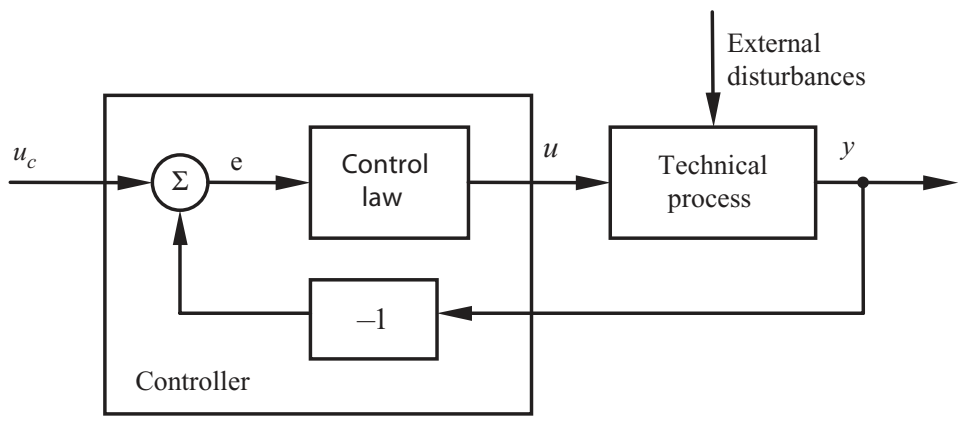

Figure 10.2 Simple feedback control structure.

Sometimes the disturbances can be measured upstream, before they hit the plant, for example the influent flow rate, or influent COD or ammonia-nitrogen concentrations. Then the information can be forwarded from such a sensor to partly compensate ahead for the disturbance. Such control action is called feedforward. For example, the aeration can be increased before a load increase hits the plant. Another example is when the return sludge pumping can be increased to lower the sludge blanket as a preparation of the settler for an expected increase in the hydraulic load.

\subsubsection{Low level control}

The "low level control" includes all control actions that are made to keep the plant running, such as the control of local flow rates, liquid levels, air pressures or various concentrations that are not immediately connected to the effluent quality. Most of these control actions are traditional process control loops, as illustrated in Figure 10.2. In most of these cases the reference value (setpoint) is kept constant. The process variable is subject to disturbances and the regulator is used to make the process variable approach the setpoint in the best possible way.

The dominant type of controller in wastewater treatment (and in most process industries) is the PID (proportional-integral-derivative) controller. Referring to Figure 10.2, the control error is first calculated as:

$$
e=u_{c}-y
$$

where $u_{c}$ is the setpoint value and $y$ the measurement (the sensor signal). The controller consists of four terms:

$$
u=K \cdot\left(e+\frac{1}{T_{i}} \int e \cdot d \tau+T_{d} \frac{d e}{d t}\right)+u_{0}
$$

where $K$ is the controller gain, $T_{i}$ the integral time and $T_{d}$ the derivative time. The first term, the proportional part, reacts at the present control error. The second term, the integral part, sums up all the previous control 
errors. The third term, the derivative part, predicts future control errors by using the derivative of the control error, or the rate of change of the error. The last term $u_{0}$ is used to define the controller output for zero control error.

It is worth noting that in commercial products the proportional gain $K$ is often replaced by the proportional band $\mathrm{PB}$, that is, the range of error that causes a full range change of the control variable:

$$
P B=\frac{100}{K}
$$

Usually the derivative term is calculated using only the measured variable $y$ instead of the error $e$ :

$$
u=K \cdot\left(e+\frac{1}{T_{i}} \int e \cdot d \tau-T_{d} \frac{d y}{d t}\right)+u_{0}
$$

The reason is that the control signal $u$ will get an unnecessary "kick" if the setpoint is suddenly changing, which will make $d e / d t$ very large.

The controller can be used with all its parts or with only P, PI or PID control. In a large majority of cases the controller is a PI (proportional-integral) controller $\left(T_{D}=0\right)$. Figure 10.3 shows the principal behavior of $\mathrm{P}, \mathrm{PI}$ and PID controllers for a step change in the setpoint value. In particular, note that P control cannot eliminate the steady-state offset.

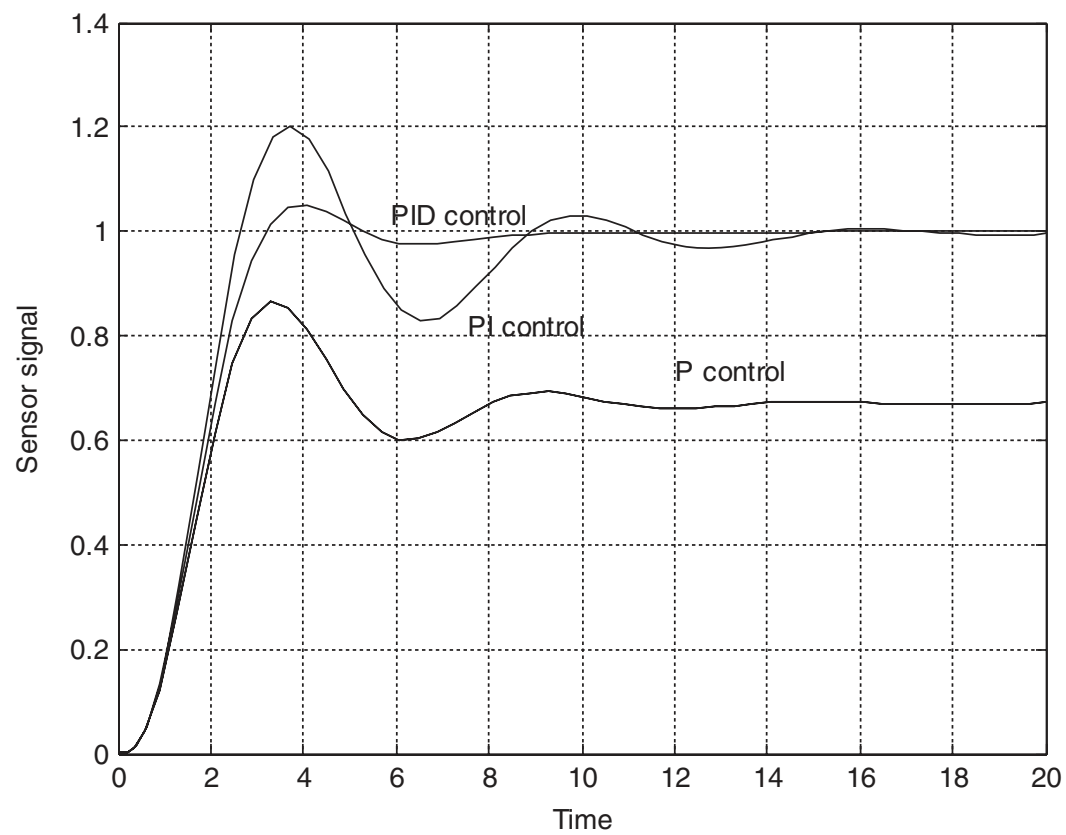

Figure 10.3 The setpoint has been changed 1 unit. The resulting sensor signal is shown for P, PI and PID control respectively. The I-term of the PI controller will eliminate the steady state off-set. The D-term increases the damping and decreases the overshoot. 


\subsubsection{Integral action}

The purpose of the integral part of the PID controller is only to eliminate the stationary error (the steady state off-set), in other words to make $e=0$ after some time, see Figure 10.3. The integral action can be understood intuitively in the following way. In steady-state all variables are constant. For the argument, assume that $e$ would be constant and nonzero. Then the integral in Equations 10.2 or 10.4 would increase and the $u$ term would increase, meaning that it is not in steady-state. So, the only way to keep $u$ constant after a long time is to make $e=0$.

One of the most well-known possible sources of degradation of performance is the so-called integrator windup phenomenon. This occurs when the controller output saturates (for example, a valve becomes fully open, or a motor runs at full speed). This problem is of particular concern at the process start-up. In this case the system operates as in the open-loop case, since the actuator is at its maximum (or minimum) limit, independently of the process output. The control error $e$ decreases more slowly as in the ideal case (when there are no saturation limits) and therefore the integral term becomes large (it winds up). Thus, even when the value of the process variable attains that of the reference signal, the controller still saturates due to the integral term and this generally leads to large overshoots and controller settling times. For more details, see Olsson \& Newell (1999).

Most commercial computer based PID controllers today are supplied with anti-windup features. They solve the problem either by putting an upper limit on the integral term or by turning off the integral action when the controller output saturates. A problem with the latter approach is that the actuator or the manipulated variable itself may saturate before the controller output.

\subsubsection{Derivative action}

Derivative action adds a kind of predictive capability by reacting to the rate of change of the error. In the absence of noise, this adds a stabilising effect, which can counteract the destabilising effect of integral action. Most of the processes in a wastewater treatment plant are relatively slow and do not have any oscillatory behavior. This means that the measured variable will change in only one direction, when the control actions are changed. For example, if the air flow is changed, then the DO concentration will change in one direction, up or down. If a pump speed increases, then the flow rate will increase and a level in a tank will increase. The motivation to use the D term is to speed up the correction. For example, consider two cases of DO concentration changes:

(1) The DO concentration is $1 \mathrm{mg} / \mathrm{l}$ below the setpoint and is decreasing.

(2) The DO concentration is $1 \mathrm{mg} / \mathrm{l}$ below the setpoint but is increasing.

It is intuitively obvious that the air flow increase should be larger in case (1). This is why the D term can help. The term $d e / d t$ (or $-d y / d t$ ) is positive in case (1) and negative in case (2). This will adjust the size of the air flow rate $(u)$.

Still it is not common that the D term is used, and the PI controllers are much more common. The reason is that the signal $y$ is often corrupted by noise. To take a derivative of a noisy signal cannot be recommended, since the $d y / d t$ value will become even more noisy. This will result in a control signal $u$ that is not smooth at all, and will wear out the equipment and provide a poor control instead of an improved one. So, the use of the $\mathrm{D}$ term requires more elaborate controller tuning.

There are two kinds of solutions to the $\mathrm{D}$ term challenge. One is to first smooth the signal $y$ in a filter. In the simplest case the filtered signal can be obtained simply by taking an average. For example: the DO concentration can be measured every 10 seconds, while the air flow is changed only every 10 minutes. In this case the averaged DO concentration every 10 minutes is used by the controller. 
The other solution is by sampling in the computer realization. The derivate is replaced by a difference over the sampling interval. This is discussed below.

\subsubsection{Computer realisation of the PID controller}

When realised in a computer (which is the normal case) the continuous controller (Equation 10.2 or 10.4) is approximated so that the integral term is replaced by a summation and the derivative term by a difference. The process output error (Equation 10.1) is calculated at each sampling instant $(k=1,2,3, \ldots$.$) :$

$$
e(k h)=u_{c}(k h)-y(k h)
$$

It is assumed that the sampling period $h$ is constant. Any signal variations that may take place during the sampling interval are neglected. Alternatively, the signal is calculated as an average value, as noted above. The time-discrete form of the PID controller (Equation 10.4) is:

$$
u(k h)=u_{P}(k h)+u_{I}(k h)+u_{D}(k h)+u_{0}
$$

where $u_{P}$ is the proportional part, $u_{I}$ the integral part and $u_{D}$ the derivative part. The offset signal $u_{0}$ is used to define the controller output for zero control error. According to Equation 10.4 the proportional part of the controller is:

$$
u_{P}(k h)=K \cdot e(k h)
$$

The integral in Equation 10.4 is approximated by finite differences and is equal to:

$$
u_{I}(k h)=u_{I}[k h-h]+K \cdot \frac{h}{T_{i}} e(k h)
$$

The integral part of the digital controller forms a recursive expression, which means that its value is updated at every sampling instance. The last term may become very small for a small $h$ and a large $T_{i}$.

In the derivative part the derivative in (10.4) is replaced by a difference approximation:

$$
u_{D}(k h)=-K \cdot T_{d} \frac{y(k h)-y(k h-h)}{h}
$$

It is very important how to select the sampling time $h$. In Section 10.3 we noted that the sampling time for DO control should not be too short.

In a computer implementation there are additional features that have to be included in the PID controller. An important part is anti-windup that is easily implemented in the digital form.

\subsubsection{When is PID control appropriate?}

It can be observed that a majority of controllers in the process industry are PI controllers. Actually PI control is adequate for all processes where the dynamics are represented by a first order, such as level control in single well-mixed reactors. Often the process has been designed so that it does not require tight control. This means that even if the process has somewhat more complex dynamics, proportional control is adequate if it is complemented with integral action to provide a zero steady-state offset.

PID control is appropriate for processes where the dominant dynamics are of second order. In a system characterized by two response times that differ in magnitude then a $\mathrm{D}$ action can improve the operation.

When there is a dominant time delay a PID controller is typically not adequate, and a dead time compensator is usually needed. With such a compensator the loop gain can be increased and the 
response improved. Also, systems with oscillatory modes usually require more sophisticated control than a PID can offer. Such systems, however, are not common in wastewater treatment systems.

\subsubsection{Controller tuning}

To find the optimum values of $K, T_{i}$ and $T_{d}$ is called controller tuning. Good control performance can be achieved with a proper choice of the controller parameters, but poor performance and even instability can result from a poor choice of values. Controller tuning methods based on the dynamic performance have been used for many decades and here we will give some guidance for the tuning. Controller tuning for wastewater treatment systems is discussed in Section 17.3 of Olsson \& Newell (1999) and more general tuning methods are described in many control engineering books, for example Marlin (2000), Chapter 10.

Generally speaking we have the following qualitative considerations to make concerning the settings of the controller parameters:

- If the gain $K$ is too small, then the control action will become too slow and the controller is not acting as quickly as we wish.

- If $K$ is too large, then the controller is too sensitive to disturbances and may overreact. In some cases the controller will cause the system to be unstable, that is the process variable will oscillate with increasing amplitudes. This is illustrated in Figure 10.4 (left figure).

- If the integral time $T_{i}$ is made short, then the regulator may overreact. It is too "ambitious" to make the error equal to zero, and the control system may be unstable. On the other hand, if $T_{i}$ is too large, then the error may approach zero too slowly. See Figure 10.4 (right figure).

- $T_{i}$ should be longer than the typical time constant of the individual process unit, so that the error $e$ gradually approaches zero.

- Increasing the derivative time constant $T_{d}$ gives a damping effect (Figure 10.3). However, much care should be taken to avoid increasing it too much. Otherwise the controller may be too sensitive to the rate of change and may overreact.
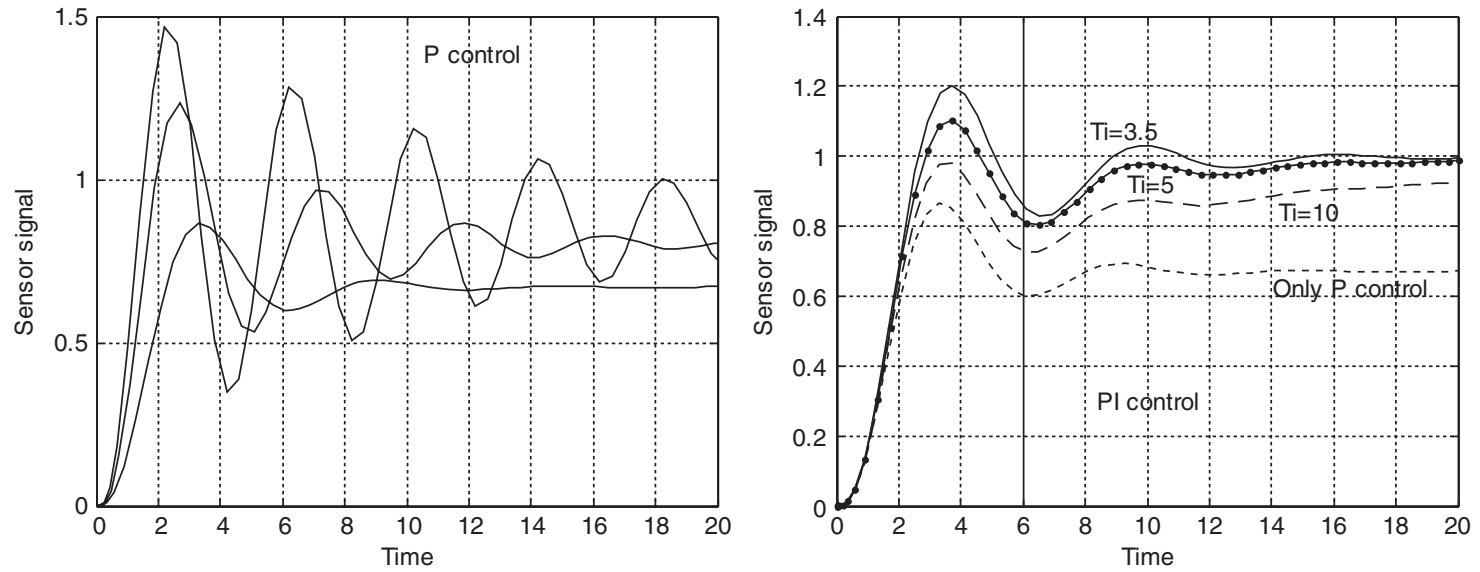

Figure 10.4 A setpoint change of 1 unit and the resulting sensor signal. Left figure: $P$ control with varying $K$. As $K$ increases the response time gets shorter, but the oscillatory behavior will increase. In all cases there is a steady-state offset. Right figure: Tuning of the integral time $T_{i}$ for a fixed $K$. With $T_{i}=\infty$ (only $\mathrm{P}$ control) there is a steady state offset. As $T_{i}$ decreases the steady state is reached earlier, but at a price of more oscillatory behavior. 
The very first task in tuning a control loop is to be clear on the objectives. What is the purpose of the control loop? There are three main types of loops:

- Servo loops: in which the setpoint varies and the controller needs to be tuned to follow frequent and quite rapid changes in the desired output or setpoint as quickly and as accurately as possible. Examples are the inner loops of cascade controllers and valve positioners. Cascade control consists of two or more feedback controllers with the outputs of the higher-level controllers cascading to the setpoints of those below. This is discussed in more detail in Section 10.7, DO control.

- Regulator loops: in which the setpoint is usually constant and the controller is used for disturbance rejection. The controller should try and keep the sensor signal as close as possible to a desired output which seldom changes. This is the majority of control loops in a process plant.

- Averaging loops: these are used to damp out disturbances, usually controlling the level or pressure of buffer tanks, which try to maintain a constant outflow at the average of the quite variable inflow. Examples are equalization tank level control in two stage anaerobic digesters, and level control in tanks for buffering filter backwash.

The second task is now to find the controller parameters. The general rule is to use as few parameters as possible, for example:

- Use only P action:

- for liquid levels in vessels, unless it is an averaging loop or the actual level is important, $\circ$ on the inner loop of cascade loops.

- Use only I action:

$\circ$ for averaging loops,

o where adherence to the exact desired output setting is important.

- Use D action:

o for high order process dynamics, where the initial reaction is slow,

- but: use extra care with D action when the measurement is noisy.

No matter what tuning technique is chosen, and there are nearly as many techniques as there are control engineers, the general procedure involves three steps:

- Identify a simple model of the process (the form of the model).

- Estimate parameters for the model form chosen, usually by some form of stimulus-response experiment on the process.

- Choose the controller parameters according to some rule.

The tuning of servo controllers differs slightly from that for regulatory controllers. The former are generally tuned a little more tightly (higher gains) with the emphasis on tracking changes in setpoint as quickly as possible. Slave controllers in cascade loops are often tuned for a servo response.

\subsubsection{Manual PI tuning}

Manual tuning of PID control is surprisingly common. The tuning procedure relies on the specific properties of the three terms described above. We restrict our discussion to P and PI control because D control is a little specialized. The systematic tuning goes as follows:

(1) Determine whether the priority for the closed-loop system is reference tracking (i.e. a setpoint that is changing) or load disturbance (when the setpoint is constant). 
(2) Determine whether steady state accuracy is essential to the control system performance.

(3) P control tuning: Introduce proportional action by increasing the value of the proportional gain $K$ until the speed of the response is acceptable. This is illustrated in Figure 10.4, left figure.

(4) I control tuning: If steady state accuracy is considered important, then introduce integral action into the controller by slowly decreasing the integral time from $T_{i}=\infty$ (when no integral control takes place) to smaller values. The $T_{i}$ should be decreased so that an acceptable settle time is achieved. See Figure 10.4.

(5) Balancing the controller terms: Increasing $K$ may increase the overshoot. To compensate for this $K$ has to be decreased. A little fine tuning between $K$ and $T_{i}$ will be necessary to achieve acceptable time responses.

The manual procedure is a trial and error process. It is hoped that steps (4) and (5) will eventually converge to an acceptable solution. Basically, while $K$ changes the speed of response, changing $T_{i}$ alters the settling time, with a tendency to introduce overshoot. Excessive overshoot usually needs to be avoided, but the settle time must be reasonably short so that the desired output level is reached.

Naturally the manual tuning method is somewhat laborious, time-consuming and an ineffective use of resources. We can do better by using some system knowledge.

\subsubsection{Ziegler-Nichols frequency response method}

Two methods for controller tuning were presented by Ziegler and Nichols as long ago as 1942. The methods are still widely used, either in their original form or in some modification. One method is based on the open loop step response and the other is based on the frequency response. It should be emphasized that the methods usually provide a first approximation of an acceptable control performance but most often not the best tuning. A large number of tuning rules have been devised in the last 70 years (see Åström \& Hägglund, 1995, 2006). The rules are generally based on a simple model of the plant.

The frequency tuning method works as follows:

- Set the controller as a $\mathrm{P}$ controller (with $T_{i}=\infty$ and $T_{d}=0$ ). Increase the gain $K$ until the process output oscillates, being at the stability margin. Note the value of the gain $K_{u}$.

- Note the period time $P_{u}$ of the oscillations.

The parameters of the P, PI, and PID controllers are calculated according to Table 10.1 and comparative responses are shown in Figure 10.5.

Table 10.1 Ziegler-Nichols tuning of PID parameters.

\begin{tabular}{lllc}
\hline Controller & \multicolumn{1}{c}{$\boldsymbol{K}$} & \multicolumn{1}{c}{$\boldsymbol{T}_{\boldsymbol{i}}$} & $\boldsymbol{T}_{\boldsymbol{d}}$ \\
\hline $\mathrm{P}$ & $0.5 K_{u}$ & - & - \\
$\mathrm{PI}$ & $0.45 K_{u}$ & $0.83 P_{u}$ & - \\
$\mathrm{PID}$ & $0.6 K_{u}$ & $0.5 P_{u}$ & $0.125 P_{u}$ \\
\hline
\end{tabular}

There are some apparent drawbacks with this Z-N method. First, not all processes can be allowed to oscillate close to the stability limit. Second, many processes in wastewater treatment are relatively slow, so the tuning experiment will take too long. 


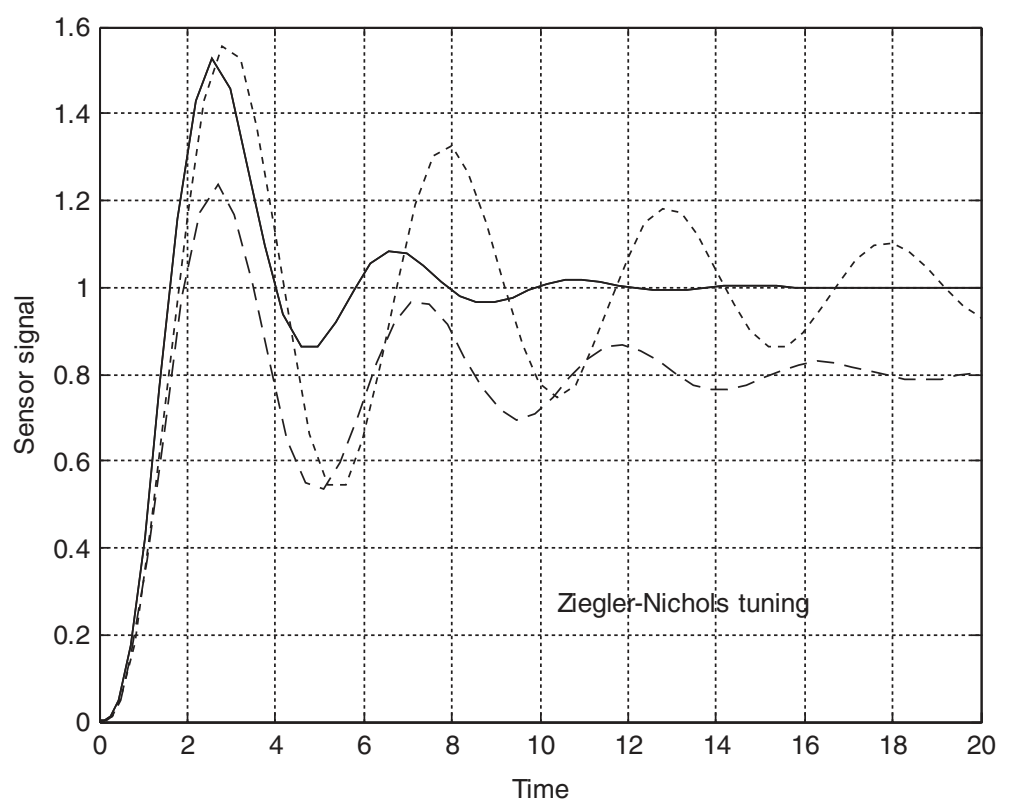

Figure 10.5 The sensor signal for a setpoint change of 1 unit. The controller tunings are set according to the Ziegler-Nichols rules in Table 10.1. The P controller (broken line) has a steady-state offset. The PI controller (dotted line) has become quite oscillatory because of the I-term, but will finally obtain a zero steady-state offset. The PID controller (solid line) has a better damping and reaches steady state more quickly.

\subsubsection{Autotuning}

Today most commercial computer control systems are delivered with PID controllers including automatic tuning, or autotuning. The identification of the process model and the tuning of the controller are made automatically. An identification experiment is automatically performed after a specific request by the operator and the values of the PID parameters are updated at the end of it. For this reason the overall procedure is also called one-shot automatic tuning or tuning-on-demand.

The design of an automatic tuning procedure involves many critical issues. The choice of the identification procedure is usually based on an open-loop step response or on a relay feedback experiment. In the latter case the controller is simply (automatically) replaced by an on-off controller that will cause the process output to oscillate slightly. The process model parameters are found from this identification experiment. Finally a tuning rule is executed. At the end the tuned PID controller will automatically take over the control.

The autotuning methods have been developed over the last two decades and show very good results in the process industry, see Åström- \& Hägglund (2006).

\subsection{INSTRUMENTATION AND MONITORING}

\subsubsection{Instruments}

To measure is to know. Due to developments over the last two decades, instrumentation is no longer the main obstacle for ICA (Olsson \& Newell, 1998, 1999; Olsson et al., 2005). The increased confidence in 
instrumentation is now driven by the fact that clear definitions of performance characteristics and standardized tests for instrumentation have become available (ISO 15839:2003). The most common online instrumentation is shown in Table 10.2.

Table 10.2 Commonly used online instrumentation.

\begin{tabular}{lll}
\hline Physical variables & Primary wastewater properties & Advanced online sensors \\
\hline Flow rate & Dissolved oxygen (DO) & Organic content \\
Level & Turbidity & (COD, TOC) \\
Pressure & Suspended solids & Ammonium \\
Temperature & Sludge concentration & Nitrite/nitrate \\
Conductivity & Sludge blanket level & Phosphate \\
pH & & \\
Redox (ORP) & & \\
Biogas flow rate & & \\
\hline
\end{tabular}

It is always important to screen the sensor data for high-frequency noise, missing data, values out of range or trends from drifting sensors. The screened measurement is then a basis for monitoring or directly for control.

To track the process operational state via the instrumentation is called monitoring. Even reliable instrumentation can fail during operation, which can have serious consequences if the instrumentation is used in closed loop control. Therefore real time data validation is needed before using measurements for control purposes. If confidence in a measurement decreases, it might be possible (on a short-term basis) to use an estimated value, but eventually control must be set to a default scheme until confidence in the measurement has been restored.

\subsubsection{Estimating the oxygen uptake rate}

Let us consider one apparent example of monitoring, to estimate the oxygen uptake rate (OUR) directly from DO concentration measurements. In order to see the relationship been the DO and the OUR we set up the DO mass balance for an aerator zone. Using the nomenclature of Section 6.2.1 and the additional parameters defined below, the DO mass balance can be formulated as follows:

$$
\frac{d C}{d t}=\frac{Q_{\text {in }}}{V} C_{\text {in }}-\frac{Q_{\text {out }}}{V} C_{w}+K_{L} a\left(C_{s}-C_{w}\right)-r_{M}
$$

where

$$
\begin{aligned}
C_{\text {in }} & =\text { DO concentration in reactor inflow } \\
C_{w} & =\text { DO concentration in reactor outflow } \\
Q_{\text {in }} & =\text { reactor inflow } \\
Q_{\text {out }} & =\text { reactor outflow rate } \\
V & =\text { reactor volume }
\end{aligned}
$$

and other parameters are defined in Section 6.2.1.

The left hand side is the rate of change of the DO concentration in a zone that is considered to be well mixed. The first term on the right hand side denotes the mass of DO that will enter the zone via the 
water flow, while the second term similarly denotes the amount of DO leaving the zone. Here we have assumed that the concentration of DO is the same in the whole zone. The third term represents the oxygen transfer from gaseous oxygen to dissolved oxygen (see Equation 6.6). Finally, the oxygen consumption, called $r_{M}$ (see Equation 6.7), is the biomass respiration rate.

Looking more closely at the size of the terms the first two terms are much smaller than the last two. Let us now assume that the DO is controlled and constant. This means that the term $d C / d t$ is zero. Neglecting the first two terms we now have:

$$
K_{L} a\left(C_{s}-C_{w}\right) \approx r_{M}
$$

For diffused air aeration, Figure 6.6 shows that the oxygen transfer efficiency $\left(\mathrm{gO}_{2} / \mathrm{m}^{3}\right.$ air $/ \mathrm{m}$ depth) typically varies by only about $15 \%$ over the normal operating range. In other words: the OUR (or $r_{M}$ ) varies approximately proportionally to the air flow rate. This means that the air flow can be used as an important indicator of the biological activity of the organisms in the aerator.

In a sophisticated treatment plant there is a huge data flow from the process. More instrumentation will provide even more data. Unlike humans, computers are infinitely attentive and can detect abnormal patterns in plant data. The capability of computers to extract patterns (useful information) is rarely utilized beyond simple graphing. Information technology is not commonly used to encapsulate process knowledge, that is knowledge about how the process works and how to best operate it. If process knowledge can be encapsulated, then not only is it retained but the computer can also assist decision-making in plant operation (Rosen et al., 2004). The potential of substantial operator support for diagnosis and for corrective actions exists and has been demonstrated.

\subsection{PUMPING \\ 10.6.1 Pump characteristics}

Pumping and aeration are the two most energy intensive operations in a wastewater treatment plant. It is quite logical to consider the pumping operations from an energy point of view. Furthermore, the consequences of pump control for the behavior of the wastewater treatment plant also need to be considered. In particular, the clarifiers are sensitive not only to the flow rate but also to the rate of change of the flow rate. As a consequence the influent pumping ought to be as smooth as possible in order not to upset the clarifiers. As a consequence we look at two basic properties of pumps:

- Pump efficiency

- Variable speed control

The operating point (or duty point) of a pump is determined by the intersection of the pump (QH curve) and system characteristics, as shown in Figure 10.6. The $Q H$ curve defines the pressure (usually measured as "head" in meters) that the pump can produce as a function of the flow rate. The system curve (the load) defines the pressure needed to produce a certain flow rate. The intersection between the two curves is the duty point A that defines the operating point of the pump.

Control by "throttling" is like trying to control your car's speed by braking with one foot while continuing to accelerate with the other. Of course there is a waste of energy, and furthermore it causes excessive wear and tear on the equipment.

When selecting a pump it is important to choose a pump where the duty point is located within the high efficiency area, Figure 10.6. Here the pump losses have a minimum. In a system with variable flow 
it is of course impossible to operate the pump at the maximum efficiency point all the time. However, the pump has to be designed so that the most common flow rates are around the most efficient operating point of the pump.

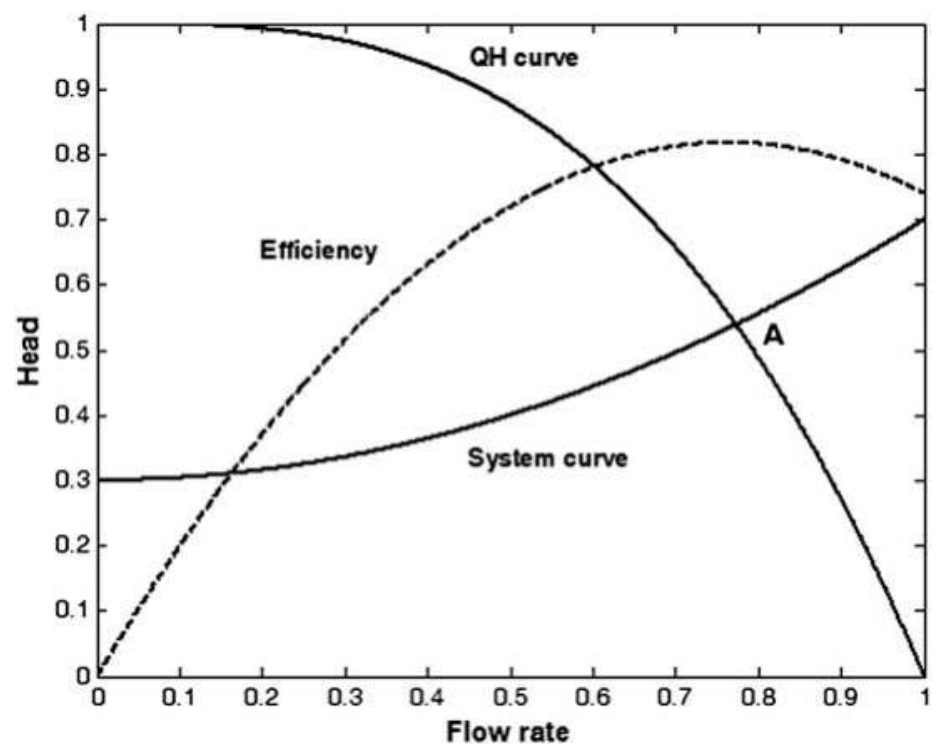

Figure 10.6 The duty point $A$ of a pump is determined by the intersection of the QH curve and the system curve. The efficiency for a typical centrifugal pump is also shown. If the pump speed is changed then the $\mathrm{QH}$ curve will be raised for higher speeds and lowered for smaller speeds, thus changing the duty point. Similarly, if a throttle valve is used to decrease the flow rate it means that the pressure of the system will increase. This will raise the system curve - while the $\mathrm{QH}$ curve remains the same - so that the duty point is moved upwards and to the left. This can simply illustrate why it is not energy efficient to use a throttle valve to change the flow rate. Consequently the energy to pump has to be increased. On the other hand, if a variable speed pump is used to decrease the flow rate, then the $\mathrm{QH}$ curve is lowered, while the system curve is not changed. Consequently the pressure can be decreased and the necessary pumping energy is not so high.

The true pump duty point will almost always differ from the theoretical one. There are inaccuracies in the calculation of main losses, as well as error margins in the published pump performance curves. Furthermore, the pump characteristics will change with use due to wear and the dynamic pressure will increase with age due to corrosion or sedimentation.

Variable speed control by means of a frequency converter is the most efficient way of adjusting pump performance exposed to variable flow requirements. This simple approach can significantly reduce the amount of electricity that a motor-pump system uses, and also lengthen the life of equipment that is no longer subject to the jolting on/off braking that results from throttling. Variable speed control is also desirable from a process operation point of view. An on/off pump creates sudden hydraulic shocks. Firstly it causes pressure shocks that will wear the equipment. Secondly, and more important, hydraulic shocks are extremely detrimental to sedimentation processes and will cause a decreasing process performance. 


\subsubsection{Relationship between flow rate and power}

The relationship between flow rate, pump speed and power requirement for a pump are described by the affinity laws and illustrated in Figure 10.7. The pump flow rate $Q$ is proportional to the pump speed $n$ :

$$
Q=\alpha \cdot n
$$

So if the speed is halved then the flow rate will be halved. The head $H$ is proportional to the square of the speed $n$ :

$$
H=\beta \cdot n^{2}
$$

The required pump power is very sensitive to the speed:

$$
P=\gamma \cdot n^{3}
$$

Equation 10.13 shows that half the flow rate requires only $1 / 8$ of the power. In reality, the pump efficiency is different at different speeds and flow rates, so the practical relationship between $P$ and $n$ is not exactly given by the equation. Still, this relationship explains why variable speed control is superior to throttle valve control from an energy point of view. To calculate more precisely how much power can be saved by variable speed control one also has to take the efficiency of the frequency converter and the motor into consideration.

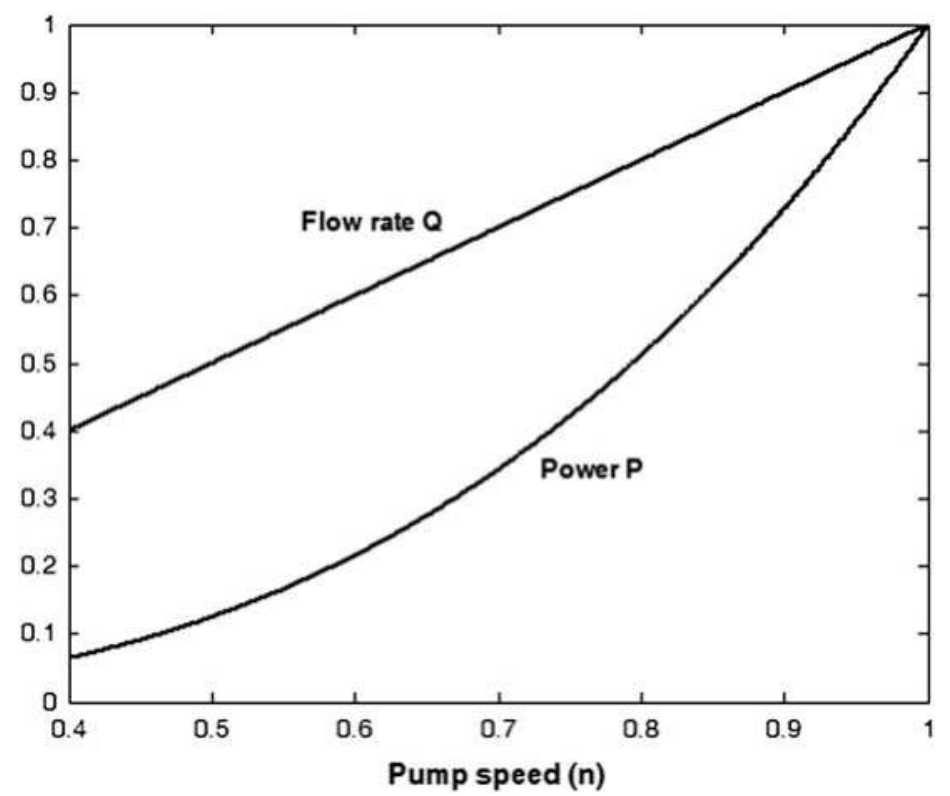

Figure 10.7 The relationship between flow rate and power requirement vs. speed, according to the affinity laws. 
There are various ways to increase pumping efficiency, and variable speed control is not the only way. For example, in one treatment plant a variable speed pump was operating satisfactorily but had too large a capacity and operated at only $60 \%$ of its maximum flow rate. At this flow rate the efficiency was only $65 \%$ for the motor plus pump unit. It was considered profitable to install a new pump with an efficiency of $80 \%$ at the most common flow rate.

\subsection{ESSENTIAL CONTROL LOOPS}

It is not sufficient to control the physical parameters only. Other variables that are directly related to the effluent quality also have to be controlled. Some key control loops are (Olsson et al., 2005):

- DO control with a constant or variable DO setpoint.

- Aeration phase-length control in alternating plants based on nutrient sensors.

- Nitrate recirculation control in a pre-denitrification plant (see Figure 3.21) based on nitrate and DO measurements in the aerator and in the anoxic zone (Ingildsen, 2002).

- Advanced solids retention time control based on local measurements of effluent ammonia concentration and estimates of nitrification capacity.

- Return sludge control based on sludge blanket measurements in the clarifiers.

- Aeration tank settling (ATS) as one way to temporarily increase the plant capacity at storm conditions (Nielsen et al., 1996, Gernaey et al., 2004).

- The control of anaerobic processes to regulate the biogas flow, while stabilizing the process and maximizing its productivity (Steyer, 2006).

- Chemical precipitation control based on local measurements of phosphate concentration (Ingildsen, 2002).

\subsubsection{Dissolved oxygen control}

DO control is of primary importance in the activated sludge process, in both continuous flow plants and in alternating or intermittent systems. The control of aeration has attracted considerable research since the 1970s, when the DO sensors reached a level of robustness and precision suitable for feedback control. Today, the control of the DO to a setpoint is a mature technology. However, even a correct DO control cannot compensate for insufficient air production at extremely high loads.

With the development of nutrient sensors in recent years the primary focus of aeration control has been the on-line adjustment of the level of oxygen supply. For a continuous system, the problem is primarily the on-line determination of appropriate DO setpoints (Ingildsen, 2002).

The importance of the DO profile in space and aeration control in plug-flow type reactors was recognized early (Olsson-Andrews, 1978). For intermittently aerated systems, the control of the aerobic phase-length has been studied intensively (Nielsen, 1983; Thornberg et al., 1993; Sorensen et al., 1994; Nielsen-Ønnerth, 1995 and Potter et al., 1996).

Adequate design of the aeration system is of course the pre-requisite for energy efficient aeration. There are two principally important parts, the compressor and the diffuser system. The compressor has to allow for variable air flow rates, which is crucial for any control of the DO.

Many activated sludge systems are either of a plug flow type or can be described as a series of well mixed tanks (see Section 6.1). The oxygen demand is much higher at the head end of the aerator than towards the outlet. This means that there has to be a higher airflow early in the aerator than in the outlet area, where the biological growth reaction should have been completed. This will require an aeration system that is tapered with a higher capacity towards the head end. 
The aeration system ideally should supply diffused air so that the DO is constant not only along the aerator length but also constant in time. This requires two features:

- There have to be separate air valves along the aerator to supply the appropriate amount of air along the aerator.

- The air valves have to be controlled so that the air flow can be varied with time.

Normally the microorganisms require around $1-3 \mathrm{mg} / \mathrm{l}$ of DO. Too many systems are still designed so that there is insufficient air supply in the head end and an excess air supply towards the outlet. This results in energy waste. In a nitrifying aerator there are two types of microorganisms that compete for the air (see Section 3.5). The organic matter is consumed mainly by the heterotrophic organisms while the ammonium nitrogen is oxidized to nitrite and nitrate via autotrophic organisms. The DO requirement is larger for the autotrophic organisms (Figure 3.15). They are slower growing than the heterotrophic ones, which means that ammonium is removed more slowly than the organic matter. This is illustrated in Figure 10.8. Just before the middle of the reactor the DO concentration rises quickly. This is an indicator that the organic matter has been consumed. The ammonium is still being oxidized and continues to consume oxygen along the reactor. At the outlet all ammonium has been oxidized to nitrate.
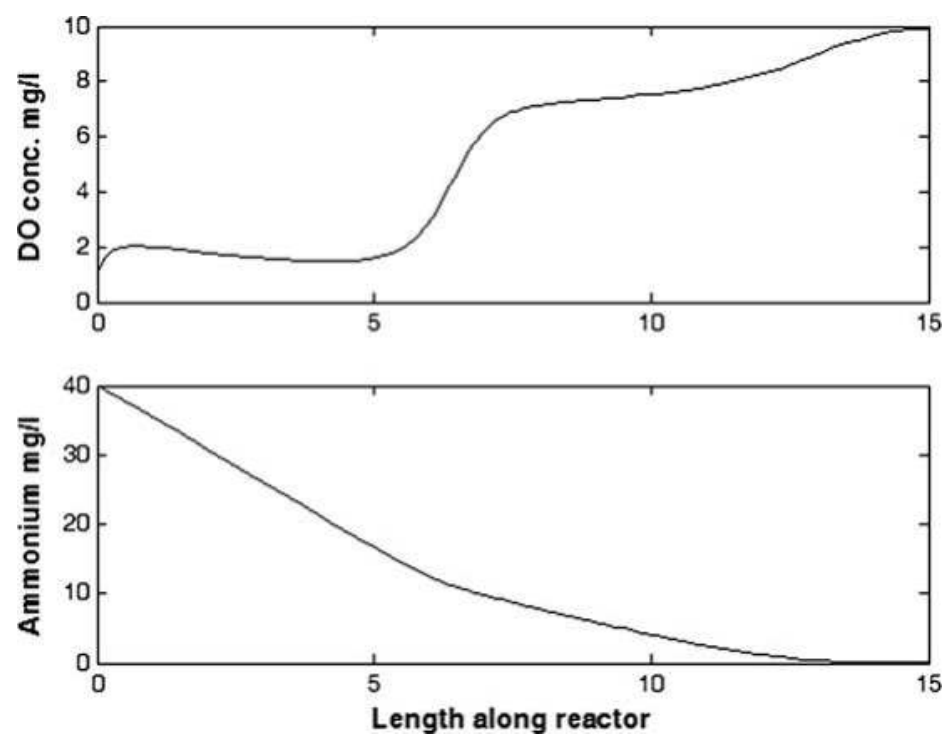

Figure 10.8 The DO profile in a plug-flow reactor for organic removal combined with nitrification. The airflow distribution along the aerator is uniform. The upper curve shows the DO profile $(\mathrm{mg} / \mathrm{l})$ and the lower curve shows how the ammonium concentration decreases along the aerator.

We now assume that the DO is measured in one point in the aerator, typically in one of the aerated zones. The air flow to this zone can be controlled independently of the other zones. Therefore the DO controller should be able to maintain the DO concentration at a given setpoint value in the zone.

The DO concentration is compared with the DO setpoint and the DO controller (the master) will calculate the necessary airflow change required to change the DO concentration towards the desired value, Figure 10.9. 


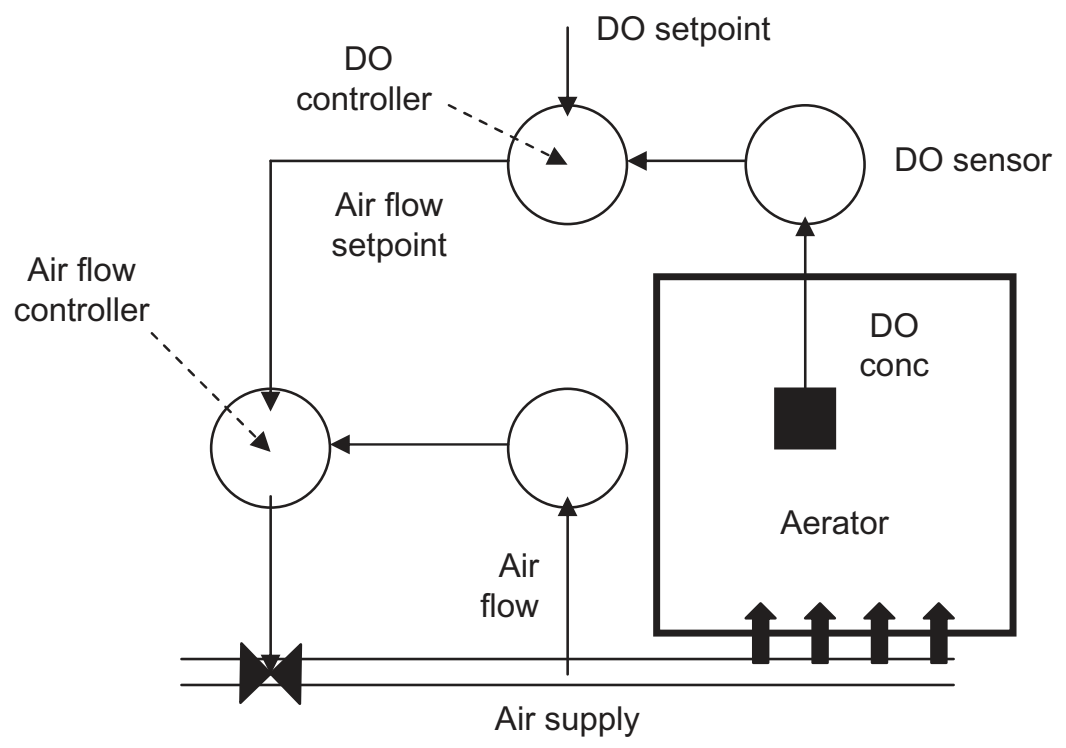

Figure 10.9 Structure of a standard cascade DO control. The master controller delivers the setpoint (air flow setpoint) to the slave controller.

Note that the DO controller does not directly manipulate the air valve. Instead the desired airflow is provided as a setpoint to an inner controller (the slave) controlling the air flow rate. This controller receives the airflow rate measurement and compares it with the desired airflow. This difference will then make the actuator (a compressor or a valve) change the airflow to the correct value. The loop is called a cascaded control loop and is the standard configuration in this kind of system.

There are two fundamental reasons why the DO controller (called the master) is not coupled directly to the valve:

(1) The first reason has to do with the valve characteristics. Usually the valves are nonlinear, as in a butterfly valve. A $10 \%$ change of the valve signal will produce significantly different responses if the valve is almost closed, in the mid-range or almost fully open. This means that a desired airflow change has to result in widely different valve movements if the valve is almost closed or if it is almost fully opened. If the airflow rate is measured, then the flow controller is able to produce just the flow rate that is demanded. Having the closed-loop slave controller in place means that the master controller will see a linear behavior of the airflow system. Without a cascade structure the DO controller would need to have a different tuning for small loads and for high loads because of the nonlinearity of the valve.

(2) The second reason has to do with the commissioning of the control system. The slave controller is always tuned first with the master controller open loop (set in manual). The slave controller is usually a simply P controller, since the steady state off-set is not critical for the slave controller. Then one can ensure that the response of the airflow system is adequate. Now the master controller will see a more ideal (and linear) behavior of the air flow system. The master controller is then put into automatic mode and subsequently tuned. Having the slave controller makes tuning of the master controller, usually a PI controller, much easier. The integral part ensures that the DO concentration has no steady-state offset. 
Just as in the equivalent human situation, the slave must be capable of reacting faster than the master to ensure stability. Unless the master controller has a very slow response, the slave controller will generally be a simple P controller. The master controller is usually of a PI type, Equation (10.4), and will remove any offset which may occur.

Certainly, more complex controllers have been tried and reported in the literature. In 1984 experiments were performed on the use of a more complex self-tuning regulator of higher order in a full-scale process (Olsson et al., 1985). Surprisingly the controller parameters converged towards a PI-controller performance. Despite this long-standing finding, attempts are still published to control the DO concentration with advanced control algorithms, providing little additional benefit in the actual implementation (Olsson, 2012a).

Figure 10.10 demonstrates DO control for a medium sized municipal plant.
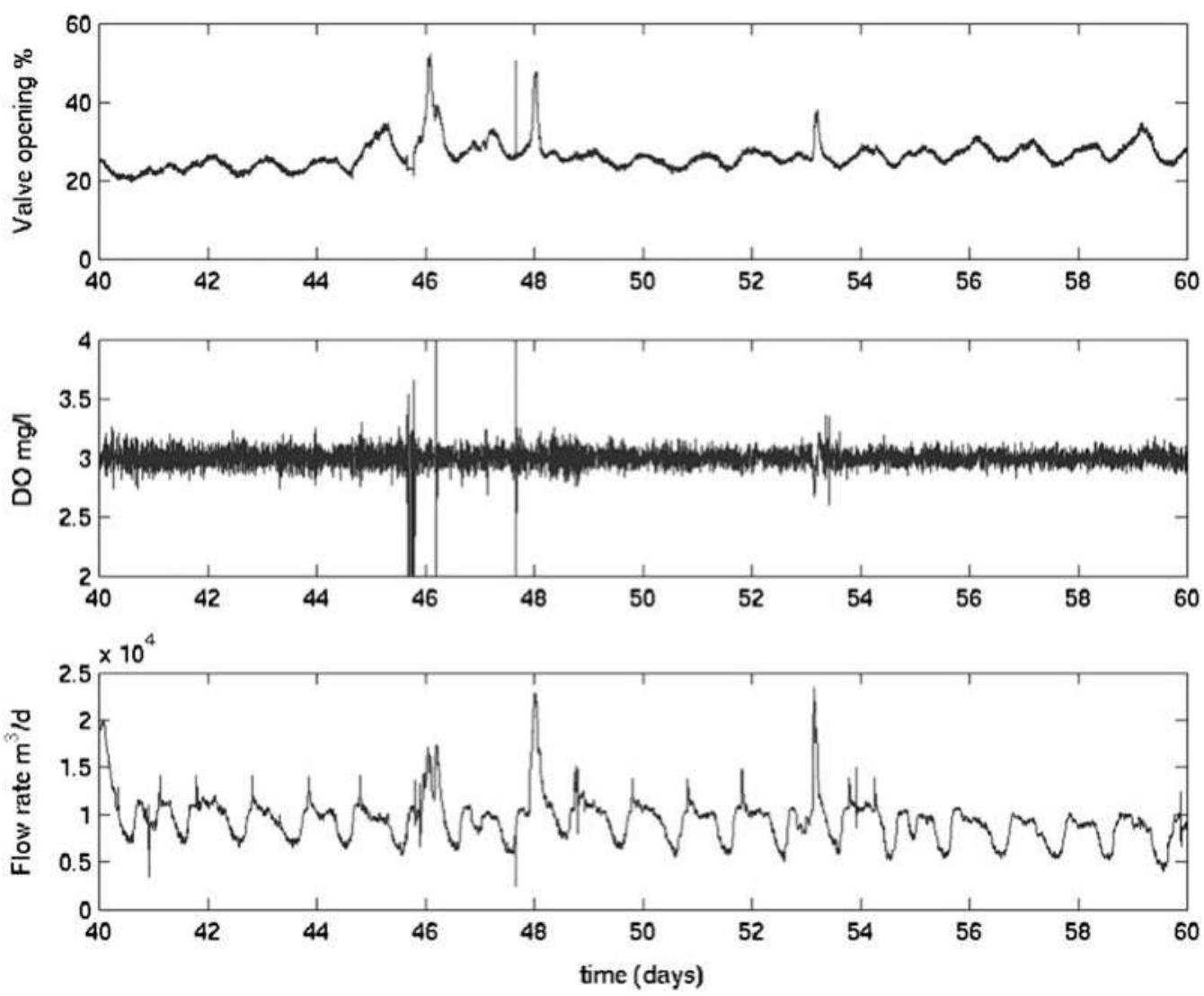

Figure 10.10 Example of DO control during 20 days of operation of a municipal plant. The DO is controlled around its setpoint value of $3 \mathrm{mg} / \mathrm{l}$ (middle curve). The upper curve shows the air valve opening and is an indicator of the oxygen uptake rate (Section 10.5.2). The lower curve shows the influent flow rate to the plant.

The real challenge today is to decide what oxygen concentration is required for the process, given disturbances and uncertainties. There are several aspects of this, one being the legislative framework which the plant has to comply with. Internationally, there are different levels of total nitrogen limits. If 
there is a limit of only the total nitrogen but not on the ammonia concentration, then the best strategy - from an energy point of view - is to maximize the ammonia concentration while satisfying the total nitrogen concentration.

There are also different time perspectives on the effluent limit compliance. For example, if the effluent criteria are defined as averages over the day or over the week, then it is not crucial to keep the DO very tight around the setpoint. On the other hand, if the effluent criteria have to be met at any time, then the control has to be much more strict.

In some countries there are effluent fees connected to the plant performance. With such a criterion it is apparent that operational costs can be compared with effluent costs, and the best strategy can be sought.

\subsubsection{Ammonia-Based DO control}

In a nitrifying aerator the organic removal is completed much before the ammonia-N removal, Figure 10.8. Therefore it is of interest to verify that the ammonia-N concentration is sufficiently low towards the outlet. It is most often profitable to measure the ammonia-N online towards the outlet, as indicated in Figure 10.11. If the measured ammonia- $\mathrm{N}$ is smaller than the setpoint value of the ammonia- $\mathrm{N}$ then the DO setpoint in the last zone of the aerator can be decreased. Consequently, if the ammonia- $\mathrm{N}$ is too large, then the DO setpoint should be increased (up to a certain limit). Still this may not be sufficient, if the load is extremely large. The DO setpoint correction should not be made more often than on an hourly basis. Usually a simple P controller is sufficient. Significant energy savings can be achieved. Compared to a fixed DO setpoint savings of 10-15\% have been reported (e.g. Ingildsen, 2002).

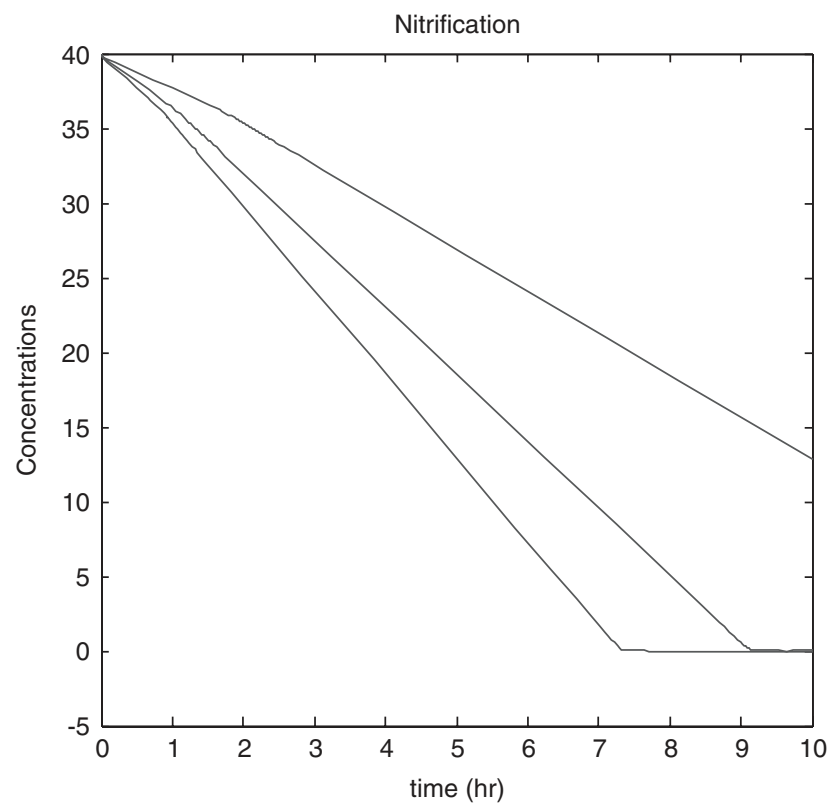

Figure 10.11 Ammonia- $\mathrm{N}$ concentration along the length of the aerator (simulated). The upper curve indicates that the nitrification has to been completed. The DO setpoint should be increased. The middle curve is an ideal ammonia- $\mathrm{N}$ removal and reaches a low value just at the outlet. The lower curve is too "ambitious" and in the last part of the aerator no more nitrification takes place. Then the DO setpoint can be lowered to slow down the nitrification rate and save energy. 


\subsubsection{Recycle flow controls}

A number of flows in the biological step of a wastewater treatment plant need to be controlled. These include the nitrate recirculation flow control, external carbon dosage control for enhancing denitrification or phosphorus removal, SRT (sludge retention time) or sludge wasting control, sludge recycling flow control. Other flows include the control of the wastewater flow through step feed, wastewater storage, and aeration tank settling. Overviews of all these control actions are presented in Chapter 6 of Olsson et al. (2005). Most of these variables may be operated relatively independently of each other. However, external carbon dosage control should preferably be controlled in combination with nitrate recirculation.

\subsubsection{Chemical precipitation}

Phosphorus removal using chemicals has been discussed in Section 3.7. For tertiary chemical phosphorus trimming downstream of a biological phosphorus removal process, the traditional control is a flow proportional controller, where the dosage is proportional to the influent flow rate. It is often adjusted for rain events and the charges of the particles and the performance is checked by grab samples or 24-hour samples. Figure 10.12 illustrates a typical phosphate concentration variation in the influent to a tertiary chemical process. It is not a trivial exercise to obtain an average effluent phosphate concentration of $0.3-0.5 \mathrm{mg} / \mathrm{L} \mathrm{PO}_{4}-\mathrm{P}$ with such a plain strategy; usually an excess dosage is used in order to satisfy the effluent requirement.

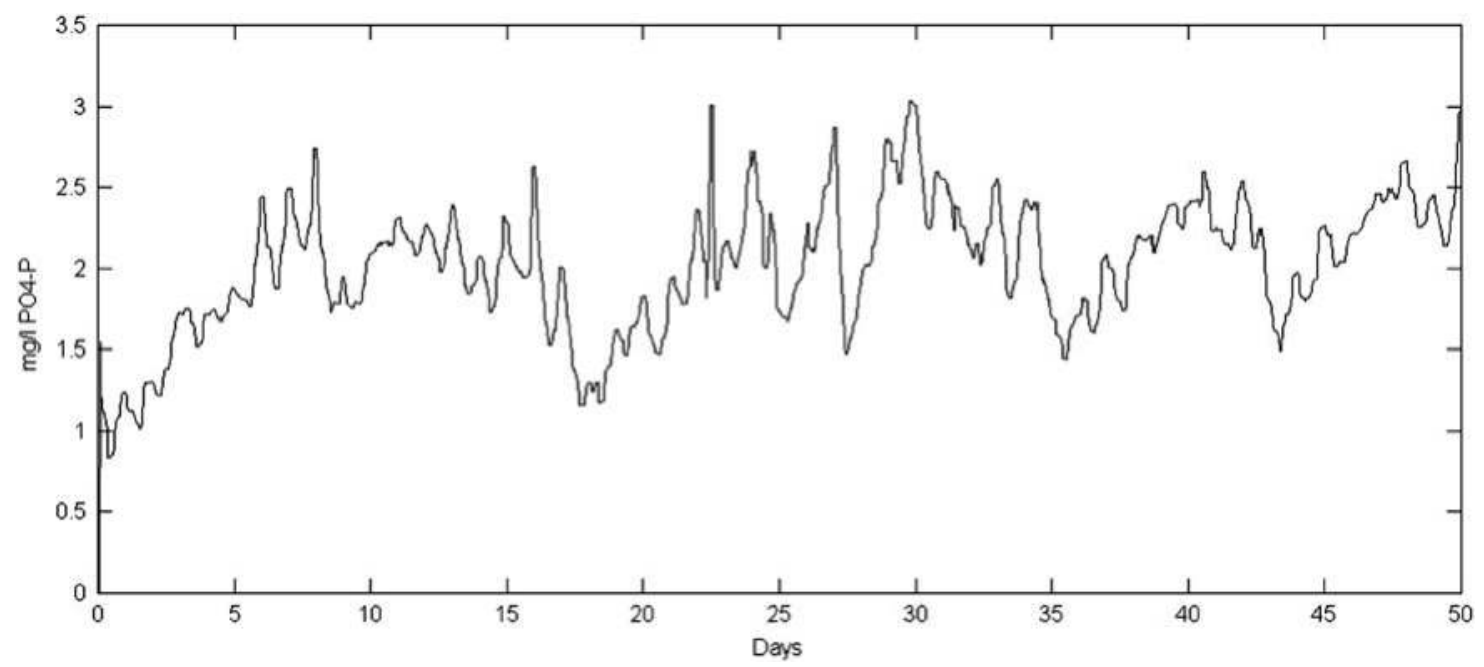

Figure 10.12 Example of variation in $\mathrm{PO}_{4}$ concentration into a tertiary process (Ingildsen, 2002).

However, using a feedback control strategy means that the dosage is controlled based on online measurements of the phosphate concentration in the flocculation chamber. The controller can be a simple PI controller. The feedback control makes it possible to reduce the dosage considerably. At the same time there is a confidence that the effluent concentration is acceptable regardless of events taking place upstream in the process. Figure 10.13 demonstrates that it is possible to control the dosage to yield a quite constant effluent phosphate concentration, close to the target of $0.5 \mathrm{mg} / \mathrm{L}$, in spite of variations in 
the influent phosphate concentration. The standard deviation of the phosphate concentration from the flocculation chamber in Figure 10.13 is $0.03 \mathrm{mg} / \mathrm{L} \mathrm{PO}_{4}$-P. Furthermore, by simply adjusting the setpoint of the controller to $0.3 \mathrm{mg} / \mathrm{L}$ the controller could readily adjust the dosage with a similar performance.

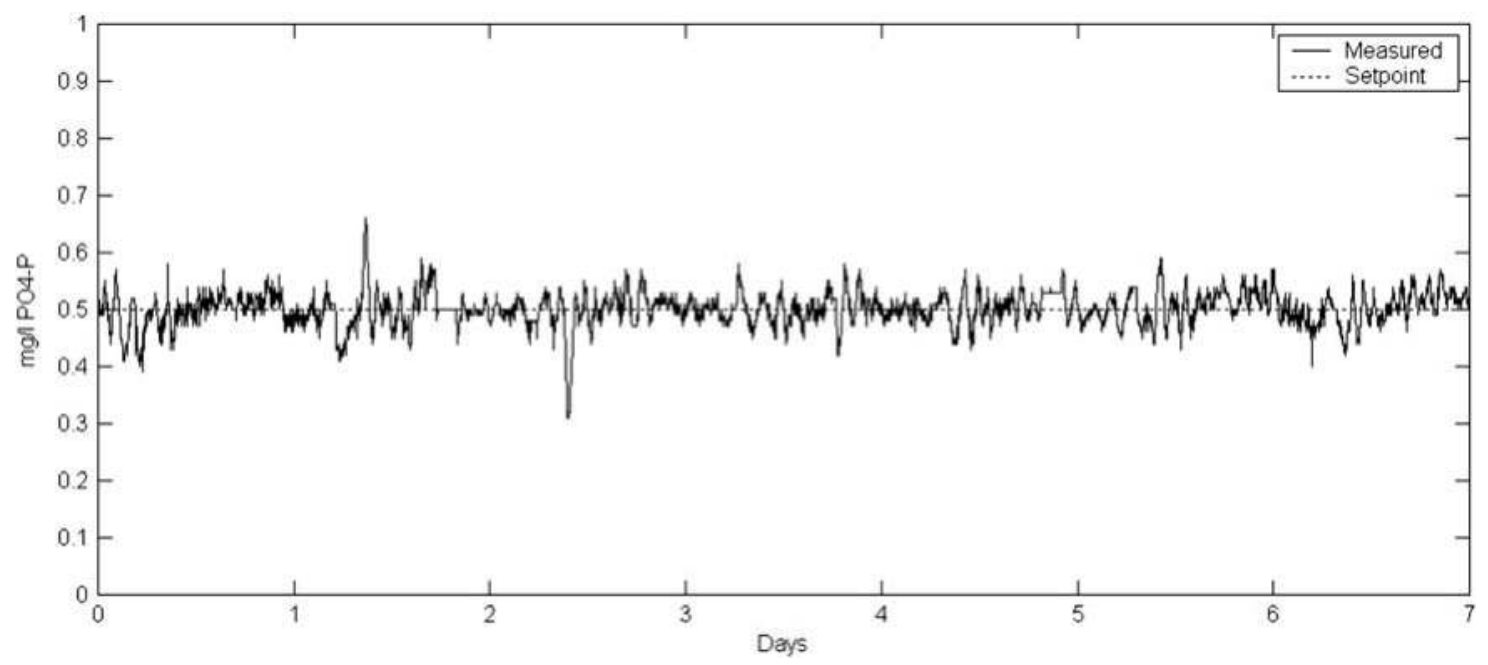

Figure 10.13 Effluent phosphate from the flocculation chamber using sensor feedback (Ingildsen, 2002).

\subsubsection{Anaerobic digestion process control}

While anaerobic digestion has not been discussed elsewhere in this book, a note is included here to provide a broader perspective on the automatic control of biological processes.

Anaerobic digestion (AD) processes are usually more sensitive to process disturbances and subject to more failures than aerobic processes. The control of biogas production can be quite unstable if the controllers are poorly tuned. Indeed, one of the main reasons for imbalances that will eventually lead to process failure is due to the inhibitory effects of the volatile fatty acids (VFA) at high concentrations. Since VFA accumulation induces a $\mathrm{pH}$ drop and since $\mathrm{pH}$ is readily available information, it is widely used for monitoring and control of $\mathrm{AD}$ processes. In $\mathrm{AD}$ operation the gas production, gas quality, volatile acids content, temperature, sludge feed rate and alkalinity could be measured in the early 1970s. It was also recognized early that a measure of organism activity was required. The volatile-acids-to-alkalinity ratio related to gas production was considered such a measure. A comprehensive review of instrumentation in anaerobic treatment can be found in Spanjers \& van Lier (2006).

The key message for better control is that it is not sufficient to base the feed rate control on only the resulting biogas production. The gas measurements are simply too late for a good control. Therefore the state of the reactor has to be monitored, such as $\mathrm{pH}$, alkalinity, and temperature. Earlier information will provide more reliable information for a better feed rate control.

In recent years there has been a lot of research and development on monitoring and control of the AD process. J.P. Steyer has written an excellent overview of control of AD processes in Chapter 7 of Olsson et al. (2005) and in Steyer et al. (1999, 2002, 2006). In particular Steyer describes an innovative work on interval-based control. In our research (Liu et al., 2004, 2006) we found that the controller itself and 
the control structure can be quite unsophisticated in the sense that a variable gain controller can achieve great improvement of the operation. The system efficiency is maintained while process stability is ensured.

\subsection{MINIMISING OPERATING COST 10.8.1 Approaches}

In each one of the unit processes the control scheme may be more elaborate. All of this depends on suitable sensors, instruments and actuators. The ultimate goal at this level is to optimize the unit process operation.

Control and automation can reduce the electrical energy requirement. A comprehensive overview of the water-energy nexus is given in the book Olsson (2012b). Here we emphasise the importance of DO control and proper operation of pumps.

The energy cost for aeration can be reduced, first by DO control with a fixed DO setpoint. By allowing the setpoint to vary, depending on the ammonia measurement, the cost can be further decreased.

A further possibility for energy saving is to allow the air pressure setpoint to be variable. This means that there is room for some energy savings by minimizing the air pressure at all times. This is accomplished by the so called "most open valve" strategy. Assume that there are two or more parallel aerators. The DO control uses the air flow valves to supply the aerator zones with the adequate air flow. The valves are most probably not fully opened. By gradually reducing the air pressure (via the compressor) all the air valves have to open up more. This can continue until the most open valve is almost fully opened. In this way the pressure drop over the air valves is minimized and some energy can be saved.

In Section 10.7 we have also seen how the cost for chemicals can be decreased. In the example shown the chemical costs were reduced by more than $35 \%$, so the phosphate analyser could be paid for within a few months.

The cost is also related to the personnel. The ICA development has meant that many plants are today satisfactorily operated un-manned during evenings, nights and weekends.

\subsubsection{The human factor}

Often it is noted that the wastewater treatment performance may be poorer than plant design performance. Sometimes the plant operators are constrained by treatment technologies. Sometimes they do not apply sufficient control because they have inadequate training. Also, many times there are insufficient incentives for the operator. These issues are addressed in Rieger \& Olsson (2012). Olsson \& Newell (1999), argue that it is the "human factor" in successful operations that is often neglected, though it could possibly create more problems than the technology.

The lack of incentives or misleading incentives for plant operating people may decrease the efficiency and cause suboptimal effluent quality. Just one example is mentioned here: since the effluent concentrations for ammonia and phosphorus are taken into account, but not total nitrogen concentration or energy and chemical consumption, the operator is often over-aerating and overdosing P-precipitates to prevent violation of effluent limits.

As stated in Rieger \& Olsson (2012), "if the implementation of the new control system is successful, the plant manager will earn praise for reduced costs. But the operators will have more work to do regarding sensor maintenance and increased demands from the new and more complex actuators. If the system fails, the chief operator will be held accountable because he is responsible for the effluent limits. This 'blame culture' is a common reason that WWTP operation is kept below possible best performance."

The lesson is that technology alone is not sufficient. Without effective incentives, the sustained application of a control concept or any other optimization measure might be jeopardized. 


\subsection{CONCLUDING REMARKS}

Disturbances are everywhere and are the main reason for control. Uncertainty in the process or in its environment makes automation both an opportunity and a great challenge. Application of automation in water operations can be said to have two primary functions: information acquisition and process control. For the former function, the level of automation is relatively high. Often many thousands of variables are gathered on-line in the SCADA systems of treatment plants and more or less sophisticated data analyses are standard components of the treatment operation. The latter function, process control, is less developed and often limited to a few unit process control loops. Future development will be exploiting the enormous capacity of data distribution that is possible today. Many SCADA systems are also applying the technology from the Internet, which gives an almost unlimited potential for remote data evaluation and decision. The distributed control room is already here. There is a limit to how much expertise a treatment plant can afford. However, given that plant data can be made available anywhere it is possible to utilize specialist competencies wherever they are located.

The increasing incorporation of ICA in water treatment operation is not only driven by the development of automation technology, including impressive technical development of instrumentation and computer technology, modelling and control algorithms. It is motivated by economy and environmental obligations and turns out to be a necessary and worthwhile investment. It is already proven in several installations that ICA investments have paid off quickly and we will see that ICA will become an increasing part of the total investments. 


\section{Chapter 11}

\section{Evolutionary operation}

This chapter completes the cycle begun with the introduction to EVOP in Chapter 1. Chapter 2 covered plant influent and effluent characteristics, Chapter 3 basic process fundamentals, Chapters $4-8$ the characteristics of the main individual processes found in BNR plants, Chapter 9 the main characteristics of the overall plant and Chapter 10 the automatic control systems. Chapter 11 discusses the non-automatic control system - the plant operator's tuning effort based on the philosophy of ongoing learning and improvement.

\subsection{LEARNING}

Conscious effort applied to any area of human activity results in improvement in performance. ${ }^{1}$ This goes without saying in fields such as sport and music. However, it is often not objectively pursued in other fields such as sewage treatment. Performance improvements have been demonstrated in construction, manufacturing and chemical processing operations and the curves of gradually increasing production rate, improving performance or decreasing cost are called learning curves or experience curves. Two disparate examples are shown in Figure 11.1.

Peck (1984) provides examples from the construction industry and highlights three key factors emerging from his experiences:

(1) Deliberate effort is needed. Where complex activities are involved, those close to the activity are frequently unable to appreciate or remove the blocks which exist in the operation. Budgetary over-runs are met by increasingly hard work, by way of long hours and physical effort doing more or less the same thing. However, relatively minor modifications can produce dramatic benefits. Monitoring emphasis should be shifted from the absolute progress figures to rate of improvement. Ongoing improvement should be a normal part of everyday operation.

(2) You have to believe that improvement is truly possible before you will seriously look for it. The potential for improvement is obvious to football teams not at the top of the table, but is not so obvious in everyday work activities. However, improvement potential always exists.

\footnotetext{
1 "There is no such thing as failure, only feedback." (Michael J Gelb)

"Practice makes perfect." (Anon)
} 
(3) Delays or interruptions to the improvement process result in "forgetting". That is, progress is inhibited or regresses in the face of external delays, interruptions, unnecessary changes to work practices, changes of personnel, reorganisations, industrial disputes and so on.

(a) Two teams in the Australian Football League competition

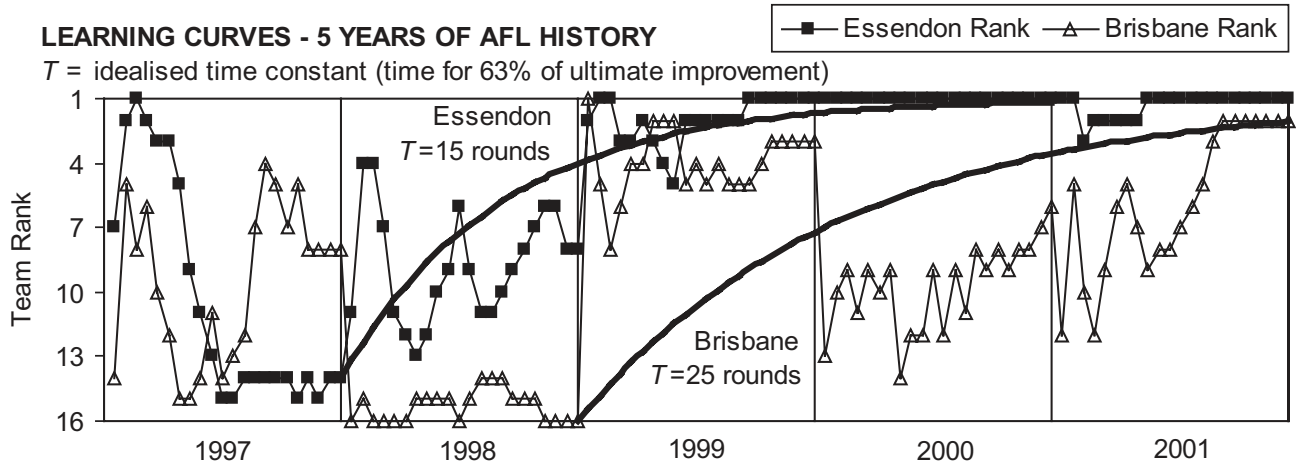

(b) Cost of limestone production in the USA (after Hirschmann, 1964)

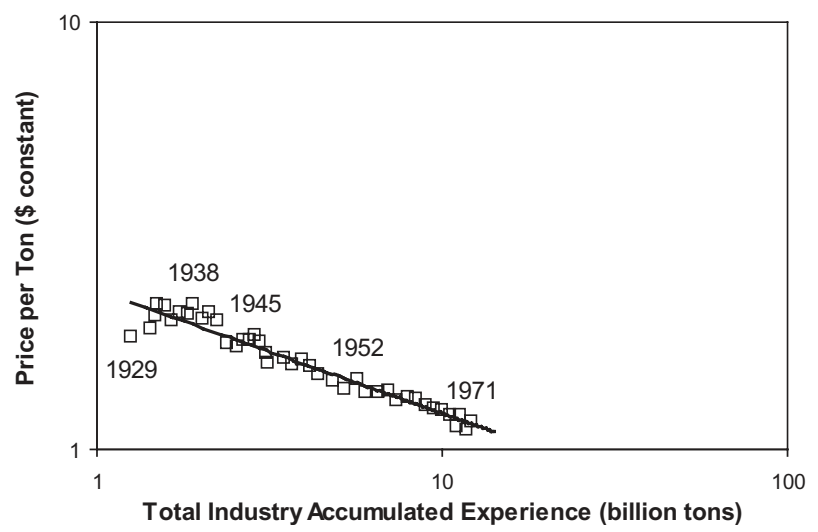

Figure 11.1 Two disparate learning curve examples. The time constant referred to in (a) is discussed in the text.

\subsection{APPLICATION TO SEWAGE TREATMENT PLANTS}

\subsubsection{Plant improvement strategies}

Historically, more effort has been applied to understanding and applying plant improvement strategies in the process industries than in the water industry. Figure 11.2(a) shows the traditional water industry approach where major plant expansions are implemented at long intervals when the plant load reaches the nominal (design) capacity. Between expansions, plant capabilities with respect to both capacity and performance are assumed to remain constant.

Figure 11.2(b) shows the approach more common to the chemical process industries (Brennan \& Stephens, 1985a, 1985b). Major expansions occur at longer time intervals because ongoing increases in 
actual plant performance capability and capacity occur through a process sometimes called performance and capacity creep. Performance and capacity enhancement generally occurs in two phases: a short-term startup phase immediately following the commissioning of new facilities and a long-term performance and capacity creep phase. Both phases can be modelled using the learning curve approach in which performance and capacity are correlated with cumulative production experience.
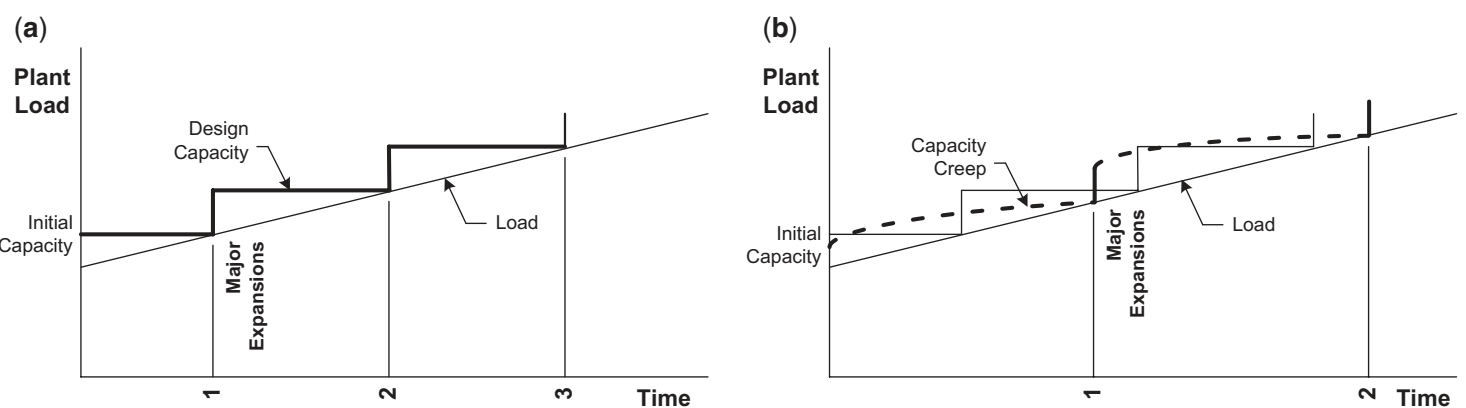

Figure 11.2 Expansion of plant capacity: (a) traditional water industry perspective, (b) process industry perspective.

\subsubsection{Learning curves}

For process plants, two logarithmic learning curve equations are commonly applied (Brennan \& Stephens, 1985a).

For capacity increase:

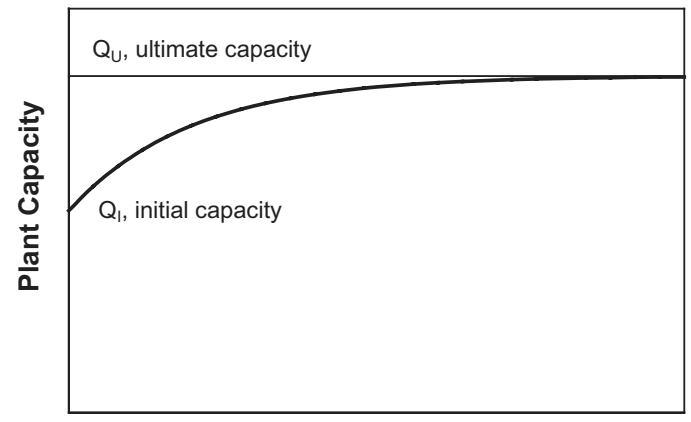

Time

$\left(\mathrm{Q}-\mathrm{Q}_{\mathrm{I}}\right) /\left(\mathrm{Q}_{\mathrm{U}}-\mathrm{Q}_{\mathrm{I}}\right)=[1-\exp (-\mathrm{t} / \tau)]=$ fraction of ultimate increase achieved

or

$$
\mathrm{Q}=\mathrm{Q}_{\mathrm{U}}-\left(\mathrm{Q}_{\mathrm{U}}-\mathrm{Q}_{\mathrm{I}}\right) \exp (-\mathrm{t} / \tau)
$$

where

$\mathrm{Q}=$ capacity at time, $\mathrm{t}$

$\mathrm{Q}_{\mathrm{I}}=$ initial capacity 


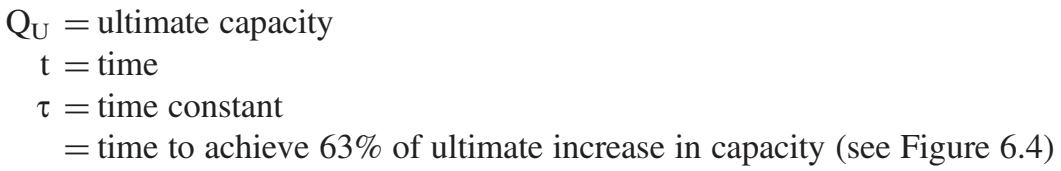

The time required to achieve $95 \%$ of the ultimate increase is $3 \tau$.

For performance improvement:

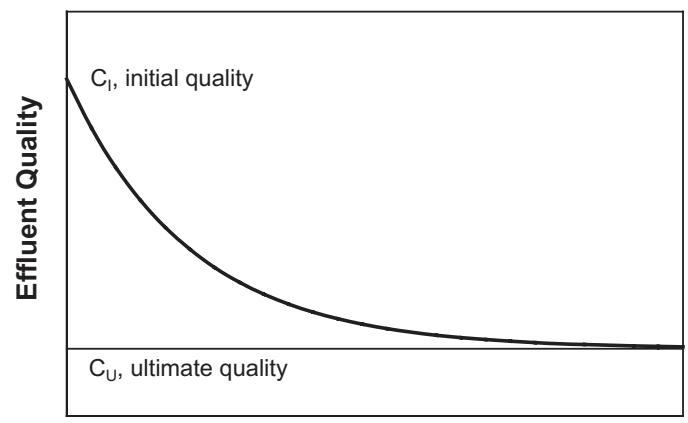

Time

$\left(\mathrm{C}_{\mathrm{I}}-\mathrm{C}\right) /\left(\mathrm{C}_{\mathrm{I}}-\mathrm{C}_{\mathrm{U}}\right)=[1-\exp (-\mathrm{t} / \tau)]=$ fraction of ultimate improvement achieved

or

$\mathrm{C}=\mathrm{C}_{\mathrm{U}}+\left(\mathrm{C}_{\mathrm{I}}-\mathrm{C}_{\mathrm{U}}\right) \exp (-\mathrm{t} / \tau)$

where

$\mathrm{C}=$ effluent concentration at time, $\mathrm{t}$

$\mathrm{C}_{\mathrm{I}}=$ initial effluent concentration

$\mathrm{C}_{\mathrm{U}}=$ ultimate effluent concentration

$\mathrm{t}=$ time

$\tau=$ time constant

$=$ time to achieve $63 \%$ of ultimate increase in capacity (see Figure 6.4)

\subsubsection{Startup phase}

\section{Experience}

Experience demonstrates that the design capacity and performance of a new process plant are only achieved through a period of intensive effort during which equipment problems are resolved and process characteristics explored.

Figures 11.3-11.5 show examples from the author's experiences with the startup of new or upgraded wastewater treatment plants incorporating relatively new technology. It can be seen that the desired results are not necessarily achieved smoothly and that learning curves are idealisations of the real world. However, the idealised learning curves depicted do reflect the intensive improvement efforts of the operators. 
(a) Effluent Nitrogen
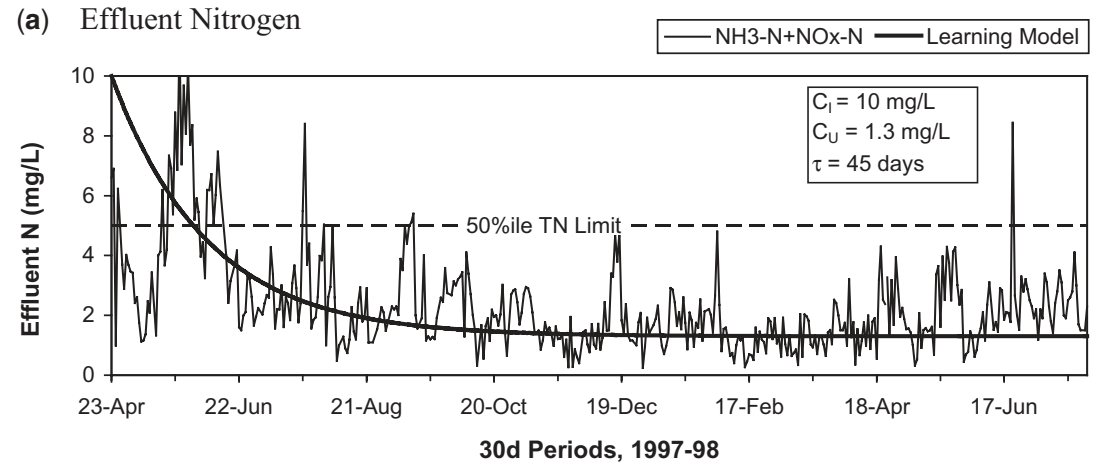

(b) Effluent Phosphorus $\quad$ - PO4-P —-Learning Model

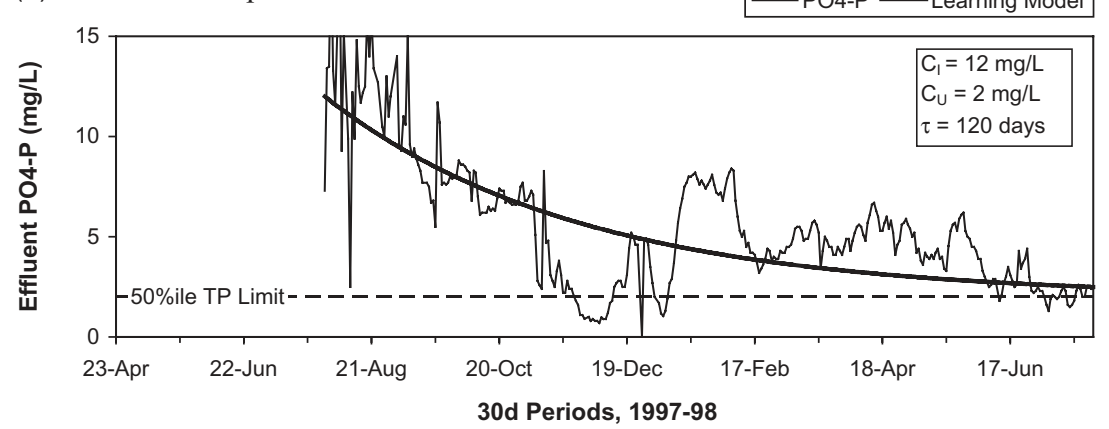

Figure 11.3 Startup phase of the new 30 kEP Thorneside BNR plant - an oxidation ditch with online activated primary tank (APT) prefermenter and anaerobic pre-reactor. The rate of improvement in bio-P removal was governed mainly by tuning of the APT (Hartley et al., 1999).

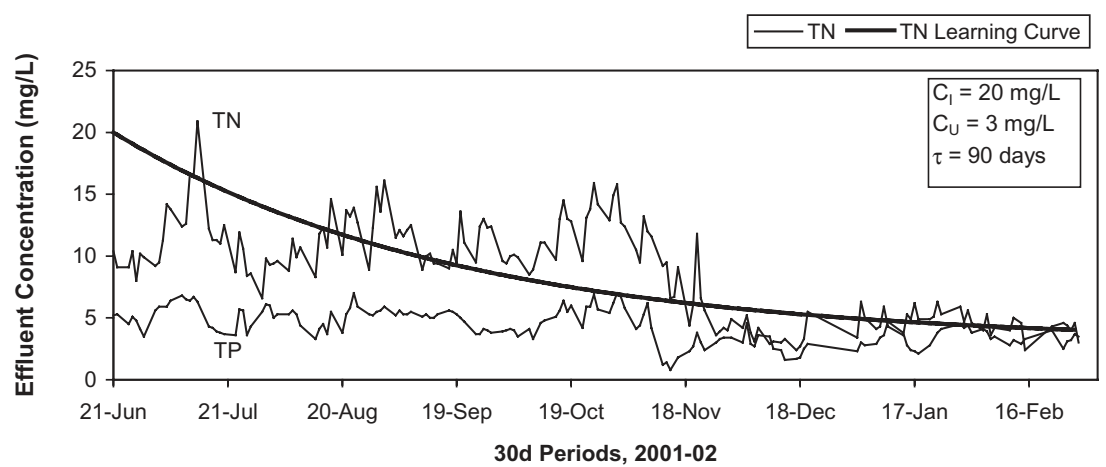

Figure 11.4 Startup phase of an expansion and BNR upgrade to the 56 kEP B Plant at Maroochydore STP Westbank process format with primary treatment, side-stream static prefermentation and anaerobic sludge digestion. Particular issues were BNR influent nutrient ratios, nitrification rate (SRT, pH), process COD distribution and foaming/wasting. 


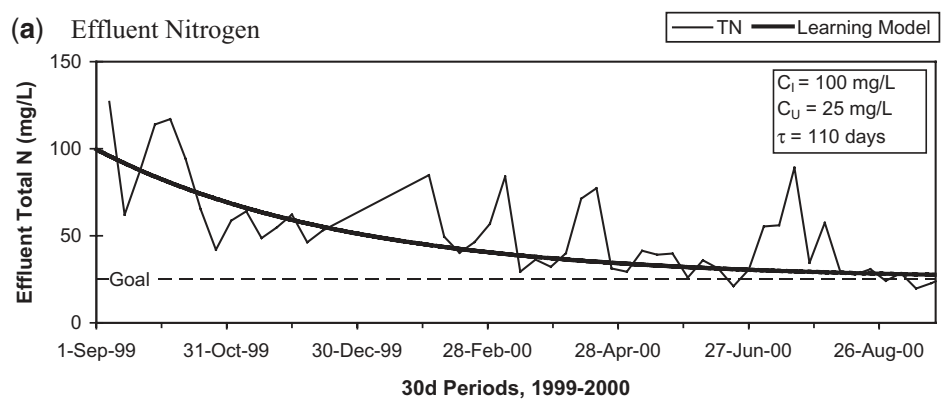

(b) Effluent Suspended Solids - - _S - Learning Model

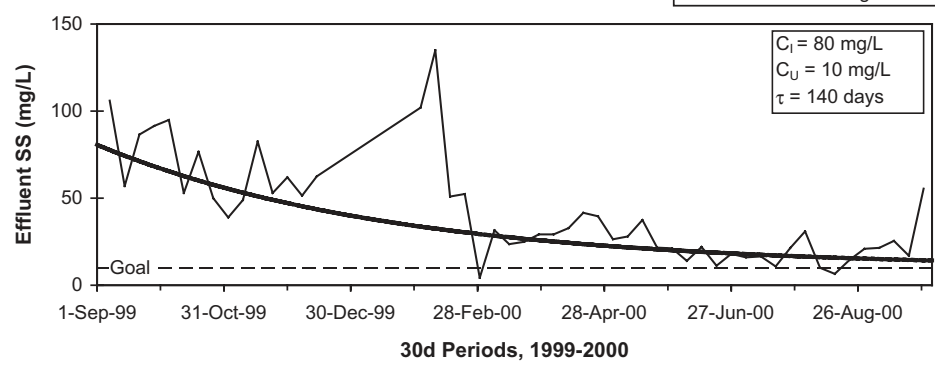

Figure 11.5 Startup phase of a BNR upgrade to a $300 \mathrm{kEP}$ abattoir WWTP with median TN/SS goals of $25 / 10 \mathrm{mg} / \mathrm{L}-$ a combined anaerobic pond/SBR process format. Particular problems were encountered with aeration capacity, wasting and sludge dewatering capacity, control of SBR feed COD/N ratio and SBR decanter solids carryover. Enhancements implemented over the startup period included increased aeration \& sludge dewatering capacity, improved load balancing, improved control interfaces, decanter modifications and operating cycle modifications.

For the plant startup phase, data from the process industries give a $\tau$ value of 8 weeks for small simple plants up to 1 year for large complex plants (Brennan \& Stephens, 1985a). The startup data for the wastewater treatment plant experience depicted in Figures 11.3 to 11.5 are summarised in Table 11.1 and give $\tau$ values ranging from $20 \mathrm{~d}$ (for simple alum dosing) to $140 \mathrm{~d}$ for SS and $\mathrm{N}$ removal from an abattoir wastewater. These values are generally consistent with the reported process industry experience.

Table 11.1 Learning curve parameters for startup phase.

\begin{tabular}{|c|c|c|c|c|c|c|c|}
\hline \multirow[t]{2}{*}{ Plant } & \multirow[t]{2}{*}{$\begin{array}{c}\text { Ave } \\
\text { SRT (d) }\end{array}$} & \multirow[t]{2}{*}{ Parameter } & \multirow[t]{2}{*}{$\mathrm{C}_{\mathrm{i}} / \mathrm{C}_{\mathrm{u}}$} & \multicolumn{2}{|c|}{$\begin{array}{c}\text { Time } \\
\text { Constant } \\
(\tau)\end{array}$} & \multicolumn{2}{|c|}{$\begin{array}{c}\text { Time to } \\
\text { Achieve } 95 \% \text { ile } \\
\text { Performance }(3 \tau)\end{array}$} \\
\hline & & & & Days & x SRT & Days & x SRT \\
\hline \multirow[t]{2}{*}{ Thorneside } & 25 & $\mathrm{TN}$ & 7.7 & 45 & 1.8 & 135 & 5.4 \\
\hline & & TP (biological) & 6.0 & 120 & 4.8 & 360 & 14 \\
\hline Maroochydore & 17 & $\mathrm{TN}$ & 6.7 & 90 & 5.3 & 270 & 16 \\
\hline
\end{tabular}


Table 11.1 Learning curve parameters for startup phase (Continued).

\begin{tabular}{|c|c|c|c|c|c|c|c|}
\hline \multirow[t]{2}{*}{ Plant } & \multirow[t]{2}{*}{$\begin{array}{c}\text { Ave } \\
\text { SRT (d) }\end{array}$} & \multirow[t]{2}{*}{ Parameter } & \multirow[t]{2}{*}{$\mathrm{C}_{\mathrm{i}} / \mathrm{C}_{\mathrm{u}}$} & \multicolumn{2}{|c|}{$\begin{array}{c}\text { Time } \\
\text { Constant } \\
(\tau)\end{array}$} & \multicolumn{2}{|c|}{$\begin{array}{c}\text { Time to } \\
\text { Achieve } 95 \% \text { ile } \\
\text { Performance }(3 \tau)\end{array}$} \\
\hline & & & & Days & x SRT & Days & x SRT \\
\hline \multirow[t]{3}{*}{ Abattoir } & 18 & SS & 12 & 140 & 7.8 & 420 & 23 \\
\hline & & $\mathrm{TN}$ & 4.4 & 140 & 7.8 & 420 & 23 \\
\hline & & TP (alum dosing) ${ }^{1}$ & 3.8 & 20 & 1.1 & 60 & 3.3 \\
\hline
\end{tabular}

${ }^{1}$ See Chapter 7, Fig. 7.7.

The data in Table 11.1 suggest the following rules of thumb:

Time constant (time to achieve $63 \%$ of ultimate startup performance): $5 \times$ SRT

Startup optimisation time (time to achieve $95 \%$ of full startup performance): $3 \times$ time constant $15 \times$ SRT

\section{Contractual startups}

Plant design and construction contracts involving performance proving at startup should provide for the extended time commonly required to shake down both equipment and process reliability in new sewage treatment facilities. The theoretical effects of the available startup time on the required design effluent quality and the resulting plant cost are illustrated in Figure 11.6. Plant cost has been assumed inversely proportional to effluent nitrogen concentration raised to the power 0.59 (Hartley, 1998).

(a)
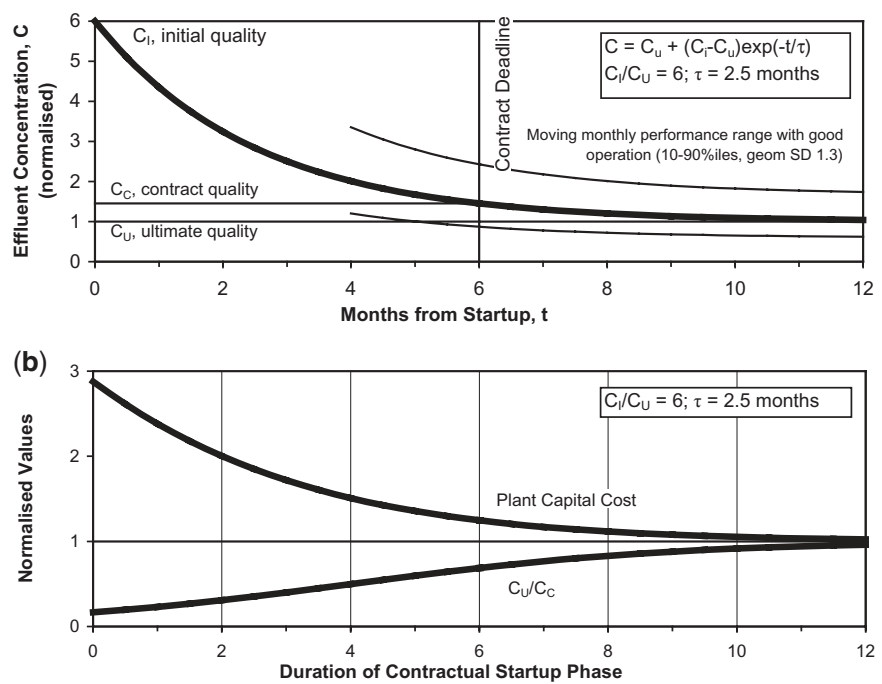

Figure 11.6 Effect of startup duration on design effluent quality and cost, arbitrarily based on effluent TN cost impact and using representative startup parameters from Table 11.1. $C_{C}$ is the contractual effluent quality required (drawn in (a) for an arbitrary six month contractual startup period), $C_{\mid}$is the initial effluent quality achieved and $\mathrm{C}_{U}$ is the ultimately achievable effluent quality for which the plant has to be designed to enable $\mathrm{C}_{C}$ to be met by the end of the contractual startup phase. Figure (a) also shows the potential variability of the moving monthly effluent quality. 
It is clear that contractual performance proving requirements can potentially have a significant effect on project cost because of the design conservatism required to meet performance guarantees within a limited time frame. Alternatively, the project completion time may have to be extended when it becomes evident during the optimisation phase that the design performance will not be met by the deadline.

Additional investment is sometimes required during the startup phase for new sewage treatment plants to enable full design capacity and performance to be demonstrated, especially when relatively new technology is involved. The author analysed eight plant projects in this category which were implemented between 1984 and 1994 to assess the magnitude of this additional startup investment. Types of projects included greenfield and brownfield, municipal and industrial, full-scale and pilot-scale. The magnitudes of the additional investment ranged from 1-31\% of the initial plant construction cost. The geometric mean was $4 \%$ with a geometric standard deviation of 3.7 (i.e. the 16-84 percentiles were $4 / 3.7-4 \times 3.7$ or $1-15 \%)$.

\subsection{LONG-TERM IMPROVEMENT}

\subsubsection{Potential}

To illustrate the degree of long term improvement potentially achievable in capacity or performance, Australian plants in the chemical process industry are reported to have achieved typical capacity increases between major expansions of around $50 \%$ over periods of $5-10$ years $\left(\mathrm{Q}_{\mathrm{U}} / \mathrm{Q}_{\mathrm{I}}=1.5, \tau=2-3\right.$ years). An example from Brennan and Stephens (1985a) is shown in Figure 11.7.

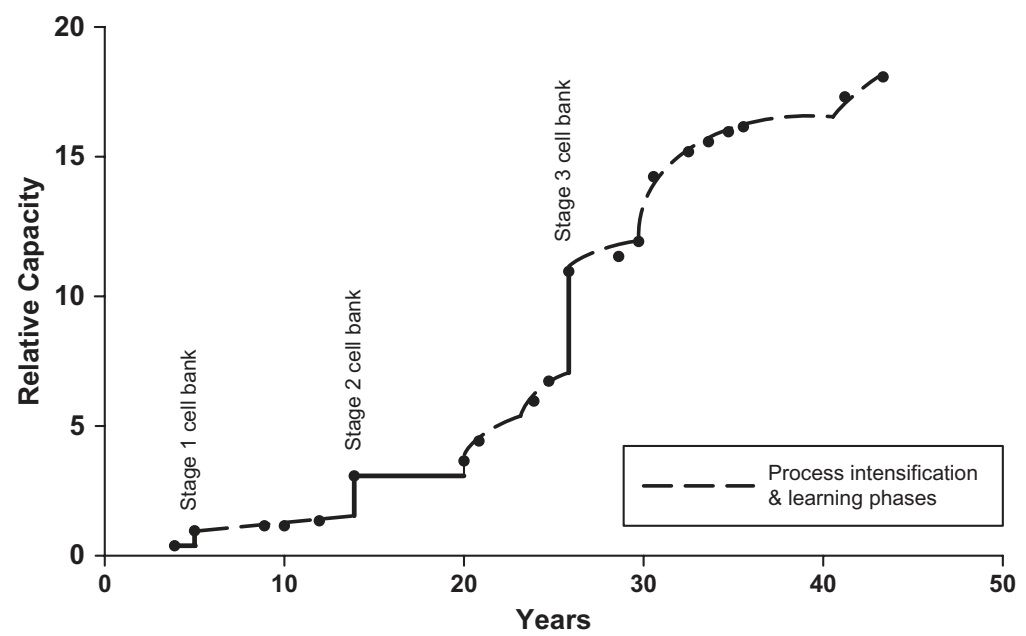

Figure 11.7 History of maximum daily capacity of chlorine manufacturing plant (after Brennan \& Stephens, 1985a).

This approach has not commonly been applied to sewage treatment plants but some degree of both performance and capacity creep does occur. It is certain, however, that significant potential gains are waiting to be exploited and there has been increasing interest in the process (Parker et al., 1999).

The overall capacity and performance creep process is illustrated in Figure 11.8. Capacity enhancement draws on two main factors: (a) design and construction margins (deliberate or otherwise), which result in a 
plant in which the various components do not all have the same capacity but a distribution of capacities, and (b) advances in technology and process understanding, facilitating process intensification. A particular cause of capacity distribution in sewage treatment plants arises from uncertain and variable quality of the sewage. It is inevitable that the actual sewage received by a new plant will differ in some respects from the design quality, resulting in the performance characteristics of various plant components differing from design expectations.

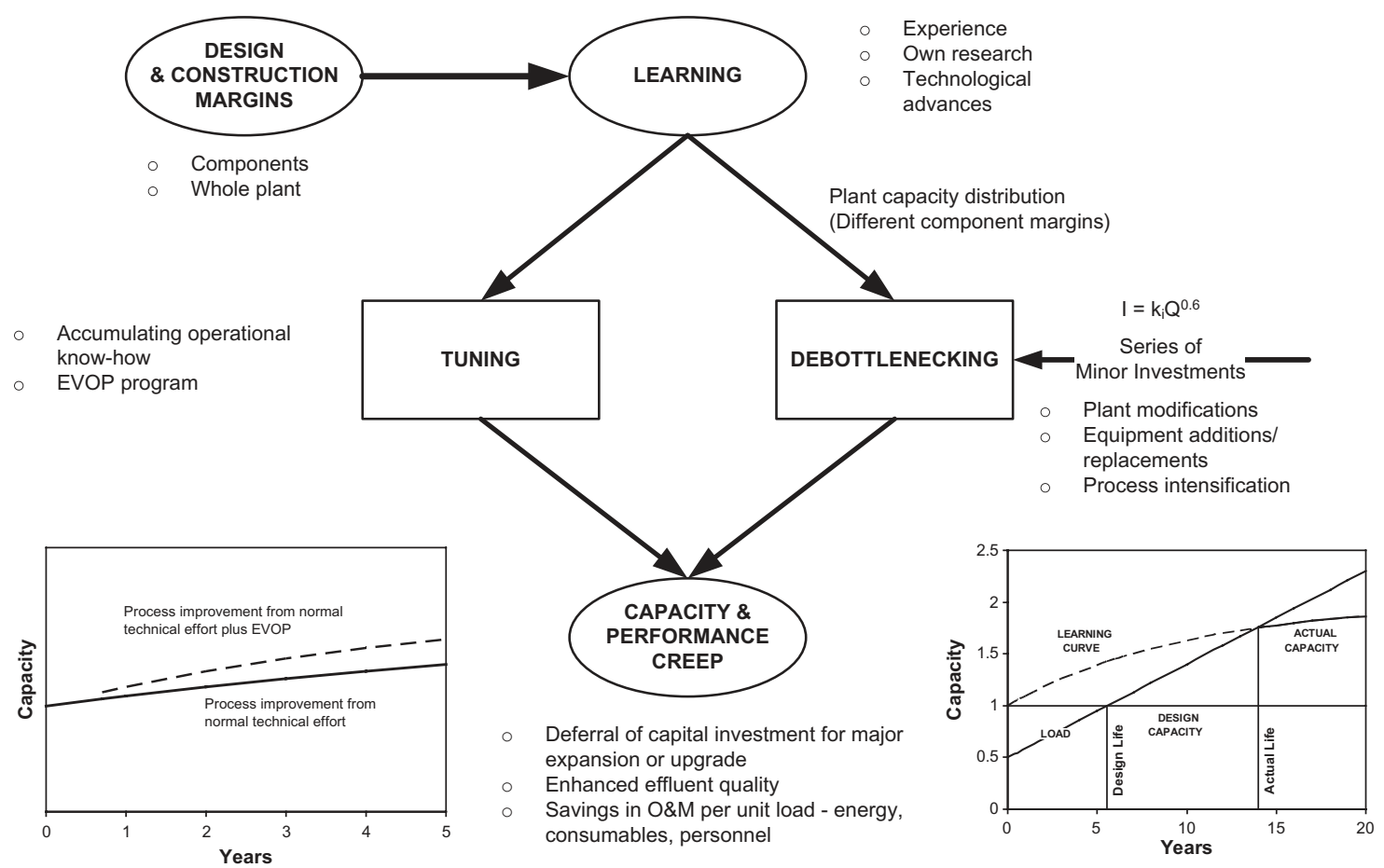

Figure 11.8 Capacity and performance creep. Minor investment cost is discussed later in this chapter.

Capacity and performance are improved through a combination of ongoing operational tuning and periodic minor investments in debottlenecking. The extent and rate of improvement achieved will depend on the effort expended.

\subsubsection{Tuning}

Tuning improves performance and enhances plant capacity by testing and pushing out the actual plant capacity envelope. This provides ongoing improvement through application of accumulating operational know-how on the plant.

Tuning can have several goals:

(1) Improve performance - effluent quality, biosolids quality, odour emission, greenhouse emissions

(2) Increase capacity - liquid stream, solids stream 
(3) Reduce consumption - energy, chemicals

(4) Reduce operating cost

A valuable technique for maximising the rate of learning is a method of routine operation called evolutionary operation, or EVOP for short (Box \& Draper, 1969). This is a structured method for deliberate learning devised for the process industries. A continuous investigative routine becomes the basic mode of operation and replaces normal static operation. EVOP is based on the principle that it is inefficient to run a plant in such a way that only a product is produced, rather, a process should be operated so as to produce not only a product but also information on how to improve the product or increase the rate of production (plant capacity).

This method of operation involves the operators in an ongoing process of continuous improvement through planned variation of operating parameters and evaluation of results. Understanding of the plant's behaviour improves and the plant is continually moved towards the optimal operating regime.

Formal statistical approaches can be applied in chemical process plants where close control of throughputs and reaction conditions can be exercised. However, the EVOP technique has to be adapted for use with sewage treatment processes, which have special characteristics:

- Uncontrolled \& variable loading

- Uncontrolled \& variable temperature

- Variable outputs

- Long process response times

- Usually operating at a load significantly less than capacity

Optimisation of a sewage treatment plant is perhaps more akin to that of a manufacturing plant as described in an absorbing novel by Goldratt and Cox (2004). The implications for application of EVOP to sewage treatment plants include the following:

- Use EVOP as an operating philosophy rather than a statistically rigorous procedure.

- Start EVOP early in the life of a plant, ideally as soon as the plant is commissioned.

- Document procedures and results carefully to minimise memory loss with time and personnel changes.

- Substitute test run time (multiple of process response time) for number of replicate cycles.

- Include load as one of the variables.

- If using a rigorous statistical approach, use a three variable scheme to limit the overall time required.

- Recognise that variability of output is as important as the average.

- Provide close professional support to the operating personnel.

The statistical sophistication of the operating trials may vary. The fundamental philosophy of EVOP, however, is that the plant should always be operated and monitored so as to deliberately improve the operators' understanding of its behavioural characteristics and allow its performance and capacity to be continually improved or optimised - a structured process of ongoing improvement. Examples of the author's approach in sewage treatment plants are discussed throughout this book.

\subsubsection{Stress testing}

The capacities of various plant components can be assessed while the plant is operating below its full capacity by conducting stress tests (Parker et al., 1999). In a stress test the load on a particular plant component is gradually increased, or the operating parameters gradually adjusted, to quantify the process response. For example, secondary clarifiers can be progressively taken off-line to assess the response of 
the remaining units to increasing load (see Section 7.5), or the process SRT can be deliberately shortened to assess the minimum practicable value.

\subsubsection{Debottlenecking}

As discussed in Chapter 9, the bottleneck principle states that the plant component with the least capacity sets the capacity of the whole plant. Debottlenecking therefore increases plant capacity by increasing the capacity of the limiting component. The capacity of the bottleneck is increased by equipment addition/replacement/modification, process intensification or other plant modification.

Although tuning is usually thought of in terms of performance and debottlenecking in terms of capacity, both can also be thought of in the opposite terms. An improvement in performance at a given capacity can alternatively yield an increase in capacity for the same performance, and vice-versa.

For debottlenecking to be applied, the distribution of capacities for the plant components must be determined. These capacities are not absolute quantities but apply only in the context of the overall plant design, the sewage quality feeding the plant and the effluent quality standards which the plant must meet. Process units generally do not have fixed individual process capacities but contribute to the overall integral plant capacity. In principle, the procedure for identifying and quantifying bottlenecks is to gradually increase the plant load (on paper or in practice) until a failure occurs - that is, one of the plant's performance objectives is breached. The cause of this failure is identified. This bottleneck is then assumed to be overcome and the increase in load is continued until a further failure occurs. And so on.

This is easily understandable in the case of a hydraulic limitation, for example. However, sometimes there is no single bottleneck and the failure could be addressed in alternative ways (of varying cost and practicality). Consider a conventional activated sludge plant. As the load is increased, the COD of the primary effluent increases, passing more load to the secondary system. The MLSS concentration in the biological reactors therefore increases, passing more load to the secondary clarifiers. Eventually the clarifiers will fail with gross loss of biomass in the effluent. What is the bottleneck? If the return activated sludge rate is the limitation, this would generally be regarded as the bottleneck. However, an increase in overall process capacity could alternatively be achieved by upgrading the primary clarifiers, or the bioreactors, or the secondary clarifiers.

Therefore, as each failure condition is reached, alternative methods of overcoming it are identified and compared. This will be an iterative process because alternative debottlenecking actions may affect the next bottleneck in different ways. Plant trials can be run to define actual capacities compared with theoretical values. In this way a debottlenecking program can be developed which correlates capacity increase with cost.

Plant capacity can be displayed using capacity and performance envelopes or diagrams (operating space diagrams) as discussed in Chapter 9. These diagrams provide insight into limiting factors, and the potential capacity gain from debottlenecking proposals can be readily seen. One typical characteristic of sewage treatment plants is immediately obvious from such capacity envelopes - there is a large investment in hydraulic (wet weather) capacity which is used for only a small percentage of the time and appears ripe for exploitation.

\subsubsection{Costs}

In studies of Australian chemical process plants expanded in the 1960's and 1970's (Brennan and Greenfield, 1994) it was found that the cumulative real fixed capital spent over successive expansions of 
an existing plant could be related to plant capacity by the relationship:

$$
\Sigma \mathrm{I}=\mathrm{k}_{\mathrm{I}} \mathrm{Q}^{\mathrm{B}}
$$

where

$$
\begin{aligned}
\Sigma \mathrm{I} & =\text { cumulative fixed capital (investment) adjusted to a real basis } \\
\mathrm{Q} & =\text { capacity } \\
\mathrm{k}_{\mathrm{I}}, \mathrm{B} & =\text { coefficients }
\end{aligned}
$$

The exponent B was approximately 0.8 for a parallel plant expansion but only 0.6 for an integral expansion (involving debottlenecking investment). This means that additional capacity can be provided more cheaply through capacity creep-type investment than through parallel plant expansions. Both the capital investment and associated ongoing maintenance costs are lower.

Additional economic benefit accrues through the deferral of capital investment until it is needed to match increasing load. Figure 11.9 illustrates the reduction achieved in the Net Present Value of a capital investment if a given expansion in plant capacity is provided in an increasing number of increments.

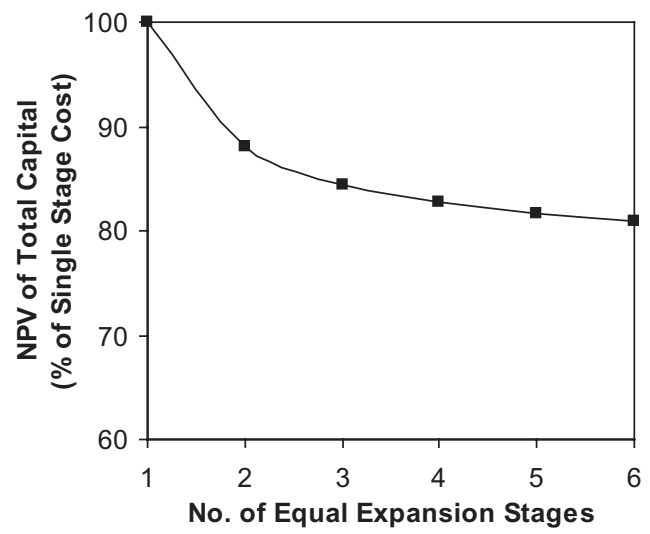

Figure 11.9 NPV reduction for incremental expansion over a 10 year period compared with single expansion at time zero; total expansion $30 \%$, discount rate $5 \%$.

Capacity creep has also been found to provide savings in unit operating costs, particularly with respect to personnel (Brennan \& Greenfield, 1994). In the process plants studied, the total number of personnel employed frequently remained unchanged despite capacity (production) growth; reductions in the personnel requirement per annual tonne of product averaged $4.5 \%$ per year. With parallel plant expansion, however, which involved significant additions of new equipment and increased materials handling, personnel numbers increased.

At any stage in the development of a plant, the economic benefit of an integral expansion can be compared with the cost of an alternative parallel expansion using the form of cost diagram shown in Figure 11.10. Total annual cost (or net present value) is used in this diagram to reflect both capital investment and annual operating and maintenance cost. Both curves, but particularly the integral expansion curve, will vary with time as experience and understanding are developed. The plant strategy therefore needs to be revisited periodically. 


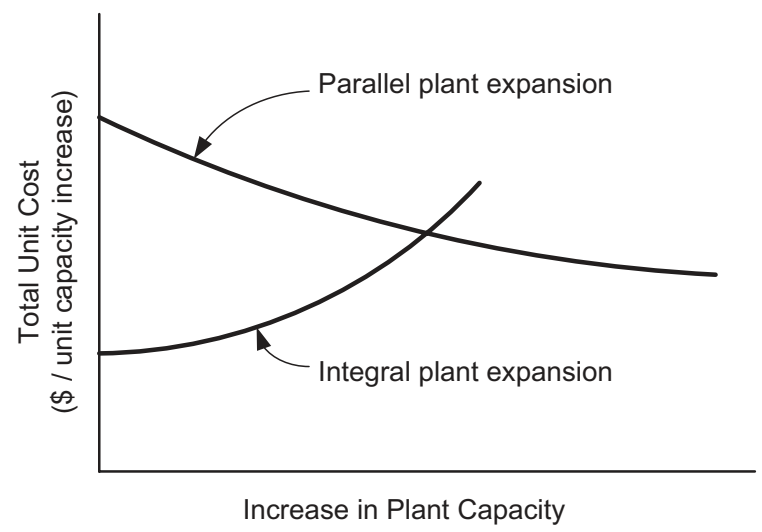

Figure 11.10 Relative costs for integral and parallel expansion.

\subsection{EVOP PROCEDURES}

As described above, the fundamental philosophy of EVOP is that the plant should always be operated and monitored so as to deliberately improve the operators' understanding of its behavioural characteristics and allow its performance and capacity to be continually improved-a structured process of ongoing improvement. This section describes methods used to enable operators to better understand and improve their plants.

\subsubsection{Method}

The EVOP program should be integrated with the regular plant monitoring and control program. It is best run by the process superintendent with the support of one or more process specialists who serve in an advisory and supportive capacity. Plant data are collated, analysed and reported at regular intervals (typically monthly) and when specific test programs have been undertaken. The operational group meet at regular intervals to review the process data, provide helpful analysis and stimulate a flow of new ideas to be incorporated in the investigation. Current progress is openly shared to facilitate input and feedback from all plant personnel.

The basic strategy (introduced in Chapter 1) is illustrated in Figure 11.11. The actions are as follows:

(1) Define goals and set targets.

(2) Set the plant control variables.

(3) Measure the outcomes - data collection program.

(4) Interpret the data and develop ideas for improvement - regular (monthly) process reviews, technical memoranda and EVOP meetings.

(5) Re-adjust the process.

(6) Conduct trials and tests on specific processes or the whole plant.

In simple terms there are three basic steps: measure, interpret, act. These steps form the basis of an ongoing EVOP strategy which will produce long-term benefits. The key to better performance is improved understanding of plant behaviour. 


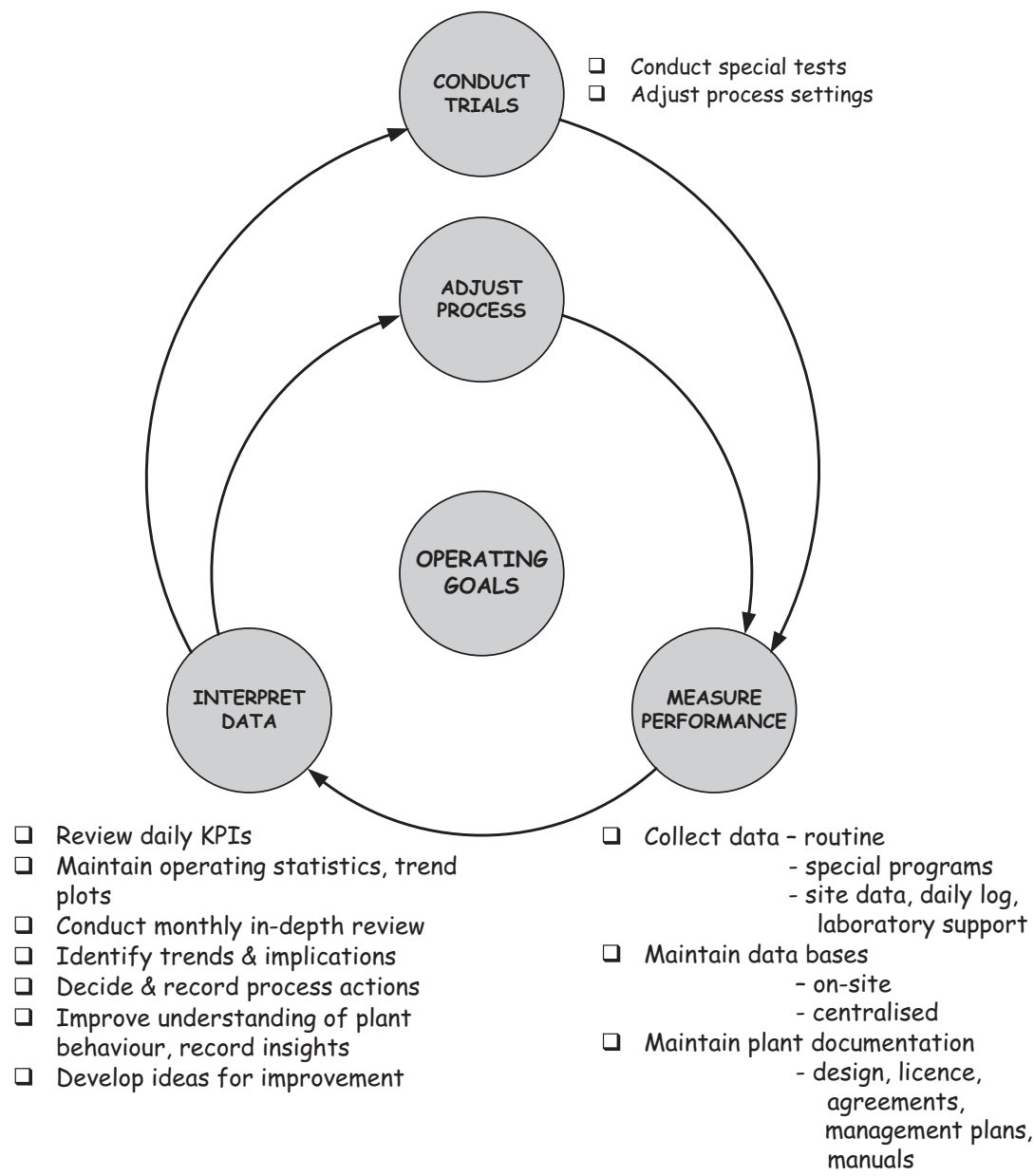

Figure 11.11 The EVOP process operating cycle.

\section{Step 1: Data collection}

Careful observation and interpretation of plant behaviour are essential if the plant is to be tuned for maximum performance. There are four distinct aspects to this monitoring effort:

- Visual observation on a daily basis.

- Operating measurements obtained both instrumentally and manually.

- Laboratory measurements of physical, chemical and biological parameters.

- Maintenance of good records and files of operating information (discussed in Data Interpretation below).

An example routine monitoring schedule is set out in Table 11.2. This is the initial schedule used for the two-year intensive performance proving phase after the new Brunswick Valley STP was commissioned at the end of 2010. The plant had the flowsheet shown in Figure 9.1 except that WAS was wasted directly to the digester. 
Evolutionary operation

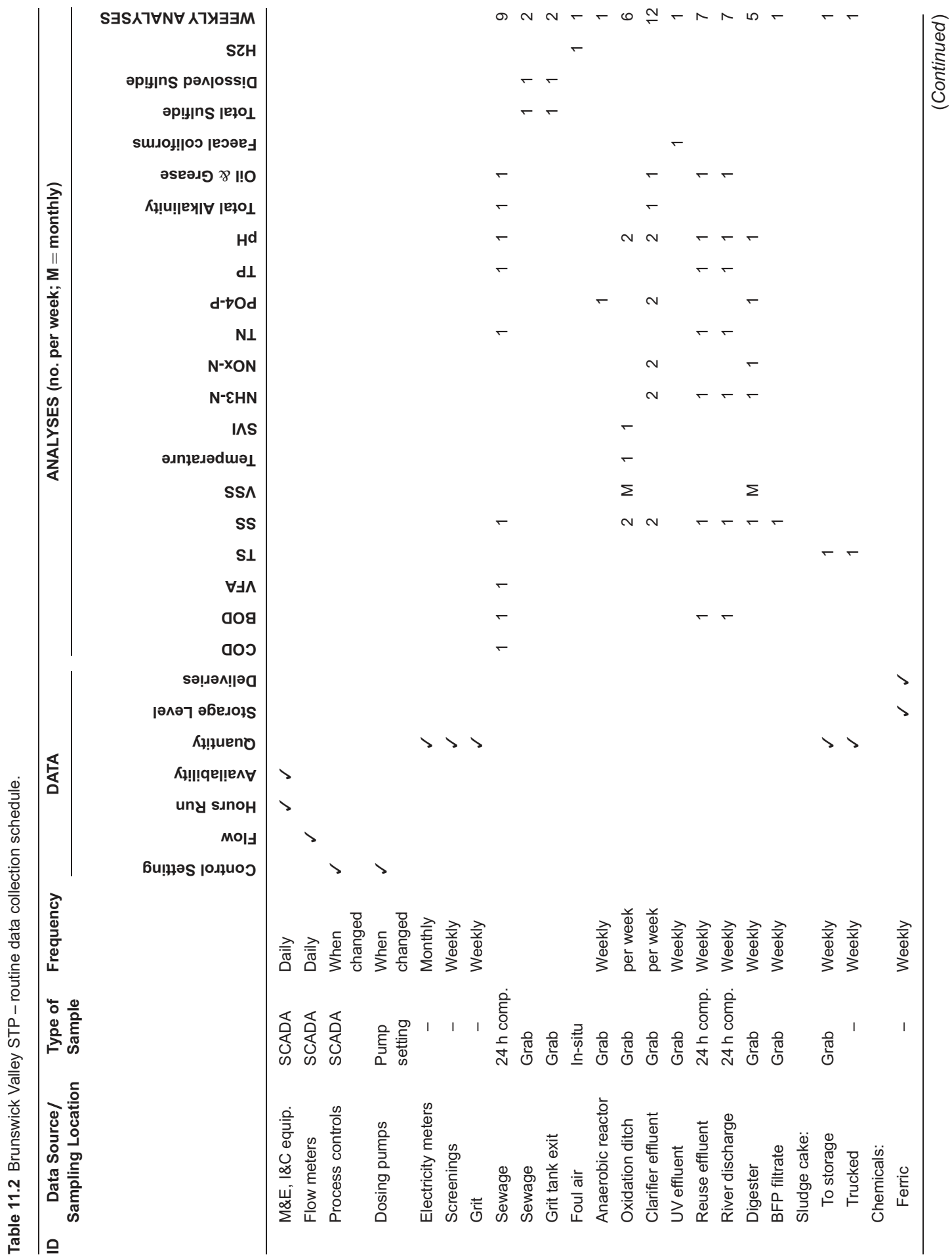




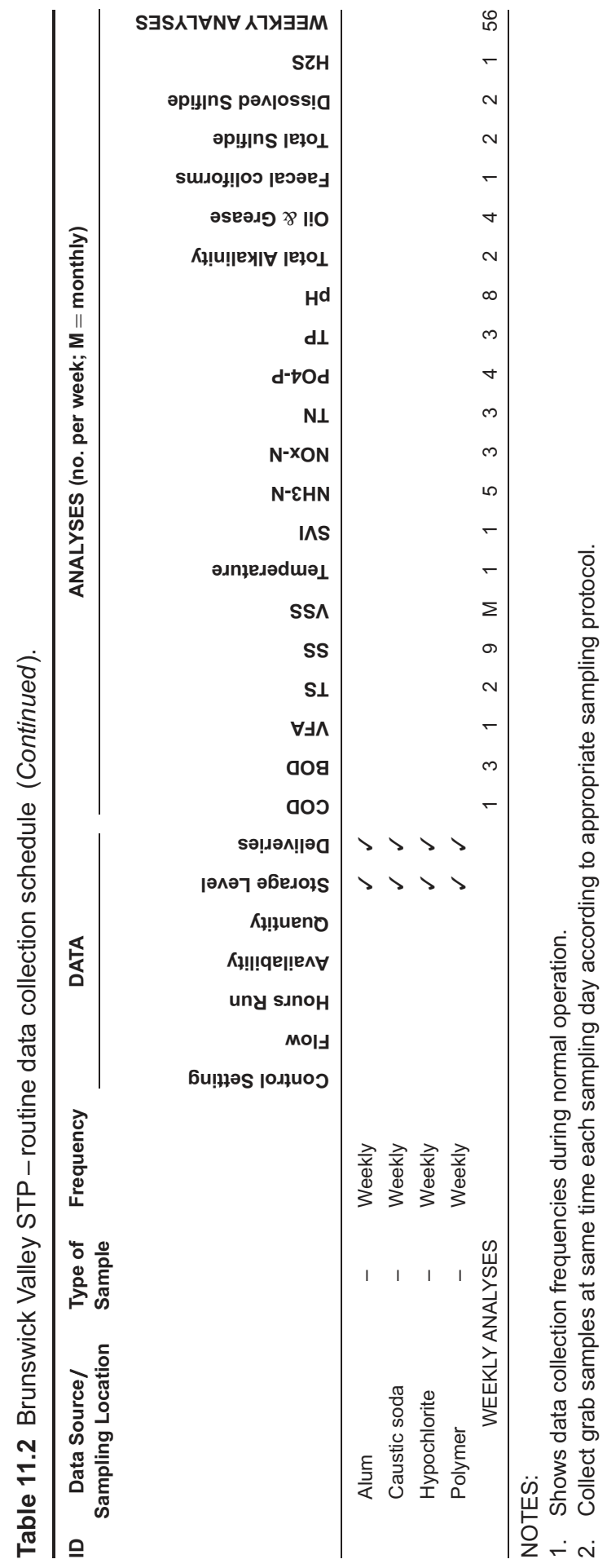


From time to time, the schedule will be adjusted or additional data collection programs implemented for specific trials or investigations. This comprehensive effort is easily justified when the overall costs are fully considered:

- The cost of the data collection program.

- The environmental cost associated with periodic discharges of inadequately treated effluent and biosolids.

- The supplementary cost of investigating and remedying upsets in plant performance.

- The additional operating cost associated with greater than necessary consumptions of energy and chemicals.

- The savings accruing from deferment of plant expansion achieved through increase in operational capacity.

\section{Step 2: Data interpretation}

The data collected are useless if they are not examined and used for operational decision-making. The two critical steps are recording and interpretation.

All data, however obtained, should be recorded in a single plant file to facilitate interpretation. The routine use of trend plots of all important parameters is by far the best way to manage and study the data. Tables camouflage trends; graphs illuminate them. The use of Excel facilitates this procedure. Trend plots are discussed below.

Useful frequencies for process reviews are daily, weekly and monthly. Because STP data are highly variable, decisions need to be made on the basis of trends. Daily data are useful only for picking up large and unexpected changes in parameters. Because of the effort involved in data analysis and trending, a few critical parameters can be reviewed weekly and the full range of plant parameters monthly.

Decisions on process adjustments must then be made. Specific issues may need to be investigated. Setpoints may need adjustment to counterbalance changes in loading or influent characteristics or season. Structured trials can be planned to evaluate the effects of operational settings on process parameters and define optimum operating regions. Capacity bottlenecks can be identified and methods for overcoming them pursued. Effort to further improve performance should be ongoing.

Specific test programs should be reported regularly in technical memoranda or reports. These documents can be structured simply as Aims, Procedure, Results, Interpretation, Conclusions, Recommendations and Appendices.

\section{Step 3: Process adjustment}

The decisions on process changes made in Step 2 are acted upon. Specific tests are conducted. The outcomes are measured (Step 1) and the cycle repeats. Improvement comes with continuing effort.

Earlier chapters have alluded to or described a sample of potential investigations and specific data gathering aimed at better understanding specific plant operating characteristics: reactor or digester tracer testing (Table 6.1), bioprocess minimum SRT testing (Chapter 6), aeration diffuser monitoring and testing (Chapter 6), bioreactor SVI optimisation (Chapter 6), clarifier stress testing (Chapter 7), sludge stability testing (Table 8.3), BFP and centrifuge testing (Tables $8.6 \& 8.8$ ), and plant load distribution (Table 9.2).

Most importantly, the process control systems need to be optimally tuned to reliably maintain the associated process variables at their set points (Chapter 10). 


\subsubsection{Trend plots}

The most useful way to understand plant behaviour is to maintain trend plots of all relevant operating parameters. Trend plots enable true trends to be differentiated from noise, highlight shifts in behaviour, facilitate comparison of related trends and display months or years of data for multiple parameters on a few understandable pages.

Figure 11.12 shows the trend plots used over the first two years of operation of the Brunswick Valley STP. The plant flowsheet corresponded with Figure 9.1, with the exception that WAS was wasted from the RAS line direct to the digester. Plots were added progressively as found useful, eventually amounting to twenty eight plots displaying eighty four parameter trends. These trends and associated tables of key operating parameters were updated monthly and used as the basis for monthly performance reviews. Effects of previous adjustments to process parameters were examined. New insights and resulting refinements to operating procedures were systematically recorded and implemented.

Useful aspects of this trending technique are as follows:

Production: Use an Excel file. Link the trends to the data sheets so they are automatically extended when new data are added. For long-term use, a time-scale of 12 or 24 months is most useful, displaying trends and relationships without requiring frequent adjustment of the plots.

Format: The proportions shown have proven their worth, allowing five plots containing multiple parameters to be shown on each A4 page at a readable size; this facilitates comparison of trends. Colours are essential for multiple trends, improving readability significantly and increasing the number of trends that can usefully be shown in each plot. A grey background can improve readability with multiple parameters. Line thickness or style and use or not of symbols are additional differentiators for ease of interpretation. Moving averages can be added to clarify trends (e.g. Plots 2 and 28). Design or target levels can also be shown.

Order: Trends can usefully be grouped as shown in the example: plant loading, effluent quality, energy consumption, chemical consumption, liquid stream operating parameters, solids stream operating parameters. Operating cost trends can also be added.

Lab vs site data: Laboratory data generally lag site data for the same or similar parameters by days or weeks, so both can be plotted for timeliness and accuracy (e.g. Plots 5-7).

Relationships: Plots can be configured to examine and highlight potential relationships, and adjusted from month to month as relationships emerge. For example, in Plot 24 the scales have been chosen to highlight the close relationship between digester alkalinity and $\mathrm{pH}$. In Plot 25 the digester SVI scale has been reversed to highlight the close relationship between BFP cake TS and the feed sludge SVI.

Similarly, Plot 17 was set up to track the relationship between plant caustic soda dose, effluent total alkalinity and mixed liquor $\mathrm{pH}$. Anaerobic reactor $\mathrm{pH}$ was added to the plot when monitoring was initiated. Plot 16 is a companion plot which trends the biological P removal calculated from the plant alum dose (influent-effluent-chemical removal) ${ }^{2}$ and also shows the correlation between bio-P removal and anaerobic zone $\mathrm{PO}_{4}-\mathrm{P}$.

Plots 14 and 15 were configured to track the close relationship between DO set point, effluent ammonia:nitrate ratio and SVI in the oxidation ditch bioreactor.

And Plot 18 was set up to determine whether there was a relationship between effluent oil and grease level and oxidation ditch scum inventory (with constant daily operating time for the scum harvester). For the data so far available no relationship is evident.

\footnotetext{
${ }^{2}$ Alum P removal was calculated using the relationships given in Chapter 3, Section 3.7.
} 
Trend Plots 1-5
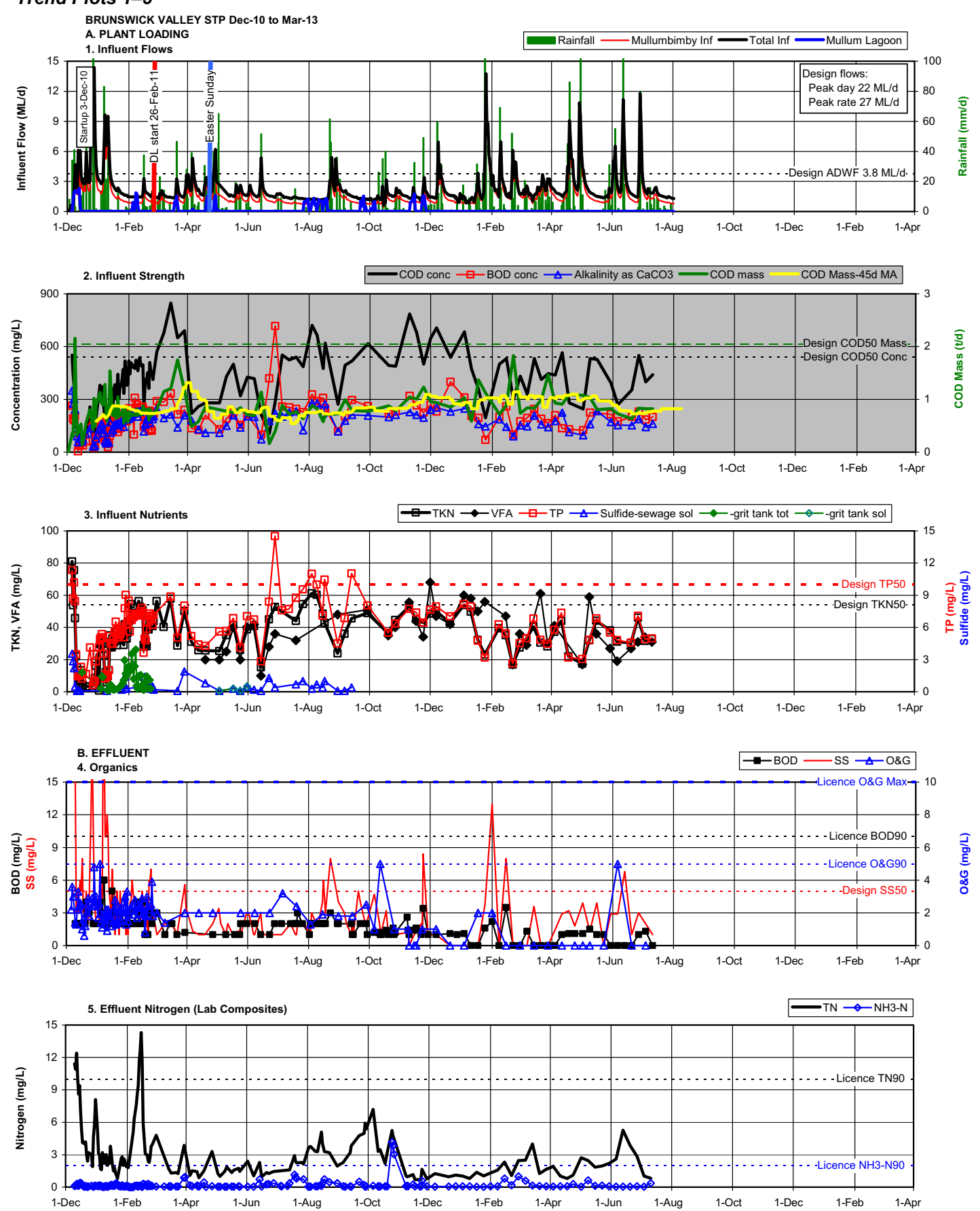

Figure 11.12 Brunswick Valley STP Process Trend Plots 1-28, being updated and reviewed monthly during the two year performance proving period. 
Trend Plots 6-10
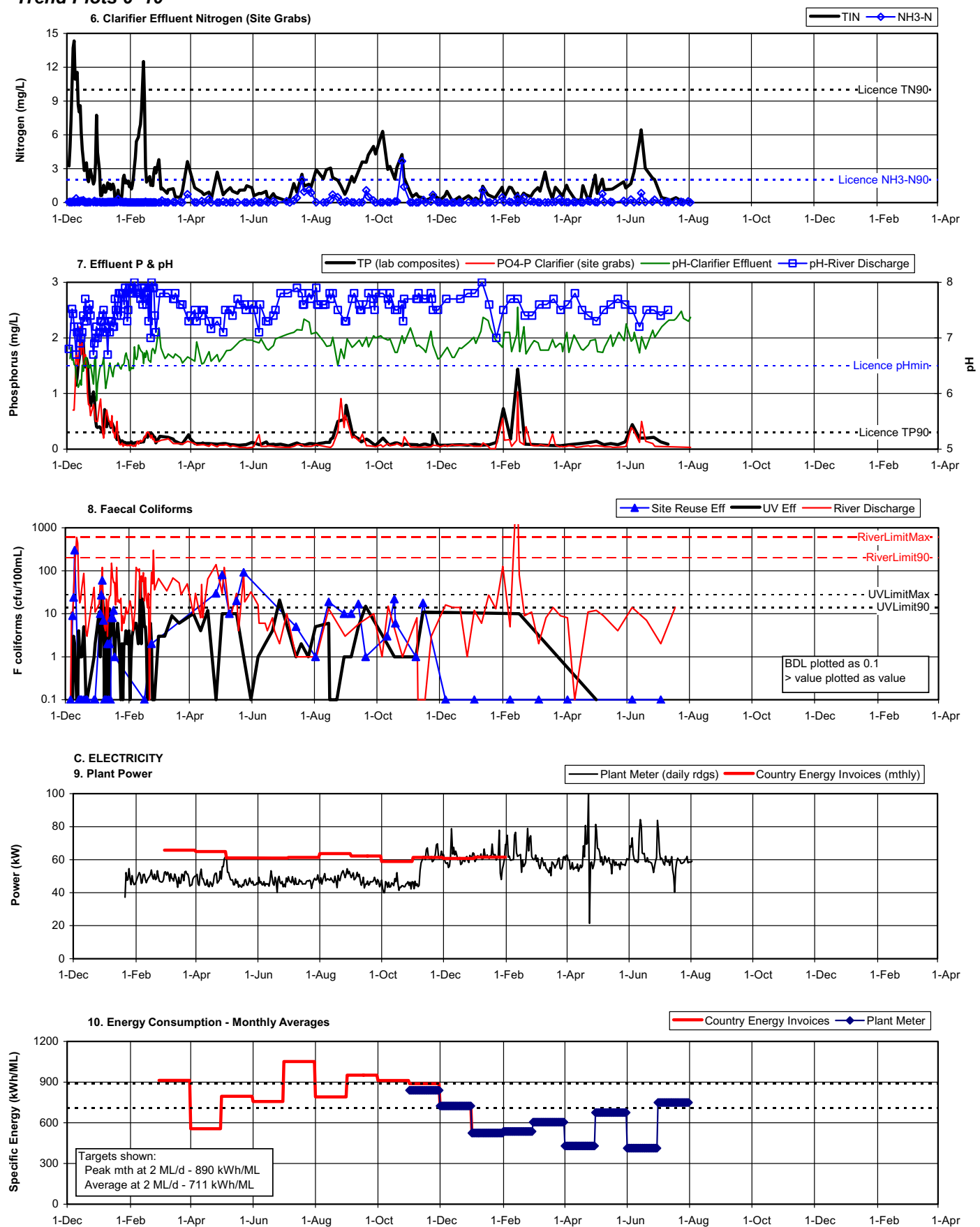

Figure 11.12 Brunswick Valley STP Process Trend Plots 1-28, being updated and reviewed monthly during the two year performance proving period (Continued). 
Trend Plots 11-15

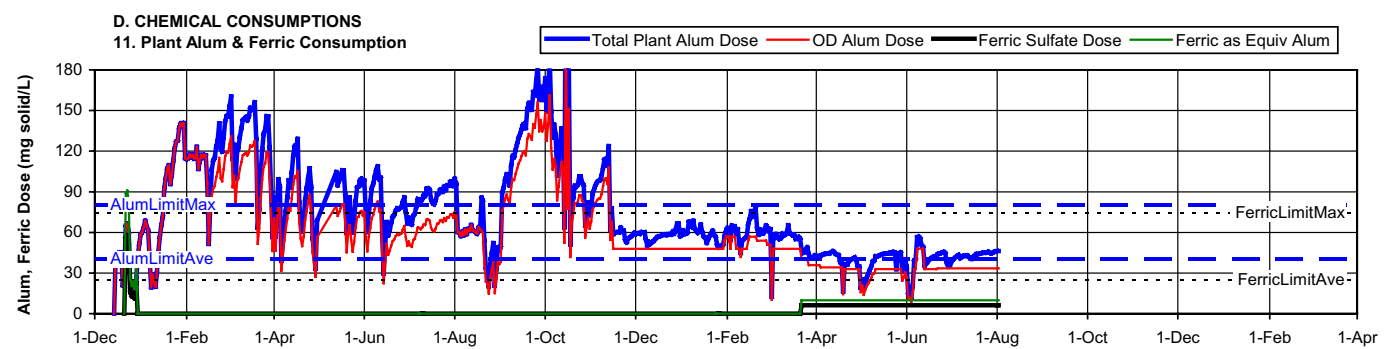

12. Plant Caustic Soda Consumption

-Total Plant Dose — OD Dose

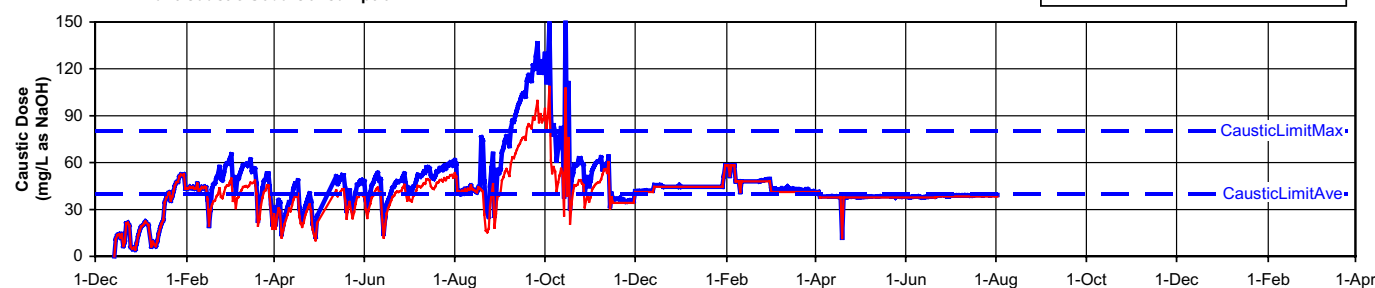

E. OPERATION - LIQUID STREAM

13. SRT, MLSS, RAS, ML Temperature $\quad-$ -
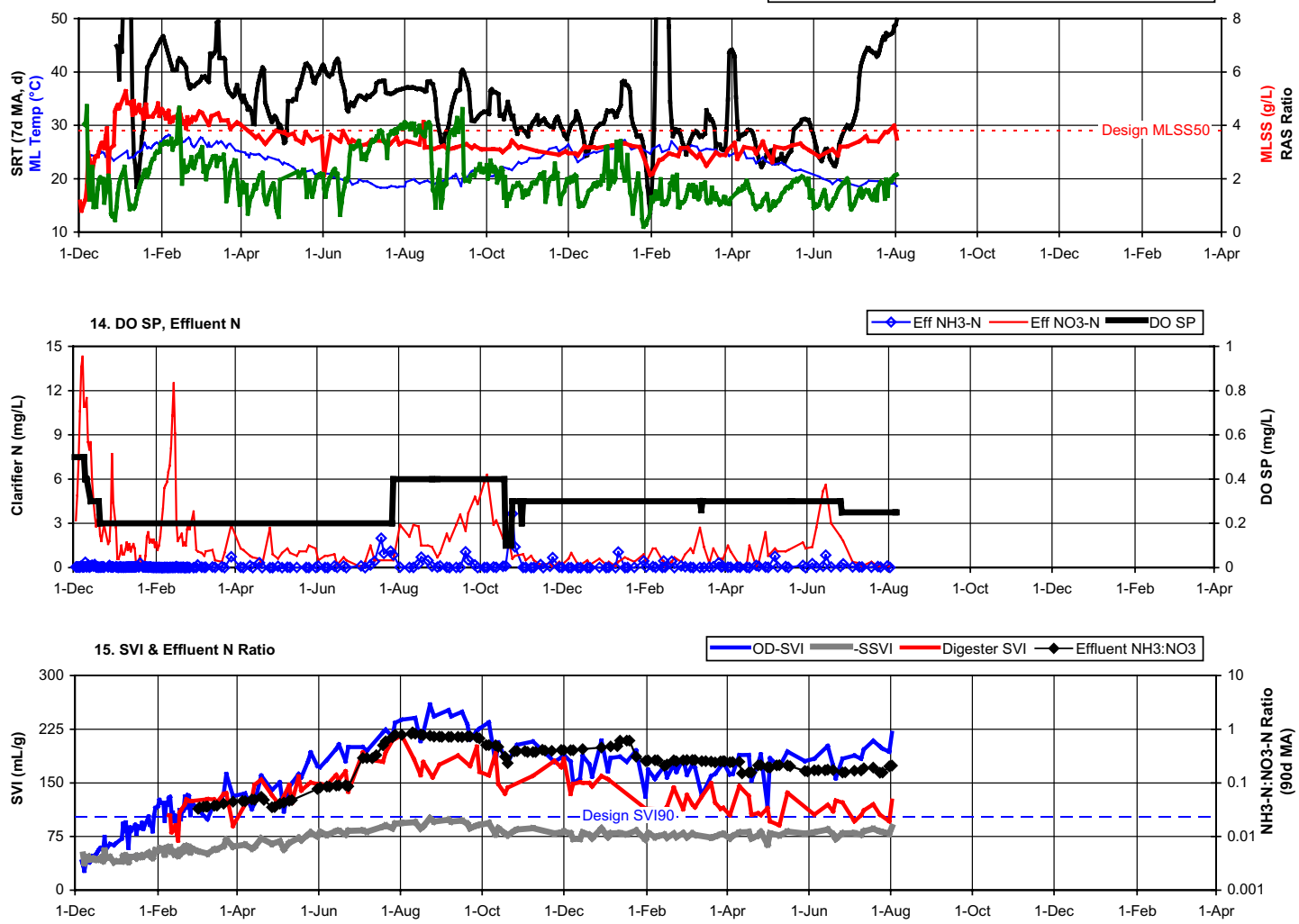

Figure 11.12 (Continued). 
Trend Plots 16-20
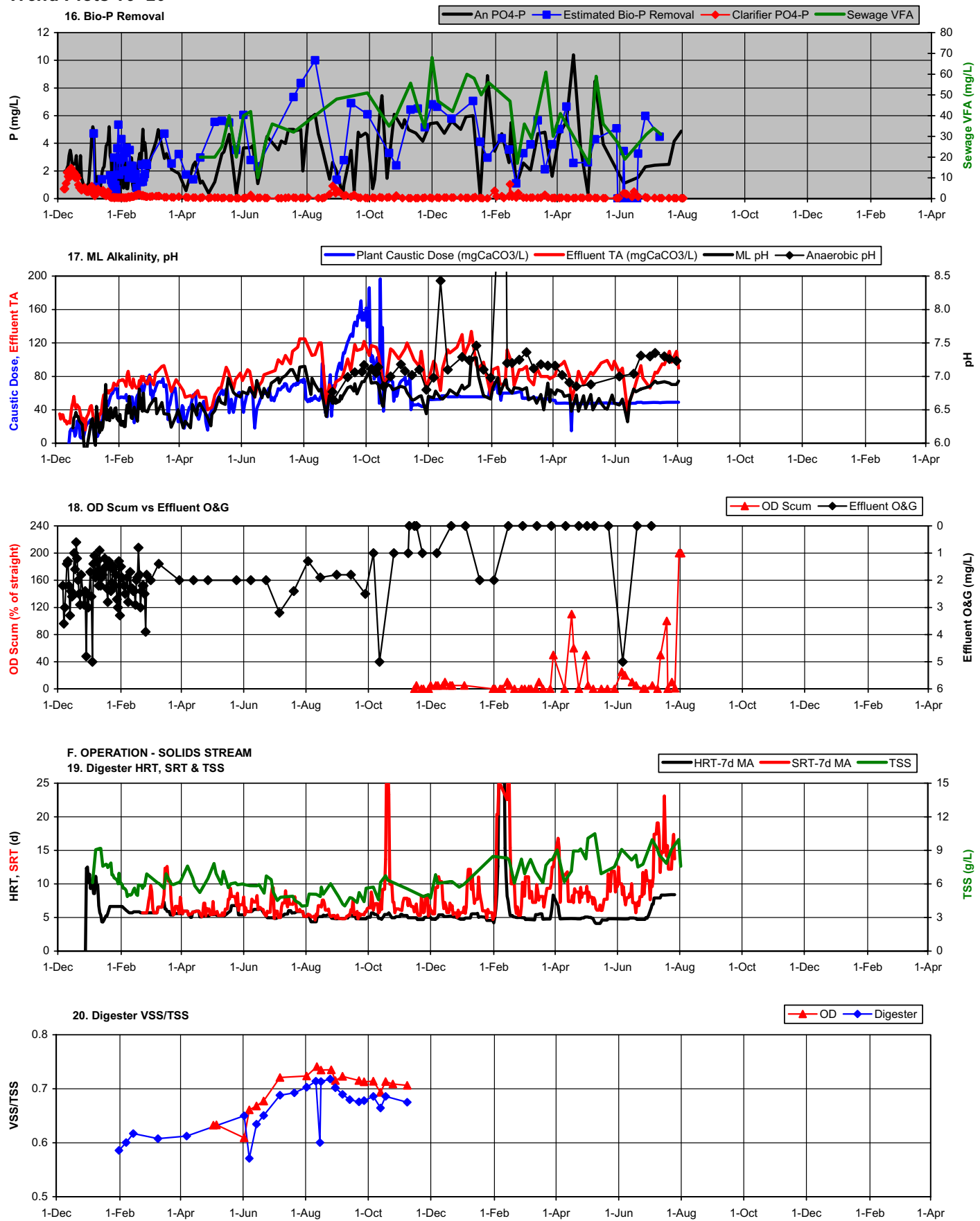

Figure 11.12 Brunswick Valley STP Process Trend Plots 1-28, being updated and reviewed monthly during the two year performance proving period (Continued). 
Trend Plots 21-25
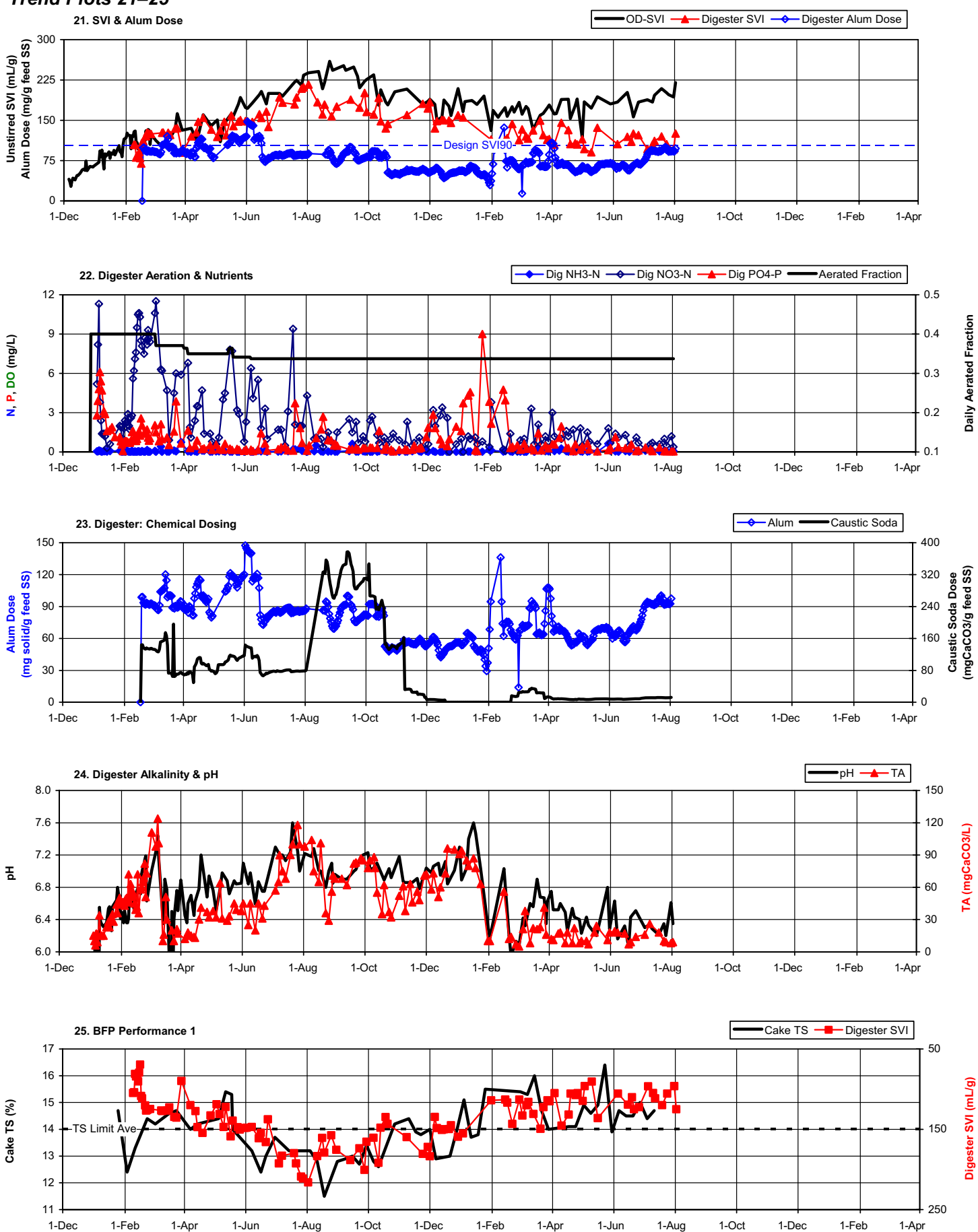

Figure 11.12 (Continued). 
Trend Plots 26-28
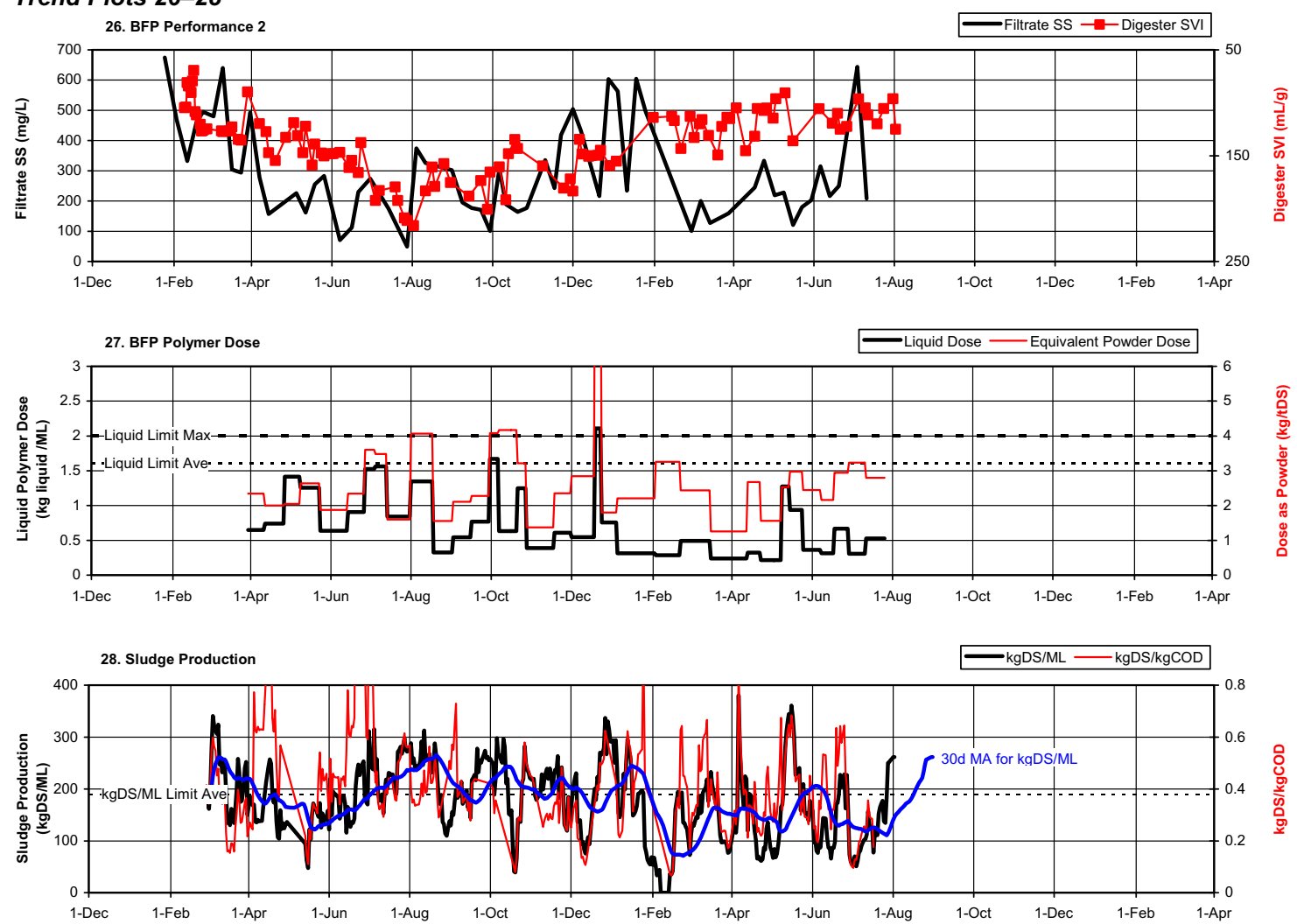

Figure 11.12 Brunswick Valley STP Process Trend Plots 1-28, being updated and reviewed monthly during the two year performance proving period (Continued).

Trends vs variability: Plot 16 is a good example of the utility of plots for discerning trends when day-to-day variability is high. Plot 11 is another example - until November, alum was dosed to the oxidation ditch at a constant daily mass rate giving a variable $\mathrm{mg} / \mathrm{L}$ rate. Despite the highly variable $\mathrm{mg} / \mathrm{L}$ value the overall downwards trend as the dosing rate was decreased is clearly evident.

\subsubsection{General principles}

Tuning a BNR plant can be complex, with many interactions between process variables. To achieve good performance it is essential to collect operating data and review performance on a regular basis. Some general principles are as follows:

(1) Biological processes are susceptible to rapid upset but are very slow to recover. It is therefore essential to monitor plant performance closely in order to identify incipient upsets and initiate recovery action as early as possible.

(2) It is difficult to have too much data. Do not skimp on analytical effort and ensure that plant instruments are regularly calibrated and maintained. 
(3) Maintain trend plots of key parameters and examine all results regularly to catch problems early.

(4) Look for interactions between and within processes so that understanding of the plant's operating characteristics can be actively enhanced. When opportunities present, conduct special tests to improve understanding and quantify operating characteristics.

(5) Be aware of interactions between processes and the likely effects that changes to one process may have on others.

(6) Best results are achieved if process operating conditions are maintained as constant as possible. Keep process operating adjustments to the necessary minimum. Ensure process equipment is reliable.

(7) Be patient. The full effects of many operating adjustments are not evident for $2-3$ solids residence times, even for changes seemingly governed by hydraulic residence time; this is because associated changes in biomass composition are often involved.

(8) With statistical licence limits a good operating strategy is to operate routinely as far below the limits as is practicable or economic; this provides a statistical buffer against periods of upset.

\subsection{FAUX EVOP}

EVOP as presented in this book would be regarded by its originators, George Box and Norman Draper, eminent statisticians both, as rather elementary. The aim here is to promote the approach rather than the mathematical detail, to encourage an interest in basic tuning to improve the performance of sewage treatment plants without the need for statistical sophistication. Both environmental and economic benefits can accrue - in terms of improved performance and deferral of plant expansions - in an industry where tuning and learning curves are not part of the vernacular. This approach to operation is also a lot of fun! 


\section{Appendix 1}

\section{A note on the statistics of variability}

For operational purposes, the main statistical issue is variability - of influent, effluent and plant operating parameters. To meet the operating goals, operators need to know how much all of these parameters vary and they should aim to reduce variability.

For simplicity this discussion is based on sets of daily data collected over lengthy periods, usually a month or a year to meet tuning, reporting and licensing requirements. To provide a reliable representation of overall performance, these data should ideally be collected at uniform time intervals.

\section{AVERAGE AND MEDIAN}

Distributions of STP data are usually positively skewed, with a long tail of infrequent, high values. Values do not vary in terms of plus and minus but in multiply and divide. The arithmetic mean (or average) is then not the same as the median or 50 percentile (the value exceeded on half of the days) because a few very high values pull the average up. Daily values are less than the average on more than $50 \%$ of days.

Most of these distributions can be normalised by taking the logarithms of the values; that is, the logarithms are normally distributed and vary in terms of plus and minus log values. For a normal distribution the mean and the median are equal. The mean of an ideal log-normal distribution is called the geometric mean and is calculated by averaging the logs of the data. The geometric mean equals the median and is therefore the value exceeded by $50 \%$ of the results, or the value exceeded $50 \%$ of the time.

In general STP use, average relates to total quantities over a period while median relates to percentage of time.

\section{PERCENTILES}

For a normal distribution $68 \%$ of the values lie within plus or minus one standard deviation of the mean. The standard deviation adds to and subtracts from the mean. For a log-normal distribution this applies to the logs of the data. Usually the data are expressed in their natural values and the geometric standard deviation multiplies and divides the geometric mean (median). An exception is microbiological data for which the variability is high; both the median and the variability are then normally expressed in logarithmic terms (plus or minus a number of logs). 


\section{APPLICATION}

Because most performance standards are expressed as upper limits, percentiles are usually expressed as percentage less than; for example, the 90 percentile is exceeded by only $10 \%$ of the values and $90 \%$ are less, or conform with the standard.

The variability of data known or assumed to be log-normally distributed is often expressed in terms of its geometric standard deviation, or alternatively by the ratio of the 90 percentile to the 50 percentile (simpler to understand). If required, other percentiles can then be estimated using the normal distribution ratios. Selected ratios are listed in the Table A1.1 below.

Table A1.1 Log-normal distribution.

\begin{tabular}{|c|c|c|c|}
\hline$\%$ less than & $\%$ greater than & No. of SDs from $50 \%$ ile & Example of practical significance \\
\hline 99.99 & 0.01 & 3.736 & Peak hour in a year \\
\hline 99.95 & 0.05 & 3.307 & Peak day in 5 years \\
\hline 99.9 & 0.1 & 3.106 & \\
\hline 99.7 & 0.3 & 2.780 & Peak day in a year \\
\hline 99 & 1 & 2.327 & \\
\hline 98 & 2 & 2.053 & Peak week in a year \\
\hline 95 & 5 & 1.643 & \\
\hline 90 & 10 & 1.282 & Peak month in a year \\
\hline 84.1 & 15.9 & 1.000 & Peak 2 months in a year \\
\hline 80 & 20 & 0.842 & \\
\hline 50 & 50 & 0.000 & Median \\
\hline 20 & 80 & 0.842 & \\
\hline 15.9 & 84.1 & 1.000 & Minimum 2 months in a year \\
\hline 10 & 90 & 1.282 & Minimum month in a year \\
\hline 5 & 95 & 1.643 & \\
\hline 2 & 98 & 2.053 & Minimum week in a year \\
\hline 1 & 99 & 2.327 & \\
\hline 0.3 & 99.7 & 2.780 & Minimum day in a year \\
\hline 0.1 & 99.9 & 3.106 & \\
\hline 0.05 & 99.95 & 3.307 & Minimum day in 5 years \\
\hline 0.01 & 99.99 & 3.736 & Minimum hour in a year \\
\hline
\end{tabular}

The simplest procedure is as follows:

(1) Determine the 50 and 90 percentiles of the data. Calculate the 90:50 percentile ratio. From Table A1.1, this is 1.282 geometric standard deviations.

(2) Estimate the values for other percentiles lying outside the data range by ratio from the number of standard deviations. For example, to estimate the value exceeded $0.3 \%$ of the time (the 99.7 percentile or peak day in Table A1.1):

$\log (99.7$ percentile $)=\log (50$ percentile $)+(2.780 / 1.282) \log (90: 50$ percentile ratio $)$ 
The ratio of the average to the geometric mean is given by:

average/geometric mean $=\left(1+v^{2}\right)^{0.5}$

where

$\mathrm{v}=$ arithmetic coefficient of variation

$=$ standard deviation/average

This has application when the total annual mass discharge of an effluent constituent must meet a limit. It is then the average daily discharge which is important, not the median discharge. Figure A1.1 shows the fit to this relationship of daily effluent $\mathrm{N}$ and $\mathrm{P}$ data from the Cleveland Bay MBR-BNR plant in Townsville which has mass discharge limits. Each data point relates to a 4-6 month seasonal period from Mar-08 to Mar-10.

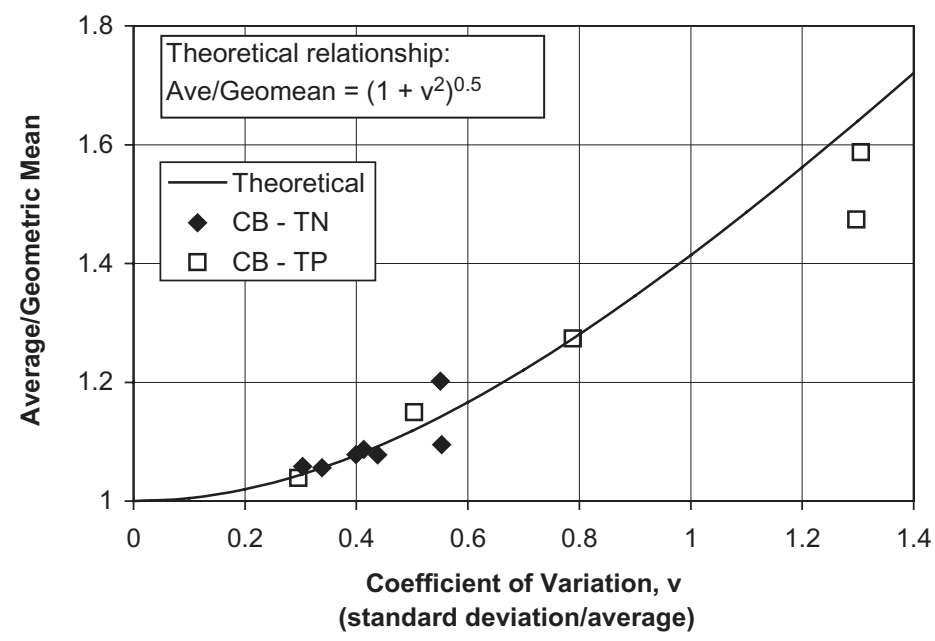

Figure A1.1 Cleveland Bay effluent data conform with the theoretical relationship between the normal and log-normal distributions. 
Appendix 2

Chemicals: useful properties 


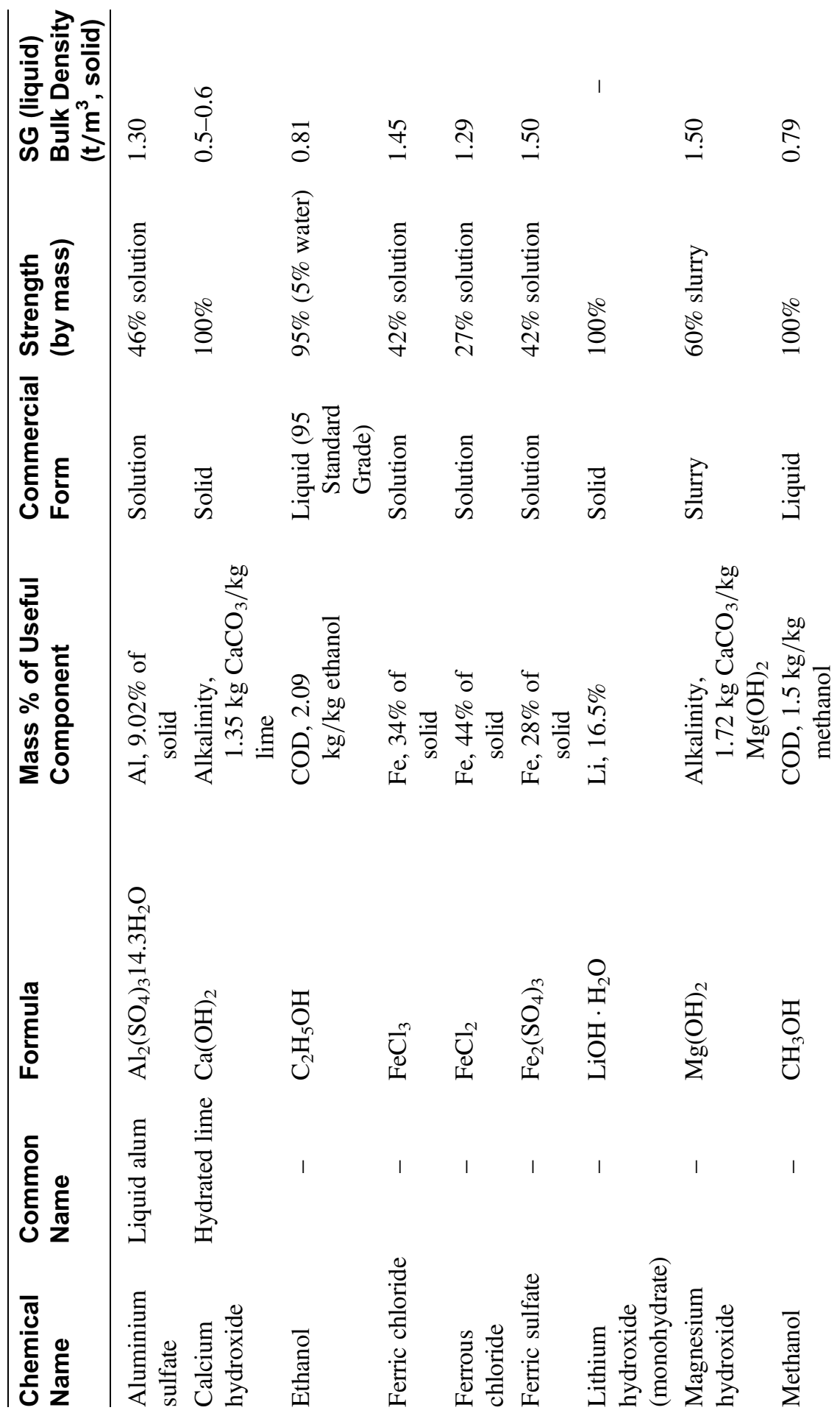




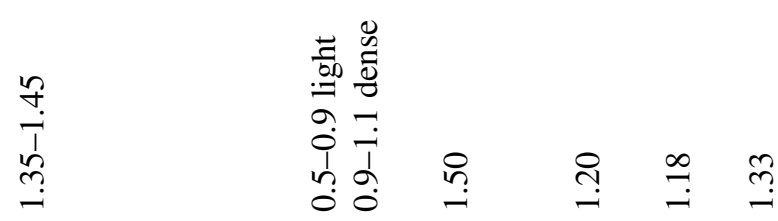

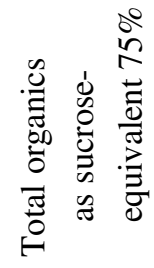

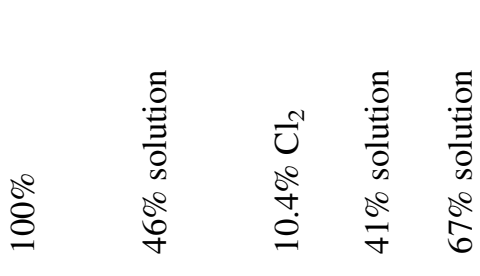

$\frac{\sigma}{3} \cdot \frac{\sigma}{3}$

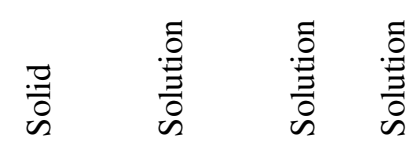

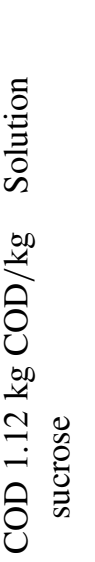

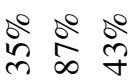

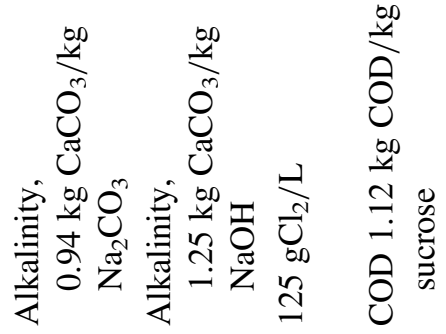

n 0 o 0 .

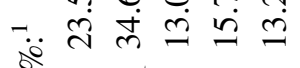

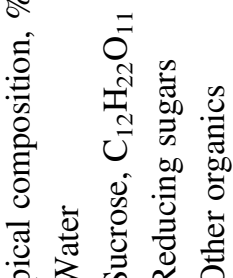

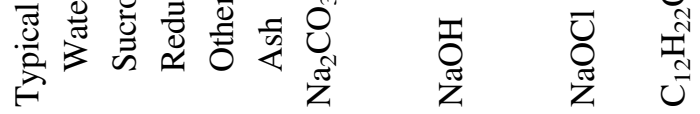

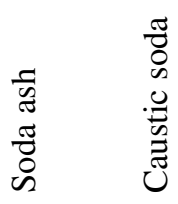

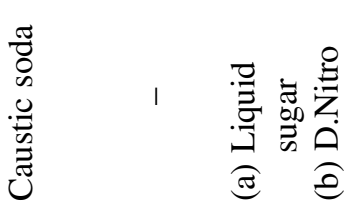

$\frac{\dot{m}}{\frac{0}{\sqrt{n}}}$

$\frac{\sqrt{10}}{\frac{0}{0}}$

즘 


\section{Appendix 3}

\section{Abbreviations}

(excludes standard laboratory terminology)

$\begin{array}{ll}\text { ACT } & \text { Australian Capital Territory } \\ \text { ADWF } & \text { average dry weather flow } \\ \text { A/O } & \text { anaerobic oxic } \\ \text { A2O } & \text { anaerobic anoxic oxic } \\ \text { APT } & \text { activated primary tank } \\ \text { BFP } & \text { belt filter press } \\ \text { BNR } & \text { biological nutrient removal } \\ \text { CASS } & \text { cyclic activated sludge system } \\ \text { CFID } & \text { continuous feed intermittent decant } \\ \text { EBPR } & \text { enhanced biological phosphorus removal } \\ \text { EP } & \text { equivalent persons } \\ \text { EPS } & \text { bacterial exopolymeric substances } \\ \text { EVOP } & \text { evolutionary operation } \\ \text { F:M ratio } & \text { food:microorganism ratio } \\ \text { GAO } & \text { glycogen accumulating organism } \\ \text { HRT } & \text { hydraulic residence time } \\ \text { ICEAS } & \text { intermittent cycle extended aeration system } \\ \text { IDAL } & \text { intermittently decanted aerated lagoon } \\ \text { IDEA } & \text { intermittently decanted extended aeration } \\ \text { JHB } & \text { Johannesburg } \\ \text { MLE } & \text { Modified Ludzack-Ettinger } \\ \text { MLSS } & \text { mixed liquor suspended solids } \\ \text { MLVSS } & \text { mixed liquor volatile suspended solids } \\ \text { MBR } & \text { membrane bioreactor } \\ \text { MRT } & \text { mean residence time } \\ \text { MUCT } & \text { Modified University of Cape Town } \\ \text { ND } & \text { nitrification denitrification } \\ \text { NDEBPR } & \text { nitrification denitrification enhanced biological phosphorus removal } \\ & \end{array}$




$\begin{array}{ll}\text { NSW } & \text { New South Wales (Australian State) } \\ \text { OD } & \text { oxidation ditch } \\ \text { OHO } & \text { oxygen transfer efficiency } \\ \text { OTE } & \text { oxygen transfer rate } \\ \text { OTR } & \text { oxygen uptake rate } \\ \text { OUR } & \text { phosphorus accumulating organism } \\ \text { PAO } & \text { Queensland (Australian State) } \\ \text { Qld } & \text { return activated sludge } \\ \text { RAS } & \text { readily biodegradable COD } \\ \text { RBCOD } & \text { residence time distribution } \\ \text { RTD } & \text { South Australia (Australian State) } \\ \text { SA } & \text { slowly biodegradable COD } \\ \text { SBCOD } & \text { sequencing batch reactor } \\ \text { SBR } & \text { secondary clarifier } \\ \text { SC } & \text { soluble microbial products } \\ \text { SMP } & \text { simultaneous nitrification and denitrification } \\ \text { SND } & \text { standard oxygen transfer efficiency } \\ \text { SOTE } & \text { standard oxygen transfer rate } \\ \text { SOTR } & \text { specific oxygen uptake rate } \\ \text { SOUR } & \text { set point } \\ \text { SP } & \text { solids residence time } \\ \text { SRT } & \text { stirred sludge volume index } \\ \text { SSVI } & \text { stirred specific volume index } \\ \text { SSVI } & \text { sewage treatment plant } \\ \text { STP } & \text { sludge volume index } \\ \text { SVI } & \text { transmembrane pressure } \\ \text { TMP } & \text { top water level } \\ \text { TWL } & \text { University of Cape Town } \\ \text { UCT } & \text { volatile active suspended solids } \\ \text { VASS } & \text { Wictoria (Australian State) } \\ \text { Vic } & \text { wastern Austivated sludge } \\ \text { WA } & \text { water depth } \\ \text { WAS } & \text { WD } \\ \text { WQCC } & \text { WWTP }\end{array}$




\section{References}

Ahmed Z., Lim B.-R., Cho J., Song K.-G., Kim K.-P. and Ahn K.-H. (2008). Biological nitrogen and phosphorus removal and changes in microbial community structure in a membrane bioreactor: effect of different carbon sources. Water Research, 42(1-2), 198-210.

Andreasen K. and Nielsen P. H. (2000). Growth of Microthrix parvicella in nutrient removal activated sludge plants: studies of in situ physiology. Water Research, 34(5), 1559-1569.

Ardern E. and Lockett W. T. (1914a). Experiments on the oxidation of sewage without the aid of filters. Society of Chemical Industry Journal, 33(10), 523-539.

Ardern E. and Lockett W. T. (1914b). The oxidation of sewage without the aid of filters: Part 2. Society of Chemical Industry Journal, 33(23), 1122-1124.

ASCE Standard ASCE/SEI 2-06 (2007). Measurement of Oxygen Transfer in Clean Water. American Society of Civil Engineers, Reston, VA, USA.

Åström K. J. and Hägglund T. (1995). PID Controllers: Theory, Design and Tuning. ISA Press, Research Triangle Park, USA.

Åström K. J. and Hägglund T. (2006). Advanced PID Control. ISA-The Instrumentation, Systems and Automation Society, USA.

AWWA (1997). BNR Plants in Australia. Australian Water \& Wastewater Association, Sydney, Australia.

Baars J. K. (1962). The use of oxidation ditches for treatment of sewage from small communities. Bulletin of the World Health Organization, 26, 465.

Bane I. H. (1997). Dewaterability of activated biosolids. Water, 24(3), 56-57.

Barnard J. L. (1973). Biological denitrification. Water Pollution Control, 72(6), 705-720.

Barnard J. L. (1976a). A review of biological phosphorus removal in the activated sludge process. Water SA, 2(3), 136-144.

Barnard J. L. (1976b). Nutrient removal in biological systems. Water Pollution Control, 74, 143-154.

Barnard J. L. (1984). Activated primary tanks for phosphate removal. Water SA, 10(3), 121-126.

Batstone D. J., Keller J., Angelidaki R. I., Kalyuzhnyi S. V., Pavlostathis S. G., Rozzi A., Sanders W. T. M., Siegrist H. and Vavilin V. A. (2002). Anaerobic Digestion Model No.1. Scientific and Technical Report No. 13, IWA Publishing, London, UK.

Beenyup WWTP Laboratory (2006). Biochemical Oxygen Demand - Reduction in the $\mathrm{BOD}_{5}$ Test Upon Storage at $<4^{\circ} \mathrm{C}$. Water Corporation, Perth, Australia.

Biggs C. A. (2000). Activated Sludge Flocculation: Investigating the Effect of Shear Rate and Cation Concentration on Flocculation Dynamics. PhD thesis, Dept of Chemical Engineering, University of Queensland, Brisbane, Australia.

Biggs C. A. and Lant P. A. (2000). Activated sludge flocculation: on-line determination of floc size and the effect of shear. Water Research, 34(9), 2542-2550. 
Bisogni J. J. and Lawrence A. W. (1971). Relationships between biological solids retention time and settling characteristics of activated sludge. Water Research, 5, 753-763.

Boisvert J.-P., To T. C., Berrak A. and Jolicoeur C. (1997). Phosphate adsorption in flocculation processes of aluminium sulphate and poly-aluminium-silicate-sulphate. Water Research, 31(8), 1939-1946.

Box G. E. P. and Draper N. R. (1969). Evolutionary Operation: A Statistical Method for Process Improvement. John Wiley, New York.

Brennan D. J. and Greenfield P. F. (1994). Competitive analysis: watch out for capacity creep. Chemical Engineering in Australia, CHE19(4), 7-8.

Brennan D. J. and Stephens G. K. (1985a). The extent and rate of capacity increase in process plants. Process Economics International, $\mathbf{V}(3 \& 4), 15-25$.

Brennan D. J. and Stephens G. K. (1985b). Changes in cost and performance resulting from plant expansion. Process Economics International, VI(1), 16-26.

Casey T. and Alexander W. V. (2001). Design and Operating Strategies to Minimize Bulking by Anoxic-Aerobic Filamentous Organisms in Nutrient Removal Activated Sludge Plants, WRC Report No. 775/1/01, Water Research Commission, Pretoria.

Casey T. G., Wentzel M. C. and Ekama G. A. (1999). Filamentous organism bulking in nutrient removal activated sludge systems. Paper 11: a biochemical/microbiological model for proliferation of anoxic-aerobic (AA) filamentous organisms. Water SA, 25(4), 443-451.

Chao A. C. and Keinath T. M. (1979). Influence of process loading intensity on sludge clarification and thickening characteristics. Water Research, 13, 1213-1223.

Chow V. T. (1959). Open-Channel Hydraulics. McGraw-Hill, New York.

Ciba-Geigy Ltd (1981). Geigy Scientific Tables, Vol 1, 8th edn., Summit, New Jersey, USA.

Daigger G. T., Randall C. W., Waltrip G. D., Romm E. D. and Morales L. M. (1987). Factors affecting biological phosphorus removal for the VIP process, a high-rate University of Cape Town process. IAWPRC Conf on Biological Phosphate Removal, Rome.

Dick R. I. and Vesilind P. A. (1969). The sludge volume index - what is it? Journal of WPCF, 41(7), 1285-1291.

Ekama G. A., Barnard J. L., Gunthert F. W., Krebs P., McCorquodale J. A., Parker D. S. and Wahlberg E. J. (1997). Secondary Settling Tanks: Theory, Modelling, Design and Operation. IAWQ Sci \& Tech Rpt No. 6.

Ekama G. A. and Marais G. v. R. (1977). The activated sludge process, Part 2 - Dynamic behaviour. Water SA, 3(1), $18-50$.

Ekama G. A., Dold P. L. and Marais G. v. R. (1986). Procedures for determining influent COD fractions and the maximum specific growth rate of heterotrophs in activated sludge systems. Water Science and Technology, 18, 91-114.

Ekama G. A., Wentzel M. C., Casey T. G. and Marais G. v. R. (1996). Filamentous organism bulking in nutrient removal activated sludge systems. Paper 6: review, evaluation and consolidation of results. Water SA, 22(2), $147-152$.

EPA NSW (1997). Environmental Guidelines: Use and Disposal of Biosolids Products. NSW Environment Protection Authority, Sydney.

Fair G. M., Geyer J. C. and Okun D. A. (1968). Water and Wastewater Engineering: Volume 2. Water Purification and Wastewater Treatment and Disposal. John Wiley, New York.

Galarneau E. and Gehr R. (1997). Phosphorus removal from wastewaters: experimental and theoretical support for alternative mechanisms. Water Research, 31(2), 328-338.

Gernaey K. V., Nielsen M. K., Thornberg D., Höök B., Munk-Nielsen T., Ingildsen P. and Jørgensen S. B. (2004). First principle suspended solids distribution modelling to support ATS introduction on a recirculating WWTP. 2nd Int. IWA Conf. on Automation in Water Quality Monitoring, Vienna, Austria.

GHD (1994). Thorneside WPCW Augmentation, Technical Memo No. 7 - Alum Dosing Jar Tests. Redland Shire Council.

GHD (1995). Thorneside WPCW Augmentation, Planning Report. Redland Shire Council.

Gloag G. (2009). Dynamic modeling study for design of Pimpama WWTP, Gold Coast, Australia. Personal communication. 
Gloag G. and Hartley K. (2005). Failure frequency analysis - quantifying the operational process capacity of wastewater treatment plants. Proceedings Australian Water Association 21st Biennial Conv, Brisbane, Australia.

Goldratt E. M. and Cox J. (2004). The Goal: A Process of Ongoing Improvement. 3rd revised edn, North River Press, Great Barrington, Massachusetts, USA.

Guisasola A., de Haas D., Keller J. and Yuan Z. (2008). Methane formation in sewer systems. Water Research, 42(6-7), $1421-1430$.

Guisasola A., Sharma K. R., Keller J. and Yuan Z. (2009). Development of a model for assessing methane formation in rising main sewers. Water Research, 43(11), 2874-2884.

Hall E. R., Monti A. and Mohn W. W. (2010). A comparison of bacterial populations in enhanced biological phosphorus removal processes using membrane filtration or gravity sedimentation for solids-liquid separation. Water Research, 44(9), 2703-2714.

Hartley K. J. (1985). Operating the Activated Sludge Process. GHD, Brisbane, Australia.

Hartley K. J. (1987). Hydraulics of horizontal shaft oxidation ditches. Journal of WPCF, 59(7), 686-694.

Hartley K. J. (1990). Fouling \& Cleaning of Fine Bubble Ceramic Dome Diffusers, Research Report No. 14, Urban Water Research Association of Australia.

Hartley K. J. (1995). Biological Nutrient Removal Plants: Review of Full-Scale Operation, Research Report No. 94, Urban Water Research Association of Australia.

Hartley K. J. (1997a). Use of the oxidation ditch reactor in BNR plants, Proc 3rd Australian Conf on BNR. Australian Water \& Wastewater Ass.

Hartley K. J. (1997b). SBR BNR Process R\&D Project - Final Report, GHD, Brisbane, Australia.

Hartley K. J. (1998). The cost of Australian BNR plants. Water, Jnl Australian Water \& Wastewater Ass, 25(1), 20.

Hartley K. J. (2000). Maroochydore STP: Energy KPI Analysis. Maroochy Water, Maroochydore, Qld, Australia.

Hartley K. J. (2002). Analysis of aeration diffuser fouling. Unpublished.

Hartley K. J. (2008). Controlling sludge settleability in the oxidation ditch process. Water Research, 42(6-7), $1459-1466$.

Hartley K. J. (2009). Cleveland Bay WTF: Review of Biological P Removal Performance. Townsville Water, Townsville, Qld, Australia.

Hartley Ken (2012). Loganholme WWTP: Stage 7 Process Commissioning. Logan Water Alliance, Brisbane, Australia.

Hartley K. J. and Gobbie M. R. (1991). Fouling and cleaning of fine bubble ceramic dome diffusers. Proc Australian Water \& Wastewater Ass 14th Fed Conv, Perth, Australia.

Hartley K. J. and Lant P. A. (2006). Eliminating non-renewable $\mathrm{CO}_{2}$ emissions from sewage treatment: an anaerobic migrating bed reactor pilot plant study. Biotechnology \& Bioengineering, 95(3), 384-398.

Hartley K. and Lant P. (2010). Sludge settleability in BNR processes. Water, Jnl Australian Water Ass, 37(3), 64-70.

Hartley K., Hertle C., Komarowski S. and Walpole R. (1999). Operating experience with two activated primary tanks for sewage prefermentation. Proc Australian Water \& Wastewater Ass 18th Fed Conv, Adelaide, Australia.

Henze M., Gujer W., Mino T. and van Loosdrecht M. (2000). Activated Sludge Models ASM1, ASM2, ASM2d and ASM3. IWA Publishing, London.

Henze M., van Loosdrecht M. C. M., Ekama G. A. and Brdjanovic D. (eds) (2008). Biological Wastewater Treatment: Principles, Modelling and Design. IWA Publishing, London.

Hirschmann W. B. (1964). Profit from the learning curve. Harvard Business Review, 42(1), 125-139.

Holbrook R. D., Higgins M. J., Murthy S. N., Fonseca A. D., Fleischer E. J., Daigger G. T., Grizzard T. J., Love N. G. and Novak J. T. (2004). Effect of alum addition on the performance of submerged membranes for wastewater treatment. Water Environment Research, 76(7), 2699-2702.

Ingildsen P. (2002). Realising Full-Scale Control in Wastewater Treatment Systems Using In-Situ Nutrient Sensors. PhD thesis, Dept. of Ind. Electrical Engineering and Automation (IEA), Lund University, Lund, Sweden.

ISO15839 2003. Water Quality - On-line Sensors/Analysing Equipment for Water - Specifications and Performance Tests. 1st edn, 2003-10-15, SAI Global.

Jenkins D., Richard M. G. and Daigger G. T. (2004). Manual on the Causes and Control of Activated Sludge Bulking, Foaming, and Other Solids Separation Problems. 3rd edn, CRC Press, Boca Raton \& IWA Publishing, London. 
John Wilson \& Partners (2001). Nambour STP, Loads \& Impacts Study. Maroochy Water, Maroochydore, Qld, Australia.

Lai F. Y., Ort C., Gartner C., Carter S., Prichard J., Kirkbride P., Bruno R., Hall W., Eaglesham G. and Mueller J. F. (2011). Refining the estimation of illicit drug consumption from wastewater analysis: co-analysis of prescription pharmaceuticals and uncertainty assessment. Water Research, 45(15), 4437-4448.

Lee S.-E., Koopman B., Bode H. and Jenkins D. (1983). Water Research, 17(10), 1421-1426.

Letterman R. D., Amirtharajah A. and O'Melia C. R. (1999). Coagulation and flocculation. In: Water Quality and Treatment: A Handbook of Community Water Supplies, R. D. Letterman (ed.), 5th edn, McGraw-Hill, New York, Chapter 6.

Levenspiel O. (1972). Chemical Reaction Engineering. 2nd edn, John Wiley, New York.

Liu J., Olsson G. and Mattiasson B. (2004). Control of an anaerobic reactor towards maximum biogas production. Water Science and Technology, 50(11), 189-198.

Liu J., Olsson G. and Mattiasson B. (2006). Extremum-seeking with variable gain control for intensifying biogas production in anaerobic fermentation. Water Science and Technology, 53(4-5), 35-44.

Loewenthal R. E. and Marais G. v. R. (1976). Carbonate Chemistry of Aquatic Systems: Theory and Application. Vol 1. Ann Arbor Science, Ann Arbor, Michigan, USA.

Lopez-Vazquez C. M., Oehmen A., Hooijmans C. M., Brdjanovic D., Gijzens H. J., Yuan Z. and van Loosdrecht M. C. M. (2009). Modeling the PAO-GAO competition: effects of carbon source, $\mathrm{pH}$ and temperature. Water Research, 43(2), 450-462.

Ludzack F. J. and Ettinger M. B. (1962). Controlling operation to minimize activated sludge effluent nitrogen. Journal of $W P C F$, 34, 920-931.

Ma Y., Peng Y., Wang S., Yuan Z. and Wang X. (2009). Achieving nitrogen removal via nitrite in a pilot-scale continuous pre-denitrification plant. Water Research, 43(3), 563-572.

Mamais D., Jenkins D. and Pitt P. (1993). A rapid physical-chemical method for the determination of readily biodegradable soluble COD in municipal wastewater. Water Research, 27(1), 195-197.

Marais G. v. R. and Ekama G. A. (1976). The activated sludge process part 1 - steady state behaviour. Water SA, 2(4), 164-200.

Marlin T. E. (2000). Process Control. Designing Processes and Control Systems for Dynamic Performance. 2nd edn, McGraw Hill, New York.

Metcalf \& Eddy (2003). Wastewater Engineering: Treatment and Reuse. 4th edn, McGraw-Hill, New York.

Mohlman F. W. (1934). The sludge index. Sewage Works Journal, 6(1), 119-122.

Monod J. (1949). The growth of bacterial cultures. Annual Review of Microbiology, 3, 371.

Monteith H. D. and Stephenson J. P. (1981). Mixing efficiencies in full-scale anaerobic digesters by tracer methods. Journal of WPCF, 53(1), 78-84.

Monti A. and Hall E. R. (2008). Comparison of nitrification rates in conventional and membrane-assisted biological nutrient removal processes. Water Environment Research, 80(6), 497-505.

Monti A., Hall E. R., Dawson R. N., Husain H. and Kelly H. G. (2006). Comparative study of biological nutrient removal (BNR) processes with sedimentation and membrane-based separation. Biotechnology and Bioengineering, 94(4), 740-752.

Morales L. M., Daigger G. T. and Borberg J. R. (1991). Capability assessment of biological nutrient removal facilities. Research Journal of WPCF, 63(6), 900-909.

Muller A., Wentzel M. C., Loewenthal R. E. and Ekama G. A. (2003). Heterotroph anoxic yield in anoxic aerobic activated sludge systems treating municipal wastewater. Water Research, 37(10), 2435-2441.

Natural Resource Management Ministerial Council, Environment Protection and Heritage Council and Australian Health Ministers' Conference (2006). Australian Guidelines for Water Recycling: Managing Health and Environmental Risks.

Nielsen H. L., Carns K. E. and DeBoice J. N. (1973). Alum sludge thickening and disposal. Journal of AWWA, 65, 385 .

Nielsen M. K. (1983). Computer Control of Nitrogen Removal in a Single Sludge Sewage Treatment Plant. PhD thesis, Inst. for Kemiteknik Danish Technical Univ., Denmark. 
Nielsen M. K. and Ønnerth T. (1995). Improvement of a recirculating plant by introducing STAR control. Water Science and Technology, 31(2), 171-180.

Nielsen M. K., Carstensen J. and Harremöes P. (1996). Combined control of sewer and treatment plant during rainstorm. Water Science and Technology, 34(3-4), 181-187.

Nowak O. (2002). Benchmarks for the energy demand of nutrient removal plants. Proc IWA World Congress, Melbourne.

Olsson G. (2012a). ICA and me - a subjective review. Water Research, 46(6), 1585-1624.

Olsson G. (2012b). Water and Energy - Threats and Opportunities. IWA Publishing, London, UK.

Olsson G. and Andrews J. F. (1978). The dissolved oxygen profile - a valuable tool for the control of the activated sludge process. Water Research, 12, 985-1004.

Olsson G. and Newell R. B. (1998). Talking of RAS - reviewing, assessing and speculating. Final address at the 7th IAWQ Symp. on ICA, Brighton, UK, July, 1997. Water Science and Technology, 37(12), 397-401.

Olsson G. and Newell R. B. (1999). Wastewater Treatment Systems. Modelling, Diagnosis and Control. IWA Publishing, London, UK.

Olsson G., Nielsen M. K., Yuan Z., Lynggaard-Jensen A. and Steyer J. P. (2005). Instrumentation, Control and Automation in Wastewater Treatment Systems. Scientific and Technical Report No.15. IWA Publishing, London, UK.

Olsson G., Rundqwist L., Eriksson L. and Hall L. (1985). Self-tuning control of the dissolved oxygen concentration in activated sludge systems. In: Advances in Water Pollution Control, R. A. R. Drake (ed.), Int. Assoc. on Water Pollution Res. and Control (IAWPRC), London, pp. 473-480.

Orhon D., Sozen S. and Artan N. (1996). The effect of heterotrophic yield on the assessment of the correction factor for anoxic growth. Water Science and Technology, 34(5-6), 67-74.

Osborn D. W. and Nicholls H. A. (1978). Optimisation of the activated sludge process for the biological removal of phosphorus. Progress in Water Technology, 10(1-2), 261-277.

Pajdak-Stos A. and Fialkowska E. (2012). The influence of temperature on the effectiveness of filamentous bacteria removal from activated sludge by rotifers. Water Environment Research, 84(8), 619-625.

Palm J. C., Jenkins D. and Parker D. S. (1980). Relationship between organic loading, dissolved oxygen concentration and sludge settleability in the completely-mixed activated sludge process. Journal of WPCF, $\mathbf{5 2}$ (10), 2484-2506.

Parker D. S. (1983). Assessment of secondary clarification design concepts. Journal of WPCF, 55(4), 349-359.

Parker D. S., Kaufman W. J. and Jenkins D. (1971). Physical conditioning of activated sludge floc. Journal of WPCF, 43 (9), 1817-1833.

Parker D. S., Kaufman W. and Jenkins D. (1972). Floc breakup in turbulent processes. Jnl Sanitary Engineering Div, Proc ASCE, 98(SA1), 79-99.

Parker D., Wahlberg E., Buttz J., Daigger G., Dentel S., Farrell J., Stephenson J. and Sutton P. (1999). Research Priorities for Debottlenecking, Optimizing and Rerating Wastewater Treatment Plants. Project 99-WWF-1. Water Environment Research Foundation, Alexandria, VA, USA.

Parkin G. F. and Owen W. F. (1986). Fundamentals of anaerobic digestion of wastewater sludges. Journal of Environmental Engineering, ASCE, 112(5), 867-920.

Pasveer A. (1959). Contribution to the development in activated sludge treatment. Journal and Proceedings of the Institute of Sewage Purification, 4, 436.

Peck G. M. (1984). The principles of learning and forgetting. Inst. of Engrs Aust, Muli-Disciplinary Engg Trans, pp. $95-106$.

Pipes W. O. (1979). Bulking, deflocculation and pinpoint floc. Journal of WPCF, 51(1), 62-70.

Potter T., Koopman B. and Svoronos A. (1996). Optimisation of a periodic biological process for nitrogen removal from wastewater. Water Research, 30(1), 142-152.

Rabinowitz B. and Marais G. v. R. (1980). Chemical and Biological Phosphorus Removal in the Activated Sludge Process. Research Report No. W32, Civil Engineering Department, University of Cape Town, South Africa.

Rieger L. and Olsson G. (2012). Why many control systems fail. Water Environment \& Technology, Water Environment Federation, June 2012, 24(6), 43-45. 
Rosen C., Ingildsen P., Guildal T., Nielsen M. K., Jacobsen B. N. and Ønnerth T. (2004). On-line estimation of nitrification and denitrification capacity at Avedøre wastewater treatment plant. Aquatech, Int. Conf. Upgrading of Wastewater Treatment Plants, 30 September-1 October 2004, Amsterdam, The Netherlands.

Rosso D. and Stenstrom M. K. (2006). Economic implications of fine-pore diffuser aging. Water Environment Research, 78(8), 810-815.

Sezgin M. (1982). Variation of sludge volume index with activated sludge characteristics. Water Research, 16, 83-88.

Sezgin M., Jenkins D. and Parker D. S. (1978). A unified theory of filamentous activated sludge bulking. Journal of WPCF, 50(2), 362-381.

Sharma K. R., Yuan Z., de Haas D., Hamilton G., Corrie S. and Keller J. (2008). Dynamics and dynamic modelling of $\mathrm{H}_{2} \mathrm{~S}$ production in sewer systems. Water Research, 42(10-11), 2527-2538.

Shipin O. V., Meiring P. G. J., Phaswana R. and Kluever H. (1999). Integrating ponds and activated sludge process in the PETRO process. Water Research, 33(8), 1767-1774.

Siebritz I. D., Ekama G. A. and Marais G. v. R. (1982). A parametric model for biological excess phosphorus removal. Water Science and Technology, 15(3-4), 127-152.

Snidaro D., Zartarian F., Jorand F., Bottero J. Y., Block J. C. and Manem J. (1997). Characterisation of activated sludge flocs structure. Water Science and Technology, 36(4), 313-320.

Sørensen J., Thornberg D. and Nielsen M. K. (1994). Optimisation of a nitrogen-removing biological wastewater treatment plant using on-line measurements. Water Environment Research, 66(3), 236-242.

Spanjers H. and van Lier J. B. (2006). Instrumentation in anaerobic treatment - research and practice. Water Science and Technology, 53(4-5), 63-76.

Sperandio M., Urbain V., Audic J. M. and Paul E. (1999). Use of carbon dioxide evolution rate for determining heterotrophic yield and characterising denitrifying biomass. Water Science and Technology, 39(1), $139-146$.

Standard Methods for the Examination of Water and Wastewater (1998). 20th edn, American Public Health Association/American Water Works Association/Water Environment Federation, Washington, DC, USA.

Stanier R. Y., Adelberg E. A. and Ingraham J. L. (1976). General Microbiology. 4th edn, Prentice-Hall, Upper Saddle River, NJ, USA.

Steyer J. P., Buffiére P., Rolland D. and Moletta R. (1999). Advanced control of anaerobic digestion processes through disturbances monitoring. Water Research, 33(9), 2059-2068.

Steyer J. P., Bouvier J. C., Conte T., Gras P. and Sousbie P. (2002). Evaluation of a four year experience with a fully instrumented anaerobic digestion process. Water Science and Technology, 45(4-5), 495-502.

Steyer J. P., Bernard O., Batstone D. J. and Angelidaki I. (2006). Lessons learnt from 15 years of ICA in anaerobic digesters. Water Science and Technology 53(4-5), 25-33.

Stobbe C. T. (1964). Uber das Verhaltern von Belebten Schlammes in Aufsteigender Wasserbewegung, Veroffentlichungen, des Institut fur Siedlungswasserwirtschaft der Technischen Hochschule Hannover. (Study of the Behaviour of Activated Sludge in Effluent Clarification. Institute for Urban Water Management, Technical Institute of Hannover, Germany.)

Tarong Energy (2000). Macro Energy Audit, Water \& Wastewater Infrastructure. Brisbane Water, Brisbane, Australia. Ternes T. A. and Joss A. (eds) (2006). Human Pharmaceuticals, Hormones and Fragrances. IWA Publishing, London.

Thornberg D., Nielsen M. K. and Andersen K. (1993). Nutrient removal: on-line measurements and control strategies. Water Science and Technology, 28(11-12), 549-560.

Trussell R. S., Merlo R. P., Hermanowicz S. W. and Jenkins D. (2006). The effect of organic loading on process performance and membrane fouling in a submerged membrane bioreactor treating municipal wastewater. Water Research, 40(14), 2675-2683; Corrigendum 40(18), 3479.

Trussell R. S., Merlo R. P., Hermanowicz S. W. and Jenkins D. (2007). Influence of mixed liquor properties and aeration intensity on membrane fouling in a submerged membrane bioreactor at high mixed liquor suspended solids concentrations. Water Research, 41(5), 947-958.

University of Cape Town, City Council of Cape Town \& NIWR. (1984). Theory, Design and Operation of Nutrient Removal Activated Sludge Processes. Water Research Commission, Pretoria.

US EPA. (1989). Design Manual: Fine Pore Aeration Systems. EPA/625/1-89/023, EPA Office of Research and Development, Cincinnati. 
US EPA. (2009). Nutrient Control Design Manual. EPA/600/R-09/012, EPA Office of Research and Development, Cincinnati.

Vesilind P. A. (1974). Treatment and Disposal of Wastewater Sludges. Ann Arbor Science, Ann Arbor.

Wanner O., Panagiotidis V., Clavadetscher P. and Siegrist H. (2005). Effect of heat recovery from raw wastewater on nitrification and nitrogen removal in activated sludge plants. Water Research, 39(19), 4725-4734.

Wastewater Futures. (2007). Secondary Treatment Augmentation Project, ActewAGL Project No. WC-20045, Sludge Settleability Study Stage 2. Actew AGL.

Wentzel M. C., Ekama G. A., Dold P. L. and Marais G. v. R. (1990). Biological excess phosphorus removal - steady state process design. Water $S A, \mathbf{1 6}(1), 29-48$.

Wentzel M. C., Ekama G. A., Loewenthal R. E., Dold P. L. and Marais G. v. R. (1989). Enhanced polyphosphate organism cultures in activated sludge systems. Part 2: Experimental behaviour. Water SA, 15(2), 71-88.

Wentzel M. C., Mbewe A. and Ekama G. A. (1995). Batch test for measurement of readily biodegradable COD and active organism concentrations in municipal waste waters. Water $S A, \mathbf{2 1}(2), 117-124$.

White M. J. D. (1975). Settling of Activated Sludge. Tech Report TR11, Water Research Centre.

White M. J. D. (1976). Design and control of secondary settlement tanks. Water Pollution Control, 75, 459-467.

Wilderer P. A., Irvine R. L. and Goronszy M. C. (eds.) (2001). Sequencing Batch Reactor Technology, Sc \& Tech Rpt No. 10, IWA Publishing, London.

Wilen B.-M., Lumley D., Mattsson A. and Mino T. (2010). Dynamics in flocculation and settling properties studied at a full-scale activated sludge plant. Water Environment Research, 82(2), 155-168.

Wood D. K. and Tchobanoglous G. (1975). Trace elements in biological waste treatment. Journal of WPCF, 47(7), 1933-1945.

WSAA. (1999). The Australian Urban Water Industry: WSAAfacts'99. Water Services Association of Australia, Melbourne.

Yamamoto R. I., Komori T. and Matsui S. (1991). Filamentous bulking and hindrance of phosphate removal due to sulfate reduction in activated sludge. Water Science and Technology, 23, 927-935. 


\section{Index}

A

Abattoir wastewater treatment, 130, 202-203

Activated sludge history, 27

Aeration (See also Reactors, oxidation ditch, aerator characteristics)

diffusers:

aeration characteristics, 98

cleaning, 99

fouling, 97

pressure loss, 97

oxygen transfer:

effect on mixed liquor $\mathrm{pH}, 99-100$

efficiency, 99

transfer rate, 96, 184

Aerobic digesters:

aeration, 139-140, 142, 145

alkali dosing, 140-145

alum dosing, 140-145

denitrification rate, 48

description, 137

flowsheet, 137

interaction with liquid stream

processes, 137

nutrient release, 140

operating principles, 145

$\mathrm{pH}, 144$

residence time:

hydraulic, 138

solids, 138 sludge dewaterability, 144

sludge settleability, 144

sludge stabilisation (see specific oxygen uptake rate)

specific oxygen uptake rate (SOUR):

performance, 138

test procedure, 140

Alkalinity \& pH, 67-69

aerobic digester:

alkali dosing, 140, 145

bioreactor:

alkali dosing, 99-100

effect of aeration efficiency on mixed liquor $\mathrm{pH}, 99-100$

effects of alkalinity and dissolved $\mathrm{CO}_{2}$ on mixed liquor $\mathrm{pH}, 68$

Alum dosing (See also Chemicals):

aerobic digesters (see Aerobic digesters, alum dosing)

bioreactors:

effects on:

alkalinity and $\mathrm{pH}, 64,65$

effluent chlorine demand, 66

effluent SS, 61, 130

effluent true colour, 61

floc size, 130

nitrification, 44, 66

organic $\mathrm{N}$ removal, 66

phosphorus removal, 60-65

simultaneous nitrification and denitrification, 130

sludge settleability, 80, 130 
Alum dosing (Continued)

estimation of biological phosphorus

removal, 64, 66, 157

process response time, 80

solids production, $64-65$

rules of thumb, 69

B

Bacterial composition, 38

Belt filter press, 137, 144, 146-149

operating and performance characteristics, 146-149 alum, effect of, 144-145

test procedure, 147

operating guidelines, 147

Biological phosphorus removal (see Phosphorus removal, biological)

Bioreactors, (see Reactors)

BNR process (see Process, BNR)

BNR process formats (see Process formats, BNR)

BOD, effect of sample storage, 17

Bottlenecks (see Plants, capacity, bottlenecks)

C

Capacity (see Plants, capacity)

Capacity creep, 199, 204-205, 208 (See also Learning curves)

Capacity expansion:

integral expansion, 208

parallel expansion, 208-209

Carbon dioxide stripping, 99

Catchment:

nutrient balance, 6

Centrifuge, solid bowl, 148-154

operating and performance characteristics, 153

operation:

guidelines, 154

variables, 150

pool volume, 151

test procedure, $152-153$

Chemicals:

Dosing, see Alum dosing; Alkalinity and $\mathrm{pH}$

Properties of following chemicals, Appendix 2

Alum, 228

Caustic soda, 229

Ethanol, 228

Ferric, ferrous salts, 228

Lime, 228

Lithium hydroxide, 228

Magnesium hydroxide, 228

Methanol, 228
Molasses, 229

Sucrose, 229

Soda ash, 229

Sodium hypochlorite, 229

Clarifiers:

primary:

effect on influent characteristics, 23

performance, 23

secondary (See also Effluent characteristics;

Nitrification, effects of clarifier sludge mass;

Sludge settleability)

description, 121

effluent SS concentration, effects of:

alum dosing, 130

environmental chemistry, 128

flocculation, 128

MLSS concentration, 129

overflow rate, 132

rising sludge, 133

scraper speed, 127

SRT, 128

SSVI, 129, 132

effluent quality, other effects, 133

failure (see Clarifiers, secondary, operating diagrams)

feed wells, effect of, 133

mass balance, 122

operating diagrams, 124

rising sludge, 127

solids profile, $122-124$

stress testing, 133

Contractual startups (see also Learning curves)

Control, see Process control

D

Debottlenecking (see Tuning)

Denitrification, 47 (See also Simultaneous nitrification and denitrification)

alkalinity, 47

anoxic mass fraction, 49

carbon dosing, 48

COD requirement, 47

denitrification rate

aerobic digester, 48

liquid stream, 48

effects of:

anaerobic reactor, 51

dissolved oxygen, 50

mixing regime, 92

recycle ratio, 50

rules of thumb, 69 
Diffusers (see Aeration)

Digester, aerobic (see Aerobic digesters)

DSVI (see Sludge settleability)

E

Effluent characteristics, 23, 25

disinfected effluent, 26

interactions, 25

suspended solids concentration (see Alum dosing,

bioreactors, effects on effluent SS; Clarifiers, secondary, effluent SS concentration)

variability, 26, Appendix 1

Energy consumption (See also Plants, energy consumption)

water businesses, 164-165

water cycle, 164

Ethanol (see Chemicals)

Equivalent persons (see Human body; Sewage)

Evolutionary operation (EVOP), 1, 197-221

(See also Tuning)

application:

chemical process plants, 204-206

manufacturing plants, 1, 206

STPs, 197-221

costs, effect on, 207-209

data collection and interpretation, 210-213

monitoring schedules, 211-212

principles, 206, 220

procedures, 209

trend plots, 214

EVOP (see Evolutionary operation)

\section{F}

Failure curves (see Plant capacity, failure curves)

Ferric dosing (see Alum dosing; Chemicals)

First order reactions (see Reactions, first order)

Flocculation (see Mixing, flocculation)

Foam, 81

Formats (see Process formats)

\section{H}

History (see Activated sludge history)

Human body, mass balance, 9

Human factors, 195

\section{I}

Influent (see Sewage)

Instrumentation (see Process control, instrumentation)
$\mathbf{L}$

Learning curves, 197 (See also Evolutionary operation; Operation; Startup; Tuning)

capacity creep, 199

contractual startups, 203-204

costs, effect on, 207

equations, 199

football, 198

limestone production, 198

performance creep, 200-203, 205

phases:

startup, 200-204

long-term, 204-205

time constant (see Time constants)

Lime (see Chemicals)

Lithium hydroxide (see Chemicals)

M

Magnesium hydroxide (see Chemicals)

Mass balances, 155 (See also Reactors)

biological $\mathrm{P}$ removal, 157

plant, 155

reactors:

Johannesburg, 102

MBR, 112

Modified UCT, 101

UCT, 101

Westbank, 102

secondary clarifiers, 122,155

sludge dewatering, 145, 157

sludge thickeners, 145, 156

MBR (see Reactors, membrane bioreactor)

Membrane bioreactors (see Reactors, membrane bioreactor)

Membranes (See also Reactors)

permeability, 114

chemical dosing, effect of, 114

monitoring, 114

Methanol (see Chemicals)

Mixing (See also Tracer testing)

arbitrary flow, 91-92

cells or reactors in series, 91

complete mix, 89-91

first order reaction, 91

flocculation, 94

intensity, 94

nitrification, effect on (see Nitrification, effects of, mixing regime)

plug flow, 89-91

power (see Mixing, intensity) 
Mixing (Continued)

regime, 89

residence time distribution (RTD), 89-90

response time (see Time constants)

series, cells or reactors (see Mixing, cells or reactors in series)

time constant (see Time constants)

velocity gradient (see Mixing, flocculation)

Molasses (see Chemicals)

\section{$\mathbf{N}$}

Nitrification, 40

effects of:

alum dosing, see Alum dosing

ammonia concentration, 42

biological phosphorus removal, 44

clarifier sludge mass, 45

dissolved oxygen concentration, 43

load variability, 44

mixing regime, 92

$\mathrm{pH}, 43$

salinity, 44

SRT, 41

temperature, 42

unaerated mass fraction, 45

rules of thumb, 69

Nitrification capacity, 46

Nitrogen cycle, 40

Nitrogen removal, rules of thumb, 69

Nutrient cycle, 1

Nutrient requirements (see Process, BNR, nutrient requirements)

\section{O}

Operation (See also Evolutionary operation; Learning curves; Tuning)

operating goals, 3

operating cycle, 3

Oxidation ditch (see Reactors)

Oxygen demand (See also Process, BNR, oxygen demand) dynamic loading, effect of, 53

$\mathbf{P}$

Performance creep (see Learning curves)

Person (see Human body)

pH (see Alum dosing; Alkalinity \& pH)

Phosphorus removal, biological, 53

effects of:

anaerobic mass fraction, 55

cells in series, 55 dissolved oxygen, 58

influent TKN:COD ratio, 58

nitrate, 58

PAO-GAO competition, 59

$\mathrm{pH}, 59$

RBCOD, 56

SRT, 55

substrate composition, 59

sulfide, 58

rules of thumb, 69

Phosphorus removal, chemical (see Alum dosing)

Plants:

capacity:

bottlenecks, 158

capacity envelopes:

continuous flow plants, 160

SBRs, 162

clarifier stress testing, 133

debottlenecking, 207

failure curves, 159

failure frequency analysis, 159

flow distribution, 158

stress testing, 133, 206

energy consumption (See also Energy consumption)

energy balance, 165

energy models, 166

historical data, 167

effect of plant load, 167-168

MBRs, 167-169

Tuning, 170

loading (see Sewage)

mass balances, 155-157

named in this book:

Albury, NSW, 167

Banora Point, NSW, 167

Beenyup, WA, 17

Bendigo, Vic, 167

Brendale, Qld, 167

Brunswick Valley, NSW, 82, 106, 143-144, 148-149, 167

Bucasia, Qld, 78

Bushkoppie, South Africa, 77

Cleveland Bay, Qld, cover, 7, 9, 60, 108-109, 114, 169, Appendix 1

Coolum, Qld, 78-80, 167

Daspoort, South Africa, 77

Eastern, Vic, 132

Flagstone, Qld, 78

Gibson Island, Qld, 167

Goudkoppies, South Africa, 77 
Jimboomba, Qld, 78, 81, 129

Johannesburg, South Africa, 84

Loganholme, Qld, 77, 133

Lower Molonglo, ACT, 123-124, 129

Maroochydore, Qld, 6-7, 12, 26, 66, 80, 130, 167-168, 201-202

Nambour, Qld, 26, 167

Noosa Coastal, Qld, 167

Northern, South Africa, 77

Olifantsvlei, South Africa, 77

Penrith, NSW, 167

Port Pirie, SA, 7, 17, 18

Redcliffe, Qld, 9, 13, 26, 128

Rynfield, South Africa, 77

South Windsor, NSW, 167

St Marys, NSW, 167

Subiaco, WA, 17

Thorneside, Qld, 58, 167, 201-202

Vlakplaats, South Africa, 77

Wacol, Qld, 95, 167

West Byron, NSW, 66, 78, 81, 129-130, 141-144

West Wodonga, Vic, 167

Westbank, Canada, 85

Woodford, Qld, 7, 8

Primary clarifiers (see Clarifiers, primary)

Primary treatment (see Clarifiers, primary)

Process, BNR:

biological phosphorus removal (see Biological phosphorus removal)

biological process fundamentals, 27

denitrification (see Denitrification)

nitrification (see Nitrification)

nutrient requirements, 38

oxygen demand, 39,52

diurnal variation, 53

sludge mass, 36, 57

kinetics, 29

F:M ratio, 35

SRT, 32

Process balances (see Mass balances)

Process control, 171

Anaerobic digester control, 194

Chemical control, 193

Control priorities, 173

Controller tuning, 180

Costs, operation, minimizing, 195

DO control, 188

Human factors, 195

Instrumentation, 183
PID control, 179

Recycle control, 193

Process formats, BNR:

Bardenpho, 83

basic, 28

Johannesburg, 84

MBR, 85

MLE, 48, 83

Modified Bardenpho, 84

Modified UCT, 84

Phoredox, 84

UCT, 84

VIP (see Modified UCT)

Westbank, 85

$\mathbf{R}$

Rainfall (see Catchment; Sewage, flow characteristics)

Return activated sludge (RAS) (see Clarifiers, secondary)

Reactions, first order, 91

Reactors (See also Mass balances; Mixing)

compartmentalized, 100

operating principles, 103

process characteristics, 100

membrane bioreactor, 110 (See also Membranes)

operating principles, 115

process characteristics, 111

oxidation ditch, 103

aerator characteristics

horizontal shaft, 109

vertical shaft, 109

diffused air, 106

operating principles, 110

process characteristics, 103

sequencing batch reactor, 28, 115 (See also

Simultaneous nitrification and denitrification)

operating principles, 120

process characteristics, 116

series (see Mixing, cells or reactors in series)

Residence time distribution (see Mixing, cells or reactors in series)

Response time (see Time constants)

Rules of thumb

nutrient removal, 69

oxygen demand, diurnal variation, 53

S

Salinity (see Nitrification, effects of, salinity; Sewage, salinity)

Sampling (see Sewage, sampling)

SBR (see Reactors, sequencing batch reactor) 
Scum (see Foam)

Secondary clarifiers (see Clarifiers, secondary)

Settleability (see Sludge settleability)

Sequencing batch reactors (see Reactors, sequencing batch reactor)

Sewage (See also Catchment; Human body)

COD fractionation, 19, 24

energy content, 22

flow characteristics, 6

load characterization, 15

pathogens, 15

per capita loading, 9, 22

quality characteristics, 9-22

effect of primary treatment, 23

sampling, 13, 14, 17

salinity, 9,18

sewer transformations, 23

variability, 12, 18, Appendix 1

Sewage treatment plants (see Plants)

Sewer transformations (see Sewage, sewer transformations)

Simultaneous nitrification \& denitrification (SND), 51, 130

effect of alum dosing, 130

Sludge dewatering (see Belt filter press; Centrifuge)

Sludge digestion (see Aerobic digesters)

Sludge flocculation (see Clarifiers, secondary, effluent SS concentration, effects of, flocculation)

Sludge settleability (See also Aerobic digesters, sludge settleability)

effect on effluent SS, 81

relationships between settleability parameters

(DSVI, SSVI, sSVI, SVI), 74

settling rates, 73

factors affecting:

alum/ferric dosing, 80 (See also alum dosing)

ammonia:nitrate ratio, 78

anoxic fraction, 76

denitrification (see Sludge settleability, settling rates, factors affecting, microbubbles)
DO concentration, 75

feed quality, 75,79

microbubbles, 124

prefermentation, 79

reactor mixing characteristics, 76

selectors, 76

solids retention time, 75

test procedures, 72

SND (see Simultaneous nitrification \& denitrification)

Soda ash (see Chemicals)

Sodium hypochlorite (see Chemicals)

Solids retention time (see Aerobic digesters, SRT control; Process, BNR, SRT)

Specific oxygen uptake rate (see Aerobic digesters, specific oxygen uptake rate)

Startup, 36 (See also Learning curves)

Statistics, Appendix 1

Sucrose (see Chemicals)

Sugar (see Chemicals)

SVI (see Sludge settleability)

T

Time constants, 94, 199-200

Tracer testing, 92-93 (See also Mixing)

Trend plots, 214-220

Tuning (See also Evolutionary operation; Learning curves; Operation)

debottlenecking, 207

goals, 1,3

principles, 220

$\mathbf{V}$

Variability:

Effluent (see Effluent characteristics, variability)

Influent (see Sewage, variability)

W

Wastewater (see Sewage) 
Tuning Biological Nutrient Removal Plants increases interest in tuning to enhance both performance and capacity, to provide insight into typical plant operating characteristics, and to stimulate operators' interest in studying the behaviour of their own plants. The book focuses on understanding of plant behavioural characteristics so that optimum performance can be achieved and maintained.

Tuning Biological Nutrient Removal Plants is carefully organized to cover:

- influent and effluent characteristics;

- process fundamentals;

- individual process characteristics;

- overall plant characteristics;

- the evolutionary operation approach to tuning.

The approach is practical and the use of mathematics is kept to a minimum and information is supplied in graphical and tabular form. Real operating data from a wide range of plant experiences is included. The book draws on the generosity of many Australian plant owners in permitting their plant data to be incorporated. Not all process types are covered but the tuning principles expounded are universally applicable.

The capacity and performance capabilities of a plant are not fixed; both are amenable to on-going enhancement through systematic and enthusiastic effort. The book will help to set new benchmarks in plant operation.

Tuning Biological Nutrient Removal Plants is a valuable resource for sewage treatment operations and operations support personnel, sewage process design engineers - operating authorities, consultants, contractors, operators of industrial wastewater treatment plants and sewage treatment lecturers in chemical engineering departments and other training organisations. 